\title{
LA LÓGICA EN LA FORMACIÓN DE MAESTROS: ¿NECESARIA? ¿SUFICIENTE?
}

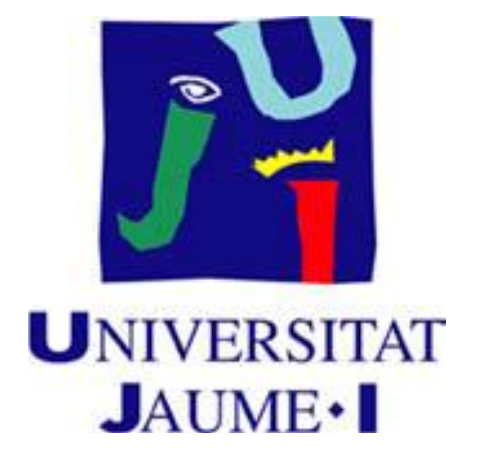

Departamento de Matemáticas

TESIS DOCTORAL

Presentada por:

Laura Peydró Pons

Dirigida por:

Pilar Orús Báguena

FEBRERO 2016 



\section{Agradecimientos}

La realización de la presente Tesis ha sido un largo y duro trabajo que no habría podido llegar a buen término sin la ayuda y colaboración de muchas personas a las que quiero públicamente expresar mi agradecimiento.

En primer lugar, quiero agradecer a mi directora de tesis, Dra. Pilar Orús, la oportunidad que me ha brindado y el excelente apoyo científico y personal ofrecido, así como la confianza que ha depositado en mí durante el desarrollo de esta Tesis Doctoral.

Agradezco a Ana Lluch y Pablo Gregori sus comentarios y consejos para mejorar la presentación y redacción de la Tesis. A Pedro Nieves, Inma Pérez, Carmen Melchor y Clara Rodríguez sin cuya colaboración no habría sido posible la realización de los trabajos con los estudiantes de la UJI.

Quiero expresar mi agradecimiento a los compañeros de la Universidad de Jaén que me acogieron durante mi estancia en la misma, especialmente a Luisa Ruiz-Higueras y a Javier García que, además, colaboró en la obtención de parte de los datos experimentales con sus estudiantes de la UJA.

A Irene por el camino compartido y el intercambio de ideas, trabajos, penas y alegrías.

A todos los compañeros del departamento de Educación de la UJI que me han mostrado su apoyo y amistad en estos años.

Por último, pero de ningún modo menos importante, quiero dar las gracias a mi familia que nunca ha dejado de estar a mi lado y apoyarme incondicionalmente hasta el final. 



\section{ÍNDICE}

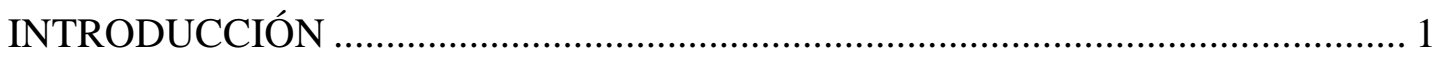

CAPÍTULO 1. RAZONAMIENTO LÓGICO Y DOMINIOS DE REFERENCIA MODELIZADO SEGÚN BROUSSEAU

1.1 Dominios de referencia del razonamiento lógico en el sistema de enseñanza según la modelización del enfoque epistemológico

1.1.1 El razonamiento y la Psicología ................................................ 19

1.1.2 El razonamiento y la Lógica.................................................. 21

1.1.3 El razonamiento y las Matemáticas .......................................... 26

1.1.4 El razonamiento y la Lógica Informal.................................... 30

1.1.5 El razonamiento y la Inteligencia Artificial ............................. 31

1.1.6 El razonamiento y la Didáctica de las Matemáticas

1.2 Antecedentes de investigación sobre el razonamiento en la enseñanza de las matemáticas

1.3 El razonamiento y la modelización del enfoque epistemológico de la Didáctica de las Matemáticas. 45

1.3.1 El razonamiento según la modelización de la TSD 47

1.3.2 El razonamiento lógico según la modelización de la TAD ....... 69

$1.4 \mathrm{El}$ razonamiento en el sistema educativo español............................... 74

1.5 El razonamiento en la Formación de Maestros ...................................... 84

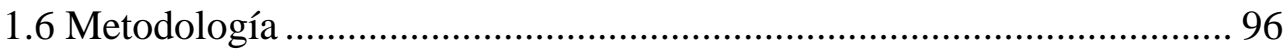

CAPÍTULO 2. UN INSTRUMENTO DE DIAGNÓSTICO DEL RAZONAMIENTO LÓGICO DE FUTUROS MAESTROS ................................ 101

2.1 Presentación del cuestionario Q ........................................................... 103

2.2 Estudio a priori del cuestionario Q ................................................ 111

2.2.1 Modelización lógico-matemática de las preguntas del cuestionario Q 
2.2.2 Matriz a priori del cuestionario $\mathrm{Q}$

2.2.3 Conclusiones sobre el estudio a priori del cuestionario Q ...... 148

2.3 Fase I de la experimentación: Primera aplicación del cuestionario Q

(Universidad Jaume I de Castellón, 2015).....

2.3.1 Análisis de los resultados del cuestionario Q

2.3.2 Análisis de los resultados del cuestionario Q utilizando el Análisis Estadístico Implicativo 168

2.4 Fase I de la experimentación: Segunda aplicación del cuestionario Q y comparación de resultados (Universidad de Jaén, 2015) ........................ 176

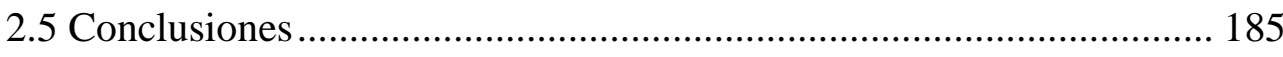

\section{CAPÍTULO 3. DEVOLUCIÓN DE LA SITUACIÓN DE CORRECCIÓN DEL}

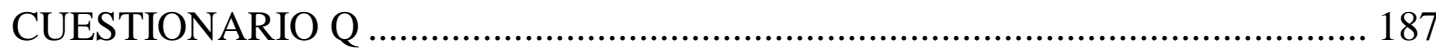

3.1 Presentación y análisis a priori de la situación didáctica: la corrección del cuestionario Q ........................................................................... 189

3.1.1 Descripción del medio y de la situación.................................. 190

3.1.2 Organización del aula y material utilizado............................. 224

3.1.3 Ficha didáctica............................................................... 226

3.2 Desarrollo y observación de la situación de corrección del

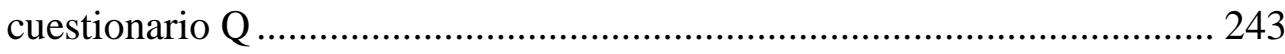

3.2.1 Crónica y resultados de la observación de la situación ............ 243

3.2.2 Análisis de la observación de la situación de corrección del cuestionario Q........................................................................ 266

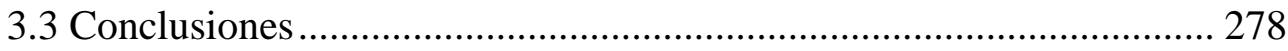

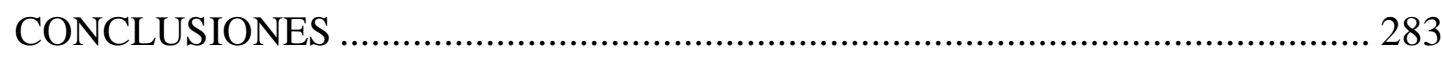

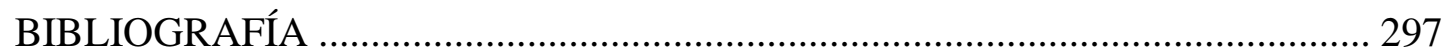

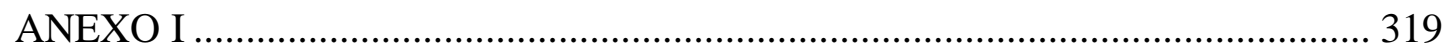

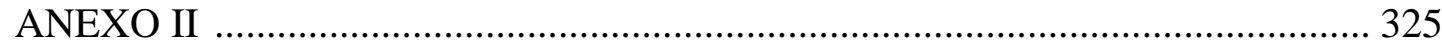

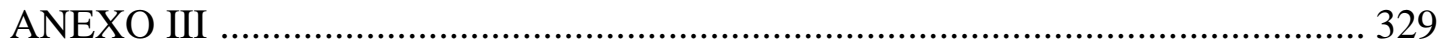

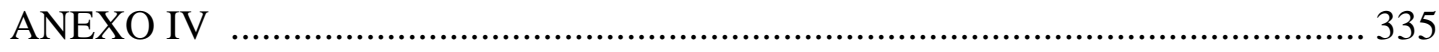


INTRODUCCIÓN 
Si nos preguntaran, como profesores de matemáticas, sobre el grado de importancia que le concedemos al razonamiento en nuestro trabajo, creemos que habría un gran consenso, con respuestas rozando los valores máximos de la escala numérica propuesta o eligiendo calificativos como "muy importante", "esencial", "imprescindible", "necesario", etc. si fueran escalas cualitativas. Pero si nos preguntaran, sobre el porqué le concedemos esa importancia, pensamos que las respuestas serían más diversas, ya que cada uno se la ha otorgado en función de lo que entiende por "razonamiento". Para ello además, se necesitaría generalmente, adjetivar o complementar el sustantivo, para poder explicarlo o identificarlo: razonamiento lógico, razonamiento deductivo, razonamiento formal, razonamiento-proceso mental, razonamiento verbal o razonamiento explicitado a través del lenguaje, razonamiento como justificación de acciones, decisiones, o respuestas, etc. Y si siguieran indagando un poco más, sobre cuándo lo utilizamos en clase, en qué momentos o para qué lo utilizamos, las respuestas serían todavía más dispares ya que en ese caso, se añadirían las valoraciones que cada profesor haría en función de cómo entiende la enseñanza y las propias matemáticas, y por tanto la enseñanza de las matemáticas.

Santaló, en la conferencia inaugural del I Congreso Iberoamericano de Educación Matemática (CIBEM, 1990), nos ofrece un ejemplo concreto sobre la importancia que él le concede al razonamiento en la enseñanza de la matemática; en su caso se refiere a los razonamientos lógicos desde una perspectiva integral de la educación:

“Desde los primeros grados hay que ir educando no sólo en la matemática propiamente dicha, sino también en el razonamiento lógico y deductivo, que es la base de la matemática, pero que es también imprescindible para ordenar y asimilar toda clase de conocimiento. Hay que ir educando al alumno en el lenguaje apropiado para comprender la nomenclatura y funcionamiento de la actual tecnología, así como la base científica que la sustenta. Por tanto, hay ciertos conocimientos de lógica que deben usarse 
con frecuencia en la clase, para que vayan siendo asimilados como parte natural del lenguaje y del pensar cotidiano, más que como conceptos adquiridos a través de un aprendizaje especial. No hace falta incluir en los programas una parte de lógica, con silogismos, cuantificadores y tablas de verdad como conocimientos básicos a los que se hará referencia cuando llegue el momento. Es mejor ir aprendiendo las leyes del razonamiento de manera natural, como algo inherente al lenguaje, de la misma manera como se aprende a hablar sin conocer la etimología de las palabras. Por ejemplo, las ideas de inducción, demostración por reducción al absurdo, condición necesaria y suficiente o "si y sólo si", hay que aprenderlas como ejemplos referentes a casos concretos a medida que van apareciendo, sin pretender filosofar sobre su significado abstracto. Lo mismo puede decirse de la teoría de conjuntos, que a este nivel de la enseñanza para todos debe ser tan solo un lenguaje, de aplicación continua sobre la marcha del curso y muy útil para mejor comprender y expresar razonamientos y resultados, pero por tratarse de un medio y no de un fin, la parte de teoría de conjuntos que no se vaya a utilizar puede y debe suprimirse. Otra cosa es, naturalmente, para los estudios de nivel terciario y para alumnos de carreras matemáticas, para los cuales la teoría de conjuntos es esencial en sí misma." (Santaló, 1990, pp. 6-7)

En esta conferencia, Santaló habla de la importancia de un tipo de razonamiento, el razonamiento lógico y deductivo en la enseñanza de las matemáticas, como base de las matemáticas, proponiendo abordarlo desde los primeros años ${ }^{1}$. Pero a la vez se refiere a la importancia de otros aspectos del razonamiento: la producción de nuevos conocimientos (el razonamiento como proceso mental) y a su relación con el lenguaje (razonamiento verbal), como medio para ir aprendiendo las normas del razonamiento

\footnotetext{
${ }^{1}$ El énfasis marcado por el resaltado en "negrita" de las referencias, es nuestro.
} 
(razonamiento formal). Presenta también unas propuestas muy interesantes, para conseguir el desarrollo correcto del razonamiento, a través de la enseñanza de las matemáticas, de las que retenemos: la importancia que le concede a la lógica en ese proceso de formación del razonamiento, pero no de forma directa incluyéndola en los programas, sino a través de casos concretos y la importancia del lenguaje, para ir aprendiendo las normas del razonamiento.

Muchos son los esfuerzos realizados y que siguen realizando los profesores, para conseguir esta formación del razonamiento de sus alumnos a través de la enseñanza de las matemáticas, pero aun así se siguen observando dificultades en la comprensión lógica de los estudiantes. Todavía no se puede decir que existan respuestas en la comunidad educativa sobre cómo lograrlo. Si nos centramos en el aprendizaje del alumno, frecuentemente los profesores consideran que razonar correctamente es un logro, un objetivo que se alcanza indirectamente a través de las diferentes áreas de las matemáticas: se habla de razonamiento geométrico, razonamiento numérico, razonamiento estadístico, razonamiento probabilístico, razonamiento algebraico, razonamiento analítico, etc. Y esos son los razonamientos que el docente puede abordar en clase de matemáticas, los ligados al saber matemático; pero entre ellos no se encuentran los conocimientos básicos de la Lógica. El propio Santaló, parece que aboga en ese sentido:

"las ideas de inducción, demostración por reducción al absurdo, condición necesaria y suficiente o "si y sólo si", hay que aprenderlas como ejemplos referentes a casos concretos a medida que van apareciendo, sin pretender filosofar sobre su significado abstracto".

Por otro lado, los profesores apelan continuamente al razonamiento personal de los alumnos, para que estos lleguen a sus propias conclusiones a partir de las informaciones que se les da, para resolver un problema, por ejemplo o para que tomen sus propias decisiones en la selección y tratamiento de las informaciones y de los datos para buscar las respuestas a esos problemas; es decir, para que lleven a cabo sus propios zonamientos 
matemáticos y lógicos que permitan aprender los conceptos matemáticos en juego, relacionarlos y aplicarlos en la resolución de problemas. Y este razonamiento personal, subjetivo, de producción de nuevos conocimientos a partir de los anteriores, es otro tipo de razonamiento, que el profesor utiliza y necesita en clase, pero que al no ser "matemático" no puede abordar directamente, ni por supuesto ser objeto de enseñanza o aprendizaje. Desde la perspectiva del profesor, el razonamiento en general y el razonamiento lógico en particular, es una herramienta necesaria para la enseñanza, aprendizaje y estudio de las matemáticas y al mismo tiempo, contribuir al desarrollo del razonamiento, es uno de los objetivos de la enseñanza de las matemáticas. No es tarea fácil, dada la naturaleza compleja y paradójica que parece presentar tal proceso.

Desde el marco de la Teoría de Situaciones Didácticas (Brousseau, 1979) (TSD, a partir de este momento), Orús ya identifica esta paradoja como un problema de contrato didáctico (Orús, 1986, 1992). En su tesis doctoral de Didáctica de las Matemáticas (DM) "Le raisonnement des élèves dans la relation didactique; effets d'une initiation à l'analyse classificatoire dans la scolarité obligatoire" (Orús, 1992), muestra la dificultad de los docentes en la gestión del razonamiento de los estudiantes en clase de matemáticas, así como las diferentes paradojas del contrato didáctico a las que da lugar esta gestión de las diversas formas en las que el razonamiento aparece en la relación didáctica, tanto en el alumno, como en el profesor y en diferentes momentos de la actividad escolar (paradoja de la devolución, paradoja de las situaciones de adaptación, paradojas del aprendizaje por adaptación y la paradoja del comediante, etc $)^{2}$. Así mismo, utilizó los distintos tipos de situaciones escolares, que la TSD, propone en su modelización de la relación didáctica, para identificar diferentes tipos de razonamientos. Cada tipo de situación

\footnotetext{
2 Brousseau, G. (1986). Fundamentos y métodos de la didáctica de las matemáticas. Recherches en didactique des mathematiques, 7(2), 33-115.
} 
conlleva un tipo de razonamiento; las situaciones adidácticas ${ }^{3}$ movilizan a su vez, diversos razonamientos según aparezcan o puedan aparecer en situaciones de acción, de formulación o de prueba (Balacheff, 1988). En ese sentido, se identifica el razonamientoacción, el razonamiento-formulación y el razonamiento-validación. En las situaciones didácticas de institucionalización (Rouchier, 1991), el único razonamiento posible que el profesor de Matemáticas puede reconocer, es el razonamiento ligado al conocimiento matemático a institucionalizar (Orús, 1992). Y es, en las llamadas situaciones didácticas, en donde se puede identificar y describir a priori, la naturaleza de las dificultades de los profesores de matemáticas, para gestionar toda esta diversidad de situaciones y la coexistencia de razonamientos de naturaleza y funciones muy diferentes. También es en este tipo de situaciones, las didácticas, donde pueden ser observadas.

Esta problemática sobre el razonamiento en la relación didáctica está incluida, según el propio Brousseau -director de la tesis de Orús-, en un conjunto de trabajos sobre las nociones que en Didáctica de las Matemáticas se conocen como protomatemáticas y paramatemáticas (Chevallard, 1985) ${ }^{4}$ que constituyen un obstáculo para la adquisición de conocimientos matemáticos: los procesos de enumeración en el aprendizaje del número (Briand, 1993), el dominio del espacio para el aprendizaje de la geometría (Berthelot y Salin, 1992) y el razonamiento natural, para la adquisición de las nociones lógicas (Orús, 1992).

\footnotetext{
${ }^{3}$ El término situación a-didáctica designa toda interacción entre un sujeto y un medio sin intervención del profesor en lo concerniente al saber que se pone en juego.

${ }^{4}$ La Transposición Didáctica, proceso del que habla Chevallard en sus primeras aproximaciones a la teoría Antropológica de lo Didáctico y mediante el cual el saber sabio es transformado en objeto de enseñanza, pone de manifiesto tres tipos de nociones: nociones matemáticas, paramatemáticas y protomatemáticas. Las nociones matemáticas son reconocidas explícitamente como objeto de estudio, las paramatemáticas son activadas y utilizadas como herramientas pero no son reconocidas explícitamente como objeto de estudio, a pesar de hacer referencia a ellas continuamente, y las protomatemáticas son las nociones activadas implícitamente en la actividad matemática pero en ningún momento son reconocidas ni como herramienta ni como objeto de estudio.
} 
Esta identificación del razonamiento natural del alumno, como obstáculo epistemológico para la adquisición de los conocimientos lógicos, cuestiona las afirmaciones de los profesores de matemáticas que, como Santaló, piensan que dichas nociones lógicas se deben ir aprendiendo de forma natural, (como algo inherente al lenguaje, o a través de ejemplos, como casos concretos...). Y los resultados de Orús (Orús, 1992), Pitarch (Pitarch, 2002), y Zamora (Zamora y otros, 2009), muestran las dificultades que presentan los alumnos de diferentes edades, desde 10-12 años hasta estudios preuniversitarios, respecto a nociones lógicas muy elementales y que estas persisten en ausencia de cualquier trabajo específico al respecto, pese a la maduración mental que supone la edad y una mayor formación matemática escolar.

Si la gestión del razonamiento en la relación didáctica es un problema docente, parece azonable que los futuros profesores de matemáticas en general y los maestros en particular debieran tener una formación al respecto. Esto nos plantea diversas cuestiones respecto a la formación de los maestros y su relación con el conocimiento, tanto matemático como didáctico.

¿Qué conocimientos serían necesarios, en la formación del profesorado, para lograr una gestión adecuada del razonamiento en situación escolar y poder superar la situación paradójica que supone su gestión a los profesores? ¿Qué conocimientos matemáticos? ¿Qué conocimientos didácticos?

Y en relación con dichos conocimientos didácticos: ¿Puede la DM, desde sus resultados de investigación, aportar conocimientos útiles, para la formación de maestros? ¿Qué transposición exigirán esos conocimientos? ¿Qué conceptos teóricos o metodológicos de $\mathrm{DM}$, necesitaría dicha transposición?

Retomando la línea de investigación de Orús y basándonos en los resultados de los trabajos anteriores ya referidos anteriormente, nos cuestionamos también en concreto, sobre los conocimientos lógicos que tienen los futuros maestros, para poder afrontar y gestionar ellos mismos, como docentes, los razonamientos de sus alumnos. 
¿Cuáles son los conocimientos lógicos de los "futuros maestros", alumnos actuales del Grado de maestro? ¿Siguen presentando las dificultades observadas en otros alumnos de cursos inferiores (Orús, 1986-1992), (Pitarch, 2002, 2015), (Zamora y otros, 2009)?

Identificar y describir los conocimientos lógicos, de alumnos del Grado de Maestro, es uno de los objetivos de nuestro trabajo. Para ello utilizaremos varios instrumentos metodológicos para abordarlos: un instrumento de diagnóstico semejante al utilizado en los trabajos precedentes, un cuestionario basado en unas tablas de datos binarios; el análisis a priori de dicho cuestionario, para identificar los conocimientos lógicomatemáticos que exigen las respuestas al cuestionario; la ingeniería didáctica para la elaboración de una situación didáctica de corrección colectiva del cuestionario, que permita la devolución a los alumnos de dicha corrección, permitiendo explicitar los razonamientos y validaciones de las respuestas individuales de los alumnos al cuestionario; y por último, la experimentación y observación de dicha ingeniería. Este trabajo será abordado en los Capítulos 2 y 3 de nuestro trabajo.

Previamente, en el capítulo 1, "El razonamiento lógico y la enseñanza de las ${ }^{5}$ Matemáticas", analizamos en profundidad el objeto "razonamiento" y las diferentes relaciones que pueden tener los sujetos con dicho objeto en las diferentes instituciones ligadas a los dominios de referencia en donde puede existir este objeto (Chevallard, 1989) y que estén relacionadas con la enseñanza de las matemáticas (Orús, 1992). Para ello se utilizarán las modelizaciones teóricas de la relación didáctica y del sistema de enseñanza, que el enfoque epistemológico de la Didáctica de las Matemáticas propone a través de la Teoría de las situaciones didácticas (TSD) y Teoría Antropológica de lo Didáctico $(T A D)$. Este análisis nos permitirá mostrar cómo, lo que era un problema docente, se ha convertido en un problema de investigación y cómo se va abordar; cuáles son las cuestiones concretas que nos hemos planteado y con qué métodos vamos a buscar respuestas, presentando los conceptos teóricos que se utilizan como metodología

\footnotetext{
${ }^{5}$ Señalados en el texto en cursiva.
} 
específica de investigación y que ya hemos ido apuntando: modelizaciones de la relación didáctica a través de la noción de medio y de situación de Brousseau (1996), y mediante la transposición didáctica y las praxeologías en Chevallard (1989, 1991, 1995, 1999) y muchas otras nociones asociadas: ingeniería didáctica, contrato didáctico, devolución, fenómenos y paradojas ligadas a la devolución, etc.

Como hemos apuntado anteriormente, en los capítulos 2 y 3, hemos diseñado una ingeniería didáctica que va a permitirnos conocer, observar y describir los conocimientos lógicos de alumnos del Grado de Maestro. Hemos partido de los resultados de las investigaciones anteriores, en el marco de la TSD, respecto al desarrollo del pensamiento lógico, y nos hemos planteado cómo pueden ser utilizados para la formación del profesorado. Concretamente rescatamos la situación fundamental diseñada por Orús para la enseñanza de la lógica (Orús, 1986, 1992), adaptada posteriormente por Pitarch para estudiantes de Educación Secundaria (Pitarch, 2002, 2015). La adaptaremos ahora, al nivel de los estudiantes universitarios, también con un doble objetivo: utilizarla como un instrumento de diagnóstico del conocimiento lógico de los futuros maestros y poder diseñar (a partir de los resultados) una lección, cuya experimentación nos permitirá completar la información obtenida con el cuestionario (considerado como situación fundamental). Este trabajo se aborda en el segundo capítulo. Se presenta la situación fundamental y su proceso de adaptación, se expone el diseño de la situación con su correspondiente análisis a priori y los resultados del diagnóstico llevado a cabo con estudiantes de las titulaciones de Maestro en Educación Primaria y en Educación Infantil. Las universidades que colaboran en la investigación son la Universitat Jaume I de Castellón y la Universidad de Jaén. En el último capítulo se presenta la lección diseñada, su realización y los resultados de la experimentación. En este caso, la lección se lleva a cabo únicamente con un grupo de estudiantes de la Titulación de Maestro de Educación Primaria de la Universitat Jaume I de Castellón, debido a la complejidad del dispositivo y las dificultades encontradas para gestionar cada uno de los elementos que intervienen en la experimentación, principalmente relacionadas con la dedicación horaria que ello 
implica por parte del profesorado y de los estudiantes, bastante limitada tal y como veremos más adelante.

Las conclusiones expondrán los resultados que podemos aportar en nuestra tesis, así como sus limitaciones, y el trabajo que queda por abordar para futuras investigaciones. 
RAZONAMIENTO LÓGICO Y DOMINIOS DE REFERENCIA MODELIZADO SEGÚN BROUSSEAU 
La presente tesis se enmarca en el enfoque epistemológico de la Didáctica de las Matemáticas, donde se ubican la TSD y la TAD, cuyas metodologías específicas de investigación van a marcar el desarrollo de este trabajo. En este capítulo presentaremos las nociones de "rapport au savoir" (Chevallard, 1989) y transposición didáctica de la TAD (Chevallard, 1985) así como las modelizaciones del sistema de enseñanza y de la relación didáctica en ambos enfoques (Brousseau, 1986, 1990; Chevalard, 1985, 1992). Analizaremos el razonamiento que existe en las diferentes instituciones que, como veremos luego, lo reconocen como tal, en función de la relación que tienen con dicho objeto (producirlo, estudiarlo, utilizarlo,...). Mostraremos que estos análisis nos permiten identificar diferentes tipos de razonamiento en la enseñanza de las matemáticas (Orús, 1992), entre ellos el razonamiento lógico y el razonamiento matemático, estableciendo las Matemáticas y la Lógica como instituciones de referencia. También analizaremos el razonamiento lógico en el sistema educativo español, institución de referencia que establece las relaciones "oficiales" (directrices generales para la enseñanza de las matemáticas, contenidos a enseñar, etc.) con el razonamiento lógico considerado como objeto. Por último presentaremos la metodología general de la tesis.

\subsection{Dominios de referencia del razonamiento lógico en el sistema de enseñanza según la modelización del enfoque epistemológico}

Desde el enfoque epistemológico de la didáctica, un objeto de saber existe en una institución si ésta lo reconoce como tal (Chevallard, 1989). La relación con dicho objeto debe ser entendida como el conjunto de prácticas sociales que tienen que ver con la institución y que implican el objeto en cuestión:

"La connaissance - et le savoir comme une certaine forme d'organisation de connaissances

- entre alors en scène avec la notion de rapport: un objet existe s'il existe un rapport à cet objet, c'est-à-dire si un sujet ou une institution le " (re)connaît » en tant qu'objet. Étant donné un objet (par exemple un objet de savoir) et une institution, la notion de rapport 
renvoie aux pratiques sociales qui se réalisent dans l'institution et qui mettent en jeu l'objet en question, soit donc à « ce qui se fait dans l'institution avec cet objet 》. Connaître un objet c'est avoir à faire avec - et souvent avoir affaire à - cet objet. (Bosch y Chevallard, 1999, p. 4)

Además, siguiendo con la modelización que supone la noción de "rapport au savoir" de Chevallard, toda relación personal con un objeto emerge de un conjunto complejo de relaciones institucionales, que han situado en algún momento al sujeto en una posición determinada dentro de la institución (Chevallard, 1989). En el artículo de Catel, Coquidé y Gallezot titulado "Rapport au savoir et apprentissage différencié de savoirs scientifiques de collégiens et de lycéens: quelle questions" los autores explican así la teorización de Chevallard (Catel, 2002):

\footnotetext{
"Dans la théorisation de Chevallard, le rapport au savoir est un rapport aux savoirs, c'està-dire à des objets de savoir reconnus comme tels par le sujet, mais aussi par les institutions prises au sens large (école, classe, famille...). Le sujet n'est plus défini ici par rapport à l'objet mais par rapport à l'institution, en tant que personne assujettie, simultanément ou successivement, à une ou plusieurs institutions. L'appropriation d'un objet de savoir, dans cette théorisation, est considérée comme une mise en conformité institutionnelle du rapport personnel au savoir.” (Catel y otros, 2002, p. 126)
}

Por otro lado, según Brousseau (Brousseau, 1999) el sistema de enseñanza, en su labor de aculturar a la sociedad, es la institución que posibilita la relación entre los individuos y los saberes culturales que la sociedad considera necesarios para sus miembros y para su desarrollo (Fregona, 2013).

En este sentido, las instituciones vinculadas por el sistema de enseñanza son la sociedad y la cultura, donde un mismo objeto existe de forma distinta, ya que las relaciones con un determinado objeto son diferentes en la cultura y en la sociedad. En el Diccionario de la Real Academia Española se puede encontrar una muestra de la diversidad de prácticas sociales que se reconocen al razonamiento: 


\section{Razonamiento:}

1. Acción y efecto de razonar.

Razonar.

1. Exponer razones para explicar o demostrar algo.

2. Ordenar y relacionar ideas para llegar a una conclusión.

3. Exponer razones o argumentos.

2. Serie de conceptos encaminados a demostrar algo o a persuadir o mover a oyentes o lectores.

La distinción entre las acciones de explicar, demostrar y argumentar ya sugiere un tratamiento distinto de los razonamientos según su función.

La modelización que hace Brousseau del sistema de enseñanza y su relación con las diferentes instituciones (figura 1.1), nos servirá para identificar las prácticas sociales y culturales relacionadas con el razonamiento.

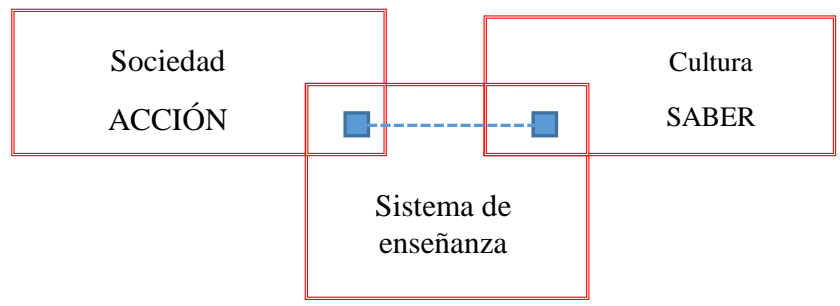

Fig. 1.1: Modelización del sistema de enseñanza

¿Cuáles son los razonamientos que el Sistema de Enseñanza toma de la Cultura? ¿Y de la Sociedad? ¿Cuál es su función?

Este esquema puede ser utilizado para ubicar las instituciones o dominios de referencia de los saberes culturales y de las prácticas sociales relativas al razonamiento: 


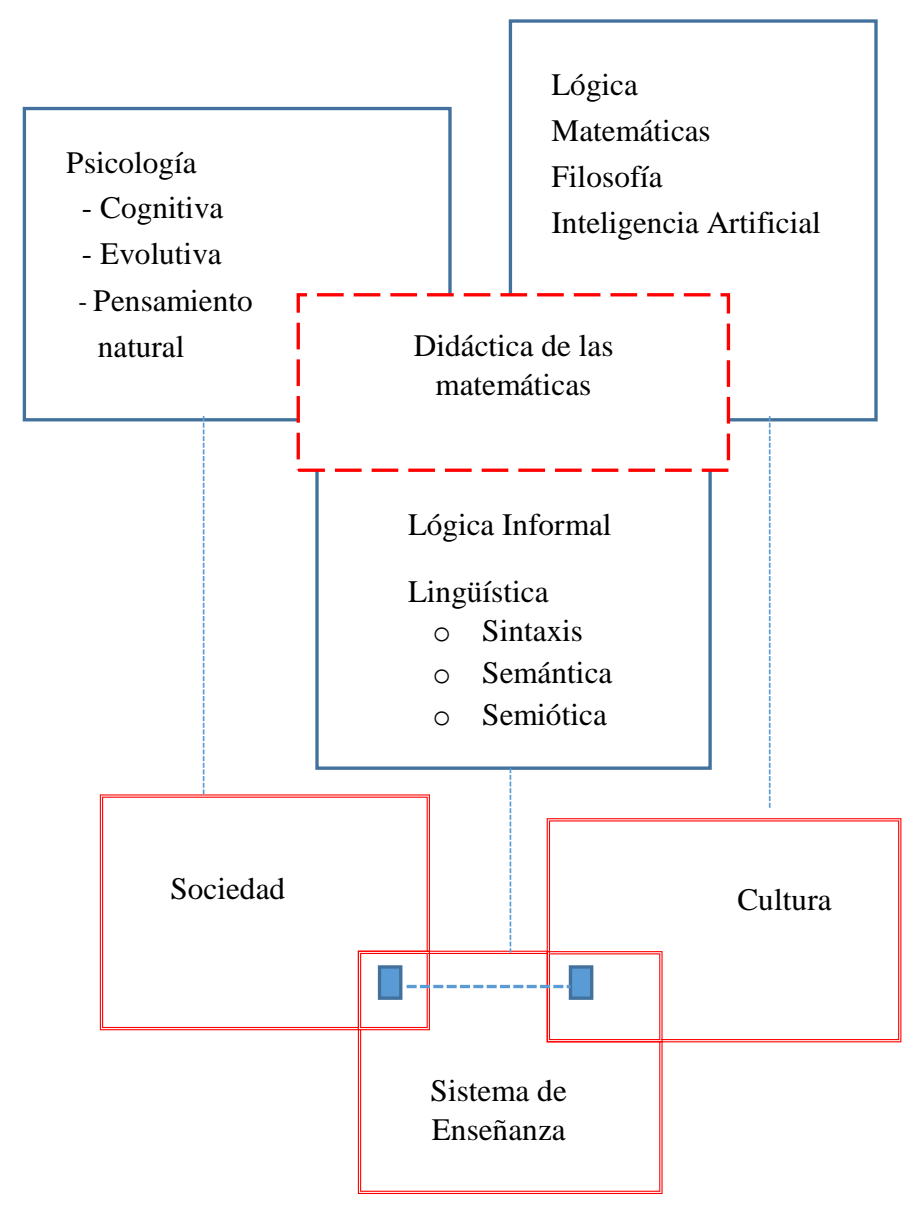

Fig. 1.2: Dominios de referencia del razonamiento en el Sistema de Enseñanza según la modelización de Brousseau

Tal y como podemos ver en la figura 1.2, esta modelización del sistema de enseñanza conduce a diferentes dominios de referencia para el objeto razonamiento. En el sistema de enseñanza se encuentran los razonamientos que se definen según las Matemáticas, la Lógica, la Inteligencia Artificial o la Filosofía (Lógica Formal) que sirven de referente para el razonamiento de las matemáticas. Estos saberes de referencia son los razonamientos lógicos y matemáticos, que son los razonamientos válidos para el correcto funcionamiento de los conocimientos matemáticos. Al mismo tiempo, en el sistema de 
enseñanza se encuentran los razonamientos llevados a cabo por los individuos, tanto públicamente (argumentaciones) como privados (razonamientos personales, subjetivos) donde la Psicología, la Linguiística o la Argumentación, sin pretender ser normativos, explican estos procesos. Y la Didáctica de las Matemáticas, que estudia los razonamientos en la relación didáctica.

Antes de continuar abordando el análisis de los razonamientos en la relación didáctica, desde la óptica de la Didáctica de las Matemáticas se expondrán algunas de las aportaciones realizadas en los diferentes dominios de referencia, que contribuyen a la identificación del objeto razonamiento en el sistema de enseñanza. Estas aportaciones nos servirán también para ir analizando las diferentes acepciones culturales del objeto razonamiento desde los diferentes dominios de referencia, según las relaciones que establecen con él las diferentes instituciones de referencia que presentamos.

\subsubsection{El razonamiento y la Psicología}

En psicología los razonamientos son procesos mentales relacionados con la adquisición de conocimiento (Sánchez, 2002). Este conocimiento puede tener su origen en el mundo real, un mundo externo al sujeto, o puede ser producto de la mente, procesando conexiones entre las ideas y los conceptos que ya posee. Esto quiere decir que las personas tienen la capacidad de producir conocimiento nuevo mediante la actividad mental, sin recurrir a la experiencia. El mecanismo mental mediante el cual el ser humano es capaz de convencerse de la veracidad de una afirmación, sin tener que verificarla en la realidad, se llama razonamiento. Entre todas las formas de pensamiento, el razonamiento es identificado como un procedimiento mediante el cual se maneja información con la finalidad de obtener nueva información. En general, todo razonamiento tiene una información que sustenta la veracidad de la conclusión. 
"Lo especifico, por tanto, de un razonamiento o inferencia es que consiste en derivar una conclusión a partir de unas premisas" (Deaño, 1974, p. 32)

"El razonamiento humano es un proceso, por lo general consciente y sistemático, mediante el cual sacamos conclusiones a partir de hechos, creencias o normas" (Dasi y Algarabel, 2003, p. 440)

Los razonamientos, incluidos dentro de los procesos del pensamiento humano, han sido estudiados con detalle, dando lugar a numerosos resultados que ayudan a comprender la complejidad de este tipo de procesos. En Introducción al razonamiento humano (Santamaría, 1995) podemos encontrar una recopilación de las principales teorías psicológicas que explican lo que ocurre en la mente cuando se resuelve un problema de razonamiento. Según el autor, estas teorías se agrupan en tres grupos: las teorías de reglas formales, las teorías que proponen la existencia en la mente de reglas específicas que dependen del contenido del enunciado y otras que niegan la existencia de reglas formales, considerando el razonamiento basado en un proceso de manipulación semántica. Todas estas explicaciones, procedentes del campo de la psicologia, muestran cómo es posible encontrar diferentes formas de razonar que, en numerosas ocasiones, vienen determinadas por las características del contexto y del sujeto. Esta interpretación psicológica del proceso mediante el cual se relaciona la información para llegar a obtener información nueva es muy interesante desde una perspectiva educativa, ya que permite explicar la forma de adquirir conocimiento y por lo tanto, la forma de aprender, en general.

Hay que recordar la relevancia que tuvieron los estudios de epistemología genética de Piaget, que trataban de explicar el pasaje del pensamiento concreto del niño al pensamiento formal del adolescente (Inhelder y Piaget, 1985), y que influyeron en los contextos educativos de la época, aún presentes en nuestras aulas. Según la teoría piagetiana, en las operaciones del pensamiento de los jóvenes estudiantes se pueden distinguir las operaciones correspondientes a la lógica formal, aunque conviviendo con otras que, al mismo tiempo que avanzan hacia los primeros episodios de la madurez, van 
evolucionando hacia la lógica formal. Siguiendo las ideas de Piaget, los estudios de Wermus sobre el pensamiento natural ${ }^{6}$ (PN) y su formalización (Wermus, 1976), tratan de explicar sus reglas de funcionamiento. Para Wermus el PN transforma y organiza representaciones de objetos o situaciones concretas, no formales, y para explicar la diferencia entre el PN y la lógica formal, modeliza el PN a partir de los predicados amalgamados y sus transformaciones (centración, decantación, activación,...), los prefunctores y los esquemas de inferencia natural dando lugar a una lógica incompleta no determinista, que explica la diversidad de comportamientos y la complejidad del pensamiento (Anexo I).

Si se tiene en cuenta que la información utilizada en un razonamiento proviene del propio sujeto, las conclusiones alcanzadas tienen carácter subjetivo. Como afirma Popper, (Popper, 1988) las percepciones y las creencias de los individuos configuran sus propias teorías, a partir de las cuales interpretan el mundo y construyen conocimiento. Se trata del conocimiento del sentido común, que siempre presupone al sujeto cognoscente.

\subsubsection{El razonamiento y la Lógica}

La única manera de disponer del conocimiento, sin tener en cuenta la interpretación del sujeto, para que pueda ser aceptado o rechazado por otros individuos, es hacerlo explícito mediante el uso de un lenguaje. Sólo de esta manera el conocimiento abandonará el plano de lo subjetivo y podrá ser criticado o validado por los demás, dando lugar al conocimiento objetivo. (Popper, 1988). En el desarrollo del conocimiento, especialmente en los dominios científicos, los razonamientos deductivos, por la capacidad de preservar la verdad de las razones expuestas como premisas, han sido considerados de vital importancia. Así lo destaca Popper, afirmando que el conocimiento objetivo es construido a partir de enunciados contrastadores, es decir, aquellos que, a pesar de tener su origen en la observación, una vez expresados en algún lenguaje, tienen que sobrevivir a la crítica.

${ }^{6}$ Se utiliza la expresión «razonamiento natural» para designar el razonamiento espontáneo de un individuo. 
La lógica deductiva es el órgano de esta crítica; la transmisión de la verdad y la importancia de la retransmisión de la falsedad de la conclusión a las premisas, hacen que sólo sea posible hablar de conocimiento objetivo cuando éste es formulado $\mathrm{y}$, consecuentemente, contrastado. La evolución del conocimiento objetivo desencadena un proceso crítico que hace que, teorías que han sido aceptadas como válidas en un momento dado, puedan ser refutadas (momento de logro y avance científico) tal y como muestra la historia. Esta interpretación, siguiendo las ideas de Popper, habla del conocimiento objetivo como el conjunto de teorías que más se acercan a la verdad, porque no existen hasta el momento evidencias que las contradigan. Por lo tanto la verdad y el conocimiento que se tiene de ella podrían no coincidir. El conocimiento siempre estará fundamentado en enunciados hipotéticos, en conjeturas, y a partir de ellos, la lógica abre el camino a la exploración de la verdad (Popper, 1988). Así, la lógica se equipara con otras disciplinas en su relación con el desarrollo del conocimiento. Esta disciplina favorece la adquisición del conocimiento y contribuye al desarrollo de numerosos campos, como la computación, que tienen sus raíces en la lógica (Andrews, 2002):

"Let us put the study of logic into perspective. Humans are born with hands, but the development of tools has vastly expanded what humans can do. Humans are born with eyes, but the study of optics and other relevant disciplines has made it possible to develop sophisticated telescopes and microscopes which vastly expand what we can see, leading to amazing advances in fields such as astronomy and biology. We are endowed with the ability to reason, and the study of logic can serve the following purposes:

(1) enhance our ability to reason correctly, deeply, and with well founded confidence;

(2) prepare us to use, and perhaps help develop, the automated reasoning tools which are being developed and which will have revolutionary impact on many intellectual activities;

(3) prepare us to study the many deep and fascinating questions in mathematics, philosophy, and computer science which have their roots in logic." (Andrews, 2002, p. 1) 
El carácter científico de la lógica se debe a su poder normativo. La lógica no sólo explica las diferentes formas que presentan los razonamientos, sino que los califica de válidos y no válidos, abstrayendo de ellos lo único que determina su validez: la forma. La lógica formal considera como razonamientos válidos aquellos que, partiendo de premisas verdaderas, necesariamente se infieren conclusiones verdaderas, dando lugar a las leyes lógicas, que sirven de corrección para los procesos de inferencia, calificándolos de válidos o no válidos por la forma del razonamiento y no por el contenido o significado del mismo. En términos lógicos es muy importante diferenciar entre validez y verdad: se verifican los juicios, se validan los razonamientos.

Los razonamientos parecen ser los objetos que dan lugar a una reflexión sobre su validez. En ese sentido, la lógica formal, haciendo una abstracción de la estructura formal de este tipo de razonamientos y teorizando el concepto de inferencia válida, abre una puerta al conocimiento científico: la deducción.

Según Kneller el objeto de estudio de la Lógica no son los razonamientos concretos sino sus resultados y su corrección (Kneller, 1969):

\footnotetext{
"La lógica no es el estudio de los procesos concretos de razonamiento. Aquellos hechos mentales que juntos forman una secuencia dada de razonamiento son, hablando con propiedad, materia de la psicología. Al lógico le importa la corrección de los productos del razonamiento. Más aún, aquello que le interesa en estos productos es la conexión entre las conclusiones que afirman y los fundamentos (o evidencia) sobre los cuales éstas son afirmadas.

$[\ldots]$

Los productos del razonamiento son expresados en palabras, proposiciones y razonamientos. El estudio de estos elementos ofrece la forma de acceso más fácil a las distintas ramas de la lógica” (Kneller, 1969, pp.1,2)
}

De entre las diferentes formas de razonamiento identificadas por la lógica, tienen especial interés los razonamientos deductivos, es decir, aquellos que la verdad de la conclusión se 
sigue necesariamente de la verdad de las premisas. Estos razonamientos, conocidos como razonamientos válidos, ya fueron reconocidos por pensadores y filósofos en tiempos remotos. En la Grecia Antigua, identificar las formas de este tipo de razonamientos se consideró de vital importancia en la vida política, porque un discurso libre de ser refutado era indicio de estar en posesión de la verdad. De esta manera nace la Lógica formal como una rama de la Filosofía y de la Argumentación, cuyo principal representante y precursor fue Aristóteles (384-322 a. C.) quien estableció los principios de la lógica clásica. Hoy en día la lógica es independiente de la filosofía y está constituida como una ciencia formalizada.

En la obra de Deaño (1980), "Las concepciones de la Lógica”, el autor inicia un recorrido filosófico que trata de esclarecer la naturaleza de este término. No se va a hablar aquí de filosofía, aunque como punto de partida, creo que aporta definiciones bastante esclarecedoras.

En primer lugar, afirma el autor, que la lógica formal

"suele aparecer como aquella ciencia que se ocupa de la relación de consecuencia entre enunciados, en el sentido en que estudia los principios según los cuales un enunciado se sigue válidamente de otro u otros enunciados que se toman como premisas" (Deaño, 1980, p. 10)

Cabe añadir otra definición aportada en el mismo texto, y que voy a citar, dada la complejidad del término:

"es un canon de la inferencia deductiva; es el estudio de los principios de la inferencia formalmente válida; la teoría de las verdades formales” (Deaño, 1980, p. 10, 11)

Como se puede ver, los orígenes de esta ciencia están precisamente en el estudio de los razonamientos, tratando de caracterizar aquellos razonamientos que son considerados como válidos. La validez, en lógica, hace referencia a la aceptación de la conclusión. Por lo tanto, la lógica no trata de verificar, sino de validar. 
La lógica formal, constituida actualmente en ciencia formalizada, es lo que se conoce como lógica simbólica o lógica matemática.

"El carácter formal de la lógica se revela en el hecho de que esta disciplina se ocupa únicamente de estructuras formales, y de las relaciones entre tales estructuras. Una de estas relaciones es, por ejemplo, la deducibilidad.

$[\ldots]$

Sin embargo, una lógica puede ser formal sin ser todavía formalizada. Una lógica se halla formalizada cuando se enumeran en ella todos los signos no definidos; se especifica en qué condiciones una fórmula dada pertenece al sistema; se enumeran los axiomas usados como premisas y las reglas de inferencia consideradas como aceptables, etc." (Ferrater Mora, 1971, p. 20)

A partir de las bases asentadas por la lógica aristotélica, la lógica no ha dejado de evolucionar pasando de ser una modelización de los razonamientos válidos a constituirse en sistemas lógicos axiomáticos, totalmente independientes. Esta evolución de la disciplina se conoce como lógica matemática.

Actualmente, dentro de la lógica matemática, se han desarrollado dos tipos de lógica, la lógica clásica y la lógica no clásica. La lógica clásica se basa en los principios de la lógica aristotélica y las lógicas no clásicas son sistemas lógicos que transgreden alguno de estos principios y que no serán parte de este trabajo por rebasar los límites de nuestro estudio.

La lógica, como sistema formalizado, actúa como las matemáticas, modeliza algún conjunto de fenómenos que funcionan según los principios del sistema.

Por ejemplo, la lógica de primer orden es un modelo de las leyes del razonamiento matemático. También existen otros modelos basados en el pensamiento inteligente, que tratan de modelizar las formas de pensar del ser humano, cuya finalidad es la programación de computadoras (inteligencia artificial)

Teniendo en cuenta lo expuesto, se puede decir que la Lógica se desarrolla como una ciencia deductiva, con identidad propia, con sus sistemas axiomáticos, sus teoremas, 
siendo ésta la lógica de los lógicos puros, quienes han contribuido a su formación y desarrollo, y siguen contribuyendo. Pero a su vez, la Lógica es una ciencia propedéutica, que hace falta conocer para el estudio y desarrollo de otras materias o disciplinas como es el caso de la lógica de las matemáticas, que es la parte de la lógica necesaria para la comprensión de las matemáticas: definiciones, teoremas, demostraciones, etc.

\subsubsection{El razonamiento y las Matemáticas}

En matemáticas, se habla de la aplicación de las formas del pensamiento abstracto para solucionar problemas de justificación y de generalización, que son las dos prácticas clave que participan en el razonamiento matemático así como la simbolización, representación y comunicación, prácticas matemáticas fundamentales y sobre las que se apoyan las anteriores (Brodie, 2009).

Es muy frecuente encontrar en los textos matemáticos la expresión "razonamiento matemático" para hacer referencia a los razonamientos requeridos en la actividad matemática:

"Mathematical reasoning is reasoning about and with the objects of mathematics." (Brodie, 2009, p. 7)

Sin embargo, no todos los razonamientos que se pueden procesar en contexto matemático son de la misma naturaleza. Generalmente se suele decir que las dos formas de razonar en matemáticas son la inducción y la deducción.

Los razonamientos deductivos o también razonamientos válidos, tal y como hemos dicho en Lógica, son aquellos que, a partir de ciertos enunciados (premisas) se deriva otro enunciado (la conclusión) de manera tal que siempre que las premisas sean verdaderas, la conclusión también es verdadera.

La inducción es aquel tipo de razonamiento no deductivo que consiste en atribuir a todos los elementos de un conjunto una propiedad constatada en algunos elementos de ese 
conjunto, es decir, a partir de verdades particulares, se infiere una verdad generalizada (Panizza, 2005).

En matemáticas las reglas del razonamiento válido son las que dicta la lógica. En palabras de Suppes y Hill (1986):

“El paso lógico de las premisas a la conclusión es una deducción. La conclusión que se obtiene se dice que es una consecuencia lógica de las premisas si cada paso que se da para llegar a la conclusión está permitido por una regla. La idea de inferencia se puede expresar de la manera siguiente: de premisas verdaderas se obtienen sólo conclusiones que son verdaderas. Es decir, si las premisas son verdaderas, entonces las conclusiones que se derivan de ellas lógicamente, han de ser verdaderas" (Suppes y Hill, 1986, p. 44)

Cuando se consideran los razonamientos como procesos mentales, cabe la posibilidad de obtener conclusiones que no se deriven de razonamientos deductivos. Sin embargo, una de las condiciones para expresar los enunciados matemáticos y probar la veracidad de los mismos, dentro del ámbito de las matemáticas, es mediante el uso correcto de las reglas lógicas.

“la matemática aparece, de manera cada vez más clara, como la ciencia que estudia las relaciones entre ciertos entes abstractos definidos de manera arbitraria, con la única condición de que estas definiciones no conduzcan a una contradicción. Sería necesario añadir, sin embargo, para no confundir la matemática con la lógica, que estas definiciones arbitrarias han sido sugeridas primariamente por analogías con objetos reales." (Borel, 1962, p. 25)

La utilización de un lenguaje formal en contextos matemáticos o lógicos evita la ambigüedad que se presenta normalmente cuando se hace uso del lenguaje natural, que está expuesto a muchas interpretaciones que, en gran medida se deben al contexto y al factor humano. La lógica formal, ciencia que estudia los razonamientos deductivos recibe el calificativo de formal porque está constituida como una ciencia formal, con un lenguaje 
formal propio y unas reglas de formulación. La lógica formal es un instrumento útil y necesario para el desarrollo de las teorías científicas y por ello el lenguaje lógico es utilizado continuamente en dominios científicos distintos a la lógica entre ellos las Matemáticas.

La Lógica y las Matemáticas son ciencias formales porque no tratan de hechos, sino de entes ideales, es decir, que los lógicos y los matemáticos no tratan con la realidad, sino que construyen sus propios objetos. Seguramente se pueda decir que, muchas veces, estos entes sean abstracciones que se hacen de la realidad, como por ejemplo el concepto de número, tan extendido su uso y con el que todo el mundo está familiarizado como si de un objeto real se tratara. Estas ciencias necesitan inventar un lenguaje simbólico para denotar los objetos a los que hacen referencia así como para relacionarlos entre ellos, de ahí que se califiquen de formales. La importancia de estas ciencias y el motivo de su proliferación ha sido la capacidad que tienen para verter sobre estos signos una cantidad ilimitada de contenidos correspondientes a diferentes aspectos de la realidad y con ello expresar de manera clara y precisa, con rigor y exactitud, sin ambigüedad, ciertas partes de la realidad. Por ello tanto las Matemáticas como la Lógica han servido de herramienta para representar y relacionar conceptos y fenómenos de todas las ciencias empíricas como pueden ser la física, la química, la informática e incluso la psicología convirtiéndose ambas ciencias en herramientas imprescindibles en los procesos de modelización, de explicación o de predicción dentro de diferentes dominios.

“Esto es, podemos establecer correspondencias entre esas formas (u objetos formales), por una parte, y cosas y procesos pertenecientes a cualquier nivel de la realidad por la otra. Así es como la física, la química, la fisiología, la psicología, la economía, y las demás ciencias recurren a la matemática, empleándola como herramienta para realizar la más precisa reconstrucción de las complejas relaciones que se encuentran entre los hechos y entre los diversos aspectos de los hechos; dichas ciencias no identifican las formas ideales con los 
objetos concretos, sino que interpretan las primeras en términos de hechos y de experiencias (o lo que es equivalente, formalizan enunciados fácticos)

Lo mismo vale para la lógica formal: algunas de sus partes -en particular, pero no exclusivamente, la lógica proposicional bivalente - pueden hacerse corresponder a aquellas entidades psíquicas que llamamos pensamientos. Semejante aplicación de las ciencias de la forma pura a la inteligencia del mundo de los hechos, se efectúa asignando diferentes interpretaciones a los objetos formales. Estas interpretaciones son, dentro de ciertos límites, arbitrarias; vale decir, se justifican por el éxito, la conveniencia o la ignorancia. En otras palabras el significado fáctico o empírico que se les asigna a los objetos formales no es una propiedad intrínseca de los mismos. De esta manera, las ciencias formales jamás entran en conflicto con la realidad. Esto explica la paradoja de que, siendo formales, se "aplican" a la realidad: en rigor no se aplican, sino que se emplean en la vida cotidiana y en las ciencias fácticas a condición de que se les superpongan reglas de correspondencia adecuada. En suma, la lógica y la matemática establecen contacto con la realidad a través del puente del lenguaje, tanto el ordinario como el científico." (Bunge, 1963, p.2)

Y no sólo han sido utilizadas en ciencias experimentales sino que también se han ayudado mutuamente, interviniendo la lógica en el desarrollo de las matemáticas y las matemáticas en el desarrollo de la lógica, haciendo muy difícil, en ocasiones, la diferenciación entre ambas. La lógica ha contribuido a definir las matemáticas como ciencia deductiva, y las estructuras matemáticas, a su vez, han estructurado el conocimiento lógico.

Por lo tanto, desde un punto de vista matemático, la importancia de la lógica formal radica en los procesos deductivos que sostienen el constructo matemático. Las matemáticas, partiendo de axiomas, es decir, verdades matemáticas que sirven como punto de partida, construyen enunciados que son deducidos a partir de estos axiomas. Los enunciados matemáticos tienen carácter verdadero si son demostrados a partir de otros enunciados verdaderos y ello se hace mediante deducciones. Las deducciones se pueden llevar a cabo 
directamente mediante una regla de inferencia (un único paso) o varias reglas de inferencia (es necesario más de un paso).

Según lo expuesto, las matemáticas incorporan en su actividad unas determinadas formas de razonamiento, los razonamientos deductivos, caracterizados por sus reglas de inferencia, así como un lenguaje sin ambigüedades, que incluye los conectores lógicos y los cuantificadores. Todo ello permite construir proposiciones, funciones proposicionales, demostrar teoremas o contrastar hipótesis y conjeturas, elementos imprescindibles en su desarrollo.

\subsubsection{El razonamiento y la Lógica Informal}

Los razonamientos, como ya se ha dicho anteriormente, se consideran procesos mentales en el dominio de la psicología, que para ser observados y evaluados, han de ser expresados haciendo uso de un lenguaje verbal o escrito. Según Kneller (1969):

"Los productos del razonamiento son expresados en palabras, proposiciones y razonamientos" (Kneller, 1969, p. 2)

Además de los lenguajes simbólicos, encontramos todos los días argumentos expresados en lenguaje natural. Hay que tener presente que no todos los razonamientos verifican la condición de validez. En numerosas ocasiones, las conclusiones no son obtenidas mediante procesos de inferencia válida, y como consecuencia, surge otra modalidad de lógica, la lógica informal.

"Cuando la lógica formal es la lógica de la demostración, la lógica informal es la de la argumentación. Cuando la demostración es correcta o incorrecta, valorada en el primer caso y sin valor en el segundo, los argumentos son más o menos fuertes, más o menos pertinentes, más o menos convincentes. En la argumentación no se trata de mostrar, como en la demostración, que una cualidad objetiva, como la verdad, pase de las premisas a la conclusión, sino si es permitido admitir el carácter razonable, aceptable de una decisión, a 
partir de lo que el auditorio admite ya, a partir de tesis a las cuales adhiere con intensidad suficiente. El discurso persuasivo apunta, a una transferencia de adhesión de una cualidad subjetiva que puede variar de espíritu a espiritu” (Perelman, 2007, p. 141).

Por lo tanto, la Lógica informal o Ciencia de la Argumentación es la parte de la lógica que trata de analizar la fortaleza de un argumento no deductivo, es decir, la lógica informal da herramientas para analizar los argumentos de la vida real, expresados en lenguaje natural. La lógica informal no anula la lógica formal, sino que la toma como referencia, sirviéndole de modelo. Los argumentos son ejemplares lingüísticos resultantes de unos actos del habla, que pretenden el intercambio de razones con el fin de llegar a acuerdos en contextos de diálogo razonado especialmente la pragmática, parte de la lingüística que estudia los actos del habla donde se buscan, exponen y se contrastan razones para justificar conocimientos y acciones en un contexto de diálogo (Miranda, 2002). La Lingüística estudia los diferentes aspectos del lenguaje natural, que engloba, entre otros, el significado e interpretación de los signos linguísticos (semántica), sus reglas de combinación (sintaxis) o el significado social de las oraciones en ciertos contextos lingüísticos (pragmática).

\subsubsection{El razonamiento y la Inteligencia Artificial}

La Inteligencia Artificial es una rama de la Informática que tiene como objetivo la construcción de ordenadores cada vez más inteligentes. La inteligencia Artificial no concibe los ordenadores únicamente como métodos de trabajo e investigación, sino también de interpretación de la realidad. Esta nueva perspectiva ha dado lugar a una nueva rama de saber, las Ciencias Cognitivas, que tienen como objeto de estudio el análisis y la experimentación sobre el conocimiento, visto como un proceso de adquisición, codificación, manipulación, producción y transferencia de nueva información. En esta rama del saber confluyen dos líneas de investigación. Una de ellas es la teoría cognitiva que construye modelos para las diferentes formas del pensamiento que constituyen la base 
del comportamiento inteligente: actitudes, creencias, deseos y capacidades. La otra línea de investigación es conocida como Tecnología Intelectual y tiene como objetivo el diseño y construcción de máquinas inteligentes. Ambas líneas convergen en un mismo propósito, la modelización y comprensión del comportamiento humano.

La Inteligencia Artificial es una fusión de diferentes ramas de saber, de naturaleza científica y tecnológica:

"La Inteligencia Artificial, definida usualmente como la ciencia de construir máquinas de manera que, si las hicieran los humanos, requerirían inteligencia, toma un sentido científico viable, como disciplina informática moderna, durante la segunda mitad de este siglo. Es el resultado directo de la confluencia de diversas corrientes intelectuales (Teoría de la Computación, Cibernética, Teoría de la Información, Procesamiento Simbólico) desarrolladas sobre los cimientos formales de la Lógica y la Matemática Discreta, e impulsadas por el desarrollo de los computadores digitales”.'(Galipienso y otros, 2003, p. 4)

A pesar de esta confluencia de saberes, dos son las ramas que le han servido de cimientos a la Inteligencia Artificial: la Ingeniería y la Lógica Matemática. La Lógica Matemática se define en este caso como aquella orientación de la Lógica que estudia el razonamiento humano con métodos algebraicos, que utiliza símbolos inequívocos, definiciones precisas $\mathrm{y}$ axiomas que facilitan el razonamiento y las demostraciones rigurosas de modo mecánico (Álvarez, 1994). La Lógica es utilizada dentro y fuera de la Inteligencia Artificial para representar conocimiento y realizar inferencias sobre el mismo, y su importancia en este campo se debe a su capacidad para expresar y resolver gran cantidad de problemas y para efectuar inferencias de manera automática

El recorrido llevado a cabo sobre el significado del término "razonamiento" muestra la complejidad que envuelve a este concepto. Se puede hablar de razonamiento como un proceso, pero también como el resultado de dicho proceso. Se puede hablar de la manipulación de la información, para producir nueva información (invención, 
descubrimiento), pero también se puede hablar de razonamiento como proceso de validación, que tiene como fin asegurar la veracidad de una proposición (explicación, justificación, demostración). También repara en la importancia del individuo y el contexto como elementos que condicionan el uso y la validez de los razonamientos.

En cuanto a los dominios de referencia que estudian el objeto razonamiento, hemos destacado la Psicología, la Lógica, las Matemáticas, la Lógica informal o la Inteligencia Artificial. La Psicología se hace cargo de los razonamientos subjetivos. La Lingüística y las Ciencias de la Argumentación estudian las expresiones de los razonamientos en lenguaje natural, medio de comunicación utilizado por los individuos de la sociedad y las Matemáticas, la Lógica y la Inteligencia Artificial modelizan los razonamientos que sirven de modelo para el sistema de enseñanza. Y por último, la Didáctica de las Matemáticas, dominio de referencia que aborda el estudio del objeto razonamiento y utiliza todos estos saberes con el fin de "formar matemáticamente" los razonamientos de los estudiantes.

¿Qué nos dice la Didáctica de las Matemáticas respecto al razonamiento y la enseñanza de las Matemáticas?

\subsubsection{El razonamiento y la Didáctica de las Matemáticas}

El interés por el desarrollo del razonamiento lógico ${ }^{7}$ desde los primeros niveles de la educación es una línea de investigación fundamental en Didáctica de las Matemáticas y de forma especial en la Universidad de Burdeos. A partir de la modelización del conocimiento matemático en términos de situación, los razonamientos lógicos involucrados en la actividad matemática no sólo dependen de un saber oficial, las Matemáticas, sino que también la Lógica juega un papel importante.

\footnotetext{
7 Se considera el razonamiento lógico lo mismo que el razonamiento válido y que el razonamiento deductivo.
} 
El problema de la enseñanza de la Lógica ya fue abordado por Orús en la investigación llevada a cabo en su tesis (Orús, 1992). Orús propone una ingeniería didáctica que muestra cómo es posible, a partir de un contenido curricular -la clasificación de plantasprovocar en el estudiante una ruptura que permita movilizar un nuevo conocimiento, en este caso un conocimiento lógico. Pitarch continúa la misma línea de investigación en Educación Secundaria, con el objetivo de acceder al conocimiento lógico mediante la enseñanza de la Estadística, conocimiento matemático incluido en el currículo (Pitarch, 2002 y 2015).

Estas situaciones para la enseñanza de la lógica, desarrolladas para alumnos de Educación Infantil y Primaria en la Escuela Michelet de Talence (Burdeos, Francia), reportó la conocida "trilogía" sobre las nociones protomatemáticas y paramatemáticas ${ }^{8}$ relacionadas con la clasificación y que han mostrado ser útiles en el desarrollo de las actividades lógicas de los niños: los procesos de enumeración en el aprendizaje del número (Briand, 1993), el dominio del espacio para el aprendizaje de la geometría (Berthelot y Salin, 1992) o los razonamientos en la relación didáctica (Orús, 1992). Estas investigaciones retomaban los trabajos anteriores de (Salin ,1976; Digneau, 1980; Maudet, 1982; Peres 1984). A lo largo de estos trabajos se presentan las situaciones didácticas que, tras años de realizaciones en las aulas y de observaciones sistemáticas, dieron lugar a muchos de los resultados que sirvieron para acrecentar la Teoría de las Situaciones Didácticas.

En la escuela infantil, se elaboraron situaciones que supusieron todo un cambio de concepción en la formación lógica de los niños. La búsqueda del sentido para la construcción del conocimiento lógico, permitió comprobar la importancia de las situaciones adidácticas en la construcción del sentido del conocimiento.

\footnotetext{
${ }^{8}$ Terminología utilizada por Chevallard para referirse a las nociones utilizadas implícita y explícitamente en la enseñanza de las matemáticas pero sin ser consideradas objeto de enseñanza (Chevallard, 1998).
} 
Los trabajos sobre la creación de un código de designación en la escuela infantil (Salin, 1976; Digneau, 1980; Peres, 1984) así como la función de la conjunción como conectiva lógica (Maudet, 1980) muestran las posibilidades de los niños respecto a los conocimiento lógicos, y muestran cómo se activan los procesos lógicos de los alumnos, implicados en las actividades matemáticas. Las diferentes situaciones adidacticas se revelan necesarias para el funcionamiento de los razonamientos que sin la oportunidad de comunicar y validar los resultados de sus acciones no pasarían del plano de lo subjetivo. El código de designación es resultado de una necesidad colectiva, que debe contener la información necesaria para identificar y para distinguir aquello que representa.

El concepto de salto informacional surge precisamente en la devolución de las situaciones adidácticas. Se refiere a la modificación necesaria de una variable didáctica, llevada a cabo por el profesor, para que el alumno abandone la estrategia en uso por inadecuada y busque otra alternativa. Este concepto supone el control de la situación por parte del docente, ya que la modificación ha de invalidar la estrategia anterior pero sin provocar la ruptura del contrato didáctico.

En este mismo nivel educativo destacó también el trabajo de Briand con la identificación de la enumeración como conocimiento protomatemático previo a la numeración (Briand, 1993).

Otra de las líneas de investigación abiertas a partir de estos resultados se corresponde con los conocimientos protomatemáticos asociados a las actividades geométricas (Berthelot y Salin, 1992). El dominio del espacio (microespacio, mesoespacio y macroespacio ${ }^{9}$ ) se manifiesta como un obstáculo en la construcción del conocimiento lógico, que no surge de manera espontánea a partir de la incesante obsevación de los objetos ostensivos.

\footnotetext{
${ }^{9}$ Conceptos propuestos por Gálvez (1985, citado en Berthelot y Salin, 1992).para clasificar el tamaño del espacio con el cual el sujeto entra en interacción en determinada tarea. El micro-espacio constituye el espacio ligado a la manipulación de los objetos pequeños; el meso-espacio es el espacio del desplazamiento del sujeto en un dominio controlado por la vista, los objetos están fijos y miden entre 0,5 y 50 veces el tamaño del sujeto; el macro-espacio corresponde a un sector del espacio cuya dimensión es tal que se puede abarcar solamente por intermedio de una sucesión de visiones locales, separadas entre ellas por los desplazamientos del sujeto en la superficie terrestre.
} 
Y por último, para completar la triple temática derivada de estas investigaciones, el estudio del razonamiento en la relación didáctica (Orús, 1992), con resultados interesantes para el desarrollo de la TSD como los diferentes estatus del razonamiento según el tipo de situación adidáctica, la identificación del pensamiento natural como un obstáculo en el desarrollo del razonamiento lógico o la posibilidad de enseñar lógica a alumnos de educación primaria a partir de contenidos curriculares. Orús, a partir de un problema docente con una actividad de clasificación de plantas, se plantea la posibilidad de llevar a cabo una ingeniería didáctica para la enseñanza de la lógica. La ingeniería está organizada en tres etapas, tomando como modelo epistemológico de referencia el análisis tipológico. La primera etapa "El juego del viaje" consiste en una clasificación jerárquica a partir de los gustos de los alumnos, con el objetivo de trabajar operaciones lógicas como la implicación, la conjunción o la disyunción. En segundo lugar se trata de una “clasificación de hojas”, con las operaciones conjuntistas que conlleva y en último lugar, “El juego de coalición” situación fundamentada en las relaciones sociales y que moviliza conocimientos como reconocimiento de similitudes y diferencias entre individuos, así como su proximidad o distancia, y formación de agrupamientos homogéneos.

Orús (1992) basándose en los conceptos teóricos de la TSD, muestra en su tesis cómo la modelización del sistema de enseñanza posibilita la gestión de los razonamientos de los alumnos en el aula. Los diferentes tipos de situaciones identificadas en una situación de enseñanza-aprendizaje, permite diferenciar las diferentes formas de funcionar los razonamientos de los alumnos. Así pues, los razonamientos personales de los alumnos funcionan cuando éstos se enfrentan y actúan por primera vez con el medio didáctico. A partir de las primeras intervenciones personales, el sujeto reacciona y además reflexiona sobre los resultados obtenidos, pasando a ser un sujeto epistémico, fuente de conocimiento, y los razonamientos personales pasarán a ser razonamientos de formulación y de validación, origen de los razonamientos matemáticos, cuya finalidad es encontrar la solución a problemas matemáticos y poder probar que la solución obtenida es válida. En primer lugar, estos razonamientos son internos al sujeto, pero según el 
modelo teórico, el sujeto pasará por momentos en los que tenga que comunicar sus resultados y convencer a otros, y no sólo a sí mismo, de la verdad. De esta manera los razonamientos pasarán del plano subjetivo al objetivo con todos los requisitos que ello conlleva. El razonamiento, en la didáctica de las matemáticas, será por un lado, un medio para el aprendizaje de las matemáticas, y por otro, un conocimiento en sí mismo, contextualizado.

Nuestro trabajo continúa con la línea de investigación de los trabajos citados, concretamente sobre el razonamiento lógico en la enseñanza de las matemáticas y su formación.

Desde un punto de vista más amplio, se pueden considerar otras investigaciones realizadas sobre el razonamiento en la enseñanza de las matemáticas.

\subsection{Antecedentes de investigación sobre el razonamiento en la enseñanza de las matemáticas}

Desde diferentes ámbitos de investigación se ha tratado de esclarecer, como caso particular, el razonamiento y sus funciones dentro de la relación didáctica. En el ámbito de la Psicología, se vienen realizando abundantes estudios interdisciplinares en relación a los procesos mentales de adquisición y producción del conocimiento en general y de los conocimientos matemáticos en particular. Mencionaremos especialmente los trabajos desarrollados por el grupo internacional Psychology of Mathematics Educacion (PME, http://www.igpme.org/) ${ }^{10}$ Entre la gran variedad de temas abordados, se encuentra la

\footnotetext{
${ }^{10}$ El grupo internacional Psychology of Mathematics Educacion, se constituye como grupo interdisciplinar de investigación en 1976, en el tercer Congreso Internacional de Educación Matemática (ICME3) celebrado en Karlsruhe, Alemania. Hay que señalar que cuando sólo se habían celebrado dos congresos internancionales de Educación Matemática, ya se desgaja la PME constituyendo una corriente de investigación interdisciplinar para abordar la problemática cognitiva de la investigación de la educación matemática, aunque de marcado carácter psicológico. Desde entonces viene organizando sus propias Conferencias anuales, independientemente del ICME. El libro Handbook of Research on the Psychology of Mathematics Education. Past, Present and Future, editado en 2006 por A. Gutierrez (Universidad de
} 
problemática del razonamiento en la educación matemática, considerado éste, desde el punto de vista cognitivo, como proceso mental de producción de nuevos conocimientos. Estos trabajos se identifican como trabajos sobre el pensamiento (thinking), encontrando trabajos específicos sobre el pensamiento asociado a los diversos aspectos del conocimiento matemático, como por ejemplo el pensamiento numérico (numerical thinking) (Verschaffel, Greer, Torbeyns, 2006). Desde esta perspectiva cognitiva, las investigaciones más generales sobre el razonamiento matemático (mathematical thinking) se enmarcan en el Advanced Mathematical Thinking (AMT), cuyo principal exponente es Tall a través de su obra "Psichology of Advanced Mathematical Thinking" (Tall, 1991; Trigueros, 2005). En esta línea de investigación, el razonamiento se ha convertido en pensamiento y el enseñar a razonar en enseñar a pensar. Este deslizamiento, nos parece una dificultad para los profesores de matemáticas para avanzar en la problemática que estamos esbozando, y podría complicar todavía más su tarea docente. Si para gestionar el razonamiento los profesores tienen un referente en la lógica formal ¿donde encontramos los referentes para el "pensamiento"?

En Matemáticas, el razonamiento lógico está directamente relacionado con los procesos de prueba y demostración matemática, así como con la resolución de problemas o la toma de decisiones, entre otras actividades de naturaleza matemática.

“Pour qu'un raisonnement puisse être une démonstration, il est necessaire qu'il soit un raisonnement valide” (Duval, 1992, p. 42)

En este sentido, son numerosas las investigaciones realizadas en el campo de la Didáctica de las Matemáticas. Los estudios de Balacheff (1988) sobre la enseñanza de la demostración se pueden considerar un ejemplo de la preocupación generalizada sobre los razonamientos de los estudiantes en relación a la enseñanza y aprendizaje de las matemáticas. Balacheff, basándose en estudios anteriores sobre la enseñanza y

Valencia, España) y P. Boero ( Universidad de Gérnova, Italia), recoge las principales aportaciones de este grupo PME. 
aprendizaje de la demostración (Reynolds, 1967, Bell, 1976; Stein, 1981, Fischbein, 1982; Vinner, 1983) habla de la dificultad que tienen los estudiantes para comprender y llevar a cabo demostraciones matemáticas así como para entender la relación entre demostración y validación. La diferenciación que hace entre explicación, prueba y demostración, como niveles de actividad distintos, clarifica la manera que tienen los estudiantes de llegar a convencerse de la validez de la solución. Mientras que en una explicación alguien parte de una afirmación, a su parecer verdadera, y trata de hacer inteligibles sus razones a otra persona, en la prueba la verdad depende de la aceptación colectiva de dicha explicación. En matemáticas la prueba dominante es la demostración, una serie de enunciados que se organizan según unas reglas establecidas (reglas lógicas). Así pues diferencia dos tipos de prueba, la pragmática (de tipo empírico) y la intelectual (se apoyan en las formulaciones de las propiedades y en sus relaciones). En este último caso lo más importante no es la verdad de las afirmaciones sino la necesidad de su validez. En cuanto al lenguaje, dice servir de herramienta para el cálculo lógico y no solamente como medio de comunicación. Su elaboración requiere en ese caso una descontextualización, despersonalización y destemporalización de la acción, lo cual se consigue únicamente con un lenguaje simbólico. Para pasar de la prueba pragmática a la intelectual, la transición se apoya en tres polos: el de los conocimientos, el lingüístico y el de la validación. En cuanto a la enseñanza de la demostración, pone el acento en las relaciones sociales como motor de la validación y retoma el problema de la argumentación (Perelman, 1970; Oleron, 1983, 1985; Moeschler, 1985) en tanto que medio para conseguir la adhesión del interlocutor. Con todo ello Balacheff analiza los procesos de prueba y concluye la dificultad que supone pensar en situaciones que no solo construyan la herramienta prueba sino que la problematicen.

Balacheff, a partir de investigaciones relativas a las prácticas de los alumnos, sostiene que la prueba presenta una evolución jerarquizada, diferenciando cuatro niveles. En primer lugar el empirismo naíf, que consiste en dar por verdadero un resultado tras ser comprobado en algunos casos particulares; en segundo lugar, se trata del experimento 
crucial, que permite elegir entre dos hipótesis; el tercer nivel, el ejemplo genérico, que se refiere a aquellos casos en los que los estudiantes explican las razones que apoyan la verdad de una afirmación apoyándose en las características de un objeto, actuando éste como representante de una clase. Y por último, el experimento pensado o experimento mental, que evoca la acción internalizada y separada de una representación particular. Debe haber una ruptura cognitiva para pasar de un nivel a otro y avanzar en la apropiación del sentido de la prueba y además, como afirma el autor, no únicamente el lenguaje utilizado por los alumnos en las pruebas matemáticas sirve para esclarecer el nivel en el que se encuentra. El enfoque riguroso en la resolución de problemas así como tener en cuenta el estatus del conocimiento implicado ayuda a analizar el carácter demostrativo o genérico de los medios de validación utilizados.

Los razonamientos de los estudiantes, bajo el marco conceptual ofrecido por Balacheff en relación a la demostración y su enseñanza, son entendidos como procesos mentales que se consideran procesos de validación cuando hay un convencimiento por parte del sujeto respecto a la nueva información. Este convencimiento (Moreira, 1993) en su estudio sobre el tratamiento de la verdad matemática en la escuela, relaciona el razonamiento con la verdad considerando esta última como la sanción, reconocimiento $o$ producción de un buen razonamiento.

Demostrar en matemáticas no siempre tiene la misma finalidad. Así lo afirma De Villiers en su trabajo sobre el papel y la función de la demostración en matemáticas (De Villiers, 1993). Las funciones que De Villiers diferencia en el uso de la demostración son las siguientes:

- La demostración como medio de verificación/convicción.

- La demostración como medio de explicación.

- La demostración como medio de sistematización

- La demostración como medio de descubrimiento

- La demostración como medio de formulación 
Y en relación con el aprendizaje, este autor afirma:

"La enseñanza de las matemáticas debería (al menos en parte) reflejar la naturaleza de las matemáticas y lo que es realmente significativo para los matemáticos en activo.

Como seres humanos en funcionamiento cognitivo, los alumnos tienen básicamente la misma necesidad de actividades significativas que los matemáticos, lo que incluye el conocimiento, la comprensión y experimentación de la funcionalidad (utilidad) de las actividades en las que participan." (De Villiers, 1993, pp. 27-28)

Arsac pone de relieve la importancia que tiene el reconocimiento de las verdades matemáticas para razonar correctamente (Arsac, 1988). Los estudios llevados a cabo por el autor muestran cómo, en contextos geométricos, es frecuente razonar a partir de verdades que funcionan como axiomas y sin embargo no son evidentes para los estudiantes. Este obstáculo, de naturaleza lógica, interfiere en los procesos de prueba y justificación e indirectamente sobre la construcción del conocimiento matemático.

En la web http://www.lettredelapreuve.org/ creado por Balacheff y col. podemos encontrar un espacio donde se comparten numerosos trabajos de investigación sobre prueba y demostración publicados en la revista International Newsletter on the Teaching and Learning of Mathematical Proof.

El Decimonoveno Estudio de la Comisión Internacional de Instrucción Matemática (ICMI Study 19) ha reunido las diferentes líneas de investigación relacionadas con la prueba y la demostración. Las principales aportaciones a este encuentro se recogen y estructuran en el documento elaborado por Hanna y De Villiers, con el objetivo de dar a conocer el estado de las investigaciones aportadas así como de mostrar el interés de la temática tratada (Hanna y De Villiers, 2008).

En primer lugar y a rasgos generales, las tres ideas claves bajo las que se enfoca el estudio de la prueba y la demostración actualmente son: 
- Los programas escolares, un vínculo con la disciplina de la prueba, compartida por los matemáticos.

- La prueba y demostración, una forma de pensar que profundiza en la comprensión de las matemáticas y en sentido más amplio la naturaleza del razonamiento humano.

- La prueba y demostración, fundamentales pero complejas, deberían ser introducidas gradualmente desde los niveles más tempranos.

En segundo lugar, cabe destacar la variedad de contextos a los que hacen referencia los trabajos:

- Contexto simbólico

- Contexto verbal

- Contexto visual

- Contexto tecnológico

- Contexto social

Y en cada uno de estos contextos, los siguientes temas cobran a su vez protagonismo:

- Las opiniones y creencias de los docentes.

- La preparación de los docentes y desarrollo profesional.

- Los materiales curriculares y su apoyo a la enseñanza.

A partir de estas investigaciones, hemos seleccionado las ideas que, a nuestro parecer, nos han parecido más relevantes para nuestro trabajo:

La prueba, desde una perspectiva cognitiva, es una construcción conceptual que tiene su origen en la actividad humana, a través del espacio y del tiempo, destacando como actividad principal involucrada en el proceso, la formulación del conocimiento así como el interés por los esfuerzos llevados a cabo para alcanzarlo, y todo ello haciendo uso del lenguaje y de la lógica. Este resultado, desde un punto de vista didáctico, plantea la posibilidad de contribuir, desde las aulas, en la construcción de dicho concepto. También se considera importante para la cuestión didáctica el rol de la prueba dentro de las matemáticas, tanto desde un punto de vista histórico como epistemológico. Con todo ello 
se concluye que es necesario incluir la prueba como objeto de enseñanza, donde el papel del profesor es fundamental. Revisiones teóricas en educación matemática, entre ellas, la Teoría de las Situaciones Didácticas (Brousseau, 1986), ayudan a explicar el rol del profesor en relación con el objeto 'prueba'.

Entre las investigaciones llevadas a cabo sobre la prueba, se encuentran aquellas que focalizan su estudio en la lógica. La lógica es abordada principalmente desde dos perspectivas: la transición entre la argumentación y la prueba y el rol de la lógica en la enseñanza de la prueba. La argumentación es considerada un amplio dominio de referencia en el que la prueba es un caso especial, y a partir de las reglas de validación que normalmente son utilizadas en la argumentación, se puede iniciar a los estudiantes en el uso de símbolos y reglas más estrictas; buscar entornos que puedan facilitar la argumentación y la prueba en las aulas es uno de los objetivos de estas investigaciones. Además se destaca la importancia de enseñar lógica junto con las matemáticas, porque la lógica opera tanto en la sintaxis como en la semántica del discurso matemático. A través de diferentes estudios se muestra la dificultad que presenta una gran parte de los estudiantes universitarios en la ejecución y comprensión de los textos formalizados, que incluyen definiciones, teoremas y demostraciones. La interpretación lógica de sus componentes no se lleva a cabo, en absoluto, de manera espontánea y obstaculiza el proceso de aprendizaje. Las investigaciones llevadas a cabo constatan que la lógica formal de los estudiantes universitarios, necesaria para llevar a cabo las deducciones formales, no es suficiente. Estas investigaciones ponen de manifiesto la necesidad de una lógica de la cuantificación para llevar a cabo demostraciones matemáticas correctamente. (DurandGuerrier, 1996a, 1996b, 2005; Durand-Guerrier y Arsac, 2003, 2009)

En un estudio sobre los razonamientos de los estudiantes, en primeros cursos universitarios, Durand-Guerrier y Arsac muestran cómo la lógica aplicada a la obtención de conclusiones no sigue un modelo teórico de lógica. El modelo de la lógica formal constituida como ciencia formal está ausente y los estudiantes recurren a formas de 
razonamiento cuyo rigor se basa en rutinas de comportamiento ligadas al contexto o dominio de aplicación. Esto desencadena una serie de problemas en los procesos de demostración matemática y de resolución de problemas, cuando el alumnado está ante una situación nueva o no habitual. El dominio de referencia no es identificado y el estudiante no está seguro de su forma de proceder, esperando muchas veces que se le enseñe a razonar dentro de ese nuevo dominio (Durand-Guerrier y Arsac, 2003).

Se valora el uso de pruebas en las aulas de niveles inferiores, no universitarios, pero se destaca que trabajar exclusivamente con pruebas que tienen un soporte visual, como es el caso de las pruebas en geometría, no es suficiente para la comprensión lógica de la demostración. Es necesario considerar la lógica como una parte del contenido a enseñar, construyendo significados de los conceptos lógicos e iniciando a los estudiantes en el uso del lenguaje simbólico.

Todo lo que se ha dicho sobre razonamiento lógico y sobre la lógica, en relación con la adquisición de conocimiento, en general, y con las matemáticas, en particular, justifica la necesidad del conocimiento lógico para guiar los razonamientos de los estudiantes.

Los razonamientos lógicos no son siempre espontáneos y se incorporan al conjunto total de razonamientos que, de forma natural, llevamos a cabo todas las personas. Ser capaz de diferenciar los razonamientos válidos y utilizarlos correctamente debe ser uno de los objetivos de la educación en general y de la educación matemática en particular. Las matemáticas pueden ofrecer contextos en los que las relaciones lógicas son una constante y de esta manera hacer posible que, poco a poco, y desde los primeros niveles educativos, los alumnos se apropien de una manera de hacer y de pensar, como pueden ser las pruebas y las demostraciones matemáticas.

Ser conocedor de un modelo de razonamiento correcto facilita la posibilidad de hacer un uso consciente del mismo y para ello se puede actuar desde los sistemas de enseñanza. 


\subsection{El razonamiento y la modelización del enfoque epistemológico de la Didáctica de las Matemáticas}

Una breve introducción sobre la evolución de la investigación en la Educación Matemática nos permite identificar la especificidad del enfoque epistemológico de la investigación en Didáctica de las Matemáticas que comparten la Teoría de las Situaciones Didácticas (TSD) y la Teoría Antropológica de lo Didáctico (TAD) ${ }^{11}$.

La Educación Matemática se ha preocupado, desde sus orígenes, por la problemática didáctica general, proporcionando explicaciones a los diferentes fenómenos relacionados con la enseñanza de las matemáticas. Estos fenómenos han sido observados, descritos y explicados a partir de la interpretación hecha desde diferentes disciplinas científicas, como la pedagogía, la psicología, o las matemáticas. Estos dominios de referencia, utilizados para dar respuesta a la problemática general de la Educación Matemática, tienen sus propios objetos de estudio, interpretando los fenómenos de acuerdo a los objetos observados: la metodología del profesor, el aprendizaje del alumno o la epistemología de las matemáticas, entre otros. Una de las corrientes que cambiaron la perspectiva de las investigaciones en Educación Matemática fue el interés suscitado por el profesor, provocando un desplazamiento del centro de atención que hasta entonces estaba en el alumno, hacia el profesor (Brousseau, 1984). Este cambio dio lugar a numerosos estudios sobre las creencias, conocimientos y prácticas de los profesores (Artigue, 2011). Los diferentes problemas que pronto surgen en el seno de la Educación Matemática como institución ponen en evidencia que las disciplinas que hasta entonces sustentaban las investigaciones en Educación matemática eran insuficientes, generando la necesidad de un nuevo planteamiento teórico. Así pues, aparece un nuevo marco teórico capaz de abarcar las ampliaciones de la problemática didáctica. Tal y como explica

\footnotetext{
${ }^{11}$ A lo largo del texto nos referiremos a la Teoría de las Situaciones Didácticas y a la Teoría Antropológica de lo Didáctico, con las siglas TSD y TAD, respectivamente.
} 
Gascón en uno de sus artículos (Gascón, 2002), la evolución de la Educación Matemática hacia la Didáctica de las Matemáticas se debe a una doble ruptura:

- El fracaso de la Pedagogía en su intento de dar respuestas al problema de la Educación Matemática, dando paso al Programa Cognitivo.

“Históricamente el nacimiento del Programa cognitivo de Investigación en Didáctica de las Matemáticas estuvo determinado explícitamente por la insuficiencia manifiesta de la noción general de aprendizaje humano para abordar el Problema de la Educación Matemática y la necesidad de modelizar el aprendizaje matemático del alumno.

$[\ldots]$

El problema de la Educación Matemática puede ser abordado y resuelto a partir del análisis de ciertas características individuales de los sujetos (actitudinales, cognitivas, metacognitivas, motivacionales, lingüísticas, etc.) relativas a su relación con los objetos matemáticos. Por tanto para tratar dicho problema, la Didáctica de las Matemáticas debe construir y contrastar empíricamente modelos: (a) De la estructura cognitiva asociada a un concepto; (b) Del desarrollo del pensamiento matemático del sujeto” (Gascón, 2002, p. 16)

- La ruptura con el modelo existente hasta el momento de las matemáticas como conjunto de saberes perfectamente identificados, lo que supuso la diferenciación entre el Programa Cognitivo y el Programa Epistemológico

“El Programa Epistemológico de Investigación en Didáctica de las Matemáticas surgió de la convicción de que el origen del problema de la Educación Matemática está en las propias matemáticas. El nacimiento del Programa Epistemológico constituye una respuesta a la insuficiencia manifiesta de los modelos epistemológicos de las matemáticas $[\ldots]$

El problema de la Educación Matemática puede ser abordado a partir del análisis de las prácticas matemáticas que se llevan a cabo en las diferentes instituciones (no sólo docentes). Por tanto, para tratar dicho problema, la Didáctica de las Matemáticas debe construir y contrastar empíricamente: (a) Un modelo epistemológico general de las matemáticas y 
modelos locales de sus diferentes ámbitos; (b) Modelos de la génesis y el desarrollo de las organizaciones matemáticas de cada una de las instituciones” (Gascón, 2002, p. 19)

A partir de este momento la Didáctica de las Matemáticas despega como una ciencia con identidad propia, que integra en su estudio todo aquello que está relacionado con la enseñanza y difusión de las matemáticas en las diferentes instituciones implicadas en el proceso:

"Ciencia de las condiciones específicas de la difusión (impuesta) de los saberes matemáticos útiles a las personas y a las instituciones humanas (Brousseau, 1994)" (Gascón, 1998, p. 11)

Brousseau fue el precursor en considerar la Didáctica de las Matemáticas como disciplina científica. A partir de sus primeras ideas sobre 'epistemología experimental' Brousseau defiende que el conocimiento matemático es producto de una actividad matemática en la que se ve involucrado el sujeto que aprende, y está vinculado a las situaciones que lo han generado (Brousseau, 1986). De esta manera se abre paso a una nueva línea de investigación conocida como Didáctica Fundamental y que ha dado lugar a diferentes teorías, consideradas como teorías científicas, dado el carácter experimental de las mismas, entre ellas, la TSD y la TAD. Como afirma Gascón, (Gascón, 1998) desde el punto de vista de la Didáctica Fundamental, debe asumirse la responsabilidad de elaborar y contrastar empíricamente los modelos de la actividad matemática que forzosamente se utilizan.

\subsubsection{El razonamiento según la modelización de la TSD}

La TSD ha sido una de las aportaciones más relevantes en el campo de la Educación Matemática. Así lo confirman ambas medallas Felix Klein, de reconocido prestigio, obtenidas por Brousseau en 2003 y Artigue en 2013. Estos galardones concedidos por la Comisión Interna de Instrucción Matemática (ICMI) son el reconocimiento a sus aportaciones, esenciales para el campo de la investigación en Educación Matemática. Las 
visiones epistemológicas, cognitivas y sociales que sustentan esta teoría constituyen una visión original a la vez que productiva para las investigaciones sobre el aprendizaje en el aula. El punto de vista constructivista en que se basa la TSD sostiene que el conocimiento matemático es producto de una actividad matemática, en la que se ve involucrado el sujeto que aprende, y está vinculado a las situaciones que lo han generado. Esta idea "clave" de la que parte y que antepone en el tiempo, la situación al conocimiento, surge a partir de la vinculación de Brousseau con la escuela piagetiana y de la influencia que ejercieron los estudios sobre 'epistemología genética', que interpretaban el aprendizaje humano a partir de los procesos de 'adaptación al medio'. La primera noción de situación, que dará el nombre a la teoría como la Teoría de las Situaciones en Didáctica, considera la situación el corazón de la actividad matemática y la que provocará la génesis del conocimiento en situación escolar, constituyéndose así en una herramienta para el profesor. En palabras de Brousseau:

\footnotetext{
"Una situación, es un modelo de interacción entre un sujeto y un medio determinado. El recurso del que dispone el sujeto para alcanzar o conservar en este medio un estado favorable es una gama de decisiones que dependen del uso de un conocimiento preciso".
} (Brousseau, 2007, p. 17)

Esta primera concepción de 'situación', que servía de herramienta para el profesor y que éste utilizaba para enseñar, no tenía en cuenta en su modelización el rol del profesor. Más adelante, al considerar la Didáctica de las Matemáticas como ciencia de las condiciones de la difusión y apropiación de los conocimientos matemáticos, esta modelización se ve ampliada al ser reconocida la importancia del profesor en el proceso de enseñanza y de aprendizaje, siendo responsable último de la difusión de los conocimientos matemáticos. En esta modelización, la situación, ahora denominada situación didáctica va a tener en cuenta el entorno del alumno, incluyendo toda componente relacionada con su formación matemática dando lugar a la Teoría de las Situaciones Didácticas, nombre con el que hoy conocemos esta teoría. 
Toda situación didáctica implica, en primer lugar, la interacción entre el sujeto que aprende y un medio. La palabra medio es una traducción de "milieu", término utilizado originalmente por Brousseau y que tiene el significado de "entorno", en inglés "environment". Se considera como medio el entorno que rodea al alumno dentro del proceso de enseñanza-aprendizaje y que mantiene una relación con el conocimiento. El medio estará constituido por materiales, objetos (si los hubiera, aunque podría no haberlos), pero también por los actores de la situación de enseñanza y aprendizaje, por sus acciones y por sus funciones o sus tareas. El medio debe dar lugar a una problemática, de la que el profesor no solo es consciente, sino que es causante de la misma, y que el alumno debe resolver apropiándose del conocimiento matemático puesto en juego. Para que esto sea posible, en toda situación didáctica debe existir una confrontación del alumno con el problema, que debe trabajar de la forma más autónoma posible. El profesor, dentro de la situación didáctica, no debe indicar nunca al alumno cuáles son los pasos a seguir o qué estrategia debe utilizar, debe ser el alumno mediante sus interacciones con el medio que le proporciona la situación, sus procesos de razonamiento, sus decisiones, sus errores, etc., quien construya el conocimiento. El docente sólo deberá facilitar las situaciones que hagan posible que el alumno, de manera autónoma, resuelva el problema, y esta acción lleve a la adquisición del conocimiento matemático. Esta etapa del aprendizaje es conocida en la teoría de las situaciones como situación adidáctica, parte necesaria del proceso, aunque no suficiente. Se debe diferenciar entre el conocimiento matemático que se produce en una situación particular y el saber matemático, organizado y estructurado, a partir de descontextualizaciones, generalizaciones, interrelaciones,... Por este motivo para acceder al saber matemático, hay que integrar las acciones y relaciones que permiten la resolución de un problema, en una estructura teórica que abarque dichas relaciones. Cualquier actividad matemática debe estar pensada con una finalidad didáctica, y debe formar parte de ese hacer cultural que permita llegar a una construcción formal. Como indica Brousseau: 
"Un medio sin intenciones didácticas es claramente insuficiente para inducir en el alumno todos los conocimientos culturales que se desea que él adquiera" (Brousseau, 2007, p.31)

Las situaciones adidácticas situan al alumno en confrontación con el medio, y bajo su responsabilidad debe tratar de solucionar la situación que se le plantea. El conocimiento puesto en juego solamente depende de la dialéctica establecida entre el alumno y el medio. La situación adidáctica se convertirá en didáctica cuando la intervención del profesor condicione esta relación. Esta diferenciación entre las situaciones didácticas y adidácticas en función de la intervención del profesor nos hacen plantearnos si habrá también diferencias en cuanto a los razonamientos de los alumnos.

¿Qué razonamientos aparecen en cada una de ellas?

\section{A. Tipos de razonamiento en la situación adidáctica}

En una primera aproximación podríamos conjeturar que dada la diferencia entre situación didáctica y adidáctica, no se puede hablar del mismo tipo de razonamiento. El papel del profesor es posibilitar la transición entre los razonamientos como objetos socio-culturales a objetos de saber. En la situación adidáctica el alumno es un sujeto que interactúa directamente con el medio y por lo tanto el razonamiento es un razonamiento personal, subjetivo, que en la situación didáctica debe gestionar el profesor.

Las relaciones del alumno con el medio pueden ser clasificadas en tres categorías:

\section{- Situación de acción:}

El alumno debe actuar sobre un medio resolviendo el problema planteado. Estas situaciones sólo requieren del alumno que utilice conocimientos implícitos o previos. Son sus primeros intentos por resolver un problema propuesto por el profesor. Se caracteriza por la ausencia de interlocutor. El sujeto es responsable de sus acciones, que están dirigidas por decisiones internas. 
¿Qué tipo de razonamiento estará presente en esta situación?

El razonamiento presente en este tipo de situación es el razonamiento personal del alumno, que moviliza los conocimientos ya adquiridos, y junto a la información procedente del medio, decide llevar a cabo una acción.

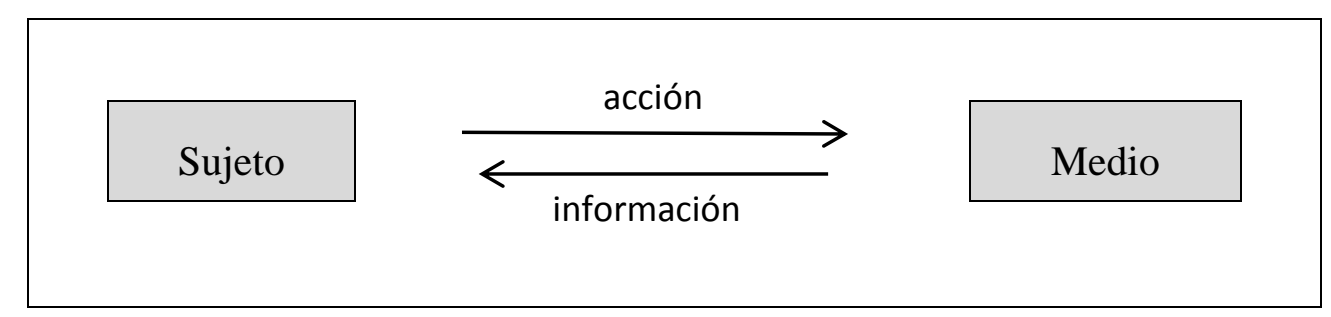

Fig. 1.3: Esquema de una situación de acción

\section{Situación de formulación}

Un alumno debe comunicar un mensaje a otro alumno, que debe entender el mensaje y en consecuencia, actuar según éste. El emisor del mensaje puede ser un solo alumno o un grupo de alumnos. Este modelo se caracteriza por la presencia de un receptor y/o transmisor mediante el cual el sujeto intercambia mensajes. El objetivo de esta situación no es que el sujeto actúe sobre el receptor para ejercer alguna influencia sobre él, sino actuar sobre el 'medio' mediante su intervención, que requerirá la utilización de algún tipo de codificación o lenguaje. El sujeto emisor utiliza expresiones propias del lenguaje natural.

¿Qué tipo de razonamiento estará presente en esta situación?

Los razonamientos personales siguen presentes en la comunicación (en cuanto formulación ligada a la acción), aunque con la necesidad de creación de un código común. Ese lenguaje se tendrá que acomodar en un lenguaje "más normativo" para que pueda ser compartido después, desprendiéndose progresivamente de la subjetividad. 


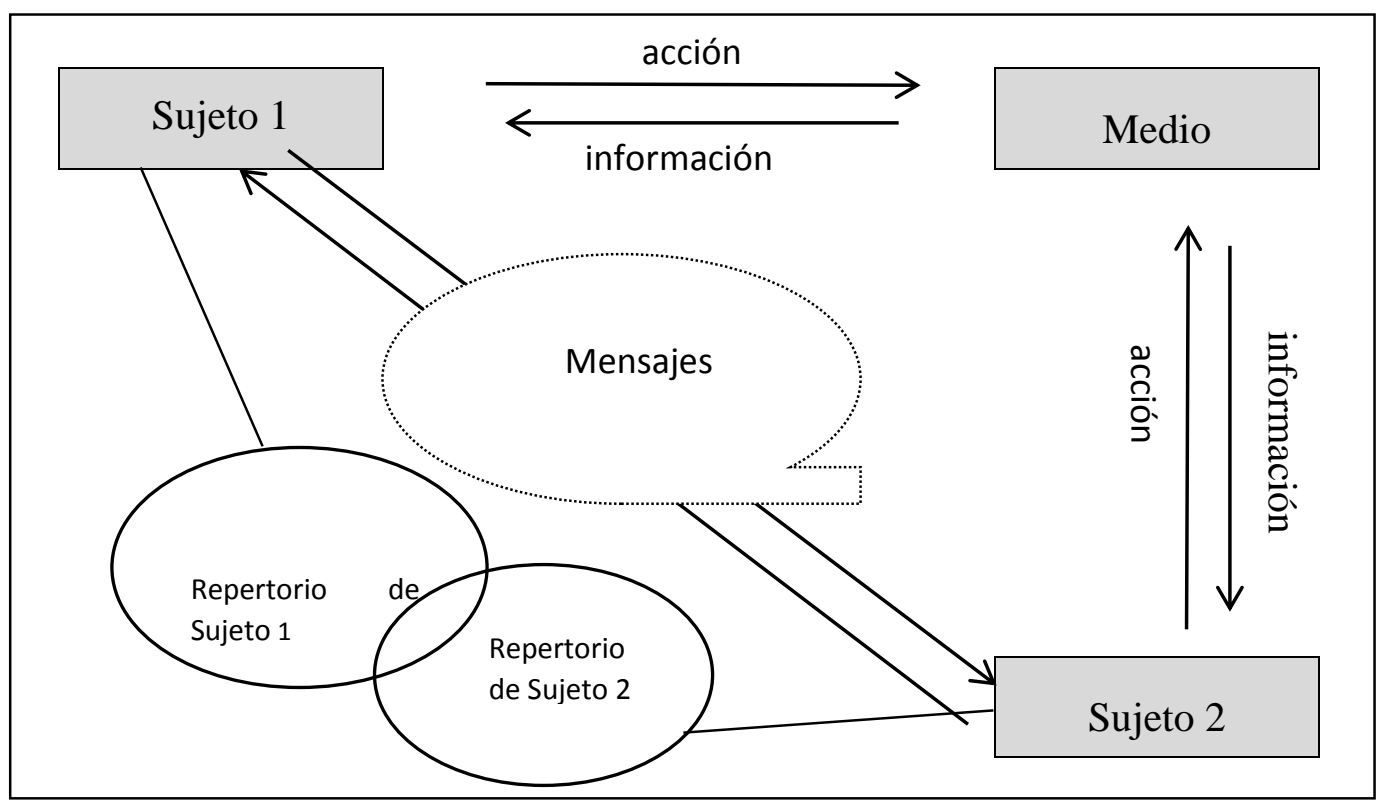

Fig. 1.4: Esquema de una situación de formulación

\section{Situación de validación}

La situación de validación se caracteriza por la necesidad de emitir juicios y contrastar opiniones sobre las diferentes acciones o formulaciones, entre dos o más sujetos. No sirve la simple comprobación empírica, deben ser capaces de argumentar su validación o rechazo. Las situaciones de formulación van a propiciar la aparición de mensajes, cada vez más próximos al discurso matemático, pero sin tener el significado de un discurso matemático. Cada uno de los emisores y receptores de la información juegan el papel de oponentes, y por este motivo cada uno de ellos tiene que comprobar el mensaje recibido tomando como referente el medio. Es importante destacar que los sujetos que intervienen en la validación deben tener una misma posición ante el dominio de la situación u obtención de la solución (relación simétrica respecto al saber). Sólo de esta manera será posible que los alumnos se involucren realmente en los procesos de validación. En esta fase los mensajes que se intercambian incorporan al lenguaje natural el lenguaje 
matemático, y los razonamientos personales de los sujetos se manifiestan en los juicios y explicaciones.

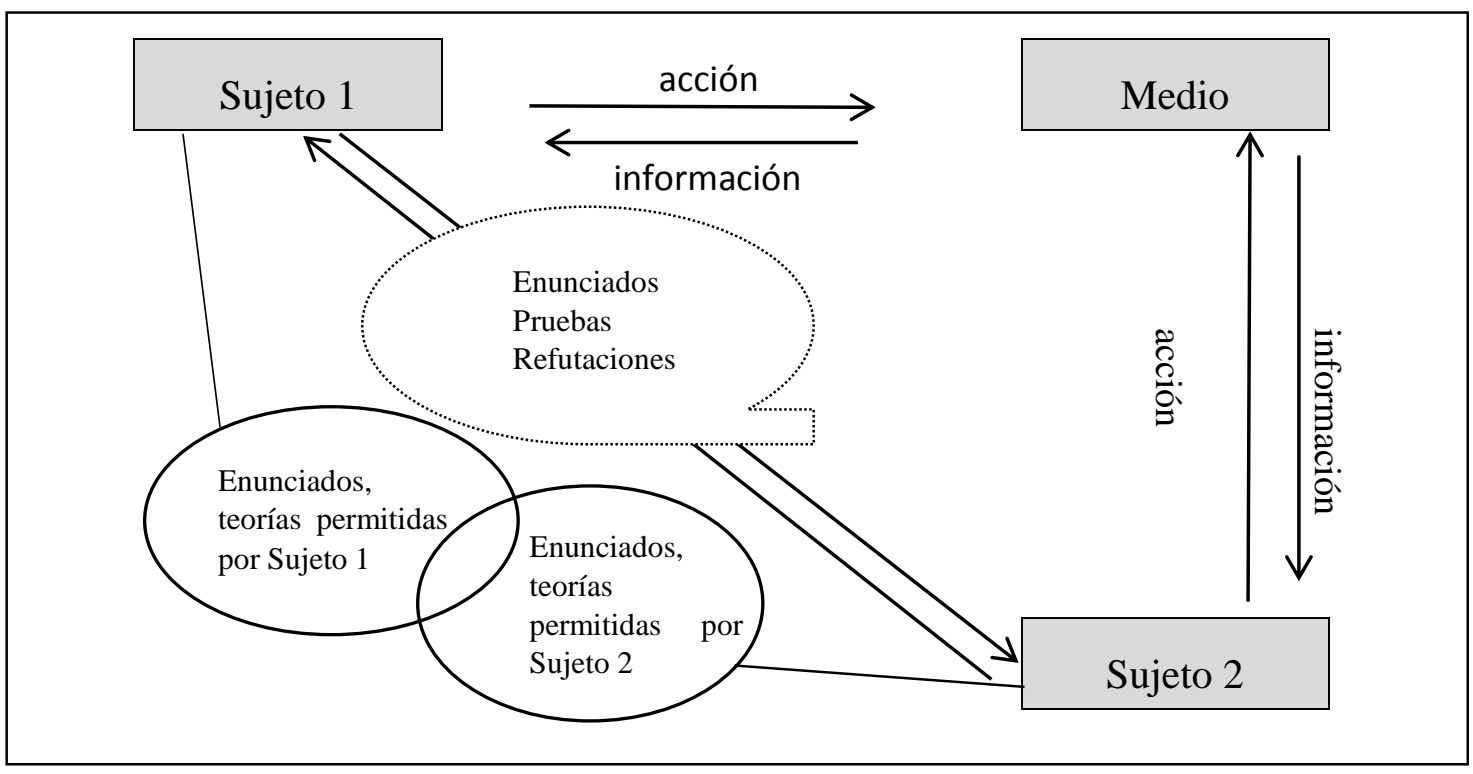

Fig. 1.5: Esquema de una situación de validación

Los razonamientos representan los conocimientos del sujeto en cada momento del aprendizaje y dan lugar a las interacciones entre el sujeto y el medio. Las interacciones corresponden a las diferentes necesidades que plantea la situación. Estas necesidades no surgen por casualidad sino que modelizan las necesidades a las que tendría que responder un matemático, desde la identificación de un saber, hasta su aceptación por el resto de la comunidad matemática. Así pues, según el tipo de interacción sujeto-medio, se puede hablar de al menos tres grandes categorías: intercambio de información no codificada o que no utiliza ningún lenguaje, intercambio de información codificada en un lenguaje e intercambio de juicios. Tal y como indica Vergnaud en la Teoría de los Campos Conceptuales, el conocimiento matemático se basa en el lenguaje y sus funciones, ligadas a las situaciones y a las acciones (Vergnaud, 1990). El conocimiento que permite el control de estas interacciones, según Brousseau, se presenta en tres formas diferentes, 
cada una de las cuales corresponde a cada una de las categorías anteriores. Estas formas son, respectivamente, los teoremas en acto, las formulaciones y los juicios.

- Los teoremas en acto son los conocimientos del sujeto que guían sus acciones. La interpretación de este tipo de conocimiento no es fácil debido a su naturaleza subjetiva. Tan solo la observación de regularidades en los comportamientos de los sujetos permite hablar de ciertos "modelos implícitos" que controlan la actividad así como su relación con la adquisición del conocimiento. En ese sentido, la psicología ha aportado resultados interesantes y han servido de apoyo a la didáctica (la formación de conceptos, la negación y la contradicción, el pensamiento natural,...).

- Las formulaciones se refieren al tipo de conocimiento ligado a la utilización de algún lenguaje. Con el uso del lenguaje se describen las acciones llevadas a cabo y se hacen explícitos los modelos implícitos de la acción.

- Por último, se habla de juicios cuando se trata de expresiones sobre la adecuación de las descripciones y de los modelos, haciendo referencia a su contingencia, a su necesidad o a su consistencia.

De esta manera, las tres formas de conocimiento que funcionan en situación adidáctica identifican tres tipos de razonamiento: R-acción, R-formulación y R-validación (Orús, 1992) 


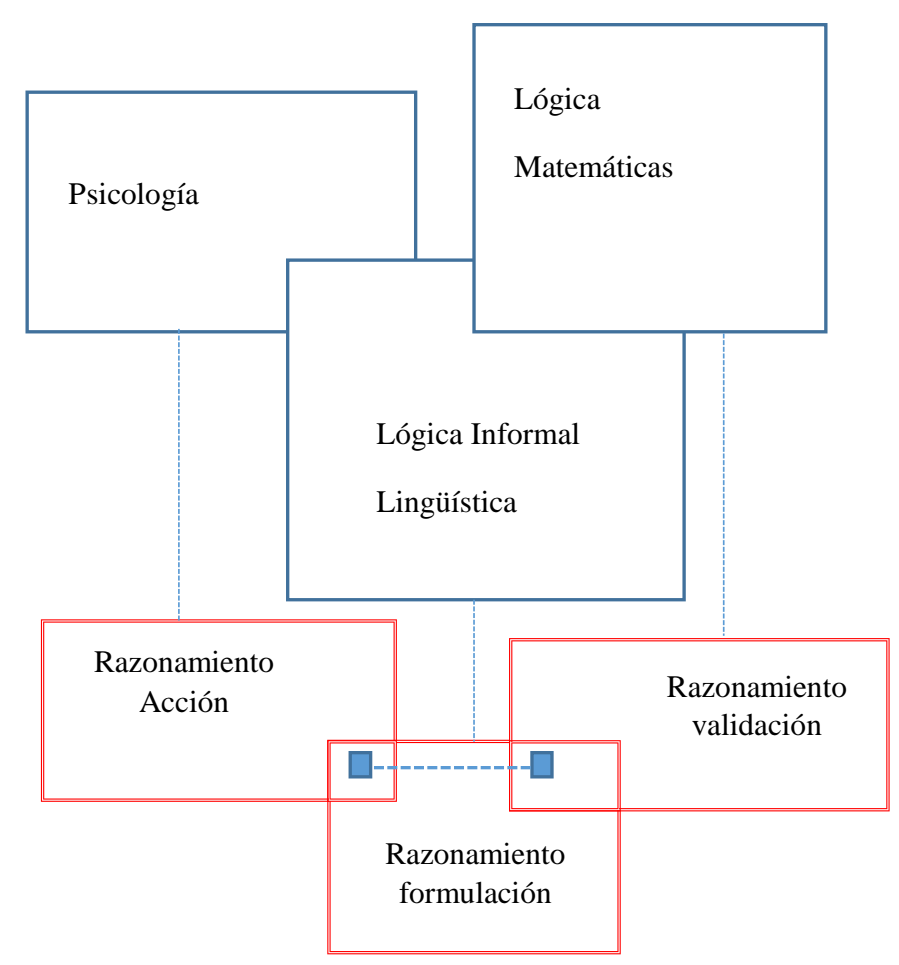

Fig. 1.6: Tipos de razonamiento en la situación adidáctica y sus principales dominios de referencia

- Los razonamientos acción son los razonamientos personales de los estudiantes, movilizados por la propia situación. Las características individuales de cada sujeto, como son los conocimientos previos, las percepciones, las intuiciones, las habilidades o incluso las dudas que se van generando, determinan los razonamientos responsables de sus actos y de sus decisiones.

- Los razonamientos formulación son diferentes a los razonamientos en situación de acción, ya que estos últimos son los responsables de las acciones y de las decisiones de los sujetos, pero no de la comunicación de sus resultados. Los productos de los razonamientos son expresados en palabras, proposiciones y argumentos, sin más aspiración que informar o explicar los resultados de sus acciones.

- Por último, los razonamientos de validación son los juicios que un sujeto emite sobre los resultados de las acciones. Los juicios tienen que validar precisamente los 
conocimientos puestos en juego en la situación. Al tratarse de conocimientos matemáticos, los razonamientos lógicos y matemáticos serán los responsables de llevar a cabo las pruebas o demostraciones matemáticas.

Por lo tanto, la modelización de la TSD ha puesto de manifiesto la naturaleza de los razonamientos en la relación didáctica así como la relación inherente con la situación de aprendizaje, convirtiéndose así el razonamiento en un objeto de estudio para la Didáctica de las Matemáticas. En caso contrario, sería trasladar el problema a la Psicología, la Lógica o las Matemáticas.

\section{B. El razonamiento lógico: un problema de contrato didáctico}

El profesor, a menudo, solicita a los estudiantes que justifiquen las afirmaciones que surgen en el transcurso de sus clases. Otras veces les pide que lleguen ellos mismos a obtener soluciones. La forma de no equivocarse y de llevar a cabo el designio del profesor es mediante la construcción de razonamientos lógicos. Sólo cuando estos razonamientos, lógicos o no, dejan de producir los resultados esperados, el profesor repara en ello para corregirlos, dejando en manos de la "casualidad" que los estudiantes reconozcan cómo llevarlos a cabo, cuándo y por qué. La responsabilidad de llevar a cabo los razonamientos de forma adecuada, recae sobre los estudiantes, pero el profesor no ha tomado a su cargo la responsabilidad de enseñar cómo hacerlo, dando lugar a situaciones paradójicas.

En la Teoría de la Transposición Didáctica Chevallard reconocía la existencia de nuevos objetos de estudio que hasta el momento no eran considerados como parte de la problemática docente. Estos objetos aparecían generalmente como herramientas para describir otros objetos matemáticos o simplemente permanecían invisibles en la actividad matemática, lo que se conoce bajo el nombre de nociones paramatemáticas y nociones protomatemáticas (Chevallard, 1991), nociones entre las cuales podríamos incluir los razonamientos lógicos. 
La naturaleza axiomática y formal del conocimiento matemático necesita establecer reglas para el correcto funcionamiento del lenguaje, tanto en los procesos de comunicación del saber matemático como en los procesos de validación. Los razonamientos deductivos son por excelencia, las formas de razonar correctamente en las demostraciones matemáticas. En cambio, no es la forma natural de los razonamientos de los estudiantes. ¿Cómo superar dicho obstáculo? ¿Se puede aprender a razonar lógicamente? ¿Se puede enseñar?

Según Brousseau los obstáculos no son una falta de conocimiento, sino más bien conocimientos construidos que persisten y se resisten a ser modificados. El origen de los obstáculos puede ser de diferente naturaleza. Brousseau, retomando el concepto de obstáculo epistemológico de Bachelard (1938), define tres tipos de obstáculos ligados a las situaciones didácticas: ontogenéticos, epistemológicos y didácticos.

- Los obstáculos ontogenéticos son aquellos que tienen su origen en el alumno. Las características cognitivas de los estudiantes y sus limitaciones condicionan el acceso a ciertos tipos de conocimiento, por su propia naturaleza y complejidad.

- Los obstáculos epistemológicos son inherentes al conocimiento matemático. No se puede escapar de ellos porque tienen un papel formativo en el conocimiento buscado. Por regla general reflejan los mismos obstáculos que la historia de las matemáticas ha tenido que superar y en cierto modo han dado lugar al saber constituido.

- Los obstáculos didácticos son aquellos que se originan debido a las diferentes elecciones tomadas en el sistema educativo, abarcando tanto las decisiones del profesor dentro del aula como las decisiones impuestas desde los diferentes órganos institucionales.

Los obstáculos se manifiestan en forma de errores, y deben ser superados en situaciones de aprendizaje. El significado de un conocimiento matemático no se define únicamente por el conjunto de problemas que resuelve sino también por las concepciones, los errores que evitan, los procesos seguidos, las formulaciones utilizadas,... Por lo tanto, superar 
los errores forma parte del propio proceso de aprendizaje. La superación de un obstáculo en situación adidáctica es, en sí misma, una evidencia del conocimiento. Si los razonamientos de los estudiantes se manifiestan como obstáculos para el aprendizaje de las matemáticas, ¿cuál es el origen de estas dificultades?, ¿cómo puede gestionar el profesor los razonamientos de los estudiantes?

Los obstáculos (epistemológicos), origen de estos errores, son el pensamiento natural y el lenguaje natural (Orús, 1992) utilizados por los estudiantes de manera espontánea.

Las reglas que sigue el pensamiento natural no coinciden con las reglas del pensamiento formal. A través de la modelización del pensamiento natural realizado por Wermus (1976), se pueden explicar estas diferencias entre ambos pensamientos: la formalización del pensamiento natural, permite representar los razonamientos espontáneos de los estudiantes así como los errores o equivocaciones que cometen. Los principales elementos de esta modelización (los predicados amalgamados, los prefunctores y sus reglas de inferencia), dan lugar a una lógica incompleta y por lo tanto menos determinista que la lógica formal (ver anexo I) provocando la diversidad de respuestas de los estudiantes, que solamente en ocasiones coinciden con las respuestas esperadas.

El lenguaje natural actúa como medio de comunicación. La dualidad de lenguajes en clase de matemáticas (lenguaje natural y lenguaje formal) así como la ambigüedad de uno frente a la exactitud del otro, provocan conflictos en los procesos de comunicación.

Los razonamientos legítimos en matemáticas se ajustan a las reglas de la lógica formal, y son los que puede reconocer el profesor en relación con el saber matemático. Sin embargo, los razonamientos de los estudiantes no responden a las necesidades de las matemáticas como saber oficial, entre otras cosas porque no disponen de los conocimientos lógicos necesarios para poder llevar a cabo, de forma consciente, los razonamientos lógicos. El razonamiento lógico no es tratado como un conocimiento matemático, sino protomatemático (a veces paramatemático) y consecuentemente no es objeto de enseñanza. 


\section{El razonamiento y los niveles de estructuración del medio}

La necesidad teórica de un medio viene justificada por la ausencia de situaciones didácticas fuera del aula. El sujeto que aprende dentro del aula, se verá en un futuro ante la necesidad de resolver problemas fuera de la misma, siendo el único responsable de sus decisiones. Es una manera de trabajar en el aula, más cercana a la realidad. Sin embargo hay que señalar que el "medio" de aprendizaje concebido de la misma manera que fuera del aula no es considerado un medio "suficiente" para el aprendizaje. El aprendizaje resulta de la evolución de los diferentes tipos conocimiento. Tal y como explica Brousseau (1990) se diferencian tres tipos de aprendizaje: En primer lugar habla de los aprendizajes que surgen cuando un sujeto no obtiene los resultados esperados en una situación determinada y necesita algún sistema de control para la acción (nueva información, conocimientos, saberes, decisiones,...). En segundo lugar identifica los aprendizajes por adaptación, que ocurren cuando los saberes aprendidos dejan de ser suficientes o adecuados para asegurar la eficacia o el control de la acción y deben ser cambiados o adaptados (transformado en conocimiento personal) y por último, el aprendizaje que supone el reconocimiento de un saber personal como un saber cultural dentro de una comunidad (válido, reutilizable, comunicable o relacionado con un saber) convirtiéndose entonces en un saber para el alumno. En este sentido, la intervención del profesor es una de las intervenciones fundamentales en el desarrollo de la situación, ya que modifica las condiciones de funcionamiento del saber que debe ser aprendido. El contrato didáctico ${ }^{12}$, entendido como el reparto de responsabilidades en la relación didáctica, establece que el docente no debe ser un mero transmisor de conocimientos sino que debe hacer posible la construcción del conocimiento por el propio sujeto que aprende, movilizando así los razonamientos de los alumnos. Proporcionar esas condiciones

\footnotetext{
${ }^{12}$ El contrato didáctico se refiere al conjunto de reglas que deben regir la situación, las responsabilidades y las expectativas de los protagonistas. El diseño de una situación requiere la explicitación de dicho contrato, que implica tanto al profesor como al alumno.
} 
favorables, de las que surja algo nuevo, útil y que forme parte de un constructo cultural, será el objetivo de toda situación didáctica. La acción mediante la cual el docente responsabiliza al alumno de hacerse cargo del problema se llama devolución. Esta mediación del profesor en situación adidáctica no debe interponerse ni condicionar la relación de los sujetos con el saber.

"Devolution is the act by which the teacher makes the student accept the responsibility for an (adidactical) learning situation or for a problem, and accepts the consequences of this transfer of this responsibility” (Brousseau, 1997, p. 230)

Con la intervención del profesor, el alumno se sitúa de nuevo en situación adidáctica con unas nuevas condiciones (sujeto-medio adidáctico). Se trata de una intervención necesaria para el funcionamiento de la situación, sin ella el proceso de aprendizaje quedaría bloqueado.

"The intervention of the teacher modifies the conditions under which knowledge functions, conditions which are also part of what student should learn. The final aim of learning is that the student be able to put this knowledge to use in situations from which the teacher has disappeared which is why we distinguish between a didactical functioning and an adidactical functioning of the student in the classroom." (Brousseau, 1997, p. 226)

La característica que diferencia una situación adidáctica de una situación no didáctica es la presencia de un profesor, de un representante del saber matemático, responsable de proporcionar todo aquello necesario para hacer que el aprendizaje tenga lugar. Además, la construcción de un objeto matemático necesita de un reconocimiento por parte de la comunidad matemática, que lo acepte y le ponga nombre; es el proceso de institucionalización. La institucionalización tiene un carácter social muy importante, es el reconocimiento por parte del alumno de una "enseñanza" y el reconocimiento por parte del profesor de un "aprendizaje". La institucionalización es el acto mediante el cual el profesor hace un reconocimiento "legal" de un conocimiento, encontrado o utilizado por los estudiantes, y lo comparte con toda la clase. Mediante esta intervención del profesor, 
el conocimiento matemático podrá formar parte del registro de conocimientos del estudiante y que le podrán ser útiles en otro momento. Los estudiantes, pueden, entonces, reconocer el valor de lo que han aprendido.

La inclusión de estos conceptos conduce a la estructuración del medio (Brousseau, 1990) como modelización de la relación didáctica, que incluye los momentos de intervención del alumno (situaciones adidácticas) y además del profesor (devolución e institucionalización).

El medio es un elemento de la situación didáctica que se concibe como un elemento en constante evolución. Las interacciones del sujeto con el medio así como las interacciones con el profesor en respuesta a las necesidades del contrato didáctico, dan lugar a diferentes niveles del medio. Los sujetos (alumnos) y el profesor intervienen de manera que las condiciones iniciales son constantemente modificadas, bien intencionadamente por parte del profesor, bien mediante los diferentes intentos de los estudiantes para obtener la solución. Esta dialéctica con el medio permite diferenciar cinco niveles, en función de las relaciones didácticas, tal y como muestra el siguiente esquema (Brousseau, 1990):

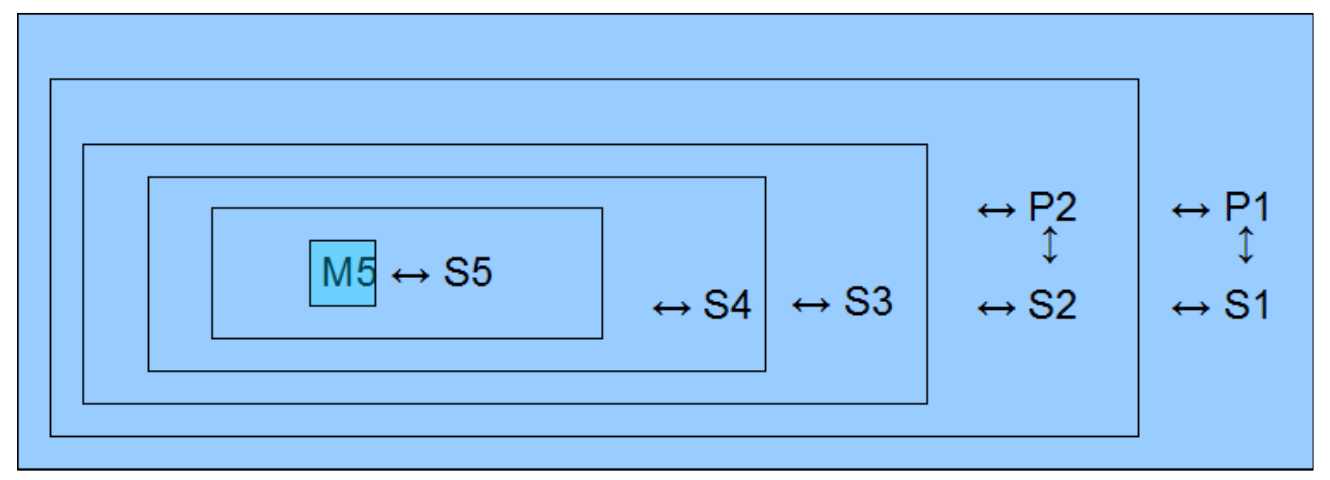

Fig.1.7: Representación de los diferentes niveles de estructuración del medio

$\mathrm{M}$ se refiere al medio, $\mathrm{S}$ al sujeto (alumno) y $\mathrm{P}$ al profesor. La interacción entre el sujeto y el medio o entre el sujeto y el profesor o el profesor y el medio (como tres de los 
elementos propuestos por la TSD) se representa mediante una doble flecha. Cada cuadro representa una situación que va cambiando a medida que avanza el proceso de enseñanzaaprendizaje.

Dada la complejidad del esquema anterior, realizaremos una fragmentación del proceso global para proporcionar más detalles sobre cada uno de los elementos y obtener una mejor visión de su evolución.

\section{El medio material (M5) y la situación objetiva (M5↔S5)}

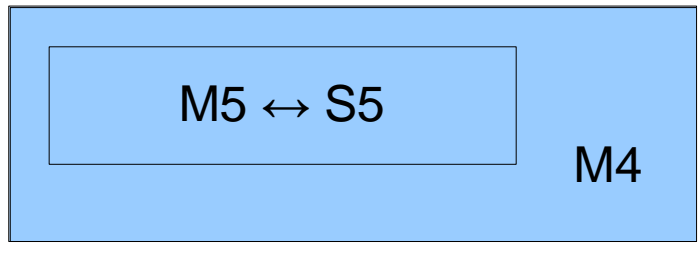

M5 es el medio material que se les va a presentar a los alumnos tal y como lo ha pensado y lo ha diseñado el profesor. S5 es el sujeto "virtual" que imagina el profesor interaccionando con M5 y cuyas acciones estan condicionadas a la lógica del juego. S5 es un sujeto genérico en el que el profesor debe pensar cuando prepara la clase y debe ser capaz de resolver y salir victorioso de la situación, utilizando o construyendo el objeto matemático puesto en juego. Para ello el profesor debe ser consciente de cuáles son los conocimientos implícitos de sus estudiantes. El profesor no solo parte de los saberes matemáticos que supuestamente debe utilizar S5, sino que prevé los razonamientos lógicos que conducirán a un conocimiento determinado. 


\section{El medio objetivo (M4) y la situación de referencia $(M 4 \leftrightarrow S 4)$}

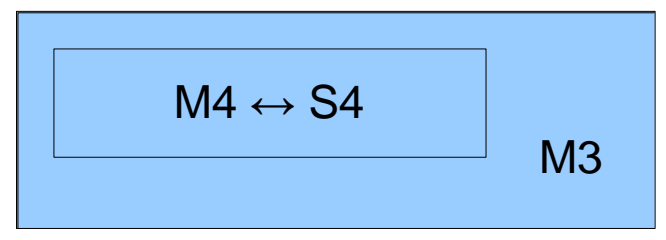

M4 es el medio objetivo sobre el que actua el alumno S4 en posición de actuante (un estudiante real) con el fin de resolver el problema presentado. La acción de S4 genera una respuesta (observada por el profesor, sin intervenir) y, como consecuencia de esa interacción, surge la situación de referencia. El sujeto reflexiona sobre la acción $(\boldsymbol{R}$ acción) y esto marca la aparición de un sujeto epistémico S3.

\section{El medio de referencia (M3) y la situación a-didáctica (M3 $\leftrightarrow$ S3)}

$$
\mathrm{M} 3 \leftrightarrow \mathrm{S} 3
$$

M3 es el medio de referencia para S3, que imagina a S4 actuando sobre M4. La anticipación de los resultados de sus acciones (R-acción), fruto de la reflexión, permitirá los cambios de estrategia, así como la comunicación de los resultados de sus acciones, para explicarlos (R-formulación) o para probarlos (R-validación). S3 es el sujeto "que aprende". Por lo tanto, las conclusiones o reflexiones obtenidas a partir de la situación de referencia, en la situación a-didáctica, manifestadas mediante cambios de estrategia, mediante situaciones de comunicación o mediante situaciones de validación, dan lugar a las diferentes formas de conocimiento, que tal y como ya habíamos avanzado, se corresponden con las diferentes formas de razonamiento. 
La estructuración del medio, que tiene en cuenta al profesor en sus actos de devolución, permite diferenciar cinco fases en el desarrollo de la situación adidáctica:

\section{- Primera fase: Devolución del problema}

El profesor posiciona al estudiante ante una situación nueva para él, sin saber el objetivo final ni la intención que tiene el profesor con ello. Todos, o al menos casi todos los estudiantes, deben poder responder (R-acción). En esta fase, la forma de llegar a una respuesta es, generalmente, de forma empírica, es decir, actuando directamente sobre el medio.

\section{- Segunda fase: anticipación de la solución:}

El profesor interviene sobre el medio cambiando alguna de sus condiciones iniciales. La finalidad es que los estudiantes tengan la tentativa de anticipar la solución antes de encontrarla (R-acción). Seguidamente, la comprobación de la respuesta se lleva a cabo como en la fase anterior.

\section{- Tercera fase: la afirmación y la prueba}

El profesor solicita la anticipación de la respuesta (R-acción) pero necesita que la respuesta vaya acompañada de una explicación (R-formulación). Ante las explicaciones de los estudiantes el profesor permanece neutral. Será de nuevo el medio el que valide la respuesta. Puede ocurrir que la respuesta sea la correcta pera no la justificación.

- Cuarta fase: devolución e institucionalización de una situación de aprendizaje adidáctica

El objetivo es que los estudiantes reconozcan en el problema planteado la existencia de una forma de encontrar la solución, segura y rápida, aunque no evidente. Para ello hay que hacer públicas las explicaciones de cada uno y entre todos, a modo de pequeña discusión, decidir cuál de ellas podría ser la buena. (R-formulación y R-validación) 


\section{- Quinta fase: anticipación de la prueba}

En este caso, el estudiante ha de comprobar por sí mismo la garantía de la prueba. Para ello debe ser consciente de que es posible llegar a la solución y aceptarla sin necesidad de comprobarla cada vez. De esta forma se dará sentido a las diferentes formas del conocimiento matemático, destacando la validación, como proceso que permite diferenciar entre la contingencia y la necesidad, concepto fundamental en los razonamientos matemáticos. (R-validación)

Se puede considerar legítimo, en esta fase, que el profesor proponga algún método o estrategia que no haya surgido anteriormente y que los estudiantes valoren su aceptación.

\section{El medio de aprendizaje (M2) y la situación didáctica (M2 $\leftrightarrow S 2 / P 2)$}

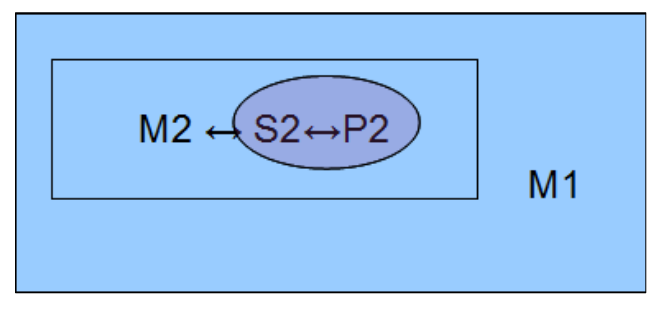

M2 es el medio de aprendizaje que forma parte de la situación didáctica y el primer nivel del medio donde interviene el profesor. El sujeto que aprende, S3, pasará a ser "el alumno" S2, ya que interacciona tanto con el medio M2 como con el profesor P2. E1 profesor reenvía a S2 a la posición de sujeto que aprende, sujeto epistémico, al hacerle conocedor de un saber constituido. El profesor marca el aprendizaje, debe completar el proceso de enseñanza del saber matemático obtenido como solución de la situación de aprendizaje propuesta. Hasta que el sujeto no da indicios de haber conseguido construir por sí mismo algo nuevo, el profesor no puede completar su proyecto de enseñanza. Los razonamientos que utiliza el profesor para la enseñanza son los razonamientos propios del saber matemático (R-matemáticos $\boldsymbol{y}$ R-lógicos). También son este tipo de razonamientos los que espera de los alumnos, porque son, de alguna manera, los únicos 
razonamientos que pueden validar el conocimiento matemático. Sin embargo, ya hemos dicho que el pensamiento natural supone un obstáculo para el razonamiento lógico y da lugar a los errores.

¿Cómo puede el profesor hacer frente a esta dificultad? El contrato didáctico establece que el profesor debe devolver al alumno la responsabilidad de utilizar y construir el saber en situación adidáctica, pero esto a su vez lleva a situaciones paradójicas cuando por algún motivo no sucede. Brousseau (1986) identifica cuatro tipos de paradojas: la paradoja de la transmisión de las situaciones, las paradojas de la adaptación de las situaciones (inadaptación a la exactitud e inadaptación a una situación posterior), las paradojas del aprendizaje por adaptación (negación del saber y destrucción de su causa) y la paradoja del comediante, algunas de la cuales retomaremos a continuación por su relación directa con la gestión de los razonamientos.

Tal y como mostró Orús en sus investigaciones (Orús, 1992) el problema docente de la gestión de los razonamientos en el aula, en términos de la TSD, es un problema de contrato didáctico. Los estudiantes necesitan el razonamiento lógico para el aprendizaje de las matemáticas, pero éste no es enseñado porque no es considerado un objeto de enseñanza. Para continuar con el proyecto docente, el profesor debe reaccionar ante tal dificultad, dando lugar a diferentes paradojas del contrato. Orús identifica tres tipos de paradoja debidos a los problemas de contrato didáctico causados por la gestión de los razonamientos: las paradojas de la adaptación de las situaciones, las paradojas del aprendizaje por adaptación y la paradoja del comediante.

- Las paradojas de la adaptación de las situaciones: la construcción del conocimiento matemático generalmente pasa por diferentes etapas, necesarias para dar el sentido correcto al conocimiento. Hay etapas donde las formas del conocimiento son aún inadecuadas o no definitivas. La paradoja se da cuando el profesor quiere reconocer un conocimiento matemático en alguna de estas etapas: 
Si va directamente al saber formal, estará despojado de sentido; no dejará al alumno la responsabilidad de construir por sí mismo el conocimiento.

Si trata de dar sentido a lo que sucede en cada etapa, adaptará las situaciones de tal manera que estará enseñando un saber provisional pero falso, que funcionará como un obstáculo y se resistirá a desaparecer.

- Las paradojas del aprendizaje por adaptación: El aprendizaje por adaptación puede dar lugar a dos tipos de paradoja. Cuando un alumno se adapta a una situación nueva por sus propios medios, obteniendo soluciones satisfactorias, puede pensar que no ha habido nada nuevo y que el motivo de su éxito ha sido el conjunto de conocimientos ya adquiridos. Esta negación del saber se contradice con la idea de aprendizaje como obtención de nuevos conocimientos. Además, las situaciones de adaptación, por naturaleza, suelen ser repetitivas y dan lugar a la destrucción de su causa, es decir, las situaciones de adaptación transforman el conocimiento en método.

La paradoja del comediante: El profesor evita el problema. Produce tanto las preguntas como las respuestas, privando al alumno de la posibilidad de actuar.

Por lo tanto, los razonamientos de los estudiantes se manifiestan entonces no sólo como obstáculos para el aprendizaje de las matemáticas sino también para su enseñanza. Su gestión da lugar a diferentes paradojas de contrato didáctico.

\section{El medio didáctico (M1) y la situación metadidáctica (M1 $\leftrightarrow$ S1/P1)}

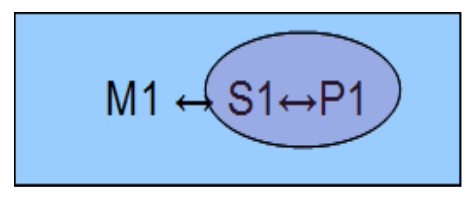

M1 es el medio didáctico constituido por la interacción entre M2-S2 o entre M2-P2 o también de manera conjunta M2-S2/P2.

La relación M1-S1 se establece como una reflexión del alumno sobre la situación didáctica y del mismo modo ocurre en la relación M1-P1. La relación conjunta entre el 
medio M1, el profesor y el alumno permite una reflexión sobre la situación didáctica y además permite al profesor preparar nuevas situaciones didácticas. Se puede decir que la situación metadidáctica da lugar a un aprendizaje del profesor: un aprendizaje en su labor didáctica como profesor (aprender a enseñar). Facilitar las condiciones que den lugar a una génesis artificial de un conocimiento matemático será la tarea didáctica más complicada. Conlleva un trabajo de elaboración, experimentación y de análisis de resultados, que permitan considerar dicha situación didáctica como una herramienta didáctica útil, específica de un conocimiento matemático.

Así pues, hemos mostrado que la relación didáctica es un lugar de encuentro entre diferentes formas de razonamiento. Por un lado, siguiendo la identificación hecha por Orús (1992) se trata de los razonamientos de acción, formulación y validación llevados a cabo por los alumnos en situación adidáctica, y por otro los razonamientos que el profesor debe utilizar para reconocer y validar los conocimientos de los alumnos, que son los razonamientos lógicos y matemáticos. Tal y como hemos mostrado anteriormente estos razonamientos no siempre coinciden, siendo el pensamiento natural un obstáculo para la construcción del razonamiento lógico.

¿Qué hacer con los conocimientos de naturaleza lógica? Como acabamos de mostrar, estamos ante un problema de contrato didáctico cuya respuesta, por parte del profesor se traduce en términos de paradoja. La dificultad de los estudiantes está relacionada con las reglas que siguen sus razonamientos, que distan de las reglas formales exigidas por las matemáticas. Para conocer estas reglas, hay que recurrir a la lógica, conocimiento protomatemático, y por lo tanto no reconocido como objeto de enseñanza. Se trata de un conocimiento transparente porque no son reconocidos ni por el maestro ni por el alumno (Margolinas, 2011)

¿Qué puede hacer el profesor para no caer en las paradojas del contrato didáctico? Adelantado en la introducción, este trabajo se sitúa en el conjunto de investigaciones relacionadas con la enseñanza de la Lógica, en el marco de la TSD. Estas investigaciones 
plantean la posibilidad de considerar los conocimientos lógicos en la enseñanza de las matemáticas desde los primeros niveles educativos. Las situaciones fundamentales para la creación de un código de designación en la escuela infantil (Salin, 1976; Digneau, 1980; Peres, 1984), la función de la conjunción como conectiva lógica (Maudet, 1980) o la enseñanza de la lógica en educación primaria (Orús, 1992) son fruto de estas investigaciones y constituyen un referente para nuestro trabajo, tal y como veremos más adelante.

\subsubsection{El razonamiento lógico según la modelización de la TAD}

La TAD integra en su estudio todo aquello que está relacionado con la enseñanza y difusión de las matemáticas, tanto en situación escolar como en las diferentes instituciones implicadas en el proceso. En este sentido comparten con la TSD el enfoque epistemológico de la Didáctica de las Matemáticas, considerando diversos autores que la TAD supone una ampliación de la TSD.

En el enfoque epistemológico de la Didáctica de las Matemáticas se pone de manifiesto la imposibilidad de interpretar la actividad matemática escolar sin tener en cuenta los fenómenos relacionados con la reconstrucción escolar de las matemáticas, proceso que se extiende hasta la propia institución productora del saber matemático. Es el estudio de los fenómenos de la transposición didáctica (Chevallard, 1985).

Desde esta perspectiva, la TAD ha sido pionera en considerar como objeto de estudio e investigación, no sólo las actividades de enseñanza y aprendizaje en el aula, sino todo el proceso de transposición del saber desde la institución "sabia"hasta el saber aprendido por el alumno. Lo matemático y lo didáctico se consideran empíricamente inseparables; lo didáctico no se refiere únicamente al proceso de enseñanza-aprendizaje sino que tiene en cuenta cualquiera de los aspectos del proceso de estudio. Tanto lo matemático como lo didáctico la TAD lo modeliza mediante praxeologías (Chevallard, 1999). 
La Teoría de la Transposición Didáctica distingue diferentes tipos de "saberes" según el lugar o momento de la transposición, tal y como se presenta en el siguiente esquema (Bosch y Gascón, 2004, p. 56):

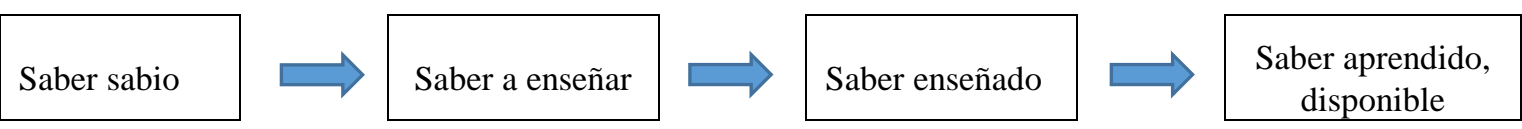

Fig.1.8: Etapas en el proceso de transposición didáctica

Aplicando este esquema nos podemos plantear cuáles serán los diferentes tipos de saberes si consideramos el objeto razonamiento.

- ¿Cuál es el saber sabio de referencia según la institución o instituciones en las que se considera el objeto razonamiento?

La Lógica es la ciencia del razonamiento formalmente válido. La Lógica es el saber cultural de referencia para las prácticas sociales del razonamiento, entre ellas la producción de los razonamientos formales necesarios para el aprendizaje de las matemáticas.

- ¿Los razonamientos lógicos son un saber a enseñar?

Los conocimientos lógicos, tal y como comprobaremos más adelante con la revisión de los documentos curriculares, no forman parte de los contenidos a enseñar en el currículum de matemáticas de la Educación Primaria ni de la Educación Secundaria. Estos conocimientos son introducidos eventualmente en niveles superiores para justificar, en cierta forma, el uso implícito o explícito que se hace de ellos en los itinerarios curriculares posteriores, generalmente ligados a las enseñanzas de las ramas científicas.

- ¿Los razonamientos lógicos forman parte del saber enseñado?

No hay un saber enseñado porque no es un saber a enseñar. 
- ¿Los razonamientos lógicos forman parte del saber aprendido o del saber disponible de los alumnos?

Trabajos anteriores nos permiten decir que los conocimientos de naturaleza lógica (razonamientos lógicos) no son aprendidos de manera espontánea con las actividades matemáticas, al menos en educación primaria y secundaria (Orús, 1986, 1992; Pitarch, 2002, 2015; Zamora y otros, 2009). Pero sí son conocimientos necesarios para la actividad matemática (conocimientos paramatemáticos o protomatemáticos), como apunta Chevallard.

- ¿Y los futuros maestros? ¿Qué conocimientos lógicos tienen disponibles?

En los capítulos siguientes buscaremos respuestas a estas preguntas.

En la Teoría de la Transposición Didáctica, Chevallard ya hace la distinción entre "los objetos de saber y otros objetos" y pone de manifiesto que solamente las nociones matemáticas son objetos de saber y por lo tanto objetos de enseñanza. Como "otros objetos" identifica las nociones paramatemáticas y las nociones protomatemáticas. Las primeras son reconocidas por los matemáticos como herramientas para la actividad matemática, y forman parte de su percepción didáctica (ecuación, parámetro, demostración,...). Estas nociones suelen ser “mostradas" para ser utilizadas pero no son objeto de enseñanza. Las segundas, las nociones protomatemáticas, son movilizadas por las características del contrato didáctico, pero tampoco son objeto de enseñanza; podría decirse que son reconocidas como capacidades del alumno y forman parte de los prerrequisitos del contrato, permaneciendo invisibles ante el profesor y ante los alumnos. Estas nociones sólo se manifiestan si dan lugar a errores y a rupturas de contrato (dificultades protomatemáticas). Las nociones matemáticas, paramatemáticas y protomatemáticas constituyen capas cada vez más profundas del conocimiento matemático y pueden ascender de una capa a otra en los diferentes niveles de enseñanza o en diferentes campos de estudio (Chevallard, 1997). Por ejemplo, los razonamientos lógicos pueden ser nociones protomatemáticas en educación primaria, porque no se habla 
explícitamente de ellos, aunque son considerados como una capacidad en el desempeño de la actividad matemática, y pueden ser considerados nociones paramatemáticas en niveles superiores cuando se pide explícitamente a los estudiantes que razonen sus respuestas.

¿Qué lugar ocupan las nociones protomatemáticas en la actividad matemática?

La modelización de la actividad matemática, en la TAD, utiliza como herramienta fundamental la noción de praxeología, concepto utilizado por Chevallard para referirse a la unidad básica de análisis de toda actividad humana (Chevallard, 2006), considerando la actividad matemática como una actividad humana más.

Las praxeologías (matemáticas) diferencian dos niveles de organización del saber (matemático), la praxis y el logos. La praxis se refiere a las prácticas (matemáticas): por un lado, los tipos de problemas o tareas que se estudian, y por otro, las técnicas o maneras de hacer, sistemáticas y compartidas, que se utilizan para llevar a cabo las tareas. El logos contiene el discurso (matemático) sobre la praxis: la tecnología, que describe, interpreta y justifica el funcionamiento de las técnicas, incluso fundamenta la producción de nuevas técnicas y la teoría, que da sentido a los problemas planteados y permite fundamentar las descripciones y justificaciones tecnológicas.

Toda praxeología surge como respuesta a cuestiones problemáticas planteadas dentro de una institución determinada, que acaban concretándose en un conjunto de tareas, para las cuales dicha institución tiene las técnicas adecuadas para realizarlas. Estas técnicas están justificadas por la tecnología, que aporta elementos para su comprensión y desarrollo, y que a su vez requieren un último nivel de justificación institucional, la teoría.

Por lo tanto, en términos de la TAD, toda actividad matemática puede interpretarse como una actividad de estudio y producción de praxeologías con el objetivo de responder a ciertas cuestiones problemáticas. Esta interpretación integra la actividad de resolución de problemas en el resto de componentes praxeológicas, y de esta manera no puede separarse 
ni de las técnicas de las que dispone una institución determinada ni del discurso tecnológico-teórico. Esta relación entre las componentes praxeológicas permite diferenciar diferentes tipos de praxeologías según su grado de complejidad dentro de la institución:

- Praxeologías puntuales, generadas por un único tipo de tareas.

- Praxeologías locales, que integran diversas praxeologías puntuales, en torno a un mismo discurso tecnológico.

- Praxeologías regionales, que integran diversas praxeologías locales y cuya articulación depende de una teoría común. Dicha teoría requiere la elaboración de un lenguaje que permita describir, interpretar, relacionar, justificar y producir las diferentes tecnologías de las praxeologías locales que integran la praxeología regional.

Si partimos del sistema de enseñanza, los conocimientos matemáticos presentes en la relación didáctica también se modelizan mediante praxeologías matemáticas y las actividades del profesor mediante praxeologías didácticas (Ruiz y García, 2011). Para resolver una tareas es necesario tomar decisiones, elgir las técnicas de resolución adecuadas, explicar y validar las soluciones,... en definitiva, se necesita movilizar los razonamientos de los estudiantes (noción protomatemática) apareciendo las dificultades protomatemáticas ¿cuáles son las técnicas para saber razonar lógicamente? ¿Son técnicas matemáticas? ¿Y la tecnología? ¿Se trata de un discurso matemático?

Los razonamientos lógicos necesarios para llevar a cabo las tareas suponen una dificultad protomatemática que no puede ser abordada por técnicas matemáticas, que puedan a su vez ser explicadas y justificadas por un logos constituído por un discurso matemático. Se trata de un problema ligado a la resolución de una tarea. 


\subsection{El razonamiento en el sistema educativo español}

En el proceso de transposición didáctica, encontramos el saber a enseñar como uno de los momentos de la transposición, en el que las instituciones responsables del saber a enseñar, la noosfera, determinan el saber que tiene que ser enseñado. Esto se traduce, a rasgos generales, en las matemáticas oficiales, los programas curriculares, las editoriales, los libros de texto y otros recursos didácticos, y los centros educativos, en los que se encuentran los maestros como el último eslabón de la transposición.

Para analizar el razonamiento lógico como saber a enseñar, hemos llevado a cabo un recorrido por los programas curriculares que estipulan las directrices generales. Los niveles educativos incluidos en este estudio han sido Educación Infantil, Educación Primaria y Formación de Maestros, lo que nos ofrecerá una panorámica del objeto razonamiento como saber a enseñar, tanto para los alumnos en edad escolar como para formación de los futuros maestros.

En primer lugar, presentaremos el planteamiento que se hace del razonamiento en la educación obligatoria, desde los marcos teóricos de las pruebas de evaluación internacionales TIMSS y PISA, cuyos estándares de evaluación sirven de referentes curriculares y marcan los criterios a considerar en el rendimiento académico de los estudiantes (la información sobre las pruebas de evaluación internacionales puede consultarse en la página web publicada por el Ministerio de Educación, Cultura y Deporte http://educalab.es/inee/evaluaciones-internacionales). En segundo lugar, se mostrará en qué medida está presente el razonamiento lógico en los programas curriculares de Educación Infantil, Primaria y Formación de Maestros del sistema educativo español.

El Estudio Internacional de Tendencias en Matemáticas y Ciencias (TIMSS), tiene como objetivo proporcionar a los diversos países participantes la información necesaria para mejorar la enseñanza y el aprendizaje en las áreas de Matemáticas y Ciencias curriculares. Para ello cada cuatro años TIMSS evalúa los logros en Matemáticas y Ciencias en $4^{\circ}$ 
curso de Educación Primaria, obteniendo así datos comparativos internacionales del rendimiento en estas áreas de conocimiento a los 10 años de edad, y complementando las evaluaciones periódicas que de esas mismas competencias realiza PISA a los alumnos de 15 años. El Marco Teórico de evaluación de las Matemáticas para TIMSS se organiza en torno a dos dimensiones, una dimensión de contenido, especificando los dominios o asignaturas que han de evaluarse dentro de las Matemáticas (números, geometría,...) y una dimensión cognitiva, especificando los dominios de los procesos de pensamiento a evaluar, que son en este caso «conocer», «aplicar»y «razonar». Estos dominios cognitivos se consideran dominios comunes para las Matemáticas y las Ciencias y se desglosan a su vez en un conjunto de habilidades o destrezas. Dentro del dominio «razonar»se encuentran las siguientes destrezas o habilidades: analizar, generalizar, integrar/sintetizar, justificar con pruebas de validez matemática y resolver problemas no rutinarios en contextos no conocidos. En este sentido, el último estudio TIMSS considera que razonar matemáticamente implica el pensamiento lógico y sistemático. Los problemas que requieren razonamiento pueden hacerlo de diferentes maneras, debido a la novedad del contexto o la complejidad de la situación, el número de decisiones y pasos, y pueden basarse en el conocimiento y la comprensión de las diferentes áreas de las matemáticas. El razonamiento implica formulación de conjeturas, deducciones lógicas basadas en supuestos y reglas específicas, y justificación de los resultados (Mullis y Martin, 2014).

En cuanto a la prueba de evaluación del Programa Internacional de Evaluación de Estudiantes (PISA) para centros educativos, está definida por la Organización para la Cooperación y el Desarrollo Económico (OCDE) como una herramienta de evaluación dirigida a alumnos de 15 años, con el fin último, no solo de apoyar la investigación sino de permitir una evaluación comparativa y sobre todo un apoyo de los esfuerzos de mejora de los centros educativos. Esta prueba proporciona información descriptiva y analiza las habilidades y capacidades de aplicación práctica de los conocimientos de los estudiantes de dicho nivel educativo en cuanto a Matemáticas. PISA 2015 incluye entre sus 
propósitos la alfabetización matemática incluyendo en particular el razonamiento matemático y el uso de conceptos matemáticos. De todo lo expuesto (que puede ser ampliado, en la documentación de PISA 2015) se deriva el interés que dicho proyecto representa en el sistema educativo, siendo sus estándares de evaluación una representación de los criterios más valorados en la formación matemática de los estudiantes, reproduciendo las matemáticas utilizadas en todos los aspectos de sus vidas personales, cívicas y profesionales, tanto para aquellos estudiantes que finalizan sus estudios matemáticos como para los estudiantes que van a continuar con estudios matemáticos más avanzados.

El razonamiento es reconocido explícitamente en este marco teórico como parte de la competencia matemática. A efectos Pisa 2015, la competencia matemática se define como la capacidad personal para formular, emplear e interpretar las matemáticas en distintos contextos. Incluye el razonamiento matemático y la utilización de conceptos, procedimientos, datos y herramientas matemáticas para describir, explicar y predecir fenómenos. Ayuda a las personas a reconocer el papel que las matemáticas desempeñan en el mundo y a emitir los juicios y las decisiones bien fundadas que necesitan los ciudadanos constructivos, comprometidos y reflexivos.

Del mismo modo, añadiremos cuál es el alcance del razonamiento lógico en uno de los recursos para la enseñanza de las matemáticas, la colección actual "Didáctica de las operaciones mentales" de la editorial Narcea (2015), en coedición con el el Ministerio de Educación, Cultura y Deporte, considerada como "esencial" para la formación de los docentes, por sus editores, que supone un claro ejemplo de ese deslizamiento hacia la formación del pensamiento de los alumnos, encubriendo el razonamiento con las diferentes operaciones mentales de los estudiantes relacionadas con el aprendizaje:

\footnotetext{
“El objetivo de esta Colección, que une teoría y práctica docente, es empezar a contemplar el aprendizaje desde el punto de vista de la mente y de sus operaciones, identificando aquellas construcciones mentales que son fundamentales para generar los significados de
} 
las cosas. Se han seleccionado el núcleo fundamental de operaciones mentales: Comprender, Crear, Evaluar, Experimentar, Observar, Comparar, Reflexionar, Realizar hipótesis, Producir, Juzgar, Interpretar y Describir. Estas operaciones mentales se presentan como interdependientes y se estructuran de tal modo que están presentes en diferentes campos del saber y de las acciones relativas al aprendizaje. La nueva orientación didáctica que se propone en esta colección, incentiva y motiva los dinamismos conscientes del aprendizaje con el fin de construir un nuevo "sistema de los aprendizajes", esencial sin duda para la formación de los docentes. (Edit. Narcea y MECD, 2015: http://narceaediciones.es/277$\underline{\text { didactica-de-las-operaciones-mentales) }}$

A continuación, procederemos con la búsqueda en los programas curriculares de Educación Infantil, Primaria y Formación de Maestros, sobre la formación del razonamiento lógico. Tan sólo se presentarán los sitios donde, de manera explícita se hace referencia al desarrollo del razonamiento, con el propósito de mostrar la importancia que se le atribuye, no sólo en los textos de Didáctica y Educación Matemática, sino también como una de las directrices marcadas desde la institución escolar.

\section{EDUCACIÓN INFANTIL Y PRIMARIA}

En Educación Infantil, entre los objetivos de ciclo, encontramos dos que directa o indirectamente hacen referencia a los razonamientos:

“- Desarrollar habilidades comunicativas en diferentes lenguajes y formas de expresión.

- Iniciarse en habilidades lógico-matemáticas, en la lecto-escritura y en el movimiento, el gesto y el ritmo” (Real Decreto 1630/06, p. 474)

También se hace referencia explícita a la capacidad de razonar en los criterios de evaluación:

“Se valorará el interés y el gusto por la utilización pertinente y creativa de la expresión oral para regular la propia conducta, para relatar vivencias, razonar, resolver situaciones conflictivas, comunicar sus estados anímicos y compartirlos con los demás. Igualmente este 
criterio se refiere a la capacidad para escuchar y comprender mensajes, relatos, producciones literarias, descripciones, explicaciones, informaciones que les permitan participar en la vida del aula". (Real Decreto 1630/06, p. 482)

En La Ley Orgánica 8/2013, para la Mejora de la Calidad Educativa, y por el cual se establece el currículo básico de la Educación Primaria, dentro del bloque de contenidos comunes, se considera como uno de los estándares de aprendizaje evaluables:

\footnotetext{
"Busca, selecciona y organiza información concreta y relevante, la analiza, obtiene conclusiones, reflexiona acerca del proceso seguido y lo comunica oralmente y/o por escrito” (Real Decreto 126/2014, p. 19374)
}

Y también en este mismo Decreto, en el bloque de Procesos, métodos y actitudes en matemáticas, se consideran evaluables los siguientes estándares de aprendizaje:

“Comunica verbalmente de forma razonada el proceso seguido en la resolución de un problema de matemáticas o en contextos de la realidad.

$[\ldots]$

Utiliza estrategias heurísticas y procesos de razonamiento en la resolución de problemas.

$[\ldots]$

Desarrolla y aplica estrategias de razonamiento (clasificación, reconocimiento de las relaciones, uso de contraejemplos) para crear e investigar conjeturas y construir y defender argumentos” (Real Decreto 126/2014, p. 19388)

\section{FORMACIÓN DE MAESTROS}

En la ORDEN ECI/3854/2007, de 27 de diciembre, por la que se establecen los requisitos para la verificación de los títulos universitarios oficiales que habiliten para el ejercicio de la profesión de Maestro en Educación Infantil, la materia las matemáticas también son materia del módulo didáctico y disciplinar, junto con otras materias, bajo el nombre de 
Aprendizaje de las Ciencias de la Naturaleza, de las Ciencias Sociales y de la Matemática. A este conglomerado de materias se le asigna las siguientes competencias:

"Conocer los fundamentos científicos, matemáticos y tecnológicos del currículo de esta etapa así como las teorías sobre la adquisición y desarrollo de los aprendizajes correspondientes Conocer estrategias didácticas para desarrollar representaciones numéricas y nociones espaciales, geométricas y de desarrollo lógico. Comprender las matemáticas como conocimiento sociocultural. Conocer la metodología científica y promover el pensamiento científico y la experimentación. Adquirir conocimientos sobre la evolución del pensamiento, las costumbres, las creencias y los movimientos sociales y políticos a lo largo de la historia. Conocer los momentos más sobresalientes de la historia de las ciencias y las técnicas y su trascendencia. Elaborar propuestas didácticas en relación con la interacción ciencia, técnica, sociedad y desarrollo sostenible. Promover el interés y el respeto por el medio natural, social y cultural a través de proyectos didácticos adecuados. Fomentar experiencias de iniciación a las tecnologías de la información y la comunicación" (ORDEN ECI/3854/2007, p. 53737)

En la ORDEN ECI/3857/2007, de 27 de diciembre, por la que se establecen los requisitos para la verificación de los títulos universitarios oficiales que habiliten para el ejercicio de la profesión de Maestro en Educación Primaria, las matemáticas aparecen como materia del módulo didáctico y disciplinar, asignándole como competencias a adquirir:

“Adquirir competencias matemáticas básicas (numéricas, cálculo, geométricas, representaciones espaciales, estimación y medida, organización e interpretación de la información, etc). Conocer el currículo escolar de matemáticas. Analizar, razonar y comunicar propuestas matemáticas. Plantear y resolver problemas vinculados con la vida cotidiana. Valorar la relación entre matemáticas y ciencias como uno de los pilares del pensamiento científico. Desarrollar y evaluar contenidos del currículo mediante recursos didácticos apropiados y promover las competencias correspondientes en los estudiantes" (ORDEN ECI/3857/2007, p. 53750) 
Para tener una visión más real del tratamiento del razonamiento lógico en la formación de maestros, se ha llevado a cabo una revisión de los programas de diversas universidades españolas, concretamente en Didáctica de las Matemáticas. La siguiente tabla recoge las competencias y contenidos que lo relacionan. Las celdas vacías indican que no aparece ninguna competencia ni contenido que hable de razonamineto o de lógica:

Universitat Jaume I (UJI)

\begin{tabular}{|l|l|l|}
\hline Titulación & Asignatura & Competencia/contenido \\
\hline $\begin{array}{l}\text { Grado en Maestro o } \\
\text { Maestra de Educación } \\
\text { Primaria }\end{array}$ & Didáctica de las Matemáticas I & $\begin{array}{l}\text { Desarrollar la capacidad para analizar, } \\
\text { razonar y comunicar situaciones } \\
\text { matemáticas }\end{array}$ \\
\hline & $\begin{array}{l}\text { Didáctica de las Matemáticas } \\
\text { II }\end{array}$ & $\begin{array}{l}\text { Desarrollar la capacidad para analizar, } \\
\text { razonar y comunicar situaciones } \\
\text { matemáticas }\end{array}$ \\
\hline $\begin{array}{l}\text { Grado en Maestro o } \\
\text { Infaestra de Educación }\end{array}$ & $\begin{array}{l}\text { Desarrollo del Pensamiento } \\
\text { Matemático y su Didáctica }\end{array}$ & $\begin{array}{l}\text { - Conocer la metodología matemática y } \\
\text { desarrollar la capacidad para promover } \\
\text { el pensamiento matemático y el } \\
\text { razonamiento lógico dico } \\
\text { Conocer las estrategias didácticas } \\
\text { adecuadas para desarrollar } \\
\text { representaciones numéricas yociones } \\
\text { espaciales, geométricas y de desarrollo } \\
\text { lógico/ Conceptos lógicos }\end{array}$ \\
\hline
\end{tabular}

Universidad de Jaén (UJA)

\begin{tabular}{|l|l|ll|}
\hline Titulación & Asignatura & Competencia/contenido \\
\hline $\begin{array}{l}\text { Grado en Educación } \\
\text { primaria }\end{array}$ & $\begin{array}{l}\text { Didáctica de la estadística y la } \\
\text { probabilidad en educación } \\
\text { primaria }\end{array}$ & $\begin{array}{l}\text { Analizar, razonar y comunicar } \\
\text { propuestas matemáticas }\end{array}$ \\
\hline & $\begin{array}{l}\text { Didáctica de la geometría en } \\
\text { educación primaria }\end{array}$ & $\begin{array}{l}\text { Analizar, razonar y comunicar } \\
\text { propuestas matemáticas }\end{array}$ \\
\hline $\begin{array}{l}\text { Didáctica de la numeración, } \\
\text { cálculo y medida en educación } \\
\text { primaria }\end{array}$ & $\begin{array}{l}\text { Analizar, razonar y comunicar } \\
\text { propuestas matemáticas }\end{array}$ \\
\hline $\begin{array}{l}\text { Grado en Educación } \\
\text { infantil }\end{array}$ & $\begin{array}{l}\text { Didáctica de las matemáticas } \\
\text { en educación infantil }\end{array}$ & $\begin{array}{l}\text { Conocer estrategias didácticas para } \\
\text { desarrollar representaciones numéricas } \\
\text { nociones espaciales, geométricas y de } \\
\text { desarrollo lógico. }\end{array}$ \\
\hline
\end{tabular}


Universidad de Alcalá (UAH)

\begin{tabular}{|l|l|l|}
\hline Titulación & Asignatura & Competencia/contenido \\
\hline $\begin{array}{l}\text { Grado en Magisterio } \\
\text { de Educación }\end{array}$ & Didáctica de las Matemáticas & $\begin{array}{l}\text { Elaborar razonamientos críticos y } \\
\text { consensuar acuerdos. }\end{array}$ \\
\hline $\begin{array}{l}\text { Grado en Magisterio } \\
\text { de Educación Infantil }\end{array}$ & $\begin{array}{l}\text { Enseñanza y Aprendizaje de la } \\
\text { Matemática }\end{array}$ & $\begin{array}{l}\text { Elaborar razonamientos críticos y } \\
\text { consensuar acuerdos. }\end{array}$ \\
\hline & $\begin{array}{l}\text { Didáctica de la geometría en en } \\
\text { educación primaria }\end{array}$ & $\begin{array}{l}\text { Analizar, razonar y comunicar } \\
\text { propuestas matemáticas }\end{array}$ \\
\hline
\end{tabular}

Universidad Autónoma de Madrid (UAM)

\begin{tabular}{|c|c|c|}
\hline Titulación & Asignatura & Competencia/contenido \\
\hline \multirow[t]{3}{*}{$\begin{array}{l}\text { Grado en Educación } \\
\text { Primaria }\end{array}$} & Matemáticas y su Didáctica I & $\begin{array}{l}\text { Analizar, razonar y comunicar } \\
\text { propuestas matemáticas. }\end{array}$ \\
\hline & Matemáticas y su Didáctica II & $\begin{array}{l}\text { Analizar, razonar y comunicar } \\
\text { propuestas matemáticas. }\end{array}$ \\
\hline & Matemáticas y su Didáctica III & $\begin{array}{l}\text { Analizar, razonar y comunicar } \\
\text { propuestas matemáticas. }\end{array}$ \\
\hline $\begin{array}{l}\text { Grado de Maestro en } \\
\text { Educación Infantil }\end{array}$ & $\begin{array}{l}\text { Desarrollo del Pensamiento } \\
\text { Matemático y su Didáctica }\end{array}$ & $\begin{array}{l}\text { Conocer las estrategias metodológicas } \\
\text { para el desarrollo de las nociones } \\
\text { numéricas, espaciales, geométricas y } \\
\text { del pensamiento lógico y para } \\
\text { desarrollar la creatividad matemática } \\
\text { infantil. }\end{array}$ \\
\hline
\end{tabular}

\section{Universidad Complutense de Madrid (UCM)}

\begin{tabular}{|l|l|l|}
\hline Titulación en & Asignatura & Competencia/contenido \\
\hline $\begin{array}{l}\text { Maestro yducación Primaria } \\
\text { Edemáticas y su didáctica I }\end{array}$ & $\begin{array}{l}\text { Analizar, razonar y comunicar } \\
\text { propuestas matemáticas. }\end{array}$ \\
\hline & $\begin{array}{l}\text { Didáctica de la geometría y de la } \\
\text { medida de magnitudes }\end{array}$ & \\
\hline $\begin{array}{l}\text { Maestro educación Infantil en } \\
\text { lógico-matemático y su y } \\
\text { didáctica I }\end{array}$ & $\begin{array}{l}\text { Conocer estrategias didácticas para } \\
\text { desarrollar representaciones } \\
\text { numéricas y nociones espaciales, } \\
\text { geométricas y de desarrollo lógico. }\end{array}$ \\
\hline
\end{tabular}


Universidad Rey Juan Carlos (URJC)

\begin{tabular}{|l|l|l|}
\hline Titulación & Asignatura & Competencia/contenido \\
\hline $\begin{array}{l}\text { Grado en educacion } \\
\text { Primaria }\end{array}$ & Matematicas y su didactica I & $\begin{array}{l}\text { Analizar, razonar y comunicar } \\
\text { propuestas matemáticas }\end{array}$ \\
\hline & Matematicas y su didactica II & $\begin{array}{l}\text { Analizar, razonar y comunicar } \\
\text { propuestas matemáticas }\end{array}$ \\
\hline $\begin{array}{l}\text { Grado en educacion } \\
\text { Infantil }\end{array}$ & $\begin{array}{l}\text { Desarrollo del pensamiento } \\
\text { matematico }\end{array}$ & \\
\hline & Didactica de las matematicas & \\
\hline & $\begin{array}{l}\text { Laboratorio de juegos } \\
\text { matematicos }\end{array}$ & \\
\hline
\end{tabular}

Universitat Autònoma de Barcelona (UAB)

\begin{tabular}{|c|c|c|}
\hline Titulación & Asignatura & Competencia/contenido \\
\hline \multirow{4}{*}{$\begin{array}{l}\text { Grado de Educación } \\
\text { Primaria }\end{array}$} & Matemáticas para maestros & \\
\hline & $\begin{array}{l}\text { Aprendizaje de las matemáticas } \\
\text { y currículum }\end{array}$ & .../Razonamiento y prueba \\
\hline & $\begin{array}{l}\text { Gestión e innovación al aula de } \\
\text { matemáticas }\end{array}$ & $\begin{array}{l}\text { Analizar, razonar i comunicar } \\
\text { propuestas matemáticas }\end{array}$ \\
\hline & $\begin{array}{l}\text { Juego y actividades matemáticas } \\
\text { en la educación primaria }\end{array}$ & $\begin{array}{l}\text { Analizar, razonar i comunicar } \\
\text { propuestas matemáticas }\end{array}$ \\
\hline \multirow[t]{2}{*}{$\begin{array}{l}\text { Grau d'Educació } \\
\text { Infantil }\end{array}$} & $\begin{array}{l}\text { Las matemáticas en el } \\
\text { currículum de educación infantil }\end{array}$ & $\begin{array}{l}\text { - Conocer estrategias didácticas para } \\
\text { desarrollar representaciones } \\
\text { numéricas y nociones espaciales, } \\
\text { geométricas y de desarrollo lógico. } \\
\text { - Demostrar que conocen y } \\
\text { comprenden los objetivos }\end{array}$ \\
\hline & $\begin{array}{l}\text { La pràctica matemàtica a l'aula } \\
\text { d'educació infantil }\end{array}$ & \\
\hline
\end{tabular}

\section{Universitat de Girona (UdG)}

\begin{tabular}{|l|l|l|}
\hline Titulación & Asignatura & Competencia/contenido \\
\hline $\begin{array}{l}\text { Grado en Maestro/a } \\
\text { en Educación } \\
\text { Primaria }\end{array}$ & Matemáticas 1 lógico- \\
\hline & $\begin{array}{l}\text { Desarrollo del pensamiento } \\
\text { matemático. }\end{array}$ \\
\hline $\begin{array}{l}\text { Grado en Maestro/a } \\
\text { en Educación Infantil }\end{array}$ & $\begin{array}{l}\text { Aprendizaje de las ciencias } \\
\text { naturales, sociales y matemáticas } \\
\text { Aprendizaje de las matemáticas }\end{array}$ & $\begin{array}{l}\text { Estrategias didácticas para desarrollar } \\
\text { representaciones numéricas y } \\
\text { nociones espaciales, geométricas y de } \\
\text { desarrollo lógico / } \\
\text { El razonamiento lógico-matemático }\end{array}$ \\
\hline
\end{tabular}


Universitat Rovira i virgili (URV)

\begin{tabular}{|l|l|l|}
\hline Titulación & Asignatura & Competencia/contenido \\
\hline $\begin{array}{l}\text { Grado de Educación } \\
\text { Primaria }\end{array}$ & $\begin{array}{l}\text { Enseñanza y aprendizaje de las } \\
\text { Matemáticas I }\end{array}$ & $\begin{array}{l}\text { Aplicar el pensamiento crítico, } \\
\text { lógico y creativo, demostrando } \\
\text { capacidad de innovación. }\end{array}$ \\
\hline & $\begin{array}{l}\text { Enseñanza y aprendizaje de las } \\
\text { Matemáticas II }\end{array}$ & $\begin{array}{l}\text { Aplicar el pensamiento crítico, } \\
\text { lógico y creativo, demostrando } \\
\text { capacidad de innovación. }\end{array}$ \\
\hline & $\begin{array}{l}\text { Enseñanza y aprendizaje de las } \\
\text { Matemáticas III }\end{array}$ & $\begin{array}{l}\text { Aplicar el pensamiento crítico, } \\
\text { lógico y creativo, demostrando } \\
\text { capacidad de innovación. }\end{array}$ \\
\hline $\begin{array}{l}\text { Grado de Educación } \\
\text { Infantil }\end{array}$ & $\begin{array}{l}\text { Enseñanza y aprendizaje de las } \\
\text { ciencias experimentales, ciencias } \\
\text { sociales y matemáticas I }\end{array}$ & $\begin{array}{l}\text { Aplicar el pensamiento crítico, } \\
\text { lógico y creativo, demostrando } \\
\text { capacidad de innovación. }\end{array}$ \\
\hline
\end{tabular}

\section{Universitat de València (UV)}

\begin{tabular}{|l|l|l|}
\hline Titulación & Asignatura & Competencia/contenido \\
\hline $\begin{array}{l}\text { Grado de Maestro/a en } \\
\text { Educación Primaria }\end{array}$ & Matemáticas para maestros & $\begin{array}{l}\text { Analizar, razonar i comunicar } \\
\text { propuestas matemáticas }\end{array}$ \\
\hline $\begin{array}{l}\text { Grado de Maestro/a en } \\
\text { Educación Primaria }\end{array}$ & Matemáticas para maestros & $\begin{array}{l}\text { Analizar, razonar i comunicar } \\
\text { propuestas matemáticas }\end{array}$ \\
\hline & $\begin{array}{l}\text { Didáctica de las matemáticas de la } \\
\text { educación infantil }\end{array}$ & \\
\hline
\end{tabular}

En los niveles educativos presentados, el razonamiento se considera parte integral de las capacidades a adquirir. En cuanto al "razonamiento lógico", muy pocas veces se habla de él de manera explícita. Se opta por el "razonamiento" en general o el "razonamiento matemático".

En Educación Infantil se habla de habilidades lógico-matemáticas, y son consideradas dentro de los objetivos de ciclo.

En Educación Primaria, el razonamiento está relacionado con los estándares de evaluación, tanto en el bloque de contenidos comunes como en el bloque de procedimientos, métodos y actitudes, haciendo alusión a la comunicación verbal y a la defensa de argumentos. 
En la Formación de Maestros, el razonamiento se presenta como parte de los equipamientos praxeológicos del maestro para desarrollar su profesión.

¿Qué significa razonar propuestas matemáticas? ¿A qué tipo de razonamiento se refiere? ¿Son suficientes sus conocimientos lógicos?

Aunque no se han presentado los resultados correspondientes a los niveles de Educación Secundaria Obligatoria y Bachillerato, nos gustaría destacar la presencia de la Lógica como saber a enseñar a través de la asignatura de Filosofía. Así, la enseñanza de la Lógica se incluye de forma breve y esporádica en el sistema educativo. Actualmente, la LOMCE ha incluido esta asignatura en $4^{\circ}$ de ESO y $1^{\circ}$ y $2^{\circ}$ de Bachillerato, aumentando así su presencia en el currículum.

Concluimos que los razonamientos lógicos, en los textos curriculares, son nociones no matemáticas, ya que se consideran, por regla general, habilidades adquiridas en el aprendizaje y para el aprendizaje (protomatemáticas o paramatemáticas).

El tratamiento del razonamiento en las instituciones es poco conciso, y deja en manos del profesor la responsabilidad de capacitar a los estudiantes en este tipo de "habilidad" al mismo tiempo que los estudiantes deben hacer todo lo posible por conseguirlo, puesto que forma parte de los criterios de evaluación (problema de contrato didáctico)

A pesar de que los currículos oficiales consideran el desarrollo de la capacidad de razonamiento lógico un objetivo fundamental, la lógica no es reconocida de forma explícita como un contenido a enseñar.

\subsection{El razonamiento en la Formación de Maestros}

La formación del profesorado es un eje de investigación que ha sido abordado en el ámbito de la Educación Matemática según ha ido evolucionando la problemática didáctica, y que ha empezado a ser abordada recientemente con gran interés desde el ámbito de la Didáctica de las Matemáticas. 
Tal y como recoge Marcelo en su libro Formación del profesorado para el cambio educativo (Marcelo, 1999), y retomando las palabras de Medina y Domínguez, la formación del profesorado en general ha sido un tema de interés en el ámbito de la educación:

\footnotetext{
"La formación del profesorado, progresivamente se va presentando como "una matriz disciplinar potente, en la que su propia proyección pone de manifiesto tanto su consolidación científica, como el esfuerzo de afianzamiento epistemológico permanente, tanto por la rigurosidad de sus paradigmas, como por el empleo y producción de modelos y métodos de investigación propios" (Medina y Domínguez, 1989:105).” (Marcelo, 1999, p. 11)
}

Para tener una perspectiva del interés suscitado por la formación de profesores de matemáticas, remito al lector a la revisión realizada por Llinares (2009), donde clasifica las principales vías de investigación en España y recoge los aspectos investigados relativos a cuestiones relacionadas con el aprendizaje del profesor y con la práctica profesional del profesor. El primer grupo de cuestiones a las que hace referencia Llinares incluye el conjunto de problemáticas que surgen en torno al aprendizaje de los conocimientos necesarios para enseñar, y se aplican tanto a la formación inicial de profesores como a los profesores en formación continua. Los objetos de estudio sobre los que recaen estas investigaciones son, principalmente, conocimiento de matemáticas y de contenido pedagógico, procesos de socialización, y evolución y cambio de creencias y conocimiento (Gutiérrez, Jaime y Fortuny, 1991; Llinares y García, 1994, 1998; Azcárate, 1996; Castro y Castro, 1996; Oliveras, 1996; Azcárate, Cardeñoso y Porlán, 1998; Gutiérrez y Jaime, 1996; 1999; Maza, 2000; Rico y otros, 2000; ...). Las investigaciones al respecto dan cuenta de la influencia que las experiencias específicamente diseñadas dentro del programa de formación tienen sobre las formas de conocer y las creencias de los profesores, pero considerando diferentes referencias en cuanto a la noción de «aprender a enseñar». El segundo grupo de cuestiones aborda diferentes aspectos de la práctica profesional del profesor de matemáticas, y en su tarea 
de modelizarla, tratan de comprender los procesos de enseñanza-aprendizaje, los procesos de reforma y desarrollo del curriculum, siendo objetos de esta problemática las creencias y concepciones, las formas de conocer el contenido matemático como objeto de enseñanza-aprendizaje y la organización y gestión del proceso de enseñanza-aprendizaje (Blanco, 1991, 1992; Carrillo, 1997; Cardeñoso, 1998; Llinares, 1999, 2000; Goñi, 1999; Gil, 2000; Alfonso y otros, 1999; ...). Las investigaciones centradas en la práctica del profesor muestran la variedad de planteamientos epistemológicos que pueden ser usados aportando información complementaria en los intentos por comprender y conocer científicamente la actividad didáctica del profesor.

Una de las ideas preconcebidas respecto a los profesores en general, y los maestros en particular, es la de considerar socialmente la profesión como una semiprofesión, término acuñado por Etzioni en su obra The semi-professions and their organization: teachers, nurses, social workers. Nueva York: Free Press.y que retoma Ruiz en su tesis (Ruiz, 2015). La autora, a partir del término utilizado por Etzioni y de acuerdo con Chevallard (2010), describe el estado de la profesión como un estado de subdesarrollo práctico, profesional, científico y epistemológico, afirma:

\footnotetext{
"si partimos de la idea de profesión como un conjunto de actores, con distintas funciones, dedicados a desarrollar e impulsar a lo largo del tiempo y en un esfuerzo continuado el oficio de la enseñanza, podemos concluir que todavía este oficio se mantiene en un estado de semiprofesión." (Ruiz, 2014, p. 20)
}

En su trabajo Ruiz prosigue la investigación en busca de la respuesta institucional al problema de la formación de profesores de secundaria, y en este sentido, abordaremos la Formación de Maestros. La Formación de Maestros finaliza con el Grado, titulación que le capacita para realizar su profesión, por lo tanto existe una diferencia considerable entre la Formación del Profesorado de Secundaria, que necesitan una formación de postgrado para habilitarse, y las titulaciones de Maestro. Aunque no vamos a realizar un estudio exhaustivo de los planes de estudios, merece una reflexión sobre el agravio comparativo 
entre la formación matemática de los profesores de secundaria y la formación matemática de los futuros maestros, que aunque reconocemos el nivel elemental de los contenidos en la educación primaria, nos cuestionamos si el nivel de formación es suficiente.

Actualmente numerosas líneas de investigación trabajan en ese sentido. El trabajo de Shulman (1986) fue pionero en reconocer específico el conocimiento del contenido para la enseñanza y propuso tres categorías: conocimiento de la materia, conocimiento pedagógico del contenido (PCK) y conocimiento curricular, lo que ha supuesto el inicio de diferentes líneas de investigación, tanto en España como en el resto del mundo.

Según Brousseau (1989, 1991, 1999) los docentes esperan que la formación les proporcione las herramientas necesarias para llevar a cabo su trabajo así como los conocimientos necesarios para utilizarlas correctamente. Es lo que necesitan, como mínimo, para ejecutar bien su trabajo, aunque es la formación recibida inicialmente y a lo largo de la vida profesional, la que puede dotar de capacidades para innovar o cambiar, para adaptarse a los cambios y para responder a situaciones imprevistas, en definitiva, para tomar decisiones con el propósito de mejorar en su profesión. Según Brousseau, la Didáctica es el fundamento de la profesionalización de la actividad de los profesores. Es desde este ámbito que se proporcionarán, al menos, las técnicas específicas de las nociones a enseñar, técnicas locales (preparaciones de las lecciones, material de enseñanza, métodos claves puestos a punto, instrumentos de gestión, objetivos y evaluación) y técnicas globales (currícula para todo un sector de matemáticas y programas para varios años). También esperan que la Didáctica considere los diferentes aspectos inherentes a la profesión, (los alumnos y sus comportamientos, las condiciones en el desarrollo de las situaciones de enseñanza, las condiciones de gestión de la clase, los fenómenos didácticos). Todo ello comporta una adaptación por parte del sistema que afecta tanto a la visión de los conocimientos a enseñar como a la necesidad de adoptar un lenguaje específico para expresar los fenómenos observados y actuar sobre ellos. Por lo tanto, la didáctica no proporciona soluciones ni recetas para los profesores, pero trata de 
ayudar a modificar su estatus, su formación y sus relaciones con la sociedad. Es el saber de referencia y que privilegia a los profesores en su papel como profesionales de la enseñanza. Parafraseando a Brousseau (1999) respecto al interés de la Didáctica de las Matemáticas para la formación de maestros:

"Al proporcionar a los profesores una ciencia integradora y una memoria propia, la didáctica permite la creación de una cultura común así como consideración de la experiencia adquirida y de los resultados de la investigación científica. La dependencia de la enseñanza respecto a numerosos campos del conocimiento conduce a una saturación desalentadora en la formación. La didáctica reduce las redundancias que se producen y facilita la organización de cursos centrados en la principal actividad a la que se apunta la enseñanza.

Apoyada sobre un edificio científico, la ingeniería que la didáctica propondrá no estará necesariamente acompañada de un práctica más elegante que la de los mejores maestros, pero podrá mejorar los resultados del conjunto y evitar ciertas catástrofes.

Por otra parte, la enseñanza de la didáctica a los maestros en formación presenta dificultades que provienen del hecho de que la transposición didáctica de la didáctica misma es, todavía, un trabajo por hacer. El volumen y la complejidad de los resultados de investigaciones fragmentarias, dispersos en numerosos campos disciplinarios dispares y concurrentes, ha crecido mucho más aprisa que lo que dura la formación y también más aprisa que la posibilidad de jerarquizar adecuadamente dichos resultados en textos de síntesis para los principiantes.

Para comprender y utilizar uno de estos resultados en una clase, se requieren conocimientos previos sobre todos los demás temas, conocimientos que sólo algunos maestros poseen." (Brousseau, 1999, p. 33)

La idea de una transposición didáctica del saber didáctico es retomada por Portugais (1995) quien afronta el riesgo de la transposición de la didáctica, y considera la TSD como un modelo epistemológico para la formación de profesorado. Portugais intenta 
diseñar situaciones a-didácticas para la construcción de conocimiento didácticomatemático, constatando la complejidad y dificultad que ya advertía Brousseau.

En el marco de la Teoría Antropológica de lo Didáctico, encontramos trabajos relacionados con el diseño y análisis de las organizaciones didácticas (Sierra, 2006; Gascón y Sierra 2002; Cirade 2006; Ruiz-Higueras y García, 2011; Ruiz, 2014). En este marco teórico, se afronta la formación del profesorado de matemáticas como tema de investigación, donde la problemática general se reformula en términos de praxeologías, las cuales han de ser descritas y analizadas para su viabilidad:

“¿Cuál es el equipamiento praxeológico necesario (o por lo menos útil) para que los profesores puedan intervenir de manera efectiva y pertinente en la formación matemática de los estudiantes (de tal o cual etapa educativa) y qué se puede hacer para ayudar a que los profesores dispongan de él?" (Bosch y Pérez, 2009, p. 94)

Entre las aportaciones de Ruiz a la investigación en formación del profesorado de educación secundaria (Ruiz, 2014), incidiremos en la importancia que le concede a los conocimientos que deben ser incluidos en la formación docente, y que no tienen por qué formar parte de los conocimientos a enseñar ni que les han sido enseñados, pero que se manifiestan como una necesidad para la enseñanza de las matemáticas:

\footnotetext{
“la necesidad de incluir en la formación del profesorado conocimientos matemáticos que no se limitan a los contenidos que el profesor debe enseñar y que, en general, no forman parte de la formación disciplinar básica que los futuros profesores han recibido en los diferentes grados universitarios. (Ruiz, 2014, p. 128)
}

La problemática abordada en el trabajo de Ruiz surge a partir de un fenómeno didáctico detectado en el diseño y gestión de la enseñanza y aprendizaje de la modelización funcional elemental, y que nos parece vinculante a nuestra problemática. Se trata de la ausencia de problematización de los sistemas de variación, que se utilizan de forma transparente y accesoria. Siguiendo a Cirade (2006), la autora estructura el conjunto de 
praxeologías relacionadas con la formación del profesorado de matemáticas en tres niveles de complejidad y amplitud creciente: por enseñar, para la enseñanza y de la profesión y reconoce el trabajo aún por hacer si se desea tener cierto conocimiento sobre la profesión docente, que podemos comprender dada la complejidad del estudio y la corta trayectoria de las investigaciones, aún recientes en Didáctica de las Matemáticas.

En el enfoque ontosemiótico sobre el conocimiento y la instrucción matemática (Godino, 2009), también se aborda la problemática de los conocimientos del profesor y apuesta por un modelo que engloba prácticamente todos los enfoques de la enseñanza, con el objetivo de ofrecer una herramienta de análisis para los procesos de enseñanza y a la vez para los profesores sobre su propia práctica. En cuanto a la formación de maestros Godino afirma:

"La preparación de los futuros profesores de primaria en el área de Didáctica de la Matemática debe centrarse en los conocimientos profesionales sobre la enseñanza y el aprendizaje de las matemáticas del nivel educativo correspondiente. Sin embargo, el estudio de los problemas didácticos no es posible sin un conocimiento suficiente del contenido disciplinar al que se refieren dichos conocimientos didácticos, en nuestro caso los contenidos matemáticos propuestos en los curriculos de primaria (básicamente, sistemas numéricos, geometría elemental, medida y tratamiento de la información). Esto obliga a los futuros maestros a tener que estudiar también matemáticas.

No se trata sólo de que los estudiantes de magisterio tengan una base matemática insuficiente con frecuencia encontramos estudiantes con este problema sino que incluso aunque tales aspirantes hubieran cursado previamente una licenciatura de matemáticas sería necesario “volver a mirar de nuevo" los contenidos matemáticos elementales desde una perspect iva epistemológica diferente (más amplia y profunda).

El núcleo básico de la didáctica de las matemáticas sobre contenidos impartidos en los primeros niveles educativos es la construcción del sentido del lenguaje, los conceptos y métodos matemáticos por parte de los niños, mediante su referencia a las situaciones y problemas matemáticos presentes en la vida cotidiana. Esta atribución de significado a las 
tareas matemáticas escolares requiere conocimientos y destrezas matemáticas por parte del profesor que con frecuencia no están disponibles para los futuros profesores, y por tanto se deben contemplar en el periodo de su formación inicial." (Godino, 2002, p. 3)

En el ámbito de la Educación Matemática (EM) - considerada como un campo de investigación y un campo de práctica - de donde se distanció la PME, veamos si entre sus aportaciones en estos años, se pueden encontrar aportaciones a nuestra problemática. Para aproximarnos a este ámbito, tomemos como referente a Michèle Artigue, medalla Felix Klein, 2013 de la comisión internacional ICMI, International Commission on Mathematical Instruction y vicepresidenta (1998-2006) y presidenta de dicha comisión (2007-2009), y la interesante e instructiva revisión que hace de dicho ámbito en su doble vertiente, investigación y práctica educativa, en la conmemoración de los 50 años de la fundación de la Conferencia Interamericana de educación Matemática (CIAEM), (Brasil, 2011).

Lo primero que queremos destacar de esta revisión de Artigue, es la "juventud" de la Educación Matemática como campo de la investigación, ya que señala que, el ICME (International Commission on Mathematical Instruction), aunque creada en 1908, no se planteó la necesidad de constituirse como campo de investigación hasta 1967, año en que el Hans Freudenthal ${ }^{13}$ asume la presidencia y plantea dicha necesidad, tomando también la iniciativa para la creación de la revista Educational Studies in Mathematics .

... “Hace cincuenta años, la educación matemática como campo de investigación sólo comenzaba a emerger. Recordemos que si celebramos hoy el cincuentenario de la CIAEM, el primer congreso ICME tuvo lugar en 1969 y la revista Educational Studies in Mathematics fue creada en 1968 por iniciativa de Hans Freudenthal, entonces Presidente de la ICMI. A

\footnotetext{
${ }^{13}$ Hans Freudenthal:. en 1971 fundó el Institute for the Development of Mathematical Education (IOWO) en la Universidad de Utrecht, que después de su muerte fue bautizado como Freudenthal Institute, y que ahora se llama Freudenthal Institute for Science and Mathematics Education .
} 
principios de los años sesenta, como lo demostró muy bien la importante obra histórica que acompañó la celebración de su centenario (Menghini, Furinghetti, Giacardi y Arzarello, 2008), ICMI seguía confinado en la tradición de estudios e informes que fueron puestos en obras a partir de su creación en 1908. Hans Freudenthal iba a cambiar esta tradición, renovando las ambiciones de esta venerable institución, y poniendo de relieve la necesidad de establecer la educación matemática no sólo como un campo de práctica y reflexión sobre la práctica sino también como un campo de investigación."(Artigue, 2011, pp. 1,2)

Pero pese a su juventud, este impulso ha llevado a la realización de abundantes trabajos de investigación realizados en este ámbito de la Educación Matemática, pero también a la multiplicidad de conceptos y marcos teóricos, lo que ha llevado a cuestionar a este dominio como un campo científico.

A lo largo de los años, este campo de investigación se ha ido gradualmente institucionalizando. Laboratorios y centros de investigación, programas de maestría y doctorado, revistas especializadas, libros y conferencias asociaciones y redes se han ido multiplicando en el mundo. El caso de América Latina, como tal, es particularmente instructivo. Hoy en día, es imposible que un investigador en educación matemática pueda pretender conocer este campo de investigación en su globalidad, dominar la multiplicidad de conceptos y marcos teóricos que se han desarrollado. Igual que en cualquier campo científico se han creado dominios y subdominios, $\mathrm{y}$ « Handbooks » permiten a cada uno hacerse una idea de cómo el conocimiento avanza más allá de su dominio personal de competencia.

Esta multiplicidad de conceptos y marcos teóricos y la indefinición científica que esto conllevaba en el ámbito de la EM, determinó a Guy Brousseau, Medalla Felix Klein 2003 del ICMI, a plantear la Didáctica de las Matemáticas, como "ciencia que estudia los fenómenos ligados a la difusión de los conocimientos matemáticos, en situación escolar”.

“Cette médaille récompense la contribution essentielle que Guy Brousseau a apportée au développement de la didactique des mathématiques comme champ de recherche scientifique, 
à travers les travaux théoriques et expérimentaux qu'il a menés dans ce domaine pendant une quarantaine d'années. Elle récompense aussi les efforts permanents qu'il a déployés tout au long de sa carrière pour que ces recherches contribuent à l'amélioration de la formation mathématique des élèves et des enseignants". (Cita de la Commission Internationale de l'Enseignement des Mathématiques, CIEM, a proposito de la concesión de la medalla Felix Klein, 2003)

Así mismo queremos destacar, la evolución de las problemáticas de investigación de la Educación Matemática que señala Artigue y cómo se introduce al docente como otro actor esencial y problemático en la relación didáctica y por tanto, nuevo objeto de investigación:

“Una constatación unánime es que la investigación, inicialmente centrada en el alumno, en la comprensión de su funcionamiento cognitivo y en la elaboración de organizaciones didácticas respetuosas tanto de la epistemología de la disciplina como del funcionamiento cognitivo, se ha desplazado hacia el docente, considerándolo como un actor esencial y problemático de la relación didáctica. La investigación se interesó en sus creencias, conocimientos y prácticas. Los investigadores trataron de identificar los conocimientos necesarios para realizar esa labor, entender sus características, sus interconexiones, la manera de cómo se forman y se desarrollan (Even y Ball, 2008)”. (Artigue, 2014, p. 46)

Una de las consideraciones a tener en cuenta en la formación del profesorado, y que todos los enfoques de la didáctica parecen estar de acuerdo, es la necesidad de concretar cuáles son los conocimientos necesarios del profesor para llevar a cabo las tareas propias de la profesión.

En relación a nuestra problemática, y tras el estudio llevado a cabo sobre la relación entre el razonamiento lógico y la relación didáctica, postulamos la necesidad del conocimiento lógico para la gestión de los razonamientos y nos cuestionamos si ese conocimiento es suficiente para el desarrollo de su profesión. Así pues, en los siguientes capítulos se va a llevar a cabo un diagnóstico del conocimiento lógico de nuestros estudiantes 
universitarios, futuros maestros y se implementará una situación didáctica que mostrará la capacidad de la herramienta utilizada, no solamente como instrumento de diagnóstico, sino como posible situación para la formación lógica y didáctica de los estudiantes.

La TAD ha estado siempre íntimamente relacionada con la formación inicial y continua del profesorado de matemáticas, últimos responsables de la enseñanza y difusión del saber matemático. La actividad llevada a cabo por los profesores de matemáticas también se modelizará en términos de praxeologías. Se hablará así de praxeologías didácticas, que incluyen tanto las praxeologías matemáticas que los profesores deben enseñar a sus alumnos como las diferentes praxeologías para la enseñanza. Estas últimas son las praxeologías que se activan con las praxeologías matemáticas a enseñar, que pueden ser también matemáticas (praxeologías matemáticas para la enseñanza). Es importante resaltar que las praxeologías no son construcciones individuales, sino una amalgama de praxeologías y elementos praxeológicos que configuran el equipamiento praxeológico, lo que se corresponde con los conocimientos, capacidades y competencias de una persona dentro de una institución.

A partir de la definición de equipamiento praxeológico, la TAD formula la siguiente cuestión generatriz de la problemática de la formación de profesorado:

\footnotetext{
¿Cuál es el equipamiento praxeológico necesario (o por lo menos útil) para que los profesores puedan intervenir de manera efectiva y pertinente en la formación matemática de los estudiantes (de tal o cual etapa educativa) y qué se puede hacer para ayudar a que los profesores dispongan de él? (Bosch y Gascón, 2009, p. 94)
}

Para responder a esta pregunta y no caer en la tentación de idealizar al profesor, la TAD hace referencia a las restricciones que puede encontrar un profesor para llevar a cabo estas praxeologías, y añade la siguiente cuestión: 
¿Cuáles son las cuestiones cruciales con las que deben enfrentarse los profesores en su práctica docente y qué puede hacer la formación para ayudarles a construir respuestas satisfactorias a estas cuestiones? (Bosch y Gascón, 2009, p. 95)

Los niveles de codeterminación (Chevallard, 2001) ayudan a estructurar el conjunto de condiciones y restricciones que afectan a la formación de praxeologías didácticas:

Civilización $\rightarrow$ Sociedad $\rightarrow$ Escuela $\rightarrow$ Pedagogía $\rightarrow$ Disciplina $\rightarrow$ Área Sector Tema Cuestión

"Los profesores en su práctica docente se encuentran con restricciones y condiciones que afectan su trabajo matemático en el aula con sus alumnos y que son específicos de la disciplina que enseña: se requiere disponer de determinadas nociones o herramientas matemáticas antes de poder construir otras, etc. Como profesores pueden actuar sobre alguna de estas condiciones pero no sobre otras (que actúan entonces como restricciones). $Y$ también se encuentran con restricciones y condiciones que provienen de los niveles superiores de codeterminación” (Bosch y Gascón, 2009, p. 95)

La Lógica es una disciplina científica que no forma parte del conjunto de enseñanzas escolares. No se trata de una restricción de la disciplina matemática, sino de una disciplina ausente, y por lo tanto sobre la que no se puede incidir. El problema del conocimiento lógico necesario para el aprendizaje de las matemáticas debe solucionarse desde dentro de las matemáticas. ¿Cómo llevar a cabo la transposición didáctica para enseñar este conocimiento en los diferentes niveles educativos?

La TSD nos ha proporcionado algunas respuestas para la educación infantil y primaria, se trataría de praxeologías matemáticas a enseñar.

Cuando se introduce una praxeología nueva en una institución, surgen nuevas preguntas: ¿Cuál será el equipamiento praxeológico necesario para realizar estas praxeologías matemáticas a enseñar? 
Para reformular la problemática, Ruiz-Higueras y García utilizan el modelo de análisis de las praxeologías didácticas, a partir de la formulación del problema de la formación de maestros (Ruiz-Higueras y García, 2011):

\footnotetext{
“Cómo concebir, expresar, gestionar y evaluar procesos de estudio $\delta(O M, O D)$ en una institución $I_{F M}$ con el fin de que los sujetos de $I_{F M}$ sean capaces de reconstruir, articular, gestionar y evaluar pares (OM, OD) optimizados en otra institución escolar $I_{E}$ ?" (RuizHigueras y García, 2011, p. 435)
}

Estos autores describen un modelo de las praxeologías didácticas, praxeología didáctica del profesor, a partir de los modelos desarrollados por Artaud (Artaud, 2007), Chopin (Chopin, 2007), Sensevy (Sensevy y otros, 2000, 2005) у Margolinas (Margolinasy otros, 2005).

De entre las tareas del profesor, se encuentran definir, regular, devolver e institucionalizar. En cuanto al porqué de estas tareas, distinguen tres niveles, la reflexión general del profesor sobre la enseñanza y el aprendizaje; la concepción general sobre cómo organizar un tema de enseñanza: nociones a estudiar y conocimiento a adquirir y proyecto didáctico local específico de una lección o conjunto de lecciones: objetivos y organización del trabajo.

\subsection{Metodología}

Este trabajo de investigación se engloba en el conjunto de investigaciones relacionadas con el dominio de las nociones paramatemáticas llevadas a cabo en el marco del enfoque epistemológico de la Didáctica de las Matemáticas, denominado también Didáctica Fundamental. Por tanto, la metodología utilizada viene marcada por el marco teórico de referencia elegido. Los principales conceptos teóricos de la TSD y de la TAD, como instrumentos metodológicos, han permitido empezar a abordar nuestro problema de 
investigación en torno a las dos preguntas iniciales: ¿Es necesaria la lógica en la formación de maestros? ¿Es suficiente?

A continuación se proseguirá con la parte experimental. Esta parte, desarrollada a lo largo de los capítulos segundo y tercero, consistirá en la realización de una secuencia didáctica. Para ello utilizaremos la ingeniería didáctica como metodología de investigación específica, a nivel de micro-ingeniería.

\footnotetext{
"La teorización de las situaciones didácticas ha tenido también consecuencias metodológicas. Es así como ella ha conducido a desarrollar, en oposición con los paradigmas comparativos clásicos de experimentación en clase, una metodología específica: la "ingeniería didáctica”. Esta metodología de la ingeniería didáctica se basa en un control a priori de las situaciones que se ponen en juego dentro del proceso experimental. Este control se efectúa a través de un análisis a priori que busca precisar las posibilidades que se han seleccionado, los valores de las variables didácticas que se producen como consecuencia de esta selección y el sentido que pueden tomar los comportamientos previstos teniendo en cuenta estos valores. En seguida, en el análisis a posteriori, este análisis a priori se compara con la realización efectiva y se busca lo que rechaza o confirma las hipótesis sobre las cuales estaba basado”. (Artigue, 1995, p.12)
}

Se utiliza este término micro-ingeniería cuando se estudia la complejidad de los fenómenos dentro del aula, reservando el término macro-ingeniería para las investigaciones que llevan a cabo el estudio de los fenómenos asociados a la duración de las relaciones entre enseñanza y aprendizaje, quedando así la micro-ingeniería integrada dentro de la macro-ingeniería. (Artigue y otros, 1995).

La metodología de investigación aquí presentada se caracteriza por el carácter experimental de su realización (concepción, realización, observación y análisis de secuencias didácticas) y por los criterios de validación interna que utiliza (confrontación entre el análisis a priori y a posteriori). 
En primer lugar se llevará a cabo una revisión teórica relacionada con el objeto de estudio. Ello servirá tanto para realizar la adaptación y diseño de la situación como para las fases de análisis a posteriori y validación de la situación. En términos de esta metodología esta fase es conocida como fase de los análisis preliminares de la ingeniería. Los resultados de este análisis no siempre se hacen explícitos, pero constituyen los pilares sobre los que se apoya toda investigación: análisis epistemológico de los contenidos, análisis de las concepciones y dificultades de los estudiantes, análisis de las restricciones para la experimentación, etc. que de forma natural van apareciendo a lo largo de todo el trabajo.

A lo largo del segundo capítulo, se llevará a cabo la adaptación de la situación fundamental. Para ello se llevará a cabo la selección de variables didácticas consideradas pertinentes en la consecución de nuestro objetivo. Seguidamente, se procederá con el análisis a priori, que consistirá en la descripción del proceso llevado a cabo y en la predicción de los resultados. El objetivo del análisis a priori es determinar en qué medida las elecciones llevadas a cabo van a permitir el control de los comportamientos de los estudiantes y su significado.

También se llevará a cabo una "preexperimentación" con el fin de comprobar la viabilidad de la situación y diagnosticar las dificultades de los estudiantes. La preexperimentación no se limitará a los estudiantes que posteriormente vayan a participar en la secuencia didáctica, sino que se ampliará el número de estudiantes, para reforzar la validez de los resultados. Para examinar los resultados de la preexperimentación, serán utilizados todos los análisis previos. También la utilización de otras metodologías externas, como son las herramientas estadísticas para el tratamiento de la información (análisis estadístico de datos y análisis estadístico implicativo (Gras y Kuntz, 2009) y software CHIC (Gras, Couturier y Bodin, 2007)), nos ayudarán a completar el análisis a priori.

Por último, en el tercer capítulo, y partiendo del trabajo anterior, se diseñará una situación didáctica para ser implementada en clase. El análisis de esta actividad se llevará a cabo 
mediante la observación en el aula. Brousseau, desde sus inicios como investigador, ya entendía la observación de las prácticas didácticas como un método específico de investigación para la Didáctica de las Matemáticas. Precisamente este convencimiento desencadenó el proyecto de investigación del COREM ${ }^{15}$, institución creada para permitir a los matemáticos llevar a cabo las observaciones de manera sistemática y sostenida. Como afirma Brousseau en su artículo de 1978 "L'observation des activites didactiques" para observar un fenómeno preciso, hay que realizar una situación determinada, por lo tanto las realizaciones didácticas forman parte de una planificación experimental, que además no puede llevarse a cabo por una única persona. Las dialécticas de acción, formulación y validación de las situaciones didácticas para la investigación necesitan de la intervención tanto de maestros como investigadores que intervengan en la planificación y observación:

"Pour observer un phénoméne précis il faut réaliser une situation déterminée et par conséquent la réalisation didactique fait partie du dessein expérimental. Toute expérience didactique fournit donc à la fois des documents practiques pour la clase et des documents théoriques ou scientifiques.

$[\cdots]$

Je considère que ces réalisations font partie inégrante de l'activité des chercheurs, comme ce serait le cas pour la conception d'un appareil nouveau de recherche en physique.

Il n'est pas nécessaire que la même personne contrôle un tel système. Mais si elle n'est pas impliquée dans un système de ce type, elle peut s'égarer très vite. L'observation est bien plus une entreprise collective qu'une activité personnelle. C'est pourquoi des débats comme ceuxci sont très importants" (Brousseau, 1978, p. 133, 134)

Así pues para llevar a cabo la observación se dispondrá de la colaboración de otros investigadores observando la lección junto al profesor que habitualmente imparte clase a los estudiantes, y todo ello reforzado con las producciones escritas tanto de los estudiantes

${ }^{15}$ Centre pour l'Observation et la Recherche sur l'Enseignement des Mathématiques (Centro para la Observación y la Investigación de la Enseñanza de las Matemáticas) 
como de los colaboradores, el uso de grabadoras y cámara de vídeo, con el propósito de recoger la mayor información posible.

Para llevar a cabo la gestión de los razonamientos de los alumnos de Educación Primaria y no caer en las paradojas del contrato hay que llevar a cabo actividades matemáticas que tengan la lógica como un fin en sí mismo y no como un medio para el aprendizaje de las matemáticas.

Para no entrar de nuevo en la paradoja del contrato didáctico en la formación de los maestros, postulamos que es necesario incluir la lógica en el equipamiento praxeológico de los maestros. Para ello habrá que comprobar cuáles son los conocimientos lógicos de los futuros maestros y plantear la necesidad de la formación en lógica de estos estudiantes. 


\section{CAPÍTULO 2}

UN INSTRUMENTO DE DIAGNÓSTICO DEL RAZONAMIENTO LÓGICO DE FUTUROS MAESTROS 
En este capítulo se llevará a cabo un diagnóstico del razonamiento lógico de un grupo de estudiantes universitarios, utilizando como instrumento un cuestionario diseñado para nuestra investigación. Se trata de una adaptación del cuestionario que conforma la situación fundamental "El juego del viaje”, concebida para la enseñanza de la lógica en la enseñanza primaria, en Francia (Orús, 1986, 1992).

En primer lugar se llevará a cabo la presentación del propio cuestionario, así como su correspondiente análisis a priori. A continuación y tras llevar a cabo la correspondiente experimentación, se presentarán los resultados obtenidos a posteriori y las conclusiones obtenidas.

Todo este proceso tiene como objetivo diagnosticar el conocimiento lógico de futuros maestros en una situación adidáctica elaborada en el marco de la TSD.

\subsection{Presentación del cuestionario Q}

El diseño del cuestionario presentado en este capítulo, responde a la necesidad de utilizar en el aula situaciones adidácticas para la formación de futuros maestros, situaciones en las que el conocimiento lógico se considere como un objeto a enseñar y no como un medio para la construcción de otros conocimientos. No se pretende observar el razonamiento ligado a conocimientos matemáticos, como podría ser el razonamiento geométrico, numérico o algebraico, ya que en este caso los conocimientos lógicos se involucran en los conocimientos matemáticos implicados.

En ese sentido, no se trata de un cuestionario típico de preguntas y respuestas, donde se ponen a prueba directamente los conocimientos lógicos de los estudiantes. Tampoco se ha utilizado un cuestionario tipo test, de los utilizados en los estudios psicológicos, donde se ponen a prueba distintos aspectos del razonamiento lógico: relaciones analógicas, 
series numéricas y matrices lógicas ${ }^{16}$. En nuestro caso se trata de un cuestionario pensado para hacer funcionar los conocimientos lógicos disponibles de los estudiantes mediante los razonamientos que dan lugar a sus respuestas.

El cuestionario Q consiste en una serie de preguntas que tienen que ser respondidas utilizando los datos de una tabla de datos binarios asociada, sin la cual el cuestionario carecería de sentido. Esta tabla de datos sirve de materialización de los conceptos y operaciones lógicas que suponen las actividades necesarias para responder a las diferentes preguntas del cuestionario. El interés que encierra el cuestionario Q reside en el trabajo lógico que es posible llevar a cabo con él, tal y como ya mostraron en trabajos anteriores Orús y Pitarch (Orús, 1992; Pitarch, 2002).

La situación fundamental conocida como El Juego del Viaje (Orús, 1986), fue confeccionada inicialmente para estudiantes de educación primaria en la escuela Jules Michelet de Talence (Francia). Esta escuela formaba parte del Centro de Observación y de Investigación sobre la Enseñanza de las Matemáticas (COREM) dirigido por Guy Brousseau durante los 25 años que duró dicha institución (1973-1998). La colaboración entre investigadores y docentes hizo posible la observación de situaciones de clase, desarrollando así nuevos conceptos de la TSD, y generando diferentes ingenierías didácticas, concebidas y construidas por los investigadores para la enseñanza de las matemáticas en educación infantil y primaria. Entre estas aportaciones, encontramos el El Juego del Viaje, formando parte de una ingeniería didáctica desarrollada a lo largo de tres cursos escolares, seis grupos y cinco profesores diferentes, que dio lugar a su tesis doctoral «Le raisonnement des élèves dans la relation didactique; effets d'une initiation

\footnotetext{
${ }^{16}$ En la tesis de Pitarch «Desarrollo de la competencia "tratamiento de la informacion" en la ESO, a través de la lógica y del análisis estadístico de los datos» se pueden encontrar algunos ejemplos de los ítems que aparecen en este tipo de pruebas de aptitud, realizadas por los gabinetes psicopedagógicos para niveles de educación primaria y secundaria, donde se evalúan los aspectos cognitivos relacionados con el razonamiento lógico: relaciones analógicas, series numéricas y matrices lógicas (Pitarch, 2015, pp. 356370)
} 
à l'analyse classificatoire dans la scolarité obligatoire» con el fin de introducir el trabajo lógico sobre tablas de datos en la enseñanza primaria.

Esta situación didáctica ha sido adaptada posteriormente para estudiantes de Educación Secundaria en Castellón (España) donde Pitarch, en su trabajo de investigación titulado «Estudio sobre la viabilidad y el interés didáctico del tratamiento de la información en la $E S O »$, estudia la viabilidad del cuestionario en estos niveles educativos (Pitarch, 2002), trabajo que actualmente ha sido retomado en su tesis doctoral «Desarrollar la competencia tratamiento de la información en la ESO, a través del trabajo conjunto de la lógica y los datos» con la realización de una ingeniería didáctica que analiza los razonamientos de los estudiantes utilizando simultáneamente el Tratamiento de Datos, la Lógica y la Estadística Elemental. Asimismo, se pueden encontrar resultados sobre la adaptación del cuestionario para niveles preuniversitarios en el trabajo «Tratamiento de datos, lógica y estadística elemental en la enseñanza preuniversitaria. Un estudio mediante la aplicación del chic» desarrollado en Cuba (Zamora y otros, 2009) donde se sigue la misma línea de investigación propuesta por Pitarch.

Estos trabajos, que preceden a nuestra investigación, han puesto de manifiesto las dificultades que tienen los estudiantes de los niveles educativos indicados para utilizar los razonamientos lógicos, fuertemente condicionados por el pensamiento natural, lo que pone de manifiesto que esos conocimientos no se adquieren de forma natural o espontánea como consecuencia de una madurez intelectual propia de la edad, ni tampoco con la formación matemática adquirida de la que cabe esperar contribuya a su desarrollo. En los resultados obtenidos a partir de la resolución del cuestionario con estudiantes de educación secundaria, Pitarch concluye que, a pesar de haber una leve mejoría en los resultados de $3^{\circ}$ y $4^{\circ}$ de la ESO, los estudiantes en general presentan dificultad en las preguntas del cuestionario con operaciones lógicas combinadas, destacando aquéllas en las que intervienen la implicación o el cuantificador universal (Pitarch, 2015). Asimismo, la información procedente de las respuestas de los estudiantes preuniversitarios también muestran dificultades en cuanto a los razonamientos lógicos (Zamora y otros, 2009) 
Si las reglas del pensamiento natural se imponen a las reglas del pensamiento formal, al menos en los niveles educativos anteriormente citados, ¿cabe esperar una situación similar con estudiantes universitarios? Siguiendo con las investigaciones al respecto, citadas anteriormente, nos planteamos las siguientes cuestiones:

P1: ¿Sigue habiendo preguntas en el cuestionario que presentan mayor dificultad para los estudiantes, futuros maestros?

P2: ¿Las preguntas con mayor dificultad son el mismo tipo de preguntas que presentaban dificultad en alumnos de educación primaria y secundaria?

P3: ¿Podemos reconocer en el cuestionario una herramienta válida para el diagnóstico de dificultades de razonamiento de futuros maestros?

Los criterios establecidos para el diseño del cuestionario ya han tenido en cuenta los trabajos previos, que muestran una persistencia en los errores de naturaleza lógica, y sobre todo cuando intervienen la lógica de predicados o las operciones lógicas combinadas. Estas dificultades se vuelven a presentar en la adaptación del cuestionario, con el propósito de comprobar si persisten las dificultades, a pesar de la edad y de la formación matemática recibida. Además se han incluido preguntas en el cuestionario que requieren de razonamientos lógicos para ser contestadas, sin tratarse de respuestas directas sobre la tabla. Estas preguntas incrementan el nivel de dificultad y pensamos que así se verá reflejado en los resultados.

El primer paso ha sido la adaptación del cuestionario al nivel educativo de los estudiantes con los que se va a realizar la actividad. La confección de las nuevas preguntas se ha llevado a cabo teniendo en cuenta tanto la tabla como el cuestionario en función del tema sobre el que versará el cuestionario Q.

En versiones anteriores del cuestionario, se han utilizado temas muy variados para contextualizar la actividad, como la agencia de viajes, los tipos de películas, los gustos musicales o la clasificación de plantas. En nuestro caso, se ha considerado adecuado utilizar como tema central del cuestionario "la agencia de viajes". Se trata de una 
situación ficticia que sitúa a los estudiantes ante los datos de un grupo de jóvenes, sobre sus gustos a la hora de elegir un destino turístico. Se solicita la colaboración de los estudiantes para analizar dichos datos y obtener información de la encuesta realizada, introduciendo así a los estudiantes en una situación que puede ser reconocible y atractiva para ellos, como puede ser la organización de un viaje.

Con el propósito de ajustar las preguntas a los gustos de nuestros estudiantes y con el fin de elegir tipos de viajes apropiados para su edad, se ha pasado una encuesta previa, a un grupo de estudiantes de primer curso de la Titulación de Maestro, preguntándoles sobre lo que les gusta a la hora de viajar:

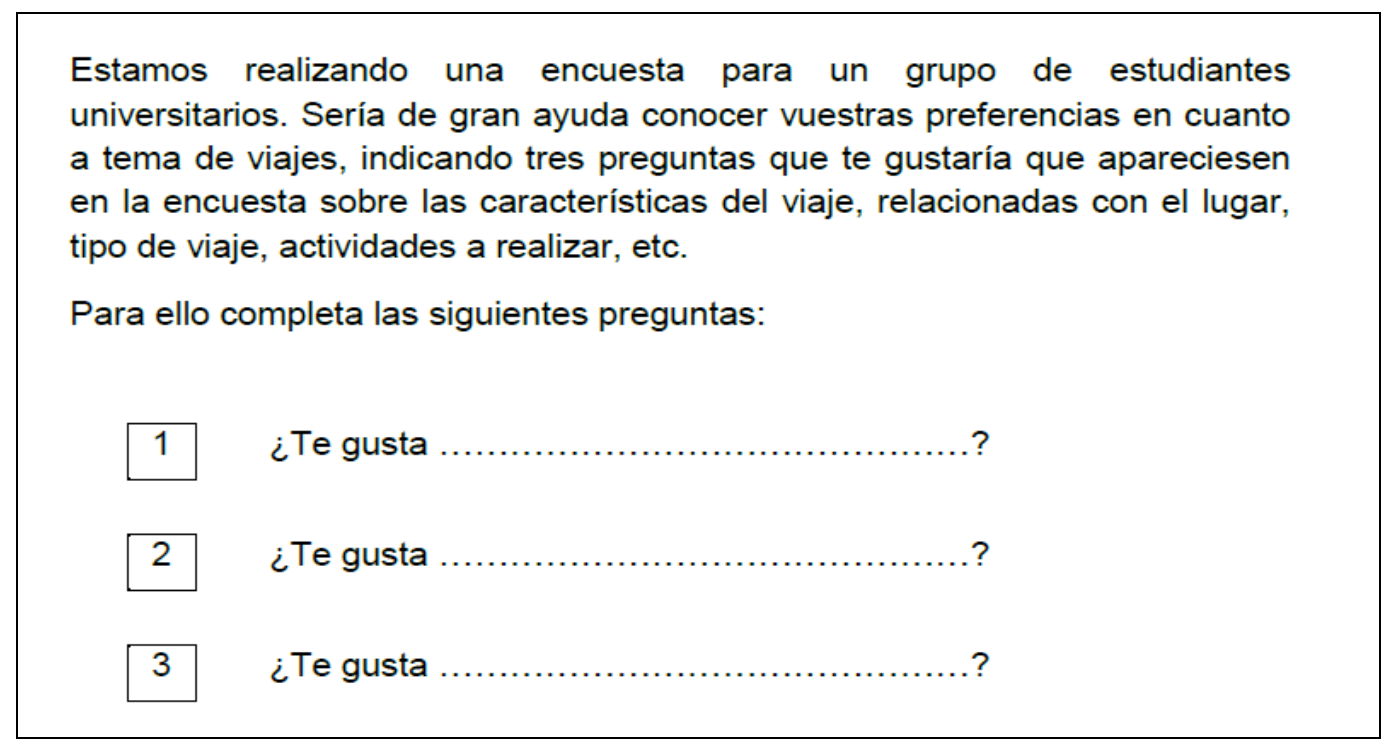

Fig. 2.1: Plantilla utilizada para la obtención de criterios

A partir de las respuestas de los estudiantes encuestados, se han definido los criterios y los valores de la tabla de datos binarios del cuestionario Q. Así, en la primera fila se pregunta: ¿Te gusta la gran ciudad?, siendo la gran ciudad uno de los atractivos turísticos reconocidos por muchos de los estudiantes consultados. Esta conexión de la tabla de datos "reales", en parte subjetivos, puede convertirse en un punto de encuentro entre el 
pensamiento natural y el razonamiento formal, es decir, entre lo subjetivo y lo objetivo, entre otros aspectos.

Para diseñar la tabla de datos se ha optado por utilizar el tamaño de la tabla binaria original de dimensiones $15 \times 20$, considerando que la cantidad de elementos a manejar es suficiente, también en el nivel de educación superior. Una vez diseñada la tabla de datos, se ha procedido a la adaptación de las preguntas del cuestionario. Las preguntas están fundamentadas en los conocimientos lógicos que se quiere diagnosticar. Las diferentes cuestiones se han elaborado para observar el funcionamiento de determinados conocimientos lógicos relacionados con la lógica proposicional y la lógica de predicados a través de sus respuestas. Dichos conocimientos son:

- proposición lógica

- predicado/función proposicional

- conectores lógicos (negación, conjunción, disyunción y condicional)

- construcción de fórmulas de la lógica proposicional y de la lógica de predicados

- transformación de fórmulas y atribución del valor de verdad.

El lenguaje empleado en la redacción de las preguntas se ha escogido intencionadamente. La finalidad es propiciar posibles conflictos necesarios para dar sentido al conocimiento lógico implícito en su resolución y para conseguir la observación del pensamiento natural, que puede ser el obstáculo para la aparición de dicho conocimiento lógico.

A continuación, se presentan la tabla de datos binarios y el cuestionario (figuras 2.2 y 2.3), tal y como se presentarán a los estudiantes de la experimentación descrita en este capítulo. 


\section{Consigna:}

Se ha hecho una encuesta a 20 estudiantes sobre sus gustos respecto a viajes: actividades, destinos, ... La siguiente tabla recoge las respuestas de los estudiantes. A la izquierda de la tabla aparece la lista de preguntas, por ejemplo, “ ¿Te gusta el clima frío?", y en la parte superior, cada letra mayúscula representa el nombre de un estudiante, como por ejemplo, "estudiante B"

Se quiere ayudar a la obtención de información a partir de los datos recogidos en la tabla $\mathrm{T}$.

Tabla T

\begin{tabular}{|c|c|c|c|c|c|c|c|c|c|c|c|c|c|c|c|c|c|c|c|c|}
\hline ¿Te gusta... & A & B & C & D & E & $\mathbf{F}$ & G & $\mathbf{H}$ & I & $\mathbf{J}$ & $\mathbf{K}$ & $\mathbf{L}$ & M & $\mathrm{N}$ & o & $\mathbf{P}$ & $\mathrm{Q}$ & R & $\mathrm{s}$ & $\mathbf{T}$ \\
\hline $\begin{array}{l}\text { la gran ciudad? } \\
\text { (C1) }\end{array}$ & 1 & 1 & 1 & 0 & 1 & 0 & 1 & 0 & 1 & 0 & 0 & 1 & 1 & 0 & 0 & 1 & 1 & 0 & 1 & 0 \\
\hline $\begin{array}{l}\text { practicar deporte? } \\
\text { (C2) }\end{array}$ & 1 & 0 & 0 & 1 & 0 & 0 & 0 & 1 & 0 & 0 & 0 & 0 & 0 & 0 & 1 & 0 & 0 & 0 & 1 & 0 \\
\hline $\begin{array}{l}\text { disfrutar la } \\
\text { naturaleza? (C3) }\end{array}$ & 1 & 1 & 0 & 0 & 1 & 1 & 1 & 1 & 0 & 0 & 1 & 1 & 1 & 1 & 1 & 1 & 1 & 1 & 1 & 1 \\
\hline el clima frío? (C4) & 0 & 1 & 0 & 1 & 1 & 0 & 1 & 1 & 0 & 0 & 1 & 1 & 0 & 0 & 1 & 1 & 0 & 0 & 1 & 0 \\
\hline $\begin{array}{l}\text { salir de noche? } \\
\text { (C5) }\end{array}$ & 0 & 0 & 0 & 1 & 0 & 1 & 1 & 1 & 1 & 0 & 1 & 0 & 0 & 1 & 1 & 0 & 1 & 0 & 1 & 0 \\
\hline la playa? $(\mathrm{C} 6)$ & 1 & 1 & 1 & 1 & 1 & 1 & 1 & 1 & 1 & 1 & 1 & 1 & 1 & 1 & 1 & 1 & 1 & 1 & 1 & 1 \\
\hline el relax? (C7) & 0 & 1 & 0 & 1 & 1 & 0 & 1 & 0 & 0 & 0 & 1 & 1 & 1 & 0 & 0 & 1 & 0 & 0 & 1 & 1 \\
\hline $\begin{array}{l}\text { visitar museos? } \\
\text { (C8) }\end{array}$ & 1 & 1 & 0 & 0 & 1 & 1 & 1 & 1 & 0 & 0 & 1 & 1 & 1 & 1 & 1 & 1 & 1 & 1 & 1 & 1 \\
\hline la montaña? (C9) & 1 & 0 & 0 & 1 & 1 & 0 & 1 & 0 & 0 & 0 & 0 & 0 & 0 & 0 & 0 & 0 & 0 & 0 & 1 & 0 \\
\hline $\begin{array}{l}\text { conocer otras } \\
\text { culturas? }(\mathrm{Cl} 0)\end{array}$ & 1 & 1 & 1 & 0 & 1 & 1 & 1 & 1 & 1 & 1 & 1 & 1 & 1 & 1 & 1 & 1 & 1 & 1 & 1 & 1 \\
\hline $\begin{array}{l}\text { visitar lugares } \\
\text { históricos? (11) }\end{array}$ & 0 & 1 & 0 & 1 & 1 & 0 & 1 & 0 & 1 & 0 & 1 & 1 & 0 & 0 & 0 & 1 & 1 & 0 & 1 & 0 \\
\hline esquiar? (C12) & 0 & 1 & 1 & 1 & 1 & 1 & 1 & 1 & 0 & 0 & 1 & 1 & 1 & 1 & 1 & 1 & 1 & 1 & 1 & 1 \\
\hline $\begin{array}{l}\text { vivir aventuras? } \\
\text { (C13) }\end{array}$ & 1 & 0 & 1 & 1 & 0 & 1 & 0 & 1 & 1 & 0 & 1 & 0 & 0 & 1 & 1 & 0 & 1 & 0 & 1 & 1 \\
\hline $\begin{array}{l}\text { el clima cálido? } \\
\text { (C14) }\end{array}$ & 1 & 1 & 1 & 0 & 1 & 0 & 1 & 0 & 1 & 0 & 1 & 1 & 1 & 0 & 0 & 1 & 0 & 0 & 1 & 0 \\
\hline $\begin{array}{l}\text { los deportes } \\
\text { acuáticos? (C15) }\end{array}$ & 1 & 1 & 1 & 1 & 1 & 0 & 0 & 1 & 0 & 0 & 1 & 1 & 1 & 1 & 1 & 1 & 1 & 0 & 1 & 1 \\
\hline
\end{tabular}

Fig. 2.2: Consigna y tabla de datos binarios asociada al cuestionario $Q$ 


\section{Cuestionario Q}

Q1. ¿Al estudiante C le gusta salir de noche?

Q2. ¿A cuántos estudiantes les gusta vivir aventuras?

Q3. ¿Cuántas cosas le gustan al estudiante $Q$ para viajar?

Q4. ¿Hay algo que les guste a todos los estudiantes? En caso afirmativo, indica lo que es.

Q5. ¿Hay algín estudiante a quien le guste todo? En caso afirmativo, indica su nombre

Q6. ¿Hay más estudiantes a quienes les guste todo? En caso afirmativo, indica cuáles

Q7. ¿A cuántos estudiantes no les gustan las grandes ciudades y salir de noche?

Q8. ¿Todo lo que le gusta al estudiante $\mathrm{R}$ le gusta al estudiante $\mathrm{J}$ ?

Q9. ¿Todo lo que le gusta al estudiante $\mathrm{J}$ le gusta al estudiante $\mathrm{R}$ ?

Q10. ¿A todos los estudiantes les gusta salir de noche o practicar deporte?

Q11. Los estudiantes N y $\mathrm{R}$ ¿tienen el mismo gusto para viajar? ¿Por qué?

Q12. ¿A qué pareja crees que es más probable encontrar en un mismo viaje, a $\mathrm{J}$ y $\mathrm{R}$ o

G y T? ¿Por qué?

Q13. Si fueras el agente de viajes, ¿qué tres criterios de los que aparecen en la tabla elegirias para proponer un viaje a estos estudiantes? ¿Por qué?

\begin{tabular}{|l|l|l|l|}
\cline { 2 - 4 } Di si las siguientes afirmaciones son verdaderas o falsas & VERDADERO & FALSO & NO SÉ \\
\hline Q14. Al estudiante que le gusta el frío, le gusta esquiar. & & & \\
\hline $\begin{array}{l}\text { Q15. A todos los estudiantes que les gusta esquiar les } \\
\text { gusta el frío. }\end{array}$ & & & \\
\hline $\begin{array}{l}\text { Q16. Si a un estudiante no le gusta el deporte, entonces no } \\
\text { le gustan los deportes acuáticos. }\end{array}$ & & & \\
\hline Q17. Al estudiante E le gusta la playa o la montaña. & & & \\
\hline $\begin{array}{l}\text { Q18. Lo que les gusta a los estudiantes C y F le gusta al } \\
\text { estudiante L. }\end{array}$ & & & \\
\hline
\end{tabular}

Si fuera cierta la información sobre el grupo de que "a todos los estudiantes que les gusta practicar deporte les gusta nadar", indica si son verdaderas o falsas las siguientes afirmaciones:

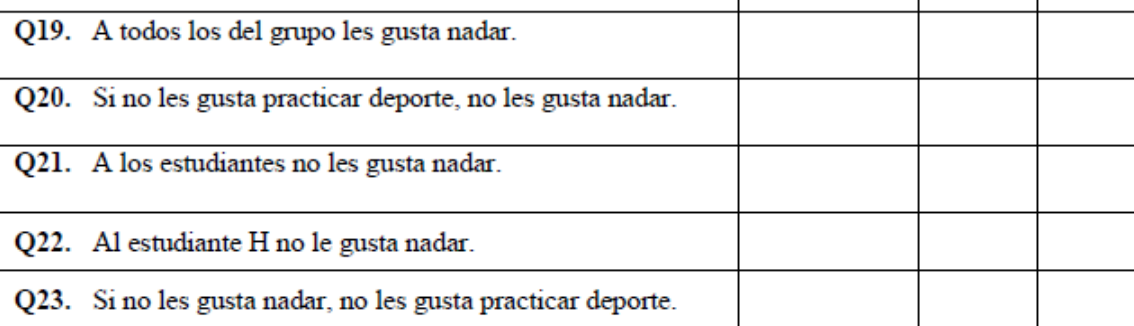

Fig. 2.3: Cuestionario Q 


\subsection{Estudio a priori del cuestionario Q}

Dado que el cuestionario es concebido como una ingeniería didáctica en el marco de la TSD, la metodología exige la realización de un análisis a priori del cuestionario Q, que tiene por objetivo "determinar en qué las selecciones hechas permiten controlar los comportamientos de los estudiantes y su significado» (Artigue, 1995, p. 45). Para controlar el significado que está en juego en cada momento, se considera necesario reconocer las diferentes opciones de resolución de las que dispone el estudiante, teniendo en cuenta sus posibilidades, así como prever las dificultades a las que podría enfrentarse el sujeto en el desarrollo de la actividad. Todo ello es importante en la relación didáctica, tanto para tomar decisiones en la preparación y experimentación en el aula, como para interpretar, a posteriori, lo que ha sucedido realmente.

La caracterización de las preguntas del cuestionario Q y la relación entre ellas que supone el estudio a priori, será impescindible para prever y comprender la lógica de las respuestas de los estudiantes e interpretar su significado. Con el estudio a priori del cuestionario se van a determinar las características que hacen de él un instrumento adecuado en la consecución del objetivo propuesto con la experimentación.

Al presentar el cuestionario se puso de relieve que el interés del cuestionario sobre la tabla de datos binarios reside, fundamentalmente, en el trabajo matemático y lógico que se puede llevar a cabo con ella. En este sentido, cada una de las preguntas que conforman el cuestionario puede ser caracterizada según este trabajo.

Como punto de partida, se presenta el trabajo lógico-matemático identificado en el uso de la tabla $\mathrm{T}$, que permitirá en adelante identificar este trabajo en cada una de las cuestiones de Q. En el cuestionario inicial (Orús, 1992) se diferencian cuatro tipos de actividades relacionadas con las preguntas:

- La lectura de una tabla de datos.

- La interpretación conjuntista de la tabla de datos. 
- La interpretación lógica de la tabla de datos binarios.

- La interpretación estadística de la tabla de datos.

A pesar de ser posible el trabajo estadístico con T, la experimentación que se lleva a cabo en esta investigación es limitada. Aunque es posible interpretar la respuesta de alguna de las cuestiones como un trabajo estadístico, no se considera uno de los objetivos de nuestro trabajo, que se centra en los conocimientos lógicos. La interpretación estadística se ha incluido en este apartado, para mostrar el potencial de la tabla $\mathrm{T}$ de datos binarios y las diferentes posibilidades que puede ofrecer la utilización de un único instrumento, que permite trabajar los datos lógica o estadísticamente para obtener información (Orús, 1992; Pitarch, 2002, 2015). En nuestro caso, tan solo abordaremos la interpretación lógica y conjuntista de la tabla.

Para realizar el análisis a priori, se ha utilizado una caracterización similar a la caracterización realizada por Pitarch en el "Cuestionario sobre gustos musicales" (Pitarch, 2002). Se han seleccionado algunos criterios relacionados con la lectura de la tabla, el recuento de valores, la comparación de filas o columnas, los conectores lógicos y las argumentaciones. Además se ha ampliado la caracterización incluyendo otros criterios debido a la complejidad de las nuevas cuestiones, que utilizan uno o varios predicados, operaciones lógicas combinadas, razonamientos lógicos, reglas de inferencia o atribución del valor de verdad. Los criterios relacionados con la estadística se han mantenido fuera de nuestra caracterización.

\subsubsection{Modelización lógico-matemática de las preguntas del cuestionario Q}

La tabla de datos binarios se puede interpretar como un conjunto de diferentes conjuntos de elementos: un conjunto de estudiantes, un conjunto de criterios o gustos, un conjunto de filas, un conjunto de columnas, etc.

Cada conjunto admite una definición lógico-matemática, tal y como presentamos a continuación. 
La tabla establece una relación entre los elementos de dos conjuntos, que son el conjunto de 20 estudiantes y el conjunto de 15 criterios:

$$
\mathrm{C}=\left\{\mathrm{C}_{\mathrm{i}}\right\}_{\mathrm{i}=1}^{15}
$$

(Representará al conjunto de los 15 criterios)

$$
E=\{E j\}_{j=1}^{20}
$$

(Representará al conjunto de los 20 estudiantes)

Los valores de la tabla vienen representados por los valores de la variable binaria $\mathrm{X}_{\mathrm{i}, \mathrm{j}}$, que indican la asignación del criterio $\mathrm{C}_{\mathrm{i}}$ al estudiante $\mathrm{E}_{\mathrm{j}}$. Por ejemplo:

$$
\mathrm{X}_{\mathrm{i}, \mathrm{j}}=\mathrm{C}_{\mathrm{i}}\left(\mathrm{E}_{\mathrm{j}}\right)
$$

(Significa que el criterio $C_{i}$ está entre los gustos del estudiante $E_{j}$, o también que al estudiante $\mathrm{E}_{\mathrm{j}}$ le gusta $\mathrm{C}_{\mathrm{i}}$ )

$$
\mathrm{x}_{3,7}=\mathrm{C}_{3}\left(\mathrm{E}_{7}\right)=1
$$

(Significa que disfrutar de la naturaleza está entre los gustos del estudiante G, o también que al estudiante G le gusta disfrutar de la naturaleza)

$$
\mathrm{X}_{3,4}=\mathrm{C}_{3}\left(\mathrm{E}_{4}\right)=0
$$

(Significa que disfrutar de la naturaleza no está entre los gustos del estudiante D, o también que al estudiante D no le gusta disfrutar de la naturaleza)

Asimismo, cada fila representa un predicado sobre los elementos del conjunto E, que es el universo del discurso para todos los predicados representados por las filas de T. El predicado «tener entre sus gustos $C_{k}$ » corresponde a la fila k-ésima de la tabla:

$$
\forall \mathrm{E}_{\mathrm{j}} \in \mathrm{E} \quad \mathrm{C}_{\mathrm{k}}(\mathrm{Ej})
$$

(Predicado correspondiente a la fila k-ésima de la tabla T) 
Este predicado hace una partición sobre el conjunto E, diferenciando dos partes, el subconjunto formado por los elementos que verifican el predicado y el subconjunto formado por los elementos que no lo verifican, es decir, su complementario:

$$
\begin{gathered}
E=E_{C k} \cup E_{C_{k}}^{C} \\
E_{C_{k}}=\left\{E_{j} \in E / C_{k}(E j)=1\right\}_{j=1}^{20}
\end{gathered}
$$

(Conjunto de estudiantes que verifican el criterio $\mathrm{C}_{\mathrm{k}}$ )

$$
\mathrm{E}_{\mathrm{C}_{\mathrm{k}}}^{\mathrm{C}}=\left\{\mathrm{E}_{\mathrm{j}} \in \mathrm{E} / \mathrm{C}_{\mathrm{k}}(\mathrm{Ej})=0\right\}_{\mathrm{j}=1}^{20}
$$

(Conjunto de estudiantes que no verifican el criterio $\mathrm{C}_{\mathrm{k}}$ )

Del mismo modo que cada fila representa un predicado sobre los elementos del conjunto E, cada columna también puede ser interpretada como un predicado sobre los elementos del conjunto $\mathrm{C}$, siendo éste el universo del discurso para todos los predicados representados por las columnas de $\mathrm{T}$. El predicado «gustar al estudiante $\mathrm{E}_{\mathrm{h}}$ » corresponde a la columna h-ésima de la tabla:

$$
\forall \mathrm{C}_{\mathrm{i}} \in \mathrm{C} \quad \mathrm{E}_{\mathrm{h}}(\mathrm{Ci})
$$

(Predicado correspondiente a la columna h-ésima de la tabla T)

Este predicado hace una partición sobre el conjunto $\mathrm{C}$, diferenciando los elementos que verifican el predicado de los que no los verifican.

$$
\begin{gathered}
\mathrm{C}=\mathrm{C}_{\mathrm{E}_{\mathrm{h}}} \cup \mathrm{C}_{\mathrm{E}_{\mathrm{h}}}^{\mathrm{C}} \\
\mathrm{C}_{\mathrm{E}_{\mathrm{h}}}=\left\{\mathrm{C}_{\mathrm{i}} \in \mathrm{C} / \mathrm{E}_{\mathrm{h}}\left(\mathrm{C}_{\mathrm{i}}\right)=1\right\}_{\mathrm{i}=1}^{15}
\end{gathered}
$$

(Conjunto de criterios que están entre los gustos de $\mathrm{E}_{\mathrm{h}}$ )

$$
\mathrm{C}_{\mathrm{E}_{\mathrm{h}}}^{\mathrm{C}}=\left\{\mathrm{C}_{\mathrm{i}} \in \mathrm{C} / \mathrm{E}_{\mathrm{h}}\left(\mathrm{C}_{\mathrm{i}}\right)=0\right\}_{\mathrm{i}=1}^{15}
$$

(Conjunto de criterios que no están entre los gustos de $\mathrm{E}_{\mathrm{h}}$ ) 
Los predicados utilizados en los enunciados de las preguntas del cuestionario definen subconjuntos de $\mathrm{E}$ y de $\mathrm{C}$, mediante el uso de conectores lógicos. A partir de la interpretación lógico-matemática de la tabla de datos binarios, procedemos con la modelización lógico-matemática de las preguntas.

Pregunta Q1: ¿Al estudiante C le gusta salir de noche? No

La lectura de un dato binario permite conocer si un estudiante tiene cierto gusto o si un criterio determinado está entre los gustos de un estudiante.

$$
\mathrm{C}_{5}\left(\mathrm{E}_{3}\right)=0 \text { o también } \mathrm{E}_{3}\left(\mathrm{C}_{5}\right)=0
$$

Pregunta Q2: ¿A cuántos estudiantes les gusta vivir aventuras? A 12 estudiantes

Para responder a esta pregunta hay que calcular el cardinal del conjunto de estudiantes a los que les gusta vivir aventuras:

$$
\text { Card }\left\{\mathrm{E}_{\mathrm{j}} / \mathrm{C}_{13}\left(\mathrm{E}_{\mathrm{i}}\right)=1\right\}_{j=1}^{20}=12
$$

Pregunta Q3: ¿Cuántas cosas le gustan al estudiante Q para viajar? Le gustan 10 cosas. Para responder a esta pregunta hay que calcular el cardinal del conjunto de criterios que están entre los gustos del estudiante Q:

$$
\text { Card }\left\{\mathrm{C}_{\mathrm{i}} / \mathrm{E}_{17}\left(\mathrm{C}_{\mathrm{i}}\right)=1\right\}_{\mathrm{i}=1}^{15}=10
$$

Pregunta Q4: ¿Hay algo que les guste a todos los estudiantes? En caso afirmativo, indica lo que es. Sí, la playa $\left(\mathrm{C}_{6}\right)$ gusta a todos los estudiantes.

$$
i \exists \mathrm{C}_{\mathrm{i}} \in \mathrm{C} / \mathrm{C}_{\mathrm{i}}(\mathrm{Ej})=1 \quad \forall \mathrm{j} \in\{1, \ldots, 20\} ?
$$

La respuesta es afirmativa porque existe una fila de la tabla con todos los valores unitarios. 


$$
\mathrm{C}_{6}\left(E_{j}\right)=1 \quad \forall \mathrm{j} \in\{1, \ldots, 20\}
$$

Pregunta Q5: ¿Hay algún estudiante a quien le guste todo? En caso afirmativo, indica su nombre. Sí, al estudiante $\mathrm{S}\left(\mathrm{E}_{19}\right)$ le gustan todos los criterios de la tabla.

$$
i \exists \mathrm{E}_{\mathrm{j}} \in \mathrm{E} \quad / \mathrm{E}_{\mathrm{j}}\left(\mathrm{C}_{\mathrm{i}}\right)=1 \quad \forall \mathrm{i} \in\{1, \ldots, 15\} ?
$$

La respuesta es afirmativa porque existe una columna de la tabla con todos los valores unitarios.

$$
\mathrm{E}_{19}\left(\mathrm{C}_{\mathrm{i}}\right)=1 \quad \forall \mathrm{i} \in\{1, \ldots, 15\}
$$

Pregunta Q6: ¿Hay otros? En caso afirmativo, indica cuáles No, porque para todos los estudiantes, excepto para el estudiante $\mathrm{S}$, hay al menos un criterio que no está entre sus gustos, es decir, en las columnas correspondientes existe al menos un cero:

$$
\forall \mathrm{j} \neq 19 \quad \exists \mathrm{i}_{\mathrm{j}} \in\{1, \ldots, 15\} / \mathrm{E}_{\mathrm{j}}\left(\mathrm{C}_{\mathrm{i}_{\mathrm{j}}}\right)=0
$$

Pregunta Q7: ¿A cuántos estudiantes no les gustan las grandes ciudades y salir de noche? Hay 16 estudiantes a los que no les gustan las dos cosas.

Para responder a esta cuestión hay que calcular el cardinal del conjunto de estudiantes que no verifiquen la conjunción de dos predicados. Se pueden seguir dos procesos para la obtención de la respuesta:

Se puede obtener el conjunto de estudiantes que verifica la conjunción de predicados y después, calcular el cardinal de su conjunto complementario:

$$
\operatorname{Card}\left\{E_{j} \in E / C_{1}\left(E_{j}\right)=1 \wedge C_{5}\left(E_{j}\right)=1\right\}^{C}
$$

O también se puede utilizar la ley de De Morgan para la negación de la conjunción

$$
\forall \mathrm{E}_{\mathrm{j}} \in \mathrm{E} \neg\left(\mathrm{C}_{1} \wedge \mathrm{C}_{5}\right)\left(\mathrm{E}_{\mathrm{j}}\right) \leftrightarrow \quad \forall \mathrm{E}_{\mathrm{j}} \in \mathrm{E} \neg \mathrm{C}_{1}\left(\mathrm{E}_{\mathrm{j}}\right) \vee \neg \mathrm{C}_{5}\left(\mathrm{E}_{\mathrm{j}}\right)
$$


y obtener el conjunto de estudiantes que verifiquen dicha disyunción:

$$
\begin{array}{r}
\operatorname{Card}\left\{E_{j} \in E / C_{1}\left(E_{j}\right)=0 \vee C_{5}\left(E_{j}\right)=0\right\}= \\
=\operatorname{Card}\left\{E_{j} \in E /\left(C_{1}\left(E_{j}\right)=0 \wedge C_{5}\left(E_{j}\right)=1\right) \vee\right. \\
\vee\left(C_{1}\left(E_{j}\right)=1 \wedge C_{5}\left(E_{j}\right)=0\right) \vee \\
\left.\vee\left(C_{1}\left(E_{j}\right)=0 \wedge C_{5}\left(E_{j}\right)=0\right)\right\}
\end{array}
$$

Pregunta Q8: ¿Todo lo que le gusta al estudiante R le gusta al estudiante J? No.

Hay que comprobar que el conjunto de criterios que verifican el predicado «gustar al estudiante $R$ » también verifica el predicado «gustar al estudiante $J$ »

$$
i \forall \mathrm{C}_{\mathrm{i}} \in \mathrm{C} \quad \mathrm{E}_{18}\left(\mathrm{C}_{\mathrm{i}}\right)=1 \rightarrow \mathrm{E}_{10}\left(\mathrm{C}_{\mathrm{i}}\right)=1 ?
$$

La respuesta es negativa porque existe un contraejemplo:

$$
\mathrm{E}_{18}\left(\mathrm{C}_{3}\right)=1 \wedge \mathrm{E}_{10}\left(\mathrm{C}_{3}\right)=0
$$

Pregunta Q9: ¿Todo lo que le gusta al estudiante J le gusta al estudiante R? Sí

Hay que comprobar que el conjunto de estudiantes que verifican el predicado «gustar al estudiante $J »$ también verifica el predicado «gustar al estudiante $R$ »

$$
i \forall \mathrm{C}_{\mathrm{i}} \in \mathrm{C} \quad \mathrm{E}_{10}\left(\mathrm{C}_{\mathrm{i}}\right)=1 \rightarrow \mathrm{E}_{18}\left(\mathrm{C}_{\mathrm{i}}\right)=1 ?
$$

La respuesta es afirmativa porque no hay contraejemplos.

Pregunta Q10: ¿A todos los estudiantes les gusta salir de noche o practicar deporte? No Hay que comprobar si todos los estudiantes verifican la disyunción de dos predicados: «tener el gusto salir de noche o tener el gusto practicar deporte»

$$
i \forall \mathrm{j} \in\{1, \ldots, 20\} \quad \mathrm{C}_{5}(\mathrm{Ej})=1 \vee \mathrm{C}_{2}(\mathrm{Ej})=1 ?
$$


La respuesta es negativa porque existe al menos un contraejemplo. El estudiante B no tiene entre sus gustos ni el criterio $\mathrm{C}_{5}$ ni el criterio $\mathrm{C}_{2}$ :

$$
\mathrm{C}_{5}\left(\mathrm{E}_{2}\right)=0 \wedge \mathrm{C}_{2}\left(\mathrm{E}_{2}\right)=0
$$

Pregunta Q11: Los estudiantes N y R ¿tienen el mismo gusto para viajar? No

Hay que comprobar si los criterios que tiene el estudiante $\mathrm{N}$ son los mismos que tiene el estudiante R:

$$
\text { ¿ } \forall i \in\{1, \ldots, 15\} \quad \mathrm{E}_{14}\left(\mathrm{C}_{\mathrm{i}}\right)=\mathrm{E}_{18}\left(\mathrm{C}_{\mathrm{i}}\right) ?
$$

Falso. $\mathrm{E}_{14}\left(\mathrm{C}_{5}\right) \neq \mathrm{E}_{18}\left(\mathrm{C}_{5}\right)$

Pregunta Q12: ¿A qué pareja crees que es más probable encontrar en un mismo viaje, a $\mathrm{J}$ y $\mathrm{R}$ o $\mathrm{G}$ y $\mathrm{T}$ ? ¿Por qué? A la pareja $\mathrm{J}$ y $\mathrm{R}$ porque coinciden en más criterios (coinciden 12 veces: 10 coausencias en los criterios $\mathrm{C}_{1}, \mathrm{C}_{2}, \mathrm{C}_{4}, \mathrm{C}_{5}, \mathrm{C}_{7}, \mathrm{C}_{9}, \mathrm{C}_{11}, \mathrm{C}_{13}, \mathrm{C}_{14}$ y $\mathrm{C}_{15} .2$ copresencias en los criterios $\mathrm{C}_{6} \mathrm{y}_{10}$ )

Hay que calcular el número de coincidencias (copresencias y coausencias) para cada pareja:

$$
\begin{aligned}
& \text { Card }\left\{\mathrm{C}_{\mathrm{i}} / \mathrm{E}_{14}\left(\mathrm{C}_{\mathrm{i}}\right)=\mathrm{E}_{18}\left(\mathrm{C}_{\mathrm{i}}\right)\right\}_{i=1}^{15}=12 \\
& \text { Card }\left\{\mathrm{C}_{\mathrm{i}} / \mathrm{E}_{7}\left(\mathrm{C}_{\mathrm{i}}\right)=\mathrm{E}_{20}\left(\mathrm{C}_{\mathrm{i}}\right)\right\}_{i=1}^{15}=7
\end{aligned}
$$

Pregunta Q13: Si fueras el agente de viajes, ¿qué tres criterios de los que aparecen en la tabla elegirías para proponer un viaje a estos estudiantes? ¿Por qué? $\mathrm{C}_{6}, \mathrm{C}_{12}$ y $\mathrm{C}_{10}$ porque son aquellos criterios que han sido elegidos por mayor número de estudiantes.

Hay que buscar los tres criterios $\mathrm{C}_{\mathrm{i} 1}, \mathrm{C}_{\mathrm{i} 2}, \mathrm{C}_{\mathrm{i} 3}$, verificados por mayor número de estudiantes. 
Pregunta Q14: Al estudiante que le gusta el frío, le gusta esquiar: Verdadero

Hay que comprobar que el conjunto de estudiantes que verifican el predicado «tener el gusto frío» también verifica el predicado «tener el gusto esquiar»

$$
i \forall \mathrm{E}_{\mathrm{j}} \in \mathrm{E} \quad \mathrm{C}_{4}\left(\mathrm{E}_{\mathrm{j}}\right)=1 \rightarrow \mathrm{C}_{12}\left(\mathrm{E}_{\mathrm{j}}\right)=1 ?
$$

Es una afirmación verdadera porque no existe ningún contraejemplo:

$$
\forall \mathrm{j} \in\{1, \ldots, 20\} \quad \mathrm{C}_{4}\left(\mathrm{E}_{\mathrm{j}}\right)=1 \rightarrow \mathrm{C}_{12}\left(\mathrm{E}_{\mathrm{j}}\right)=1
$$

Pregunta Q15: A todos los estudiantes que les gusta esquiar les gusta el frío: Falso

Hay que comprobar que el conjunto de estudiantes que verifican el predicado «tener el gusto esquiar » también verifica el predicado «tener el gusto frío »

Es una afirmación falsa porque existe un contraejemplo:

$$
\mathrm{C}_{12}\left(\mathrm{E}_{3}\right)=1 \rightarrow \mathrm{C}_{4}\left(\mathrm{E}_{3}\right)=0
$$

Pregunta Q16: Si a un estudiante no le gusta el deporte, entonces no le gustan los deportes acuáticos: Falso

Hay que comprobar que el conjunto de estudiantes que no verifican el predicado «tener el gusto deporte » tampoco verifica el predicado «tener el gusto deportes acuáticos »

$$
\forall \mathrm{j} \in\{1, \ldots, 20\} \quad \mathrm{C}_{2}\left(\mathrm{E}_{\mathrm{j}}\right)=0 \rightarrow \mathrm{C}_{15}\left(\mathrm{E}_{\mathrm{j}}\right)=0
$$

Es una afirmación falsa porque existe al menos un contraejemplo, como es el caso del estudiante $\mathrm{E}_{5}$ al que no le gusta el deporte pero sí le gustan los deportes acuáticos:

$$
\mathrm{C}_{2}\left(\mathrm{E}_{5}\right)=0 \wedge \mathrm{C}_{15}\left(\mathrm{E}_{5}\right)=1
$$


Pregunta Q17: Al estudiante E le gusta la playa o la montaña: Verdadero

Se trata de una proposición compuesta por la disyunción de dos proposiciones:

$$
\begin{gathered}
\mathrm{E}_{5}\left(\mathrm{C}_{6}\right)=1 \vee \mathrm{E}_{5}\left(\mathrm{C}_{9}\right)=1 \\
\text { Verdadero porque } \mathrm{E}_{5}\left(\mathrm{C}_{6}\right)=1 \wedge \mathrm{E}_{5}\left(\mathrm{C}_{9}\right)=1
\end{gathered}
$$

Pregunta Q18: Lo que les gusta a los estudiantes C y F le gusta al estudiante L: Falso En esta pregunta se encuentra una implicación lógica, con una conjunción en el antecedente:

$$
\forall \mathrm{i} \in\{1, \ldots, 15\} \quad \mathrm{E}_{3}\left(\mathrm{C}_{\mathrm{i}}\right)=1 \wedge \mathrm{E}_{6}\left(\mathrm{C}_{\mathrm{i}}\right)=1 \rightarrow \mathrm{E}_{12}\left(\mathrm{C}_{\mathrm{i}}\right)=1
$$

Falso, porque existe al menos un contraejemplo: a los estudiantes $\mathrm{C}$ y $\mathrm{F}$ les gusta vivir aventuras pero al estudiante L no le gusta vivir aventuras.

$$
\left(\mathrm{E}_{3}\left(\mathrm{C}_{13}\right)=1 \wedge \mathrm{E}_{6}\left(\mathrm{C}_{13}\right)=1\right) \wedge \mathrm{E}_{12}\left(\mathrm{C}_{13}\right)=0
$$

\section{PREMISA}

\section{"A todos los estudiantes que les gusta practicar deporte les gusta nadar"}

Este enunciado, que sirve de premisa, introduce un nuevo criterio, $\mathrm{C}_{16}$ (tener entre sus gustos nadar), que actúa como predicado sobre los sujetos del conjunto $\mathrm{E}_{\mathrm{C} 2} \subset \mathrm{E}$, siendo $\mathrm{E}_{\mathrm{C} 2}=\left\{\mathrm{E}_{1}, \mathrm{E}_{4}, \mathrm{E}_{8}, \mathrm{E}_{15}, \mathrm{E}_{19}\right\}$

Pregunta Q19: A todos los del grupo les gusta nadar: No sé. No se puede atribuir un valor de verdad.

Hay que comprobar que a todos los estudiantes les gusta nadar:

$$
\forall \mathrm{j} \in\{1, \ldots, 20\} \quad \mathrm{C}_{16}\left(\mathrm{E}_{\mathrm{j}}\right)=1 \text {. }
$$


No se puede comprobar. No tenemos esa información. Sólo se tiene información relativa al criterio $\mathrm{C}_{16}$ para aquellos estudiantes que les gusta practicar deporte.

Pregunta Q20: Si no les gusta practicar deporte, no les gusta nadar: No sé. No se puede atribuir un valor de verdad.

$$
\forall \mathrm{j} \in\{1, \ldots, 20\} \quad \mathrm{C}_{2}\left(\mathrm{E}_{\mathrm{j}}\right)=0 \rightarrow \mathrm{C}_{16}\left(\mathrm{E}_{\mathrm{j}}\right)=0 .
$$

No se puede comprobar. No tenemos esa información.

Pregunta Q21: No les gusta nadar: Falso

$$
\forall \mathrm{j} \in\{1, \ldots, 20\} \quad \mathrm{C}_{16}\left(\mathrm{E}_{\mathrm{j}}\right)=0
$$

Falso porque existe al menos un contraejemplo, ya que el conjunto de estudiantes que les gusta practicar deporte no es un conjunto vacío. Por ejemplo, al estudiante A le gusta practicar deporte, por lo tanto, según la premisa, le gusta nadar

$$
\mathrm{C}_{16}\left(\mathrm{E}_{1}\right)=1
$$

Pregunta Q22: Al estudiante H no le gusta nadar: Falso

El estudiante $\mathrm{H}$ es un ejemplo que verifica la premisa. Se trata de un estudiante que le gusta practicar deporte, por lo tanto le gusta nadar.

$$
\mathrm{C}_{2}\left(\mathrm{E}_{8}\right)=1 \Rightarrow \mathrm{C}_{16}\left(\mathrm{E}_{8}\right)=1
$$

Por lo tanto, el enunciado de la pregunta Q22 es falso.

Pregunta Q23: Si no les gusta nadar, no les gusta practicar deporte: Verdadero La premisa, además de proporcionar información sobre los estudiantes a los que les gusta practicar deporte, también proporciona información sobre los estudiantes a los que no les 
gusta nadar. La equivalencia lógica entre una condicional y su contrarrecíproca nos permite afirmar

$$
\mathrm{C}_{2}(\mathrm{Ej})=1 \rightarrow \mathrm{C}_{16}\left(\mathrm{E}_{\mathrm{j}}\right)=1 \leftrightarrow \mathrm{C}_{16}\left(\mathrm{E}_{\mathrm{j}}\right)=0 \rightarrow \mathrm{C}_{2}\left(\mathrm{E}_{\mathrm{j}}\right)=0
$$

Por lo tanto, se trata de una afirmación verdadera, porque es equivalente a la premisa.

\subsubsection{Matriz a priori del cuestionario $Q$}

Inicialmente, partimos de una clasificación de las preguntas, atendiendo a los criterios generales utilizados en la elaboración del cuestionario:

- Bloque 1=\{Q1, Q2, Q3 $\}$ Preguntas cuya respuesta supone la lectura correcta de la tabla: la interpretación de los datos binarios como asignación de un criterio a un estudiante o de un estudiante a un criterio.

- Bloque 2=\{Q4, Q5, Q6, Q7, Q8, Q9, Q10 $\}$ Preguntas con cuantificador, cuya respuesta requiere la interpretación conjuntista de la tabla.

- Bloque 3=\{Q11, Q12, Q13 $\}$ Preguntas que apelan al pensamiento subjetivo

- Bloque 4=\{Q14, Q15, Q16, Q17, Q18 $\}$ Preguntas con operaciones lógicas

- Bloque 5=\{Q19, Q20, Q21, Q22, Q23 $\}$ Preguntas que necesitan llevar a cabo un razonamiento lógico

En el estudio a priori del cuestionario Q, además de reconocer la naturaleza matemática y lógica de las cuestiones, se han identificado otros factores que podrían interferir en el funcionamiento del conocimiento lógico. Hasta ahora, en el análisis realizado, no se han tenido en cuenta las divergencias del pensamiento fuera del contexto formal. Para tener una lectura más acertada de las respuestas de los estudiantes es necesario reparar en los diferentes aspectos que determinan tanto el pensamiento formal como el pensamiento natural e identificarlos dentro de un mismo contexto. Por este motivo, el lenguaje utilizado en los enunciados, la similitud entre las preguntas que conforman el cuestionario 
así como el tipo de respuesta requerida (verdadera, falsa, respuesta numérica o respuesta subjetiva), son algunos de los aspectos relevantes y a tener en cuenta en la presente investigación.

A continuación se presentan los criterios utilizados en la caracterización de las preguntas del cuestionario. Con el fin de agilizar la lectura se ha incluído la codificación ${ }^{17}$ utilizada en los análisis posteriores, así como la relación de preguntas que son caracterizadas por cada uno de los criterios:

TABL: Trabajo sobre un elemento concreto de la tabla: fila/s, columna/s, pero no sobre toda la tabla en general. [Q1, Q2, Q3, Q7, Q8, Q9, Q10, Q11, Q12, Q14, Q15, Q16, Q17, Q18].

ROBL: Se ha de hacer un recuento obligatorio. [Q2, Q3, Q7, Q13]

RALT: Se puede hacer un recuento alternativo, de manera opcional, pero no necesariamente. [Q4, Q5, Q6, Q10, Q11, Q12]

FDIF: Hay que fijarse sólo en los valores no coincidentes entre las filas/columnas, es decir, calcular la frecuencia de parejas con valores diferentes: parejas de valores (0-1) o (1-0). [Q11]

FCOI: Hay que fijarse tanto en las coincidencias positivas $(1,1)$, como en las negativas, es decir, calcular la frecuencia de parejas con valores coincidentes: (0- 0). [Q12]

FPRE: Hay que fijarse únicamente en las co-presencias $(1,1)$ entre filas o entre columnas, es decir, calcular la frecuencia de parejas con co-presencias. [Q8, Q9, Q14, Q15, Q18]

FAUS: Hay que fijarse únicamente en las co-ausencias $(0,0)$ entre filas o columnas, es decir, calcular la frecuencia de parejas con co-ausencias. [Q16]

CSEM: Comparación entre los criterios de la tabla a partir de la relación semántica que pueda existir entre ellos. El significado de las palabras que intervienen en el enunciado puede afectar a la respuesta. [Q11, Q12, Q13, Q14, Q15, Q16, Q17, Q20, Q23]

LIMP: Implicación lógica. [Q8, Q9, Q14, Q15, Q16, Q18, Q20, Q23]

LIMPR: Implicación lógica recíproca. Es la recíproca de otra implicación anterior. [Q9, Q15, Q23]

LOPC: Hay operaciones lógicas combinadas. [Q7, Q16, Q18, Q20, Q23]

LUNIUP: Conectores lógicos universales actuando sobre un único predicado [Q4, Q5, Q6, Q19, Q21]

LUNIVP: Conectores lógicos universales actuando sobre varios predicados. [Q8, Q9, Q10, Q14, Q15, Q16, Q18, Q20, Q23]

LCON: Conjunción lógica. [Q7, Q18]

LDIS: Disyunción lógica. [Q10, Q17]

LNEG: Negación lógica. [Q7, Q16, Q20, Q21, Q22, Q23]

${ }^{17}$ En la tabla se han destacado en negrita las iniciales de las palabras clave que forman parte de la codificación de los criterios. 
LMPON La respuesta requiere utilizar la regla de inferencia lógica Modus Ponens [Q21, Q22]

LFAL: La respuesta puede dar lugar al uso de falacias lógicas o argumentativas. [Q15, Q20]

ARGU: Dar una explicación o argumentación sobre la respuesta. [Q11, Q12, Q13]

NTABL: La respuesta no se encuentra en la tabla. [Q19, Q20, Q21, Q22, Q23]

GEN: Generalización. [Q19, Q21]

CONTR: Contrarrecíproco de una condicional. [Q23]

RDAF: Respuesta directa afirmativa ( directamente la respuesta. [Q4, Q5, Q9]

RDNEG: Respuesta directa negativa ( $\operatorname{cin}$ asignar valor de verdad). La lectura de la tabla da directamente la respuesta. [Q1, Q6, Q8, Q10, Q11]

AV: $\quad$ Asignación del valor de verdad. [Q14, Q15, Q16, Q17, Q18, Q19, Q20, Q21, Q22, Q23]

AVERD: Asignación del valor Verdadero. [Q14, Q17, Q23]

AFALS Asignación del valor Falso. [Q15, Q16, Q18, Q21, Q22]

ANS No se puede asignar ningún valor de verdad porque no se sabe la respuesta. [Q19, Q20]

Tabla 2.1: Variables para la caracterización de las preguntas del cuestionario Q y su codificación

La caracterización resuelta para cada una de las preguntas del cuestionario, según nuestro punto de vista, ha sido la siguiente ${ }^{18}$ : Q1. ¿Al estudiante C le gusta salir de
noche?

Q2. ¿A cuántos estudiantes les gusta vivir aventuras?

Q3. ¿Cuántas cosas le gustan al estudiante $Q$ para viajar?

Q4. ¿Hay algo que les guste a todos los estudiantes? En caso afirmativo, indica lo que es.
- Trabajo sobre un elemento concreto de la tabla: fila/s, columna/s, pero no sobre toda la tabla en general

- Respuesta directa negativa (sin asignar valor de verdad). La lectura de la tabla da directamente la respuesta

- Trabajo sobre un elemento concreto de la tabla: fila/s, columna/s, pero no sobre toda la tabla en general

- Se ha de hacer un recuento obligatorio

- Trabajo sobre un elemento concreto de la tabla: fila/s, columna/s, pero no sobre toda la tabla en general - Se ha de hacer un recuento obligatorio

- Se puede hacer un recuento de manera opcional, pero no necesariamente

- Cuantificador lógico universal actuando sobre un único predicado

- Respuesta directa afirmativa (sin asignar valor de verdad). La lectura de la tabla da directamente la respuesta

\footnotetext{
${ }^{18}$ Se han destacado en negrita los criterios más representativos de cada pregunta, o al menos aquellos que inicialmente han influido más en la construcción del cuestionario Q.
} 
Q5. ¿Hay algún estudiante a quien le guste todo? En caso afirmativo, indica su nombre

Q6. ¿Hay más estudiantes a quienes les guste todo? En caso afirmativo, indica cuáles

Q7. ¿A cuántos estudiantes no les gustan las grandes ciudades y salir de noche?

Q8. ¿Todo lo que le gusta al estudiante $\mathrm{R}$ le gusta al estudiante $\mathrm{J}$ ? estudiante $\mathrm{J}$ le gusta al estudiante $\mathrm{R}$ ?

Q10. ¿A todos los estudiantes les gusta salir de noche o practicar deporte?

Q11. Los estudiantes $\mathrm{N}$ y $\mathrm{R}$ ¿tienen el mismo gusto para viajar? ¿Por qué?

Q12. ¿A qué pareja crees que es más probable encontrar en un mismo
- Se puede hacer un recuento de manera opcional, pero no necesariamente

- Cuantificador lógico universal actuando sobre un único predicado

- Respuesta directa afirmativa (sin asignar valor de verdad). La lectura de la tabla da directamente la respuesta

- Se puede hacer un recuento de manera opcional, pero no necesariamente

- Cuantificador lógico universal actuando sobre un único predicado

- Respuesta directa negativa (sin asignar valor de verdad). La lectura de la tabla da directamente la respuesta

- Trabajo sobre un elemento concreto de la tabla: fila/s, columna/s, pero no sobre toda la tabla en general

Se ha de hacer un recuento obligatorio

- Hay operaciones lógicas combinadas

- Conjunción lógica

- Negación lógica

- Trabajo sobre un elemento concreto de la tabla: fila/s, columna/s, pero no sobre toda la tabla en general

- Hay que fijarse únicamente en las co-presencias $(1,1)$, entre filas o entre columnas

- Implicación lógica

- Cuantificador lógico universal actuando sobre varios predicados

- Respuesta directa negativa (sin asignar valor de verdad). La lectura de la tabla da directamente la respuesta

- Trabajo sobre un elemento concreto de la tabla: fila/s, columna/s, pero no sobre toda la tabla en general

- Hay que fijarse únicamente en las co-presencias $(1,1)$, entre filas o entre columnas

- Implicación lógica

- Implicación lógica recíproca. Es la recíproca de otra implicación anterior

- Cuantificador lógico universal actuando sobre varios predicados

- Respuesta directa afirmativa (sin asignar valor de verdad). La lectura de la tabla da directamente la respuesta

- Trabajo sobre un elemento concreto de la tabla: fila/s, columna/s, pero no sobre toda la tabla en general

- Se puede hacer un recuento de manera opcional, pero no necesariamente

- Cuantificador lógico universal actuando sobre varios predicados

- Disyunción lógica

- Respuesta directa negativa (sin asignar valor de verdad). La lectura de la tabla da directamente la respuesta

- Trabajo sobre un elemento concreto de la tabla: fila/s, columna/s, pero no sobre toda la tabla en general

- Se puede hacer un recuento de manera opcional, pero no necesariamente

- Hay que fijarse sólo en los valores no coincidentes entre las filas/columnas, es decir, en las parejas de valores (0-1) o (1-0)

- Hay relación semántica. El significado de las palabras que intervienen en el enunciado puede afectar a la respuesta

- Dar una explicación o argumentación sobre la respuesta

- Respuesta directa negativa (sin asignar valor de verdad). La lectura de la tabla da directamente la respuesta

- Trabajo sobre un elemento concreto de la tabla: fila/s, columna/s, pero no sobre toda la tabla en general

- Se puede hacer un recuento de manera opcional, pero no necesariamente 


\begin{tabular}{|c|c|}
\hline $\begin{array}{l}\text { viaje, a } \mathrm{J} \text { y } \\
\text { qué? }\end{array}$ & $\begin{array}{l}\text { - Hay que fijarse tanto en las coincidencias positivas }(1,1) \text {, como en las } \\
\text { negativas }(0-0) \\
\text { - Hay relación semántica. El significado de las palabras que intervienen } \\
\text { en el enunciado puede afectar a la respuesta }\end{array}$ \\
\hline $\begin{array}{l}\text { Q13. Si fueras el agente de viajes, } \\
\text { ¿qué tres criterios de los que } \\
\text { aparecen en la tabla }\end{array}$ & $\begin{array}{l}\text { - Se ha de hacer un recuento obligatorio } \\
\text { - Hay relación semántica. El significado de las palabras que intervienen } \\
\text { en el enunciado puede afectar a la respuesta } \\
\text { - Dar una explicación o argumentación sobre la respuesta }\end{array}$ \\
\hline $\begin{array}{l}\text { Q14. Al estudiante que le gusta el } \\
\text { frío, le gusta esquiar. }\end{array}$ & $\begin{array}{l}\text { - Trabajo sobre un elemento concreto de la tabla: fila/s, columna/s, pero no } \\
\text { sobre toda la tabla en general } \\
\text { - Hay que fijarse únicamente en las co-presencias }(1,1) \text {, entre filas o entre } \\
\text { columnas } \\
\text { - Hay relación semántica. El significado de las palabras que intervienen en } \\
\text { el enunciado puede afectar a la respuesta } \\
\text { - Implicación lógica } \\
\text { - Cuantificador lógico universal actuando sobre varios predicados } \\
\text { - Asignación del valor de verdad } \\
\text { - Asignación del valor Verdadero }\end{array}$ \\
\hline $\begin{array}{l}\text { Q15. A todos los estudiantes que les } \\
\text { gusta esquiar les gusta el frío. }\end{array}$ & $\begin{array}{l}\text { - Trabajo sobre un elemento concreto de la tabla: fila/s, columna/s, pero no } \\
\text { sobre toda la tabla en general } \\
\text { - Hay que fijarse únicamente en las co-presencias }(1,1) \text {, entre filas o entre } \\
\text { columnas } \\
\text { - Hay relación semántica. El significado de las palabras que intervienen en } \\
\text { el enunciado puede afectar a la respuesta } \\
\text { - Implicación lógica } \\
\text { - Implicación lógica recíproca. Es la recíproca de otra implicación } \\
\text { anterior } \\
\text { - Cuantificador lógico universal actuando sobre varios predicados } \\
\text { - La respuesta puede dar lugar al uso de falacia argumentativa } \\
\text { - Asignación del valor de verdad } \\
\text { - Asignación del valor Falso }\end{array}$ \\
\hline $\begin{array}{l}\text { Q16. Si a un estudiante no le gusta } \\
\text { el deporte, entonces no le gustan los } \\
\text { deportes acuáticos. }\end{array}$ & $\begin{array}{l}\text { - Trabajo sobre un elemento concreto de la tabla: fila/s, columna/s, pero no } \\
\text { sobre toda la tabla en general } \\
\text { - Hay que fijarse únicamente en las co-ausencias }(0,0) \text { entre filas o columnas } \\
\text { - Hay relación semántica. El significado de las palabras que intervienen } \\
\text { en el enunciado puede afectar a la respuesta } \\
\text { - Implicación lógica } \\
\text { - Hay operaciones lógicas combinadas } \\
\text { - Cuantificador lógico universal actuando sobre varios predicados } \\
\text { - Negación lógica } \\
\text { - Asignación del valor de verdad } \\
\text { - Asignación del valor Falso }\end{array}$ \\
\hline $\begin{array}{l}\text { Q17. Al estudiante E le gusta la } \\
\text { playa o la montaña. }\end{array}$ & $\begin{array}{l}\text { - Trabajo sobre un elemento concreto de la tabla: fila/s, columna/s, pero no } \\
\text { sobre toda la tabla en general } \\
\text { - Hay relación semántica. El significado de las palabras que intervienen en } \\
\text { el enunciado puede afectar a la respuesta } \\
\text { - Disyunción lógica } \\
\text { - Asignación del valor de verdad } \\
\text { - Asignación del valor Verdadero }\end{array}$ \\
\hline $\begin{array}{l}\text { Q18. Lo que les gusta a los } \\
\text { estudiantes C y F le gusta al } \\
\text { estudiante L. }\end{array}$ & $\begin{array}{l}\text { - Trabajo sobre un elemento concreto de la tabla: fila/s, columna/s, pero no } \\
\text { sobre toda la tabla en general }\end{array}$ \\
\hline
\end{tabular}




\begin{tabular}{|c|c|}
\hline & $\begin{array}{l}\text { - Hay que fijarse únicamente en las co-presencias }(1,1) \text {, entre filas o entre } \\
\text { columnas } \\
\text { - Hay operaciones lógicas combinadas } \\
\text { - Implicación lógica } \\
\text { - Cuantificador lógico universal actuando sobre varios predicados } \\
\text { - Conjunción lógica } \\
\text { - Asignación del valor de verdad } \\
\text { - Asignación del valor Falso }\end{array}$ \\
\hline $\begin{array}{l}\text { Q19. A todos los del grupo les gusta } \\
\text { nadar. }\end{array}$ & $\begin{array}{l}\text { - Cuantificador lógico universal actuando sobre un único predicado } \\
\text { - La respuesta no se encuentra en la tabla } \\
\text { - Generalización } \\
\text { - Asignación del valor de verdad } \\
\text { - No se sabe la respuesta }\end{array}$ \\
\hline $\begin{array}{l}\text { Q20. Si no les gusta practicar } \\
\text { deporte, no les gusta nadar. }\end{array}$ & $\begin{array}{l}\text { - Hay relación semántica. El significado de las palabras que intervienen } \\
\text { en el enunciado puede afectar a la respuesta } \\
\text { - Implicación lógica } \\
\text { - Hay operaciones lógicas combinadas } \\
\text { - Cuantificador lógico universal actuando sobre varios predicados } \\
\text { - Negación lógica } \\
\text { - La respuesta puede dar lugar al uso de falacia argumentativa } \\
\text { - La respuesta no se encuentra en la tabla } \\
\text { - Asignación del valor de verdad } \\
\text { - No se sabe la respuesta }\end{array}$ \\
\hline $\begin{array}{l}\text { Q21. A los estudiantes no les gusta } \\
\text { nadar. }\end{array}$ & $\begin{array}{l}\text { - Cuantificador lógico universal actuando sobre un único predicado } \\
\text { - Negación lógica } \\
\text { - La respuesta requiere utilizar la regla de inferencia Modus Ponens } \\
\text { - La respuesta no se encuentra en la tabla } \\
\text { - Generalización } \\
\text { - Asignación del valor de verdad } \\
\text { - Asignación del valor Falso }\end{array}$ \\
\hline $\begin{array}{l}\text { Q22. Al estudiante } \mathrm{H} \text { no le gusta } \\
\text { nadar. }\end{array}$ & $\begin{array}{l}\text { - Negación lógica } \\
\text { - La respuesta requiere utilizar la regla de inferencia Modus Ponens } \\
\text { - La respuesta no se encuentra en la tabla } \\
\text { - Asignación del valor de verdad } \\
\text { - Asignación del valor Falso } \\
\end{array}$ \\
\hline $\begin{array}{l}\text { Q23. Si no les gusta nadar, no les } \\
\text { gusta practicar deporte. }\end{array}$ & $\begin{array}{l}\text { - Hay relación semántica. El significado de las palabras que intervienen en } \\
\text { el enunciado puede afectar a la respuesta } \\
\text { - Implicación lógica } \\
\text { - Implicación lógica recíproca. Es la recíproca de otra implicación anterior } \\
\text { - Hay operaciones lógicas combinadas } \\
\text { - Cuantificador lógico universal actuando sobre varios predicados } \\
\text { - Negación lógica } \\
\text { - La respuesta no se encuentra en la tabla } \\
\text { - Contrarrecíproco de una condicional } \\
\text { - Asignación del valor de verdad } \\
\text { - Asignación del valor Verdadero }\end{array}$ \\
\hline
\end{tabular}

Tabla 2.2: Caracterización de las preguntas del cuestionario $Q$

A partir de la caracterización de las preguntas podemos realizar una primera agrupación, tanto de las variables utilizadas como de las cuestiones que forman el cuestionario. 
En primer lugar, entre las variables utilizadas en la caracterización del cuestionario hemos diferenciado tres grupos:

\section{Grupo 1: G1=\{TABL, ROBL, RALT, FDIF, FCOI, FPRE, FAUS $\}$}

Este grupo de variables hace referencia al trabajo sobre la tabla, bien de búsqueda de elementos de la tabla, bien de operaciones con sus elementos, como el recuento de valores o la búsqueda de parejas (coincidencias y/o no coincidencias).

Este grupo de variables se tendrá en cuenta en el análisis de las respuestas de los estudiantes, para confirmar que se hace un uso correcto de la tabla y que los valores son interpretados según las reglas.

Grupo 2: G2=\{LIMP, LIMPR, LOPC, LUNIUP, LUNIVP, LCON, LDISLNEG, LMPON, AV, AVERD, AFALS, ANS \}

Se trata de caracterizar las operaciones lógicas implícitas en cada pregunta, tanto si están presentes en la elaboración de las respuestas como en la interpretación de los enunciados.

Las preguntas pertenecientes a este grupo posibilitarán la manifestación y la observación del conocimiento lógico de los estudiantes, concretamente en relación con los diferentes funcionamientos de la implicación, conjunción o disyunción, tanto en lenguaje natural como en lenguaje formal.

\section{Grupo 3: G3=\{LFAL, CSEM, ARGU, NTABL, GEN, CONTR, RDAF, RDNEG $\}$}

Se trata de identificar en las preguntas del cuestionario $Q$ diferentes formas de razonamiento. En general, los razonamientos incorrectos se vinculan a respuestas incorrectas pero en muchas ocasiones, hay respuestas correctas que pueden ocultar falsos razonamientos, que permanecen ocultos tras una conclusión verdadera. En este sentido, las cuestiones con características pertenecientes a este grupo pueden producir el funcionamiento de las reglas de la lógica formal, pero también las reglas 
de los razonamientos espontáneos de los estudiantes, que responden a otro tipo de lógica, conocida como lógica natural.

En cuanto a las preguntas del cuestionario, se observa una estructura inicial, resultado de las decisiones tomadas en su elaboración, al mismo tiempo que permite hacer una previsión respecto al grado de dificultad:

En primer lugar diferenciaremos las preguntas sin atribución del valor de verdad $(\mathrm{Q} 1, \ldots$, Q13) y las preguntas con atribución del valor de verdad (Q14, .., Q23).

Entre las trece primeras preguntas, las seis primeras se han incluido para comprobar si se hace un uso correcto de la tabla, tratándose a priori de las preguntas con menor grado de dificultad. El resto de preguntas suponen un incremento de la dificultad debido a las operaciones lógicas (la disyunción de Q10 y la negación de la conjunción de Q7) y al pensamiento subjetivo que puede conducir a una diversidad de respuestas (Q11, Q12 y Q13).

A partir de la pregunta Q14 se atribuye el valor de verdad correspondiente, incrementando la dificultad respecto a las demás preguntas.

Las preguntas Q14,.., Q18 incluyen operaciones lógicas, con búsqueda de respuesta sobre la tabla. A partir de la pregunta Q19, sin prescindir de las operaciones lógicas, se precisan respuestas razonadas.

El conjunto de variables que caracteriza las preguntas del cuestionario Q debería ofrecer una visión lo más completa posible de aquello que viene representado por el cuestionario. Toda la información que se deriva del análisis a priori, se considerará útil en las fases posteriores, con el fin de plantear hipótesis, validarlas o explicar los resultados obtenidos a posteriori. Como afirma Brousseau en uno de sus trabajos sobre análisis de datos en didáctica (Brousseau, 1993), no hay que limitar los estudios de didáctica a los resultados de los estudiantes. El conjunto de preguntas o condiciones bajo las cuales han aparecido ciertos comportamientos son el verdadero objeto de estudio, por lo tanto las variables constituyen la muestra a describir: 
"Il n'y a aucune raison de se cantonner en didactique à l'examen des caractéristiques des sujets, des élèves en l'occurence. Il est peut être tout aussi intéressant de s'interroger sur le rôle des variables elles mêmes, c'est à dire des questions, ou des situations. Le véritable objet d'étude est l'ensemble des questions, ou des conditions des comportements: ils constituent l'échantillon des variables à décrire. Les élèves sont les révélateurs des structures de cet ensemble de questions ou de conditions" (Brousseau, 1993, p. 7)

El estudio a priori que se ha presentado hasta el momento pone de manifiesto todas y cada una de las decisiones tomadas por el investigador y las reflexiones personales al respecto, teniendo en cuenta los análisis preliminares que fundamentan el trabajo.

A pesar de las bases teórico-didácticas que dirigen la acción de la investigación y que nos permiten obtener una interpretación fundamentada de nuestros resultados, consideramos necesario disponer de alguna herramienta estadística para manejar el total de información. Todo investigador, a pesar de intentar ser lo más objetivo posible, no escapa de verse influenciado por sus intencionalidades, experiencias personales e incluso por sus limitaciones, condicionando las decisiones a tomar.

Por este motivo y con el propósito de extraer más información a partir de las variables explicativas asignadas a las preguntas del cuestionario, se ha llevado a cabo un análisis estadístico de las preguntas. Cualquier tipo de información obtenida de dicho análisis es relevante, tanto para realizar posibles modificaciones sobre el cuestionario como para ser utilizada en el análisis de los resultados.

El método de análisis utilizado ha sido el análisis estadístico implicativo (Analyse Statistique Implicative, ASI, en francés) que ha sido implementado con el programa informático CHIC (Classification Hiérarchique Implicative et Cohésitive). Este método no sólo ayuda a la observación de los hechos sino que permite establecer reglas a partir de los hechos (Orús, Zamora y Gregori, 2009). 
En Didáctica de las Matemáticas, dominio donde surgieron las primeras cuestiones que dieron lugar al ASI, es difícil establecer reglas para los procesos de enseñanza y aprendizaje. Generalmente se habla de tendencias o comportamientos relacionados con cierto contenido matemático, que son fruto de la observación e interpretación de los hechos didácticos. Sin embargo, esta interpretación está condicionada por las variables explicativas, que varían según el aspecto a tratar y que, a priori, no tienen ninguna relación causal. En este sentido el ASI proporciona un marco metodológico para prever posibles relaciones entre las variables, es decir, las diferentes clases que se van estableciendo entre las variables. Esta información, que refleja la realidad delimitada por los datos y los criterios establecidos, es de gran ayuda a la hora de describir, explicar e incluso predecir los diferentes fenómenos didácticos.

Hay que tener en cuenta que, si bien este método de análisis estadístico es un instrumento para el investigador, sus resultados no se pueden establecer como conclusiones determinantes (Lacasta, 1997). Su utilidad reside en la posibilidad de estructurar datos, interrelacionarlos con las variables y extraer reglas inductivas que, a partir de la contingencia de estas reglas, dirigen las explicaciones y las previsiones en ámbitos no empíricos (Gras y Kuntz, 2009).

En nuestro trabajo, el ASI ha sido utilizado, tanto en el estudio a priori como en el análisis de los resultados del cuestionario. En el estudio a priori constituye una valiosa herramienta para validar el cuestionario utilizado, ya que con su implementación se obtiene una estructuración real del cuestionario a partir de la información que se ha considerado relevante, aportando información nueva o reforzando lo que ya se había previsto.

El programa CHIC se ha aplicado sobre la matriz booleana que recoge los datos correspondientes a los valores de las variables para cada una de las preguntas del cuestionario, a la que llamaremos matriz a priori del cuestionario, en adelante MAP. (Ver MAP en anexo II) 


\section{RESULTADOS DEL ANÁLISIS ESTADÍSTICO IMPLICATIVO:}

Los resultados obtenidos sobre MAP en el análisis estadístico implicativo, mediante el software CHIC, se han interpretado según tres gráficos diferentes: el árbol de similaridad, el árbol de cohesiones y el grafo implicatvo, tal y como se mostrará a continuación. Los dos primeros gráficos, en función del cálculo elegido (similaridad o cohesión), son de tipo jerárquico. La jerarquía parte de un nivel inicial (nivel 0), donde están presentes todas las variables, y cada una de ellas forma una "clase" (en sí misma), aislada de las demás.

La pareja de clases del nivel 0 que mayor similaridad (o cohesión) presenta, se reúne para ser una nueva clase del nivel 2 de la jerarquía. El resto de clases del nivel 2 de la jerarquía son las mismas que las del nivel anterior (exceptuando las dos que se han reunido).

Normalmente, el algoritmo continúa hasta el último nivel, en el que queda una sola clase que aglutina a todas las variables. El árbol describe la evolución del algoritmo, de modo que el investigador puede apreciar los grupos existentes a cada nivel, como racimos de variables, y elige la partición más adecuada a su interpretabilidad.

Además, el ASI proporciona información adicional sobre la formación de cada nueva clase: al reunir dos clases del nivel anterior, analiza los índices de similaridad (o cohesión) de los pares de variables que aparecen reunidos hasta dicho nivel, y los compara con los índices de similaridad (o cohesión) de los pares de variables que siguen separadas hasta dicho nivel. Si el valor promedio de unos frente a los otros es significativamente superior, entonces considera a la nueva clase (las variables recién reunidas) como "especial" (por el motivo referido) y lo llama "nodo significativo". El investigador queda informado del carácter especial de dicho nodo, y prestar especial atención a su interpretación.

Por otro lado, el ASI proporciona información sobre los individuos de la muestra que más influyen a la formación de cada nueva clase (concepto de contribución), y los que se comportan de manera más acorde a la clase formada (concepto de tipicalidad). Estos conceptos son especialmente útiles en el análisis de la MAP, donde el investigador tiene 
el control sobre los "individuos", que son los rasgos elegidos para caracterizar las preguntas del cuestionario.

El árbol de similaridad estructura las variables en torno al concepto de similaridad, que es simétrico. Por contra, el árbol de cohesiones estructura las variables en torno a las implicaciones entre ellas, que tienen un carácter, obviamente, no simétrico. Por ello aparecen flechas indicando la "direccionalidad" de las clases formadas, y conduce, más que a agrupaciones, a implicaciones entre implicaciones.

En tercer lugar, el programa CHIC utilizado incorpora el grafo implicativo, que permite conocer otras reglas de implicación entre las variables, con distintas intensidades de implicación. Los gráficos se acompañan de resultados numéricos que completan la información, como coeficientes de correlación, índices de similaridad y de cohesión o la tipicalidad de los individuos y su contribución en la formación de las clases.

A partir de la matriz a priori (MAP) se pueden presentar los siguientes resultados en forma gráfica. Los gráficos presentados en este capítulo, corresponden a la siguiente configuración del programa:

- CHIC: versión 5.0

- Índice de similaridad definido según la teoría clásica.

- Modelo probabilístico según la ley de Poisson 


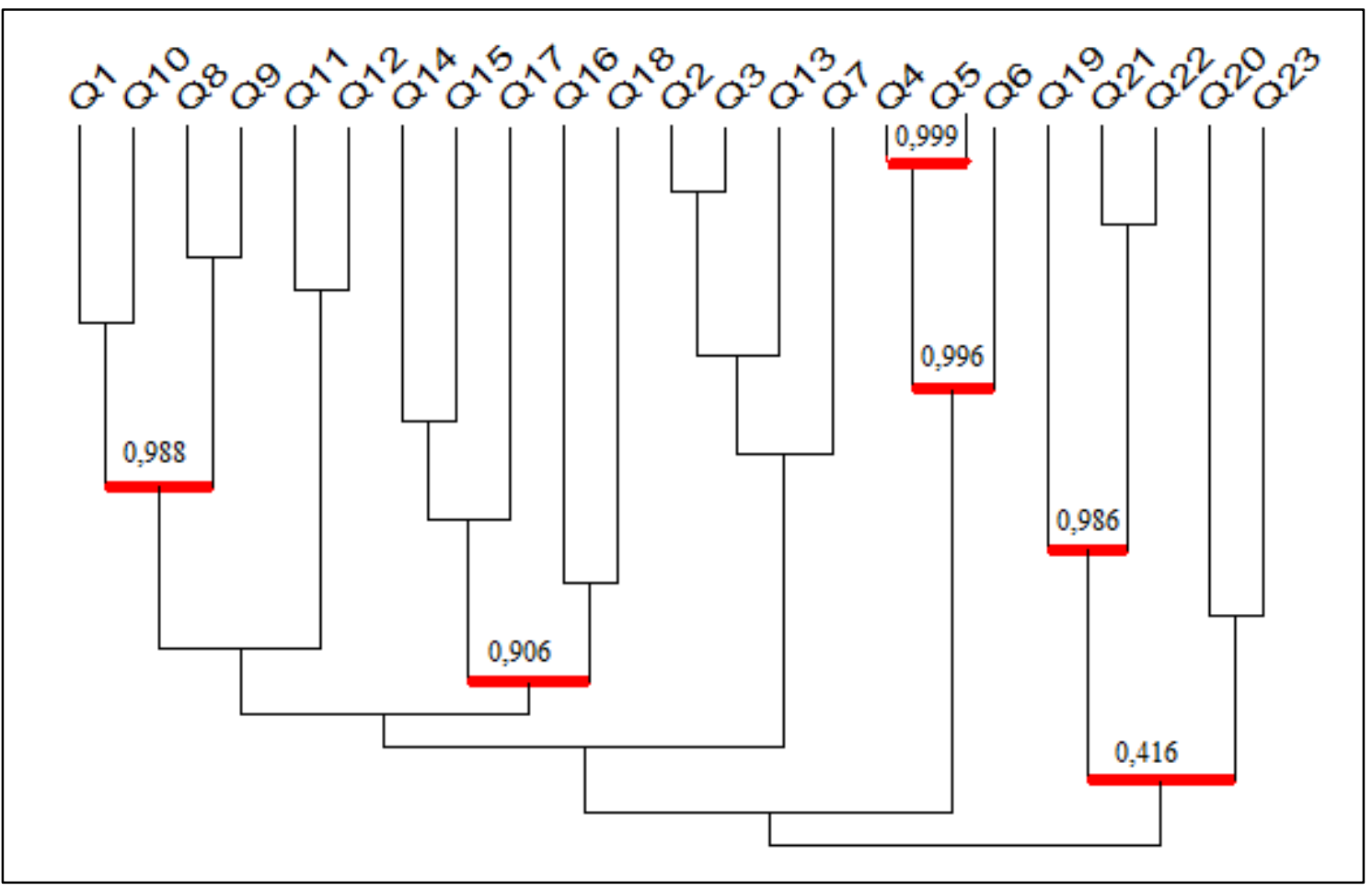

Fig. 2.4: Árbol de similaridad de la matriz a priori

La aplicación del análisis de similaridad sobre la matriz MAP -mediante el programa CHIC - nos ha proporcionado cuatro clases de cuasi-equivalencia.

Las clases S1 y S2 corresponden a las preguntas con cuantificador universal, diferenciándose las que actúan sobre un único predicado de las que actúan sobre más de un predicado.

La notación que vamos a aplicar a continuación para representar el esquema de las clases de similaridad, utiliza paréntesis para los enlaces no significativos y corchetes para las clases significativas. 
- $\quad \mathrm{S} 1=[$ [Q4, Q5], Q6]

La clase significativa [Q4, Q5, Q6] incluye una clase significativa formada por las preguntas [Q4, Q5] a nivel 1, y con un índice de similaridad de 0,999. En el nivel 8, con un índice de similaridad igual a 0,996 se les une significativamente Q6.

Las preguntas de S1 son preguntas con cuantificador universal, actuando sobre un único predicado. Las respuestas a estas preguntas se encuentran en la tabla de datos.

- $\quad \mathrm{S} 2=[(\mathrm{Q} 1, \mathrm{Q} 10),(\mathrm{Q} 8, \mathrm{Q} 9)]$

Las preguntas Q1, Q10 se unen a Q8, Q9 en una clase significativa a nivel 11, con índice de similaridad de 0,988 .

Entre las preguntas de S2, destacaremos Q8, Q9 y Q10, preguntas con cuantificador universal actuando sobre varios predicados. Estas preguntas también tienen respuesta directa sobre la tabla. La pregunta Q1 se encuentra en este grupo porque sus dos únicas variables explicativas (TABL y RDNEG) son comunes a Q8 y Q10.

Esta relación no parece indicar nada más allá que la similaridad que presentan estas preguntas respecto a la utilización correcta de la tabla.

Las clases S3 y S4 corresponden a las preguntas con atribución del valor de verdad, diferenciándose las que son respondidas a partir de una búsqueda directa sobre la tabla de las que no tienen la respuesta directa sobre la tabla. Las clases S3 y S4 se corresponden con el último y penúltimo bloque de preguntas del cuestionario $\mathrm{Q}$, tal y como ya se había planteado a priori en el diseño del cuestionario.

- $\quad \mathrm{S} 3=[[\mathrm{Q} 19,(\mathrm{Q} 21, \mathrm{Q} 22)],(\mathrm{Q} 20, \mathrm{Q} 23)]$

En el grupo S3 se unen dos clases significativas. A nivel 13, con índice de similaridad igual a 0,986 se unen [Q19, Q21, Q22] y en el nivel 15, con índice de similaridad igual a 0,982 se agrega la clase [Q20, Q23].

Este grupo de preguntas corresponde claramente a la ausencia de respuesta sobre la tabla, último bloque de preguntas del cuestionario. 
- $\quad \mathrm{S} 4=[((\mathrm{Q} 14, \mathrm{Q} 15), \mathrm{Q} 17),(\mathrm{Q} 16, \mathrm{Q} 18)]$

La clase significativa S4 se forma a nivel 17, con índice de similaridad igual a 0,906.

Este grupo de preguntas se caracteriza por ser preguntas de atribución del valor de verdad, con búsqueda directa sobre la tabla.

El programa CHIC también nos proporciona información respecto a las variables (los criterios) que han contribuido a la formación de cada una de las clases de cuasiequivalencia. La siguiente figura muestra un ejemplo de los resultados proporcionados por el programa respecto a las variables que han contribuido en este caso a la formación de la clase formada por las preguntas [Q4, Q5, Q6], primer nivel y octavo nivel de agregación de preguntas, ambos significativos:

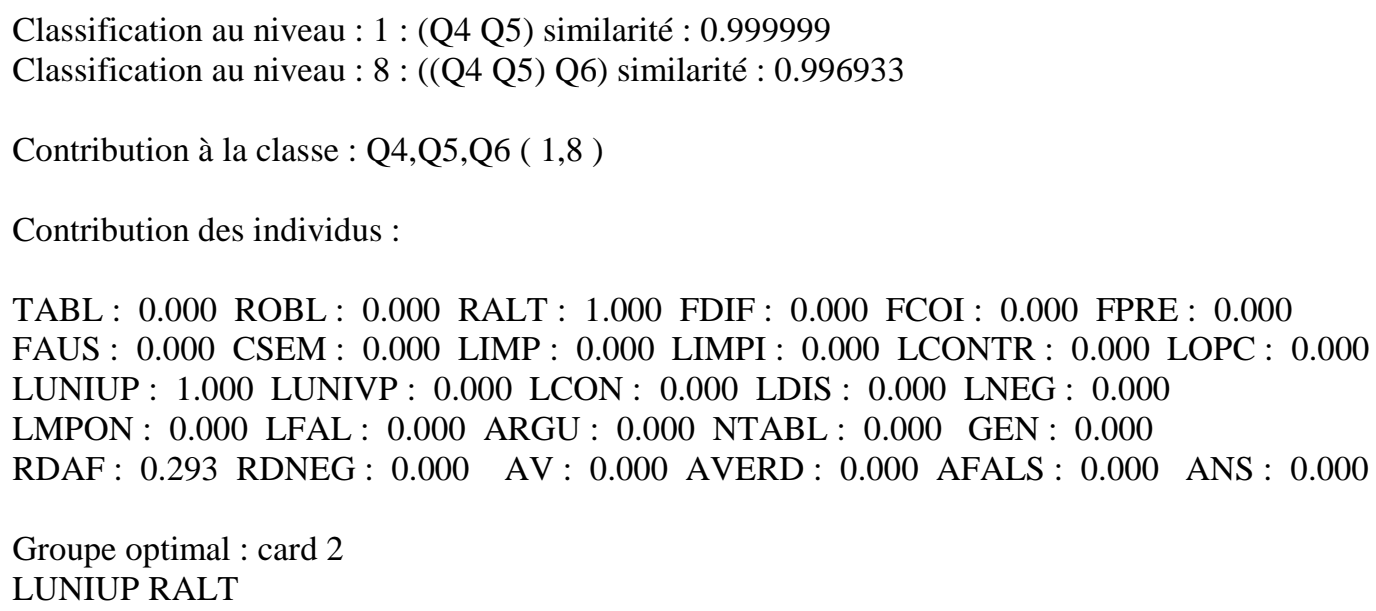

Fig. 2.5: Resultado CHIC: Índice de similaridad y variables que han contribuido a la formación de la clase [Q4, Q5, Q6].

La contribución tiene por valor máximo 1, valor que toma en el caso de la figura 2.5 para las variables LUNIUP y RALT. Esta información nos indica que, de acuerdo con nuestra caracterización de las preguntas del cuestionario, estas variables han contribuido de manera decisiva, en la formación de la clase. 
En la siguiente tabla (tabla 2.3) se recoge la información más relevante proporcionada por el programa CHIC respecto al árbol de similaridad para cada una de las clases. En la primera columna se presentan las cuestiones que forman parte de una misma clase de cuasi-equivalencia con nodos significativos, es decir, que no se debe al azar. En la segunda columna aparecen las variables que han contribuido a esta formación con una contribución máxima y en la tercera columna se indica el índice de similaridad correspondiente al nivel de clasificación correspondiente:

\begin{tabular}{|c|c|c|}
\hline GRUPOS SIGNIFICATIVOS & $\begin{array}{l}\text { VARIABLES QUE HAN CONTRIBUIDO } \\
\text { (Según resultados del programa CHIC) }\end{array}$ & $\begin{array}{l}\text { ÍNDICE } \\
\text { SIMILARI- } \\
\text { DAD }\end{array}$ \\
\hline $\begin{array}{l}\text { Q4. ¿Hay algo que les guste a todos } \\
\text { los estudiantes? En caso } \\
\text { afirmativo, indica lo que es. } \\
\text { Q5. ¿Hay algún estudiante a quien } \\
\text { le guste todo? En caso afirmativo, } \\
\text { indica su nombre }\end{array}$ & $\begin{array}{l}\text { - Se puede hacer un recuento de manera } \\
\text { opcional, pero no necesariamente (RALT) } \\
\text { - Cuantificador lógico universal actuando } \\
\text { sobre un único predicado (LUNIUP) } \\
\text { - Respuesta directa afirmativa (sin asignar } \\
\text { valor de verdad). La lectura de la tabla da } \\
\text { directamente la respuesta (RDAF) }\end{array}$ & $\begin{array}{l}0,999 \\
\text { (nivel 1) }\end{array}$ \\
\hline $\begin{array}{l}\text { Q6. ¿Hay más estudiantes a } \\
\text { quienes les guste todo? En caso } \\
\text { afirmativo, indica cuáles }\end{array}$ & $\begin{array}{l}\text { - Se puede hacer un recuento de manera } \\
\text { opcional, pero no necesariamente (RALT) } \\
\text { - Cuantificador lógico universal actuando } \\
\text { sobre un único predicado (LUNIUP) }\end{array}$ & $\begin{array}{l}0,996 \\
\text { (nivel 8) }\end{array}$ \\
\hline $\begin{array}{l}\text { Q1. ¿Al estudiante C le gusta salir } \\
\text { de noche? } \\
\text { Q10. ¿A todos los estudiantes les } \\
\text { gusta salir de noche o practicar } \\
\text { deporte? } \\
\text { Q8. ¿Todo lo que le gusta al } \\
\text { estudiante R le gusta al estudiante } \\
\text { J? } \\
\text { Q9. ¿Todo lo que le gusta al } \\
\text { estudiante J le gusta al estudiante } \\
\text { R? }\end{array}$ & $\begin{array}{l}\text { - Trabajo sobre un elemento concreto de la } \\
\text { tabla: fila/s, columna/s, pero no sobre toda la } \\
\text { tabla en general (TABL) }\end{array}$ & $\begin{array}{l}0,988 \\
\text { (nivel 11) }\end{array}$ \\
\hline $\begin{array}{l}\text { Q19. A todos los del grupo les } \\
\text { gusta nadar. } \\
\text { Q21. A los estudiantes no les gusta } \\
\text { nadar. } \\
\text { Q22. Al estudiante H no le gusta } \\
\text { nadar }\end{array}$ & $\begin{array}{l}\text { - La respuesta no se encuentra en la tabla } \\
\text { (NTABL) } \\
\text { - Asignación del valor de verdad (AV) }\end{array}$ & $\begin{array}{l}0,986 \\
\text { (nivel 13) }\end{array}$ \\
\hline
\end{tabular}


Q20. Si no les gusta practicar deporte, no les gusta nada

Q23. Si no les gusta nadar, no les gusta practicar deporte
- La respuesta no se encuentra en la tabla (NTABL)

- Asignación del valor de verdad (AV)

0,416

(nivel 20)

Q14. Al estudiante que le gusta el frío, le gusta esquiar

Q15. A todos los estudiantes que les gusta esquiar les gusta el frío Q17. Al estudiante E le gusta la playa o la montaña

Q16. Si a un estudiante no le gusta el deporte, entonces no le gustan los deportes acuáticos

Q18. Lo que les gusta a los estudiantes $\mathrm{C}$ y $\mathrm{F}$ le gusta al estudiante $\mathrm{L}$
- Trabajo sobre un elemento concreto de la tabla: fila/s, columna/s, pero no sobre toda la 0,906 tabla en general (TABL)

- Implicación lógica (LIMP)

- Cuantificador lógico universal actuando sobre varios predicados (LUNIVP)

- Asignación del valor de verdad (AV)

Tabla 2.3: Grupos significativos en el árbol de similaridad

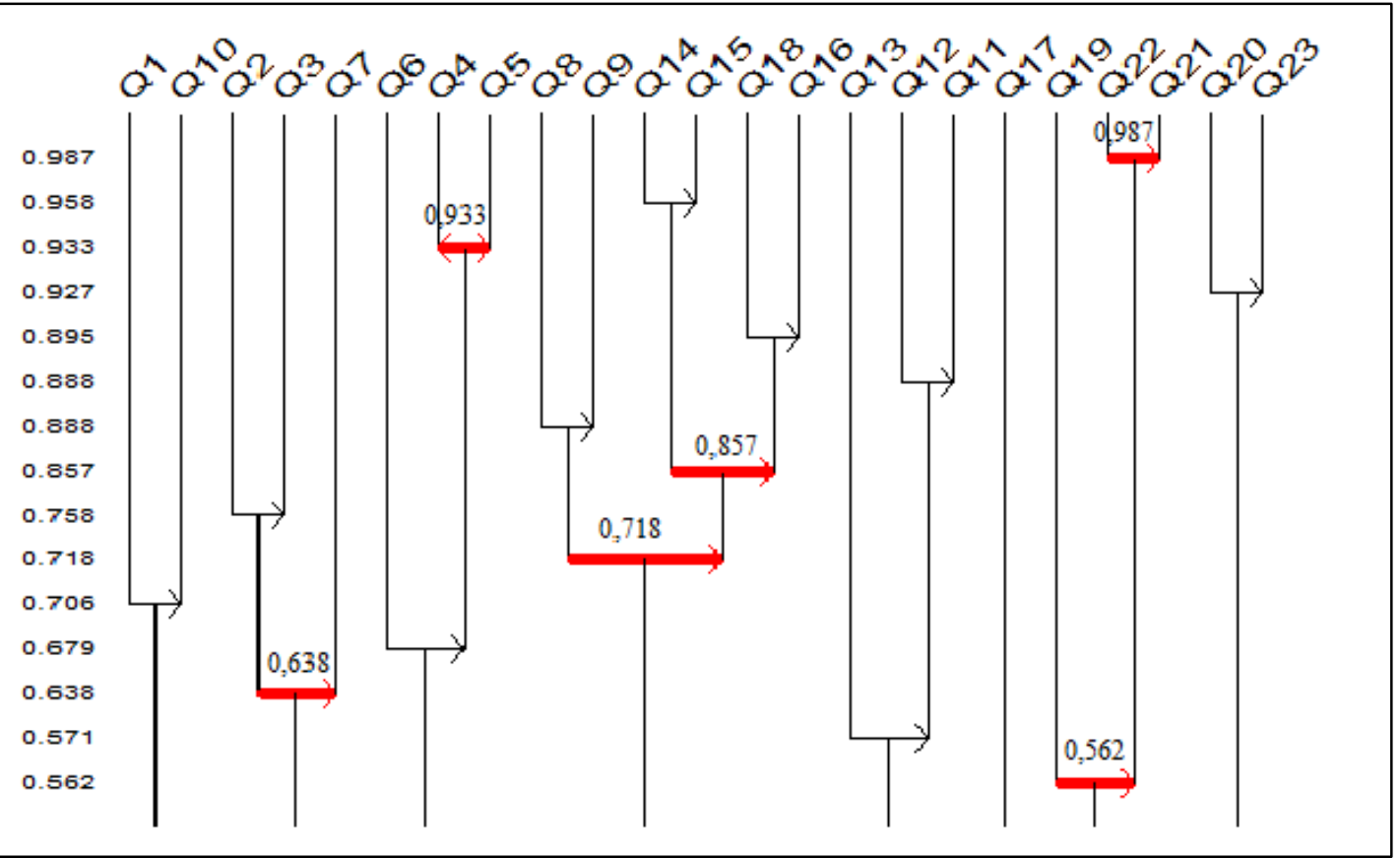

Fig. 2.6: Árbol cohesitivo de la matriz a priori 
En el árbol cohesitivo, el sentido de la implicación revela la relación de inclusión entre el conjunto de variables explicativas correspondiente a cada pareja de preguntas, estructurando de nuevo las preguntas del cuestionario, mostrando dentro de cada nivel de agregación, la cuasi-implicación entre las variables agregadas. En cada nivel hay variables (criterios a priori de las preguntas) cuya contribución ha sido máxima para la formación de ese nivel, formando el denominado grupo optimal. La siguiente figura es un ejemplo de cómo se presentan en el programa CHIC los resultados correspondientes a la cohesión entre Q22 y Q21, mostrando el grupo optimal formado formado por las variables AFALS, LMPON, NTABL, LNEG, AV, que han contribuido a la formación de la clase [Q22, Q21] en el primer nivel de cohesión, implicando Q22 a Q21.

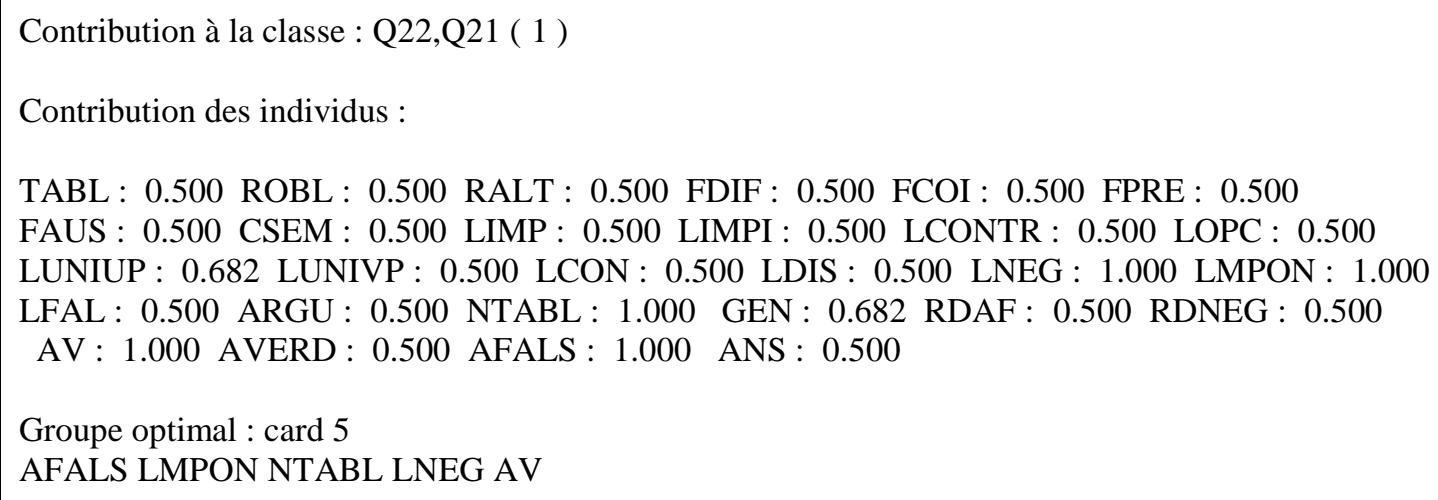

Fig. 2.7: Resultado CHIC: Contribución de las variables a la formación de [Q22, Q21].

A continuación se presenta la estructura de las preguntas del cuestionario Q, especificando los niveles de los nodos significativos y el grupo optimal de las variables que han contribuido en la agrupación.

La cohesión establece cuatro clases significativas que vamos a denominar J1, J2, J3 y J4, que a su vez incluyen otras clases significativas. El árbol cohesitivo mantiene parte de la estructura básica de las preguntas del cuestionario Q, manifestada anteriormente en el 
árbol de similaridad, al mismo tiempo que permite visualizar otras relaciones, como veremos a continuación.

- $\quad$ Clase J1

$$
\mathrm{Q}_{19} \underset{\substack{\text { nivel 15 } \\ 0,562}}{\bar{\rightleftharpoons}} \quad\left(\mathrm{Q}_{22} \underset{\substack{\text { nivel 1 } \\ 0,987}}{\longrightarrow} \mathrm{Q}_{21}\right)
$$

El nivel de cohesión más significativo es $\left(Q_{22} \Longrightarrow Q_{21}\right)$, núcleo de la clase $\mathrm{J} 1$, con un índice de cohesión de 0,987.

Grupo optimal de criterios que contribuyen a la formación de la clase J1:

$$
\text { \{LUNIUP, GEN, \{LNEG, LMPON, NTABL, AV, AFALS }\} \text { \} }
$$

Preguntas correspondientes a esta clase:

$$
\mathrm{J} 1=[\mathrm{Q} 22, \mathrm{Q} 21, \mathrm{Q} 19]
$$

Las variables explicativas de la pregunta Q22, que a su vez son variables explicativas de la pregunta Q21 son \{LNEG, LMPON, NTABL, AV, AFALS .

Las variables $\{$ NTABL, AV $\}$ son la caracterización común a las tres preguntas, Q19, Q21 y Q22, y corresponde a la misma caracterización hecha anteriormente a estas preguntas a partir del árbol de similaridad: atribución del valor de verdad sin búsqueda sobre la tabla.

- $\quad$ Clase J2

$$
Q_{6} \underset{\substack{\text { nivel 12 } \\ 0,679}}{\longrightarrow}\left(Q_{4} \underset{\substack{\text { nivel 3 } \\ 0,933}}{\longrightarrow} Q_{5}\right)
$$

La relación de implicación entre Q4 y Q5, a nivel 3 con un índice de cohesión de 0,933, se debe a que ambas preguntas tienen respuesta directa sobre la tabla y cuantificador universal que actúa sobre un mismo predicado. La pregunta Q6, cuyos criterios presentan la misma caracterización que Q5, se agrega a la clase significativa [Q4, Q5], en el nivel 
12 y con un índice de cohesión de 0,679 no significativo. Este nivel marca la agrupación de preguntas (Q4, Q5, Q6) que conforman la clase J2.

Grupo optimal de criterios que contribuyen a la formación de la clase J2:

$\{$ RALT, LUNIUP, RDAF $\}$

Preguntas correspondientes a esta clase:

$$
\mathrm{J} 2=\{\mathrm{Q} 4, \mathrm{Q} 5, \mathrm{Q} 6\}
$$

La clase $\mathrm{J} 2$ corresponde a preguntas de recuento alternativo, respuesta directa sobre la tabla y cuantificador actuando sobre un único predicado.

- $\quad$ Clase J3

$$
\left(Q_{8} \underset{\substack{\text { nivel 7 7 } \\ 0,888}}{\underset{0,718}{\longrightarrow}} Q_{9}\right) \underset{\substack{\text { nivel 10 } \\ 0,958}}{\Longrightarrow}\left[\left(Q_{14} \underset{\substack{\text { nivel 2 } \\ 0,958}}{\longrightarrow} Q_{15}\right) \underset{\substack{\text { nivel 8 } \\ 0,857}}{\longrightarrow}\left(Q_{18} \underset{\substack{\text { nivel 5 } \\ 0,895}}{\longrightarrow} Q_{16}\right)\right]
$$

La clase $\mathrm{J} 3$ presenta dos niveles de cohesión significativos, nivel 8 y nivel 10, tratándose en ambos casos de una implicación de clases. En el nivel 8 la clase [Q14, Q15] implica a la clase [Q18, Q16], con un índice de cohesión de 0,857 y en el nivel 10, la clase [Q8, Q9] se agrega a la anterior, con un índice de cohesión igual a 0,718.

Grupo optimal de criterios que contribuyen a la formación de la clase J3:

\{TABL, LIMP, LUNIV, AV, AFALS $\}$

Preguntas correspondientes a esta clase:

$$
\mathrm{J} 3=\{\mathrm{Q} 14, \mathrm{Q} 15, \mathrm{Q} 16, \mathrm{Q} 18, \mathrm{Q} 8, \mathrm{Q} 9\}
$$

Esta cadena relaciona el conjunto de preguntas caracterizadas por la implicación lógica y trabajo sobre la tabla (LIMP, TABL). Además, en el nivel 8 encontramos asociadas las preguntas que, además de la implicación lógica y el trabajo sobre la tabla, tienen 
atribución del valor de verdad (AV), marcando la diferencia con las preguntas Q8 y Q9, que no verifican este criterio.

- $\quad$ Clase J4:

$$
\left(Q_{2} \underset{\substack{\text { nivel 9 } \\ 0,758}}{\longrightarrow} Q_{3}\right) \underset{\substack{\text { nivel 13 } \\ 0,638}}{\Longrightarrow} Q_{7}
$$

Grupo optimal de criterios que contribuyen a la formación de la clase J3:

$\{$ TABL, ROBL $\}$

Preguntas correspondientes a esta clase:

$$
\mathrm{J} 4=\{\mathrm{Q} 2, \mathrm{Q} 3, \mathrm{Q} 7\}
$$

Las preguntas Q2 y Q3 se caracterizan únicamente por criterios que se refieren al uso correcto y básico de la tabla de datos. Estas preguntas se asocian en la clase del nivel 9, con un índice de cohesión igual a 0,758 , aunque sin tratarse de un nivel significativo. Sin embargo, la clase [Q2, Q3, Q7] que aparece en el nivel 8, sí que tiene un nivel significativo de cohesión 0,638 , y el grupo optimal de criterios que contribuyen a su formación siguen siendo el trabajo sobre la tabla y el recuento obligatorio (TABL, ROBL).

La información aportada por el programa CHIC en el árbol cohesitivo, referente a los grupos con nodos significativos, se resume en la siguiente tabla: 


\begin{tabular}{|c|c|c|}
\hline GRUPOS SIGNIFICATIVOS & $\begin{array}{l}\text { VARIABLES QUE HAN CONTRIBUIDO } \\
\text { (Según resultados del programa CHIC) }\end{array}$ & $\begin{array}{l}\text { ÍNDICE } \\
\text { COHESIÓN }\end{array}$ \\
\hline $\begin{array}{l}\text { Q21. A los estudiantes no les gusta } \\
\text { nadar. } \\
\text { Q22. Al estudiante } \mathrm{H} \text { no le gusta nadar. }\end{array}$ & $\begin{array}{l}\text { - Negación lógica (LNEG) } \\
\text { - La respuesta requiere utilizar la regla de inferencia } \\
\text { Modus Ponens (LMPON) } \\
\text { - La respuesta no se encuentra en la tabla (NTABL) } \\
\text { - Asignación del valor de verdad (AV) } \\
\text { - Asignación del valor Falso (AFALS) }\end{array}$ & $\begin{array}{l}0,987 \\
\text { (nivel 1) }\end{array}$ \\
\hline $\begin{array}{l}\text { Q19. A todos los del grupo les gusta } \\
\text { nadar. }\end{array}$ & $\begin{array}{l}\text { - Cuantificador lógico universal actuando sobre un } \\
\text { único predicado (LUNIUP) } \\
\text { - Generalización (GEN) }\end{array}$ & $\begin{array}{l}0,562 \\
\text { (nivel 15) }\end{array}$ \\
\hline $\begin{array}{l}\text { Q4. ¿Hay algo que les guste a todos los } \\
\text { estudiantes? En caso afirmativo, indica } \\
\text { lo que es. } \\
\text { Q5. ¿Hay algún estudiante a quien le } \\
\text { guste todo? En caso afirmativo, indica su } \\
\text { nombre }\end{array}$ & $\begin{array}{l}\text { - Se puede hacer un recuento de manera opcional, pero } \\
\text { no necesariamente (RALT) } \\
\text { - Cuantificador lógico universal actuando sobre un } \\
\text { único predicado (LUNIUP) } \\
\text { - Respuesta directa afirmativa (sin asignar valor de } \\
\text { verdad). La lectura de la tabla da directamente la } \\
\text { respuesta (RDAF) }\end{array}$ & $\begin{array}{l}0,933 \\
\text { (nivel 3) }\end{array}$ \\
\hline $\begin{array}{l}\text { Q14. Al estudiante que le gusta el frío, } \\
\text { le gusta esquiar. } \\
\text { Q15.A todos los estudiantes que les } \\
\text { gusta esquiar les gusta el frío. } \\
\text { Q18. Lo que les gusta a los estudiantes } \\
\text { C y F le gusta al estudiante L. } \\
\text { Q16. Si a un estudiante no le gusta el } \\
\text { deporte, entonces no le gustan los } \\
\text { deportes acuáticos }\end{array}$ & $\begin{array}{l}\text { - Trabajo sobre un elemento concreto de la tabla: fila/s, } \\
\text { columna/s, pero no sobre toda la tabla en general } \\
\text { (TABL) } \\
\text { - Implicación lógica (LIMP) } \\
\text { - Cuantificador lógico universal actuando sobre varios } \\
\text { predicados (LUNIVP) } \\
\text { - Asignación del valor de verdad (AV) } \\
\text { - Asignación del valor Falso (AFALS) }\end{array}$ & $\begin{array}{l}0,85 \\
\text { (nivel 8) }\end{array}$ \\
\hline $\begin{array}{l}\text { Q8. ¿Todo lo que le gusta al estudiante } \\
\text { R le gusta al estudiante J? } \\
\text { Q9. ¿Todo lo que le gusta al estudiante J } \\
\text { le gusta al estudiante R? }\end{array}$ & & $\begin{array}{l}0,718 \\
\text { (nivel 10) }\end{array}$ \\
\hline $\begin{array}{l}\text { Q2. ¿A cuántos estudiantes les gusta } \\
\text { vivir aventuras? } \\
\text { Q3. ¿Cuántas cosas le gustan al } \\
\text { estudiante Q para viajar? } \\
\text { Q7. ¿A cuántos estudiantes no les gustan } \\
\text { las grandes ciudades y salir de noche? }\end{array}$ & $\begin{array}{l}\text { - Trabajo sobre un elemento concreto de la tabla: fila/s, } \\
\text { columna/s, pero no sobre toda la tabla en general } \\
\text { (TABL) } \\
\text { - Se ha de hacer un recuento obligatorio (ROBL) }\end{array}$ & $\begin{array}{l}0,638 \\
\text { (nivel 13) }\end{array}$ \\
\hline
\end{tabular}

Tabla 2.4: Grupos significativos del árbol cohesitivo, contribución de las variables e índices de cohesión

En la agrupación J1, destaca la cohesión entre las preguntas Q19, Q21 y Q22, preguntas con atribución del valor de verdad, sin búsqueda sobre la tabla. Estas preguntas también aparecían agrupadas en el análisis de similaridad como clase dentro de la clase S3. Recordemos que en la clase S3 además de la clase significativa de preguntas [Q19, Q21, Q22] se agrupaba la clase [Q20, Q23] en un nivel no significativo (nivel 4 e índice de 
cohesión 0,927), con la misma caracterización: atribución del valor de verdad sin búsqueda sobre la tabla. El árbol cohesitivo separa estas dos clases, manteniendo como clase de cohesión significativa la agrupación J1 (Q19, Q21, Q22) y dejando Q20 y Q23 fuera, con implicación no significativa entre ellas. La distinción puede venir marcada por la diferencia entre las operaciones lógicas de esas preguntas, siendo Q20 y Q23 preguntas en torno a la operación lógica condicional, incluyendo la negación de predicados, característica no presente en las preguntas de $\mathrm{J} 1$.

El grupo J2 constituido por las preguntas Q4 y Q5, se corresponde con el resultado obtenido a partir del árbol de similaridad y la clase S1. Se trata de las preguntas del cuestionario con respuesta directa sobre la tabla y cuantificador universal que actúa sobre un mismo predicado.

Por último, el grupo J3 relaciona las mismas preguntas de la clase S3 del árbol de similaridad. En el árbol cohesitivo ha prevalecido el criterio de implicación lógica sobre el criterio de atribución del valor de verdad, incluyendo de este modo las preguntas Q8 y Q9 y excluyendo la pregunta Q17.

Hay que destacar en el análisis del árbol implicativo que las implicaciones vienen determinada por los valores de la MAP. Se trata de valores binarios utilizados para atribuir los criterios que van a caracterizar a cada una de las preguntas. De esta forma, no se trata de una caracterización única. Asimismo, en la interpretación de los resultados representados en el árbol cohesitivo, el sentido de las implicaciones es arbitrario. Si se cambiaran los unos por los ceros, cambiaría el sentido de las implicaciones.

\section{GRAFO IMPLICATIVO DEL ANÁLISIS DE LA MATRIZ A PRIORI}

En las siguientes figuras se presentan y reconocen algunos caminos de implicación entre las cuestiones que ya aparecían en los niveles significativos del árbol cohesitivo. Estos caminos van a permitir observar más detalladamente la relación de implicación entre cada pareja de preguntas del cuestionario Q. 


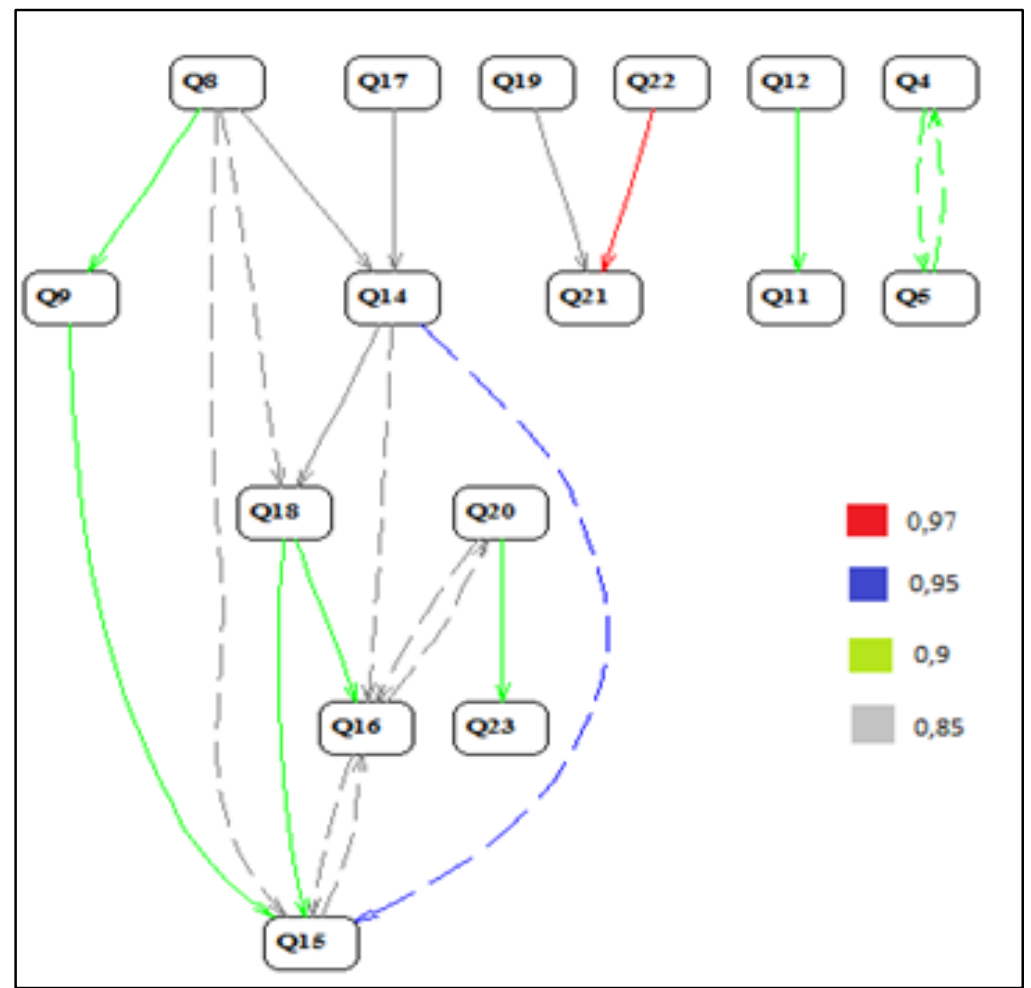

Fig. 2.8: Grafo implicativo de la matriz a priori con la opción de «transitividad» del programa CHIC

En la siguiente figura se van a mostrar de forma separada las cadenas de implicación de las preguntas correspondientes a los grupos significativos $\mathrm{J} 1, \mathrm{~J} 2$ y J3, resultantes del análisis cohesitivo. Hay que señalar que las preguntas del grupo J4 no aparecen en este grafo directamente relacionadas en ningún camino de implicación. 


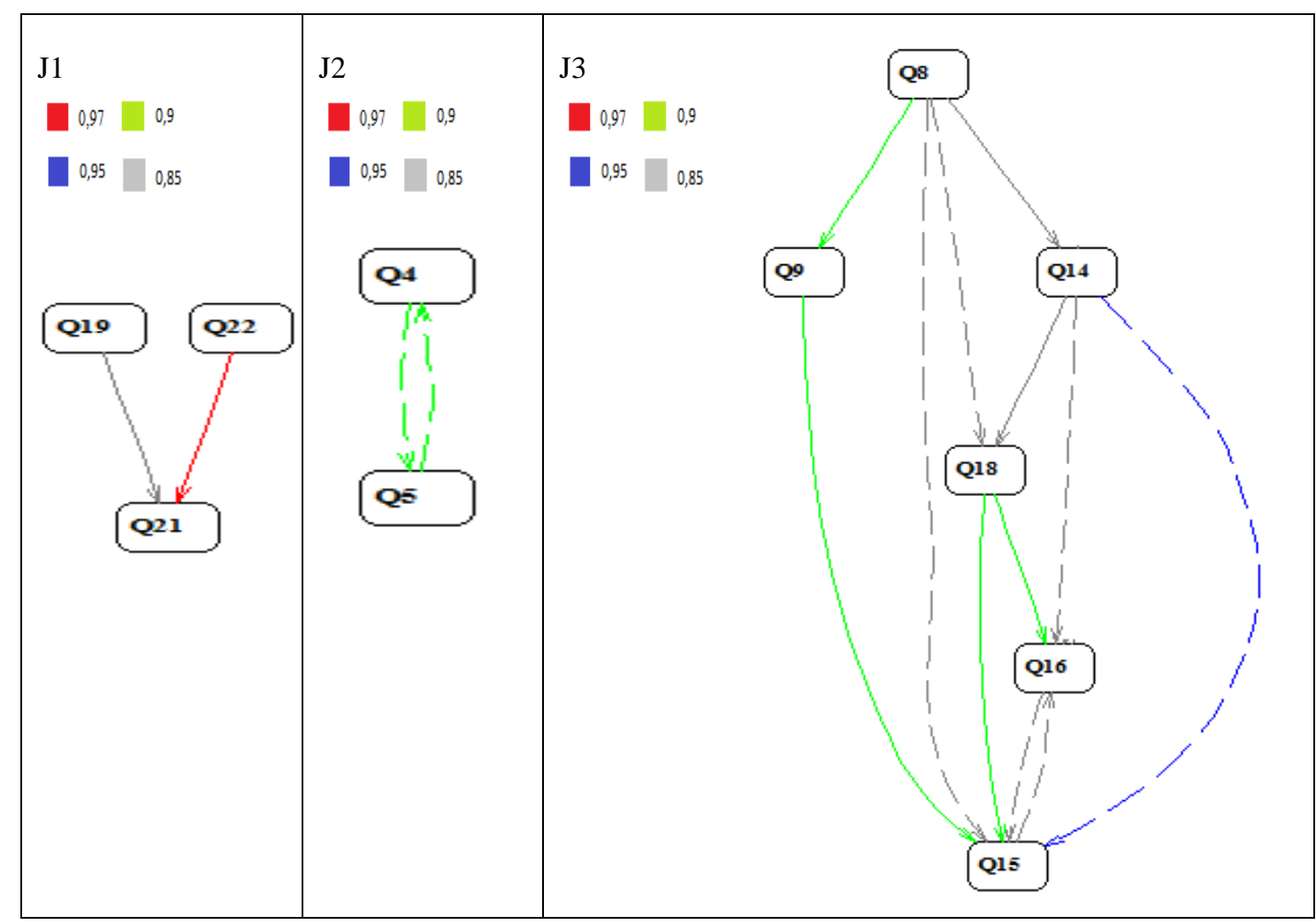

Fig. 2.9: Implicaciones del grafo implicativo entre las preguntas de los grupos con niveles de cohesión significativos $(\mathbf{J 1}, \mathbf{J 2}, \mathbf{J 3})$

En el grafo implicativo aparece de nuevo el grupo formado por las preguntas Q19, Q21 y Q22, preguntas de atribución del valor de verdad sin respuesta directa sobre la tabla. Este grupo, ya identificado en los análisis anteriores, aparecía incluido en la clase S3 del análisis de similaridad y como clase J1 en el análisis cohesitivo. La implicación $\mathrm{Q} 19 \Rightarrow \mathrm{Q} 21$ presenta un índice de implicación de 0,85 y la implicación Q22 $\Rightarrow$ Q21 presenta un índice de implicación de 0,97.

También se observa la relación entre las preguntas Q14, Q15, Q16 y Q18, todas ellas preguntas con implicación lógica, que también aparecían incluidas en las clases S4 y J3 de los análisis anteriores. Hay que señalar que las implicaciones representadas en el grafo con líneas discontinuas marcan que esa implicación se debe a la transitividad entre variables. La transitividad no la realiza el programa CHIC de forma automática pero 
permite seleccionarla como opción en el análisis implicativo. En este grafo se ve que Q8 implica Q9 y Q9 implica Q15, ambas con índice de implicación igual a 0,9, pero Q8 no implica directamente Q15. Al elegir en el programa CHIC la opción «transitividad», recalcula las implicaciones y muestra las nuevas implicaciones que se verifican entre las variables. En nuestro caso Q8 sí que implica Q15 pero por transitividad, con un índice de implicación de 0,95. En la figura 2.8 se puede observar, por el contrario, la cadena de implicaciones $\mathrm{Q} 17 \Rightarrow \mathrm{Q} 14 \Rightarrow \mathrm{Q} 18$, pero sin aparecer la implicación entre Q17 y Q18, a pesar de estar seleccionada la opción de transitividad.

Dentro de cada grupo de preguntas similares, hemos considerado como nivel de exigencia de una pregunta el número de variables explicativas que las caracterizan, es decir, la cantidad de criterios presentes en cada pregunta. De esta forma, las cadenas del grafo implicativo nos servirán para identificar dentro de cada grupo las preguntas que, según nuestra caracterización, se pueden considerar más exigentes, es decir, aquellas que involucran más tipos de conocimiento en su resolución y por lo tanto con mayor número de criterios. Estas preguntas con mayor nivel de exigencia son las que aparecen en los extremos finales de los caminos del grafo implicativo, como son las preguntas Q15 o Q21. La relación Qi $\Rightarrow$ Qj indica que la mayor parte de los criterios de Qi también lo son de Qj, por lo tanto Qj será más exigente que Qi. Por ejemplo, la cadena $Q 8 \Rightarrow Q 9 \Rightarrow Q 15$, correspondiente al grupo J3, indica que Q15 es más exigente que Q9 y a su vez, Q9 más exigente que Q8, tal y como podemos comprobar en la siguiente tabla:

\begin{tabular}{|l|ll|l|}
\hline $\begin{array}{l}\text { Q8. ¿Todo lo que le gusta al estudiante } \\
\text { R le gusta al estudiante J? }\end{array}$ & TABL & LIMP & RDNEG \\
\hline $\begin{array}{l}\text { Q9. ¿Todo lo que le gusta al estudiante J } \\
\text { le gusta al estudiante R? }\end{array}$ & TABL & LIMP & LIMPR \\
\hline & LPRE & RDAF \\
$\begin{array}{l}\text { Q15. A todos los estudiantes que les } \\
\text { gusta esquiar les gusta el frío. }\end{array}$ & TABL & LIMP & LIMPR \\
& & LSEM \\
& & LFAL \\
& & AV \\
\hline
\end{tabular}

Tabla 2.6: Caracterización de la cadena de preguntas Q8, Q9, Q15 
Del mismo modo que aparece la cuestión Q15 en el extremo del final de una cadena de implicación, también aparecen las cuestiones Q23, Q21 y Q11. Estas preguntas son una representación de las preguntas más exigentes del cuestionario $\mathrm{Q}$, es decir, que según nuestra caracterización verifican más criterios.

El análisis implicativo llevado a cabo con el programa CHIC marca relaciones significativas entre preguntas del cuestionario que no habían aparecido ni en el análisis de similaridad ni en el análisis cohesitivo del cuestionario Q, mostrando su estructura, según la interpretación a priori del cuestionario y complementando nuestra agrupación inicial.

\subsubsection{Conclusiones sobre el estudio a priori del cuestionario $Q$}

El estudio a priori de las preguntas del cuestionario Q se ha iniciado con la caracterización de cada una de estas cuestiones mediante criterios que identifican la actividad que supone la elaboración de sus respuestas, tal y como se presentó en la tabla 2.2. En ella se indican no solo el conjunto de decisiones tomadas inicialmente en la construcción del cuestionario respecto a los conocimientos lógicos puestos en juego sino incluyendo también otras características inherentes al lenguaje y al razonamiento natural. La matriz a priori MAP resume y codifica toda esta caracterización.

A. Los criterios atribuidos a cada una de las cuestiones Qi ha permitido establecer inicialmente una primera representación del cuestionario, diferenciando, a rasgos generales, tres grupos de preguntas. Estos grupos de preguntas se ajustan a los tipos de criterios utilizados, que responden principalmente a la lectura y uso de la tabla, a las operaciones lógicas representadas en el cuestionario y a los diferentes razonamientos llevados a cabo en sus respuestas. Los grupos identificados son: 
Grupo 1:

Criterios relacionados con el trabajo sobre la tabla:

\{TABL, ROBL, RALT, FDIF, FCOI, FPRE, FAUS \}

Preguntas más representativas de estas variables:

$$
\text { [Q1, Q2, Q3, Q4, Q5, Q6] }
$$

Grupo 2:

Criterios relacionados con las operaciones lógicas:

\{LIMP, LIMPR, LOPC, LUNIUP, LUNIVP, LCON, LDISLNEG, LMPON, AV, AVERD, AFALS, ANS \}

Preguntas más representativas de estas variables:

$$
\text { [Q7, Q8, Q9, Q10, Q14, Q15, Q16, Q17, Q18] }
$$

\section{Grupo 3:}

Criterios relacionados con el razonamiento:

\{LFAL, CSEM, ARGU, NTABL, GEN, CONTR, RDAF, RDNEG $\}$

Preguntas más representativas de estas variables:

$$
\text { [Q11, Q12, Q13, Q19, Q20, Q21, Q22, Q23] }
$$

B. La clasificación anterior muestra nuestra visión inicial del cuestionario. Con la ayuda del análisis estadístico implicativo llevado a cabo con el programa CHIC sobre la matriz a priori MAP, ha sido posible reconocer además otras relaciones posibles entre las preguntas y los criterios, tal y como se ha mostrado en los apartados anteriores. 
$\checkmark \quad$ Las clasificaciones que han aportado tanto el árbol de similaridad como el árbol cohesitivo indican que los criterios establecidos determinan de manera significativa cuatro clases de preguntas. Los criterios que han contribuido fundamentalmente en estas clasificaciones han sido la atribución del valor de verdad (AV), la posibilidad de búsqueda de respuesta sobre la tabla (TABL, NTABL) y el cuantificador universal sobre uno o varios predicados (LUNIUP, LUNIVP). Hay que señalar que en todos los casos, a excepción de Q10, las preguntas en las que aparece el cuantificador universal actuando sobre varios predicados (LUNIVP) coinciden con las preguntas en las que aparece la implicación (LIMP), cuya contribución a la formación de las clases también es máxima. Así pues, los grupos destacados a partir de estos resultados son:

Clase 1:

$$
\text { [Q4, Q5, Q6] }
$$

Criterios con mayor contribución a la formación de la clase 1:

$$
\{\text { LUNIUP }\}
$$

Clase 2:

$$
\text { [Q8, Q9, Q14, Q15, Q16, Q18] }
$$

Criterios con mayor contribución a la formación de la clase 2:

$$
\text { \{LUNIVP, LIMP\} }
$$

Clase 3:

$$
\text { [Q14, Q15, Q16, Q18] }
$$

Criterios con mayor contribución a la formación de la clase 3:

$$
\{\mathrm{AV}, \mathrm{TABL}\}
$$

Clase 4:

$$
\text { [Q19, Q20, Q21, Q22, Q23] }
$$

Criterios con mayor contribución a la formación de la clase 4 :

$$
\{A V, N T A B L\}
$$


Con el grafo implicativo se han identificado cuatro bloques de preguntas interrelacionadas entre sí. Dentro de cada grupo, la variable situada en el extremo inicial es la de menor nivel de exigencia y la del extremo final la de mayor nivel de exigencia. La exigencia, tal y como habíamos explicado anteriormente, hace referencia al número de criterios que verifican las preguntas, considerándose una pregunta más exigente que otra cuando presenta mayor número de criterios. De esta forma, si varias preguntas están relacionadas por los criterios que verifican, posiblemente las preguntas de mayor nivel de exigencia se traten de preguntas que vayan a presentar mayor dificultad para los estudiantes. Sin embargo, hablar de nivel de exigencia no es lo mismo que hablar de nivel de dificultad. Sólo tiene sentido comparar los niveles de exigencia si los criterios de las preguntas establecen una relación entre ellas.

Según las relaciones que han aparecido a lo largo del análisis, hemos destacado como preguntas que marcan el máximo nivel de exigencia y posiblemente mayor nivel de dificultad entre las preguntas relacionadas, las siguientes, marcadas en negrita dentro de su clase:

[Q4, Q5, Q6]:

Q4, Q5 aparecen ambas en el mismo nivel de exigencia.

[Q14, Q15, Q16, Q18], [Q8, Q9, Q14, Q15, Q16, Q18]:

Q15 aparece en el extremo final de las cadenas de implicaciones que relacionan las preguntas de implicación lógica (LIMP) y las preguntas con cuantificador universal actuando sobre varios predicados con búsqueda sobre la tabla (LUNIUP, TABL)

[Q19, Q20, Q21, Q22, Q23]: Dentro de la clase de preguntas caracterizadas por la atribución del valor de verdad sin búsqueda sobre la tabla (AV, NTABL), Q21 y Q23 se sitúan en los extremos finales de las cadenas correspondientes, indicando así que q21 tiene más nivel de exigencia que Q19 y Q22, y que Q23 tiene mayor nivel de exigencia que Q20. 
$\checkmark \quad$ Según los resultados del estudio a priori, destacamos algunas preguntas que no han presentado un comportamiento similar a ninguno de los grupos significativos identificados. Se trata principalmente de la pregunta Q7, caracterizada por las operaciones combinadas negación y conjunción (LOPC, LCON, LNEG) así como la pregunta Q10, caracterizada por la disyunción (LDIS). Lo mismo ha ocurrido con las preguntas Q11, Q12 y Q13, utilizadas en el cuestionario para representar el pensamiento subjetivo, donde el criterio que las caracteriza es la interpretación semántica del enunciado (CSEM) y la argumentación (ARGU), criterios que no han contribuido de manera significativa, según el análisis llevado a cabo con el programa CHIC.

Las similitudes y las diferencias entre las preguntas del cuestionario, explicitadas en el estudio a priori, han dado lugar a una estructuración del cuestionario que, junto a los resultados de las experimentaciones, ayudará a dar sentido a los diferentes comportamientos de los estudiantes.

\subsection{Fase I de la experimentación: Primera aplicación del cuestionario Q (Universidad Jaume I de Castellón, 2015)}

En este apartado se presentan los resultados correspondientes a la realización de la primera fase de la experimentación. Se ha utilizado el cuestionario Q como herramienta para diagnosticar ciertos fenómenos relacionados con los razonamientos de los estudiantes, como ya indicamos al principio del capítulo. Al mismo tiempo se pretende comprobar si el cuestionario, tal y como se ha diseñado, es adecuado para estudiantes universitarios.

El cuestionario se ha aplicado en Castellón, Universidad Jaume I (UJI), durante el curso académico 2014/2015. El cuestionario ha sido contestado por un total de 214 estudiantes, de los cuales 113 pertenecen a la titulación de Maestro/a de Educación Infantil ( $2^{\circ}$ Curso) y 101 a la titulación de Maestro/a de Educación Primaria ( $1^{\text {er }}$ Curso), de la UJI. Se han 
elegido estos dos niveles porque corresponden a los cursos en los que se imparte por primera vez la asignatura de Didáctica de las Matemáticas dentro de ambas titulaciones.

Los estudiantes de cada titulación están distribuidos en subgrupos según la siguiente organización:

\begin{tabular}{|c|c|c|}
\cline { 2 - 3 } \multicolumn{1}{c|}{} & Maestro/a Infantil & Maestro/a Primaria \\
\hline Grupo A & 57 estudiantes & 52 estudiantes \\
\hline Grupo B & 56 estudiantes & 49 estudiantes \\
\hline
\end{tabular}

Tabla 2.7: Número de estudiantes encuestados por grupo (UJI)

Estos grupos de estudiantes habían participado anteriormente en la propuesta de criterios para la elaboración del cuestionario Q.

En esta fase se presenta el cuestionario a los estudiantes y se les pide que lo contesten individualmente. Hay que destacar la participación por parte de todos los estudiantes presentes en las clases, que han aceptado contestar al cuestionario.

Esta primera fase de aplicación del cuestionario tiene como finalidad comprobar si la tabla y las cuestiones muestran los resultados esperados, es decir, si se detectan errores relacionados con el conocimiento lógico que aconsejen proseguir con la siguiente fase.

Antes de pasar el cuestionario y como punto de partida se tenía además la opinión proporcionada por los profesores de los estudiantes que iban a realizar el cuestionario. Estos profesores asignaron el porcentaje de respuestas correctas que esperaban de sus alumnos (menos del 75\%, entre el 75\% y el 95\% y más del 95\%) (Ver anexo III). Según la opinión de los profesores, el cuestionario presentaba algunas preguntas que no iban a alcanzar un porcentaje de aciertos superior al 75\%, entre ellas las preguntas con disyunción así como las preguntas con operaciones lógicas combinadas, y muy pocas con porcentajes superiores al $95 \%$. 


\subsubsection{Análisis de los resultados del cuestionario $Q$}

Para llevar a cabo el análisis de los resultados del cuestionario Q se ha optado por considerar la totalidad de estudiantes que han participado, como si de un único grupo se tratara, ya que al analizar los grupos de manera individual, sus respuestas presentaban comportamientos similares.

La información procedente de la corrección del cuestionario se ha traducido a 23 variables binarias. Cada valor representa el éxito o fracaso en cada una de las preguntas. Para el cálculo de porcentajes, la ausencia de respuesta se ha considerado como fracaso, asignando en tal caso a la variable el valor cero. El porcentaje de respuestas correctas se mueve dentro de los márgenes que van desde el $0 \%$ hasta el 99\%, lo que indica niveles de dificultad muy diferentes entre las preguntas. Uno de los casos más extremos y sorprendentes ha sido la pregunta Q7, que tan solo ha conseguido una respuesta correcta. La pregunta Q7 es considerada una pregunta compleja, con operaciones lógicas combinadas, por lo que ya se esperaba un bajo nivel de respuestas correctas, aunque no un porcentaje prácticamente nulo. En el otro extremo encontramos las respuestas a las preguntas Q1 y Q2, que ponen de manifiesto que el manejo de la tabla no ha supuesto ningún problema a los estudiantes encuestados, con unos porcentajes de éxito muy elevados $(98,5 \%)$, muy similares a los porcentajes obtenidos en las respuestas de las preguntas Q6 y Q8, cuya naturaleza analizaremos más adelante. El siguiente gráfico presenta los porcentajes de respuestas correctas obtenidos en cada una de las preguntas del cuestionario: 


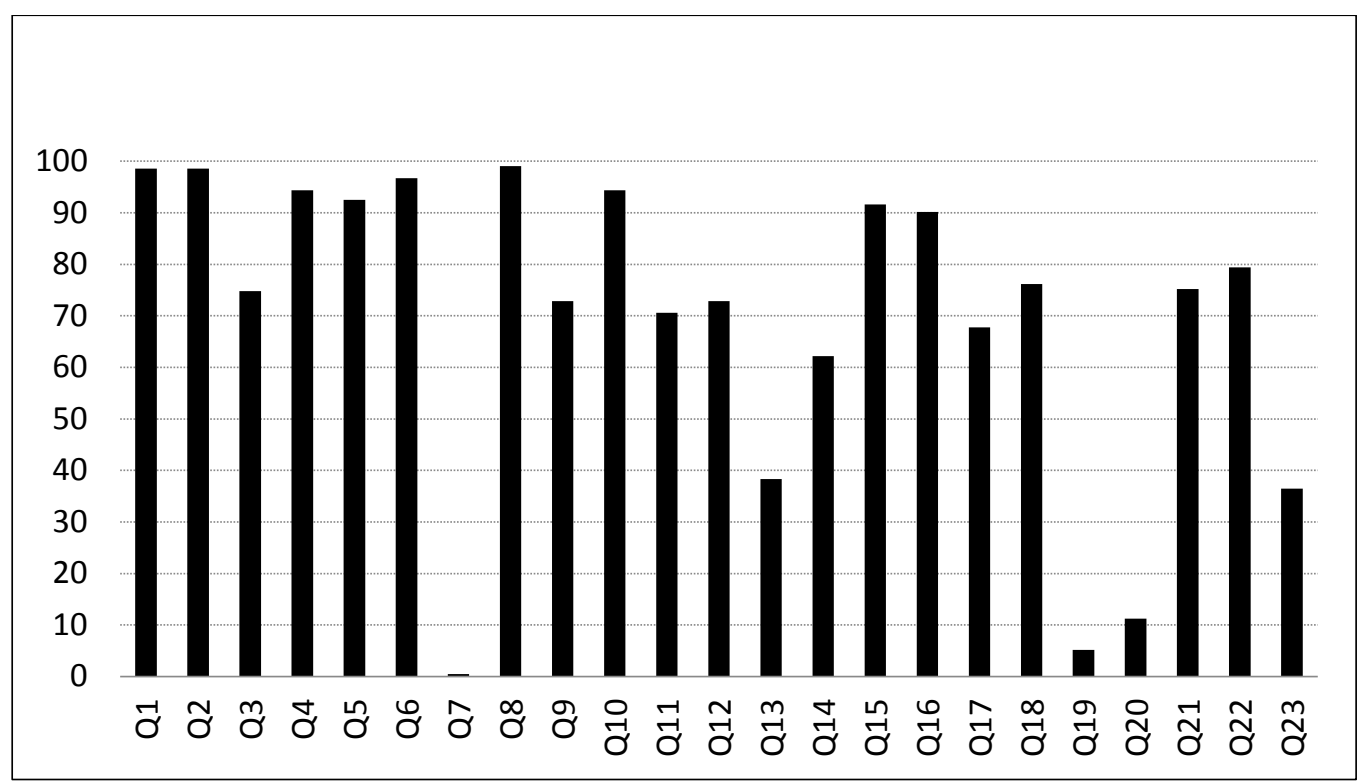

Fig. 2.10: Porcentaje de respuestas correctas para cada pregunta del cuestionario (UJI)

Entre las preguntas del cuestionario vamos a diferenciar cuatro niveles de dificultad, atendiendo al porcentaje de respuestas correctas:

- $\quad$ El primer nivel de dificultad se refiere a las cuestiones que han sido respondidas correctamente por más de un $95 \%$ de los encuestados, donde se encontrarían las cuestiones Q1, Q2, Q6 y Q8.

- $\quad$ El segundo nivel de dificultad, que representa un porcentaje de aciertos entre $75 \%$ y 95\%, formado por las cuestiones Q4, Q5, Q10, Q15, Q16, Q18, Q21 y Q22.

- El tercer nivel de dificultad, cuyo porcentaje de respuestas correctas varía entre $40 \%$ y75\%. Este grupo está formado por las preguntas Q3, Q9, Q11, Q12, Q14 y Q17.

- Y por último, en el cuarto nivel, las preguntas que han sido respondidas correctamente por menos del 40\% de los estudiantes, Q7, Q13, Q19, Q20 y Q23, tratándose de las preguntas que han presentado mayor dificultad. 
Esta variación de porcentajes muestra que el cuestionario Q está adaptado al nivel de primer año de universidad y parece adecuado para diagnosticar los diferentes niveles de control de los conocimientos lógicos, según las operaciones y la complejidad de las actividades puestas en juego.

Así pues, se prosigue con el estudio de las preguntas, donde se va a realizar un análisis detallado de cada una de las cuestiones y de los errores cometidos por los estudiantes, con el fin de aportar información suficiente que permita validar el cuestionario. Los resultados obtenidos en las respuestas de los estudiantes encuestados, así como el análisis a priori de la caracterización del cuestionario, nos van a permitir explicar algunos de los resultados obtenidos.

- $\quad$ Primer nivel de dificultad: Ls cuestiones Q1, Q2, Q6 y Q8 son contestadas correctamente por más del $95 \%$ de los estudiantes es decir, no presentan dificultad. Dentro de este grupo de preguntas se pueden distinguir las preguntas Q1, Q2, que corresponden a la lectura de la tabla y las preguntas Q6, Q8 que verifican otros criterios de la matriz a priori.

Preguntas Q1 y Q2:

Q1. ¿Al estudiante C le gusta salir de noche? R: No

Q2. ¿A cuántos estudiantes les gusta vivir aventuras? R: A 12 estudiantes

Las cuestiones Q1 y Q2 han sido respondidas correctamente por casi todos los estudiantes, tal y como se esperaba. Con estas preguntas se ha pretendido comprobar si los valores de la tabla son interpretados de forma correcta. Los resultados globales indican que la interpretación se ha realizado correctamente. Hay alguna excepción, pero observando el resto de respuestas de estos mismos estudiantes, asumimos que se trata de errores de tipo material (equivocarse de fila o de columna o saltarse algún valor al contar). 
Preguntas Q6 y Q8:

Q6. ¿Hay más estudiantes a quienes les guste todo? En caso afirmativo, indica cuáles. $R$ : No

Q8. ¿ ¿Todo lo que le gusta al estudiante R le gusta al estudiante J? R: Sí La pregunta Q6 incluye el cuantificador universal y la pregunta Q8, además del cuantificador universal, la implicación lógica. Estas preguntas han sido respondidas correctamente prácticamente por todos los estudiantes encuestados, lo que lleva a pensar que no conllevan ningún tipo de dificultad para los estudiantes. Más adelante, el análisis de los resultados de las cuestiones Q5 y Q9, similares a Q6 y Q8 respectivamente, pero con menor porcentaje de aciertos, nos llevará a abordar de nuevo estas cuestiones, poniendo en duda esta ausencia de dificultad.

- Segundo nivel de dificultad: Estas cuestiones, con un porcentaje de respuestas correctas entre $75 \%$ y $95 \%$, son cuestiones que, a pesar de presentar resultados incorrectos en las respuestas, pueden considerarse dentro de lo "normal" porque el porcentaje de error no alcanza el $25 \%$ de la totalidad de respuestas. En este grupo se incluyen las preguntas Q4, Q5, Q10, Q15, Q16, Q18, Q21 y Q22.

Preguntas Q4 y Q5:

Q4. ¿Hay algo que les guste a todos los estudiantes? En caso afirmativo, indica lo que es. $R$ : Sí, la playa.

Q5. ¿Hayalgún estudiante a quien le guste todo? En caso afirmativo, indica su nombre. R: Sí, el estudiante $S$.

La pregunta Q4 ha obtenido un 94,4\% de respuestas correctas y la pregunta Q5 un 92,5\%. Para responder correctamente a la pregunta Q4 hay que encontrar una fila con todos los valores unitarios. La playa gusta a todos los estudiantes, criterio correspondiente a la sexta fila y que a simple vista se identifica fácilmente. Sin embargo, se han encontrado 12 casos que han respondido incorrectamente. Estos estudiantes pueden haber recurrido al pensamiento subjetivo, respondiendo a partir de sus propias ideas, sin ceñirse a la 
información dada en la tabla. La idea preconcebida de que, en general, todas las personas no tienen por qué tener los mismos gustos habría prevalecido sobre la información aportada por la tabla. Respecto a la pregunta Q5, sobre la existencia de algún estudiante a quien le guste todo, ha podido ocurrir lo mismo, con un total de 16 estudiantes con respuesta errónea. Se observa además que los estudiantes que han contestado mal en la pregunta Q4 no son los mismos estudiantes que han contestado mal a la pregunta Q5. Sólo hay 5 estudiantes que han contestado mal a las dos preguntas. También podría tratarse, en algunos casos, de un error material.

En el estudio a priori del cuestionario, estas preguntas son prácticamente equivalentes. ¿Por qué han respondido correctamente a una pregunta e incorrectamente a otra cuando la única diferencia ha sido cambiar el sujeto por el objeto? La comprobación del cuantificador universal sobre el sujeto o sobre el objeto afecta a la búsqueda por filas o por columnas, aunque esta distinción no ha sido recogida en los criterios de la matriz a priori, considerando que no era relevante en la caracterización de las preguntas, asumiendo que la búsqueda por filas o por columnas no supone ningún problema para nuestros estudiantes.

En relación a la pregunta Q6, que ha sido respondida correctamente por un 96,7\% de los estudiantes, hay que destacar su conexión con Q5.

Q6. ¿Hay más estudiantes a quienes les guste todo? En caso afirmativo, indica cuáles. $R$ : No

La respuesta de Q6 sólo tiene sentido si se sabe responder a Q5. Aun así, responder incorrectamente a Q5 no induce necesariamente a responder incorrectamente a Q6, lo que podría justificar el aumento de aciertos en la pregunta Q6.

Pregunta Q10:

Q10. ¿A todos los estudiantes les gusta salir de noche o practicar deporte? $R: N o$

El porcentaje de respuestas correctas en esta cuestión es del 94,4\%, por tanto se trata de una pregunta con un nivel de dificultad bastante bajo. La disyunción lógica, de forma 
aislada, no se puede considerar una operación lógica problemática según este porcentaje. Sin embargo, al realizar el análisis de la pregunta Q17, veremos que la disyunción presenta complicaciones.

Preguntas Q15, Q16 y Q18:

Q15. A todos los estudiantes que les gusta esquiar les gusta el frío. Verdadero, falso o no sé. R: Falso

Q16. Si a un estudiante no le gusta el deporte, entonces no le gustan los deportes acuáticos. Verdadero, falso o no sé. R: Falso

Q18. Lo que les gusta a los estudiantes $C$ y F le gusta al estudiante $L$. Verdadero, falso o no sé. R: Falso

Estas tres cuestiones tienen atribuida la implicación lógica en su caracterización. Las cuestiones Q15 y Q16 tienen prácticamente el mismo porcentaje de error. Un 90\% de los estudiantes han respondido correctamente.

Se trata de una implicación: «A todos ... entonces ...», « $\mathrm{Si}$... entonces ...». Son las primeras preguntas que aparecen en el cuestionario cuyas respuestas requieren la atribución del valor de verdad y ambas falsas. Además, ambas se caracterizan por tener enunciados que pueden dar lugar a diferentes interpretaciones semánticas. Por ejemplo, en la pregunta Q16, los datos de la tabla indican que es falso mientras que el enunciado podría conducir a afirmar lo contrario: «si a una persona no le gusta ningún deporte, no le pueden gustar los deportes acuáticos».

En la pregunta Q15, además de la asociación semántica esquí-frío, se encuentra entre sus variables explicativas, LFAL y LIMPR, es decir, que su enunciado posibilita el uso de una falacia argumentativa y además le precede en el cuestionario una pregunta que se corresponde con su implicación recíproca. En el primer caso se trata de la falacia formal conocida como la afirmación del consecuente, un razonamiento que transforma la condicional en su recíproca, proposiciones no equivalentes en lógica proposicional, tal y como muestra la siguiente tabla de verdad: 


\begin{tabular}{|c|c|c|c|c|}
\hline $\mathrm{p}$ & $\mathrm{q}$ & $\begin{array}{c}\mathrm{p} \rightarrow \mathrm{q} \\
\text { condicional }\end{array}$ & $\begin{array}{c}\mathrm{q} \rightarrow \mathrm{p} \\
\text { condicional recíproca }\end{array}$ & $\begin{array}{c}((\mathrm{p} \rightarrow \mathrm{q}) \wedge \mathrm{q}) \rightarrow \mathrm{p} \\
\text { Afirmación del consecuente }\end{array}$ \\
\hline $\mathrm{V}$ & $\mathrm{V}$ & $\mathrm{V}$ & $\mathrm{V}$ & $\mathrm{V}$ \\
\hline $\mathrm{V}$ & $\mathrm{F}$ & $\mathrm{F}$ & $\mathrm{V}$ & $\mathrm{V}$ \\
\hline $\mathrm{F}$ & $\mathrm{V}$ & $\mathrm{V}$ & $\mathrm{F}$ & $\mathrm{F}$ \\
\hline $\mathrm{F}$ & $\mathrm{F}$ & $\mathrm{V}$ & $\mathrm{V}$ & $\mathrm{V}$ \\
\hline
\end{tabular}

Tabla 2.8: Tabla de verdad correspondiente a la condicional, su recíproca, bicondicional y falacia conocida como «la afirmación del consecuente»

Vemos en la tabla, que la proposición condicional, cuandor el antecedente es falso, es verdadera, pero su recíproca es falsa.

Tanto la utilización de una falacia argumentativa como la equivalencia entre una implicación y su recíproca, relacionan las preguntas Q14 y Q15, recíprocas entre sí, tal y como se verá más adelante, cuando analicemos la pregunta Q14, correspondiente al tercer nivel de dificultad.

La pregunta Q18, también es una pregunta con implicación lógica, atribución del valor de verdad y falsa. Se trata además de una combinación de operaciones lógicas en la que intervienen la conjunción y la condicional. El 24\% de respuestas incorrectas es debido, posiblemente, a dicha combinación, $(\mathrm{p} \wedge \mathrm{q}) \rightarrow \mathrm{s}$, es decir, una proposición condicional con una conjunción en el antecedente.

Esta combinación podría conducir a la siguiente fórmula no equivalente: $(\mathrm{p} \rightarrow \mathrm{s}) \wedge(\mathrm{q} \rightarrow \mathrm{s})$. La tabla de verdad muestra que una conjunción en el antecedente no es lógicamente equivalente a la conjunción de los condicionales (si estuviera la conjunción en el consecuente, sí sería equivalente a la conjunción de los condicionales): 


\begin{tabular}{|c|c|c|c|c|}
\hline $\mathrm{p}$ & $\mathrm{q}$ & $\mathrm{s}$ & $(\mathrm{p} \wedge \mathrm{q}) \rightarrow \mathrm{s}$ & $(\mathrm{p} \rightarrow \mathrm{s}) \wedge(\mathrm{q} \rightarrow \mathrm{s})$ \\
\hline $\mathrm{V}$ & $\mathrm{V}$ & $\mathrm{V}$ & $\mathrm{V}$ & $\mathrm{V}$ \\
\hline $\mathrm{V}$ & $\mathrm{F}$ & $\mathrm{V}$ & $\mathrm{V}$ & $\mathrm{V}$ \\
\hline $\mathrm{F}$ & $\mathrm{V}$ & $\mathrm{V}$ & $\mathrm{V}$ & $\mathrm{V}$ \\
\hline $\mathrm{F}$ & $\mathrm{F}$ & $\mathrm{V}$ & $\mathrm{V}$ & $\mathrm{V}$ \\
\hline $\mathrm{V}$ & $\mathrm{V}$ & $\mathrm{F}$ & $\mathrm{F}$ & $\mathrm{F}$ \\
\hline $\mathrm{V}$ & $\mathrm{F}$ & $\mathrm{F}$ & $\mathrm{V}$ & $\mathrm{F}$ \\
\hline $\mathrm{F}$ & $\mathrm{V}$ & $\mathrm{F}$ & $\mathrm{V}$ & $\mathrm{F}$ \\
\hline $\mathrm{F}$ & $\mathrm{F}$ & $\mathrm{F}$ & $\mathrm{V}$ & $\mathrm{V}$ \\
\hline
\end{tabular}

Tabla 2.9: Tabla de verdad correspondiente a: condicional con conjunción en el antecedente y conjunción de condicionales.

Preguntas Q21 y Q22:

Q21. A los estudiantes no les gusta nadar. Verdadero, falso o no sé.

R: Falso

Q22. Al estudiante H no le gusta nadar. Verdadero, falso o no sé.

R: Falso

El porcentaje de respuestas correctas es de un 75,2\% para la pregunta Q21 y de un 79,4\% para la pregunta Q22. Son las preguntas con mayor dificultad dentro de este grupo, tratándose de preguntas con atribución del valor de verdad, falsas y sin respuesta sobre la tabla. La respuesta requiere de un razonamiento lógico (ley de inferencia Modus Ponendo Ponens). Las preguntas Q21 y Q22 corresponden al último bloque de preguntas del cuestionario, caracterizadas por no tener la respuesta sobre la tabla (NTABL) y presentan un nivel de dificultad menor respecto a las demás.

- Tercer nivel de dificultad: el porcentaje de respuestas correctas varía entre $40 \%$ y 75\% y está formado por las preguntas Q3, Q9, Q11, Q12, Q14 y Q17. 


\section{Pregunta Q3}

Q3. ¿Cuántas cosas le gustan al estudiante Q para viajar? R: 10 cosas

Esta cuestión, formalmente equivalente a Q2 (se trata de un predicado representado por los valores de una columna), requiere una reflexión a posteriori, dado que hay un número de 54 errores en total, lo que supone un $25 \%$ de las respuestas de los estudiantes, mientras que Q2 tiene un 98,5\% de respuestas correctas. Partiendo de que los estudiantes interpretan correctamente la tabla, ¿qué ha podido suceder para responder de forma incorrecta? El nivel de exigencia de esta pregunta, según la caracterización recogida en la matriz MAP, viene representado únicamente por los criterios relacionados con el uso correcto de la tabla. Sin embargo, los resultados muestran que ha habido algún tipo de interpretación del enunciado que no hemos tenido en cuenta a priori.

\section{Pregunta Q9}

Q9. ¿ ¿Todo lo que le gusta al estudiante J le gusta al estudiante R? R: Sí

La pregunta Q9 es formalmente la misma pregunta que Q8, y ha obtenido un 72,8\% de respuestas correctas. Ambas preguntas se caracterizan por la implicación lógica. Sin embargo la cuestión Q8 ha sido la que mayor número de aciertos ha conseguido a lo largo de todo el cuestionario (99\%), incluso más que Q1 y Q2, que tan solo requieren la lectura de la tabla. Uno de los criterios que las diferencia, y que podría haber influido en las respuestas de los estudiantes, es la relación de implicación recíproca que existe entre ambas preguntas. En tal caso, afectaría a la pregunta Q9 por aparecer en segundo lugar, cuya respuesta se apoyaría en la respuesta negativa de Q8, respondiendo también negativamente y dando lugar a error. También se diferenciancian por el tipo de respuesta, negativa en el caso de la pregunta Q8 y afirmativa en el caso de la pregunta Q9.

Preguntas Q11, Q12

Q11. Los estudiantes $N$ y $R$ ¿tienen el mismo gusto para viajar? ¿Por qué?

$R$ : No, porque tienen al menos un gusto diferente. 
Q12. ¿A qué pareja crees que es más probable encontrar en un mismo viaje, a $J$ y $R \quad o \quad G$ y T? ¿Por qué? $R$ : J y $R$, porque tienen mayor número de coincidencias.

Este grupo de preguntas, con un porcentaje de respuestas correctas alrededor del $70 \%$, tienen un lugar en el cuestionario, junto a la cuestión Q13, para hacer aparecer el pensamiento subjetivo de los estudiantes, dando lugar, tal y como se ha comprobado, a diferentes respuestas.

Pregunta Q14

Q14. Al estudiante que le gusta el frío, le gusta esquiar. Verdadero, falso o no sé. R: Verdadero

Esta cuestión es formalmente similar a la pregunta Q15. Sin embargo, el nivel de dificultad ha sido mayor. Sólo un $62 \%$ de estudiantes la han respondido correctamente frente a un 91,5\% que han respondido correctamente a la pregunta Q15.

Q14. Al estudiante que le gusta el frío, le gusta esquiar. Verdadero, falso o no sé. $R$ : Verdadero

Q15. A todos los estudiantes que les gusta esquiar les gusta el frío. Verdadero, falso o no sé. R: Falso

El orden de aparición de estas dos preguntas podría haber influido sobre las respuestas de los estudiantes. Como ya se ha adelantado en el análisis de la pregunta Q15, ésta tiene atribuidos los criterios LIMPLR y LFAL, es decir, que está precedida por una pregunta que corresponde a su recíproca y además es posible llevar a cabo una falacia argumentativa en su resolución. Así pues, una vez respondida la cuestión Q14, los errores a esta pregunta, que son más que los aciertos, podrían haber conducido a respuestas iguales para su contrarrecíproca, favoreciendo a la pregunta Q15. Esto explicaría la diferencia respecto al nivel de dificultad que representan los resultados obtenidos, a pesar de ser preguntas formalmente equivalentes. 


\section{Pregunta Q17}

Q17. Al estudiante E le gusta la playa o la montaña. Verdadero, falso o no sé. $R$ : Verdadero

Q17 es una proposición verdadera, cuyo valor de verdad se obtiene a partir de la disyunción de dos proposiciones, que a su vez son ambas verdaderas. Parece ser que la operación disyunción utilizada por muchos de los estudiantes ha sido la disyunción exclusiva, muy frecuente en el lenguaje natural. La disyunción exclusiva se verifica cuando una única parte de la disyunción es verdadera pero no cuando lo son las dos a la vez, tal y como muestra la siguiente tabla de verdad:

\begin{tabular}{|c|c|c|c|}
\hline $\mathrm{p}$ & $\mathrm{q}$ & $\begin{array}{c}\mathrm{p} \vee \mathrm{q} \\
\text { (disyunción lógica) }\end{array}$ & $\begin{array}{c}\mathrm{p} \bar{\vee} \mathrm{q} \\
\text { (disyunción exclusiva) }\end{array}$ \\
\hline $\mathrm{V}$ & $\mathrm{V}$ & $\mathrm{V}$ & $\mathrm{F}$ \\
\hline$F$ & $\mathrm{~V}$ & $\mathrm{~V}$ & $\mathrm{~V}$ \\
\hline $\mathrm{V}$ & $\mathrm{F}$ & V & $\mathrm{V}$ \\
\hline $\mathrm{F}$ & $\mathrm{F}$ & $\mathrm{F}$ & $\mathrm{F}$ \\
\hline
\end{tabular}

Tabla 2.10: Tabla de verdad correspondiente a: disyunción lógica (inclusiva) y disyunción exclusiva

La cuestión Q10 (¿A todos los estudiantes les gusta salir de noche o practicar deporte?), parecía evidenciar el dominio de la disyunción lógica por parte de los estudiantes, con un 94\% de respuestas correctas. Sin embargo, Q17 parece revelar que esto no es así, con solo un $68 \%$ de aciertos. ¿A qué puede deberse esta diferencia de resultados entre ambas respuestas? Para dar respuesta a Q10, se tienen que comparar dos filas de la tabla de datos. La respuesta correcta es negativa porque hay algún caso en el que se encuentran dos ceros, lo que responde a la negación del tipo 'ni la playa ni la montaña' ¿Qué habrían respondido los estudiantes en el caso de no haber ningún par de ceros?

Q10 no discrimina las respuestas correctas obtenidas utilizando la disyunción lógica, de las respuestas obtenidas con la disyunción exclusiva, ya que la doble negación en ambos 
casos conduce a la misma respuesta. Seguramente, esto ha sido el motivo por el cual el número de respuestas correctas ha sido superior para Q10.

¿Se podría considerar una posible diferenciación en el uso de la conjunción, para la afirmación o la interrogación? Tal vez, aunque no hay suficientes indicios para plantear esta hipótesis. La segunda parte de la experimentación tal vez pueda ofrecer muestras de ello.

- Cuarto nivel de dificultad: corresponde a las preguntas Q7, Q13, Q19, Q20 y Q23 y han sido respondidas correctamente por menos del 40\% de los estudiantes.

Preguntas Q19, Q20 y Q23

Q19. A todos los del grupo les gusta nadar. Verdadero, falso o no sé.

R: No sé

Q20. Si no les gusta practicar deporte, no les gusta nadar. Verdadero, falso o no sé. R: No sé

Q23. Si no les gusta nadar, no les gusta practicar deporte. Verdadero, falso o no sé. R: Verdadero

Las preguntas Q19, Q20 y Q23 están caracterizadas por la atribución del valor de verdad sin respuesta sobre la tabla, destacando Q19 y Q20 por su elevado número de respuestas incorrectas. Se trata de las únicas preguntas del cuestionario que tienen por respuesta correcta «No sé» Esta respuesta no parece ser una opción a considerar por los estudiantes. El enunciado de la pregunta Q19 es la generalización del predicado «tener el gusto nadar», extendido a todos los elementos del conjunto de estudiantes.

La pregunta Q20 puede dar lugar a dos formas distintas de razonar la respuesta. Por un lado, la fuerza semántica del enunciado lleva a la conclusión de que nadar es practicar un deporte y por lo tanto lo que dice el enunciado es verdad. Por otro lado, es posible recurrir a la siguiente falacia argumentativa, conocida como la negación del antecedente:

$$
\begin{aligned}
& p \rightarrow q \\
& \neg p \\
& \neg q
\end{aligned}
$$


dando lugar a la verificación de la proposición inversa de la condicional, $\neg p \rightarrow \neg q$. En la siguiente tabla de verdad se muestran los valores de verdad de las diferentes proposiciones compuestas a las que estamos haciendo referencia, para comprobar que, partiendo de la veracidad de la premisa $\mathrm{p} \rightarrow \mathrm{q}$, este argumento falaz no siempre es verdadero, y tampoco lo es $\neg p \rightarrow \neg q$.

\begin{tabular}{|c|c|c|c|c|}
\hline $\mathrm{p}$ & $\mathrm{q}$ & $\mathrm{p} \rightarrow \mathrm{q}^{19}$ & $\begin{array}{c}\neg p \rightarrow \neg q \\
\text { condicional inversa }\end{array}$ & $\begin{array}{c}(\mathrm{p} \rightarrow \mathrm{q}) \wedge \neg p) \rightarrow \neg q \\
\text { negación del antecedente }\end{array}$ \\
\hline $\mathrm{V}$ & $\mathrm{V}$ & $\mathrm{V}$ & $\mathrm{V}$ & $\mathrm{V}$ \\
\hline $\mathrm{V}^{*}$ & $\mathrm{~F}^{*}$ & $\mathrm{~F}^{*}$ & $\mathrm{~V}^{*}$ & $\mathrm{~V}^{*}$ \\
\hline $\mathrm{F}$ & $\mathrm{V}$ & $\mathrm{V}$ & $\mathrm{F}$ & $\mathrm{F}$ \\
\hline $\mathrm{F}$ & $\mathrm{F}$ & $\mathrm{V}$ & $\mathrm{V}$ & $\mathrm{V}$ \\
\hline
\end{tabular}

Tabla 2.11: Tabla de verdad correspondiente a la implicación, la inversa de la implicación, y la conjunción de la implicación y la negación del antecedente

Para responder correctamente a la pregunta Q23, sería suficiente conocer la equivalencia lógica entre la condicional y su contrarrecíproca:

\begin{tabular}{|c|c|c|c|}
\hline $\mathrm{p}$ & $\mathrm{q}$ & $\mathrm{p} \rightarrow \mathrm{q}$ & $\neg \mathrm{q} \rightarrow \neg \mathrm{p}$ \\
\hline $\mathrm{V}$ & $\mathrm{V}$ & $\mathrm{V}$ & $\mathrm{V}$ \\
\hline $\mathrm{V}^{*}$ & $\mathrm{~F}^{*}$ & $\mathrm{~F}^{*}$ & $\mathrm{~F}$ \\
\hline $\mathrm{F}$ & $\mathrm{V}$ & $\mathrm{V}$ & $\mathrm{V}$ \\
\hline $\mathrm{F}$ & $\mathrm{F}$ & $\mathrm{V}$ & $\mathrm{V}$ \\
\hline
\end{tabular}

Tabla 2.12: Tabla de verdad correspondiente a la implicación y su contrarrecíproca

\footnotetext{
${ }^{19}$ La proposición $\mathrm{p} \rightarrow \mathrm{q}$ corresponde a la premisa del cuestionario Q, que es verdadera, por lo tanto la opción correspondiente, marcada con asterisco, no ha de tenerse en cuenta. La tabla de verdad se ha completado para mostrar la equivalencia lógica entre las proposiciones $\neg p \rightarrow \neg q$ y $((\mathrm{p} \rightarrow \mathrm{q}) \wedge \neg p) \rightarrow \neg q$
} 
Esta regla de transformación es utilizada frecuentemente en los razonamientos matemáticos, sin embargo un número elevado de estudiantes ha fracasado en sus respuestas.

\section{Pregunta Q7}

Q7. ¿A cuántos estudiantes no les gustan las grandes ciudades y salir de noche?

Esta pregunta tan solo ha sido respondida de forma correcta por un único estudiante. El fracaso ante esta pregunta posiblemente se deba a la combinación de las operaciones lógicas que se deben llevar a cabo para dar la respuesta correcta. La negación de una conjunción no se ha operado correctamente y la respuesta que más veces aparece ha considerado correcto contar los 3 casos en que no les gustan ni las grandes ciudades ni salir de noche. La operación incorrecta realizada por los estudiantes sería, en estos casos, considerar la fórmula $\neg(A \wedge B)$ equivalente a la fórmula $\neg A \wedge \neg B$. La segunda respuesta más repetida ha sido 19; correspondiendo estos casos a aquellos estudiantes que han contado por un lado los individuos a los que no les gustan las grandes ciudades y por otro lado los individuos a los que no les gusta salir de noche. Después han sumado los resultados, sin restar el cardinal de la intersección. La operación incorrecta entre conjuntos no disjuntos ha sido la igualdad entre los cardinales siguientes: $|A \cup B|$ y $|A|+|B|$. También ha habido algunos estudiantes que han respondido, separadamente, que a 9 estudiantes no les gustan las grandes ciudades y a 10 estudiantes no les gusta salir de noche.

\section{Pregunta Q13}

Q13. Si fueras el agente de viajes, ¿qué tres criterios de los que aparecen en la tabla elegirías para proponer un viaje a estos estudiantes? ¿Por qué? $R$ : La playa, conocer otras culturas y esquiar, gustos que tienen más número de estudiantes. 
Tal y como habíamos avanzado en el análisis de las preguntas Q11 y Q12, la pregunta Q13 se caracteriza por ser una de las preguntas que dan lugar a diferentes formas de argumentación, apelando al pensamiento subjetivo. El porcentaje de aciertos ha sido del 38\%, bastante inferior al 70\% obtenido en las preguntas Q11 y Q12. La pregunta Q13 es más abierta, dando lugar a mayor variedad de respuestas que Q11 y Q12, que tan solo permiten dos posibles respuestas y tal vez por este motivo haya sido mayor su número de aciertos.

Una vez analizadas todas las cuestiones, y con el fin de interpretar con mayor precisión los resultados obtenidos a partir de la primera aplicación del cuestionario, se ha realizado un análisis estadístico implicativo de los datos, aplicando el programa CHIC a la matriz de respuestas correctas e incorrectas, igual que se hizo con la matriz a priori (Tabla 2.3)

\subsubsection{Análisis de los resultados del cuestionario Q utilizando el Análisis Estadístico Implicativo}

Como ya se ha indicado, la matriz a posteriori se trata de una matriz de datos binarios que recoge información sobre las respuestas de los estudiantes al cuestionario Q, representando el éxito o fracaso en cada una de las preguntas. El análisis estadístico implicativo de los datos, aplicando el programa CHIC a la matriz de respuestas correctas e incorrectas, igual que se hizo con la matriz a priori, ha proporcionado los siguientes gráficos, obtenidos con la misma configuración del programa CHIC utilizada con la matriz MAP en el apartado 2.2.2:

- CHIC: versión 5.0

- Índice de similaridad definido según la teoría clásica.

- Modelo probabilístico según la ley de Poisson 


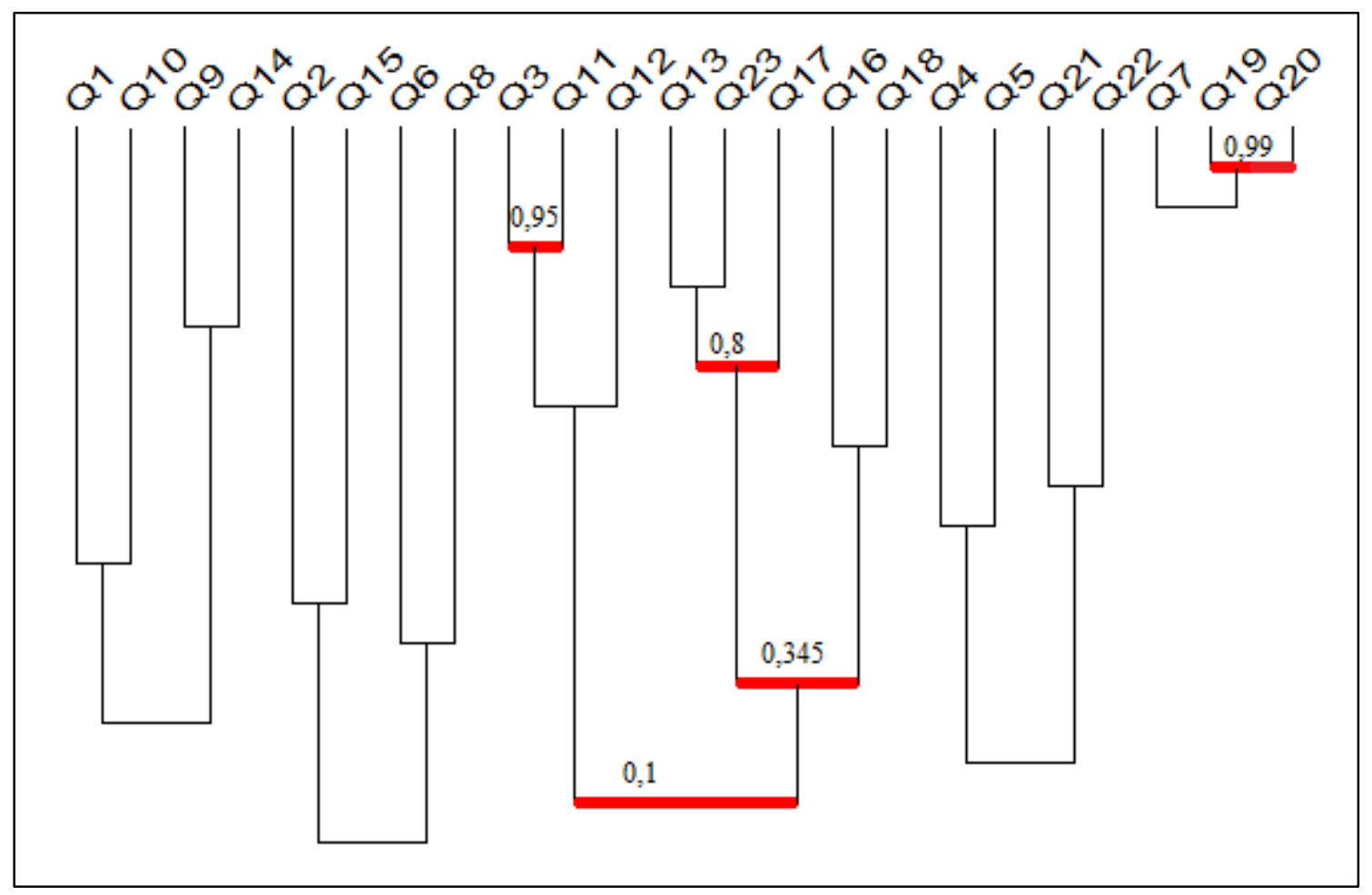

Fig. 2.11: Árbol de similaridad de la matriz a posteriori (UJI)

El árbol de similaridad separa cinco clases de preguntas, entre las cuales sólo tres son significativas:

- $\quad$ Clase 1 (UJI): [ ( [Q3, Q11], Q12 ), [ [ (Q13, Q23), Q17 ], (Q16, Q18) ] ]

La notación utilizada en la presentación de las clases seguirá siendo la misma que la notación utilizada en el estudio de la MAP, es decir, se utilizarán paréntesis para los enlaces no significativos y corchetes para las clases significativas.

La clase 1 está formada por tres clases significativas. A nivel 3 y con un índice de similaridad de 0,95 se encuentra la clase formada por las preguntas [Q3, Q11] y a nivel 
14 con un índice de 0,34 la clase formada por las preguntas [ [(Q13, Q23), Q17], Q16, Q18]. Dentro de esta clase se encuentra [(Q13, Q23), Q17] clase significativa a nivel 6 con índice de similaridad 0,8, que incluye la clase no significativa (Q13, Q23) con índice de similaridad igual a 0,93 .

- $\quad$ Clase 2 (UJI): [Q19, Q20]

A nivel 1 y con un índice de similaridad igual a 0,999 se encuentra la clase formada por las preguntas [Q19, Q20].

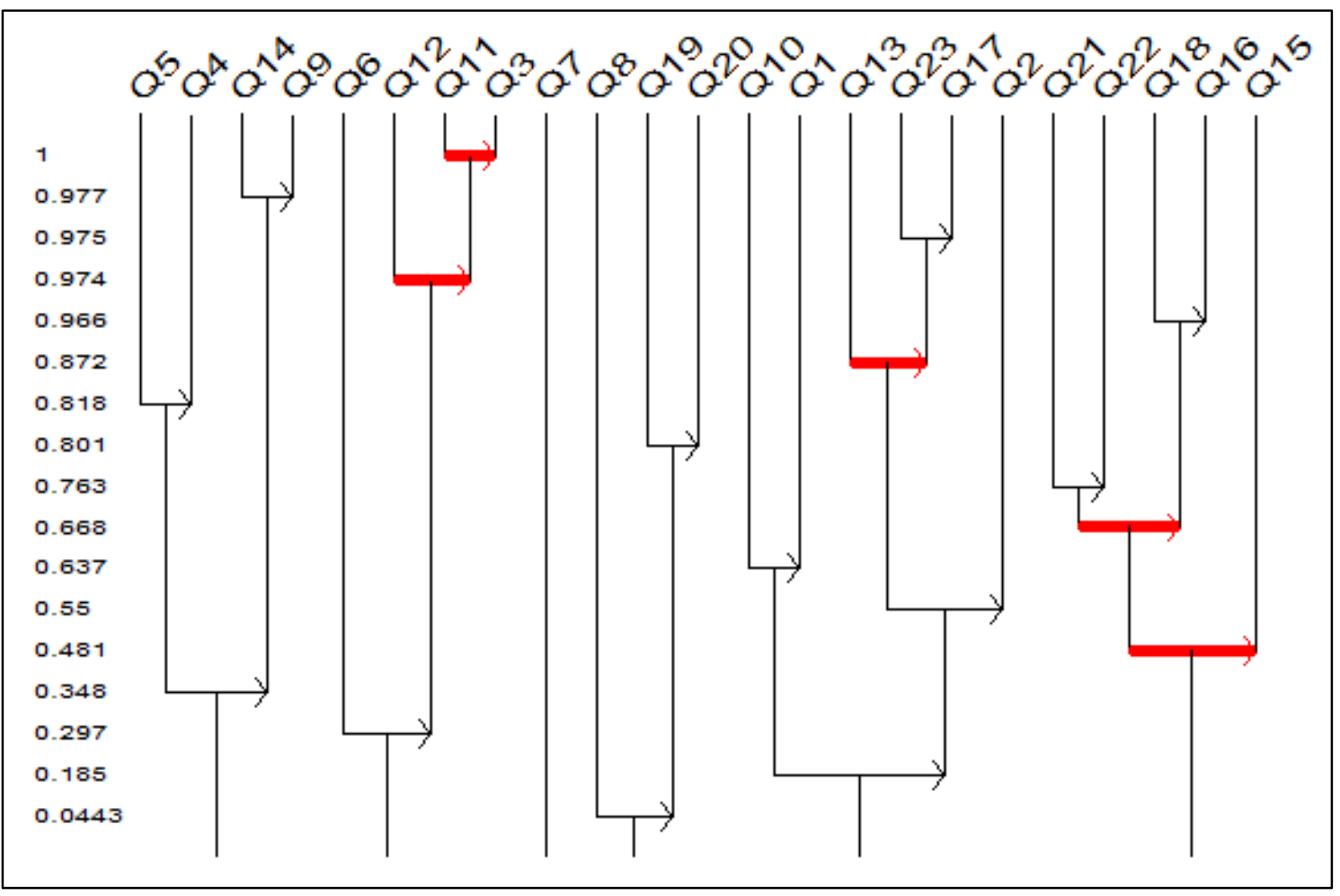

Fig. 2.12: Árbol cohesitivo de la matriz a posteriori (UJI) 
El sentido de las implicaciones del grafo cohesitivo nos informa de la relación de inclusión entre los estudiantes que han respondido correctamente a cada pareja de preguntas, permitiendo establecer reglas del tipo:

"si un estudiante ha respondido correctamente a la pregunata Qi, también ha respondido correctamente a la pregunta $Q j{ }^{\prime}$

También en el árbol cohesitivo se han diferenciado cinco clases de preguntas, tres de ellas significativas, que a su vez incluyen otras clases. Hay que destacar la pregunta Q7, que no aparece dentro de ninguna clase. El hecho de no ser respondida correctamente por ningún estudiante hace que no se relacione con ninguna otra cuestión.

En el árbol de similaridad esta misma pregunta aparecía dentro de la clase no significativa (Q7, [Q19, Q20]), clase de similaridad formada por las preguntas del cuestionario con menor número de respuestas correctas.

Las clases significativas del árbol cohesitivo son las siguientes:

- Clase 3 (UJI): $\quad \mathrm{Q}_{12} \underset{\substack{\text { nivel } \\ 0,974}}{\longrightarrow}\left(\mathrm{Q}_{11} \underset{\substack{\text { nivel } 1 \\ 1}}{=} \mathrm{Q}_{3}\right)$

Tal y como indicamos en el esquema, el nivel de cohesión más significativo es el nivel 1, $\left(Q_{11} \Longrightarrow Q_{3}\right)$, con un índice de cohesión igual a 1 . A esta clase se le agrega significativamente la pregunta Q12, a nivel 4 y con un índice de cohesión igual a 0,974. Sabemos que las preguntas Q11 y Q12, según su caracterización a priori, apelan ambas al pensamiento subjetivo. En cambio, la pregunta Q3 no tiene a priori dicha característica, presentando un comportamiento no esperado, como ya habíamos apuntado en el apartado anterior.

Siguiendo la notación anterior, se simbolizará el nivel significativo con la doble flecha $(\Longrightarrow)$, mientras que para indicar que dicho nivel no es significativo se utilizará la flecha simple $(\longrightarrow)$ 
- Clase 4 (UJI): $\quad \mathrm{Q}_{13} \underset{\substack{\text { nivel 6 6 } \\ 0,872}}{\longrightarrow}\left(\mathrm{Q}_{23} \underset{\substack{\text { nivel 3 3 } \\ 0,975}}{\longrightarrow} \mathrm{Q}_{17}\right)$

La clase 4, del árbol cohesitivo, ya aparecía en el árbol de similaridad, dentro de la clase 1. El criterio que tiene en común la pregunta Q13 con las preguntas Q23 y Q17 es la interpretación semántica de los enunciados. El nivel 3, a pesar de no ser significativo, se forma en tercer lugar y con un índice de cohesión muy alto.

- Clase 5 (UJI): $\quad\left(\left(Q_{21} \underset{\substack{\text { nivel 9 } \\ 0,763}}{\underset{\longrightarrow}{\longrightarrow}} Q_{22}\right) \underset{\substack{\text { nivel 10 } \\ 0,668}}{=}\left(Q_{18} \underset{\substack{\text { nivel 5 } \\ 0,966}}{\longrightarrow} Q_{16}\right)\right) \underset{\substack{\text { nivel 13 } \\ 0,481}}{\Longrightarrow} Q_{15}$ Las características que tienen en común las preguntas pertenecientes a esta clase, son la atribución del valor de verdad, siendo todas ellas falsas ((AV, AFALS). Además son las únicas preguntas que verifican ambos criterios a la vez. En el grafo implicativo se puede Observar que Q18, Q15 también están relacionadas en una misma clase. 
GRAFO IMPLICATIVO DE LOS RESULTADOS DE LOS ESTUDIANTES DE LA UJI

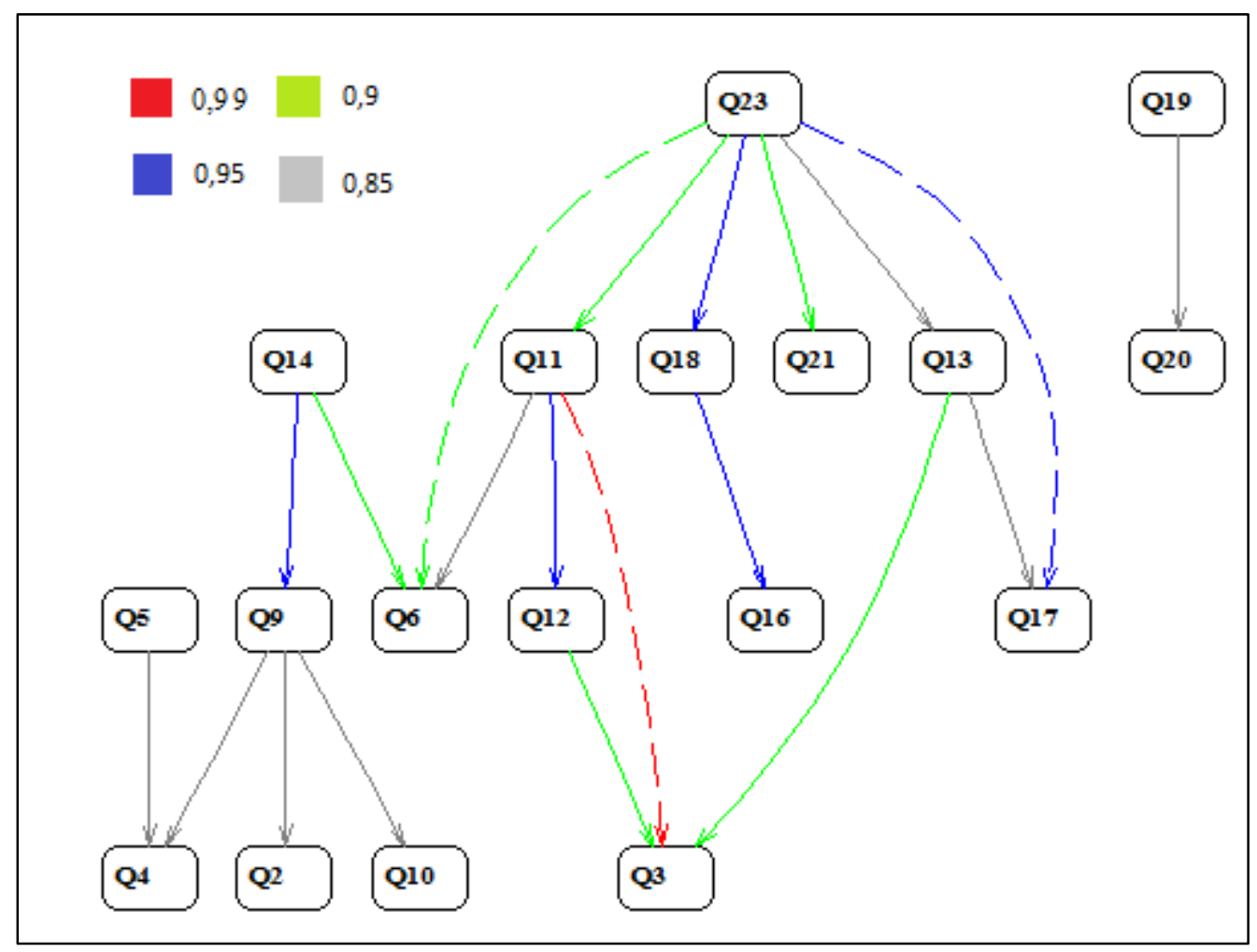

Fig. 2.13: Grafo implicativo de la matriz a posteriori (UJI) con la opción de «transitividad» del programa CHIC

En el grafo implicativo las preguntas Q19 y Q20 aparecen separadas del resto de preguntas. Estas preguntas son las únicas cuya respuesta correcta es «No sé». La implicación $\mathrm{Q} 19 \Rightarrow \mathrm{Q} 20$ presenta un índice de implicación de 0,85 e indica que, según las respuestas de los estudiantes, si se contesta correctamente a la pregunta Q19, se espera que la respuesta a Q20 también sea correcta. Estas dos preguntas formaban una clase de similaridad significativa en el árbol de similaridad, con un índice igual a 0,99 y también se relacionaban mediante la implicación Q19 $\rightarrow$ Q20, en el ábol cohesitivo, con un índice de cohesión de 0,8 , a nivel 8 y no significativo. 
Las implicaciones entre el resto de preguntas relacionadas en el grafo implicativo permiten diferenciar dos árboles de implicación. En uno de ellos, la pregunta Q23 aparece en el extremo superior. Esta posición señala que la pregunta Q23 es una pregunta representativa del máximo nivel de dificultad para los estudiantes, sobre las preguntas implicadas dentro de los caminos a los que pertenece: los estudiantes que hayan respondido correctamente a Q23 (en este caso un 36,4 \% del total) es más probable que hayan respondido correctamente al resto de preguntas de los caminos implicativos. El otro bloque de preguntas implicadas parte de la pregunta Q14, respondida correctamente por el $62,1 \%$ de los estudiantes. La siguiente figura muestra, de forma separada, cada una de las partes del grafo implicativo que acabamos de diferenciar:

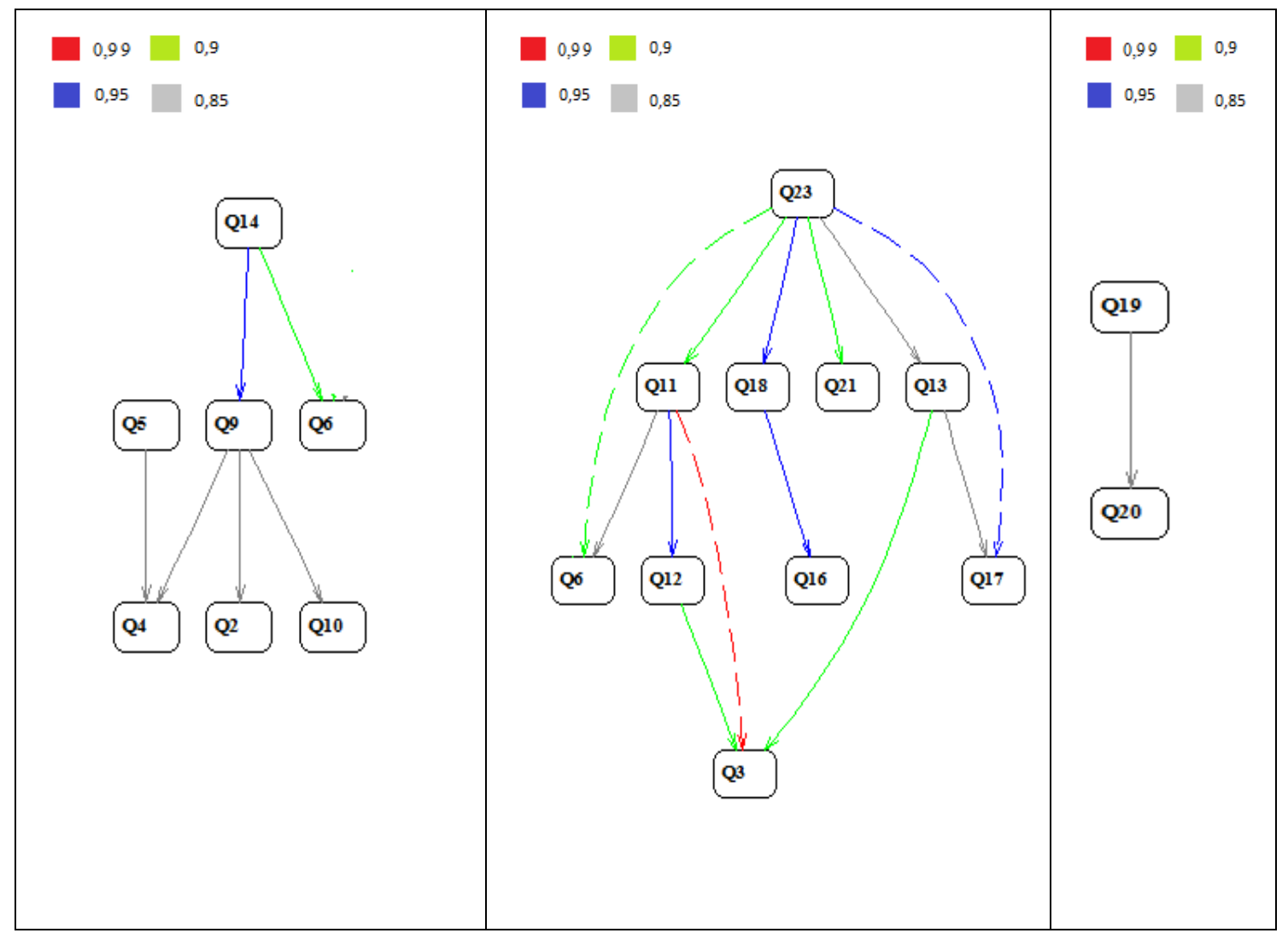

Fig. 2.14: Diferentes ramas de implicación del grafo implicativo de la matriz a posteriori (UJI) 
En este grafo, reaparecen implicaciones que ya aparecían en el árbol cohesitivo, y que formaban a su vez clases en el árbol de similaridad. A continuación vamos a comentar dichas agrupaciones, ya que el hecho de aparecer de forma reiterada en el análisis implicativo llevado a cabo por el programa $\mathrm{CHIC}$, indica cierta tendencia en las respuestas de los estudiantes:

- $\quad$ Las preguntas $\{$ Q13, Q17, Q23 $\}$ presentaban un índice de similaridad igual a 0,872. Según el orden de implicación indicado en los grafos, los estudiantes que responden correctamente a Q23 (36,4\%), responden correctamente a Q17 (67,7\%), siendo la pregunta Q23 una implicación sin búsqueda sobre la tabla y Q17 una disyunción de proposiciones.

- Las preguntas $\{Q 14, Q 9\}$ presentan un índice de similaridad de 0,869. La implicación Q14 $\rightarrow$ Q9, con índice de implicación de 0,95, se repite tanto en el árbol de similaridad como en el árbol de cohesión. En el árbol cohesitivo esta clase no es significativa pero aparece en uno de los primeros niveles (nivel 2) y con alto índice de similaridad (0.977). Los estudiantes que responden correctamente a Q14 (62,1\%), también responden correctamente a Q9 (72,9\%). Tratándose ambas preguntas de una implicación, la atribución del valor de verdad es sólo una característica de Q14.

- Dentro del grupo de preguntas $\{$ Q3, Q11, Q12\}, la implicación Q11 $\Rightarrow$ Q3, ya destacada en el análisis cohesitivo por tener índice de cohesión 1, indica que los estudiantes que han acertado la respuesta de la pregunta Q11 (70,6\%), por regla general, también han acertado la respuesta de la pregunta Q3 $(74,8 \%)$,. El criterio que las diferencia es la interpretación semántica de Q11. Dado el porcentaje de respuestas correctas tan igualado, así como el resultado del árbol de similaridad que las clasifica de forma significativa a nivel 3 y con índice de similaridad de 0,95 , podemos decir que los estudiantes han contestado de forma similar a ambas preguntas. La pregunta Q12 aparece relacionada con ellas en los tres grafos, cuya caracterización es similar a Q11. 
- Las preguntas $\{\mathrm{Q} 18, \mathrm{Q} 16\}$ forman otra de las agrupaciones que aparecen representadas en los tres gráficos. La implicación Q18 $\rightarrow$ Q16 tiene índice de similaridad 0’718, índice de cohesión 0,966 e índice de implicación 0,95. Cabe esperar que los estudiantes que responden correctamente a la pregunta Q18 $(76,2 \%)$ también conozcan la respuesta correcta de la pregunta Q16 (90,2\%). Se trata de la atribución del valor de verdad a dos implicaciones con operaciones lógicas combinadas, presentando mayor dificultad la pregunta Q18 que es una implicación con conjunción en el antecedente.

- $\quad$ El grupo de preguntas $\{$ Q4, Q5 $\}$ en el grafo implicativo vienen relacionadas con la implicación Q5 $\rightarrow$ Q4, con un índice de implicación de 0,85. Así pues, si los estudiantes han respondido de forma correcta a la pregunta Q5 (92,5\%), también lo han hecho a la pregunta Q4 (94,4\%). No se unen en niveles significativos, ni en el árbol de similaridad ni en el árbol cohesitivo, aunque ello podría ser debido al elevado porcentaje de aciertos en ambas preguntas, que en la matriz a priori se traducen en valores unitarios. El índice de similaridad de Lerman utilizado por el programa CHIC prima los casos raros, es decir, las copresencias de casos raros son más significativas. En este caso, al ser la mayor parte de respuestas correctas, existen muchas copresencias y la significatividad disminuye. Aun así, consideramos relevante el hecho de ser una clasificación que se repite a lo largo de todo el análisis. Ambas son preguntas con cuantificador universal actuando sobre un único predicado.

\subsection{Fase I de la experimentación: Segunda aplicación del cuestionario Q y comparación de resultados (Universidad de Jaén, 2015)}

Para dar mayor rigor a los resultados obtenidos a partir de la primera aplicación del cuestionario, se ha considerado conveniente aplicarlo a otro grupo de estudiantes universitarios de una universidad diferente. Así pues, en esta segunda etapa de la fase I se presentan los resultados obtenidos a partir de 287 estudiantes de la Universidad de Jaén, de los cuales 106 pertenecen a la titulación de Maestro/a en Educación Primaria y 
181 a la titulación de Maestro/a de Educación Infantil. Los estudiantes vienen distribuidos en diferentes grupos:

\begin{tabular}{|c|c|c|}
\hline & Maestro/a Primaria & Maestro/a Infantil \\
\hline Grupo A & 55 estudiantes & 63 estudiantes \\
\hline Grupo B & 51 estudiantes & 61 estudiantes \\
\hline Grupo C & & 57 estudiantes \\
\hline
\end{tabular}

Tabla 2.13: Número de estudiantes encuestados por grupo (UJA)

Al igual que ha ocurrido con los grupos de la UJI, el comportamiento de los resultados del total de estudiantes es similar al comportamiento que presentan los subgrupos cuando son considerados de forma separada. Por este motivo, los gráficos presentados a continuación, correspondientes a la totalidad de los estudiantes, se ha considerado suficiente para la interpretación de los resultados.

En el cuestionario de Jaén se ha insertado una pregunta nueva, situada entre Q22 y Q23. Se trata de la siguiente cuestión:

\section{QN23. Al estudiante F le gusta nadar}

Con ello se pretende observar si la cuestión QN23, al no utilizar explícitamente la palabra deporte en el enunciado, y necesariamente tener que utilizar la tabla como fuente de información, conduce a los estudiantes a una respuesta distinta.

El conjunto de respuestas de los estudiantes de la UJA ha conducido a resultados muy similares a los obtenidos en la aplicación llevada a cabo con los estudiantes de la UJI, hecho que apoya la validez de nuestro cuestionario. 


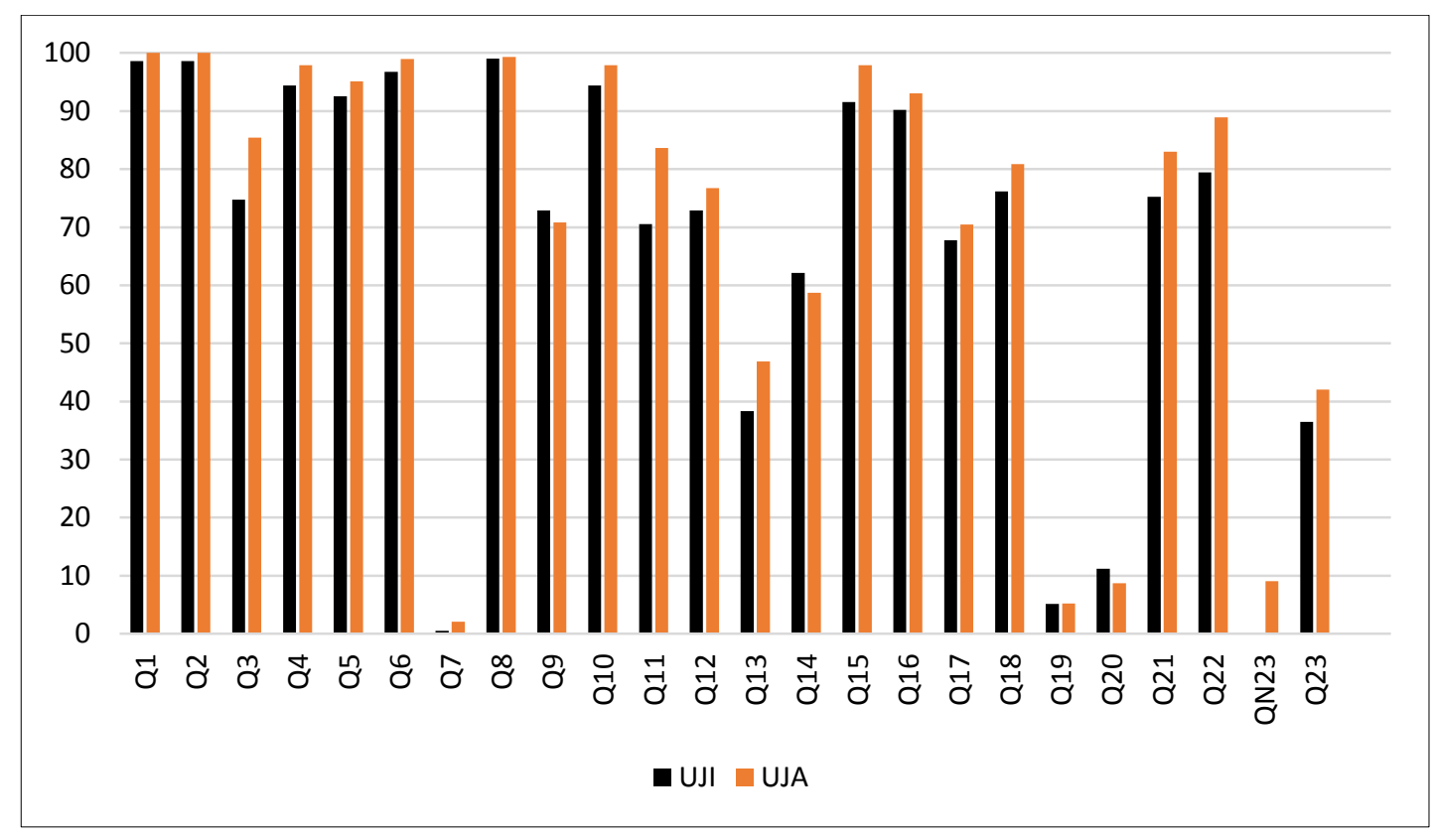

Fig. 2.15: Comparación de porcentajes de respuestas correctas UJI/UJA

Como se puede observar en el gráfico, los porcentajes de respuestas correctas obtenidos a partir de las respuestas de los estudiantes de la UJA presentan, a rasgos generales, un comportamiento similar a los porcentajes de respuestas correctas de los estudiantes de la UJI. La estructura de las preguntas del cuestionario permanece estable. Tan solo alguna cuestión podría ser considerada en un nivel de dificultad diferente, pero sin que ello suponga un cambio de tendencia, ya que se trata de preguntas con porcentajes próximos a los límites entre un nivel de dificultad y otro. La pregunta Q3 no alcanza el $40 \%$ de respuestas correctas de los estudiantes de la UJI, mientras que ahora ha obtenido un $46,8 \%$, pasando del cuarto nivel de dificultad al tercero; lo mismo ha ocurrido con Q23 que había obtenido un porcentaje de respuestas correctas del 36,4\% (cuarto nivel de dificultad) y ahora presenta un porcentaje del $42 \%$ (tercer nivel de dificultad). También cambiarían el nivel de dificultad, tal y como lo habíamos definido, las preguntas Q3, Q11 y Q12, que se considerarían ahora dentro del segundo nivel de dificultad en lugar del tercero, o Q4, Q5, Q10 y Q15, que pasarían del segundo al primer nivel de dificultad, a 
pesar de la pequeña variación de porcentaje (la mayor variación se da en la pregunta Q11, que pasa de un $70,5 \%$ a un $83,6 \%$ de respuestas correctas).

ÁRBOL DE SIMILARIDAD DE LOS RESULTADOS DE LOS ESTUDIANTES DE LA UJA

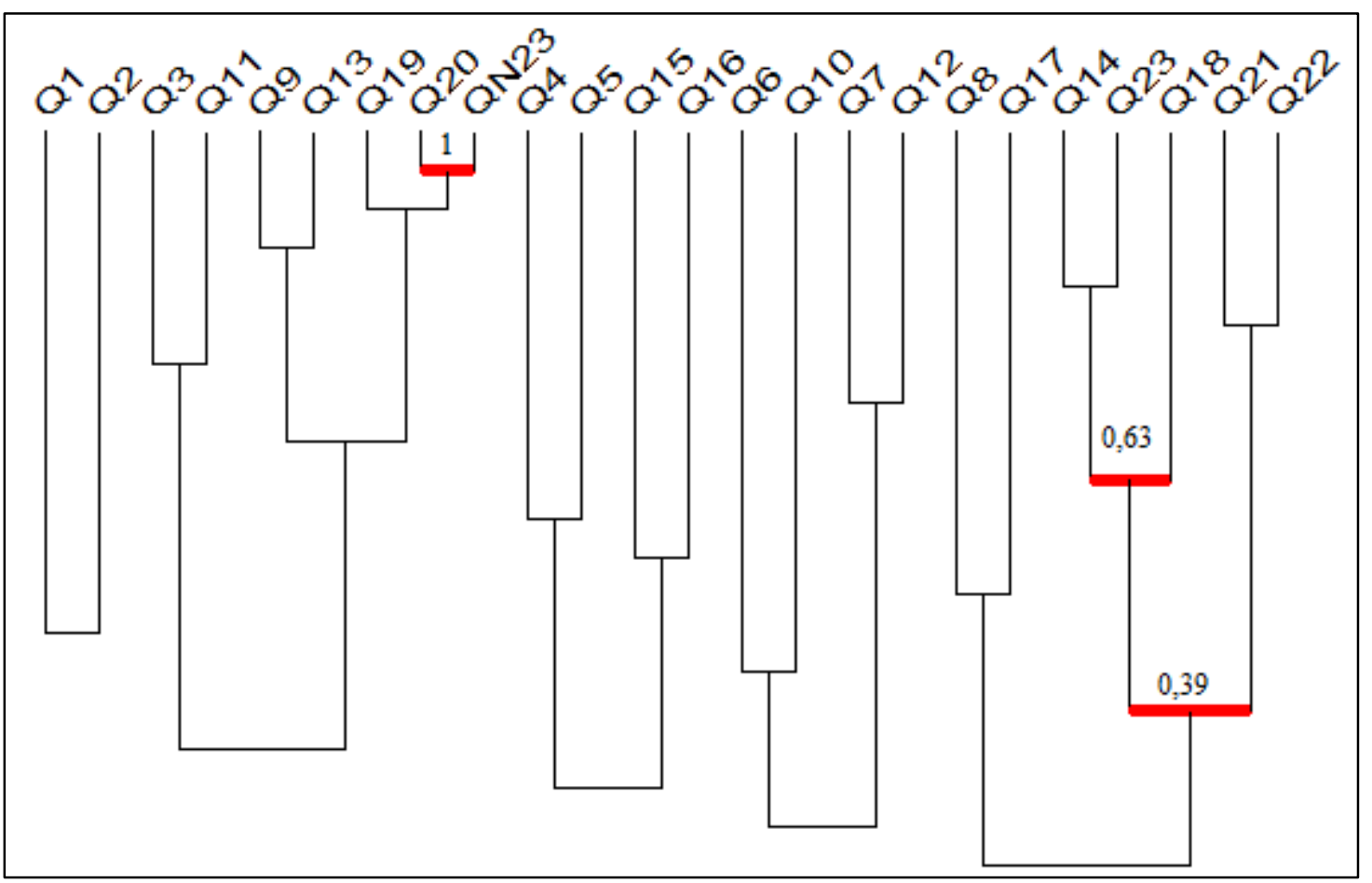

Fig. 2.5: Árbol de similaridad de la matriz a posteriori (UJA)

Las clases obtenidas a partir del análisis de similaridad reúnen preguntas a las que los estudiantes de la UJA han respondido de forma similar, es decir, correcta o incorrectamente. En el árbol de similaridad las preguntas agrupadas con un nivel significativo son las siguientes: (seguiremos utilizando la misma notación que en el análisis de los resultados de los estudiantes de la UJI, tanto para las clases obtenidas a partir del árbol de similaridad como del árbol cohesitivo) 
- $\quad$ Clase 1 (UJA): (Q19, [Q20, QN23])

La clase de preguntas SUJA1 está formada por una clase significativa [Q20, QN23], a nivel 1 y con un índice de similaridad igual a 1. La pregunta Q19, que junto a Q20 y QN23 son el grupo de preguntas caracterizadas por tener un «no sé » como respuesta, se agrega a la clase significativa [Q20, QN23] en el nivel 2, con un índice de similaridad de 0,999, aunque no significativo. Los estudiantes han respondido de forma similar a estas preguntas. Sólo un 5\% ha respondido correctamente a la pregunta Q20 y un 3,8\% a la pregunta QN23, así como el 5,2\% correspondiente a las respuestas correctas de Q19. Por lo tanto la mayor se trata de preguntas con un elevado índice de dificultad.

- $\quad$ Clase 2 (UJA): [ [(Q14, Q23), Q18], (Q21, Q22) ]

Esta clase une dos clases de preguntas en los niveles 9 y 15 . En primer lugar se forma la clase significativa [(Q14, Q23), Q18], con un índice de similaridad igual a 0,63. En segundo lugar se agrega, significativamente, la clase no significativa (Q21, Q22) con un índice de similaridad de 0,389.

Las dos clases de similaridad obtenidas, ambas significativas, unen únicamente preguntas de atribución de valor de verdad. 
ÁRBOL COHESITIVO DE LOS RESULTADOS DE LOS ESTUDIANTES DE LA UJA

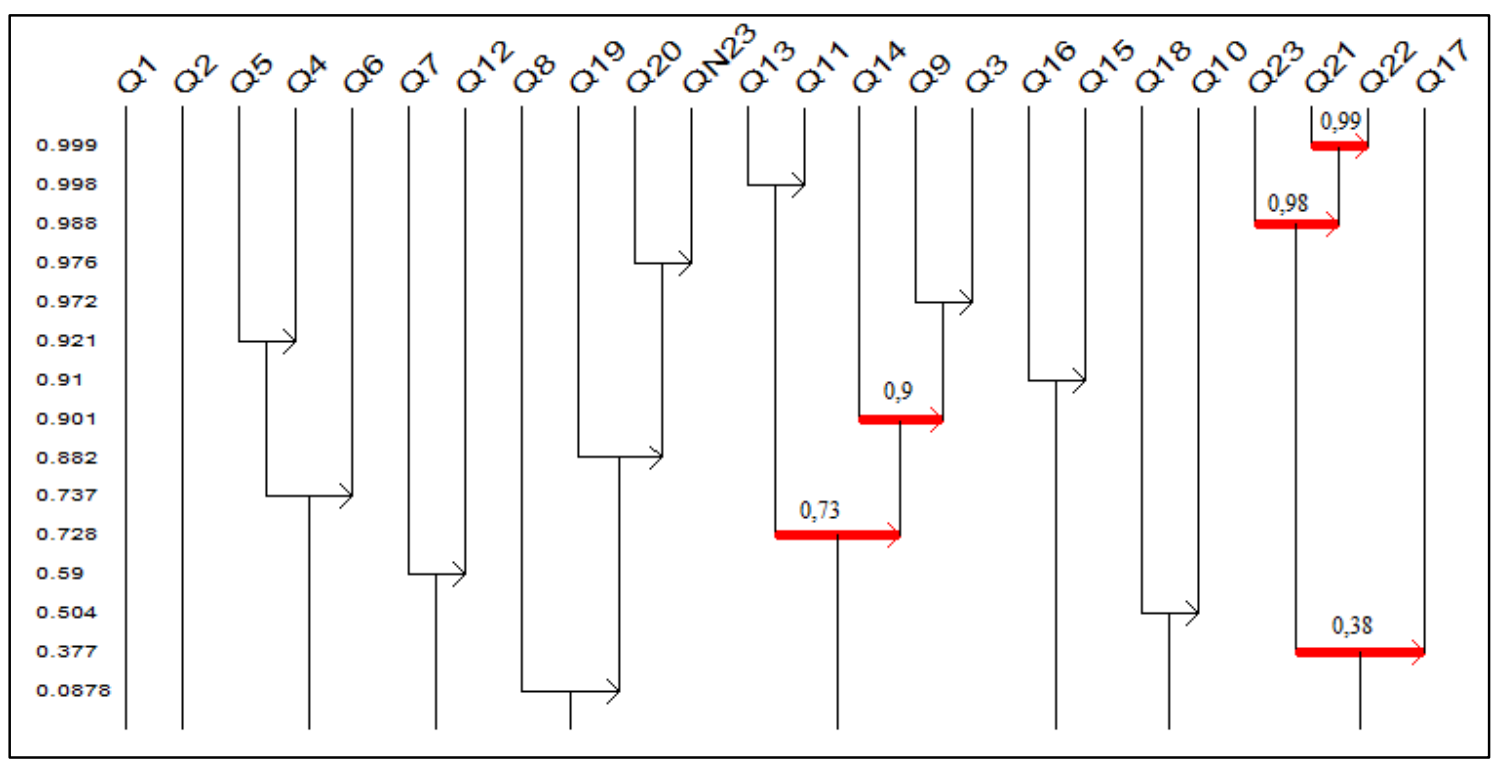

Fig. 2.6: Árbol cohesitivo de la matriz a posteriori (UJA)

- Clase 3 (UJA): $\left(\mathrm{Q}_{23} \underset{\overline{\text { nivel 3 }}}{\Longrightarrow}\left(\mathrm{Q}_{21} \underset{\overline{\text { nivel } 1}}{\Rightarrow} \mathrm{Q}_{22}\right)\right) \underset{\overline{\text { nivel 14 }}}{\rightleftharpoons} \mathrm{Q}_{17}$

El árbol de cohesión estructura en una misma clase significativa, a nivel 1, las preguntas Q21 y Q22, con un índice de cohesión de 0,99. A esta clase de preguntas se le agrega, también significativamente, a nivel 3, la pregunta Q23 y con índice de cohesión igual a 0,98. Por último, a nivel 14 se une significativamente la pregunta Q17 con índice de cohesión igual a 0,377 .

- Clase 4 (UJA): Del mismo modo el árbol cohesitivo presenta la siguiente clase significativa:

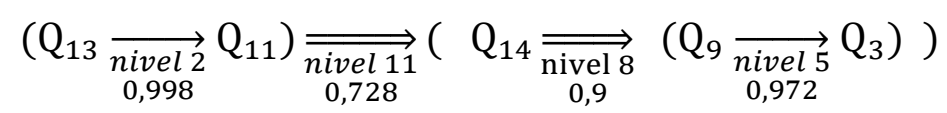


GRAFO IMPLICATIVO DE LOS RESULTADOS DE LOS ESTUDIANTES DE LA UJA

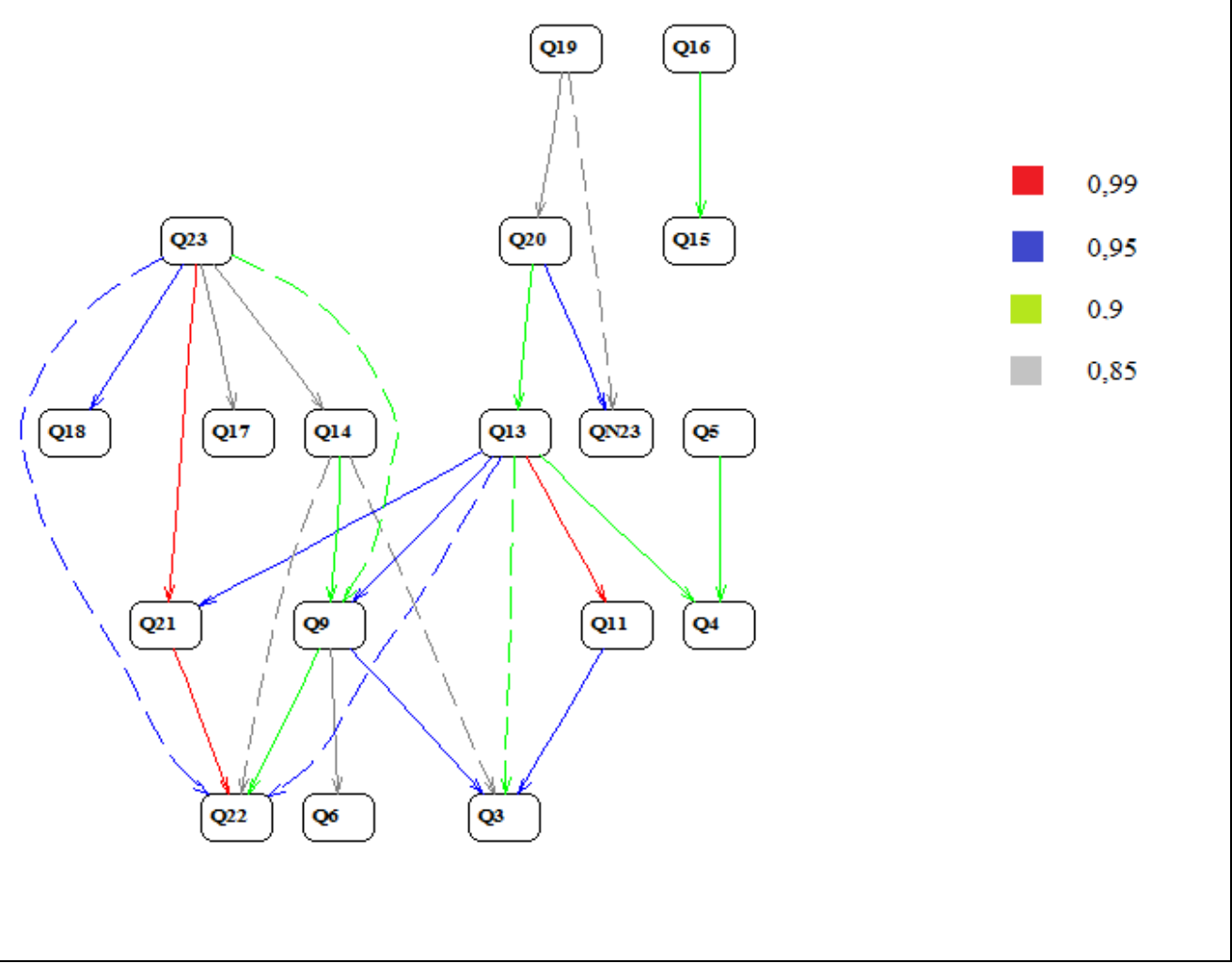

Fig. 2.7: Grafo implicativo de la matriz a posteriori (UJA) con la opción de «transitividad» del programa CHIC

En el grafo implicativo las preguntas Q15 y Q16 aparecen separadas del resto de preguntas, coincidiendo con una de las clases no significativas que aparece aislada en el árbol cohesitivo.

El resto de preguntas relacionadas en el grafo implicativo se diferencian a su vez dos caminos de implicación, marcados esta vez por las preguntas Q19 y Q23, que se sitúan en la parte superior de los respectivos caminos de implicación. Esta posición señala que Q23 es de nuevo una pregunta representativa del control de los estudiantes sobre las preguntas implicadas: los estudiantes que hayan respondido bien a Q23 (en este caso un 
$42 \%$ del total) es más probable que hayan respondido bien al resto de preguntas de los caminos implicativos. La pregunta Q19 (con un 5,2 \% del total de respuestas correctas) presenta la misma posición respecto a la rama de implicación a la que pertenece:

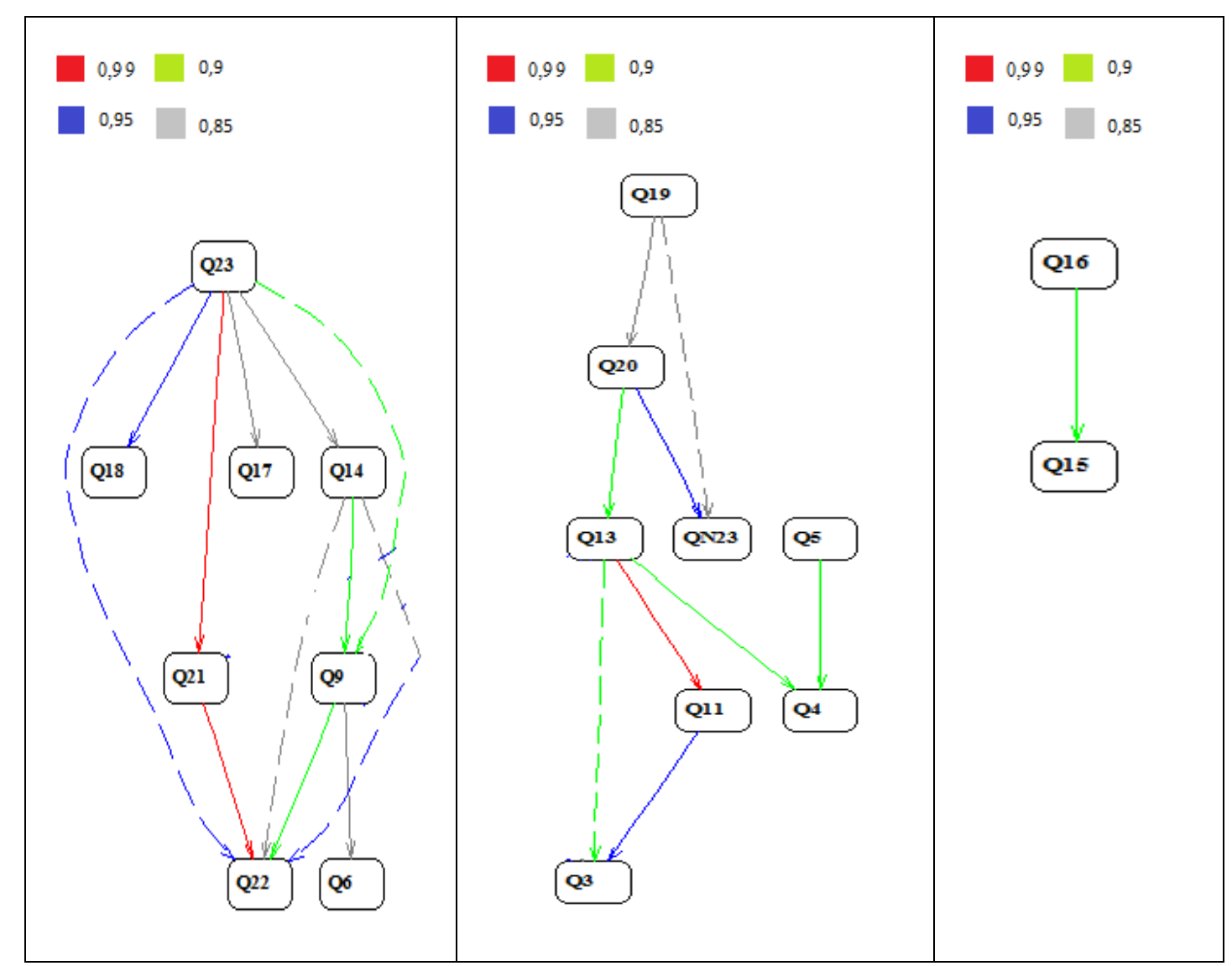

Fig. 2.19: Diferentes ramas de implicación del grafo implicativo de la matriz a posteriori (UJA)

Las implicaciones con mayor índice de implicación $(0,99)$ del grafo implicativo son:

$$
\mathrm{Q} 23 \Rightarrow \mathrm{Q} 21 \Rightarrow \mathrm{Q} 22 \quad \mathrm{y} \quad \mathrm{Q} 13 \Rightarrow \mathrm{Q} 11
$$

Estas implicaciones también vienen representadas en el árbol de cohesión como clases significativas. 
La cadena de implicaciones $\mathrm{Q} 23 \Rightarrow \mathrm{Q} 21 \Rightarrow \mathrm{Q} 22$ relaciona las cuestiones de atribución de valor de verdad, sin búsqueda sobre la tabla, con respuesta verdadera o falsa. Este último criterio marca la diferencia respecto a Q19, Q20 y QN23, preguntas con respuesta «no sé». Responder correctamente a la pregunta Q23 implica responder correctamente a la pregunta Q21 y a su vez, siguiendo la cadena de implicación, a la pregunta Q22. Asimismo, se puede decir que responder correctamente a la pregunta Q13 supone respuesta correcta en la pregunta Q11, ambas representativas del pensamiento subjetivo, siendo Q13 una pregunta más abierta que Q11.

A partir de las respuestas de los estudiantes, tanto de la UJI como de la UJA, se han obtenido algunas conclusiones respecto al cuestionario diseñado y aplicado en la presente investigación:

[Q8, Q9] A pesar de su similaridad, según la caracterización establecida, esta relación no determina su nivel de dificultad. Q8 aparece como una de las preguntas con mayor número de aciertos, $99 \%$, mientras que Q9 tan solo tiene un $73 \%$ de respuestas correctas. Por este motivo, entre las respuestas correctas de Q8, pensamos que debe de haber aciertos que respondan al azar o a un razonamiento incorrecto (de no ser así, no habrían fallado en Q9, que es formalmente la misma pregunta). En respuestas al azar, hay tendencia a elegir la opción ' $N O$ '. En cuanto a los razonamientos incorrectos, interviene la implicación recíproca.

Si se observan las respuestas de las preguntas Q14 y Q15, se puede suponer que ha ocurrido lo mismo: la respuesta más veces elegida ha sido 'falso'. Además debe tenerse en cuenta la influencia de la implicación recíproca así como la interpretación semántica de los enunciados. 
[Q19, Q20, Q21, Q22 y Q23] Las cuestiones Q19 y Q20 presentan mucha mayor dificultad que el resto de preguntas pertenecientes a este grupo porque la respuesta «no sé» es elegida por muy pocos estudiantes.

Se puede interpretar esta opción como una posibilidad que se da al estudiante, a título personal, para decir que desconoce la respuesta, en lugar de referirse a la imposibilidad de afirmar si esa afirmación es verdadera o falsa. Sin embargo, el hecho de que esta opción haya sido elegida muy pocas veces, y teniendo en cuenta la ausencia de respuesta en algunas ocasiones, nos hace pensar que los estudiantes han interpretado esta opción como corresponde, desde el punto de vista lógico.

[Q10, Q17] Este par de preguntas corresponde a la disyunción. Q10 tiene 'no' por respuesta, y su número de aciertos es superior al número de aciertos de Q17, cuya respuesta correcta es 'verdadero'.

\subsection{Conclusiones}

La teoría de Situaciones Didácticas como marco metodológico para la investigación en Didáctica de las Matemáticas, enfatiza la necesidad de llevar a cabo un exhaustivo análisis a priori de las situaciones que vayan a ser implementadas. El investigador, según el propósito de su trabajo, debe conocer y reconocer todo lo que está presente en cada momento de la situación y que puede ser relevante en su investigación. De esta forma, cuando la situación didáctica es llevada a la práctica, se ve con más detalle la realidad observada.

En nuestro caso, el estudio a priori del cuestionario nos ha permitido ver más allá de unas simples preguntas que pueden ser respondidas bien o mal. Se han convertido en un instrumento didáctico, dotado de unas características propias, que en el desarrollo de la situación podrán ser utilizadas convenientemente para seleccionar las variables didácticas, para modificarlas, para comprender los significados que se van construyendo 
por los estudiantes, etc. y siempre con un propósito, construir y mejorar las condiciones que han de servir para hacer emerger el conocimiento.

La aplicación del cuestionario llevada a cabo con los futuros maestros, nos ha permitido extaer algunas conclusiones respecto al cuestionario como herramienta de diagnóstico de ciertos conocimientos lógicos de los estudiantes. A partir de los resultados obtenidos, podemos decir que los conocimientos representados en el cuestionario Q son adecuados para el nivel de los estudiantes encuestados, que han mostrado dificultades en algunas respuestas. Basándonos en la cantidad de errores cometidos así como en la caracterización de las preguntas que conforman el cuestionario, hay indicios de ciertas dificultades de naturaleza lógica, al menos las que aparecen en el cuestionario (negación de la conjunción, equivalencia entre una implicación y su contrarrecíproca o atribución del valor de verdad). Al mismo tiempo se reconocen ciertos conocimientos lógicos ya adquiridos por los estudiantes, como la conjunción lógica y la regla de inferencia Modus Ponendo Ponens.

En el próximo capítulo se proseguirá con la segunda fase de la experimentación. Esta fase consistirá en la implementación en el aula de una situación a-didáctica, diseñada para la enseñanza de la lógica. Basándonos en los estudios previos llevados a cabo en el capítulo 2, se expondrá con detalle el diseño de la situación, su desarrollo, los resultados obtenidos y las conclusiones derivadas de todo el proceso. 
En este capítulo se prosigue con la Fase II de la experimentación. Para ello se ha elaborado una situación didáctica para la enseñanza de la lógica que ha sido implementada en el aula con un grupo de estudiantes de primer curso de la Titulación de Maestra/o de Educación Primaria de la Universidad Jaume I de Castellón. El desarrollo de esta situación ha girado en torno a la resolución del cuestionario y su corrección colectiva en clase, con el fin de mostrar los razonamientos lógicos (espontáneos y formales) de los estudiantes así como la posibilidad de considerar dicho cuestionario como una situación fundamental para la enseñanza de la lógica a nivel universitario, tal y como hizo Orús con el cuestionario original para Educación Primaria (Orús, 1992).

\subsection{Presentación y análisis a priori de la situación didáctica: la corrección del cuestionario $\mathbf{Q}$}

La fase I de la experimentación nos ha proporcionado la información necesaria para reconocer en el cuestionario Q dos condiciones fundamentales en la elaboración de la situación. Se trata de un cuestionario que los estudiantes han respondido de forma individual y ha permitido entrever las dificultades lógicas asociadas a los resultados obtenidos, tanto por la diversidad de respuestas en algunas de las cuestiones como por la ausencia de respuesta en otras.

Ante la necesidad manifestada por los estudiantes de conocer la solución del cuestionario, se plantea la corrección como una situación adidáctica en la que los estudiantes van a ser sus propios correctores, con el fin de generar la necesidad de comunicar las razones que les conducen a la elección o rechazo de las soluciones propuestas. Los conflictos surgidos a partir de su resolución deberán generar el debate necesario para la validación de las respuestas y a la vez, permitirán observar dichos procesos de validación. Es decir, la ingeniería de esta situación tiene como objetivo la devolución a los alumnos de la validación de las respuestas al cuestionario. 


\subsubsection{Descripción del medio y de la situación}

Para llevar a cabo el proceso de corrección se diferencian cinco fases. Se empieza respondiendo individualmente al cuestionario. Seguidamente, se procede a trabajar por grupos, obteniendo de esta fase una nueva respuesta al cuestionario, validada por el grupo y candidata a ser la respuesta correcta. En tercer lugar, se intercambian las respuestas entre los grupos, dos a dos, de forma que para cada grupo, la información proporcionada por el otro, enriquezca y aporte información, bien para reafirmarse en sus respuestas, bien para modificar alguna de ellas. Y por último, se realiza una puesta en común de todas las respuestas determinadas en la fase anterior, para ser valoradas y validadas, primero por toda la clase y en última instancia, por el profesor.

A continuación se procede con la descripción de cada una de las fases:

\section{Primera fase: Trabajo individual sobre la tabla de datos. Devolución de la situación}

En primer lugar se pide a los estudiantes que respondan a las cuestiones de forma individual. Este trabajo no es la primera vez que lo realizan, dado que el mismo cuestionario ya les fue pasado anteriormente para contrastar sus resultados con el análisis a priori de Q y revelando así su interés didáctico. En aquel momento el cuestionario fue anónimo, por lo que no ha sido posible devolvérselo a los estudiantes para realizar con ellos la corrección. Por otro lado la situación de corrección se debía iniciar con unos resultados "a corregir"; por lo tanto, ha sido necesario recoger otra vez la información correspondiente a las respuestas personales de los miembros de cada uno de los grupos ahora constituidos, para introducirlos en la situación.

La pregunta QN23 del cuestionario ha sido incluida en la situación de corrección. Esta pregunta, introducida en la segunda realización del cuestionario, con los estudiantes de la Universidad de Jaén, tenía como finalidad analizar la influencia de la relación semántica entre las palabras "deporte" y "nadar" que aparecían de forma explícita en el enunciado 
de la pregunta Q20. Al añadir la pregunta QN23, la palabra "deporte" no aparece en el enunciado, teniendo que recurrir a la información proporcionada por la tabla y por la premisa para razonar la respuesta. Dado el bajo porcentaje de respuestas correctas en ambas preguntas, la situación de la corrección colectiva nos permitirá observar los razonamientos de los estudiantes al respecto, permitiéndonos confirmar si se trata de una falacia argumentativa o si se trata de la relación semántica a la que hemos hecho referencia.

La primera fase de la corrección se trata de una situación de acción, porque sólo va a intervenir cada sujeto (estudiante) interactuando con el medio (el cuestionario Q y la tabla T). Las respuestas que cada estudiante dé a las preguntas de $\mathrm{Q}$ vienen determinadas por las decisiones que cada uno de ellos toma de forma autónoma y responsable, haciendo uso únicamente de la información que provenga del medio y por supuesto de sus conocimientos previos. Los estudiantes leen, interpretan, cuentan, comparan filas y columnas, y todo ello debido a motivaciones intrínsecas al sujeto.

Segunda fase: La unanimidad como primer criterio de corrección. (Inicio de la corrección)

Al finalizar la primera fase, comienza el proceso de corrección. Las respuestas correctas no están a disposición de los estudiantes, pero intuyen que tienen la información necesaria en la tabla de datos binarios para obtener la solución. En primer lugar, el criterio de corrección utilizado es la unanimidad. Hemos supuesto que una respuesta unánime es suficiente para convencerse de su validez (a nivel de acción).

Así pues, en esta fase el secretario debe tomar nota únicamente de aquellas respuestas del cuestionario en las que todos los miembros del grupo hayan contestado lo mismo, valorándolas con 1 punto. El secretario, a lo largo de las diferentes fases de la actividad va completando la siguiente plantilla de grupo, en la que queda reflejada la evolución de las respuestas: 


\begin{tabular}{|c|c|c|c|c|c|}
\hline \multicolumn{5}{|c|}{ PLANTILLA DE GRUPO PARA LAS RESPUESTAS } & GRUPO A1 \\
\hline & \begin{tabular}{|l|} 
Respuestas obtenidas \\
en Fase II (por \\
unanimidad en el grupo)
\end{tabular} & \begin{tabular}{|l|}
$\begin{array}{l}\text { Respuestas obtenidas } \\
\text { en Fase III (por consenso } \\
\text { en el grupo) }\end{array}$ \\
\end{tabular} & $\begin{array}{l}\text { Respuestas obtenidas } \\
\text { en Fase } N \text { (después de } \\
\text { reflexionar sobre } \\
\text { respuestas del otro grupo) }\end{array}$ & \begin{tabular}{|l}
$\begin{array}{l}\text { Respuestas obtenidas } \\
\text { en Fase V (tras la correccion } \\
\text { colectiva de todala la clase) }\end{array}$ \\
\end{tabular} & $\begin{array}{l}\begin{array}{l}\text { Puntuación final de cada } \\
\text { respuesta, una vez } \\
\text { conocidas las respuestas } \\
\text { correctas. }\end{array} \\
\end{array}$ \\
\hline \multicolumn{6}{|c|}{ 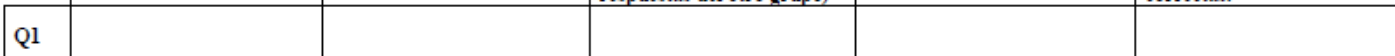 } \\
\hline \multicolumn{6}{|l|}{ Q2 } \\
\hline $\mathrm{Q}^{3}$ & & & & & \\
\hline |... & & & & & \\
\hline
\end{tabular}

Fig. 3.1: Plantilla de grupo para la segunda fase de la corrección del cuestionario $Q$, y siguientes

El profesor, al hacer que se lleve a cabo la comparación, hace al estudiante responsable de sus respuestas puesto que, bajo las mismas condiciones, han sido sus propias decisiones las que les han conducido a responder de determinada forma. De esta forma, el sujeto empieza a ser consciente de ello, recordando las razones que acompañan a la acción.

En esta segunda fase nos encontramos en una situación de formulación debido a la presencia de un interlocutor. Las respuestas procedentes del resto de estudiantes del grupo son los mensajes que modifican el medio, aportando nueva información al sujeto. La unanimidad debe servir como criterio de validación, sin provocar ningún tipo de reflexión sobre ello, sin embargo el hecho de aparecer respuestas distintas para una misma cuestión supone poner en duda su elección.

Estas situaciones de formulación se repiten en las fases siguientes pero, en ellas, evolucionan posteriormente a situaciones de validación.

Tercera fase: Confrontación entre las respuestas dentro del grupo. (Continúa la devolución de la corrección y de formulación-validación de la toma de decisiones)

El objetivo de esta fase es conseguir una respuesta única en aquellas cuestiones que no la habían obtenido anteriormente. Para llevar a cabo la validación, dentro del grupo, cada 
estudiante debe exponer sus respuestas y debatirlas, con el fin de llegar a un acuerdo (si es posible). El recurso didáctico que se ha pensado para que los estudiantes se involucren en la actividad de forma razonada es la puntuación de las respuestas. El secretario debe informar al grupo de que cada respuesta única, obtenida por acuerdo de todos, dará 1 punto al grupo, pero si la respuesta unánime, al finalizar la sesión, resulta estar equivocada, restará 2 puntos. La puntuación negativa debe provocar la reflexión sobre las respuestas dadas y evitar los acuerdos precipitados. Esta fase se considera de suma importancia, porque en ella se espera que los razonamientos de los participantes abandonen el plano de lo subjetivo y, al hacerse explícitos, evolucionen hacia el plano de lo lógico.

El debate que se espera obtener en el desarrollo de esta fase ha sido conservado mediante el uso de grabadoras con el fin de disponer de la máxima información posible.

Las respuestas consensuadas en esta fase son anotadas por el secretario en la plantilla de grupo así como las justificaciones de las respuestas, que se anotan en la siguiente plantilla:

\section{JUSTIFICA LAS RESPUESTAS A LAS PREGUNTAS CONTESTADAS EN LA FASE III}

\section{Grupo B3}

\section{PREGUNTA Q1}

PREGUNTA Q2

Fig. 3.2: Plantilla para la tercera fase de la corrección del cuestionario Q

Las justificaciones recogidas en esta plantilla suponen la primera aproximación a la lógica de sus respuestas. La evolución de las diferentes formas de expresar sus ideas, de comunicar el porqué de las respuestas y de convencer a los demás de la verdad, revela información de vital importancia en la investigación. 
El profesor quiere que los estudiantes decidan, por ellos mismos, la opción correcta. Para ello deben contrastar las razones que les han conducido a elegir cada una de las respuestas y debatirlas. La validación de las respuestas favorece la aparición de reglas.

En esta tercera fase, al igual que en las dos siguientes, los mensajes emitidos en las situaciones de formulación han de ser utilizados para validar las respuestas al cuestionario. En estos casos, las situaciones de validación tienen lugar al hacer públicas las diferentes justificaciones, primero a nivel de grupo y después a nivel de clase, situando a todos los alumnos en igualdad de condiciones en su elección.

Cuarta fase: Intercambio de respuestas entre grupos (Devolución de la corrección y desequilibrio en la toma de decisiones iniciales)

Una vez finalizada la fase anterior, cada grupo cree tener motivos suficientes para aceptar sus respuestas, bien por la unanimidad de la respuesta, bien por los acuerdos tomados en la tercera fase. Para seguir con el proceso de corrección, en esta cuarta fase se modifica el medio aportando información sobre las respuestas acordadas por uno de los otros grupos. Para ello, cada pareja de grupos, elegida al azar por el profesor, intercambia sus respuestas. De esta forma, al incrementar el número de estudiantes representados, puede haber más diversidad de respuestas y, consecuentemente, generar dudas y abrir de nuevo el debate y la reflexión sobre aquello que ya se tenía por correcto. En la siguiente plantilla se deben recoger las justificaciones de las preguntas incorporadas a la plantilla de grupo, en la columna correspondiente a la cuarta fase: 
JUSTIFICA LAS RESPUESTAS A LAS PREGUNTAS CONTESTADAS EN LA FASE IV

\section{Grupo B3}

PREGUNTA Q1

PREGUNTA Q2

Fig. 3.3: Plantilla para la cuarta fase de la corrección del cuestionario Q

De nuevo se sitúa a los estudiantes en una situación de acción. La comparación de las respuestas de ambos grupos abre la posibilidad de hacer reflexionar sobre las decisiones tomadas, tanto para afianzar las reglas como para cuestionarlas de nuevo, dando lugar de nuevo a una situación de validación.

Quinta fase: Debate colectivo entre todos los grupos y resultado final de las respuestas del cuestionario

Una vez completada la plantilla de esta fase, se hacen públicas las respuestas de cada grupo ante toda la clase, abriéndose de nuevo el debate gestionado en este punto por el profesor. En esta fase se espera que las respuestas coincidan en su gran mayoría, excepto en aquellas cuya lectura pueda dar lugar a que los estudiantes recurran a una opinión o interpretación personal. También se espera que haya discrepancias en aquellas preguntas que necesiten el conocimiento lógico para elaborar la respuesta correcta e incluso podría ocurrir que toda la clase coincidiera en su respuesta, a pesar de tratarse de una respuesta incorrecta.

El profesor debe intentar en todo momento no dar él la respuesta correcta sino conducir el debate sobre los errores de los estudiantes hacia el replanteamiento del sentido de la actividad en cuestión. La tabla deberá proporcionar los ostensivos materiales para ello: 
valores de verdad ( 0 y 1 ), formulaciones o verbalizaciones sobre los valores, gestos sobre la tabla mostrando la operación o razonamiento lógico correspondiente, etc.

Una vez finalizado el debate general, cada grupo decide las respuestas definitivas y, tras la exposición de las respuestas correctas por parte del profesor, obtiene la puntuación final.

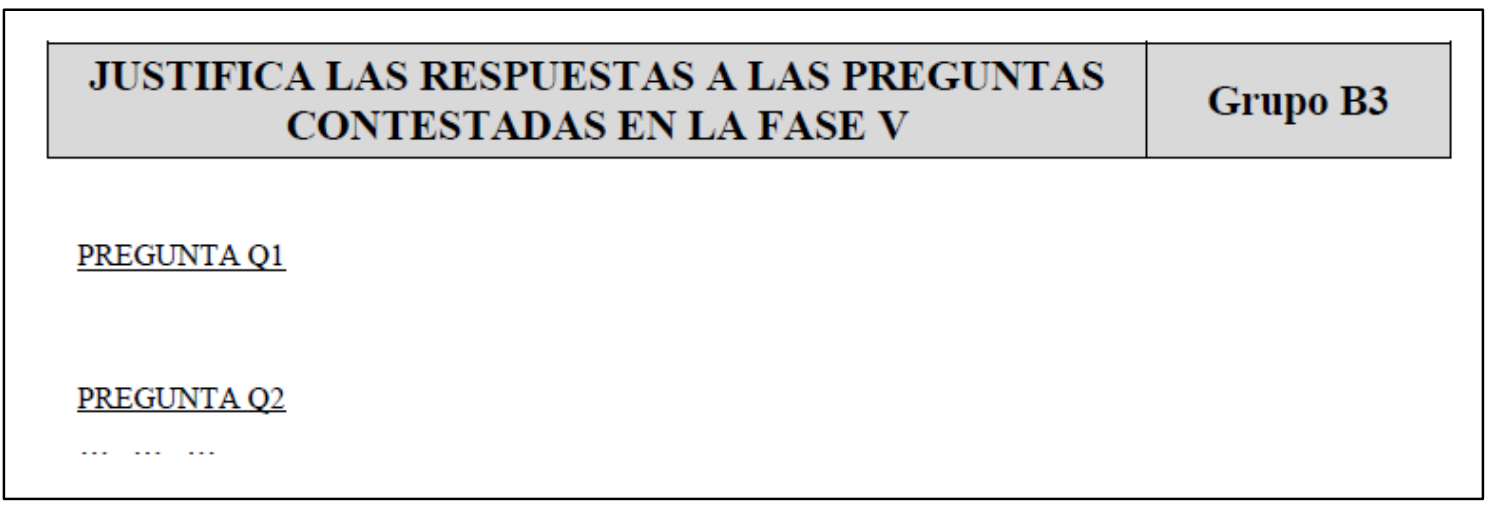

Fig. 3.4: Plantilla para la quinta fase de la corrección del cuestionario $Q$

El profesor quiere que las respuestas de cada grupo sirvan de información para todos los demás, obteniendo por último la respuesta definitiva (situación de validación), que es gestionada en última instancia por el profesor, quien es responsable de que las respuestas sean las adecuadas. En este momento se cambia el contrato didáctico que estaba establecido, pues la gestión de la validación del grupo clase llevada a cabo por el profesor debe ser determinante. La situación adidáctica da paso a la situación didáctica de validación e institucionalización implícita de respuestas correctas en el momento en que el profesor gestiona las respuestas y el grupo clase llega a un consenso sobre las respuestas correctas. Esta fase sirve para reconocer las respuestas correctas de las operaciones lógicas implícitas en cada actividad. No se descarta la posibilidad de que el grupo clase, en esta fase de validación, obtenga por consenso una respuesta no adecuada. En este caso es el profesor quien debe intervenir impidiendo que dichas respuestas incorrectas se 
instituyan pero sin desvelar la solución. Es la situación devuelta por el profesor la que debe permitir que los estudiantes abandonen por sí mismos las ideas equivocadas.

Teniendo en cuenta que el profesor que va a gestionar la situación didáctica no ha intervenido directamente como investigador y con la finalidad de garantizar la devolución de la situación de validación a los estudiantes, se le va a proporcionar junto a la ficha didáctica, una serie actividades que le podrían ayudar a gestionar los errores de los estudiantes (figura 3.6). Las actividades incluidas en este anexo (anexo de la plantilla del profesor), se centran en los errores previstos según los resultados de los cuestionarios ya realizados en la fase de diagnóstico, detallada en el capítulo anterior.

Como ya se indicó en el análisis a priori del cuestionario, la interpretación lógica y conjuntista de la tabla permite identificar cada una de las filas de la tabla como un predicado definido por un criterio, cuyo dominio de definición es el conjunto de estudiantes representados en la tabla, estableciéndose automáticamente dos conjuntos, los estudiantes que verifican el criterio y los que no lo verifican. Y a su vez una columna también es un predicado cuyo dominio de definición es el conjunto de criterios (gustos de los estudiantes) y del mismo modo se establecen dos subconjuntos, los crierios que le gustan a dicho estudiante y los que no le gustan.

A partir de esta interpretación de la tabla $\mathrm{T}$, que relaciona la lógica y la teoría de conjuntos, se abre el camino hacia el trabajo que se pretende llevar a cabo con las diferentes actividades propuestas a los estudiantes. En ese sentido la tabla funcionará como un objeto ostensivo del razonamiento y operaciones lógicas y conjuntistas. Tal y como explican Bosch y Chevallard (Bosch y Chevallard, 1999; Bosch, 2003), un ostensivo es todo aquello manipulable, que gracias a su materialidad permite ser utilizado para hacer referencia a los objetos matemáticos, que por sí solos, no pueden ser observados directamente, manteniendose una dialéctica entre lo ostensivo y lo no ostensivo: 
"Remarquons tout d'abord que, du point de vue sensoriel, l'idée d'ostension renvoie plus spécifiquement à la vue. Mais l'ostensivité dont nous parlons ici se réfère, plus généralement, à l'ensemble des sens, même si, de fait, la vue et l'oüe jouent un rôle privilégié. Signalons en second lieu que, au-delà de leur perceptibilité, ce qui apparaît propre aux objets ostensifs est le fait d'être "manipulables » par le sujet humain: un son peut être émis (et reçu), un graphisme peut être tracé (et lu), un geste peut être fait (et perçu), un objet matériel quelconque peut être manipulé concrètement de diverses manières. Par une extension de son acception commune, nous utiliserons le terme générique de manipulation pour désigner les divers usages possibles, par le sujet humain, des objets ostensifs". (Bosch y Chevallard, 1999, p. 10)

"Los objetos ostensivos son aquellos objetos que se perciben: se ven, se tocan, se oyen, etc. Son, en definitiva, los objetos materiales o los objetos dotados de cierta materialidad como las escrituras, los grafismos, los sonidos, los gestos, etc. Para utilizar una expresión general hablaremos de la "manipulación" de los objetos ostensivos aunque los ostensivos en cuestión sean escrituras, grafismos, gestos o discursos.

Los objetos no-ostensivos son entonces todos aquellos objetos que existen institucionalmente, en el sentido en que se les atribuye una determinada existencia, pero que no se pueden percibir ni mostrar por sí mismos: las ideas, los conceptos, las creencias, etc. Lo que sí se pueden es "invocar" o "evocar" mediante la manipulación de ciertos objetos ostensivos apropiados.

De manera un tanto paradójica, una vez establecida esta dicotomía, se postula la coexistencia permanente de los objetos ostensivos y los objetos no ostensivos dentro de lo que llamamos la dialéctica de lo ostensivo y de lo no-ostensivo: los objetos no ostensivos emergen de la manipulación de los objetos ostensivos pero, al mismo tiempo, dicha manipulación está siempre guiada y controlada por objetos no-ostensivos." (Bosch, 2003, p. 19) 
En nuestra situación de corrección del cuestionario Q la fase de institucionalización permitirá reconocer aquellos conocimientos lógicos explicitados en el análisis a priori, "invocando" los ostensivos que han funcionado en las fases anteriores. De esta manera, la tabla se convierte en un instrumento que permite emerger ciertos conocimientos lógicos, como los citados anteriormente: los diferentes conjuntos de criterios o de estudiantes o sus conjuntos complementarios, definidos por los predicados correspondientes. Dichos conjuntos, a su vez, pueden dar lugar a numerosos conjuntos, resultado de operaciones conjuntistas como la intersección o la unión de conjuntos, al aplicar la conjunción o disyunción de los predicados que los definen.

Junto al soporte físico que supone la tabla de datos, intervienen además todos los gestos del profesor, las expresiones verbales o las representaciones escritas (valores 0 y 1 ) que ayudan a la conceptualización de los conocimientos y que dan sentido a los razonamientos en torno a las operaciones lógicas y conjuntistas implícitas en las actividades de la situación.

A continuación se presenta, en primer lugar, las respuestas correctas del cuestionario, destacando algunos de los ostensivos que van a permitir reconstruir y explicitar los conocimientos lógicos que han funcionado implícitamente en cada una de las preguntas. En segundo lugar se mostrará una propuesta de institucionalización, en la que se incluirán no sólo los conocimientos lógicos a los que nos referimos con las preguntas del cuestionario sino también a algunos de los conocimientos didácticos que pueden ser reconocidos en la actividad. 
CORRECCIÓN DEL CUESTIONARIO HACIENDO USO OSTENSIVO DE LA TABLA DE DATOS BINARIOS

Pregunta Q1: ¿Al estudiante C le gusta salir de noche? [No]

\begin{tabular}{|c|c|c|c|c|c|c|c|c|c|c|c|c|c|c|c|c|c|c|c|c|}
\hline ¿To gosta... & $A$ & B & c & D & $\mathbf{E}$ & $\mathbf{F}$ & G & H & I & $\mathrm{J}$ & $\mathrm{K}$ & L & M & $\mathbf{N}$ & 0 & $\mathbf{P}$ & $Q$ & $\mathbf{R}$ & $\mathrm{s}$ & $\mathrm{T}$ \\
\hline la gras ciodad? (C1) & 1 & 1 & 1 & 0 & 1 & 0 & 1 & 0 & 1 & 0 & 0 & 1 & 1 & 0 & 0 & 1 & 1 & 0 & 1 & 0 \\
\hline $\begin{array}{l}\text { practicar deporte? } \\
\text { (C2) }\end{array}$ & 1 & 0 & 0 & 1 & 0 & 0 & 0 & 1 & 0 & 0 & 0 & 0 & 0 & 0 & 1 & 0 & 0 & 0 & 1 & 0 \\
\hline $\begin{array}{l}\text { dinfrutar la } \\
\text { saturaleza? (C3) }\end{array}$ & 1 & 1 & 0 & 0 & 1 & 1 & 1 & 1 & 0 & 0 & 1 & 1 & 1 & 1 & 1 & 1 & 1 & 1 & 1 & 1 \\
\hline el clima frio? (C4) & 0 & 1 & 0 & 1 & 1 & 0 & 1 & 1 & 0 & 0 & 1 & 1 & 0 & 0 & 1 & 1 & 0 & 0 & 1 & 0 \\
\hline salir de nocke? (CS) & 0 & 0 & 0 & 1 & 0 & 1 & 1 & 1 & 1 & 0 & 1 & 0 & 0 & 1 & 1 & 0 & 1 & 0 & 1 & 0 \\
\hline la plays? (C5) & 1 & 1 & 1 & 1 & 1 & 1 & 1 & 1 & 1 & 1 & 1 & 1 & 1 & 1 & 1 & 1 & 1 & 1 & 1 & 1 \\
\hline el relax? (CT) & 0 & 1 & 0 & 1 & 1 & 0 & 1 & 0 & 0 & 0 & 1 & 1 & 1 & 0 & 0 & 1 & 0 & 0 & 1 & 1 \\
\hline tüitar meseos? (CS) & 1 & 1 & 0 & 0 & 1 & 1 & 1 & 1 & 0 & 0 & 1 & 1 & 1 & 1 & 1 & 1 & 1 & 1 & 1 & 1 \\
\hline la montala? (C9) & 1 & 0 & 0 & 1 & 1 & 0 & 1 & 0 & 0 & 0 & 0 & 0 & 0 & 0 & 0 & 0 & 0 & 0 & 1 & 0 \\
\hline $\begin{array}{l}\text { cosocer otras } \\
\text { calturss? (C10) }\end{array}$ & 1 & 1 & 1 & 0 & 1 & 1 & 1 & 1 & 1 & 1 & 1 & 1 & 1 & 1 & 1 & 1 & 1 & 1 & 1 & 1 \\
\hline $\begin{array}{l}\text { tüitar lagares } \\
\text { bistoricos? C11) }\end{array}$ & 0 & 1 & 0 & 1 & 1 & 0 & 1 & 0 & 1 & 0 & 1 & 1 & 0 & 0 & 0 & 1 & 1 & 0 & 1 & 0 \\
\hline exquiar? (C12) & 0 & 1 & 1 & 1 & 1 & 1 & 1 & 1 & 0 & 0 & 1 & 1 & 1 & 1 & 1 & 1 & 1 & 1 & 1 & 1 \\
\hline $\begin{array}{l}\text { víir aventuras? } \\
\text { (C13) }\end{array}$ & 1 & 0 & 1 & 1 & 0 & 1 & 0 & 1 & 1 & 0 & 1 & 0 & 0 & 1 & 1 & 0 & 1 & 0 & 1 & 1 \\
\hline $\begin{array}{l}\text { el clima calido? } \\
\text { (C14) }\end{array}$ & 1 & 1 & 1 & 0 & 1 & 0 & 1 & 0 & 1 & 0 & 1 & 1 & 1 & 0 & 0 & 1 & 0 & 0 & 1 & 0 \\
\hline $\begin{array}{l}\text { los deportes } \\
\text { acesticos? (C15) }\end{array}$ & 1 & 1 & 1 & 1 & 1 & 0 & 0 & 1 & 0 & 0 & 1 & 1 & 1 & 1 & 1 & 1 & 1 & 0 & 1 & 1 \\
\hline
\end{tabular}

Intersección entre una fila y una columna: $\mathrm{x}_{5,3}=0$

Valor de verdad de una proposición: $\mathrm{E}_{3}\left(\mathrm{C}_{5}\right)=0 ; \mathrm{C}_{5}\left(\mathrm{E}_{3}\right)=0$ 
Q2: ¿A cuántos estudiantes les gusta vivir aventuras? [A 12 estudiantes]

\begin{tabular}{|c|c|c|c|c|c|c|c|c|c|c|c|c|c|c|c|c|c|c|c|c|}
\hline To gata... & A & B & c & D & E & $\mathbf{F}$ & G & H & I & $\mathrm{J}$ & $\mathrm{K}$ & L & M & $\mathrm{N}$ & 0 & $\mathbf{P}$ & Q & $\mathrm{R}$ & $s$ & T \\
\hline la gran ciodad? (C1) & 1 & 1 & 1 & 0 & 1 & 0 & 1 & 0 & 1 & 0 & 0 & & 1 & $\theta$ & 0 & 1 & 1 & 0 & 1 & 0 \\
\hline $\begin{array}{l}\text { practicar deporte? } \\
\text { (C2) }\end{array}$ & 1 & 0 & 0 & 1 & 0 & 0 & 0 & 1 & 0 & 0 & 0 & 0 & 0 & 0 & 1 & 0 & 0 & 0 & 1 & 0 \\
\hline $\begin{array}{l}\text { dinfratar la } \\
\text { saterslesa? (C3) }\end{array}$ & 1 & 1 & 0 & 0 & 1 & 1 & 1 & 1 & 0 & 0 & 1 & 1 & 1 & 1 & 1 & 1 & 1 & 1 & 1 & 1 \\
\hline el chima froo? (C4) & 0 & 1 & 0 & 1 & 1 & 0 & 1 & 1 & 0 & 0 & 1 & 1 & 0 & 0 & 1 & 1 & 0 & 0 & 1 & 0 \\
\hline salir de socke? (CS) & 0 & 0 & 0 & 1 & 0 & 1 & 1 & 1 & 1 & 0 & 1 & 0 & 0 & 1 & 1 & 0 & 1 & 0 & 1 & 0 \\
\hline la playa? (C5) & 1 & 1 & 1 & 1 & 1 & 1 & 1 & 1 & 1 & 1 & 1 & 1 & 1 & 1 & 1 & 1 & 1 & 1 & 1 & 1 \\
\hline el relax? (CT) & 0 & 1 & 0 & 1 & 1 & 0 & 1 & 0 & 0 & 0 & 1 & 1 & 1 & 0 & 0 & 1 & 0 & 0 & 1 & 1 \\
\hline víitar meseos? (CS) & 1 & 1 & 0 & 0 & 1 & 1 & 1 & 1 & 0 & 0 & 1 & 1 & 1 & 1 & 1 & 1 & 1 & 1 & 1 & 1 \\
\hline la montats? (C9) & 1 & 0 & 0 & 1 & 1 & 0 & 1 & 0 & 0 & 0 & 0 & 0 & 0 & 0 & 0 & 0 & 0 & 0 & 1 & 0 \\
\hline & 1 & 1 & 1 & 0 & 1 & 1 & 1 & 1 & 1 & 1 & 1 & 1 & 1 & 1 & 1 & 1 & 1 & 1 & 1 & 1 \\
\hline $\begin{array}{l}\text { véuitar hogares } \\
\text { kixtoricos? C11) }\end{array}$ & 0 & 1 & 0 & 1 & 1 & 0 & 1 & 0 & 1 & 0 & 1 & 1 & 0 & 0 & 0 & 1 & 1 & 0 & 1 & 0 \\
\hline esquiar? (C12) & 0 & 1 & 1 & 1 & 1 & 1 & 1 & 1 & 0 & 0 & 1 & 1 & 1 & 1 & 1 & 1 & 1 & 1 & 1 & 1 \\
\hline $\begin{array}{l}\text { vinir avestarss? } \\
\text { (C13) }\end{array}$ & 1 & 0 & 1 & 1 & 0 & 1 & 0 & 1 & 1 & 0 & 1 & 0 & 0 & 1 & 1 & 0 & 1 & 0 & 1 & 1 \\
\hline $\begin{array}{l}\text { el chima calido? } \\
\text { (C14) }\end{array}$ & 1 & 1 & 1 & 0 & 1 & 0 & 1 & 0 & 1 & 0 & 1 & 1 & 1 & 0 & 0 & 1 & 0 & 0 & 1 & 0 \\
\hline $\begin{array}{l}\text { los deportes } \\
\text { acteaticos? (C15) }\end{array}$ & 1 & 1 & 1 & 1 & 1 & 0 & 0 & 1 & 0 & 0 & 1 & 1 & 1 & 1 & 1 & 1 & 1 & 0 & 1 & 1 \\
\hline
\end{tabular}

Contar el número de valores unitarios de una fila

Card $\left\{\mathrm{E}_{\mathrm{j}} / \mathrm{C}_{13}\left(\mathrm{E}_{\mathrm{i}}\right)=1\right\}_{j=1}^{20}=12$

Cardinal del conjunto de estudiantes que verifican el predicado (criterio) $\mathrm{C}_{13}$ 
Pregunta Q3: ¿Cuántas cosas le gustan al estudiante Q para viajar [10 cosas]

\begin{tabular}{|c|c|c|c|c|c|c|c|c|c|c|c|c|c|c|c|c|c|c|c|c|}
\hline $6 g^{2}$ & $A$ & B & c & D & $\mathbf{E}$ & $\mathbf{F}$ & G & H & I & $\mathrm{J}$ & $\mathbf{K}$ & L & $\mathbf{M}$ & $\mathrm{s}$ & 0 & $\mathbf{P}$ & Q & $\mathbf{R}$ & $s$ & \\
\hline la grane & 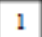 & 1 & 1 & & & 0 & 1 & 0 & & 0 & 0 & & & 0 & 0 & 1 & 1 & 0 & 1 & 0 \\
\hline $\begin{array}{l}\text { practicar d } \\
\text { (C2) }\end{array}$ & 1 & 0 & 0 & 1 & 0 & 0 & 0 & 1 & 0 & 0 & 0 & 0 & 0 & 0 & 1 & 0 & 0 & 0 & 1 & 0 \\
\hline & 1 & 1 & 0 & 0 & 1 & 1 & 1 & 1 & 0 & 0 & 1 & 1 & 1 & 1 & 1 & 1 & 1 & 1 & 1 & 1 \\
\hline el clima fr & 0 & 1 & 0 & 1 & 1 & 0 & 1 & 1 & 0 & 0 & 1 & 1 & 0 & 0 & 1 & 1 & 0 & 0 & 1 & 0 \\
\hline salir de socbe? ( & 0 & 0 & 0 & 1 & 0 & 1 & 1 & 1 & 1 & 0 & 1 & 0 & 0 & 1 & 1 & 0 & 1 & 0 & 1 & 0 \\
\hline la plays? (C & 1 & 1 & 1 & 1 & 1 & 1 & 1 & 1 & 1 & 1 & 1 & 1 & 1 & 1 & 1 & 1 & 1 & 1 & 1 & 1 \\
\hline el relax? (CT) & 0 & 1 & 0 & 1 & 1 & 0 & 1 & 0 & 0 & 0 & 1 & 1 & 1 & 0 & 0 & 1 & 0 & 0 & 1 & 1 \\
\hline víatar meseos? (CS) & 1 & 1 & 0 & 0 & 1 & 1 & 1 & 1 & 0 & 0 & 1 & 1 & 1 & 1 & 1 & 1 & 1 & 1 & 1 & 1 \\
\hline la montata? (C9) & 1 & 0 & 0 & 1 & 1 & 0 & 1 & 0 & 0 & 0 & 0 & 0 & 0 & 0 & 0 & 0 & 0 & 0 & 1 & 0 \\
\hline & 1 & 1 & , & 0 & 1 & 1 & 1 & 1 & 1 & 1 & 1 & , & 1 & 1 & 1 & , & 1 & 1 & 1 & 1 \\
\hline & . & 1 & 0 & 1 & 1 & 0 & 1 & 0 & 1 & 0 & 1 & 1 & 0 & 0 & 0 & 1 & 1 & 0 & 1 & 0 \\
\hline esquiar? (C12) & 0 & 1 & 1 & 1 & 1 & 1 & 1 & 1 & 0 & 0 & 1 & 1 & 1 & 1 & 1 & 1 & 1 & 1 & 1 & 1 \\
\hline & 1 & 0 & 1 & 1 & 0 & 1 & 0 & 1 & 1 & 0 & 1 & 0 & 0 & 1 & 1 & 0 & 1 & 0 & 1 & 1 \\
\hline $\begin{array}{l}\text { el climen calido? } \\
\text { (C14) }\end{array}$ & 1 & 1 & 1 & 0 & 1 & 0 & 1 & 0 & 1 & 0 & 1 & 1 & 1 & 0 & 0 & 1 & 0 & 0 & 1 & 0 \\
\hline $\begin{array}{l}\text { los deportes } \\
\text { actaticos? (C15) }\end{array}$ & 1 & 1 & 1 & 1 & 1 & 0 & 0 & 1 & 0 & 0 & 1 & 1 & 1 & 1 & 1 & 1 & 1 & 0 & 1 & 1 \\
\hline
\end{tabular}

Contar el número de valores unitarios de una columna

Card $\left\{\mathrm{C}_{\mathrm{i}} / \mathrm{E}_{17}\left(\mathrm{C}_{\mathrm{i}}\right)=1\right\}_{\mathrm{i}=1}^{15}=10$

Cardinal del conjunto de estudiantes que verifican el predicado (estudiante) $\mathrm{E}_{17}$

Consideramos suficiente, a nivel de formación de maestros, la institucionalización del ostensivo contar la cantidad de valores iguales a "1" de una fila/columna, la representación del cardinal de un conjunto. 
Pregunta Q4. ¿Hay algo que les guste a todos los estudiantes? En caso afirmativo, indica lo que es. [Sí, la playa]

\begin{tabular}{|c|c|c|c|c|c|c|c|c|c|c|c|c|c|c|c|c|c|c|c|c|}
\hline The go: & $A$ & B & c & D & $\mathbf{E}$ & $F$ & G & $\mathrm{H}$ & $\mathrm{I}$ & $\mathrm{J}$ & $\mathrm{K}$ & L & $\mathrm{MI}$ & $\mathrm{N}$ & 0 & $\mathbf{P}$ & $\mathrm{Q}$ & $\mathrm{R}$ & $s$ & T \\
\hline la gras ciodad? (C-1) & 1 & & & & & 0 & & & & 0 & & & & & 0 & 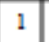 & & 0 & 1 & 0 \\
\hline & 1 & 0 & & & 0 & 0 & 0 & & & 0 & 0 & 0 & 0 & 0 & & 0 & & 0 & 1 & 0 \\
\hline & 1 & 1 & 0 & 0 & 1 & 1 & 1 & 1 & 0 & 0 & 1 & 1 & 1 & 1 & 1 & 1 & 1 & 1 & 1 & 1 \\
\hline el clima fro? (C4) & 0 & , & & & 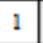 & & & & & 0 & & & & & & & & & 1 & 0 \\
\hline salir do noche? (CS) & 0 & 0 & 0 & 1 & 0 & 1 & ] & & , & 0 & & 0 & 0 & 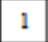 & & 0 & & 0 & 1 & 0 \\
\hline la playa? (C5) & 1 & 1 & 1 & 1 & 1 & 1 & 1 & ] & 1 & 1 & 1 & 1 & 1 & , & 1 & 1 & 1 & 1 & 1 & 1 \\
\hline el relax?" (CT) & 0 & 1 & 0 & 1 & 1 & 0 & 1 & 0 & 0 & 0 & 1 & 1 & 1 & 0 & 0 & 1 & 0 & 0 & 1 & 1 \\
\hline vìitar $n$ & 1 & 1 & 0 & & 1 & 1 & & & & 0 & & & & & & 1 & & 1 & 1 & 1 \\
\hline la monts: & 1 & 0 & 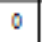 & 1 & 1 & 8 & & & & 0 & & & & & & & & & 1 & 0 \\
\hline & 1 & 1 & 1 & 0 & 1 & 1 & 1 & & 1 & 1 & ר & & 1 & 1 & & 1 & 1 & 1 & 1 & 1 \\
\hline & 0 & 1 & 0 & 1 & 1 & 0 & 1 & 0 & 1 & 0 & 1 & 1 & 0 & 0 & ( & 1 & 1 & 0 & 1 & 0 \\
\hline esquiar? (C & 0 & 1 & 1 & 1 & 1 & 1 & 1 & & 0 & 0 & 2 & 1 & 1 & 2 & 2 & 1 & 2 & 1 & 1 & 1 \\
\hline & 1 & 0 & 1 & 1 & 0 & 1 & 0 & 1 & 1 & 0 & 1 & 0 & 0 & 1 & 1 & 0 & 1 & 0 & 1 & 1 \\
\hline & 1 & 1 & 1 & 0 & 1 & 0 & 1 & 0 & 1 & 0 & 1 & 1 & 1 & 0 & 0 & 1 & 0 & 0 & 1 & 0 \\
\hline & 1 & 1 & 1 & 1 & 1 & 0 & $\theta$ & 1 & 0 & 0 & 1 & 1 & 1 & 1 & 1 & 1 & 1 & 0 & 1 & 1 \\
\hline
\end{tabular}

Buscar una fila formada únicamente por valores unitarios 
Pregunta Q5. ¿Hay algún estudiante a quien le guste todo? En caso afirmativo, indica su nombre. [Sí, al estudiante S]

Pregunta Q6. ¿Hay más estudiantes a quienes les guste todo? En caso afirmativo, indica cuáles. [No los hay]

\begin{tabular}{|l|c|c|c|c|c|c|c|c|c|c|c|c|c|c|c|c|c|c|c|c|}
\hline ¿Te gusta... & $\mathbf{A}$ & $\mathbf{B}$ & $\mathbf{C}$ & $\mathbf{D}$ & $\mathbf{E}$ & $\mathbf{F}$ & $\mathbf{G}$ & $\mathbf{H}$ & $\mathbf{I}$ & $\mathbf{J}$ & $\mathbf{K}$ & $\mathbf{L}$ & $\mathbf{M}$ & $\mathbf{N}$ & $\mathbf{O}$ & $\mathbf{P}$ & $\mathbf{Q}$ & $\mathbf{R}$ & $\mathbf{S}$ & $\mathbf{T}$ \\
\hline la gran ciudad? (C1) & 1 & 1 & 1 & 0 & 1 & 0 & 1 & 0 & 1 & 0 & 0 & 1 & 1 & 0 & 0 & 1 & 1 & 0 & 1 & 0 \\
\hline $\begin{array}{l}\text { practicar deporte? } \\
\text { (C2) }\end{array}$ & 1 & 0 & 0 & 1 & 0 & 0 & 0 & 1 & 0 & 0 & 0 & 0 & 0 & 0 & 1 & 0 & 0 & 0 & 1 & 0 \\
\hline $\begin{array}{l}\text { disfrutar la } \\
\text { naturaleza? (C3) }\end{array}$ & 1 & 1 & 0 & 0 & 1 & 1 & 1 & 1 & 0 & 0 & 1 & 1 & 1 & 1 & 1 & 1 & 1 & 1 & 1 & 1 \\
\hline el clima frío? (C4) & 0 & 1 & 0 & 1 & 1 & 0 & 1 & 1 & 0 & 0 & 1 & 1 & 0 & 0 & 1 & 1 & 0 & 0 & 1 & 0 \\
\hline salir de noche? (C5) & 0 & 0 & 0 & 1 & 0 & 1 & 1 & 1 & 1 & 0 & 1 & 0 & 0 & 1 & 1 & 0 & 1 & 0 & 1 & 0 \\
\hline la playa? (C6) & 1 & 1 & 1 & 1 & 1 & 1 & 1 & 1 & 1 & 1 & 1 & 1 & 1 & 1 & 1 & 1 & 1 & 1 & 1 & 1 \\
\hline el relax? (C7) & 0 & 1 & 0 & 1 & 1 & 0 & 1 & 0 & 0 & 0 & 1 & 1 & 1 & 0 & 0 & 1 & 0 & 0 & 1 & 1 \\
\hline visitar museos? (C8) & 1 & 1 & 0 & 0 & 1 & 1 & 1 & 1 & 0 & 0 & 1 & 1 & 1 & 1 & 1 & 1 & 1 & 1 & 1 & 1 \\
\hline la montaña? (C9) & 1 & 0 & 0 & 1 & 1 & 0 & 1 & 0 & 0 & 0 & 0 & 0 & 0 & 0 & 0 & 0 & 0 & 0 & 1 & 0 \\
\hline $\begin{array}{l}\text { conocer otras } \\
\text { culturas? (C10) }\end{array}$ & 1 & 1 & 1 & 0 & 1 & 1 & 1 & 1 & 1 & 1 & 1 & 1 & 1 & 1 & 1 & 1 & 1 & 1 & 1 & 1 \\
\hline $\begin{array}{l}\text { visitar lugares } \\
\text { históricos? C11) }\end{array}$ & 0 & 1 & 0 & 1 & 1 & 0 & 1 & 0 & 1 & 0 & 1 & 1 & 0 & 0 & 0 & 1 & 1 & 0 & 1 & 0 \\
\hline esquiar? (C12) & 0 & 1 & 1 & 1 & 1 & 1 & 1 & 1 & 0 & 0 & 1 & 1 & 1 & 1 & 1 & 1 & 1 & 1 & 1 & 1 \\
\hline $\begin{array}{l}\text { vivir aventuras? } \\
\text { (C13) }\end{array}$ & 1 & 0 & 1 & 1 & 0 & 1 & 0 & 1 & 1 & 0 & 1 & 0 & 0 & 1 & 1 & 0 & 1 & 0 & 1 & 1 \\
\hline $\begin{array}{l}\text { el clima cálido? } \\
\text { (C14) }\end{array}$ & 1 & 1 & 1 & 0 & 1 & 0 & 1 & 0 & 1 & 0 & 1 & 1 & 1 & 0 & 0 & 1 & 0 & 0 & 1 & 0 \\
\hline $\begin{array}{l}\text { los deportes } \\
\text { acuáticos? (C15) }\end{array}$ & 1 & 1 & 1 & 1 & 1 & 0 & 0 & 1 & 0 & 0 & 1 & 1 & 1 & 1 & 1 & 1 & 1 & 0 & 1 & 1 \\
\hline
\end{tabular}

Buscar una columna formada únicamente por valores unitarios.

Se puede comprobar que no hay más columnas que cumplan esta condición. 
Q7. ¿A cuántos estudiantes no les gustan las grandes ciudades y salir de noche? [A 16 estudiantes]

\begin{tabular}{|c|c|c|c|c|c|c|c|c|c|c|c|c|c|c|c|c|c|c|c|c|}
\hline ¿To gosta... & A & B & c & D & $\mathbf{F}$ & $\mathbf{F}$ & $\mathrm{G}$ & $\mathrm{H}$ & I & $\mathrm{J}$ & $\mathrm{K}$ & L & M & $\mathrm{s}$ & 0 & $\mathbf{P}$ & $Q$ & $\mathrm{R}$ & $s$ & \\
\hline la gras ciodad? (Cl) & 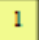 & 1 & & 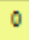 & 1 & 0 & , & 0 & , & 0 & 0 & 1 & 1 & 0 & 0 & 1 & 1 & 0 & 1 & 0 \\
\hline & 1 & 0 & 0 & 1 & 0 & 0 & 0 & 1 & 0 & 0 & 0 & 0 & 0 & 0 & 1 & 0 & 0 & 0 & 1 & \\
\hline $\begin{array}{l}\text { disfrotar la } \\
\text { saturaleza? (C3) }\end{array}$ & 1 & 1 & 0 & 0 & 1 & 1 & 1 & 1 & 0 & 0 & 1 & 1 & 1 & 1 & 1 & 1 & 1 & 1 & 1 & \\
\hline el clima & 0 & 1 & & 1 & & 0 & 1 & 1 & 0 & & 1 & ) & 0 & 0 & & 1 & 0 & & 1 & \\
\hline salir de socke? & 0 & 0 & 0 & 1 & 0 & 1 & 1 & 1 & 1 & 0 & 1 & 0 & 0 & 1 & & 0 & 1 & 0 & 1 & \\
\hline la playx? (C5) & 1 & 1 & 1 & 1 & 1 & 1 & 1 & 1 & 1 & 1 & 1 & 1 & 1 & 1 & 1 & 1 & 1 & 1 & 1 & 1 \\
\hline el relax? (CT) & 0 & 1 & 0 & 1 & 1 & 0 & 1 & 0 & 0 & 0 & 1 & 1 & 1 & 0 & 0 & 1 & 0 & 0 & 1 & 1 \\
\hline vizitar meseos? & 1 & 1 & 0 & 0 & 1 & 1 & 1 & 1 & 0 & 0 & 1 & 2 & 1 & 1 & & 1 & 1 & 1 & 1 & 1 \\
\hline la mostata? (C9) & 1 & 0 & 0 & 1 & 1 & 0 & 1 & 0 & 0 & & 0 & . & 0 & 0 & & 0 & 0 & 0 & 1 & 0 \\
\hline & 1 & 1 & 1 & 0 & 1 & 1 & 1 & 1 & 1 & 1 & 1 & 1 & 1 & 1 & 1 & 1 & 1 & 1 & 1 & 1 \\
\hline $\begin{array}{l}\text { vizitar lagares } \\
\text { bistoricos? C11) }\end{array}$ & 0 & 1 & 0 & 1 & 1 & 0 & 1 & 0 & 1 & 0 & 1 & 1 & 0 & 0 & 0 & 1 & 1 & 0 & 1 & 0 \\
\hline exquiar? (C12) & 0 & 1 & 1 & 1 & 1 & 1 & 1 & 1 & 0 & 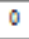 & 1 & 1 & 1 & 1 & & 1 & 1 & 1 & 1 & 1 \\
\hline $\begin{array}{l}\text { vinir avestarss? } \\
\text { (C13) }\end{array}$ & 1 & 0 & 1 & 1 & 0 & 1 & 0 & 1 & 1 & 0 & 1 & 0 & 0 & 1 & 1 & 0 & 1 & 0 & 1 & 1 \\
\hline $\begin{array}{l}\text { el clima calido? } \\
\text { (C14) }\end{array}$ & 1 & 1 & 1 & 0 & 1 & 0 & 1 & 0 & 1 & 0 & 1 & 1 & 1 & 0 & 0 & 1 & 0 & 0 & 1 & 0 \\
\hline $\begin{array}{l}\text { los deportes } \\
\text { acesticos? (C15) }\end{array}$ & 1 & 1 & 1 & 1 & 1 & 0 & 0 & 1 & 0 & 0 & 1 & 1 & 1 & 1 & 1 & 1 & 1 & 0 & 1 & \\
\hline
\end{tabular}

Hay que contar el número de estudiantes que no tienen dos unos a la vez, en los criterios $\mathrm{C}_{1}$ y $\mathrm{C}_{5}$.

Estrategia 1: buscar los unos de la fila correspondiente al criterio «la gran ciudad» y después, sin cambiar de columna, buscar el estudiante correspondiente. Lo mismo para la fila del criterio «salir de noche». Así se obtienen dos conjuntos de estudiantes definidos por dos predicados. Se buscan entonces los estudiantes que tienen en común, es decir la intersección de ambos conjuntos. Se prosigue construyendo el conjunto complementario, que corresponderá a los estudiantes que no pertenecen al conjunto intersección:

$$
\text { Card }\left\{\left\{E_{j} \in E / C_{1}\left(E_{j}\right)=1\right\} \cap\left\{E_{j} \in E / C_{5}\left(E_{j}\right)=1\right\}\right\}^{C}
$$

Estrategia 2: buscar los unos de la fila correspondiente al criterio «la gran ciudad» y después, sin cambiar de columna, comprobar si en la fila del criterio «salir de noche» hay también un valor igual a uno. Al contar el número de casos que verifican esto, tan solo habrá que restar dicho cardinal al número total de estudiantes:

$$
\operatorname{Card}\left\{E_{j} \in E / C_{1}\left(E_{j}\right)=1 \wedge C_{5}\left(E_{j}\right)=1\right\}^{C}=20-4=16
$$


Pregunta Q8. ¿ ¿Todo lo que le gusta al estudiante R le gusta al estudiante J? [No]

\begin{tabular}{|c|c|c|c|c|c|c|c|c|c|c|c|c|c|c|c|c|c|c|c|c|}
\hline ¿To gouta... & $A$ & B & c & D & $\mathbf{E}$ & $\mathbf{F}$ & G & H & I & J & $\mathrm{K}$ & $\mathrm{L}$ & M & $\mathrm{N}$ & 0 & $\mathbf{P}$ & $Q$ & $\mathbf{R}$ & $s$ & $\mathrm{~T}$ \\
\hline la gras ciodad? (C1) & 1 & 1 & 1 & 0 & 1 & 0 & 1 & 0 & 1 & 0 & 0 & 1 & 1 & 0 & 0 & 1 & 1 & 0 & 1 & 0 \\
\hline $\begin{array}{l}\text { practicar deporte? } \\
\text { (C2) }\end{array}$ & 1 & 0 & 0 & 1 & 0 & 0 & 0 & 1 & 0 & 0 & 0 & 0 & 0 & 0 & 1 & 0 & 0 & 0 & 1 & 0 \\
\hline $\begin{array}{l}\text { dinfratar la } \\
\text { saturalezs? (C3) }\end{array}$ & 1 & 1 & 0 & 0 & 1 & 1 & 1 & 1 & 0 & 0 & & & & & & & & 1 & 1 & 1 \\
\hline el clima frio? (C4) & 0 & 1 & 0 & 1 & 1 & 0 & 1 & 1 & 0 & 0 & 1 & 1 & 0 & 0 & 1 & 1 & 0 & 0 & 1 & 0 \\
\hline salir de socke? (CS) & 0 & 0 & 0 & 1 & 0 & 1 & 1 & 1 & 1 & 0 & 1 & 0 & 0 & 1 & 1 & 0 & 1 & 0 & 1 & 0 \\
\hline la plays? (C5) & 1 & 1 & 1 & 1 & 1 & 1 & 1 & 1 & 1 & 1 & 1 & 1 & 1 & 1 & 1 & 1 & 1 & 1 & 1 & 1 \\
\hline el relax? (CT) & 0 & 1 & 0 & 1 & 1 & 0 & 1 & 0 & 0 & 0 & 1 & 1 & 1 & 0 & 0 & 1 & 0 & 0 & 1 & 1 \\
\hline vïitar meseos? (CS) & 1 & 1 & 0 & 0 & 1 & 1 & 1 & 1 & 0 & 0 & 1 & 1 & 1 & 1 & 1 & 1 & 1 & (1) & 1 & 1 \\
\hline la mostata? (C9) & 1 & 0 & 0 & 1 & 1 & 0 & 1 & 0 & 0 & 0 & 0 & 0 & 0 & 0 & 0 & 0 & 0 & $\overline{0}$ & 1 & 0 \\
\hline $\begin{array}{l}\text { cosocer otras } \\
\text { calturas? (C10) }\end{array}$ & 1 & 1 & 1 & 0 & 1 & 1 & 1 & 1 & 1 & 1 & 1 & 1 & 1 & 1 & 1 & 1 & 1 & 1 & 1 & 1 \\
\hline $\begin{array}{l}\text { tizitar logares } \\
\text { historicos? (11) }\end{array}$ & 0 & 1 & 0 & 1 & 1 & 0 & 1 & 0 & 1 & 0 & 1 & 1 & 0 & 0 & 0 & 1 & 1 & 0 & 1 & 0 \\
\hline exquiar? (C12) & 0 & 1 & 1 & 1 & 1 & 1 & 1 & 1 & 0 & 0 & $\Leftrightarrow 2$ & & & & & & 2 & 1) & 1 & 1 \\
\hline $\begin{array}{l}\text { vilir aventuras? } \\
\text { (C13) }\end{array}$ & 1 & 0 & 1 & 1 & 0 & 1 & 0 & 1 & 1 & 0 & 1 & 0 & 0 & 1 & 1 & 0 & 1 & 0 & 1 & 1 \\
\hline $\begin{array}{l}\text { el clima calido? } \\
\text { (C14) }\end{array}$ & 1 & 1 & 1 & 0 & 1 & 0 & 1 & 0 & 1 & 0 & 1 & 1 & 1 & 0 & 0 & 1 & 0 & 0 & 1 & 0 \\
\hline $\begin{array}{l}\text { los deportes } \\
\text { accesticos? (C15) }\end{array}$ & 1 & 1 & 1 & 1 & 1 & 0 & 0 & 1 & 0 & 0 & 1 & 1 & 1 & 1 & 1 & 1 & 1 & 0 & 1 & 1 \\
\hline
\end{tabular}

Estrategia 1: buscar los valores unitarios de la columna correspondiente al estudiante $\mathrm{R}$ y después, sin cambiar de fila, buscar el criterio correspondiente. Lo mismo para la columna del estudiante J. Así se obtienen dos conjuntos de criterios, definidos por dos predicados. Comprobamos que el primer conjunto no es un subconjunto del segundo:

$$
\begin{gathered}
\left\{\mathrm{C}_{\mathrm{i}} \in \mathrm{C} / \mathrm{E}_{18}\left(\mathrm{C}_{\mathrm{i}}\right)=1\right\} \not \subset\left\{\mathrm{C}_{\mathrm{i}} \in \mathrm{C} / \mathrm{E}_{10}\left(\mathrm{C}_{\mathrm{i}}\right)=1\right\} \\
\mathrm{C}_{3} \in\left\{\mathrm{C}_{\mathrm{i}} \in \mathrm{C} / \mathrm{E}_{18}\left(\mathrm{C}_{\mathrm{i}}\right)=1\right\} \text { y } \mathrm{C}_{3} \notin\left\{\mathrm{C}_{\mathrm{i}} \in \mathrm{C} / \mathrm{E}_{10}\left(\mathrm{C}_{\mathrm{i}}\right)=1\right\}
\end{gathered}
$$

Estrategia 2: buscar los valores unitarios de la columna correspondiente al estudiante R y después, sin cambiar de fila, comprobar si el estudiante J también tiene valor igual a uno. Se comprueba que no se verifica para todos los casos, dada la existencia de al menos un contraejemplo

$$
\begin{gathered}
\exists C_{i} \in C \quad E_{18}\left(C_{i}\right)=1 \wedge E_{10}\left(C_{i}\right)=0 \\
\left(E_{18}\left(C_{3}\right)=1 \wedge E_{10}\left(C_{3}\right)=0\right)
\end{gathered}
$$

Aunque en este ejemplo se han señalado sobre la tabla todos los contraejemplos, tan solo sería necesario encontrar uno de ellos para responder negativamente a esta pregunta. La existencia de un contraejemplo es suficiente para negar el cuantificador universal. 
La flecha dibujada sobre la tabla representa el gesto que materializa la no simetría entre el antecedente y el consecuente en la operación condicional.

Pregunta Q9. ¿ ¿Todo lo que le gusta al estudiante J le gusta al estudiante R? [Sí]

\begin{tabular}{|c|c|c|c|c|c|c|c|c|c|c|c|c|c|c|c|c|c|c|c|c|}
\hline ¿To gata... & $A$ & B & $\mathrm{c}$ & D & F & $\mathbf{F}$ & G & H & I & $\mathrm{J}$ & $\mathrm{K}$ & L & M & 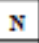 & 0 & $\mathbf{P}$ & $Q$ & $\mathbf{R}$ & $\$$ & $\mathrm{~T}$ \\
\hline la gras ciodad? (C1) & 1 & 1 & 1 & 0 & 1 & 0 & 1 & 0 & 1 & 0 & 0 & 1 & 1 & 0 & 0 & 1 & 1 & 0 & 1 & 0 \\
\hline $\begin{array}{l}\text { practicar deporte? } \\
\text { (C2) }\end{array}$ & 1 & 0 & 0 & 1 & 0 & 0 & 0 & 1 & 0 & 0 & 0 & 0 & 0 & 0 & 1 & 0 & 0 & 0 & 1 & 0 \\
\hline $\begin{array}{l}\text { dinfratar la } \\
\text { satoraleza? (C3) }\end{array}$ & 1 & 1 & 0 & 0 & 1 & 1 & 1 & 1 & 0 & 0 & 1 & 1 & 1 & 1 & 1 & 1 & 1 & 1 & 1 & 1 \\
\hline el clima frio? (C4) & 0 & 1 & 0 & 1 & 1 & 0 & 1 & 1 & 0 & 0 & 1 & 1 & 0 & 0 & 1 & 1 & 0 & 0 & 1 & 0 \\
\hline salir de voche? (CS) & 0 & 0 & 0 & 1 & 0 & 1 & 1 & 1 & 1 & 0 & 1 & 0 & 0 & 1 & 1 & 0 & 1 & 0 & 1 & 0 \\
\hline la plays? (C5) & 1 & 1 & 1 & 1 & 1 & 1 & 1 & 1 & 1 & 1 & $\mathrm{H}$ & 2 & 1 & 2 & 2 & 2 & $2 \geqslant$ & 1) & 1 & 1 \\
\hline el relax? (CT) & 0 & 1 & 0 & 1 & 1 & 0 & 1 & 0 & 0 & 0 & 1 & 1 & 1 & 0 & 0 & 1 & 0 & 0 & 1 & 1 \\
\hline vizitar maseos? (CS) & 1 & 1 & 0 & 0 & 1 & 1 & 1 & 1 & 0 & 0 & 1 & 1 & 1 & 1 & 1 & 1 & 1 & 1 & 1 & 1 \\
\hline la montata? (C9) & 1 & 0 & 0 & 1 & 1 & 0 & 1 & 0 & 0 & 0 & 0 & 0 & 0 & 0 & 0 & 0 & 0 & 0 & 1 & 0 \\
\hline $\begin{array}{l}\text { cosecer otras } \\
\text { celtars? (C10) }\end{array}$ & 1 & 1 & 1 & 0 & 1 & 1 & 1 & 1 & 1 & 1 & 1 & $T$ & 1 & $T$ & $T$ & 1 & $\rightarrow$ & 1) & 1 & 1 \\
\hline $\begin{array}{l}\text { víitar hagares } \\
\text { kistoricos? C11) }\end{array}$ & 0 & 1 & 0 & 1 & 1 & 0 & 1 & 0 & 1 & 0 & 1 & 1 & 0 & 0 & 0 & 1 & 1 & 0 & 1 & 0 \\
\hline exquiar? (C12) & 0 & 1 & 1 & 1 & 1 & 1 & 1 & 1 & 0 & 0 & 1 & 1 & 1 & 1 & 1 & 1 & 1 & 1 & 1 & 1 \\
\hline $\begin{array}{l}\text { víir avesteres? } \\
\text { (C13) }\end{array}$ & 1 & 0 & 1 & 1 & 0 & 1 & 0 & 1 & 1 & 0 & 1 & 0 & 0 & 1 & 1 & 0 & 1 & 0 & 1 & 1 \\
\hline $\begin{array}{l}\text { el clima cabido? } \\
\text { (C14) }\end{array}$ & 1 & 1 & 1 & 0 & 1 & 0 & 1 & 0 & 1 & 0 & 1 & 1 & 1 & 0 & 0 & 1 & 0 & 0 & 1 & 0 \\
\hline $\begin{array}{l}\text { los deportes } \\
\text { acesticos? (C15) }\end{array}$ & 1 & 1 & 1 & 1 & 1 & 0 & 0 & 1 & 0 & 0 & 1 & 1 & 1 & 1 & 1 & 1 & 1 & 0 & 1 & 1 \\
\hline
\end{tabular}

El proceso a seguir sería el mismo que se ha llevado a cabo en la pregunta anterior, pero en sentido contrario, es decir, empezando por la columna correspondiente al estudiante J. En este caso sí se verifica la inclusión de criterios:

Estrategia 1: $\quad\left\{\mathrm{C}_{\mathrm{i}} \in \mathrm{C} / \mathrm{E}_{18}\left(\mathrm{C}_{\mathrm{i}}\right)=1\right\} \subset\left\{\mathrm{C}_{\mathrm{i}} \in \mathrm{C} / \mathrm{E}_{10}\left(\mathrm{C}_{\mathrm{i}}\right)=1\right\}$

Estrategia 2: $\quad \forall \mathrm{C}_{\mathrm{i}} \in \mathrm{C} \quad \mathrm{E}_{18}\left(\mathrm{C}_{\mathrm{i}}\right)=1 \rightarrow \mathrm{E}_{10}\left(\mathrm{C}_{\mathrm{i}}\right)=1$ 
Pregunta Q10. ¿A todos los estudiantes les gusta salir de noche o practicar deporte? [No]

\begin{tabular}{|c|c|c|c|c|c|c|c|c|c|c|c|c|c|c|c|c|c|c|c|c|}
\hline ¿To gous.... & A & B & c & D & E & $\mathbf{F}$ & $\mathrm{G}$ & H & I & $\mathrm{J}$ & $\mathrm{K}$ & L & M & $\mathrm{N}$ & 0 & $\mathbf{P}$ & Q & R & $s$ & \\
\hline la grase ciodad? (C1) & 1 & & & & & 0 & . & & 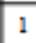 & & & & & 0 & 0 & 1 & 1 & 0 & 1 & 0 \\
\hline & 1 & 0 & & 1 & 0 & 0 & 0 & 1 & 0 & 0 & 0 & 0 & 0 & 0 & 1 & 0 & 0 & 0 & 1 & 0 \\
\hline & 1 & 1 & 0 & 0 & 1 & 1 & 1 & 1 & 0 & 0 & 1 & 1 & 1 & 1 & 1 & 1 & 1 & 1 & 1 & 1 \\
\hline el clima $\mathrm{fr}$ & 0 & 1 & 0 & 1 & 1 & 0 & t & 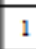 & 0 & 0 & 1 & 1 & 0 & 0 & 1 & 1 & 0 & 0 & 1 & 0 \\
\hline salir de socke? (CS) & 0 & 0 & 0 & 1 & 0 & 1 & 1 & 1 & 1 & 0 & 1 & 0 & 0 & 1 & 1 & 0 & 1 & 0 & 1 & 0 \\
\hline la playa? (C5) & 1 & 1 & 1 & 1 & 1 & 1 & 1 & 1 & 1 & 1 & 1 & 1 & 1 & 1 & 1 & 1 & 1 & 1 & 1 & 1 \\
\hline el relax? (CT) & 0 & 1 & 0 & 1 & 1 & 0 & 1 & 0 & 0 & 0 & 1 & 1 & 1 & 0 & 0 & 1 & 0 & 0 & 1 & 1 \\
\hline vỉitar meseos? (CS) & 1 & 1 & 0 & 0 & 1 & 1 & 1 & 1 & 0 & 0 & 1 & 1 & 1 & 1 & 1 & 1 & 1 & 1 & 1 & 1 \\
\hline la montata? (C9) & 1 & 0 & 0 & 1 & 1 & 0 & 1 & 0 & 0 & 10 & 0 & 0 & 0 & 0 & 0 & 0 & 0 & 0 & 1 & 0 \\
\hline & , & 1 & 1 & 0 & 1 & 1 & 1 & 1 & 1 & 1 & 1 & 1 & 1 & 1 & 1 & 1 & 1 & 1 & 1 & 1 \\
\hline & 0 & 1 & 0 & 1 & 1 & 10 & 1 & 0 & 1 & 0 & 1 & 1 & 0 & 0 & 0 & 1 & 1 & 0 & 1 & 0 \\
\hline esquiar? (C12 & 0 & 1 & 1 & 1 & 1 & 1 & 1 & 1 & 0 & 0 & 1 & 1 & 1 & 1 & 1 & 1 & 1 & 1 & 1 & 1 \\
\hline & 1 & 0 & 1 & 1 & 0 & 1 & 0 & 1 & 1 & 0 & 1 & 0 & 0 & 1 & 1 & 0 & 1 & 0 & 1 & 1 \\
\hline & 1 & 1 & 1 & 0 & 1 & 0 & 1 & 0 & 1 & 0 & 1 & 1 & 1 & 0 & 0 & 1 & 0 & 0 & 1 & 0 \\
\hline & 1 & 1 & 1 & 1 & 1 & 0 & 0 & 1 & 0 & c & 1 & 1 & 1 & 1 & 1 & 1 & 1 & 0 & 1 & 1 \\
\hline
\end{tabular}

Hay que comprobar para todos los estudiantes si en al menos uno de los criterios hay un valor igual a uno o por el contrario, existe algún estudiante que tiene en ambos criterios valores iguales a cero, en cuyo caso se trataría de un contraejemplo que negaría el cuantificador universal. Se ve sobre la tabla, marcado en color rojo, el contraejemplo. 
Pregunta Q11. Los estudiantes $N$ y $R$ ¿tienen el mismo gusto para viajar? [No]

\begin{tabular}{|c|c|c|c|c|c|c|c|c|c|c|c|c|c|c|c|c|c|c|c|c|}
\hline iTo gata... & A & B & c & D & E & $\mathbf{F}$ & $\mathrm{G}$ & H & I & $\mathrm{J}$ & $\mathrm{K}$ & $\mathrm{L}$ & $\mathbf{M}$ & $\mathrm{N}$ & 0 & $\mathbf{P}$ & Q & $\mathbf{R}$ & $s$ & T \\
\hline la gran ciodad? (C1) & 1 & 1 & 1 & 0 & 1 & 0 & 1 & 0 & 1 & 0 & 0 & ] & 1 & 0 & 0 & 1 & 1 & 0 & 1 & 0 \\
\hline $\begin{array}{l}\text { practicar deporte? } \\
\text { (C2) }\end{array}$ & 1 & 0 & 0 & 1 & 0 & 0 & 0 & 1 & 0 & 0 & 0 & 0 & 0 & 0 & 1 & 0 & 0 & 0 & 1 & 0 \\
\hline $\begin{array}{l}\text { dinfretar la } \\
\text { saterslesa? (C3) }\end{array}$ & 1 & 1 & 0 & 0 & 1 & 1 & 1 & 1 & 0 & 0 & 1 & 1 & 1 & 1 & 1 & 1 & 1 & 1 & 1 & 1 \\
\hline el clima frro? (C4) & 0 & 1 & 0 & 1 & 1 & 0 & 1 & 1 & 0 & 0 & 1 & 1 & 0 & 0 & 1 & 1 & 0 & 0 & 1 & 0 \\
\hline salir do socke? (CS) & 0 & 0 & 0 & 1 & 0 & 1 & 1 & 1 & 1 & 0 & 1 & 0 & 0 & 1 & 1 & 0 & 1 & 0 & 1 & 0 \\
\hline la playa? (C5) & 1 & 1 & 1 & 1 & 1 & 1 & 1 & 1 & 1 & 1 & 1 & 1 & 1 & 1 & 1 & 1 & 1 & 1 & 1 & 1 \\
\hline el relax? (CT) & 0 & 1 & 0 & 1 & 1 & 0 & 1 & 0 & 0 & 0 & 1 & 1 & 1 & 0 & 0 & 1 & 0 & 0 & 1 & 1 \\
\hline vizitar mescoss? (CS) & 1 & 1 & 0 & 0 & 1 & 1 & 1 & 1 & 0 & 0 & 1 & 1 & 1 & 1 & 1 & 1 & 1 & 1 & 1 & 1 \\
\hline la mostata? (C9) & 1 & 0 & 0 & 1 & 1 & 0 & 1 & 0 & 0 & 0 & 0 & 0 & 0 & 0 & 0 & 0 & 0 & 0 & 1 & 0 \\
\hline & 1 & 1 & 1 & 0 & 1 & 1 & 1 & 1 & 1 & 1 & 1 & 1 & 1 & 1 & 1 & 1 & 1 & 1 & 1 & 1 \\
\hline & 0 & 1 & 0 & 1 & 1 & 0 & 1 & 0 & 1 & 0 & 1 & 1 & 0 & 0 & 0 & 1 & 1 & 0 & 1 & 0 \\
\hline esquiar? (C12) & 0 & 1 & 1 & 1 & 1 & 1 & 1 & 1 & 0 & 0 & 1 & 1 & 1 & 1 & 1 & 1 & 1 & 1 & 1 & 1 \\
\hline $\begin{array}{l}\text { vinir avesturas? } \\
\text { (C13) }\end{array}$ & 1 & 0 & 1 & 1 & 0 & 1 & 0 & 1 & 1 & 0 & 1 & 0 & 0 & 1 & 1 & 0 & 1 & 0 & 1 & 1 \\
\hline $\begin{array}{l}\text { ol clima calido? } \\
\text { (C14) }\end{array}$ & 1 & 1 & 1 & 0 & 1 & 0 & 1 & 0 & 1 & 0 & 1 & 1 & 1 & 0 & 0 & 1 & 0 & 0 & 1 & 0 \\
\hline $\begin{array}{l}\text { los deportes } \\
\text { aceaticos? (C15) }\end{array}$ & 1 & 1 & 1 & 1 & ] & 0 & 0 & 1 & 0 & 0 & 1 & 1 & 1 & 1 & 1 & 1 & 1 & 0 & 1 & 1 \\
\hline
\end{tabular}

Para responder afirmativamente las columnas correspondientes a los estudiantes $\mathrm{N}$ y $\mathrm{R}$ deben ser iguales. 
Pregunta Q12. ¿A qué pareja crees que es más probable encontrar en un mismo viaje, a $J$ y $R$ o $G$ y $T$ ?.. [A la pareja $J$ y $R$ ]

\begin{tabular}{|c|c|c|c|c|c|c|c|c|c|c|c|c|c|c|c|c|c|c|c|c|}
\hline To gous... & A & B & c & D & E & $\mathbf{F}$ & $\mathrm{G}$ & H & I & $\mathrm{J}$ & $\mathrm{K}$ & $\mathrm{L}$ & $\mathrm{M}$ & $\mathrm{N}$ & 0 & $\mathbf{P}$ & Q & $\mathrm{K}$ & $s$ & $\mathrm{~T}$ \\
\hline la gras ciodad? (C1) & 1 & 1 & 1 & 0 & 1 & 0 & & 0 & 1 & 0 & 0 & 1 & 1 & & 0 & 1 & 1 & 0 & 1 & 0 \\
\hline $\begin{array}{l}\text { practicar deporte? } \\
\text { (C2) }\end{array}$ & 1 & 0 & 0 & 1 & 0 & 0 & 0 & 1 & 0 & 0 & 0 & 0 & 0 & 0 & 1 & 0 & 0 & 0 & 1 & 0 \\
\hline $\begin{array}{l}\text { diffretar la } \\
\text { sateralesa? (C3) }\end{array}$ & 1 & 1 & 0 & 0 & 1 & 1 & 1 & 1 & 0 & 0 & 1 & 1 & 1 & 1 & 1 & 1 & 1 & 1 & 1 & 1 \\
\hline el clima froo? (C4) & 0 & 1 & 0 & 1 & 1 & 0 & 1 & 1 & 0 & 0 & 1 & 1 & 0 & 更 & 1 & 1 & 0 & 0 & 1 & 0 \\
\hline salir de nocke? (CS) & 0 & 0 & 0 & 1 & 0 & 1 & 1 & 1 & 1 & 0 & 1 & 0 & 0 & 1 & 1 & 0 & 1 & 0 & 1 & 0 \\
\hline la playa? (C6) & 1 & 1 & 1 & 1 & 1 & 1 & 1 & 1 & 1 & 1 & 1 & 1 & 1 & 1 & 1 & 1 & 1 & 1 & 1 & 1 \\
\hline el relax? (CT) & 0 & 1 & 0 & 1 & 1 & 0 & 1 & 0 & 0 & 0 & 1 & 1 & 1 & 0 & 0 & 1 & 0 & 0 & 1 & 1 \\
\hline víitar mescos? (CS) & 1 & 1 & 0 & 0 & 1 & 1 & 1 & 1 & 0 & 0 & 1 & 1 & 1 & 1 & 1 & 1 & 1 & 1 & 1 & 1 \\
\hline la mostaks? (C9) & 1 & 0 & 0 & 1 & 1 & 0 & 1 & 0 & 0 & 0 & 0 & 0 & 0 & 0 & 0 & 0 & 0 & 0 & 1 & 0 \\
\hline $\begin{array}{l}\text { cosecer otras } \\
\text { celturss? (C10) }\end{array}$ & 1 & 1 & 1 & 0 & 1 & 1 & 1 & 1 & 1 & 1 & 1 & 1 & 1 & 1 & 1 & 1 & 1 & 1 & 1 & \\
\hline $\begin{array}{l}\text { vizitar logares } \\
\text { vistoricos? (11) }\end{array}$ & 0 & 1 & 0 & 1 & 1 & 0 & 1 & 0 & 1 & 0 & 1 & 1 & 0 & 0 & 0 & 1 & 1 & 0 & 1 & 0 \\
\hline esquiar? (C12) & 0 & 1 & 1 & 1 & 1 & 1 & 1 & 1 & 0 & 0 & 1 & 1 & 1 & 1 & 1 & 1 & 1 & 1 & 1 & 1 \\
\hline $\begin{array}{l}\text { vinir avestarss? } \\
\text { (C13) }\end{array}$ & 1 & 0 & 1 & 1 & 0 & 1 & 0 & 1 & 1 & 0 & 1 & 0 & 0 & 1 & 1 & 0 & 1 & 0 & 1 & 1 \\
\hline $\begin{array}{l}\text { el clima calido? } \\
\text { (C14) }\end{array}$ & 1 & 1 & 1 & 0 & 1 & 0 & 1 & 0 & 1 & 0 & 1 & 1 & 1 & 0 & 0 & 1 & 0 & 0 & 1 & 0 \\
\hline $\begin{array}{l}\text { los deportes } \\
\text { aceatricos? (C15) }\end{array}$ & 1 & 1 & 1 & 1 & 1 & 0 & 0 & 1 & 0 & 0 & 1 & 1 & 1 & 1 & 1 & 1 & 1 & 0 & 1 & 1 \\
\hline
\end{tabular}

La probabilidad se calcula a partir de los valores unitarios de las columnas correspondientes a cada pareja de estudiantes, interviniendo tanto los valores donde coinciden como donde no coinciden. El incremento de valores nulos aumenta la probabilidad de encontrarse en un mismo viaje.

Las cuestiones Q11 y Q12 ponen de manifiesto la validez de la información aportada tanto por los valores iguales a uno como por los valores iguales a cero. 
Pregunta Q13. Si fueras el agente de viajes, ¿qué tres criterios de los que aparecen en la tabla elegirías para proponer un viaje a estos estudiantes? [La playa $\left(C_{6}\right)$, esquiar $\left(C_{10}\right)$ y visitar otras culturas $\left.\left(C_{12}\right)\right]$

\begin{tabular}{|c|c|c|c|c|c|c|c|c|c|c|c|c|c|c|c|c|c|c|c|c|c|}
\hline iTo gonta... & $A$ & B & c & D & F & $\mathbf{F}$ & G & H & I & $\mathrm{J}$ & $\mathrm{K}$ & $\mathrm{L}$ & $\mathbf{M}$ & $\mathrm{N}$ & 0 & $\mathbf{P}$ & Q & $\mathbf{R}$ & $\$$ & $\mathrm{~T}$ & \\
\hline la gran civdad? (C1) & 1 & 1 & 1 & 0 & 1 & 0 & 1 & 0 & 1 & 0 & & 1 & 1 & 0 & 0 & 1 & 1 & 0 & 1 & 0 & 1. \\
\hline $\begin{array}{l}\text { practicar deporte? } \\
\text { (C2) }\end{array}$ & 1 & 0 & 0 & 1 & 0 & 0 & 0 & 1 & 0 & 0 & 0 & 0 & 0 & 0 & 1 & 0 & 0 & 0 & 1 & 0 & $=$ \\
\hline $\begin{array}{l}\text { dinfrotar la } \\
\text { sateraleza? (C3) }\end{array}$ & 1 & 1 & 0 & 0 & 1 & 1 & 1 & 1 & 0 & 0 & 1 & 1 & 1 & 1 & 1 & 1 & 1 & 1 & 1 & 1 & 16 \\
\hline el clina frio? (C4) & 0 & 1 & 0 & 1 & 1 & 0 & 1 & 1 & 0 & 0 & 1 & 1 & 0 & 0 & 1 & 1 & 0 & 0 & 1 & 0 & \\
\hline salir do socke? (CS) & 0 & 0 & 0 & 1 & 0 & 1 & 1 & 1 & 1 & 0 & 1 & 0 & 0 & 1 & 1 & 0 & 1 & 0 & 1 & 0 & 10 \\
\hline la playx? $(C D)$ & 1 & 1 & 1 & 1 & 1 & 1 & 1 & 1 & 1 & 1 & 1 & 1 & 1 & 1 & 1 & 1 & 1 & 1 & 1 & 1 & 20 \\
\hline el relax? (CT) & 0 & 1 & 0 & 1 & 1 & 0 & 1 & 0 & 0 & 0 & 1 & 1 & 1 & 0 & 0 & 1 & 0 & 0 & 1 & 1 & \\
\hline vüitar museos? (CS) & 1 & 1 & 0 & 0 & 1 & 1 & 1 & 1 & 0 & 0 & 1 & 1 & 1 & 1 & 1 & 1 & 1 & 1 & 1 & 1 & 16 \\
\hline la montata? (C9) & 1 & 0 & 0 & 1 & 1 & 0 & 1 & 0 & 0 & 0 & 0 & 0 & 0 & 0 & 0 & 0 & 0 & 0 & 1 & 0 & 5 \\
\hline & 1 & 1 & 1 & 0 & 1 & 1 & 1 & 1 & 1 & 1 & 1 & 1 & 1 & 1 & 1 & 1 & 1 & 1 & 1 & 1 & \\
\hline $\begin{array}{l}\text { vivitar logares } \\
\text { vistoricos? C11) }\end{array}$ & 0 & 1 & 0 & 1 & 1 & 0 & 1 & 0 & 1 & 0 & 1 & 1 & 0 & 0 & 0 & 1 & 1 & 0 & 1 & 0 & 10 \\
\hline esquiar? (C12) & 0 & 1 & 1 & 1 & 1 & 1 & 1 & 1 & 0 & 0 & 1 & 1 & 1 & 1 & 1 & 1 & 1 & 1 & 1 & 1 & 17 \\
\hline $\begin{array}{l}\text { vinir aventurss? } \\
\text { (C13) }\end{array}$ & 1 & 0 & 1 & 1 & 0 & 1 & 0 & 1 & 1 & 0 & 1 & 0 & 0 & 1 & 1 & 0 & 1 & 0 & 1 & 1 & 12 \\
\hline $\begin{array}{l}\text { el clima calido? } \\
\text { (C14) }\end{array}$ & 1 & 1 & 1 & 0 & 1 & 0 & 1 & 0 & 1 & 0 & 1 & 1 & 1 & 0 & 0 & 1 & 0 & 0 & 1 & 0 & 1 \\
\hline $\begin{array}{l}\text { los deportes } \\
\text { acteaticos? (C15) }\end{array}$ & 1 & 1 & 1 & 1 & 1 & 0 & 0 & 1 & 0 & 0 & 1 & 1 & 1 & 1 & 1 & 1 & 1 & 0 & 1 & 1 & \\
\hline
\end{tabular}

Hay que hallar el cardinal de todos los conjuntos de alumnos que definen cada uno de los predicados (criterios) para seleccionar los tres criterios que dan lugar a los tres conjuntos con mayor cardinal. En este caso, $\mathrm{C}_{6}, C_{10} \mathrm{y} \mathrm{C}_{12}$. 
- Di si las siguientes afirmaciones son verdaderas o falsas

Pregunta Q14. Al estudiante que le gusta el frío, le gusta esquiar. [V]

\begin{tabular}{|c|c|c|c|c|c|c|c|c|c|c|c|c|c|c|c|c|c|c|c|c|}
\hline ¿To gosta... & A & B & c & D & $\mathbf{E}$ & $\mathbf{F}$ & $\mathrm{G}$ & $\mathrm{H}$ & I & $\mathrm{J}$ & $\mathrm{K}$ & $\mathrm{L}$ & M & $\mathrm{N}$ & 0 & $\mathrm{P}$ & Q & $\mathrm{K}$ & $s$ & \\
\hline la gran ciodad? (C1) & 1 & 1 & 1 & 0 & 1 & 0 & 1 & 0 & 1 & 0 & 0 & 1 & 1 & 0 & 0 & 1 & 1 & 0 & 1 & 0 \\
\hline $\begin{array}{l}\text { practicar deporte? } \\
\text { (C2) }\end{array}$ & 1 & 0 & 0 & 1 & 0 & 0 & 0 & 1 & 0 & 0 & 0 & 0 & 0 & 0 & 1 & 0 & 0 & 0 & 1 & 0 \\
\hline & 1 & 1 & 0 & 0 & 1 & 1 & 1 & 1 & 0 & 0 & 1 & 1 & 1 & 1 & 1 & 1 & 1 & 1 & 1 & 1 \\
\hline el clima froto? (C4) & c & 1 & 0 & 1 & 1 & 0 & 1 & 1 & 0 & 0 & 1 & (1) & 0 & 0 & $1)$ & 1 & 20 & 0 & 1 & 0 \\
\hline salir do socke? (CS) & 0 & $d$ & 0 & & d & 1 & 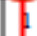 & t & 1 & 0 & & d & 0 & 1 & & d & 1 & 0 & & 0 \\
\hline la playa? (C6) & 1 & & 1 & & 1 & 1 & F & 1 & 1 & 1 & & 1 & 1 & 1 & & 1 & 1 & 1 & & 1 \\
\hline el relax? (CT) & 0 & & 0 & & 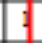 & 0 & & $p$ & 0 & 0 & & & 1 & 0 & & & 0 & 0 & & 1 \\
\hline vïitar mescos? (CS) & 1 & & 0 & & & 1 & & $\mathrm{H}$ & 0 & 0 & & & 1 & 1 & & & 1 & 1 & & 1 \\
\hline la wostata? (C9) & 1 & & 0 & & & 0 & & $p$ & 0 & 10 & & d & 0 & 0 & & d & 0 & 0 & & 0 \\
\hline & 1 & & 1 & & & 1 & & & 1 & 1 & & & 1 & 1 & & & 1 & 1 & & 1 \\
\hline & 0 & $\downarrow$ & 0 & $\downarrow$ & $\downarrow$ & 0 & \pm & $\downarrow$ & 1 & 0 & $\downarrow$ & $\downarrow$ & 0 & 0 & $\downarrow$ & $\downarrow$ & 1 & 0 & $\downarrow$ & 0 \\
\hline esquiar? (C12) & 0 & 1 & 1 & 1 & 1 & 1 & 1 & 1 & 0 & 0 & 1 & $(1$ & 1 & 1 & 1 & 1 & 1 & 1 & 1 & 1 \\
\hline $\begin{array}{l}\text { vinir avestaras? } \\
\text { (C13) }\end{array}$ & 1 & 0 & 1 & 1 & 0 & 1 & 0 & 1 & 1 & 0 & 1 & 0 & 0 & 1 & 1 & 0 & 1 & 0 & 1 & 1 \\
\hline $\begin{array}{l}\text { el clima calido? } \\
\text { (C14) }\end{array}$ & 1 & 1 & 1 & 0 & 1 & 0 & 1 & 0 & 1 & 0 & 1 & 1 & 1 & 0 & 0 & 1 & 0 & 0 & 1 & 0 \\
\hline $\begin{array}{l}\text { los deportess } \\
\text { actedticos? (C15) }\end{array}$ & 1 & 1 & 1 & 1 & 1 & 0 & 0 & 1 & 0 & & 1 & 1 & 1 & 1 & 1 & 1 & 1 & 0 & 1 & 1 \\
\hline
\end{tabular}

Estrategia 1: buscar los valores unitarios de la fila correspondiente al criterio «frío» y después, sin cambiar de columna, buscar el estudiante correspondiente. Lo mismo para la fila del criterio «esquiar». Así se obtienen dos conjuntos de estudiantes, definidos por dos predicados. De esta manera comprobamos que el primer conjunto es un subconjunto del segundo:

$$
\left\{\mathrm{E}_{\mathrm{i}} \in \mathrm{E} / \mathrm{C}_{4}\left(\mathrm{E}_{\mathrm{i}}\right)=1\right\} \subset\left\{\mathrm{E}_{\mathrm{i}} \in \mathrm{E} / \mathrm{C}_{12}\left(\mathrm{E}_{\mathrm{i}}\right)=1\right\}
$$

Estrategia 2: buscar los valores unitarios de la fila correspondiente al criterio «frío» y después, sin cambiar de fila, comprobar si el criterio «esquiar» también tiene valor igual a uno. Se comprueba que sí se verifica para todos los estudiantes:

$$
\forall \mathrm{E}_{\mathrm{i}} \in \mathrm{E} \quad \mathrm{C}_{4}\left(\mathrm{E}_{\mathrm{i}}\right)=1 \rightarrow \mathrm{C}_{12}\left(\mathrm{E}_{\mathrm{i}}\right)=1
$$


Pregunta Q15. A todos los estudiantes que les gusta esquiar les gusta el frío. [F]

\begin{tabular}{|c|c|c|c|c|c|c|c|c|c|c|c|c|c|c|c|c|c|c|c|c|}
\hline $\mathrm{Tog}^{2}$ & 5 & B & C & D & $\mathrm{E}$ & $\mathbf{F}$ & G & H & I & $\mathrm{J}$ & $\mathrm{K}$ & $\mathrm{L}$ & M & $\mathrm{N}$ & 0 & $\mathrm{P}$ & Q & $\mathrm{K}$ & $\mathrm{s}$ & \\
\hline la gras civdad? (Cl) & 1 & 1 & 1 & 0 & 1 & 6 & 1 & 0 & ] & 0 & 0 & 1 & 1 & 0 & 0 & d & 1 & 0 & 1 & 8 \\
\hline $\begin{array}{l}\text { practi } \\
\text { (C22) }\end{array}$ & 1 & 0 & 0 & 1 & 0 & 0 & 0 & 1 & 0 & 0 & 0 & 0 & 0 & 0 & 1 & 0 & 0 & 0 & 1 & 0 \\
\hline & , & 1 & 0 & 0 & 1 & 1 & 1 & 1 & 0 & 0 & 1 & 1 & 1 & 1 & 1 & 1 & 1 & 1 & 1 & 1 \\
\hline ol clima froto? (C4) & 0 & 1 & 0 & & 1 & 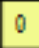 & , & 1 & 0 & 0 & 1 & 1 & . & 0 & 1 & 1 & 0 & 0 & 1 & 0 \\
\hline salir ds ascht? (CS) & 0 & 0 & $\hat{0}$ & 1 & 0 & 1 & 1 & 1 & 1 & 0 & 1 & 0 & 0 & 1 & 1 & 0 & 1 & 0 & 1 & 0 \\
\hline la plays? & 1 & 1 & $\mathrm{~b}$ & r. & 1 & 1 & 1 & 1 & 1 & 1 & 1 & 1 & 1 & 1 & 1 & 1 & 1 & 1 & 1 & 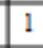 \\
\hline el relar & 0 & 1 & $p$ & 1 & 1 & 0 & 1 & 0 & 0 & 0 & 1 & 1 & 1 & 0 & 0 & 1 & 0 & 0 & 1 & 1 \\
\hline Eess? (CS) & 1 & 1 & $p$ & 0 & 1 & 1 & 1 & 1 & 0 & 0 & 1 & 1 & 1 & 1 & 1 & 1 & 1 & 1 & 1 & 1 \\
\hline la mos & 1 & 0 & 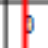 & & 1 & & , & 0 & 0 & 0 & 0 & a & & & & & 0 & 0 & 1 & 10 \\
\hline & 1 & 1 & 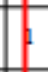 & 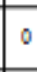 & 1 & 1 & 1 & 1 & 1 & 1 & 1 & 1 & 1 & 1 & 1 & 1 & 1 & 1 & 1 & 1 \\
\hline & 0 & 1 & 1 & 12 & 1 & 0 & 1 & 0 & 1 & 0 & 1 & 1 & 0 & 0 & 0 & 1 & 1 & 0 & 1 & 0 \\
\hline mąriar? (C12) & 0 & 1 & 1 & l & 1 & 1 & & 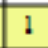 & $\theta$ & 0 & 1 & 1 & 1 & 1 & 1 & 1 & 1 & d & 1 & 1 \\
\hline $\begin{array}{l}\text { vinir avestaras? } \\
\text { (C13) }\end{array}$ & 1 & 0 & 1 & 1 & 0 & 1 & 0 & 1 & 1 & 0 & 1 & 0 & 0 & 1 & 1 & 0 & 1 & 0 & 1 & 1 \\
\hline $\begin{array}{l}\text { sl clims calidis? } \\
\text { (C14) }\end{array}$ & 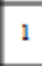 & 1 & 1 & 0 & 1 & 0 & 1 & 0 & 1 & 0 & 1 & 1 & 1 & 0 & 0 & 1 & 0 & 0 & 1 & 0 \\
\hline & , & 2 & 1 & 1 & 1 & & 0 & 1 & 0 & 0 & 1 & 1 & 1 & 1 & 1 & 1 & 1 & 0 & 1 & 1 \\
\hline
\end{tabular}

Se repite el procedimiento de la pregunta Q14. El sentido de la flecha cambia, ya que la pregunta Q15 es la recíproca de la condicional de la pregunta Q14. Esta vez se ha señalado un único contraejemplo, necesario y suficiente para negar el cuantificador universal, aunque se puede ver en la tabla que no es el único. 
Pregunta Q16. Si a un estudiante no le gusta el deporte, entonces no le gustan los deportes acuáticos. [F]

\begin{tabular}{|c|c|c|c|c|c|c|c|c|c|c|c|c|c|c|c|c|c|c|c|c|}
\hline ¿To guta... & $A$ & B & $\mathrm{c}$ & $\mathrm{D}$ & $\mathbf{F}$ & $\mathbf{F}$ & G & H & I & $\mathrm{J}$ & $\mathrm{K}$ & $\mathrm{L}$ & M & $\mathrm{N}$ & 0 & $\mathbf{P}$ & $Q$ & $\mathbf{R}$ & $s$ & $\mathrm{~T}$ \\
\hline la gras ciodad? (Cl) & 1 & 1 & 1 & 0 & 1 & 0 & 1 & 0 & 1 & 0 & 0 & 1 & 1 & 0 & 0 & 1 & 1 & 0 & 1 & 0 \\
\hline $\begin{array}{l}\text { practicar deporte? } \\
\text { (C2) }\end{array}$ & 1 & 0 & 0 & 1 & 0 & 0 & 0 & 1 & 0 & 0 & 0 & 0 & 0 & 0 & 1 & 0 & 0 & 0 & 1 & 0 \\
\hline $\begin{array}{l}\text { disfrotar la } \\
\text { sateralesa? (C3) }\end{array}$ & 1 & 1 & 0 & 0 & 1 & 1 & 1 & 1 & 0 & 0 & 1 & 1 & 1 & 1 & 1 & 1 & 1 & 1 & 1 & 1 \\
\hline el clima frio? (C4) & 0 & 1 & 0 & 1 & 1 & 0 & 1 & 1 & 0 & 0 & 1 & 1 & 0 & 0 & 1 & 1 & 0 & 0 & 1 & 0 \\
\hline salir de socke? (CS) & 0 & d & 0 & 1 & 0 & 1 & 1 & 1 & 1 & 0 & 1 & 0 & 0 & 1 & 1 & 0 & 1 & 0 & 1 & 0 \\
\hline la plays? (C5) & 1 & 1 & 1 & 1 & 1 & 1 & 1 & 1 & 1 & 1 & 1 & 1 & 1 & 1 & 1 & 1 & 1 & 1 & 1 & 1 \\
\hline el relax? (C7) & 0 & 1 & 0 & 1 & 1 & 0 & 1 & 0 & 0 & 0 & 1 & 1 & 1 & 0 & 0 & 1 & 0 & 0 & 1 & 1 \\
\hline vizitar meseos? (CS) & 1 & 1 & 0 & 0 & 1 & 1 & 1 & 1 & 0 & 0 & 1 & 1 & 1 & 1 & 1 & 1 & 1 & 1 & 1 & 1 \\
\hline In mostata? (C9) & 1 & d & 0 & 1 & 1 & 0 & 1 & 0 & 0 & 0 & 0 & 0 & 0 & 0 & 0 & 0 & 0 & 0 & 1 & 0 \\
\hline $\begin{array}{l}\text { conecer otras } \\
\text { calturas? (C10) }\end{array}$ & 1 & 1 & 1 & 0 & 1 & 1 & 1 & 1 & 1 & 1 & 1 & 1 & 1 & 1 & 1 & 1 & 1 & 1 & 1 & 1 \\
\hline $\begin{array}{l}\text { izitar hagares } \\
\text { historicos? (11) }\end{array}$ & 0 & 1 & 0 & 1 & 1 & 0 & 1 & 0 & 1 & 0 & 1 & 1 & 0 & 0 & 0 & 1 & 1 & 0 & 1 & 0 \\
\hline exquiar? (C12) & 0 & ${ }^{\circ}$ & 1 & 1 & 1 & 1 & 1 & 1 & 0 & 0 & 1 & 1 & 1 & 1 & 1 & 1 & 1 & 1 & 1 & 1 \\
\hline $\begin{array}{l}\text { vilir avestarss? } \\
\text { (C13) }\end{array}$ & 1 & d & 1 & 1 & 0 & 1 & 0 & 1 & 1 & 0 & 1 & 0 & 0 & 1 & 1 & 0 & 1 & 0 & 1 & 1 \\
\hline $\begin{array}{l}\text { el clima cabido? } \\
\text { (C14) }\end{array}$ & 1 & a & 1 & 0 & 1 & 0 & 1 & 0 & 1 & 0 & 1 & 1 & 1 & 0 & 0 & 1 & 0 & 0 & 1 & 0 \\
\hline $\begin{array}{l}\text { los deportes } \\
\text { actuticos? (C15) }\end{array}$ & 1 & 1 & 1 & 1 & 1 & 0 & 0 & 1 & 0 & 0 & 1 & 1 & 1 & 1 & 1 & 1 & 1 & 0 & 1 & 1 \\
\hline
\end{tabular}

En primer lugar hay que buscar los valores nulos de la fila correspondiente al criterio $\mathrm{C}_{2}$ y después, sin cambiar de columna, comprobar si el criterio $\mathrm{C}_{15}$ también tiene valor igual a cero.

Los conjuntos complementarios, que se definen a través de la negación de los predicados (no verifican el predicado) tienen su ostensivo en la tabla a través de los valores " 0 " 
Pregunta Q17. Al estudiante E le gusta la playa o la montaña. [V]

\begin{tabular}{|c|c|c|c|c|c|c|c|c|c|c|c|c|c|c|c|c|c|c|c|c|}
\hline ¿To gasta... & $A$ & B & c & D & $\mathbf{E}$ & $\mathbf{F}$ & G & $\mathrm{H}$ & I & $\mathrm{J}$ & $\mathrm{K}$ & L & M & $\mathrm{N}$ & 0 & $\mathbf{P}$ & Q & $\mathrm{R}$ & $s$ & $\mathrm{~T}$ \\
\hline la gras cindad? (C1) & 1 & 1 & 1 & 0 & 1 & 0 & 1 & 0 & 1 & 0 & 0 & 1 & 1 & 0 & 0 & 1 & 1 & 0 & 1 & 0 \\
\hline $\begin{array}{l}\text { practicar deporte? } \\
\text { (C2) }\end{array}$ & 1 & 0 & 0 & 1 & 0 & 0 & 0 & 1 & 0 & 0 & 0 & 0 & 0 & 0 & 1 & 0 & 0 & 0 & 1 & 0 \\
\hline $\begin{array}{l}\text { dinfratar la } \\
\text { sateraleza? (C3) }\end{array}$ & 1 & 1 & 0 & 0 & 1 & 1 & 1 & 1 & 0 & 0 & 1 & 1 & 1 & 1 & 1 & 1 & 1 & 1 & 1 & 1 \\
\hline el clima frio? (C4) & 0 & 1 & 0 & 1 & 1 & 0 & 1 & 1 & 0 & 0 & 1 & 1 & 0 & 0 & 1 & 1 & 0 & 0 & 1 & 0 \\
\hline salir de socke? (CS) & 0 & 0 & 0 & 1 & 0 & 1 & 1 & 1 & 1 & 0 & 1 & 0 & 0 & 1 & 1 & 0 & 1 & 0 & 1 & 0 \\
\hline la plays? (C5) & 1 & 1 & 1 & 1 & 1 & 1 & 1 & 1 & 1 & 1 & 1 & 1 & 1 & 1 & 1 & 1 & 1 & 1 & 1 & 1 \\
\hline el relax? (CT) & 0 & 1 & 0 & 1 & 1 & 0 & 1 & 0 & 0 & 0 & 1 & 1 & 1 & 0 & 0 & 1 & 0 & 0 & 1 & 1 \\
\hline vizitar mueses? (CS) & 1 & 1 & 0 & 0 & 1 & 1 & 1 & 1 & 0 & 0 & 1 & 1 & 1 & 1 & 1 & 1 & 1 & 1 & 1 & 1 \\
\hline la montada? (C9) & 1 & 0 & 0 & 1 & 1 & 0 & 1 & 0 & 0 & 0 & 0 & 0 & 0 & 0 & 0 & 0 & 0 & 0 & 1 & 0 \\
\hline $\begin{array}{l}\text { coesocer otras } \\
\text { caltarss? (C10) }\end{array}$ & 1 & 1 & 1 & 0 & 1 & 1 & 1 & 1 & 1 & 1 & 1 & 1 & 1 & 1 & 1 & 1 & 1 & 1 & 1 & 1 \\
\hline $\begin{array}{l}\text { vizitar hagares } \\
\text { kistoricos? (11) }\end{array}$ & 0 & 1 & 0 & 1 & 1 & 0 & 1 & 0 & 1 & 0 & 1 & 1 & 0 & 0 & 0 & 1 & 1 & 0 & 1 & 0 \\
\hline esquiar? (C12) & 0 & 1 & 1 & 1 & 1 & 1 & 1 & 1 & 0 & 0 & 1 & 1 & 1 & 1 & 1 & 1 & 1 & 1 & 1 & 1 \\
\hline $\begin{array}{l}\text { 1ทำir avestars?? } \\
\text { (C13) }\end{array}$ & 1 & 0 & 1 & 1 & 0 & 1 & 0 & 1 & 1 & 0 & 1 & 0 & 0 & 1 & 1 & 0 & 1 & 0 & 1 & 1 \\
\hline $\begin{array}{l}\text { el clime calido? } \\
\text { (C14) }\end{array}$ & 1 & 1 & 1 & 0 & 1 & 0 & 1 & 0 & 1 & 0 & 1 & 1 & 1 & 0 & 0 & 1 & 0 & 0 & 1 & 0 \\
\hline $\begin{array}{l}\text { los deportes } \\
\text { actuticos? (C15) }\end{array}$ & 1 & 1 & 1 & 1 & 1 & 0 & 0 & 1 & 0 & 0 & 1 & 1 & 1 & 1 & 1 & 1 & 1 & 0 & 1 & 1 \\
\hline sadar? (C16) & & & & & & & & & & & & & & & & & & & & \\
\hline
\end{tabular}

Hay que comprobar si el estudiante $\mathrm{E}$ tiene al menos un valor igual a " 1 " para alguno de los dos criterios, $\mathrm{C}_{6}$ o $\mathrm{C}_{9}$, es decir, si verifica alguno de los dos predicados. Se verifica esta condición, por lo tanto la pregunta Q17 es verdadera. 
Pregunta Q18. Lo que les gusta a los estudiantes $C$ y F le gusta al estudiante L. [F]

\begin{tabular}{|c|c|c|c|c|c|c|c|c|c|c|c|c|c|c|c|c|c|c|c|c|}
\hline To go & & B & c & D & L & $\mathbf{F}$ & $\mathrm{G}$ & H & 1 & $\mathrm{~J}$ & $\mathrm{~K}$ & $\mathrm{~L}$ & $\mathrm{M}$ & $\mathrm{N}$ & 0 & $\mathbf{P}$ & Q & $\mathbf{R}$ & $s$ & \\
\hline la gras ciod & & & 1 & & & & & & & & 0 & & & 1 & 0 & 1 & & & 1 & 0 \\
\hline & 1 & 0 & 0 & 1 & 0 & & 0 & 1 & 0 & 0 & 0 & 0 & 0 & 0 & 1 & 0 & 0 & 0 & 1 & 0 \\
\hline & 1 & 1 & 0 & 0 & 1 & 1 & 1 & 1 & 0 & 0 & 1 & 1 & 1 & 1 & 1 & 1 & 1 & 1 & 1 & 1 \\
\hline el clima fr & 0 & 1 & 0 & 1 & 1 & 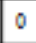 & 1 & 1 & 0 & 0 & 1 & 1 & 0 & & & 1 & 0 & 0 & 1 & 0 \\
\hline salir de socke? (CS) & 0 & 0 & 0 & 1 & 0 & 1 & 1 & 1 & 1 & 0 & 1 & 0 & 0 & 1 & 1 & 0 & 1 & 0 & 1 & 0 \\
\hline la playa? ( & 1 & 1 & 1 & 1 & 1 & 1 & 1 & 1 & 1 & 1 & 1 & 1 & 1 & 1 & 1 & 1 & 1 & 1 & 1 & 1 \\
\hline el relar & 0 & 1 & 0 & 1 & 1 & 0 & 1 & 0 & 0 & 0 & 1 & 1 & 1 & & 0 & 1 & 0 & 0 & 1 & 1 \\
\hline viuitar x & 1 & 1 & 0 & 0 & 1 & 1 & 1 & 1 & 0 & 0 & 1 & 1 & 1 & 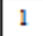 & 1 & 1 & 1 & 1 & 1 & 1 \\
\hline la mosta & 1 & 0 & 0 & 1 & 1 & 10 & 1 & 0 & 0 & 0 & 0 & 0 & 0 & 0 & 0 & 0 & 0 & 0 & 1 & 0 \\
\hline & 1 & 1 & 1 & 0 & 1 & & 1 & 1 & 1 & 1 & 1 & 1 & 1 & 1 & 1 & 1 & 1 & 1 & 1 & 1 \\
\hline & 0 & 1 & 0 & 1 & 1 & 0 & 1 & 0 & 1 & 0 & 1 & 1 & 0 & 0 & 0 & 1 & 1 & 0 & 1 & 0 \\
\hline esquiar? (C) & 0 & 1 & 1 & 1 & 1 & 1 & 1 & 1 & 0 & 0 & 1 & 1 & 1 & 1 & 1 & 1 & 1 & 1 & 1 & 1 \\
\hline $\begin{array}{l}\text { vinir avesturas? } \\
\text { (C13) }\end{array}$ & 1 & 0 & 1 & & & 8 & & & & & & 0 & 0 & 1 & 1 & 0 & 1 & 0 & 1 & 1 \\
\hline $\begin{array}{l}\text { el clima calido? } \\
\text { (C14) }\end{array}$ & 1 & 1 & 1 & 0 & 1 & 0 & 1 & 0 & 1 & 0 & 1 & 1 & 1 & 0 & 0 & 1 & 0 & 0 & 1 & 0 \\
\hline & ] & ) & 1 & 1 & 1 & & 0 & 1 & 0 & 0 & 1 & 1 & 1 & 1 & 1 & 1 & 1 & 0 & 1 & \\
\hline
\end{tabular}

Hay que buscar las parejas de unos en las columnas correspondientes a los estudiantes C y F (conjunción), y después, para cada pareja de valores unitarios y sin cambiar de fila, comprobar si estudiante L también tiene valor igual a uno. El conjunto de criterios definido por la conjunción de predicados «ser gusto del estudiante $\mathrm{C}$ » $\mathrm{y}$ «ser gusto del estudiante $\mathrm{F}$ » no está incluido en el conjunto de criterios definido por el predicado «ser gusto del estudiante L» 
- Si fuera cierta la información sobre el grupo de que "a todos los estudiantes que les gusta practicar deporte les gusta nadar", indica si son verdaderas o falsas las siguientes afirmaciones:

[Las preguntas que vienen a continuación tienen un carácter diferente a las anteriores, ya que introduce nueva información no contenida en la tabla. Antes de proseguir con la resolución de las preguntas, veamos que incorporando una nueva fila de valores, incompleta en este caso, la tabla ha permitido materializar la información proporcionada por la premisa].

\begin{tabular}{|c|c|c|c|c|c|c|c|c|c|c|c|c|c|c|c|c|c|c|c|c|}
\hline ¿To gouta... & $A$ & B & c & D & $\mathbf{E}$ & $\mathbf{F}$ & G & H & I & $\mathrm{J}$ & $\mathrm{K}$ & $\mathrm{L}$ & M & $\mathrm{N}$ & 0 & $\mathbf{P}$ & Q & $\mathrm{R}$ & $s$ & $\mathrm{~T}$ \\
\hline la gras ciodad? (C1) & 1 & 1 & 1 & 0 & 1 & 0 & 1 & 0 & 1 & 0 & 0 & 1 & 1 & 0 & 0 & 1 & 1 & 0 & 1 & 0 \\
\hline $\begin{array}{l}\text { practicar deporte? } \\
\text { (C22) }\end{array}$ & 1 & 0 & 0 & 1 & 0 & 0 & 0 & 1 & 0 & 0 & 0 & 0 & 0 & 0 & 1 & 0 & 0 & 0 & 1 & 0 \\
\hline $\begin{array}{l}\text { dinfrutar la } \\
\text { sateralesa? (C3) }\end{array}$ & 1 & 1 & 0 & 0 & 1 & 1 & 1 & 1 & 0 & 0 & 1 & 1 & 1 & 1 & 1 & 1 & 1 & 1 & 1 & 1 \\
\hline el climen frro? (C4) & 0 & 1 & 0 & 1 & 1 & 0 & 1 & 1 & 0 & 0 & 1 & 1 & 0 & 0 & 1 & 1 & 0 & 0 & 1 & 0 \\
\hline salir de socke? (CS) & 0 & 0 & 0 & 1 & 0 & 1 & 1 & 1 & 1 & 0 & 1 & 0 & 0 & 1 & 1 & 0 & 1 & 0 & 1 & 0 \\
\hline la playa? (C6) & 1 & 1 & 1 & 1 & 1 & 1 & 1 & 1 & 1 & 1 & 1 & 1 & 1 & 1 & 1 & 1 & 1 & 1 & 1 & 1 \\
\hline el relax? (CT) & 0 & 1 & 0 & 1 & 1 & 0 & 1 & 0 & 0 & 0 & 1 & 1 & 1 & 0 & 0 & 1 & 0 & 0 & 1 & 1 \\
\hline ruitar maseos? (CS) & 1 & 1 & 0 & 0 & 1 & 1 & 1 & 1 & 0 & 0 & 1 & 1 & 1 & 1 & 1 & 1 & 1 & 1 & 1 & 1 \\
\hline la montaka? (C9) & 1 & 0 & 0 & 1 & 1 & 0 & 1 & 0 & 0 & 0 & 0 & 0 & 0 & 0 & 0 & 0 & 0 & 0 & 1 & 0 \\
\hline & 1 & 1 & 1 & 0 & 1 & 1 & 1 & 1 & 1 & 1 & 1 & 1 & 1 & 1 & 1 & 1 & 1 & 1 & 1 & 1 \\
\hline $\begin{array}{l}\text { vizitar hogares } \\
\text { kintoricos? C11) }\end{array}$ & 0 & 1 & 0 & 1 & 1 & 0 & 1 & 0 & 1 & 0 & 1 & 1 & 0 & 0 & 0 & 1 & 1 & 0 & 1 & 0 \\
\hline esquiar? (C12) & 0 & 1 & 1 & 1 & 1 & 1 & 1 & 1 & 0 & 0 & 1 & 1 & 1 & 1 & 1 & 1 & 1 & 1 & 1 & 1 \\
\hline $\begin{array}{l}\text { vinir avesturss? } \\
\text { (C13) }\end{array}$ & 1 & 0 & 1 & 1 & 0 & 1 & 0 & 1 & 1 & 0 & 1 & 0 & 0 & 1 & 1 & 0 & 1 & 0 & 1 & 1 \\
\hline $\begin{array}{l}\text { el clima calido? } \\
\text { (C14) }\end{array}$ & 1 & 1 & 1 & 0 & 1 & 0 & 1 & 0 & 1 & 0 & 1 & 1 & 1 & 0 & 0 & 1 & 0 & 0 & 1 & 0 \\
\hline $\begin{array}{l}\text { los deportes } \\
\text { actedticos? (C15) }\end{array}$ & 1 & 1 & 1 & 1 & 1 & 0 & 0 & 1 & 0 & 0 & 1 & 1 & 1 & 1 & 1 & 1 & 1 & 0 & 1 & 1 \\
\hline endar? (C16) & 1 & & & 1 & & & & 1 & & & & & & & 1 & & & & 1 & \\
\hline
\end{tabular}


Pregunta Q19. A todos los del grupo les gusta nadar. [No sé]

\begin{tabular}{|c|c|c|c|c|c|c|c|c|c|c|c|c|c|c|c|c|c|c|c|c|}
\hline ¿To gosta... & $A$ & B & c & D & $\mathbf{E}$ & $\mathbf{F}$ & $\mathrm{G}$ & H & I & $\mathrm{J}$ & $\mathrm{K}$ & $\mathrm{L}$ & $\mathbf{M}$ & $\mathrm{N}$ & 0 & $\mathbf{P}$ & Q & $\mathrm{K}$ & $s$ & $\mathrm{~T}$ \\
\hline la gras ciodad? (C1) & 1 & 1 & 1 & 0 & 1 & 0 & 1 & 0 & 1 & 0 & 0 & 1 & 1 & 0 & 0 & 1 & 1 & 0 & 1 & 0 \\
\hline $\begin{array}{l}\text { practicar deporte? } \\
\text { (C2) }\end{array}$ & 1 & 0 & 0 & 1 & 0 & 0 & 0 & 1 & 0 & 0 & 0 & 0 & 0 & 0 & 1 & 0 & 0 & 0 & 1 & 0 \\
\hline $\begin{array}{l}\text { diffrotar la } \\
\text { saturalesa? (C3) }\end{array}$ & 1 & 1 & 0 & 0 & 1 & 1 & 1 & 1 & 0 & 0 & 1 & 1 & 1 & 1 & 1 & 1 & 1 & 1 & 1 & 1 \\
\hline el climen frib? (C4) & 0 & 1 & 0 & 1 & 1 & 0 & 1 & 1 & 0 & 0 & 1 & 1 & 0 & 0 & 1 & 1 & 0 & 0 & 1 & 0 \\
\hline salir de nocke? (CS) & 0 & 0 & 0 & 1 & 0 & 1 & 1 & 1 & 1 & 0 & 1 & 0 & 0 & 1 & 1 & 0 & 1 & 0 & 1 & 0 \\
\hline la plays? (C5) & 1 & 1 & 1 & 1 & 1 & 1 & 1 & 1 & 1 & 1 & 1 & 1 & 1 & 1 & 1 & 1 & 1 & 1 & 1 & 1 \\
\hline el relax? (CT) & 0 & 1 & 0 & 1 & 1 & 0 & 1 & 0 & 0 & 0 & 1 & 1 & 1 & 0 & 0 & 1 & 0 & 0 & 1 & 1 \\
\hline vüitar moveos? (CS) & 1 & 1 & 0 & 0 & 1 & 1 & 1 & 1 & 0 & 0 & 1 & 1 & 1 & 1 & 1 & 1 & 1 & 1 & 1 & 1 \\
\hline la mostata? (C9) & 1 & 0 & 0 & 1 & 1 & 0 & 1 & 0 & 0 & 0 & 0 & 0 & 0 & 0 & 0 & 0 & 0 & 0 & 1 & 0 \\
\hline $\begin{array}{l}\text { cosocer otras } \\
\text { celteras? (C10) }\end{array}$ & 1 & 1 & 1 & 0 & 1 & 1 & 1 & 1 & 1 & 1 & 1 & 1 & 1 & 1 & 1 & 1 & 1 & 1 & 1 & 1 \\
\hline $\begin{array}{l}\text { ivitar hagres } \\
\text { historicos? (11) }\end{array}$ & 0 & 1 & 0 & 1 & 1 & 0 & 1 & 0 & 1 & 0 & 1 & 1 & 0 & 0 & 0 & 1 & 1 & 0 & 1 & 0 \\
\hline esquiar? (C12) & 0 & 1 & 1 & 1 & 1 & 1 & 1 & 1 & 0 & 0 & 1 & 1 & 1 & 1 & 1 & 1 & 1 & 1 & 1 & 1 \\
\hline $\begin{array}{l}\text { Initir svestaras? } \\
\text { (C13) }\end{array}$ & 1 & 0 & 1 & 1 & 0 & 1 & 0 & 1 & 1 & 0 & 1 & 0 & 0 & 1 & 1 & 0 & 1 & 0 & 1 & 1 \\
\hline $\begin{array}{l}\text { el clima cabido? } \\
\text { (C14) }\end{array}$ & 1 & 1 & 1 & 0 & 1 & 0 & 1 & 0 & 1 & 0 & 1 & 1 & 1 & 0 & 0 & 1 & 0 & 0 & 1 & 0 \\
\hline $\begin{array}{l}\text { Jos deportes } \\
\text { actaticos? (C15) }\end{array}$ & 1 & 1 & 1 & 1 & 1 & 0 & 0 & 1 & 0 & 0 & 1 & 1 & 1 & 1 & 1 & 1 & 1 & 0 & 1 & 1 \\
\hline Eadar? (C16) & 1 & & & 1 & & & & 1 & & & & & & & 1 & & & & 1 & \\
\hline
\end{tabular}

Hay que buscar la fila correspondiente al criterio $\mathrm{C}_{16}$ y comprobar si toda la fila está

formada por unos. En este caso la ausencia de valor o casilla vacía es el ostensivo correspondiente a la imposibilidad de atribuir el valor de verdad. La atribución del valor de verdad de un predicado con cuantificador necesita o ser verificado en todo su dominio de definición o conocer al menos un contraejemplo. En este caso, no hay contraejemplos, pero hay valores desconocidos y por lo tanto no es posible atribuir el valor de verdad. 
Pregunta Q20. Si no les gusta practicar deporte, no les gusta nadar. [No sé]

\begin{tabular}{|c|c|c|c|c|c|c|c|c|c|c|c|c|c|c|c|c|c|c|c|c|}
\hline To gouts. & $A$ & B & c & D & $\mathbf{E}$ & $\mathbf{F}$ & $\mathrm{G}$ & H & I & $\mathrm{J}$ & $\mathrm{K}$ & $\mathrm{L}$ & $\mathbf{M}$ & $\mathrm{N}$ & 0 & $\mathbf{P}$ & Q & $\mathbf{R}$ & $s$ & \\
\hline la gran ciodad? (C1) & 1 & 1 & 1 & 0 & 1 & 0 & 1 & 0 & 1 & 0 & 0 & 1 & 1 & 0 & 0 & 1 & 1 & 0 & 1 & 0 \\
\hline $\begin{array}{l}\text { practicar deporte? } \\
\text { (C2) }\end{array}$ & 1 & 0 & 0 & 1 & 0 & 0 & 0 & 1 & 0 & 0 & 0 & 0 & 0 & 0 & 1 & 0 & 0 & 0 & 1 & 0 \\
\hline $\begin{array}{l}\text { dinfratar la } \\
\text { saturaleza? (C3) }\end{array}$ & 1 & 1 & 0 & 0 & 1 & 1 & 1 & 1 & 0 & 0 & 1 & 1 & 1 & 1 & 1 & 1 & 1 & 1 & 1 & 1 \\
\hline el clima frob? (C4) & 0 & 1 & 0 & 1 & 1 & 0 & 1 & 1 & 0 & 0 & 1 & 1 & 0 & 0 & 1 & 1 & 0 & 0 & 1 & 0 \\
\hline salir de soche? (CS) & 0 & d & 0 & 1 & 0 & 1 & 1 & 1 & 1 & 0 & 1 & 0 & 0 & 1 & 1 & 0 & 1 & 0 & 1 & 0 \\
\hline la playa? (C5) & 1 & 1 & 1 & 1 & 1 & 1 & 1 & 1 & 1 & 1 & 1 & 1 & 1 & 1 & 1 & 1 & 1 & 1 & 1 & 1 \\
\hline el relax? (CT) & 0 & 1 & 0 & 1 & 1 & 0 & 1 & 0 & 0 & 0 & 1 & 1 & 1 & 0 & 0 & 1 & 0 & 0 & 1 & 1 \\
\hline rüitar mescos? (CS) & 1 & 1 & 0 & 0 & 1 & 1 & 1 & 1 & 0 & 0 & 1 & 1 & 1 & 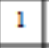 & 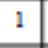 & 1 & 1 & 1 & 1 & 1 \\
\hline la montada? (C9) & 1 & & 0 & 1 & 1 & 0 & 1 & 0 & 0 & 0 & 0 & 0 & . & 0 & . & 0 & 0 & 0 & 1 & 0 \\
\hline $\begin{array}{l}\text { cosecer otras } \\
\text { celterss? (C10) }\end{array}$ & 1 & & 1 & 0 & 1 & 1 & 1 & 1 & 1 & 1 & 1 & 1 & 1 & 1 & 1 & 1 & 1 & 1 & 1 & 1 \\
\hline $\begin{array}{l}\text { viuitar hogares } \\
\text { kixtoricos? C11) }\end{array}$ & 0 & & 0 & 1 & 1 & 0 & 1 & 0 & 1 & 0 & 1 & 1 & 0 & 0 & 0 & 1 & 1 & 0 & 1 & 0 \\
\hline exquiar? (C12) & 0 & & 1 & 1 & 1 & 1 & 1 & 1 & 0 & 0 & 1 & 1 & 1 & 1 & 1 & 1 & 1 & 1 & 1 & 1 \\
\hline $\begin{array}{l}\text { vinir avestarss? } \\
\text { (C13) }\end{array}$ & 1 & & 1 & 1 & 0 & 1 & 0 & 1 & 1 & 0 & 1 & 0 & 0 & 1 & 1 & 0 & 1 & 0 & 1 & 1 \\
\hline $\begin{array}{l}\text { el climen calido? } \\
\text { (C14) }\end{array}$ & 1 & & 1 & 0 & 1 & 0 & 1 & 0 & 1 & 0 & 1 & 1 & 1 & 0 & 0 & 1 & 0 & 0 & 1 & 0 \\
\hline $\begin{array}{l}\text { los deportes } \\
\text { acteaticos? (C15) }\end{array}$ & 1 & & 1 & 1 & 1 & 0 & 0 & 1 & 0 & 0 & 1 & 1 & 1 & 1 & 1 & 1 & 1 & 0 & 1 & 1 \\
\hline sadar? (C16) & 1 & & & 1 & & & & 1 & & & & & & & 1 & & & & 1 & \\
\hline
\end{tabular}

En primer lugar hay que buscar los ceros de la fila correspondiente al criterio $\mathrm{C}_{2} \mathrm{y}$ después, sin cambiar de columna, comprobar si el criterio $\mathrm{C}_{16}$ también tiene valor igual a cero. 
Pregunta Q21. A los estudiantes no les gusta nadar. [F]

\begin{tabular}{|c|c|c|c|c|c|c|c|c|c|c|c|c|c|c|c|c|c|c|c|c|}
\hline ¿To gasta... & $A$ & B & c & D & $\mathbf{E}$ & $\mathbf{F}$ & G & H & I & $\mathrm{J}$ & $\mathrm{K}$ & $\mathrm{L}$ & M & $\mathrm{N}$ & 0 & $\mathbf{P}$ & Q & $\mathrm{K}$ & $s$ & \\
\hline la gras ciodad? (C1) & 1 & 1 & 1 & 0 & 1 & 0 & 1 & 0 & 1 & 0 & 0 & 1 & 1 & 0 & 0 & 1 & 1 & 0 & 1 & 0 \\
\hline $\begin{array}{l}\text { practicar deporte? } \\
\text { (C2) }\end{array}$ & 1 & 0 & 0 & 1 & 0 & 0 & 0 & 1 & 0 & 0 & 0 & 0 & 0 & 0 & 1 & 0 & 0 & 0 & 1 & 0 \\
\hline $\begin{array}{l}\text { dinfratar la } \\
\text { saterslesa? (C3) }\end{array}$ & 1 & 1 & 0 & 0 & 1 & 1 & 1 & 1 & 0 & 0 & 1 & 1 & 1 & 1 & 1 & 1 & 1 & 1 & 1 & 1 \\
\hline el clima frio? (C4) & 0 & 1 & 0 & 1 & 1 & 0 & 1 & 1 & 0 & 0 & 1 & 1 & 0 & 0 & 1 & 1 & 0 & 0 & 1 & 0 \\
\hline salir de socke? (CS) & 0 & 0 & 0 & 1 & 0 & 1 & 1 & 1 & 1 & 0 & 1 & 0 & 0 & 1 & 1 & 0 & 1 & 0 & 1 & 0 \\
\hline la plays? (C6) & 1 & 1 & 1 & 1 & 1 & 1 & 1 & 1 & 1 & 1 & 1 & 1 & 1 & 1 & 1 & 1 & 1 & 1 & 1 & 1 \\
\hline el relax? (CT) & 0 & 1 & 0 & 1 & 1 & 0 & 1 & 0 & 0 & 0 & 1 & 1 & 1 & 0 & 0 & 1 & 0 & 0 & 1 & 1 \\
\hline viuitar wz:eos? (CS) & 1 & 1 & 0 & 0 & 1 & 1 & 1 & 1 & 0 & 0 & 1 & 1 & 1 & 1 & 1 & 1 & 1 & 1 & 1 & 1 \\
\hline La mostata? (C9) & 1 & 0 & 0 & 1 & 1 & 0 & 1 & 0 & 0 & 0 & 0 & 0 & 0 & 0 & 0 & 0 & 0 & 0 & 1 & 0 \\
\hline $\begin{array}{l}\text { cosecter otras } \\
\text { calturas? (C10) }\end{array}$ & 1 & 1 & 1 & 0 & 1 & 1 & 1 & 1 & 1 & 1 & 1 & 1 & 1 & 1 & 1 & 1 & 1 & 1 & 1 & 1 \\
\hline $\begin{array}{l}\text { izictar hygares } \\
\text { hivtoricos? C11) }\end{array}$ & 0 & 1 & 0 & 1 & 1 & 0 & 1 & 0 & 1 & 0 & 1 & 1 & 0 & 0 & 0 & 1 & 1 & 0 & 1 & 0 \\
\hline esquiar? (C12) & 0 & 1 & 1 & 1 & 1 & 1 & 1 & 1 & 0 & 0 & 1 & 1 & 1 & 1 & 1 & 1 & 1 & 1 & 1 & 1 \\
\hline \begin{tabular}{|l|} 
livirir avesturas? \\
(C13)
\end{tabular} & 1 & 0 & 1 & 1 & 0 & 1 & 0 & 1 & 1 & 0 & 1 & 0 & 0 & 1 & 1 & 0 & 1 & 0 & 1 & 1 \\
\hline $\begin{array}{l}\text { el clima calido? } \\
\text { (C14) }\end{array}$ & 1 & 1 & 1 & 0 & 1 & 0 & 1 & 0 & 1 & 0 & 1 & 1 & 1 & 0 & 0 & 1 & 0 & 0 & 1 & 0 \\
\hline $\begin{array}{l}\text { los deportes } \\
\text { acesticos? (C15) }\end{array}$ & 1 & 1 & 1 & 1 & 1 & 0 & 0 & 1 & 0 & 0 & 1 & 1 & 1 & 1 & 1 & 1 & 1 & 0 & 1 & 1 \\
\hline sadar? (C16) & 1 & & & 1 & & & & 1 & & & & & & & 1 & & & & 1 & \\
\hline
\end{tabular}

Los valores que aparecen en la fila correspondiente al criterio $\mathrm{C}_{16}$ nos permiten identificar algunos de los estudiantes que verifican el predicado «tener el gusto nadar» pero las celdas vacías dejan sin determinar si el resto de estudiantes lo verifican o no.

Hay que buscar la fila correspondiente al criterio $\mathrm{C}_{16}$ para comprobar si toda la fila está formada únicamente por ceros, lo que no se verifica por existir un contraejemplo (hay cinco contraejemplos). 
Pregunta Q22. Al estudiante H no le gusta nadar. [F]

\begin{tabular}{|c|c|c|c|c|c|c|c|c|c|c|c|c|c|c|c|c|c|c|c|c|}
\hline ¿To gosta... & A & B & c & D & $\mathbf{F}$ & $\mathbf{F}$ & G & $\mathrm{H}$ & $\mathrm{I}$ & $\mathrm{J}$ & $\mathrm{K}$ & $\mathrm{L}$ & $\mathrm{M}$ & $\mathrm{N}$ & 0 & $\mathbf{P}$ & Q & $\mathbf{R}$ & $s$ & \\
\hline la gras ciodad? (C1) & 1 & 1 & 1 & 0 & 1 & 0 & 1 & 0 & 1 & 0 & 0 & 1 & 1 & 0 & 0 & 1 & 1 & 0 & 1 & 0 \\
\hline $\begin{array}{l}\text { practicar deporte? } \\
\text { (C2) }\end{array}$ & 1 & 0 & 0 & 1 & 0 & 0 & 0 & 1 & 0 & 0 & 0 & 0 & 0 & 0 & 1 & 0 & 0 & 0 & 1 & 0 \\
\hline $\begin{array}{l}\text { diffratar la } \\
\text { saturslesz? (C3) }\end{array}$ & 1 & 1 & 0 & 0 & 1 & 1 & 1 & & 0 & 0 & 1 & 1 & 1 & 1 & 1 & 1 & 1 & 1 & 1 & 1 \\
\hline el clima frro? (C4) & 0 & 1 & 0 & 1 & 1 & 0 & 1 & & 0 & 0 & 1 & 1 & 0 & 0 & 1 & 1 & 0 & 0 & 1 & 0 \\
\hline selir de socke? (CS) & 0 & 0 & 0 & 1 & 0 & 1 & 1 & & 1 & 0 & 1 & 0 & 0 & 1 & 1 & 0 & 1 & 0 & 1 & 0 \\
\hline la plays? (C6) & 1 & 1 & 1 & 1 & 1 & 1 & 1 & & 1 & 1 & 1 & 1 & 1 & 1 & 1 & 1 & 1 & 1 & 1 & 1 \\
\hline el relax? (CT) & 0 & 1 & 0 & 1 & 1 & 0 & 1 & & 0 & 0 & 1 & 1 & 1 & 0 & 0 & 1 & 0 & 0 & 1 & 1 \\
\hline vüitar museos? (CS) & 1 & 1 & 0 & 0 & 1 & 1 & 1 & & 0 & 0 & 1 & 1 & 1 & 1 & 1 & 1 & 1 & 1 & 1 & 1 \\
\hline la moutata? (C9) & 1 & 0 & 0 & 1 & 1 & 0 & 1 & & 0 & 0 & 0 & 0 & 0 & 0 & 0 & 0 & 0 & 0 & 1 & 0 \\
\hline $\begin{array}{l}\text { cossocer otras } \\
\text { calturss? (C10) }\end{array}$ & 1 & 1 & 1 & 0 & 1 & 1 & 1 & & 1 & 1 & 1 & 1 & 1 & 1 & 1 & 1 & 1 & 1 & 1 & 1 \\
\hline $\begin{array}{l}\text { vétarer logares } \\
\text { kixtoricos? C11) }\end{array}$ & 0 & 1 & 0 & 1 & 1 & 0 & 1 & & 1 & 0 & 1 & 1 & 0 & 0 & 0 & 1 & 1 & 0 & 1 & 0 \\
\hline esquiar? (C12) & 0 & 1 & 1 & 1 & 1 & 1 & 1 & & 0 & 0 & 1 & 1 & 1 & 1 & 1 & 1 & 1 & 1 & 1 & 1 \\
\hline $\begin{array}{l}\text { vinir avestaras? } \\
\text { (C13) }\end{array}$ & 1 & 0 & 1 & 1 & 0 & 1 & 0 & & 1 & 0 & 1 & 0 & 0 & 1 & 1 & 0 & 1 & 0 & 1 & 1 \\
\hline $\begin{array}{l}\text { el clima calido? } \\
\text { (C14) }\end{array}$ & 1 & 1 & 1 & 0 & 1 & 0 & 1 & $p$ & 1 & 0 & 1 & 1 & 1 & 0 & 0 & 1 & 0 & 0 & 1 & 0 \\
\hline $\begin{array}{l}\text { los deportes } \\
\text { acteaticos? (C15) }\end{array}$ & 1 & 1 & 1 & 1 & 1 & 0 & 0 & 5 & 0 & 0 & 1 & 1 & 1 & 1 & 1 & 1 & 1 & 0 & 1 & 1 \\
\hline sadar? (C16) & 1 & & & 1 & & & & $1)$ & & & & & & & 1 & & & & 1 & \\
\hline
\end{tabular}

Se busca la columna correspondiente al estudiante $\mathrm{H}$ y se baja hasta encontrar el valor correspondiente al criterio $\mathrm{C}_{16}$. 
Pregunta QN23. Al estudiante F le gusta nadar. [No sé]

\begin{tabular}{|c|c|c|c|c|c|c|c|c|c|c|c|c|c|c|c|c|c|c|c|c|}
\hline To gosta... & A & B & c & D & E & $\mathbf{F}$ & $\mathrm{G}$ & H & I & $\mathrm{J}$ & $\mathrm{K}$ & L & $\mathbf{M}$ & $\mathrm{N}$ & 0 & $\mathbf{P}$ & Q & $\mathbf{R}$ & $s$ & $\mathrm{~T}$ \\
\hline la gran ciodad? (C1) & 1 & 1 & 1 & 0 & 1 & 0 & 1 & 0 & 1 & 0 & 0 & ] & 1 & 0 & 0 & 1 & 1 & 0 & 1 & 0 \\
\hline $\begin{array}{l}\text { practicar deporte? } \\
(\mathrm{C} 2)\end{array}$ & 1 & 0 & 0 & 1 & 0 & 0 & 0 & 1 & 0 & 0 & 0 & 0 & 0 & 0 & 1 & 0 & 0 & 0 & 1 & 0 \\
\hline $\begin{array}{l}\text { dinfrutar la } \\
\text { sateraleza? (C3) }\end{array}$ & 1 & 1 & 0 & 0 & 1 & 1 & 1 & 1 & 0 & 0 & 1 & 1 & 1 & 1 & 1 & 1 & 1 & 1 & 1 & 1 \\
\hline el clima fro? (C4) & 0 & 1 & 0 & 1 & 1 & 0 & 1 & 1 & 0 & 0 & 1 & 1 & 0 & 0 & 1 & 1 & 0 & 0 & 1 & 0 \\
\hline salir de socke? (CS) & 0 & 0 & 0 & 1 & 0 & 1 & 1 & 1 & 1 & 0 & 1 & 0 & 0 & 1 & 1 & 0 & 1 & 0 & 1 & 0 \\
\hline Ia plays? (C5) & 1 & 1 & 1 & 1 & 1 & 1 & 1 & 1 & 1 & 1 & 1 & 1 & 1 & 1 & 1 & 1 & 1 & 1 & 1 & 1 \\
\hline el relax? (CT) & 0 & 1 & 0 & 1 & 1 & 0 & 1 & 0 & 0 & 0 & 1 & 1 & 1 & 0 & 0 & 1 & 0 & 0 & 1 & 1 \\
\hline víutar meseos? (CS) & 1 & 1 & 0 & 0 & 1 & 1 & 1 & 1 & 0 & 0 & 1 & 1 & 1 & 1 & 1 & 1 & 1 & 1 & 1 & 1 \\
\hline la mostata? (C9) & 1 & 0 & 0 & 1 & 1 & 0 & 1 & 0 & 0 & 0 & 0 & 0 & 0 & 0 & 0 & 0 & 0 & 0 & 1 & 0 \\
\hline $\begin{array}{l}\text { cosecter otras } \\
\text { Calturas? (C10) }\end{array}$ & 1 & 1 & 1 & 0 & 1 & 1 & 1 & 1 & 1 & 1 & 1 & 1 & 1 & 1 & 1 & 1 & 1 & 1 & 1 & 1 \\
\hline $\begin{array}{l}\text { vizitar logares } \\
\text { bixtoricos? C11) }\end{array}$ & 0 & 1 & 0 & 1 & 1 & 0 & 1 & 0 & 1 & 0 & 1 & 1 & 0 & 0 & 0 & 1 & 1 & 0 & 1 & 0 \\
\hline esquiar? (C12) & 0 & 1 & 1 & 1 & 1 & 1 & 1 & 1 & 0 & 0 & 1 & 1 & 1 & 1 & 1 & 1 & 1 & 1 & 1 & 1 \\
\hline $\begin{array}{l}\text { vinir aveaturss? } \\
\text { (C13) }\end{array}$ & 1 & 0 & 1 & 1 & 0 & 1 & 0 & 1 & 1 & 0 & 1 & 0 & 0 & 1 & 1 & 0 & 1 & 0 & 1 & 1 \\
\hline $\begin{array}{l}\text { el chines calido? } \\
\text { (C14) }\end{array}$ & 1 & 1 & 1 & 0 & 1 & 0 & 1 & 0 & 1 & 0 & 1 & 1 & 1 & 0 & 0 & 1 & 0 & 0 & 1 & 0 \\
\hline $\begin{array}{l}\text { los deportes } \\
\text { aceaticos? (C15) }\end{array}$ & 1 & 1 & 1 & 1 & 1 & 0 & 0 & 1 & 0 & 0 & 1 & 1 & 1 & 1 & 1 & 1 & 1 & 0 & 1 & 1 \\
\hline sadar? (C16) & 1 & & & 1 & & & & 1 & & & & & & & 1 & & & & 1 & \\
\hline
\end{tabular}

Se busca la columna correspondiente al estudiante $\mathrm{F}$ y se baja hasta encontrar el valor correspondiente al criterio $\mathrm{C}_{16}$. Al no existir información al respecto [casilla vacía] no se puede concluir sobre la verdad o falsedad de la proposición. 
Pregunta Q23. Si no les gusta nadar, no les gusta practicar deporte. [V]

\begin{tabular}{|c|c|c|c|c|c|c|c|c|c|c|c|c|c|c|c|c|c|c|c|c|}
\hline ¿To gasta... & A & B & $\mathrm{c}$ & D & $\mathbf{E}$ & $\mathbf{F}$ & G & H & I & $\mathrm{J}$ & $\mathrm{K}$ & L & $\mathbf{M}$ & $\mathrm{s}$ & 0 & $\mathbf{P}$ & Q & $\mathbf{R}$ & $s$ & T \\
\hline la gran ciodad? (Cl) & 1 & 1 & 1 & 0 & 1 & 0 & 1 & 0 & 1 & 0 & 0 & 1 & 1 & 0 & 0 & 1 & 1 & 0 & 1 & 0 \\
\hline $\begin{array}{l}\text { practicar deporte? } \\
\text { (C2) }\end{array}$ & & p & 0 & 1 & 0 & 0 & 0 & (1) & 0 & 0 & 0 & 0 & 0 & 0 & 1 & 0 & 0 & $\circ$ & (1) & 0 \\
\hline $\begin{array}{l}\text { dinfrutar la } \\
\text { sateraleza? (C3) }\end{array}$ & & it & 0 & 0 & 1 & 1 & 1 & & 0 & 0 & 1 & 1 & 1 & 1 & & 1 & 1 & 1 & & 1 \\
\hline el clima frro? (C4) & & i & 0 & 1 & 1 & 0 & 1 & & 0 & 0 & 1 & 1 & 0 & 0 & & 1 & 0 & 0 & & 0 \\
\hline salir de socke? (CS) & 8 & $\phi$ & 0 & 1 & 0 & 1 & 1 & & 1 & 0 & 1 & 0 & 0 & 1 & & 0 & 1 & 0 & & 0 \\
\hline la playn? (C6) & & 1 & 1 & 1 & 1 & 1 & 1 & & 1 & 1 & 1 & 1 & 1 & 1 & & 1 & 1 & 1 & 1 & 1 \\
\hline el relax? (CT) & $p$ & 1 & 0 & 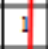 & 1 & 0 & 1 & 9 & 0 & 0 & 1 & 1 & 1 & 0 & & 1 & 0 & 0 & 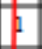 & 1 \\
\hline vizitar meseos? (CS) & & 1 & 0 & d & 1 & 1 & 1 & & 0 & 0 & 1 & 1 & 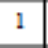 & 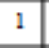 & & 1 & 1 & 1 & 1 & 1 \\
\hline la mostata? (C9) & & $\phi$ & 0 & & 1 & 0 & 1 & & 0 & 0 & 0 & 0 & 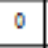 & 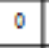 & $p$ & 0 & 0 & 0 & 1 & 0 \\
\hline $\begin{array}{l}\text { cosocer otras } \\
\text { caltursu? (C10) }\end{array}$ & & 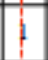 & 1 & & 1 & 1 & 1 & & 1 & 1 & 1 & 1 & 1 & 1 & 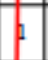 & 1 & 1 & 1 & 1 & 1 \\
\hline $\begin{array}{l}\text { veitar logares } \\
\text { vintoricos? C11) }\end{array}$ & p & 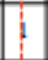 & 0 & & 1 & 0 & 1 & p & 1 & 0 & 1 & 1 & 0 & 0 & $p$ & 1 & 1 & 0 & 1 & 0 \\
\hline esquiar? (C12) & $p$ & $t$ & 1 & & 1 & 1 & 1 & & 0 & 0 & 1 & 1 & 1 & 1 & 1 & 1 & 1 & 1 & 1 & 1 \\
\hline $\begin{array}{l}\text { vinir avestarss? } \\
\text { (C13) }\end{array}$ & 1 & $p$ & 1 & & 0 & 1 & 0 & & 1 & 0 & 1 & 0 & 0 & 1 & 1 & 0 & 1 & 0 & 1 & 1 \\
\hline $\begin{array}{l}\text { el chima calido? } \\
\text { (C14) }\end{array}$ & 1 & 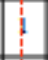 & 1 & & 1 & 0 & 1 & p & 1 & 0 & 1 & 1 & 1 & 0 & p & 1 & 0 & 0 & 1 & 0 \\
\hline $\begin{array}{l}\text { los deportes } \\
\text { actaticos? (C15) }\end{array}$ & + & $i$ & 1 & \pm & 1 & 0 & 0 & 5 & 0 & 0 & 1 & 1 & 1 & 1 & 5 & 1 & 1 & 0 & 1 & 1 \\
\hline sadar? (C16) & & & & 1 & & & & (1) & & & & & & & 1 & & & & 1) & \\
\hline
\end{tabular}

En primer lugar hay que buscar los valores nulos de la fila correspondiente al criterio $\mathrm{C}_{16}$ y después, sin cambiar de columna, comprobar si el criterio $\mathrm{C}_{2}$ también tiene valor igual a cero (la flecha dibujada con línea discontinua representa esta primera estrategia de búsqueda). Como hay casillas vacías en esta última fila, se tiene que cambiar de estrategia buscando la proposición contrarrecíproca equivalente (si les gusta practicar deporte, les gusta nadar). La tabla verifica la proposición con esta estrategia, que se trata precisamente de la premisa inicial dada como cierta. 
La evolución de las diferentes fases de la corrección, así como las intervenciones del profesor, vienen indicadas en la ficha didáctica, donde se especifica en cada momento lo que debe hacer y decir a sus estudiantes, con el fin de reproducir fielmente la situación. Por supuesto, el profesor podrá actuar fuera de estas directrices siempre que lo creyera necesario para el buen funcionamiento de la situación.

\subsubsection{Organización del aula y material utilizado}

En el aula, los estudiantes se distribuyen por grupos, generando un total de seis grupos, con una media de siete u ocho estudiantes por grupo, según la asistencia que va siendo normal a lo largo del curso.

En cada grupo hay dos figuras que no participan directamente en la corrección del cuestionario. Una de ellas es el observador y la otra el secretario. El observador es la persona encargada de redactar lo que ocurre en el grupo: cómo se está desarrollando la sesión, qué cosas hay que destacar, qué imprevistos han surgido, qué conflictos se han producido, cómo se han tomado los acuerdos (si hay debate, si hay un líder, si hay miembros del grupo que no participan, si se respetan los turnos,...), etc.

La figura del observador puede ser de gran ayuda en la investigación porque, por un lado, aporta información sobre la manera en que los estudiantes llegaron a las respuestas, y por otro, nos da a conocer cuáles son las cosas que se percibieron desde su perspectiva, cuáles les parecen interesantes, relevantes, importantes, y a su vez, las que no le causaron ningún tipo de reacción o le pasaron desapercibidas. Esto último ha sido posible con la ayuda de grabadoras y cámaras de video, con las que se intenta, por parte de los investigadores, retener toda la información posible de lo que se dice y de lo que ocurre, dentro de cada grupo y de la clase en general. De esta forma se completa la información recogida tanto por parte de los observadores como por parte de los secretarios. 
El secretario es la persona del grupo encargada de recoger la información solicitada en las plantillas para rellenar (figuras 3.1, 3.2, 3.3 y 3.4), y sus anotaciones aportan información sobre los resultados de la corrección. Al mismo tiempo, el secretario debe tratar de dirigir la sesión gestionando el tiempo y las intervenciones de los participantes, es decir, que la figura de secretario ejerce también el papel de moderador.

Las plantillas deben ser entregadas al secretario antes de comenzar la sesión y se le debe dar toda la información necesaria para saber cómo hacer uso de ellas y así evitar confusiones o complicaciones en el transcurso de la misma.

El profesor que dirige la actividad es el mismo profesor que imparte clase de la asignatura Didáctica de las Matemáticas a estos estudiantes a lo largo del curso. Se trata de una persona ajena a la investigación que, de forma voluntaria ha colaborado en nuestro trabajo. Para llevar a cabo esta colaboración fueron necesarias algunas reuniones con el equipo investigador para ser informado del trabajo que debía llevar a cabo y proporcionarle el material necesario, así como resolver las dudas que ello pudiera ocasionar.

La función del profesor, es la de llevar a cabo la devolución de la situación a los estudiantes, para que la interacción con el medio no se detenga. En el desarrollo de nuestra actividad, esto consiste en dar paso a las diferentes fases de la corrección, tal y como se describe más adelante y en garantizar el correcto funcionamiento de las mismas. En cada una de ellas, el medio es modificado, comprometiendo de nuevo a los estudiantes en la resolución del conflicto.

El propósito de la actividad es que los propios estudiantes corrijan el cuestionario. Como es de esperar, no va a ser tarea fácil puesto que cabe esperar que existan discrepancias entre las respuestas (o al menos así se espera, después de los resultados obtenidos en el primer pase del cuestionario). El proceso mediante el cual se puede llegar a tomar estas decisiones, conlleva los diferentes razonamientos de los estudiantes, tanto los que, a nivel 
interno, haya llevado a cabo cada uno de ellos para dar su respuesta inicial, como los razonamientos que, de forma explícita, necesiten construir para comunicar el porqué de su respuesta o para convencer a los demás de su resolución (momento en el que los conocimientos lógicos puestos en juego se hacen necesarios para la corrección). Esta fase de discusión es posible gracias a la confrontación entre iguales, condición característica de las situaciones adidácticas.

La organización de los estudiantes por grupos facilita la gestión y el control de la información proporcionada por todos los participantes (sus respuestas, sus acuerdos, sus desacuerdos,...). Tanto la información procedente de dentro de un grupo como la procedente de otros grupos, permite que todas las respuestas sean contrastadas, y consecuentemente, se reflexione sobre ellas, decidiendo las respuestas válidas. A pesar de no ser un juego propiamente dicho, se tiene en cuenta la puntuación de las respuestas como 'motor' de la acción, para motivar a los estudiantes y asegurar una devolución de la situación.

\subsubsection{Ficha didáctica}

\section{Fase I: Respuestas Individuales}

\section{OBJETIVO}

El objetivo de esta primera fase es devolver a los estudiantes, la situación adidáctica que supone el cuestionario, a nivel individual. Se trata de una situación de acción en la que cada estudiante responde según sus esquemas lógicos.

MATERIAL

- Plantilla individual (Tabla T y cuestionario Q) 


\section{CONSIGNA}

- $\quad$ "Hoy vamos a llevar a cabo la corrección del cuestionario que se os pasó en una de las clases del primer semestre. Esta corrección la vais a hacer vosotros y se va a desarrollar en distintas fases.

- $\quad$ En la primera fase, Fase I, responderéis otra vez el cuestionario individualmente.

[Sólo si alguien pregunta por qué hay que responder de nuevo el cuestionario, el profesor responderá:

- $\quad$ " para hacer la corrección necesitáis vuestras respuestas y el cuestionario fue anónimo, por lo tanto no ha sido posible recuperar vuestras respuestas"]

- $\quad$ Como podéis ver, en la 'Plantilla individual' tenéis la opción de poner el nombre. Así podréis saber, en cualquier momento, vuestro resultado después de la corrección.

- Podéis empezar. Tenéis 10 minutos".

DESARROLLO

Tras leer la consigna el profesor, los estudiantes comienzan a responder individualmente el cuestionario, proceso que debe terminar en 10 minutos. Si el tiempo es poco porque la gran mayoría de los estudiantes están trabajando de forma individual, el profesor puede dejar 5 minutos más.

\section{Fase II: Respuestas por Unanimidad en el Grupo}

\section{OBJETIVO}

El objetivo de esta segunda fase es la validación de las respuestas, siendo la unanimidad el criterio utilizado para considerar si una respuesta es correcta. Se trata de una situación de acción, en la que el simple hecho de comparar las respuestas devuelve información sobre su validez.

\section{MATERIAL}

Para desarrollar esta segunda fase, los estudiantes deben tener a su disposición:

- Plantilla individual (con las respuestas dadas)

- Plantilla de grupo para las respuestas

\section{CONSIGNA 1}

- $\quad$ "Terminamos el trabajo individual y pasamos al trabajo en grupo. Ahora vais a coger la plantilla que lleva por título 'Plantilla de grupo para las respuestas' [mostarla] y rellenaréis la primera columna. 
- $\quad H a y$ que hacer una puesta en común de todas las respuestas, y sólo tenéis que prestar atención a las respuestas que todos hayáis respondido por igual, es decir, por unanimidad. El secretario las escribirá en la primera columna.

- $\quad$ Tenéis 5 minutos para hacerlo.

- $\quad$ Recordad, sólo hay que escribir aquellas respuestas obtenidas por unanimidad. Si no es así, dejad la casilla en blanco".

CONSIGNA 2 [la dirá el profesor al cabo de 5 minutos de haber empezado la fase II]

- $\quad$ "Contad el número de respuestas que habéis escrito y anotadlo en la parte de arriba de la primera columna. Ésta será vuestra primera puntuación de grupo”.

[Esperar 1 minuto]

- Los que no hayáis terminado, podéis continuar después".

\section{DESARROLLO}

El profesor lee la primera consigna y los estudiantes comparan y encuentran aquellas preguntas en las que han coincidido sus respuestas. El secretario va tomando nota de estas respuestas en la primera columna de la plantilla de grupo. El tiempo empleado para ello será de 10 minutos. Una vez transcurridos los 10 minutos, el profesor leerá la segunda consigna haciendo que lleven a cabo el recuento de las respuestas unánimes y tomando nota en la parte de arriba de la columna del total, obteniendo así una primera puntuación de grupo.

\section{Fase III: Respuestas por Consenso en el Grupo}

\section{OBJETIVO}

Formulación de los razonamientos subjetivos, y validación de las respuestas mediante el consenso.

El objetivo de esta fase es que los razonamientos subjetivos que han llevado a cabo cada uno de los estudiantes para proporcionar respuestas individuales, pasen a hacerse explícitos. Esto será necesario para convencer a otros de tener la respuesta correcta o, por lo contrario para ser refutados y darse cuenta del error.

\section{MATERIAL}

Para desarrollar esta segunda fase, los estudiantes deben tener a su disposición:

- Papel en blanco.

- Plantilla individual (con las respuestas dadas) 
- Plantilla de grupo para las respuestas

- Plantilla para intercambiar

- Hoja para las justificaciones de la Fase III

\section{CONSIGNA 1}

- $\quad$ "Pasamos a la Fase III. ;Secretarios!, en primer lugar, copiad en la plantilla de intercambio la columna que ya tenéis escrita [mostrar], tal cual está, y la apartáis para más tarde. [dejar 2 minutos y continuar con la consigna]

- $\quad$ Ahora completaréis las respuestas que faltan. El grupo tendrá que ponerse de acuerdo y decidir cuál es la respuesta válida. Si se llega a un consenso, el secretario la escribirá en la siguiente columna. [mostrar plantilla de grupo para las respuestas] De no ser así, se dejará la casilla en blanco.

- $\quad$ En esta fase, además, habrá que justificar las respuestas elegidas y escribir las justificaciones en la plantilla correspondiente. [mostrar plantilla justificaciones Fase III]

- $\quad$ Tenéis 10 minutos.

\section{CONSIGNA 2}

- $\quad$ "Prestad atención: si en alguna de las respuestas no hubiera convencimiento por parte de algún compañero del grupo, podéis dejar la casilla en blanco porque icuidado! las respuestas incorrectas restarán 2 puntos.

- $\quad$ Contad el número de respuestas que habéis escrito y anotadlo en la parte de arriba de la segunda columna. Ésta será vuestra segunda puntuación de grupo, que se sumará a la primera.

- Tenéis hasta 5 minutos más, para terminar o para repasar".

\section{DESARROLLO}

Los miembros del grupo seguirán utilizando la 'plantilla individual' como soporte de trabajo. En esta ocasión sólo se trabajará sobre aquellas respuestas no unánimes, las cuales deben ser debatidas con el fin de llegar a una única respuesta. Cuando se llegue a un consenso, el secretario tomará nota de la respuesta en la segunda columna de la plantilla así como de la justificación de dicha respuesta, la cual tendrá que ser redactada entre todos y escrita en la hoja correspondiente a las justificaciones.

Es conveniente que los participantes dispongan de papel en blanco donde puedan escribir libremente para construir sus razonamientos o para anotar todo aquello que quieran retener o que les pueda ayudar en el debate. Se trata de una situación de formulación y de validación. 
En esta fase el profesor pronunciará dos consignas. En la primera consigna dirá lo que tienen que hacer y les dirá que disponen de 10 minutos. Una vez transcurridos estos primeros 10 minutos, les dirá la segunda consigna y entonces añadirá 5 o 10 minutos para repasar o terminar.

\section{Fase IV: Intercambio por Pares de Grupos}

\section{OBJETIVO}

Enriquecer el medio adidáctico con las respuestas de otro grupo y actuar en consecuencia. En un primer momento se trata de una situación de acción, que consiste en contrastar las respuestas dadas hasta el momento con las respuestas aportadas por otro grupo, ratificando sus respuestas (validación) o generando dudas cuando porque otro grupo ha sido capaz de consensuar una respuesta diferente. En un segundo momento, la situación es de formulación y validación, decidiendo qué respuesta dar en los casos de desacuerdo.

\section{MATERIAL}

- Papel en blanco.

- Plantilla individual (con las respuestas dadas)

- Plantilla de grupo para las respuestas

- Hoja para las justificaciones de la Fase IV

- Plantilla para intercambiar

\section{CONSIGNA 1}

- “CCómo va todo? ¿Todas las respuestas ya consensuadas? ¿Hay dudas? ¿Desacuerdos?

Antes de continuar, los secretarios, por favor, que copien la segunda columna, en la plantilla de intercambio [mostrar], como antes, pero en la segunda columna [dejar 2 minutos y continuar con la consigna]

- $\quad$ Ahora tendréis la oportunidad de completar las respuestas, o incluso cambiar de opinión respecto a las respuestas que ya tenéis, viendo las respuestas de otro grupo.

- Las respuestas procedentes del otro grupo os pueden ayudar a validar las vuestras jo tal vez os hagan cambiar de opinión!

- $\quad$ Entregad la plantilla de intercambio al grupo indicado en la parte de arriba. [mostrar] 
- Tenéis 10 minutos para ello”

CONSIGNA 2

- Una vez contrastadas las respuestas, si habéis hecho algún cambio, el secretario escribirá en la tercera columna de la plantilla de grupo [mostrar] la nueva respuesta y en la hoja correspondiente, su justificación. ¡No os olvidéis de la justificación!

- $\quad$ Contad el número de respuestas que habéis escrito y que antes estaban en blanco. Anotadlo en la parte de arriba de la tercera columna. Ésta será vuestra tercera puntuación de grupo. La suma de las tres puntuaciones sería la puntuación final en el caso de que todas fueran correctas.

- Tenéis 5 minutos para ello”.

DESARROLLO

El profesor lee la consigna y el secretario pasa rellenar la plantilla de intercambio, donde copiará las respuestas correspondientes a la primera y a la segunda columna de la plantilla de grupo. Una vez copiadas todas las respuestas, se intercambia esta plantilla con el grupo que viene indicado en el título. Ahora el grupo está en posesión de las respuestas del otro grupo y las compara con las suyas. Si coinciden se convencerán de que son correctas; es el criterio que se ha utilizado hasta ahora, pero entre dos grupos. Si no coinciden, se replantean de nuevo el desacuerdo entre las respuestas, razonando si la respuesta correcta es la propia o la de los demás. Para los estudiantes, es importante asegurar las respuestas correctas porque suman 1 punto, mientras que las respuestas incorrectas restan 2 puntos. Si las respuestas coinciden, no se escribe nada; si hay algún cambio, el secretario escribirá la respuesta nueva en la tercera columna así como su justificación en la hoja correspondiente.

\section{Fase V: Co-devolución de la validación al grupo-clase e institucionalización de la corrección}

\section{OBJETIVO}

Hacer una puesta en común de las respuestas dadas por todos los grupos de la clase y validarlas mediante el consenso del grupo completo (grupo-clase). En esta fase, la situación que hasta ahora era adidáctica, pasa a ser didáctica, debido a la intervención del profesor, que gestionará la institucionalización de la corrección.

MATERIAL

- Papel en blanco.

- Plantilla individual (con las respuestas dadas) 
- Plantilla de grupo para las respuestas

- Hoja para las justificaciones de la Fase V

\section{CONSIGNA}

- $\quad$ "Voy a ir preguntando cada una de las respuestas dadas, a cada uno de los grupos, pregunta por pregunta. Si hay acuerdo, jestupendo! Pero si no hay acuerdo trataremos de debatir y razonar para llegar a la respuesta válida.

- Al terminar esta quinta fase tendremos todas las soluciones escritas. Las leeré y podréis puntuar vuestras respuestas: 1 punto por cada respuesta correcta, 2 puntos negativos por cada respuesta incorrecta y 0 puntos por las preguntas sin respuestas".

- Empezamos:

Grupo A1: ¿Qué habéis contestado a la pregunta 1? ¿Estáis todos de acuerdo?

[El profesor la lee señalando al grupo y escucha la respuesta]

Grupo A2: ¿Qué habéis contestado a la pregunta 2? ¿Sí o no?

[...]

[En caso de acuerdo colectivo, se pasa a la siguiente pregunta, en caso de desacuerdo se pregunta el porqué a los grupos que discrepen, entrando en un debate colectivo].

[En el caso de que la respuesta obtenida por el grupo-clase no sea la correcta, interviene el profesor.

\section{Ver Anexo de la consigna]}

\section{DESARROLLO}

La función del profesor, en esta última fase, es la de gestionar las respuestas de los estudiantes, devolviendo la corrección al grupo-clase. La responsabilidad de la corrección deben asumirla cada uno de los grupos, mostrando sus respuestas, que tendrán que ser validadas o refutadas por el resto de los grupos.

El profesor empezará solicitando la respuesta de la primera pregunta al primer grupo, la segunda al segundo grupo y así sucesivamente hasta terminar con todas las cuestiones, al mismo tiempo que va anotándolas en la pizarra. Hay 6 grupos y 24 cuestiones, por lo tanto habrá un total de 4 respuestas por cada grupo. Si un grupo da una respuesta y el resto de grupos está de acuerdo, la respuesta será correcta. Si no es así se abre un debate que no debe prolongarse demasiado tiempo (lo gestiona el profesor), y se llega a una conclusión. Cabe esperar que, por la edad de los estudiantes y por el diseño de la actividad, siempre sea posible llegar a una respuesta consensuada, y además que dicho consenso colectivo 
coincida con la respuesta correcta. De no ser así, el profesor debe relanzar el debate generando interrogantes que les haga replantearse la respuesta.

Al finalizar la corrección, el secretario de cada grupo debe puntuar las respuestas dadas: un punto si es correcta, -2 puntos si es incorrecta y 0 puntos si se ha dejado en blanco. Al finalizar el recuento se harán públicas las puntuaciones.

\section{Fase VI: Institucionalización de la lógica implícita del cuestionario OBJETIVO}

Institucionalización de la lógica matemática implícita en el cuestionario.

\section{MATERIAL}

- La tabla y el cuestionario inicial, con las respuestas tanto individuales como grupales, incluida la corrección de la fase $\mathrm{V}$.

\section{CONSIGNA}

- ¿ ¿Qué conocimientos pensáis que se han trabajado con esta tabla? ¿Lo relacionáis con algún conocimiento estudiado anteriormente?

- ¿ ¿Qué significado tienen el 0 y el 1? ¿Por qué pensáis que se ha utilizado una tabla de datos binarios para analizar información?

[Se busca que los estudiantes reconozcan algún elemento que ayude a enlazarlo con la lógica, como 'verdadero y falso', 'negación', ... Cuando el profesor lanza las preguntas de esta consigna, no es porque obligatoriamente tengan que responder, sino para enlazar el discurso a partir de sus aportaciones, en caso de haberlas. Si no, el profesor sigue con su discurso]

- Bien, todas estas observaciones son muy interesantes.

[El profesor cita o escribe en la pizarra las aportaciones de los estudiantes]

- $\quad$ Pero ahora vamos a ir paso a paso, analizando algunas preguntas:

- La casilla $C_{6}\left(E_{3}\right)$ ¿qué información nos da?

[El profesor identifica los conocimientos lógicos implícitos en la tabla y el cuestionario Q y los va haciendo explícitos]

- El enunciado correspondiente a esta casilla, "Al estudiante C le gusta la playa» es una oración enunciativa, que informa sobre algún hecho objetivo. Las oraciones enunciativas pueden ser afirmativas o negativas. Este tipo de enunciados son precisamente los que sirven de elementos básicos 
en la lógica proposicional y se caracterizan por ser, o bien verdaderos, o bien falsos. En lógica, a este tipo de enunciados se les llama proposiciones.

- $\quad$ Ahora bien, si digo lo siguiente: «Al estudiante C le gustan la playa y la montaña» también tendré un enunciado que informa sobre un hecho objetivo y que, consecuentemente será, o bien verdadero, o bien falso. Para saber si es verdadera o falsa esta proposición, ¿qué casilla o casillas hay que consultar? ¿Qué diferencia encontráis respecto a la proposición anterior?

- $\quad$ Este tipo de proposiciones, cuyo valor de verdad depende de la verdad de otras proposiciones, se las conoce como proposiciones compuestas. ¿qué palabra os indica que hay dos informaciones distintas en una misma oración?

- $\quad$ En lógica, las conexiones entre las diferentes proposiciones, se llaman conectores lógicos, y son la negación, la conjunción, la disyunción, la condicional y la doble condicional. Suelen traducirse a lenguaje natural con las palabras no, y, o, si ... entonces, solo si ... entonces. En ocasiones la ambigüedad del lenguaje natural o las diferentes interpretaciones sgún el contexto, hacen que la misma palabra tenga diferentes significados. Esto no ocurre en lógica. Cada conector lógico tiene su definición. Es lo que se conoce como semántica de la lógica y de esta forma se conoce con exactitud si una proposición compuesta es verdadera o falsa, a partir de los valores de verdad de las proposiciones que la componen.

- $\quad$ Ahora vamos a ver de qué manera se sabe la verdad de una proposición compuesta a partir de sus componentes. Utilizaremos ejemplos basados en la tabla. Yo digo un enunciado y vosotros, individualmente, buscáis aquellas casillas que nos dan la información deseada.

«Al estudiante C no le gusta salir de noche»

«Al estudiante C le gusta la playa y el clima cálido»

«Al estudiante C le gustan la playa o el clima cálido»

«Si al estudiante C le gusta la playa entonces le gusta el clima cálido»

«Solo si al estudiante C le gusta la playa entonces le gusta el clima cálido»

- En lógica, las tablas de verdad recogen todas las combinaciones posibles de los valores de verdad de las proposiciones y el valor de verdad resultante de la operación lógica, en cada combinación. Además el valor de verdad de la proposición resultante de cada operación lógica viene dado por el criterio de verdad que define cada operación. Por ejemplo, una proposición conjunción es cierta cuando ambas proposiciones son ciertas. Estos criterios de verdad se resumen en la siguiente tabla: 
[Mostrar la tabla a los estudiantes mediante los recursos disponibles en el aula: pizarra, diapositivas,...]

\begin{tabular}{|c|c|c|c|c|c|c|}
\hline $\mathrm{p}$ & $\mathrm{q}$ & $\begin{array}{c}\neg \mathrm{p} \\
\text { negación }\end{array}$ & $\begin{array}{c}\mathrm{p} \wedge \mathrm{q} \\
\text { conjunción }\end{array}$ & $\begin{array}{c}\mathrm{p} \vee \mathrm{q} \\
\text { disyunción }\end{array}$ & $\begin{array}{c}\mathrm{p} \rightarrow \mathrm{q} \\
\text { condicional }\end{array}$ & $\begin{array}{c}\mathrm{p} \leftrightarrow \mathrm{q} \\
\text { doble condicional }\end{array}$ \\
\hline $\mathrm{V}$ & $\mathrm{V}$ & $\mathrm{F}$ & $\mathrm{V}$ & $\mathrm{V}$ & $\mathrm{V}$ & $\mathrm{V}$ \\
\hline $\mathrm{V}$ & $\mathrm{F}$ & $\mathrm{F}$ & $\mathrm{F}$ & $\mathrm{V}$ & $\mathrm{F}$ & $\mathrm{F}$ \\
\hline $\mathrm{F}$ & $\mathrm{V}$ & $\mathrm{V}$ & $\mathrm{F}$ & $\mathrm{V}$ & $\mathrm{V}$ & $\mathrm{F}$ \\
\hline $\mathrm{F}$ & $\mathrm{F}$ & $\mathrm{V}$ & $\mathrm{F}$ & $\mathrm{F}$ & $\mathrm{V}$ & $\mathrm{V}$ \\
\hline
\end{tabular}

- Las proposiciones compuestas, también conocidas como fórmulas, se pueden transformar en fórmulas equivalentes, es decir, fórmulas con los mismos valores de verdad. Del mismo modo, dos fórmulas lógicas con diferente tabla de verdad no son equivalentes y por lo tanto, no podemos sustituir una por otra. Por ejemplo, la importancia del sentido de una proposición condicional se debe precisamente a que no es lo mismo decir $\mathrm{p} \rightarrow \mathrm{q}$ que $\mathrm{q} \rightarrow \mathrm{p}$, tal y como nos confirma la tabla de verdad:

\begin{tabular}{|c|c|c|c|}
\hline $\mathrm{p}$ & $\mathrm{q}$ & $\begin{array}{c}\mathrm{p} \rightarrow \mathrm{q} \\
\text { condicional }\end{array}$ & $\begin{array}{c}\mathrm{q} \rightarrow \mathrm{p} \\
\text { condicional }\end{array}$ \\
\hline $\mathrm{V}$ & $\mathrm{V}$ & $\mathrm{V}$ & $\mathrm{V}$ \\
\hline $\mathrm{V}$ & $\mathrm{F}$ & $\mathrm{F}$ & $\mathrm{V}$ \\
\hline $\mathrm{F}$ & $\mathrm{V}$ & $\mathrm{V}$ & $\mathrm{F}$ \\
\hline $\mathrm{F}$ & $\mathrm{F}$ & $\mathrm{V}$ & $\mathrm{V}$ \\
\hline
\end{tabular}

- La lógica proposicional, se extiende a la lógica de predicados, debido a la imposibilidad de representar formalmente algunos enunciados que, a pesar de ser, o bien verdaderos, o bien falsos, necesitan diferenciar sujeto y predicado para ser tratados.

Veamos los siguientes enunciados: [mostrar]

«A todos los estudiantes les gusta la playa»

«Al estudiante C le gusta la playa»

- El enunciado que aparece en primer lugar no se puede simbolizar en lógica proposicional, sin embargo sí puede hacerse en lógica de predicados, diferenciando su estructura: sujeto y predicado. El sujeto es el objeto del que se afirma algo y el predicado, lo que se afirma. De esta forma la lógica de predicados permite utilizar diferentes sujetos (variables de individuo), que representan el dominio 
de definición para un mismo predicado. Para que esto sea posible, son necesarios los cuantificadores: $\forall$ (cuantificador universal), $\exists$ (cuantificador existencial)

- ¿Qué relación existe entre el primer enunciado y el segundo?

El segundo enunciado se dice que es un ejemplo del primero.

Veamos más ejemplos: [mostrar]

«A todos los estudiantes les gusta la playa» Verdadero, porque $\forall \mathrm{E}_{\mathrm{i}} \quad \mathrm{C}_{6}\left(\mathrm{E}_{\mathrm{i}}\right)=1$

«Al estudiante S le gusta todo » Verdadero, porque $\forall C_{j} \quad E_{19}\left(C_{j}\right)=1$

- Una función proposicional se dice que es verdadera cuando todos los sujetos tomados de su dominio de definición convierten los enunciados en proposiciones verdaderas.

Los ejemplos que hacen que una función proposicional sea falsa, se llaman contraejemplos.

Por ejemplo: [mostrar]

«A todos los estudiantes les gusta el frío »

Falso, porque $\exists E_{i} \quad C_{4}\left(E_{i}\right)=0$, por ejemplo: $C_{4}\left(E_{1}\right)=0$

Es decir, existe al menos un contraejemplo, como es

el caso del estudiante A, a quien no le gusta el clima

frío.

- $\quad$ Por último, hay que destacar el último grupo de cuestiones $(Q 19, \ldots, Q 24)$ porque no permiten buscar la respuesta sobre la tabla. Estas cuestiones son respondidas relacionando la información que se tiene como punto de partida. Este proceso, mediante el cual obtenemos conclusiones se llama proceso de inferencia. Se dice que el proceso de inferencia es válido si se hacen bajo las reglas de inferencia lógicas, porque estaremos seguros de que, a partir de información verdadera se llega a conclusiones verdaderas. Una inferencia válida, en lógica es lo mismo que una condicional tautológica, es decir, que sólo toma valores verdaderos. La representación lógica de todo proceso de inferencia es la conjunción de un conjunto de premisas conocidas de las que se deriva una conclusión: [mostrar]

$$
P_{1} \wedge P_{2} \wedge \ldots P_{n} \Rightarrow C
$$

Donde $P_{1}, P_{2}, \ldots, P_{n}$ son las premisas o información de partida y C la conclusión. El símbolo “ $\Rightarrow ”$ indica que se trata de una condicional tautológica (es decir, que siempre es verdadera). En matemáticas recibe el nombre de teorema. 
- Por ejemplo, la cuestión Q22, «Al estudiante H no le gusta nadar», a pesar de ser una proposición simple, no le corresponde ninguna casilla de la tabla. Sin embargo puedo deducir, a partir de la información ya conocida, las premisas, si es verdadera o falsa.

El razonamiento seguido es el siguiente:

«A todos los estudiantes que les gusta practicar deporte les gusta nadar» (Premisa 1)

«Al estudiante H le gusta practicar deporte» (Premisa 2)

Por lo tanto

«Al estudiante H le gusta nadar» (Conclusión)

Se ha llevado a cabo un razonamiento, conocido en lógica de clases, como silogismo. Este razonamiento es un razonamiento válido, porque preserva la verdad de sus premisas.

Hay otros, pero no hay suficiente tiempo para hablar de todos ellos.

\section{DESARROLLO}

A lo largo de esta fase el profesor relaciona la actividad llevada a cabo en el aula con el saber oficial, en este caso con la lógica formal.

El profesor tratará de averiguar si los estudiantes han identificado algún tipo conocimiento. Si es así, partirá de ello para darle un estatus formal o académico. Si no es así, les ayudará a reconocer e identificar aquello que se desea institucionalizar.

Fig. 3.5: Ficha didáctica de la corrección del cuestionario Q 


\section{ANEXO:}

\section{OBJETIVO}

En el cuestionario se encuentran algunos ejemplos que podrían consensuarse bajo una interpretación incorrecta, es decir, sin dar el significado de la lógica formal. Un ejemplo de ello podría ser una condicional, cuando es interpretada como una doble condicional; o por ejemplo la disyunción matemática, que es una disyunción inclusiva, y sin embargo se interpreta como una disyunción exclusiva. A continuación se presentan las ejemplificaciones que el profesor utilizará en caso de consenso equivocado y que le permitirán devolver la validación de estas respuestas al grupo-clase, generando dudas o interrogantes.

Algunas preguntas presentan el mismo tipo de dificultad. El profesor intervendrá cuando se haya dado respuesta a todas ellas, para no repetir lo mismo cada vez.

\section{[PREGUNTA Q7]}

\section{CONSIGNA}

- $\quad$ Supongo que llegar a la respuesta correcta de la cuestión Q7 no habrá sido fácil. Veamos si ya lo tenéis claro con este ejemplo.

[CASO 1: respuesta consensuada $=3$ ]

\begin{tabular}{|c|c|c|}
\cline { 2 - 3 } \multicolumn{1}{c|}{} & Miguel & Luis \\
\hline ¿Te gusta A? & 1 & 1 \\
\hline ¿Te gusta B? & 0 & 1 \\
\hline
\end{tabular}

$\checkmark \quad$ ¿A quién le gustan A y B?

$\checkmark \quad$ ¿A quién no?

$\checkmark$ Por lo tanto, ¿qué hemos dicho de Luis?

$\checkmark \quad$ ¿Qué hemos dicho de Miguel?

Ahora responded de nuevo a la pregunta $Q 7$

[CASO 2: Respuesta $=19$. Vamos a provocar una contradicción haciendo que al responder según lo han hecho anteriormente, la suma de los estudiantes supere el total)]

\begin{tabular}{|l|c|c|c|c|}
\cline { 2 - 5 } \multicolumn{1}{c|}{} & Juan & Mario & Miguel & Luis \\
\hline ¿Te gusta B? & 0 & 0 & 0 & 1 \\
\hline ¿Te gusta C? & 0 & 0 & 1 & 1 \\
\hline
\end{tabular}


$\checkmark \quad$ ¿A cuántos no les gustan B y C?

$\checkmark \quad$ ¿Es posible que haya 5 amigos que no les gusten B y C? ¿Por qué?

$\checkmark \quad$ ¿Cambiaríais vuestra respuesta a la pregunta $Q 7$ ?

\section{DESARROLLO}

Para dar una respuesta correcta a esta pregunta se necesita conocer el significado de la negación y el significado de la conjunción, o bien conocer la transformación de la negación de la conjunción, como la disyunción de negaciones, lo que a su vez implica el significado de la disyunción. Prever la manera de consensuar una respuesta, a su vez incorrecta, no es fácil, dada la gran variedad de conectivas lógicas implicadas. Sin embargo, el estudio de los resultados de las respuestas dadas por los estudiantes en el primer pase de este cuestionario, nos advierte de que las dos respuestas más veces repetidas son:

- «3 estudiantes»: Para dar esta respuesta han negado mal la conjunción. Desconocen la transformación de esta fórmula $(\neg(\mathrm{A} \wedge \mathrm{B})=\neg \mathrm{A} \vee \neg \mathrm{B})$ y se deduce que han llegado a la respuesta transformando de manera incorrecta $\neg(\mathrm{A} \wedge \mathrm{B})$ (negación de una conjunción) en la siguiente fórmula no equivalente $\neg \mathrm{A} \wedge \neg \mathrm{B}$ (conjunción de negaciones.)

- «19 estudiantes»: En este caso, el error es de naturaleza conjuntista, ya que parece ser que han contado por un lado los individuos a los que no les gustan las grandes ciudades y por otro lado los individuos a los que no les gusta salir de noche. Después han sumado los resultados, sin tener en cuenta la intersección.

El ejemplo presentado, con una tabla de dimensiones $2 \times 2$, donde aparecen tan solo dos individuos y dos crierios, pretende hacer que los estudiantes utilicen con sentido correcto la expresión correspondiente a la negación de la conjunción.

\section{[PREGUNTAS Q11 y Q12]}

\section{CONSIGNA}

- ¿Estáis seguros de la respuesta que habéis dado a las preguntas Q11 y Q12? Veamos un ejemplo para comprobar si la respuesta es correcta.

\begin{tabular}{|l|c|c|}
\cline { 2 - 3 } \multicolumn{1}{c|}{} & Juan & Mario \\
\hline ¿Te gusta A? & 1 & 1 \\
\hline ¿Te gusta B? & 0 & 0 \\
\hline
\end{tabular}

\begin{tabular}{|l|c|c|}
\cline { 2 - 3 } \multicolumn{1}{c|}{} & Miguel & Luis \\
\hline ¿Te gusta A? & 1 & 1 \\
\hline ¿Te gusta B? & 0 & 1 \\
\hline
\end{tabular}




\begin{tabular}{|l|l|l|}
\hline ¿Te gusta $C ?$ & 0 & 0 \\
\hline
\end{tabular}

\begin{tabular}{|l|l|l|}
\hline ¿Te gusta $C ?$ & 1 & 1 \\
\hline
\end{tabular}

$\checkmark \quad$ ¿Juan y Mario tienen el mismo gusto por viajar?

$\checkmark \quad$ ¿Miguel y Luis tienen el mismo gusto por viajar?

$\checkmark \quad$ ¿Juan y Mario irán al mismo viaje?

$\checkmark \quad$ ¿Miguel y Luis irán al mismo viaje?

$\checkmark \quad$ Por lo tanto, ¿en cuál de los dos casos es más probable que coincidan las dos personas? ¿Por qué?

$\checkmark \quad$ Entonces, las respuesta dadas a las preguntas Q11 y Q12, ¿son correctas?

\section{DESARROLLO}

Cabe esperar dos tipos de respuesta, a partir de la comparación entre los gustos para viajar:

- considerar tanto las coincidencias positivas $(1,1)$ como las coincidencias

$$
\text { negativas }(0,0) \quad(\text { CORRECTO })
$$

- $\quad$ considerar solamente las coincidencias positivas $(1,1) \quad$ (INCORRECTO $)$

El ejemplo dado debería conseguir que los estudiantes dieran una respuesta diferente a la consensuada.

\section{[PREGUNTAS Q8, Q9, Q14, Q15 y Q16]}

\section{CONSIGNA}

- $\quad$ Me parecen interesantes el grupo de preguntas Q8, Q9, Q14, Q15 y Q16. Vamos a insistir un poco más. Por ejemplo, si tenemos los siguientes datos:

\begin{tabular}{|l|c|c|c|}
\cline { 2 - 4 } \multicolumn{1}{c|}{} & Ana & Sara & Carmen \\
\hline ¿Te gusta A? & $l$ & 1 & 0 \\
\hline ¿Te gusta B? & $?$ & $?$ & $?$ \\
\hline
\end{tabular}

Cuando afirmo que:

Si te gusta A te gusta B.

Si te gusta A te gusta B, y si no te gusta A, también.

$\checkmark \quad$ ¿Qué pensáis de estas dos afirmaciones? ¿son iguales, son distintas?

$\checkmark \quad$ ¿Cuál de las dos nos da más información? Trata de rellenar los huecos con interrogantes, primero con la primera afirmación, y después con la segunda. 


\section{DESARROLLO}

La condicional es confundida con la doble condicional, añadiendo inconscientemente la palabra "solamente". Es decir, cuando se escucha 'si ocurre A entonces ocurre B' queda interpretado como 'sólo si ocurre A ocurre B', obteniendo así la tabla de verdad de una doble condicional. En este caso, se debe intervenir haciendo ver a los estudiantes que hay información que no es conocida y que, por lo tanto, no puede ser añadida porque sí.

\section{[PREGUNTA Q17]}

\section{CONSIGNA}

- $\quad$ Ahora que ya habéis dado la respuesta a la pregunta Q17, contestad a la siguiente cuestión:

Una agencia de viajes propone dos tipos de viaje: uno de playa y otro de montaña.

$\checkmark \quad$ ¿El estudiante E podrá ir de viaje con esta agencia? ¿Por qué?

$\checkmark \quad$ ¿Y el estudiante F? ¿Por qué?

$\checkmark \quad$ ¿Qué dirías que tiene que gustarte para apuntarte a esta agencia?

a. El mar y la montaña

b. El mar o la montaña

Ahora responded de nuevo a la pregunta Q17

\section{DESARROLLO}

Interpretar la disyunción como una disyunción exclusiva, es muy frecuente. Para ayudar a construir el significado de disyunción inclusiva, tal y como se entiende en el contexto matemático, habrá que ejemplificarlo con una situación que le dé el mismo sentido, con la finalidad de que los estudiantes reconozcan la necesidad de establecer como una regla el significado del lenguaje lógico-matemático.

\section{[PREGUNTAS Q19, Q20, Q21, Q22, Q23, Q24]}

[Para facilitar el trabajo, sólo se incluirán las filas involucradas en las cuestiones dadas]

\section{CONSIGNA}

- $\quad$ Me gustaría completar la tabla de datos con la información que nos da la premisa, porque pienso que puede ayudaros a estar más convencidos de la solución.

Voy a ponerla en la pantalla y vamos a ir completando casilla por casilla. 
- ¿Al estudiante A le gusta nadar?

- ¿Al estudiante B le gusta nadar?

- Y así sucesivamente...

Tabla T

\begin{tabular}{|c|l|l|l|l|l|l|l|l|l|l|l|l|l|l|l|l|l|l|l|l|}
\hline ¿Te gusta... & $\boldsymbol{A}$ & $\boldsymbol{B}$ & $\boldsymbol{C}$ & $\boldsymbol{D}$ & $\boldsymbol{E}$ & $\boldsymbol{F}$ & $\boldsymbol{G}$ & $\boldsymbol{H}$ & $\boldsymbol{I}$ & $\boldsymbol{J}$ & $\boldsymbol{K}$ & $\boldsymbol{L}$ & $\boldsymbol{M}$ & $\boldsymbol{N}$ & $\boldsymbol{O}$ & $\boldsymbol{P}$ & $\boldsymbol{Q}$ & $\boldsymbol{R}$ & $\boldsymbol{S}$ & $\boldsymbol{T}$ \\
\hline $\begin{array}{c}\text { practicar } \\
\text { deporte? (C2) }\end{array}$ & 1 & 0 & 0 & 1 & 0 & 0 & 0 & 1 & 0 & 0 & 0 & 0 & 0 & 0 & 1 & 0 & 0 & 0 & 1 & 0 \\
\hline nadar? (C16) & & & & & & & & & & & & & & & & & & & & \\
\hline
\end{tabular}

Ahora respondemos de nuevo, comprobando las respuestas en la tabla, tal y como hemos venido haciendo hasta ahora.

\section{DESARROLLO}

La dificultad a la hora de responder a estas preguntas es la ausencia de datos en la tabla y en consecuencia el tener que relacionar información dada sin poder actuar sobre un medio de validación: la tabla.

Una forma de solucionar esto es presentar la tabla ante los estudiantes, con una nueva fila, para rellenarla entre todos con la información que nos da la premisa. Al rellenar los datos, podrán darse cuenta de la información que puede obtenerse, así como mostrar que en ocasiones la respuesta no se puede saber por la ausencia de datos.

Fig. 3.6: Anexo de la ficha didáctica de la corrección del cuestionario $Q$ 


\subsection{Desarrollo y observación de la situación de corrección del cuestionario Q}

Este apartado presenta la experimentación y la observación de la situación. En primer lugar, se llevará a cabo una crónica de las sesiones, junto al análisis de los resultados obtenidos por cada uno de los grupos. En segundo lugar, se presentarán los resultados de la observación de la situación. La situación se va a observar a lo largo de dos sesiones, de dos horas de duración cada una, con alumnos de primer curso del Grado de Maestro de Educación Primaria y con el profesor que les imparte la asignatura Didáctica de las Matemáticas. En el momento de llevar a cabo la observación, ya se habían realizado las reuniones previas a cada sesión, tanto con el profesor como con los investigadores, para la preparación y revisión de la ficha didáctica. Asimismo, se llevarán a cabo reuniones posteriores para la valoración de la observación.

\subsubsection{Crónica y resultados de la observación de la situación}

El número de estudiantes ha sido una variable no controlada por la situación. La asistencia a las clases de la asignatura Didáctica de las Matemáticas no es obligatoria, y por lo tanto, el número de estudiantes varía en función de las necesidades del estudiantado. La actividad se había planificado pensando en grupos de trabajo de entre seis y ocho estudiantes por grupo, esperando un total de seis grupos de trabajo por sesión, según la previsión respecto al número de estudiantes que habitualmente asiste a estas clases. En la primera sesión se han constituido seis grupos de trabajo, tal y como se había previsto en la preparación de la actividad. Sin embargo, en la segunda sesión no ha sido posible, teniendo que distribuir a los alumnos en tan solo cuatro grupos. Se ha mantenido el número par de grupos, tal y como exige el diseño de la situación.

La distribución final del alumnado viene indicada en la siguiente tabla: 


\begin{tabular}{|c|c|c|c|c|c|c|c|c|c|c|}
\cline { 2 - 12 } \multicolumn{1}{c|}{} & \multicolumn{4}{c|}{ Sesión 1 } & \multicolumn{4}{c|}{ Sesión 2 } \\
\hline Grupos & A1 & A2 & A3 & B1 & B2 & B3 & C1 & C2 & D1 & D2 \\
\hline $\mathrm{N}^{\circ}$ de estudiantes por grupo & 6 & 7 & 8 & 11 & 8 & 8 & 6 & 8 & 7 & 8 \\
\hline
\end{tabular}

Tabla 3.1: Número de estudiantes por grupo en la corrección del cuestionario Q

Primera fase: Trabajo individual sobre la tabla de datos binarios. Devolución de la situación

En esta primera fase, se lleva a cabo la devolución de la situación de acción a los estudiantes, que deben responder individualmente a las preguntas del cuestionario. Los resultados individuales en la resolución del cuestionario van a ser el punto de partida para la corrección colectiva. Se trata de una situación de acción, en la que los estudiantes hacen uso de sus conocimientos personales.

La devolución del cuestionario ha sido aceptada por todos los estudiantes, aunque la variable tiempo ha impedido, en algunos casos, finalizar esta primera fase de la corrección. El tiempo establecido por el profesor en la consigna, 15 minutos, no ha sido suficiente para algunos estudiantes, tanto en la primera sesión como en la segunda, que han tenido que finalizar el cuestionario una vez comenzada la segunda fase. A pesar de esta observación, en la segunda sesión se ha mantenido el tiempo establecido para la primera sesión. Esta decisión se ha tomado principalmente por dos motivos. En primer lugar porque no ha sido un hecho generalizado, sino que se ha dado tan solo en algunos casos, sin haber supuesto un impedimento para la realización de la siguiente fase y en segundo lugar, porque se ha considerado poco conveniente dedicar más tiempo a esta primera fase dado que la duración de la sesión ha sido insuficiente para la realización de la situación de institucionalización.

Los resultados del cuestionario han sido similares a los resultados obtenidos en los cuestionarios ya realizados en la fase de diagnóstico, presentados en el capítulo anterior. Por lo tanto el análisis entonces realizado se puede extender también a estos resultados, 
sirviéndonos de referencia. Los errores cometidos en las respuestas del cuestionario Q parecen indicar de nuevo que algunos de los conocimientos lógicos que intervienen en la resolución de las preguntas no son conocimientos aún adquiridos. El siguiente gráfico muestra el comportamiento de las respuestas individuales de los estudiantes en cada una de las dos sesiones.

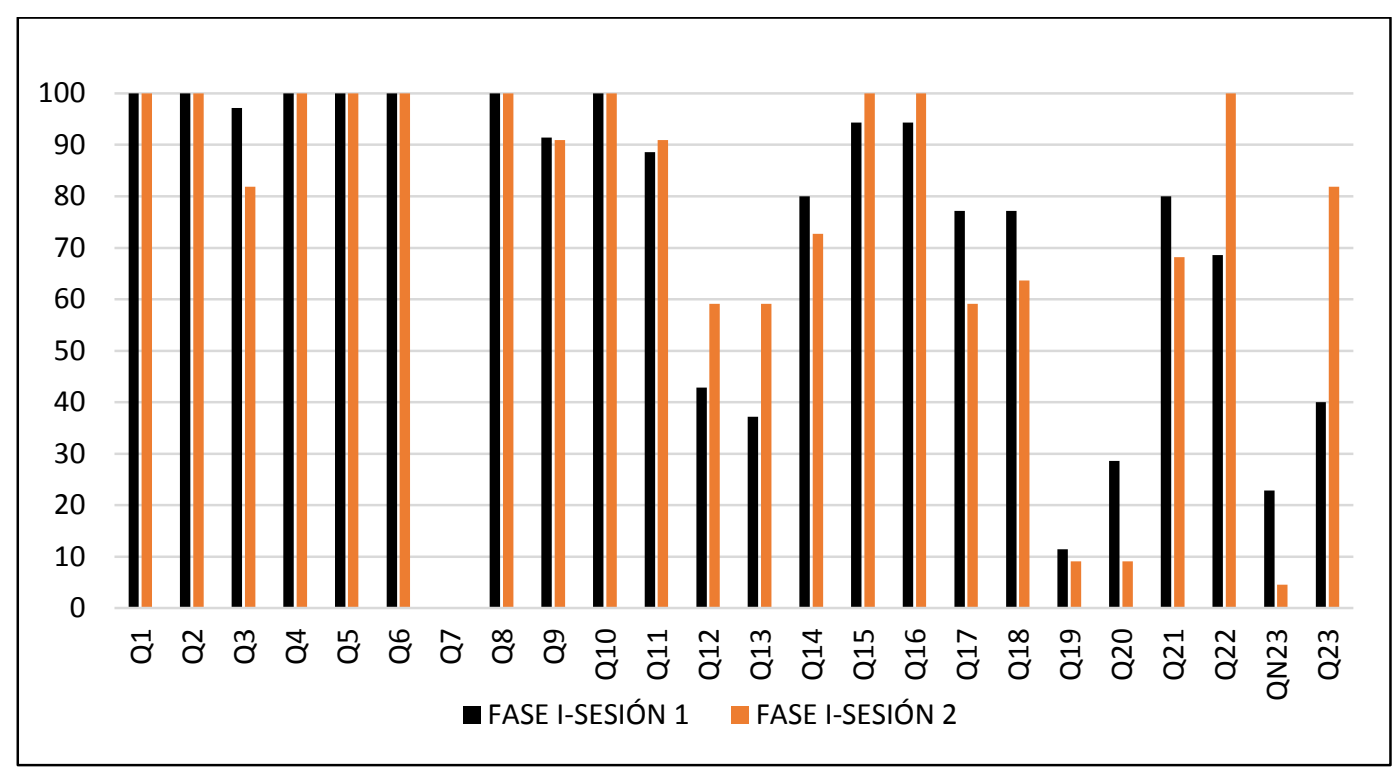

Fig. 3.7: Porcentaje de respuestas correctas obtenidas individualmente en la primera fase de la corrección del cuestionario $\mathbf{Q}$

A pesar de la similitud entre los resultados de ambas sesiones, comentaremos algunas diferencias entre la sesión 1 y la sesión 2.

El gráfico muestra cierta diferencia entre el porcentaje de respuestas correctas en las preguntas Q22 y Q23, que mejora en la sesión 2. La pregunta Q22 presenta un 68,5\% de respuestas correctas en la sesión 1 , frente al $100 \%$ de respuestas correctas que presenta en la sesión 2. Así mismo, la pregunta Q23 pasa de un 40\% de respuestas correctas en la sesión 1 a un $81,8 \%$ en la sesión 2 . 
Por el contrario, las preguntas Q20 y QN23 se muestran como preguntas de mayor dificultad para los estudiantes de la segunda sesión. La pregunta Q20 pasa de un 28,5\% de respuestas correctas en la sesión 1 a un 9\% en la sesión dos, y QN23 pasa de un 22,8\% de respuestas correctas en la sesión 1 a un 4,5\% de respuestas correctas en la sesión 2 . Tal y como se había observado anteriormente en el cuestionario utilizado con los estudiantes de la universidad de Jaén, los estudiantes de ambas sesiones presentan una dificultad similar ante estas dos cuestiones, siendo ligeramente mayor para QN23.

Segunda fase: La unanimidad como primer criterio de corrección. (Inicio de la corrección)

En esta segunda fase, de nuevo el profesor, mediante la consigna, lleva a cabo la devolución de una situación de acción. El profesor establece como criterio inicial de validación, la unanimidad de respuestas. Este criterio ha sido impuesto por el profesor en la consigna, por lo tanto no es cuestionado por los estudiantes y no supone ningún tipo de decisión personal. La unanimidad y el no cuestionamiento de la consigna lo consideramos como validación implícita de dichas respuestas y ha servido únicamente para devolver a los estudiantes la situación de corrección y ofrecer la posibilidad de actuar sobre el medio mediante la comparación de las respuestas. Esta acción ha informado a los estudiantes de que ha habido respuestas diferentes y, consecuentemente, de que la corrección no ha terminado.

Las cuestiones que no entrañan ningún tipo de problema para los estudiantes, no serán objeto de validación explícita observable en la situación.

A partir de este momento, las respuestas dejan de tener carácter individual, y se van a considerar respuestas de grupo.

En esta segunda fase los estudiantes de la sesión 1 han finalizado en un tiempo inferior al establecido. En la sesión 2, los diez minutos destinados a esta segunda fase se han 
reducido a tan solo cinco minutos. Esta decisión del profesor ha evitado perder el control de la clase, ya que los estudiantes, durante este periodo de tiempo, avanzaban en los debates colectivos, alterando el orden y la atención hacia el profesor. En la primera sesión, el profesor ha necesitado formular repetidas veces la consigna de la fase siguiente, invirtiendo más tiempo del previsto. En la segunda sesión, al reducir el tiempo dedicado a esta fase, este descontrol ha sido evitado, ganando tiempo para la fase de institucionalización.

La siguiente tabla recoge la información relacionada con los resultados en esta fase de la corrección:

\begin{tabular}{|l|l|l|}
\hline Qi & Grupos de la sesión 1 & Grupos de la sesión 2 \\
\hline Q1 & $2^{\mathrm{a}}$ fase: TODOS & $2^{\mathrm{a}}$ fase: TODOS \\
\hline Q2 & $2^{\mathrm{a}}$ fase: TODOS & $2^{\mathrm{a}}$ fase: TODOS \\
\hline Q3 & $2^{\mathrm{a}}$ fase: A2, B1, B2, B3 & $2^{\mathrm{a}}$ fase: C1, D1 \\
\hline Q4 & $2^{\mathrm{a}}$ fase: TODOS & $2^{\mathrm{a}}$ fase: TODOS \\
\hline Q5 & $2^{\mathrm{a}}$ fase: TODOS & $2^{\mathrm{a}}$ fase: C2, D1, D2 \\
\hline Q6 & $2^{\mathrm{a}}$ fase: TODOS & $2^{\mathrm{a}}$ fase: TODOS \\
\hline Q7 & $2^{\mathrm{a}}$ fase: B1, B3 & $2^{\mathrm{a}}$ fase: NINGUNO \\
\hline Q8 & $1^{\mathrm{a}}$ fase: TODOS & $1^{\mathrm{a}}$ fase: TODOS \\
\hline Q9 & $2^{\mathrm{a}}$ fase: A3, B2, B3 & $2^{\mathrm{a}}$ fase: C2, D1 \\
\hline Q10 & $2^{\mathrm{a}}$ fase: A2, A3, B1, B2, B3 & $2^{\mathrm{a}}$ fase: TODOS \\
\hline Q11 & $2^{\mathrm{a}}$ fase: B3 & $2^{\mathrm{a}}$ fase: D1, D2 \\
\hline Q12 & $2^{\mathrm{a}}$ fase: B3 & $2^{\mathrm{a}}$ fase: D1 \\
\hline Q13 & $2^{\mathrm{a}}$ fase: A2, B3 & $2^{\mathrm{a}}$ fase: D2 \\
\hline Q14 & $2^{\mathrm{a}}$ fase: A1, A3, B3 D1 \\
\hline
\end{tabular}




\begin{tabular}{|l|l|l|}
\hline Q15 & $2^{\mathrm{a}}$ fase: A1, A3, B1, B2, B3 & $2^{\mathrm{a}}$ fase: TODOS \\
\hline Q16 & $2^{\mathrm{a}}$ fase: A2, B1, B2, B3 & $2^{\mathrm{a}}$ fase: TODOS \\
\hline Q17 & $2^{\mathrm{a}}$ fase: A1, A2, A3, B1, B3 & $2^{\mathrm{a}}$ fase: D1, D2 \\
\hline Q18 & $2^{\mathrm{a}}$ fase: A1, A2, B2, B3 & $2^{\mathrm{a}}$ fase: D2 \\
\hline Q19 & $2^{\mathrm{a}}$ fase: A1, A2, B1, B2, B3 & $2^{\mathrm{a}}$ fase: D1, D2 \\
\hline Q20 & $2^{\mathrm{a}}$ fase: A1, A2, B1, B3 & $2^{\mathrm{a}}$ fase: D1, D2 \\
\hline Q21 & $2^{\mathrm{a}}$ fase: A1, A2, B2, B3 & $2^{\mathrm{a}}$ fase: D1, D2 \\
\hline Q22 & $2^{\mathrm{a}}$ fase: A1, A3, B2, B3 & $1^{\mathrm{a}}$ fase: TODOS \\
\hline QN23 & $2^{\mathrm{a}}$ fase: A2, B1, B3 & $2^{\mathrm{a}}$ fase: TODOS \\
\hline Q23 & $2^{\mathrm{a}}$ fase: A2, B3 & $2^{\mathrm{a}}$ fase: D1, D2 \\
\hline
\end{tabular}

Tabla 3.2: Grupos que han obtenido unanimidad en la segunda fase de la corrección

Las cuestiones que han obtenido unanimidad en todos los grupos, tanto en la sesión 1 como en la sesión 2, han sido las preguntas Q1, Q2, Q4, Q6 y Q8, todas ellas con respuesta correcta. Se trata de preguntas que habían presentado anteriormente un porcentaje de respuestas correctas superior al 97\%. Sin embargo, la unanimidad dentro de un grupo o incluso de más de uno, no ha sido sinónimo de respuesta correcta. Ha habido grupos que han obtenido una respuesta unánime y al mismo tiempo incorrecta. Por ejemplo, Q20 ha obtenido unanimidad en seis de los diez grupos, cuatro grupos pertenecientes a la sesión 1 y dos grupos pertenecientes a la sesión 2, de los cuales sólo uno de ellos ha dado la respuesta correcta. Esto ha ocurrido en más de una pregunta, tal y como se puede observar en el gráfico siguiente: 


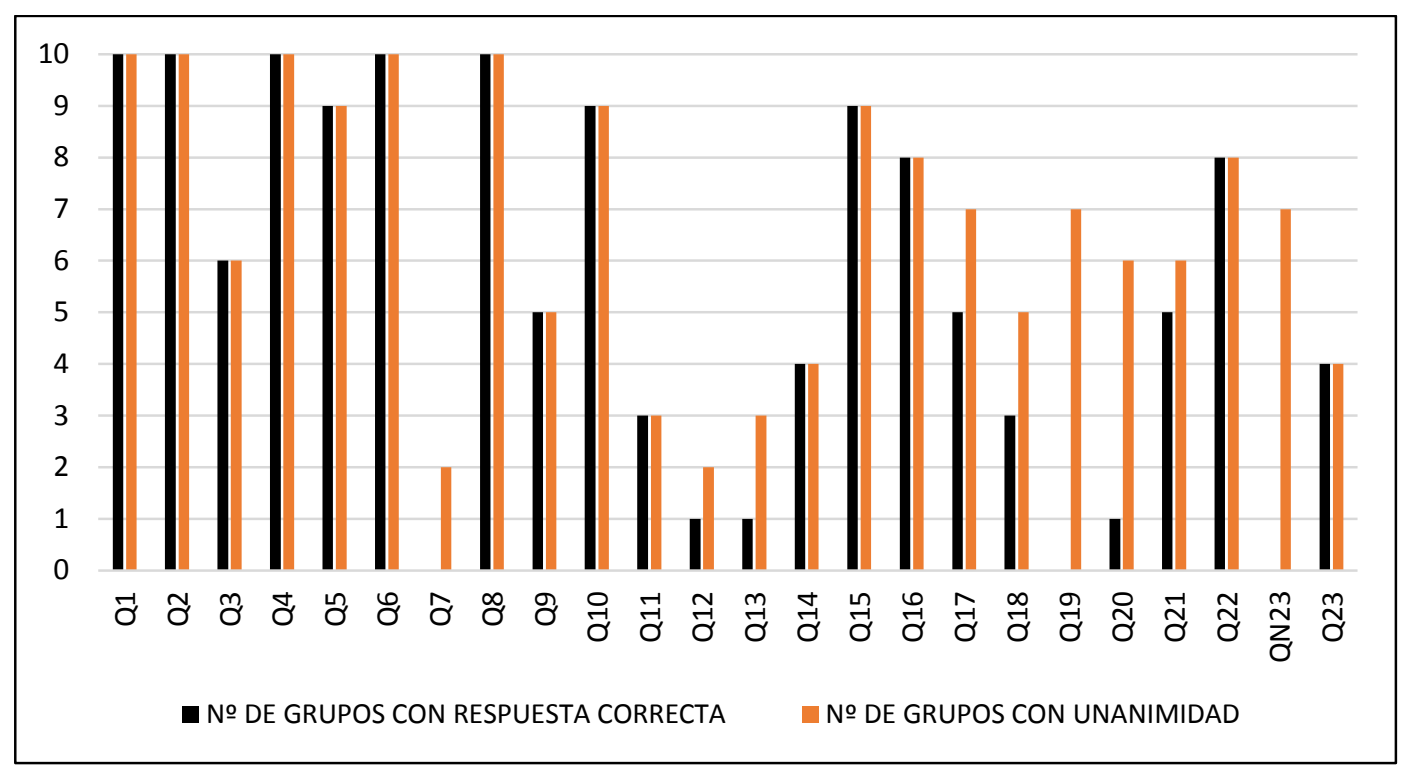

Fig. 3.8: $\mathrm{N}^{\circ}$ de grupos con respuesta correcta y con respuesta unánime, en la segunda fase de la corrección

Vemos en el gráfico que las preguntas Q7, Q12, Q13, Q17, Q18, Q19, Q20, Q21 y QN23 han obtenido respuesta unánime pero incorrecta en alguno de los grupos, destacando entre ellas Q7 y QN23 cuya respuesta consensuada es incorrecta en todos los casos. La pregunta Q7 corresponde a una operación lógica combinada con predicados: la negación de una conjunción. La pregunta QN23 es una proposición cuyo valor de verdad es desconocido. A partir de los resultados observados, en las siguientes fases cabe esperar, debido a la falta de consenso en muchos de los grupos, debates que permitan observar los razonamientos de los estudiantes.

Tercera fase: Confrontación entre las respuestas dentro del grupo. (Continúa la devolución de la corrección y de formulación-validación de la toma de decisiones)

Tras la resolución individual del cuestionario, el profesor organiza esta tercera fase en la que los estudiantes exponen sus resultados, los comparten y en caso de desacuerdo, hacen 
explícitas las razones que les han conducido a la respuesta elegida. Se trata de una situación de formulación, donde los razonamientos personales de los estudiantes se hacen explícitos, bien para describir o explicar las acciones llevadas a cabo, bien para convencer a los demás miembros del grupo de la respuesta considerada como respuesta correcta. Aun a pesar de las discusiones y de las argumentaciones, algunas de las respuestas no han alcanzado un acuerdo, dejando determinadas preguntas sin respuesta, opción permitida por indicación explícita del profesor. Por lo tanto, no siempre se da una situación de validación en esta tercera fase.

A continuación, se muestran las preguntas consensuadas en esta fase y los grupos correspondientes:

\begin{tabular}{|c|c|c|}
\hline Qi & Grupos de la Sesión 1 & Grupos de la Sesión 2 \\
\hline Q1 & $2^{\mathrm{a}}$ fase: TODOS & $2^{\mathrm{a}}$ fase: TODOS \\
\hline $\mathrm{Q} 2$ & $2^{\mathrm{a}}$ fase: TODOS & $2^{\mathrm{a}}$ fase: TODOS \\
\hline Q3 & $\begin{array}{l}2^{\mathrm{a}} \text { fase: } \mathrm{A} 2, \mathrm{~B} 1, \mathrm{~B} 2, \mathrm{~B} 3 \\
3^{\mathrm{a}} \text { fase: } \mathrm{A} 1, \mathrm{~A} 3 \text { TODOS }\end{array}$ & $\begin{array}{l}2^{\mathrm{a}} \text { fase: } \mathrm{C} 1, \mathrm{D} 1 \\
3^{\mathrm{a}} \text { fase: } \mathrm{C} 2, \mathrm{D} 2 \text { TODOS }\end{array}$ \\
\hline$\overline{\mathrm{Q} 4}$ & $2^{\text {a fase: }}$ TODOS & $2^{\mathrm{a}}$ fase: TODOS \\
\hline Q5 & $2^{a}$ fase: TODOS & $\begin{array}{l}2^{\mathrm{a}} \text { fase: } \mathrm{C} 2, \mathrm{D} 1, \mathrm{D} 2 \\
3^{\text {a }} \text { fase: } \mathrm{C} 1 \quad \text { TODOS }\end{array}$ \\
\hline Q6 & $2^{\text {a fase: }}$ TODOS & $2^{\mathrm{a}}$ fase: TODOS \\
\hline Q7 & $\begin{array}{l}2^{\mathrm{a}} \text { fase: } \mathrm{B} 1, \mathrm{~B} 3 \\
3^{\mathrm{a}} \text { fase: } \mathrm{A} 1, \mathrm{~A} 2, \mathrm{~A} 3, \mathrm{~B} 2 \text { TODOS }\end{array}$ & $\begin{array}{ll}2^{\mathrm{a}} \text { fase: } & \text { NINGUNO } \\
3^{\mathrm{a}} \text { fase: } & \mathrm{C} 1, \mathrm{C} 2, \mathrm{D} 1, \mathrm{D} 2 \text { TODOS }\end{array}$ \\
\hline Q8 & $2^{\mathrm{a}}$ fase: TODOS & $2^{\mathrm{a}}$ fase: TODOS \\
\hline Q9 & $\begin{array}{ll}2^{\mathrm{a}} \text { fase: } & \mathrm{A} 3, \mathrm{~B} 2, \mathrm{~B} 3 \\
3^{\mathrm{a}} \text { fase: } & \mathrm{A} 1, \mathrm{~A} 2, \mathrm{~B} 1 \quad \text { TODOS }\end{array}$ & $\begin{array}{l}2^{\mathrm{a}} \text { fase: } \mathrm{C} 2, \mathrm{D} 1 \\
3^{\mathrm{a}} \text { fase: } \mathrm{C} 1, \mathrm{D} 2 \text { TODOS }\end{array}$ \\
\hline Q10 & $\begin{array}{l}2^{\mathrm{a}} \text { fase: } \mathrm{A} 2, \mathrm{~A} 3, \mathrm{~B} 1, \mathrm{~B} 2, \mathrm{~B} 3 \\
3^{\mathrm{a}} \text { fase: }\end{array}$ & $2^{\mathrm{a}}$ fase: TODOS \\
\hline Q11 & $\begin{array}{ll}2^{\mathrm{a}} \text { fase: } & \mathrm{B} 3 \\
3^{\mathrm{a}} \text { fase: } & \mathrm{A} 1, \mathrm{~A} 2, \mathrm{~B} 1, \mathrm{~B} 2\end{array}$ & $\begin{array}{l}2^{\mathrm{a}} \text { fase: } \mathrm{D} 1, \mathrm{D} 2 \\
3^{\mathrm{a}} \text { fase: } \mathrm{C} 1, \mathrm{C} 2 \text { TODOS }\end{array}$ \\
\hline
\end{tabular}




\begin{tabular}{|c|c|c|}
\hline Q12 & $\begin{array}{l}2^{a} \text { fase: } B 3 \\
3^{a} \text { fase: } A 1, A 2, A 3, B 1\end{array}$ & $\begin{array}{l}2^{\mathrm{a}} \text { fase: } \mathrm{D} 1 \\
3^{\mathrm{a}} \text { fase: } \mathrm{D} 2\end{array}$ \\
\hline Q13 & $\begin{array}{l}2^{\mathrm{a}} \text { fase: } \mathrm{A} 2, \mathrm{~B} 3 \\
3^{\mathrm{a}} \text { fase: } \mathrm{A} 1, \mathrm{~A} 3, \mathrm{~B} 1, \mathrm{~B} 2, \mathrm{~B} 3 \\
\text { TODOS }\end{array}$ & $\begin{array}{l}2^{\mathrm{a}} \text { fase: } \mathrm{D} 2 \\
3^{\mathrm{a}} \text { fase: } \mathrm{C} 1, \mathrm{C} 2, \mathrm{D} 1 \mathrm{TODOS}\end{array}$ \\
\hline Q14 & $\begin{array}{ll}2^{\mathrm{a}} \text { fase: } & \mathrm{A} 1, \mathrm{~A} 3, \mathrm{~B} 3 \\
3^{\mathrm{a}} \text { fase: } & \mathrm{A} 2, \mathrm{~B} 1, \mathrm{~B} 2 \text { TODOS }\end{array}$ & $\begin{array}{ll}2^{\mathrm{a}} \text { fase: } & \mathrm{D} 1 \\
3^{\mathrm{a}} \text { fase: } & \mathrm{C} 1, \mathrm{C} 2, \mathrm{D} 2 \mathrm{TODOS}\end{array}$ \\
\hline Q15 & $\begin{array}{l}2^{\mathrm{a}} \text { fase: } \mathrm{A} 1, \mathrm{~A} 3, \mathrm{~B} 1, \mathrm{~B} 2, \mathrm{~B} 3 \\
3^{\mathrm{a}} \text { fase: }\end{array}$ & $2^{\mathrm{a}}$ fase: TODOS \\
\hline Q16 & $\begin{array}{l}2^{\mathrm{a}} \text { fase: } \mathrm{A} 2, \mathrm{~B} 1, \mathrm{~B} 2, \mathrm{~B} 3 \\
3^{\mathrm{a}} \text { fase: } \\
\mathrm{A} 1, \mathrm{~A} 3 \text { TODOS }\end{array}$ & $2^{a}$ fase: TODOS \\
\hline Q17 & $\begin{array}{ll}2^{\mathrm{a}} \text { fase: } & \mathrm{A} 1, \mathrm{~A} 2, \mathrm{~A} 3, \mathrm{~B} 1, \mathrm{~B} 3 \\
3^{\mathrm{a}} \text { fase: } & \mathrm{B} 2 \text { TODOS }\end{array}$ & $\begin{array}{l}2^{\mathrm{a}} \text { fase: } \mathrm{D} 1, \mathrm{D} 2 \\
3^{\mathrm{a}} \text { fase: } \mathrm{C} 1, \mathrm{C} 2 \text { TODOS }\end{array}$ \\
\hline Q18 & $\begin{array}{ll}2^{\mathrm{a}} \text { fase: } & \mathrm{A} 1, \mathrm{~A} 2, \mathrm{~B} 2, \mathrm{~B} 3 \\
3^{\mathrm{a}} \text { fase: } & \mathrm{A} 3, \mathrm{~B} 1 \quad \text { TODOS }\end{array}$ & $\begin{array}{ll}2^{\mathrm{a}} \text { fase: } & \mathrm{D} 2 \\
3^{\mathrm{a}} \text { fase: } & \mathrm{C} 1, \mathrm{C} 2, \mathrm{D} 1 \quad \text { TODOS }\end{array}$ \\
\hline Q19 & $2^{\mathrm{a}}$ fase: $\mathrm{A} 1, \mathrm{~A} 2, \mathrm{~B} 1, \mathrm{~B} 2, \mathrm{~B} 3$ & $\begin{array}{ll}2^{\mathrm{a}} \text { fase: } & \mathrm{D} 1, \mathrm{D} 2 \\
3^{\mathrm{a}} \text { fase: } & \mathrm{C} 1, \mathrm{C} 2 \text { TODOS }\end{array}$ \\
\hline Q20 & $\begin{array}{l}2^{\mathrm{a}} \text { fase: } \mathrm{A} 1, \mathrm{~A} 2, \mathrm{~B} 1, \mathrm{~B} 3 \\
3^{\mathrm{a}} \text { fase: } \mathrm{B} 2, \mathrm{~B} 3\end{array}$ & $\begin{array}{l}2^{\mathrm{a}} \text { fase: } \mathrm{D} 1, \mathrm{D} 2 \\
3^{\mathrm{a}} \text { fase: } \mathrm{C} 2\end{array}$ \\
\hline Q21 & $\begin{array}{l}2^{\mathrm{a}} \text { fase: } \mathrm{A} 1, \mathrm{~A} 2, \mathrm{~B} 2, \mathrm{~B} 3 \\
3^{\mathrm{a}} \text { fase: } \mathrm{B} 1\end{array}$ & $\begin{array}{l}2^{\mathrm{a}} \text { fase: } \mathrm{D} 1, \mathrm{D} 2 \\
3^{\mathrm{a}} \text { fase: } \mathrm{C} 2\end{array}$ \\
\hline Q22 & $\begin{array}{ll}2^{\mathrm{a}} \text { fase: } & \mathrm{A} 1, \mathrm{~A} 3, \mathrm{~B} 2, \mathrm{~B} 3 \\
3^{\mathrm{a}} \text { fase: } & \mathrm{A} 2, \mathrm{~B} 1 \quad \text { TODOS }\end{array}$ & $2^{\mathrm{a}}$ fase: TODOS \\
\hline QN23 & $\begin{array}{l}2^{\mathrm{a}} \text { fase: } \mathrm{A} 2, \mathrm{~B} 1, \mathrm{~B} 3 \\
3^{\mathrm{a}} \text { fase: } \mathrm{B} 2\end{array}$ & $2^{a}$ fase: TODOS \\
\hline Q23 & $\begin{array}{l}2^{\mathrm{a}} \text { fase: } \mathrm{A} 2, \mathrm{~B} 3 \\
3^{\mathrm{a}} \text { fase: } \mathrm{B} 1, \mathrm{~B} 2\end{array}$ & $\begin{array}{l}2^{\mathrm{a}} \text { fase: } \mathrm{D} 1, \mathrm{D} 2 \\
3^{\mathrm{a}} \text { fase: } \mathrm{C} 2\end{array}$ \\
\hline
\end{tabular}

Tabla 3.3: Grupos que han consensuado respuesta en la tercera fase de la corrección 
En esta fase no han obtenido una respuesta consensuada en alguno de los grupos las cuestiones Q11, Q12, Q19, Q20, Q21, QN23 y Q23, todas ellas con un elevado porcentaje de respuestas incorrectas en la primera realización del cuestionario.

Las observaciones que ha permitido esta fase han sido:

- $\quad$ El consenso de la respuesta dada a la pregunta Q7 se debe a la interpretación de la negación de la conjunción como una conjunción de negaciones.

- $\quad$ La ausencia del modelo lógico que permite la equivalencia entre la implicación y su contrarrecíproca. Esta ausencia de conocimiento lógico se pone de manifiesto en las respuestas de la pregunta QN23.

- La dificultad en reconocer que el valor de verdad de una afirmación es desconocido.

- La tendencia que tienen los estudiantes a aceptar la respuesta dada por la mayoría. Incluso cuando en el debate aparece el razonamiento lógico, éste es rechazado si no coincide con la mayoría.

Cuarta fase: Intercambio de respuestas entre grupos (Devolución de la corrección y desequilibrio en la toma de decisiones iniciales)

Esta cuarta fase es una situación de validación y ha puesto de manifiesto la inseguridad en la elección de las respuestas de algunos estudiantes. La información procedente de otro grupo bien ha servido para reafirmarse en las decisiones ya tomadas, bien ha generado dudas y desequilibrios sobre la validación anterior.

Se ha observado en algunos grupos que las decisiones tomadas por consenso no se cuestionan, rechazando cualquier otra respuesta procedente de fuera del grupo.

Los cambios producidos en esta cuarta fase se han dado en las cuestiones Q11, Q12, Q13 y Q18, tal y como se presenta en la siguiente tabla, donde se muestra la evolución de las respuestas consensuadas por grupos y fases: 


\begin{tabular}{|c|c|c|}
\hline Qi & Grupos de la Sesión 1 & Grupos de la Sesión 2 \\
\hline Q1 & $2^{\mathrm{a}}$ fase: TODOS & $2^{\mathrm{a}}$ fase: TODOS \\
\hline $\mathrm{Q} 2$ & $2^{\mathrm{a}}$ fase: TODOS & $2^{\mathrm{a}}$ fase: TODOS \\
\hline Q3 & $\begin{array}{l}2^{\mathrm{a}} \text { fase: } \mathrm{A} 2, \mathrm{~B} 1, \mathrm{~B} 2, \mathrm{~B} 3 \\
3^{\mathrm{a}} \text { fase: } \mathrm{A} 1, \mathrm{~A} 3 \text { TODOS }\end{array}$ & $\begin{array}{ll}2^{\mathrm{a}} \text { fase: } & \mathrm{C} 1, \mathrm{D} 1 \\
3^{\mathrm{a}} \text { fase: } & \mathrm{C} 2, \mathrm{D} 2 \text { TODOS }\end{array}$ \\
\hline Q4 & $2^{\mathrm{a}}$ fase: TODOS & $2^{\mathrm{a}}$ fase: TODOS \\
\hline Q5 & $2^{a}$ fase: TODOS & $\begin{array}{l}2^{\mathrm{a}} \text { fase: } \mathrm{C} 2, \mathrm{D} 1, \mathrm{D} 2 \\
3^{\mathrm{a}} \text { fase: } \mathrm{C} 1 \text { TODOS }\end{array}$ \\
\hline Q6 & $2^{a}$ fase: TODOS & $2^{\mathrm{a}}$ fase: TODOS \\
\hline Q7 & $\begin{array}{l}2^{\mathrm{a}} \text { fase: } \mathrm{B} 1, \mathrm{~B} 3 \\
3^{\mathrm{a}} \text { fase: } \mathrm{A} 1, \mathrm{~A} 2, \mathrm{~A} 3, \mathrm{~B} 2 \text { TODOS }\end{array}$ & $\begin{array}{ll}2^{\mathrm{a}} \text { fase: } & \text { NINGUNO } \\
3^{\mathrm{a}} \text { fase: } & \mathrm{C} 1, \mathrm{C} 2, \mathrm{D} 1, \mathrm{D} 2 \text { TODOS }\end{array}$ \\
\hline Q8 & $2^{\mathrm{a}}$ fase: TODOS & $2^{\mathrm{a}}$ fase: TODOS \\
\hline Q9 & $\begin{array}{l}2^{\mathrm{a}} \text { fase: } \mathrm{A} 3, \mathrm{~B} 2, \mathrm{~B} 3 \\
3^{\mathrm{a}} \text { fase: } \mathrm{A} 1, \mathrm{~A} 2, \mathrm{~B} 1 \quad \text { TODOS }\end{array}$ & $\begin{array}{ll}2^{\mathrm{a}} \text { fase: } & \mathrm{C} 2, \mathrm{D} 1 \\
3^{\mathrm{a}} \text { fase: } & \mathrm{C} 1, \mathrm{D} 2 \text { TODOS }\end{array}$ \\
\hline Q10 & $\begin{array}{l}2^{\mathrm{a}} \text { fase: } \mathrm{A} 2, \mathrm{~A} 3, \mathrm{~B} 1, \mathrm{~B} 2, \mathrm{~B} 3 \\
3^{\mathrm{a}} \text { fase: }\end{array}$ & $2^{\mathrm{a}}$ fase: TODOS \\
\hline Q11 & $\begin{array}{ll}2^{\mathrm{a}} \text { fase: } & \mathrm{B} 3 \\
3^{\mathrm{a}} \text { fase: } & \mathrm{A} 1, \mathrm{~A} 2, \mathrm{~B} 1, \mathrm{~B} 2 \\
4^{\mathrm{a}} \text { fase: } & \text { A3 TODOS }\end{array}$ & $\begin{array}{l}2^{\mathrm{a}} \text { fase: } \mathrm{D} 1, \mathrm{D} 2 \\
3^{\mathrm{a}} \text { fase: } \mathrm{C} 1, \mathrm{C} 2 \text { TODOS }\end{array}$ \\
\hline Q12 & $\begin{array}{ll}2^{\mathrm{a}} \text { fase: } & \mathrm{B} 3 \\
3^{\mathrm{a}} \text { fase: } & \mathrm{A} 1, \mathrm{~A} 2, \mathrm{~A} 3, \mathrm{~B} 1 \\
4^{\mathrm{a}} \text { fase: } & \mathrm{B} 3\end{array}$ & $\begin{array}{ll}2^{\mathrm{a}} \text { fase: } & \mathrm{D} 1 \\
3^{\mathrm{a}} \text { fase: } & \mathrm{D} 2 \\
4^{\mathrm{a}} \text { fase: } & \mathrm{C} 2\end{array}$ \\
\hline Q13 & $\begin{array}{l}2^{\mathrm{a}} \text { fase: } \mathrm{A} 2, \mathrm{~B} 3 \\
3^{\mathrm{a}} \text { fase: A1, A3, B1, B2, B3 } \\
\text { TODOS } \\
4^{\mathrm{a}} \text { fase: A2 TODOS }\end{array}$ & $\begin{array}{ll}2^{\mathrm{a}} \text { fase: } & \mathrm{D} 2 \\
3^{\mathrm{a}} \text { fase: } & \mathrm{C} 1, \mathrm{C} 2, \mathrm{D} 1 \quad \text { TODOS }\end{array}$ \\
\hline Q14 & $\begin{array}{l}2^{\mathrm{a}} \text { fase: } \mathrm{A} 1, \mathrm{~A} 3, \mathrm{~B} 3 \\
3^{\mathrm{a}} \text { fase: } \mathrm{A} 2, \mathrm{~B} 1, \mathrm{~B} 2 \text { TODOS }\end{array}$ & $\begin{array}{ll}2^{\mathrm{a}} \text { fase: } & \mathrm{D} 1 \\
3^{\mathrm{a}} \text { fase: } & \mathrm{C} 1, \mathrm{C} 2, \mathrm{D} 2 \mathrm{TODOS}\end{array}$ \\
\hline Q15 & $\begin{array}{l}2^{\mathrm{a}} \text { fase: } \mathrm{A} 1, \mathrm{~A} 3, \mathrm{~B} 1, \mathrm{~B} 2, \mathrm{~B} 3 \\
3^{\mathrm{a}} \text { fase: }\end{array}$ & $2^{\mathrm{a}}$ fase: TODOS \\
\hline Q16 & $\begin{array}{l}2^{\mathrm{a}} \text { fase: } \mathrm{A} 2, \mathrm{~B} 1, \mathrm{~B} 2, \mathrm{~B} 3 \\
3^{\mathrm{a}} \text { fase: } \mathrm{A} 1, \mathrm{~A} 3 \text { TODOS }\end{array}$ & $2^{a}$ fase: TODOS \\
\hline
\end{tabular}




\begin{tabular}{|c|c|c|}
\hline Q17 & $\begin{array}{l}2^{\mathrm{a}} \text { fase: } \mathrm{A} 1, \mathrm{~A} 2, \mathrm{~A} 3, \mathrm{~B} 1, \mathrm{~B} 3 \\
3^{\mathrm{a}} \text { fase: } \mathrm{B} 2 \text { TODOS }\end{array}$ & $\begin{array}{l}2^{\mathrm{a}} \text { fase: } \mathrm{D} 1, \mathrm{D} 2 \\
3^{\mathrm{a}} \text { fase: } \mathrm{C} 1, \mathrm{C} 2 \text { TODOS }\end{array}$ \\
\hline Q18 & $\begin{array}{l}2^{\mathrm{a}} \text { fase: } \mathrm{A} 1, \mathrm{~A} 2, \mathrm{~B} 2, \mathrm{~B} 3 \\
3^{\mathrm{a}} \text { fase: } \mathrm{A} 3, \mathrm{~B} 1 \text { TODOS } \\
4^{\mathrm{a}} \text { fase: } \mathrm{B} 3 \text { TODOS }\end{array}$ & $\begin{array}{l}2^{\mathrm{a}} \text { fase: } \mathrm{D} 2 \\
3^{\mathrm{a}} \text { fase: } \mathrm{C} 1, \mathrm{C} 2, \mathrm{D} 1 \quad \text { TODOS }\end{array}$ \\
\hline Q19 & $2^{\mathrm{a}}$ fase: $\mathrm{A} 1, \mathrm{~A} 2, \mathrm{~B} 1, \mathrm{~B} 2, \mathrm{~B} 3$ & $\begin{array}{l}2^{\mathrm{a}} \text { fase: } \mathrm{D} 1, \mathrm{D} 2 \\
3^{\mathrm{a}} \text { fase: } \mathrm{C} 1, \mathrm{C} 2 \text { TODOS }\end{array}$ \\
\hline Q20 & $\begin{array}{l}2^{\mathrm{a}} \text { fase: } \mathrm{A} 1, \mathrm{~A} 2, \mathrm{~B} 1, \mathrm{~B} 3 \\
3^{\mathrm{a}} \text { fase: } \mathrm{B} 2, \mathrm{~B} 3\end{array}$ & $\begin{array}{l}2^{\mathrm{a}} \text { fase: } \mathrm{D} 1, \mathrm{D} 2 \\
3^{\mathrm{a}} \text { fase: } \mathrm{C} 2\end{array}$ \\
\hline Q21 & $\begin{array}{l}2^{a} \text { fase: } A 1, A 2, B 2, B 3 \\
3^{\text {a fase: }} B 1\end{array}$ & $\begin{array}{l}2^{\mathrm{a}} \text { fase: } \mathrm{D} 1, \mathrm{D} 2 \\
3^{\mathrm{a}} \text { fase: } \mathrm{C} 2\end{array}$ \\
\hline Q22 & $\begin{array}{ll}2^{\mathrm{a}} \text { fase: } & \mathrm{A} 1, \mathrm{~A} 3, \mathrm{~B} 2, \mathrm{~B} 3 \\
3^{\mathrm{a}} \text { fase: } & \mathrm{A} 2, \mathrm{~B} 1 \quad \text { TODOS }\end{array}$ & $2^{\mathrm{a}}$ fase: TODOS \\
\hline QN23 & $\begin{array}{l}2^{a} \text { fase: } A 2, B 1, B 3 \\
3^{a} \text { fase: } B 2\end{array}$ & $2^{\mathrm{a}}$ fase: TODOS \\
\hline Q23 & $\begin{array}{l}2^{\mathrm{a}} \text { fase: } \mathrm{A} 2, \mathrm{~B} 3 \\
3^{\mathrm{a}} \text { fase: } \mathrm{B} 1, \mathrm{~B} 2\end{array}$ & $\begin{array}{l}2^{\mathrm{a}} \text { fase: } \mathrm{D} 1, \mathrm{D} 2 \\
3^{\mathrm{a}} \text { fase: } \mathrm{C} 2\end{array}$ \\
\hline
\end{tabular}

Tabla 3.4: Grupos que han consensuado respuesta en la cuarta fase de la corrección de $Q$

La pregunta Q11 ha obtenido una primera respuesta consensuada en esta fase por el grupo A3. , mientras que en las preguntas Q12, Q13 y Q18 se trata de un cambio de respuesta, unánime en la segunda fase y por lo tanto no cuestionadas hasta ahora. La validación no ha sido posible para todas las preguntas y grupos. En esta cuarta fase siguen sin respuesta las preguntas Q12 (grupos B2 y C1), Q19 (grupo A3), Q20 (grupos A3 y C1), Q21 (grupos A3 y C1), QN23 (grupos A1 y A3) y Q23 (grupos A1, A3 y C1).

Quinta fase: Debate colectivo entre todos los grupos y resultado final de las respuestas del cuestionario

Esta fase la situación adidáctica pasa a ser una situación didáctica, debido a la intervención del profesor. El profesor debe gestionar los razonamientos de los estudiantes 
mediante la tabla. Los estudiantes, una vez alcanzada esta fase de la corrección, están convencidos de las respuestas que han dado. En general se han resistido a cambiar la solución dada o a aceptar las respuestas de otros grupos, incluso cuando no lo tenían claro o habían dejado alguna cuestión sin responder.

En la sesión 1, el profesor no ha utilizado la tabla en la gestión de los razonamientos, hecho que ha dificultado la corrección colectiva. Ha utilizado otros recursos didácticos en la gestión de los razonamientos, principalmente preguntas que de forma espontánea surgían a partir de los comentarios de los estudiantes y analogías que representaban situaciones donde las interpretaciones del lenguaje natural coincidían con las interpretaciones del lenguaje de la lógica formal. En esta fase se ha puesto de manifiesto una vez más el obstáculo que supone el lenguaje natural en la construcción del conocimiento lógico ya que la validez de las analogías fácilmente era rebatida con otras analogías u opiniones personales.

En la sesión 2, tras los conflictos generados en la sesión anterior, el profesor ha hecho que los estudiantes utilizaran la tabla para explicar sus respuestas, poniendo de manifiesto que la tabla es, en sí misma, un instrumento de gestión y validación de los razonamientos. Además, debido a la dificultad mostrada por los estudiantes ante las seis últimas preguntas, cuyas respuestas no vienen representadas sobre la tabla, el profesor ha intervenido también mediante el uso de la tabla: se le ha añadido una última fila sin datos, haciéndola corresponder con el criterio C16, introducido por la premisa de la consigna:

«A todos los estudiantes que les gusta practicar deporte les gusta nadar»

La tabla ampliada, mostrada inicialmente por el profesor, ha sido la siguiente: 


\begin{tabular}{|l|l|l|l|l|l|l|l|l|l|l|l|l|l|l|l|l|l|l|l|l|}
\hline ¿Te gusta... & $\mathbf{A}$ & $\mathbf{B}$ & $\mathbf{C}$ & $\mathbf{D}$ & $\mathbf{E}$ & $\mathbf{F}$ & $\mathbf{G}$ & $\mathbf{H}$ & $\mathbf{I}$ & $\mathbf{J}$ & $\mathbf{K}$ & $\mathbf{L}$ & $\mathbf{M}$ & $\mathbf{N}$ & $\mathbf{O}$ & $\mathbf{P}$ & $\mathbf{Q}$ & $\mathbf{R}$ & $\mathbf{S}$ & $\mathbf{T}$ \\
\hline$\ldots$ & & & & & & & & & & & & & & & & & & & & \\
\hline $\begin{array}{l}\text { practicar } \\
\text { deporte? (C2) }\end{array}$ & 1 & 0 & 0 & 1 & 0 & 0 & 0 & 1 & 0 & 0 & 0 & 0 & 0 & 0 & 1 & 0 & 0 & 0 & 1 & 0 \\
\hline$\ldots$ & & & & & & & & & & & & & & & & & & & & \\
\hline nadar? (C16) & & & & & & & & & & & & & & & & & & & & \\
\hline
\end{tabular}

Tabla 3.5: Tabla $\mathrm{T}$ ampliada con una nueva fila (criterio C16)

A continuación el profesor ha propuesto rellenar las celdas de dicha fila con la información proporcionada por la premisa, obteniendo de este modo la siguiente tabla:

\begin{tabular}{|l|l|l|l|l|l|l|l|l|l|l|l|l|l|l|l|l|l|l|l|l|}
\hline ¿Te gusta... & $\mathbf{A}$ & $\mathbf{B}$ & $\mathbf{C}$ & $\mathbf{D}$ & $\mathbf{E}$ & $\mathbf{F}$ & $\mathbf{G}$ & $\mathbf{H}$ & $\mathbf{I}$ & $\mathbf{J}$ & $\mathbf{K}$ & $\mathbf{L}$ & $\mathbf{M}$ & $\mathbf{N}$ & $\mathbf{O}$ & $\mathbf{P}$ & $\mathbf{Q}$ & $\mathbf{R}$ & $\mathbf{S}$ & $\mathbf{T}$ \\
\hline$\ldots$ & & & & & & & & & & & & & & & & & & & & \\
\hline $\begin{array}{l}\text { practicar } \\
\text { deporte? (C2) }\end{array}$ & 1 & 0 & 0 & 1 & 0 & 0 & 0 & 1 & 0 & 0 & 0 & 0 & 0 & 0 & 1 & 0 & 0 & 0 & 1 & 0 \\
\hline$\ldots$ & & & & & & & & & & & & & & & & & & & & \\
\hline nadar? (C16) & 1 & & & 1 & & & & 1 & & & & & & & 1 & & & & 1 & \\
\hline
\end{tabular}

Tabla 3.6: Tabla $T$ ampliada con una nueva fila (criterio C16) y completada con los datos correspondientes

Este cambio ha provocado reacciones en los estudiantes, lo que ha demostrado la efectividad de la tabla $\mathrm{T}$ en la gestión de los razonamientos.

A continuación podemos ver los resultados obtenidos en esta quinta fase así como la evolución de las respuestas a lo largo de las diferentes fases y grupos. 


\begin{tabular}{|c|c|c|}
\hline Qi & Grupos de la Sesión 1 & Grupos de la Sesión 2 \\
\hline Q1 & $2^{\mathrm{a}}$ fase: TODOS & $2^{\mathrm{a}}$ fase: TODOS \\
\hline Q2 & $2^{\mathrm{a}}$ fase: TODOS & $2^{a}$ fase: TODOS \\
\hline Q3 & $\begin{array}{l}2^{\mathrm{a}} \text { fase: } \mathrm{A} 2, \mathrm{~B} 1, \mathrm{~B} 2, \mathrm{~B} 3 \\
3^{\mathrm{a}} \text { fase: } \mathrm{A} 1, \mathrm{~A} 3 \text { TODOS }\end{array}$ & $\begin{array}{l}2^{\mathrm{a}} \text { fase: } \mathrm{C} 1, \mathrm{D} 1 \\
3^{\mathrm{a}} \text { fase: } \mathrm{C} 2, \mathrm{D} 2 \text { TODOS }\end{array}$ \\
\hline Q4 & $2^{\mathrm{a}}$ fase: TODOS & $2^{\mathrm{a}}$ fase: TODOS \\
\hline Q5 & $2^{\mathrm{a}}$ fase: TODOS & $\begin{array}{ll}2^{\mathrm{a}} \text { fase: } & \mathrm{C} 2, \mathrm{D} 1, \mathrm{D} 2 \\
3^{\mathrm{a}} \text { fase: } & \mathrm{C} 1 \text { TODOS }\end{array}$ \\
\hline Q6 & $2^{\mathrm{a}}$ fase: TODOS & $2^{\mathrm{a}}$ fase: TODOS \\
\hline Q7 & $\begin{array}{l}2^{\mathrm{a}} \text { fase: } \mathrm{B} 1, \mathrm{~B} 3 \\
3^{\mathrm{a}} \text { fase: } \mathrm{A} 1, \mathrm{~A} 2, \mathrm{~A} 3, \mathrm{~B} 2 \text { TODOS }\end{array}$ & $\begin{array}{ll}2^{\mathrm{a}} \text { fase: } & \text { NINGUNO } \\
3^{\mathrm{a}} \text { fase: } & \mathrm{C} 1, \mathrm{C} 2, \mathrm{D} 1, \mathrm{D} 2 \text { TODOS }\end{array}$ \\
\hline Q8 & $2^{\mathrm{a}}$ fase: TODOS & $2^{\mathrm{a}}$ fase: TODOS \\
\hline Q9 & $\begin{array}{l}2^{\mathrm{a}} \text { fase: } \mathrm{A} 3, \mathrm{~B} 2, \mathrm{~B} 3 \\
3^{\mathrm{a}} \text { fase: } \mathrm{A} 1, \mathrm{~A} 2, \mathrm{~B} 1 \quad \text { TODOS }\end{array}$ & $\begin{array}{l}2^{\mathrm{a}} \text { fase: } \mathrm{C} 2, \mathrm{D} 1 \\
3^{\mathrm{a}} \text { fase: } \mathrm{C} 1, \mathrm{D} 2 \text { TODOS }\end{array}$ \\
\hline Q10 & $\begin{array}{l}2^{\mathrm{a}} \text { fase: } \mathrm{A} 2, \mathrm{~A} 3, \mathrm{~B} 1, \mathrm{~B} 2, \mathrm{~B} 3 \\
3^{\mathrm{a}} \text { fase: A1 TODOS }\end{array}$ & $2^{\mathrm{a}}$ fase: TODOS \\
\hline Q11 & $\begin{array}{l}2^{\mathrm{a}} \text { fase: } \mathrm{B} 3 \\
3^{\mathrm{a}} \text { fase: } \mathrm{A} 1, \mathrm{~A} 2, \mathrm{~B} 1, \mathrm{~B} 2 \\
4^{\mathrm{a}} \text { fase: }\end{array}$ & $\begin{array}{ll}2^{\mathrm{a}} \text { fase: } & \mathrm{D} 1, \mathrm{D} 2 \\
3^{\mathrm{a}} \text { fase: } & \mathrm{C} 1, \mathrm{C} 2 \text { TODOS }\end{array}$ \\
\hline Q12 & $\begin{array}{l}2^{\mathrm{a}} \text { fase: } \mathrm{B} 3 \\
3^{\mathrm{a}} \text { fase: } \mathrm{A} 1, \mathrm{~A} 2, \mathrm{~A} 3, \mathrm{~B} 1 \\
4^{\mathrm{a}} \text { fase: } \mathrm{B} 3\end{array}$ & $\begin{array}{l}2^{\mathrm{a}} \text { fase: } \mathrm{D} 1 \\
3^{\mathrm{a}} \text { fase: } \\
4^{\mathrm{a}} \text { fase: } \\
\text { C2 }\end{array}$ \\
\hline Q13 & $\begin{array}{l}2^{\mathrm{a}} \text { fase: } \mathrm{A} 2, \mathrm{~B} 3 \\
3^{\mathrm{a}} \text { fase: A1, A3, B1, B2, B3 } \\
\text { TODOS } \\
4^{\mathrm{a}} \text { fase: A2 TODOS }\end{array}$ & $\begin{array}{l}2^{\mathrm{a}} \text { fase: } \mathrm{D} 2 \\
3^{\mathrm{a}} \text { fase: } \mathrm{C} 1, \mathrm{C} 2, \mathrm{D} 1 \text { TODOS }\end{array}$ \\
\hline Q14 & $\begin{array}{ll}2^{\mathrm{a}} \text { fase: } & \mathrm{A} 1, \mathrm{~A} 3, \mathrm{~B} 3 \\
3^{\mathrm{a}} \text { fase: } & \mathrm{A} 2, \mathrm{~B} 1, \mathrm{~B} 2 \text { TODOS } \\
5^{\mathrm{a}} \text { fase: } & \text { A2 TODOS }\end{array}$ & $\begin{array}{l}2^{\mathrm{a}} \text { fase: } \mathrm{D} 1 \\
3^{\mathrm{a}} \text { fase: } \mathrm{C} 1, \mathrm{C} 2, \mathrm{D} 2 \text { TODOS }\end{array}$ \\
\hline
\end{tabular}




\begin{tabular}{|c|c|c|}
\hline Q15 & $\begin{array}{ll}2^{\mathrm{a}} \text { fase: } & \mathrm{A} 1, \mathrm{~A} 3, \mathrm{~B} 1, \mathrm{~B} 2, \mathrm{~B} 3 \\
3^{\mathrm{a}} \text { fase: } & \mathrm{A} 2 \text { TODOS } \\
5^{\mathrm{a}} \text { fase: } & \text { A2 } \\
\text { TODOS }\end{array}$ & $2^{\mathrm{a}}$ fase: TODOS \\
\hline Q16 & $\begin{array}{l}2^{\mathrm{a}} \text { fase: } \mathrm{A} 2, \mathrm{~B} 1, \mathrm{~B} 2, \mathrm{~B} 3 \\
3^{\mathrm{a}} \text { fase: } \mathrm{A} 1, \mathrm{~A} 3 \text { TODOS }\end{array}$ & $2^{\mathrm{a}}$ fase: TODOS \\
\hline Q17 & $\begin{array}{l}2^{\mathrm{a}} \text { fase: } \mathrm{A} 1, \mathrm{~A} 2, \mathrm{~A} 3, \mathrm{~B} 1, \mathrm{~B} 3 \\
3^{\mathrm{a}} \text { fase: } \mathrm{B} 2 \text { TODOS }\end{array}$ & $\begin{array}{l}2^{a} \text { fase: } D 1, D 2 \\
3^{a} \text { fase: } C 1, C 2 \text { TODOS }\end{array}$ \\
\hline Q18 & $\begin{array}{ll}2^{\mathrm{a}} \text { fase: } & \mathrm{A} 1, \mathrm{~A} 2, \mathrm{~B} 2, \mathrm{~B} 3 \\
3^{\mathrm{a}} \text { fase: } & \mathrm{A} 3, \mathrm{~B} 1 \text { TODOS } \\
4^{\mathrm{a}} \text { fase: } & \text { B3 TODOS }\end{array}$ & $\begin{array}{l}2^{\mathrm{a}} \text { fase: } \mathrm{D} 2 \\
3^{\mathrm{a}} \text { fase: } \mathrm{C} 1, \mathrm{C} 2, \mathrm{D} 1 \mathrm{TODOS}\end{array}$ \\
\hline Q19 & $2^{\mathrm{a}}$ fase: $\mathrm{A} 1, \mathrm{~A} 2, \mathrm{~B} 1, \mathrm{~B} 2, \mathrm{~B} 3$ & $\begin{array}{l}2^{a} \text { fase: } D 1, D 2 \\
3^{a} \text { fase: } C 1, C 2 \text { TODOS }\end{array}$ \\
\hline Q20 & $\begin{array}{l}2^{\mathrm{a}} \text { fase: } \mathrm{A} 1, \mathrm{~A} 2, \mathrm{~B} 1, \mathrm{~B} 3 \\
3^{\mathrm{a}} \text { fase: } \mathrm{B} 2, \mathrm{~B} 3\end{array}$ & $\begin{array}{l}2^{\mathrm{a}} \text { fase: } \mathrm{D} 1, \mathrm{D} 2 \\
3^{\mathrm{a}} \text { fase: } \mathrm{C} 2\end{array}$ \\
\hline Q21 & $\begin{array}{l}2^{\mathrm{a}} \text { fase: } \mathrm{A} 1, \mathrm{~A} 2, \mathrm{~B} 2, \mathrm{~B} 3 \\
3^{\mathrm{a}} \text { fase: } \mathrm{B} 1 \\
5^{\mathrm{a}} \text { fase: } \mathrm{A} 3 \text { TODOS }\end{array}$ & $\begin{array}{l}2^{\mathrm{a}} \text { fase: } \mathrm{D} 1, \mathrm{D} 2 \\
3^{\mathrm{a}} \text { fase: } \mathrm{C} 2\end{array}$ \\
\hline Q22 & $\begin{array}{l}2^{\mathrm{a}} \text { fase: } \mathrm{A} 1, \mathrm{~A} 3, \mathrm{~B} 2, \mathrm{~B} 3 \\
3^{\mathrm{a}} \text { fase: } \mathrm{A} 2, \mathrm{~B} 1 \text { TODOS }\end{array}$ & $2^{\mathrm{a}}$ fase: TODOS \\
\hline QN23 & $\begin{array}{l}2^{\mathrm{a}} \text { fase: } \mathrm{A} 2, \mathrm{~B} 1, \mathrm{~B} 3 \\
3^{\mathrm{a}} \text { fase: } \mathrm{B} 2 \\
5^{\mathrm{a}} \text { fase: }\end{array}$ & $2^{\mathrm{a}}$ fase: TODOS \\
\hline Q23 & $\begin{array}{l}2^{\mathrm{a}} \text { fase: } \mathrm{A} 2, \mathrm{~B} 3 \\
3^{\mathrm{a}} \text { fase: } \mathrm{B} 1, \mathrm{~B} 2\end{array}$ & $\begin{array}{l}2^{\mathrm{a}} \text { fase: } \mathrm{D} 1, \mathrm{D} 2 \\
3^{\mathrm{a}} \text { fase: } \mathrm{C} 2\end{array}$ \\
\hline
\end{tabular}

Tabla 3.7: Grupos que han consensuado respuesta en la quinta fase de la corrección de $Q$

Esta quinta fase tan solo ha dado lugar a cambios en las preguntas Q14 (grupo A2), Q15 (grupo A2), Q21 (grupo A3) y QN23 (grupo B3). 
El grupo A2 había obtenido una respuesta para las preguntas Q14 y Q15, cambiándola en esta quinta fase. El grupo A3, sin respuesta en la pregunta Q21, la ha decidido en esta quinta fase y el grupo B3 ha cambiado la respuesta que, por unanimidad, venía dada desde la segunda fase y que debido a la puesta en común de las respuestas del resto de grupos ha puesto en duda sus propias decisiones.

Una vez finalizada la corrección colectiva del cuestionario, sólo las cinco cuestiones indicadas en la siguiente tabla han quedado sin respuesta en alguno de los grupos.

\begin{tabular}{|c|c|c|c|c|c|}
\hline Qi & Q12 & Q19 & Q20 & QN23 & Q23 \\
\hline Grupos sin respuesta & B2, C1 & A3 & A3, C1 & A3 & A3, C1 \\
\hline
\end{tabular}

Tabla 3.8: Cuestiones sin respuesta en quinta fase de la corrección del cuestionario Q y los grupos correspondientes

La pregunta Q12, con porcentaje de respuestas correctas alrededor del 75\%, se trata de una pregunta con cierto carácter subjetivo. El resto de preguntas sin consensuar, corresponden al último bloque de preguntas, todas con atribución del valor de verdad y sin respuesta sobre la tabla. Además, se trata de preguntas que en los cuestionarios utilizados como diagnóstico no alcanzaron el $40 \%$ de respuestas correctas, tal y como se vio en el capítulo anterior.

Hasta el momento, tan solo se ha analizado la situación de corrección, en función de la validación de respuesta por parte de los grupos. A continuación se mostrarán los resultados de la corrección. En el siguiente gráfico se compara el número de grupos que han obtenido respuesta correcta en la segunda fase de la corrección y en la última, observando un claro aumento del número de aciertos: 


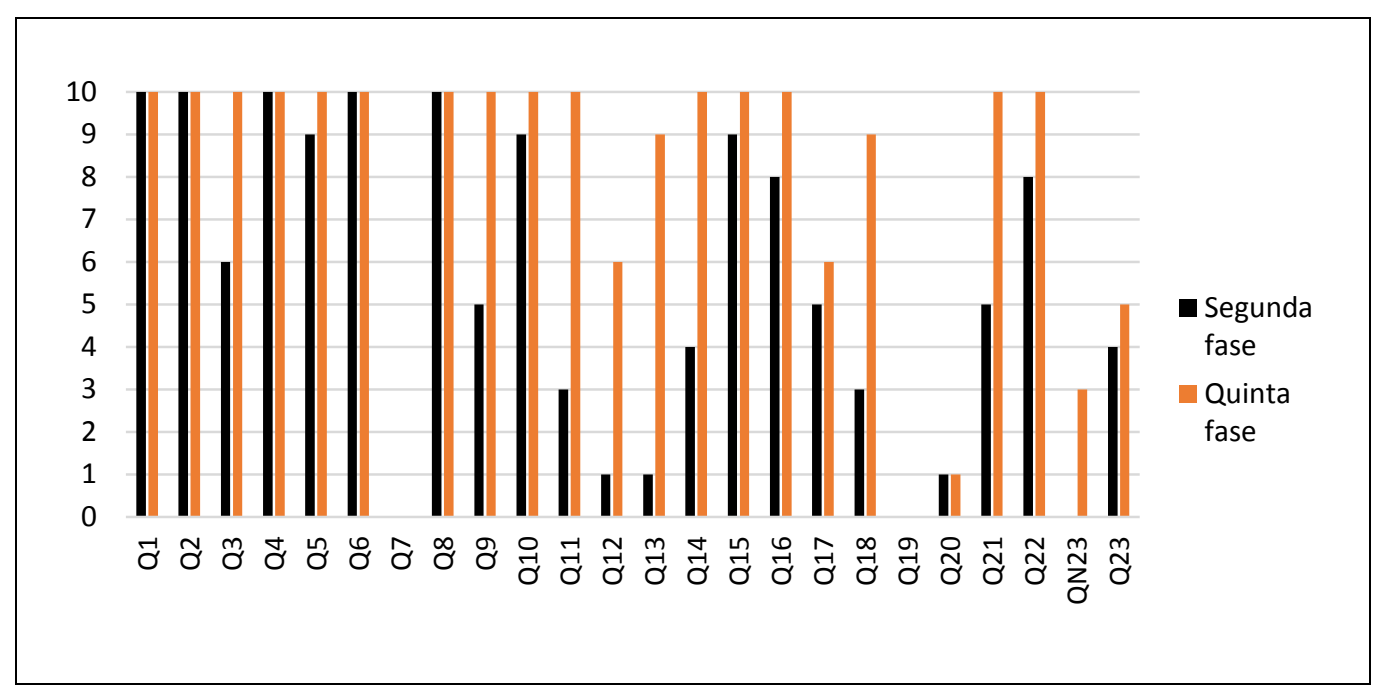

Fig. 3.9: $\mathrm{N}^{\mathrm{o}}$ de grupos que obtienen la respuesta correcta en segunda y quinta fase de la corrección del cuestionario $\mathbf{Q}$

La corrección colectiva del cuestionario ha dado lugar a una mejora en las respuestas de los estudiantes, aunque no ha hecho posible alcanzar la solución en la totalidad de las preguntas. Las siguientes tablas muestran la evolución de las respuestas de cada grupo a lo largo de las diferentes fases de la corrección del cuestionario. En ellas vienen marcadas en color amarillo aquellas preguntas cuya respuesta ha quedado sin determinar al finalizar la corrección colectiva, y en color rojo las preguntas que han obtenido respuesta incorrecta:

\begin{tabular}{|c|c|c|c|c|c|}
\hline $\begin{array}{c}\text { Grup } \\
\text { o A1 }\end{array}$ & $\begin{array}{c}2^{\mathrm{a}} \\
\text { Fas } \\
\mathrm{e}\end{array}$ & $\begin{array}{c}3^{\mathrm{a}} \\
\text { Fas } \\
\text { e }\end{array}$ & $\begin{array}{c}4^{\mathrm{a}} \\
\text { Fas } \\
\text { e }\end{array}$ & $\begin{array}{c}5^{\mathrm{a}} \\
\text { Fas } \\
\text { e }\end{array}$ & $\begin{array}{c}\text { Fin } \\
\text { correcció } \\
\text { n }\end{array}$ \\
\hline Q1 & 1 & & & & 1 \\
\hline Q2 & 1 & & & & 1 \\
\hline Q3 & & 1 & & & 1 \\
\hline Q4 & 1 & & & & 1 \\
\hline Q5 & 1 & & & & 1 \\
\hline Q6 & 1 & & & & 1 \\
\hline Q7 & & 0 & & & 0 \\
\hline Q8 & 1 & & & & 1 \\
\hline Q9 & & 1 & & & 1 \\
\hline Q10 & & 1 & & & 1 \\
\hline
\end{tabular}

\begin{tabular}{|c|c|c|c|c|c|}
\hline $\begin{array}{c}\text { Grup } \\
\text { o A2 }\end{array}$ & $\begin{array}{c}2^{\mathrm{a}} \\
\text { Fas } \\
\mathrm{e}\end{array}$ & $\begin{array}{c}3^{\mathrm{a}} \\
\text { Fas } \\
\mathrm{e}\end{array}$ & $\begin{array}{c}4^{\mathrm{a}} \\
\text { Fas } \\
\mathrm{e}\end{array}$ & $\begin{array}{c}5^{\mathrm{a}} \\
\text { Fas } \\
\mathrm{e}\end{array}$ & $\begin{array}{c}\text { Fin } \\
\text { correcció } \\
\text { n }\end{array}$ \\
\hline Q1 & 1 & & & & 1 \\
\hline Q2 & 1 & & & & 1 \\
\hline Q3 & 1 & & & & 1 \\
\hline Q4 & 1 & & & & 1 \\
\hline Q5 & 1 & & & & 1 \\
\hline Q6 & 1 & & & & 1 \\
\hline Q7 & & 0 & & & 0 \\
\hline Q8 & 1 & & & & 1 \\
\hline Q9 & & 1 & & & 1 \\
\hline Q10 & 1 & & & & 1 \\
\hline
\end{tabular}




\begin{tabular}{|c|c|c|c|c|c|}
\hline Q11 & & 1 & & & 1 \\
\hline Q12 & & 0 & & & 0 \\
\hline Q13 & & 0 & & & 0 \\
\hline Q14 & 1 & & & & 1 \\
\hline Q15 & 1 & & & & 1 \\
\hline Q16 & & 1 & & & 1 \\
\hline Q17 & 1 & & & & 1 \\
\hline Q18 & 1 & & & & 1 \\
\hline Q19 & 0 & & & & 0 \\
\hline Q20 & 0 & & & & 0 \\
\hline Q21 & 1 & & & & 1 \\
\hline Q22 & 1 & & & & 1 \\
\hline QN23 & & & 1 & & 1 \\
\hline Q23 & & & 0 & & 0 \\
\hline
\end{tabular}

Tab. 3.9: Evolución de las respuestas del grupo A1 en la corrección del cuestionario $\mathbf{Q}$

\begin{tabular}{|c|c|c|c|c|c|}
\hline Q11 & & 1 & & & 1 \\
\hline Q12 & & 1 & & & 1 \\
\hline Q13 & 0 & & 1 & & 1 \\
\hline Q14 & & 0 & & 1 & 1 \\
\hline Q15 & & 0 & & 1 & 1 \\
\hline Q16 & 1 & & & & 1 \\
\hline Q17 & 1 & & & & 1 \\
\hline Q18 & 1 & & & & 1 \\
\hline Q19 & 0 & & & & 0 \\
\hline Q20 & 0 & & & & 0 \\
\hline Q21 & 1 & & & & 1 \\
\hline Q22 & & 1 & & & 1 \\
\hline QN23 & 0 & & & & 0 \\
\hline Q23 & 1 & & & & 1 \\
\hline
\end{tabular}

Tab. 3.10: Evolución de las respuestas del grupo A2 en la corrección del cuestionario $Q$ 


\begin{tabular}{|c|c|c|c|c|c|}
\hline $\begin{array}{c}\text { Grup } \\
\text { o A3 }\end{array}$ & $\begin{array}{c}2^{\mathrm{a}} \\
\text { Fas } \\
\mathrm{e}\end{array}$ & $\begin{array}{c}3^{\mathrm{a}} \\
\text { Fas } \\
\mathrm{e}\end{array}$ & $\begin{array}{c}4^{\mathrm{a}} \\
\text { Fas }^{\mathrm{e}}\end{array}$ & $\begin{array}{c}5^{\mathrm{a}} \\
\text { Fas } \\
\mathrm{e}\end{array}$ & $\begin{array}{c}\text { Fin } \\
\text { correcció } \\
\mathrm{n}\end{array}$ \\
\hline Q1 & 1 & & & & 1 \\
\hline Q2 & 1 & & & & 1 \\
\hline Q3 & & 1 & & & 1 \\
\hline Q4 & 1 & & & & 1 \\
\hline Q5 & 1 & & & & 1 \\
\hline Q6 & 1 & & & & 1 \\
\hline Q7 & & 0 & & & 0 \\
\hline Q8 & 1 & & & & 1 \\
\hline Q9 & 1 & & & & 1 \\
\hline Q10 & 1 & & & & 1 \\
\hline Q11 & & & 1 & & 1 \\
\hline Q12 & & 1 & & & 1 \\
\hline Q13 & & 1 & & & 1 \\
\hline Q14 & 1 & & & & 1 \\
\hline Q15 & 1 & & & & 1 \\
\hline Q16 & & 1 & & & 1 \\
\hline Q17 & 0 & & & & 0 \\
\hline Q18 & & 1 & & & 1 \\
\hline Q19 & & & & & \\
\hline Q20 & & & & & \\
\hline Q21 & & & & 1 & 1 \\
\hline Q22 & 1 & & & & 1 \\
\hline Q123 & & & & & \\
\hline Q23 & & & & & \\
\hline
\end{tabular}

Tab. 3.11: Evolución de las respuestas del grupo A3 en la corrección del cuestionario $Q$

\begin{tabular}{|c|c|c|c|c|c|}
\hline $\begin{array}{c}\text { Grup } \\
\text { o B1 }\end{array}$ & $\begin{array}{c}2^{\mathrm{a}} \\
\text { Fas } \\
\mathrm{e}\end{array}$ & $\begin{array}{c}3^{\mathrm{a}} \\
\text { Fas } \\
\mathrm{e}\end{array}$ & $\begin{array}{c}4^{\mathrm{a}} \\
\text { Fas } \\
\mathrm{e}\end{array}$ & $\begin{array}{c}5^{\mathrm{a}} \\
\text { Fas } \\
\mathrm{e}\end{array}$ & $\begin{array}{c}\text { Fin } \\
\text { correcció } \\
\mathrm{n}\end{array}$ \\
\hline Q1 & 1 & & & & 1 \\
\hline Q2 & 1 & & & & 1 \\
\hline Q3 & 1 & & & & 1 \\
\hline Q4 & 1 & & & & 1 \\
\hline Q5 & 1 & & & & 1 \\
\hline Q6 & 1 & & & & 1 \\
\hline Q7 & 0 & & & & 0 \\
\hline Q8 & 1 & & & & 1 \\
\hline Q9 & & 1 & & & 1 \\
\hline Q10 & 1 & & & & 1 \\
\hline Q11 & & 1 & & & 1 \\
\hline Q12 & & 0 & & & 0 \\
\hline Q13 & & 0 & & & 0 \\
\hline Q14 & & 1 & & & 1 \\
\hline Q15 & 1 & & & & 1 \\
\hline Q16 & 1 & & & & 1 \\
\hline Q17 & 1 & & & & 1 \\
\hline Q18 & & 1 & & & 1 \\
\hline Q19 & 0 & & & & 0 \\
\hline Q20 & 1 & & & & 1 \\
\hline Q21 & & 0 & & & 0 \\
\hline Q22 & & 0 & & & 0 \\
\hline QN23 & 1 & & & & 1 \\
\hline Q23 & & 0 & & & 0 \\
\hline
\end{tabular}

Tab. 3.12: Evolución de las respuestas del grupo B1 en la corrección del cuestionario $Q$ 


\begin{tabular}{|c|c|c|c|c|c|}
\hline $\begin{array}{c}\text { Grup } \\
\text { o B2 }\end{array}$ & $\begin{array}{c}2^{\mathrm{a}} \\
\text { Fas } \\
\mathrm{e}\end{array}$ & $\begin{array}{c}3^{\mathrm{a}} \\
\text { Fas } \\
\mathrm{e}\end{array}$ & $\begin{array}{c}4^{\mathrm{a}} \\
\text { Fas } \\
\mathrm{e}\end{array}$ & $\begin{array}{c}5^{\mathrm{a}} \\
\text { Fas } \\
\mathrm{e}\end{array}$ & $\begin{array}{c}\text { Fin } \\
\text { correcció } \\
\mathrm{n}\end{array}$ \\
\hline Q1 & 1 & & & & 1 \\
\hline Q2 & 1 & & & & 1 \\
\hline Q3 & 1 & & & & 1 \\
\hline Q4 & 1 & & & & 1 \\
\hline Q5 & 1 & & & & 1 \\
\hline Q6 & 1 & & & & 1 \\
\hline Q7 & & 0 & & & 0 \\
\hline Q8 & 1 & & & & 1 \\
\hline Q9 & 1 & & & & 1 \\
\hline Q10 & 1 & & & & 1 \\
\hline Q11 & & 1 & & & 1 \\
\hline Q12 & & & & & \\
\hline Q13 & & 1 & & & 1 \\
\hline Q14 & & 1 & & & 1 \\
\hline Q15 & 1 & & & & 1 \\
\hline Q16 & 1 & & & & 1 \\
\hline Q17 & & 0 & & & 0 \\
\hline Q18 & 1 & & & & 1 \\
\hline Q19 & 0 & & & & 0 \\
\hline Q20 & & 0 & & & 0 \\
\hline Q21 & 1 & & & & 1 \\
\hline Q22 & 1 & & & & 1 \\
\hline Q123 & & 0 & & & 0 \\
\hline Q23 & & 0 & & & 0 \\
\hline
\end{tabular}

Tab. 3.13: Evolución de las respuestas del grupo B2 en la corrección del cuestionario $Q$

\begin{tabular}{|c|c|c|c|c|c|}
\hline $\begin{array}{c}\text { Grup } \\
\text { o B3 }\end{array}$ & $\begin{array}{c}2^{\mathrm{a}} \\
\text { Fas } \\
\mathrm{e}\end{array}$ & $\begin{array}{c}3^{\mathrm{a}} \\
\text { Fas } \\
\mathrm{e}\end{array}$ & $\begin{array}{c}4^{\mathrm{a}} \\
\text { Fas }^{\mathrm{e}}\end{array}$ & $\begin{array}{c}5^{\mathrm{a}} \\
\text { Fas } \\
\mathrm{e}\end{array}$ & $\begin{array}{c}\text { Fin } \\
\text { correcció } \\
\mathrm{n}\end{array}$ \\
\hline Q1 & 1 & & & & 1 \\
\hline Q2 & 1 & & & & 1 \\
\hline Q3 & 1 & & & & 1 \\
\hline Q4 & 1 & & & & 1 \\
\hline Q5 & 1 & & & & 1 \\
\hline Q6 & 1 & & & & 1 \\
\hline Q7 & 0 & & & & 0 \\
\hline Q8 & 1 & & & & 1 \\
\hline Q9 & 1 & & & & 1 \\
\hline Q10 & 1 & & & & 1 \\
\hline Q11 & 1 & & & & 1 \\
\hline Q12 & 0 & & 1 & & 1 \\
\hline Q13 & 0 & 1 & & & 1 \\
\hline Q14 & 1 & & & & 1 \\
\hline Q15 & 1 & & & & 1 \\
\hline Q16 & 1 & & & & 1 \\
\hline Q17 & 1 & & & & 1 \\
\hline Q18 & 0 & & 1 & & 1 \\
\hline Q19 & 0 & & & & 0 \\
\hline Q20 & 0 & 0 & & & 0 \\
\hline Q21 & 1 & & & & 1 \\
\hline Q22 & 1 & & & & 1 \\
\hline Q123 & 0 & & & 1 & 1 \\
\hline Q23 & 1 & & & & 1 \\
\hline
\end{tabular}

Tab. 3.14: Evolución de las respuestas del grupo B3 en la corrección del cuestionario $Q$ 


\begin{tabular}{|l|l|l|l|l|l|}
\hline $\begin{array}{c}\text { Grup } \\
\text { o C1 }\end{array}$ & $\begin{array}{c}2^{\mathrm{a}} \\
\text { Fas } \\
\mathrm{e}\end{array}$ & $\begin{array}{c}3^{\mathrm{a}} \\
\text { Fas } \\
\mathrm{e}\end{array}$ & $\begin{array}{c}4^{\mathrm{a}} \\
\text { Fas }^{\mathrm{e}}\end{array}$ & $\begin{array}{c}5^{\mathrm{a}} \\
\text { Fas } \\
\mathrm{e}\end{array}$ & $\begin{array}{c}\text { Fin } \\
\text { correcció } \\
\mathrm{n}\end{array}$ \\
\hline Q1 & 1 & & & & 1 \\
\hline Q2 & 1 & & & & 1 \\
\hline Q3 & 1 & & & & 1 \\
\hline Q4 & 1 & & & & 1 \\
\hline Q5 & & 1 & & & 1 \\
\hline Q6 & 1 & & & & 1 \\
\hline Q7 & & 0 & & & 0 \\
\hline Q8 & 1 & & & & 1 \\
\hline Q9 & & 1 & & & 1 \\
\hline Q10 & 1 & & & & 1 \\
\hline Q11 & & 1 & & & 1 \\
\hline Q12 & & & & & \\
\hline Q13 & & 1 & & & 1 \\
\hline Q14 & & 1 & & & 1 \\
\hline Q15 & 1 & & & & 1 \\
\hline Q16 & 1 & & & & 1 \\
\hline Q17 & & 1 & & & 1 \\
\hline Q18 & & 1 & & & 1 \\
\hline Q19 & & 0 & & & 0 \\
\hline Q20 & & & & & \\
\hline Q21 & & & 1 & & 1 \\
\hline Q22 & 1 & & & & 1 \\
\hline Q123 & 0 & & & & 0 \\
\hline Q23 & & & & & \\
\hline
\end{tabular}

Tab. 3.15: Evolución de las respuestas del grupo C1 en la corrección del cuestionario $Q$

\begin{tabular}{|l|l|l|l|l|l|}
\hline $\begin{array}{c}\text { Grup } \\
\text { o C2 }\end{array}$ & $\begin{array}{c}2^{\mathrm{a}} \\
\text { Fas } \\
\mathrm{e}\end{array}$ & $\begin{array}{c}3^{\mathrm{a}} \\
\text { Fas } \\
\mathrm{e}\end{array}$ & $\begin{array}{c}4^{\mathrm{a}} \\
\text { Fas }^{\mathrm{e}}\end{array}$ & $\begin{array}{c}5^{\mathrm{a}} \\
\text { Fas } \\
\mathrm{e}\end{array}$ & $\begin{array}{c}\text { Fin } \\
\text { correcció } \\
\mathrm{n}\end{array}$ \\
\hline Q1 & 1 & & & & 1 \\
\hline Q2 & 1 & & & & 1 \\
\hline Q3 & & 1 & & & 1 \\
\hline Q4 & 1 & & & & 1 \\
\hline Q5 & 1 & & & & 1 \\
\hline Q6 & 1 & & & & 1 \\
\hline Q7 & & 0 & & & 0 \\
\hline Q8 & 1 & & & & 1 \\
\hline Q9 & 1 & & & & 1 \\
\hline Q10 & 1 & & & & 1 \\
\hline Q11 & & 1 & & & 1 \\
\hline Q12 & & & 1 & & \\
\hline Q13 & & 1 & & & 1 \\
\hline Q14 & & 1 & & & 1 \\
\hline Q15 & 1 & & & & 1 \\
\hline Q16 & 1 & & & & 1 \\
\hline Q17 & & 0 & & & 0 \\
\hline Q18 & & 1 & & & 1 \\
\hline Q19 & & 0 & & & 0 \\
\hline Q20 & & 0 & & & 0 \\
\hline Q21 & & 1 & & & 1 \\
\hline Q22 & 1 & & & & 1 \\
\hline Q123 & 0 & & & & 0 \\
\hline Q23 & & 1 & & & 1 \\
\hline
\end{tabular}

Tab. 3.16: Evolución de las respuestas del grupo C2 en la corrección del cuestionario $Q$ 


\begin{tabular}{|c|c|c|c|c|c|}
\hline $\begin{array}{c}\text { Grup } \\
\text { o D1 }\end{array}$ & $\begin{array}{c}2^{\mathrm{a}} \\
\text { Fas } \\
\mathrm{e}\end{array}$ & $\begin{array}{c}3^{\mathrm{a}} \\
\text { Fas } \\
\mathrm{e}\end{array}$ & $\begin{array}{c}4^{\mathrm{a}} \\
\text { Fas } \\
\mathrm{e}\end{array}$ & $\begin{array}{c}5^{\mathrm{a}} \\
\text { Fas } \\
\mathrm{e}\end{array}$ & $\begin{array}{c}\text { Fin } \\
\text { correcció } \\
\mathrm{n}\end{array}$ \\
\hline Q1 & 1 & & & & 1 \\
\hline Q2 & 1 & & & & 1 \\
\hline Q3 & 1 & & & & 1 \\
\hline Q4 & 1 & & & & 1 \\
\hline Q5 & 1 & & & & 1 \\
\hline Q6 & 1 & & & & 1 \\
\hline Q7 & & 0 & & & 0 \\
\hline Q8 & 1 & & & & 1 \\
\hline Q9 & 1 & & & & 1 \\
\hline Q10 & 1 & & & & 1 \\
\hline Q11 & 1 & & & & 1 \\
\hline Q12 & 1 & & & & 1 \\
\hline Q13 & & 1 & & & 1 \\
\hline Q14 & 1 & & & & 1 \\
\hline Q15 & 1 & & & & 1 \\
\hline Q16 & 1 & & & & 1 \\
\hline Q17 & 0 & & & & 0 \\
\hline Q18 & & 1 & & & 1 \\
\hline Q19 & 0 & & & & 0 \\
\hline Q20 & 0 & & & & 0 \\
\hline Q21 & 1 & & & & 1 \\
\hline Q22 & 1 & & & & 1 \\
\hline Q123 & 0 & & & & 0 \\
\hline Q23 & 1 & & & & 1 \\
\hline
\end{tabular}

Tab. 3.17: Evolución de las respuestas del grupo D1 en la corrección del cuestionario $\mathbf{Q}$

\begin{tabular}{|c|c|c|c|c|c|}
\hline $\begin{array}{c}\text { Grup } \\
\text { o D2 }\end{array}$ & $\begin{array}{c}2^{\mathrm{a}} \\
\text { Fas } \\
\mathrm{e}\end{array}$ & $\begin{array}{c}3^{\mathrm{a}} \\
\text { Fas } \\
\mathrm{e}\end{array}$ & $\begin{array}{c}4^{\mathrm{a}} \\
\text { Fas }^{\mathrm{e}}\end{array}$ & $\begin{array}{c}5^{\mathrm{a}} \\
\text { Fas } \\
\mathrm{e}\end{array}$ & $\begin{array}{c}\text { Fin } \\
\text { correcció } \\
\mathrm{n}\end{array}$ \\
\hline Q1 & 1 & & & & 1 \\
\hline Q2 & 1 & & & & 1 \\
\hline Q3 & & 1 & & & 1 \\
\hline Q4 & 1 & & & & 1 \\
\hline Q5 & 1 & & & & 1 \\
\hline Q6 & 1 & & & & 1 \\
\hline Q7 & & 0 & & & 0 \\
\hline Q8 & 1 & & & & 1 \\
\hline Q9 & & 1 & & & 1 \\
\hline Q10 & 1 & & & & 1 \\
\hline Q11 & 1 & & & & 1 \\
\hline Q12 & & 1 & & & 1 \\
\hline Q13 & 1 & & & & 1 \\
\hline Q14 & & 1 & & & 1 \\
\hline Q15 & 1 & & & & 1 \\
\hline Q16 & 1 & & & & 1 \\
\hline Q17 & 1 & & & & 1 \\
\hline Q18 & 0 & & & & 0 \\
\hline Q19 & 0 & & & & 0 \\
\hline Q20 & 0 & & & & 0 \\
\hline Q21 & 0 & & 1 & & 1 \\
\hline Q22 & 1 & & & & 1 \\
\hline Q123 & 0 & & & & 0 \\
\hline Q23 & 1 & & & & 1 \\
\hline
\end{tabular}

Tab. 3.18: Evolución de las respuestas del grupo D2 en la corrección del cuestionario $Q$

Los resultados presentados en estas tablas, reflejan la información procedente de las plantillas escritas por los estudiantes. Consideramos que las plantillas escritas reflejan realmente la evolución de las respuestas a lo largo de las cuatro primeras fases. Sin embargo, se ha observado en clase que la quinta fase, de debate colectivo, debido a los conflictos y desacuerdos así como la falta de tiempo en ambas sesiones, ha dificultado que los secretarios de cada grupo pudieran prestar atención a las decisiones últimas. Consideramos que la validación de las respuestas finales, principalmente en la sesión 2 
por la utilización de la tabla $\mathrm{T}$ como ostensivo, no se ha recogido por escrito en las plantillas. En este sentido, la evolución de las respuestas correctas podría haber sido aún mejor que la evolución ya mostrada en la figura 3.9.

\section{Fase VI: Institucionalización de la lógica implícita del cuestionario}

La fase de institucionalización no se ha desarrollado con normalidad.

En la sesión 1 no se ha llevado a cabo por falta de tiempo. En la sesión 2, sí ha sido posible hablar de los conocimientos lógicos implícitos en la resolución del cuestonario Q sobre la tabla T gracias a la gestión del tiempo por parte del profesor. Sin embargo no ha sido suficiente. En lugar de desarrollar la fase VI según la consigna, se ha llevado a cabo una exposición con diapositivas, resumiendo los conocimientos lógicos y didácticos de la situación. Esta falta de tiempo estaba prevista según la experiencia vivida en la primera sesión. Así pues, se había preparado con antelación la exposición de las diapositivas para esta sexta fase, considerándola una alternativa a la fase de la ficha didáctica en caso de necesidad. (Ver presentación de las diapositivas en el anexo III)

\subsubsection{Análisis de la observación de la situación de corrección del cuestionario Q}

Una vez llevada a cabo la experimentación, se han podido comprobar ciertos fenómenos didácticos relacionados con la lógica formal y el pensamiento natural de los estudiantes. Las observaciones de las dos sesiones realizadas han puesto de manifiesto el potencial que ofrecen el cuestionario y la tabla de datos para reconocer y gestionar algunas de las dificultades lógicas de los estudiantes, es decir, ha permitido mostrar el carácter fenomenotécnico de la situación en torno al cuestionario Q. El cuestionario Q presenta tres categorías de dificultades: preguntas con predicados y operaciones combinadas, la disyunción como obstáculo epistemológico asociado a la lógica y algunas reglas de 
inferencia (Modus Ponendo Ponens y equivalencia lógica entre la implicación y su contrarrecíproca).

Vamos a presentar la naturaleza de los conocimientos asociados a las dificultades observadas en los alumnos, así como las observaciones relacionadas con el funcionamiento de la situación.

\section{A. OBSERVACIONES RELACIONADAS CON LOS CONOCIMIENTOS LÓGICOS DE LOS ESTUDIANTES}

\section{NEGACIÓN DE LA CONJUNCIÓN}

La pregunta Q7, que tiene asociada la operación lógica combinada de la negación de una conjunción, está asociada a una operación conjuntista: calcular el cardinal del complementario del conjunto intersección que definen los predicados "grandes ciudades" y "salir de noche"

Pregunta Q7: ¿A cuántos estudiantes no les gustan las grandes ciudades y salir de noche? A 16 estudiantes

La ausencia de respuestas correctas para la pregunta Q7, en las dos sesiones observadas, es uno de los resultados más destacables. No ha habido ningún grupo (ni tampoco ningún estudiante) que haya respondido correctamente a esta cuestión. Se trata de la negación de una conjunción, que sabemos por las Leyes de De Morgan, que es equivalente a la disyunción de negaciones:

$$
\forall \mathrm{x} \in \mathrm{D} \quad \neg(\mathrm{p}(\mathrm{x}) \wedge \mathrm{q}(\mathrm{x})) \leftrightarrow \neg \mathrm{p}(\mathrm{x}) \vee \neg \mathrm{q}(\mathrm{x})
$$

Los modelos implícitos que han funcionado a nivel de acción han sido tres, de los cuales uno ha sido admitido como válido por el total de grupos participantes: 
- Respuesta 1: «A 9 estudiantes no les gustan las grandes ciudades y a 10 estudiantes no les gusta salir de noche»

En esta respuesta el estudiante ha transformado una pregunta en dos, evitando de esta forma el problema generado por la negación de una conjunción.

«¿A cuántos estudiantes no les gustan las grandes ciudades?» A 9 estudiantes

$$
\operatorname{Card}\left\{E_{j} \in E: C_{1}\left(E_{j}\right)=0\right\}=9
$$

«¿A cuántos estudiantes no les gusta las salir de noche?» A 10 estudiantes

$$
\operatorname{Card}\left\{E_{j} \in E: C_{5}\left(E_{j}\right)=0\right\}=10
$$

- Respuesta 2: «A 19 estudiantes»

Los estudiantes que han dado esta respuesta, también han identificado dos conjuntos, que corresponden a los conjuntos definidos por los siguientes predicados:

«Tener el gusto grandes ciudades» $y$ «Tener el gusto salir de noche»

$\mathrm{Al}$ igual que los estudiantes del caso anterior, han calculado el cardinal de dos conjuntos, pero esta vez los han sumado para contar todos los casos. El cardinal del conjunto unión no ha tenido en cuenta el conjunto intersección, dando lugar a una respuesta incorrecta:

$\operatorname{Card}\left\{E_{j} \in E / C_{1}\left(E_{j}\right)=0\right\}+\operatorname{Card}\left\{E_{j} \in E / C_{5}\left(E_{j}\right)=0\right\}=9+10=19$

- Respuesta 3: «A 3 estudiantes»

Esta respuesta, ganadora por unanimidad al finalizar la tercera fase de la corrección, representa el modelo de validación para la negación de la conjunción. Para llevar a cabo esta operación, se ha aplicado erróneamente una supuesta propiedad distributiva de la negación respecto de la conjunción, propiedad inexistente que ha transformado este enunciado en otro, no equivalente: 
«¿A cuántos estudiantes no les gustan ni las grandes ciudades ni salir de noche?»

$$
\operatorname{Card}\left\{E_{j} \in E / C_{1}\left(E_{j}\right)=0 \wedge C_{5}\left(E_{j}\right)=0\right\}=3
$$

\section{LA IMPLICACIÓN LÓGICA Y SU CONTRARRECÍPROCA}

A continuación se van a exponer las observaciones relacionadas con las preguntas del cuestionario caracterizadas como implicaciones lógicas:

Pregunta Q8: ¿Todo lo que le gusta al estudiante R le gusta al estudiante J?

$R:$ No

Pregunta Q9: ¿Todo lo que le gusta al estudiante J le gusta al estudiante R? R: Sí

Pregunta Q14: Al estudiante que le gusta el frío, le gusta esquiar. R: Verdadero

Pregunta Q15: A todos los estudiantes que les gusta esquiar, les gusta el frío.

R: Falso

Pregunta Q16: Si a un estudiante no le gusta el deporte, entonces no le gustan los deportes acuáticos. R: Falso

Pregunta Q18: Lo que le gusta a los estudiantes $C$ y $F$ le gusta al estudiante L. R: Falso

Pregunta Q20: Si no les gusta practicar deporte, no les gusta nadar. R: No sé Pregunta Q23: Si no les gusta nadar entonces no les gusta practicar deporte.

R: Verdadero

Las preguntas del cuestionario relacionadas con el conector lógico condicional son las preguntas que aparecen en el recuadro. De todas estas preguntas, sólo Q20 y Q23 no han alcanzado la respuesta correcta en la totalidad de grupos (2 grupos han dejado Q20 sin contestar y 7 grupos han dado una respuesta incorrecta; 2 grupos han dejado Q23 sin contestar y 3 grupos han dado respuesta incorrecta). Ambas cuestiones se diferencian de las demás porque una búsqueda de valores sobre la tabla de datos no es suficiente para 
dar una respuesta. El criterio ¿te gustar nadar? está ausente en la tabla y por ello, la búsqueda de valores no es suficiente.

$$
\begin{array}{ll}
\text { Pregunta Q20: } & \forall \mathrm{j} \in\{1, \ldots, 20\}, \quad i \mathrm{C}_{2}\left(\mathrm{E}_{\mathrm{j}}\right)=0 \rightarrow \mathrm{C}_{16}\left(\mathrm{E}_{\mathrm{j}}\right)=0 ? \\
\text { Pregunta Q23: } & \forall \mathrm{j} \in\{1, \ldots, 20\}, \quad i \mathrm{C}_{16}\left(\mathrm{E}_{\mathrm{j}}\right)=0 \rightarrow \mathrm{C}_{2}\left(\mathrm{E}_{\mathrm{j}}\right)=0 ?
\end{array}
$$

Las respuestas dadas a estas preguntas han puesto de manifiesto, entre los estudiantes que han participado en la corrección, dos hechos importantes:

- Por un lado se desconoce la equivalencia entre la condicional y su contrarrecíproca:

$$
\mathrm{C}_{2}\left(\mathrm{E}_{\mathrm{j}}\right)=1 \rightarrow \mathrm{C}_{16}\left(\mathrm{E}_{\mathrm{j}}\right)=1 \leftrightarrow \mathrm{C}_{16}\left(\mathrm{E}_{\mathrm{j}}\right)=0 \rightarrow \mathrm{C}_{2}\left(\mathrm{E}_{\mathrm{j}}\right)=0
$$

- Por otro lado, se aplica la equivalencia (no verdadera) entre la condicional y su inversa:

$$
\mathrm{C}_{2}\left(\mathrm{E}_{\mathrm{j}}\right)=1 \rightarrow \mathrm{C}_{16}\left(\mathrm{E}_{\mathrm{j}}\right)=1 \leftrightarrow \mathrm{C}_{2}\left(\mathrm{E}_{\mathrm{j}}\right)=0 \rightarrow \mathrm{C}_{16}\left(\mathrm{E}_{\mathrm{j}}\right)=0
$$

Veamos algunos ejemplos de los razonamientos llevados a cabo por los estudiantes:

$\checkmark \quad$ «Si a todos los estudiantes que les gusta practicar deporte les gusta nadar, se da por hecho que al contrario también»

$\checkmark$ «Lo dice la frase, a todos los estudiantes que les gusta practicar deporte les gusta nadar, entonces, si no les gusta practicar deporte no les gusta nadar, jes lo mismo!»

\section{DISYUNCIÓN}

Las preguntas del cuestionario que utilizan la conjunción lógica son las preguntas Q10 y Q17. La interpretación de la disyunción lógica no es evidente, tratándose de una dificultad de origen epistemológico. El modelo formal de la disyunción lógica es la disyunción inclusiva. Sin embargo, tal y como hemos observado, en el uso natural de la disyunción conviven la disyunción inclusiva y exclusiva, siendo el contexto y la situación los que 
determinan su interpretación. Este tipo de dificultad no se aprende de manera espontánea, sino que precisa ser enseñado, tal y como hemos podido comprobar con los estudiantes universitarios.

Pregunta Q10: ¿A todos los estudiantes les gusta salir de noche o practicar deporte? R: No

Pregunta Q17: Al estudiante E le gusta la playa o la montaña. R: Verdadero

La cuestión Q10 ha sido respondida correctamente, pero la cuestión Q17 no (4 grupos han consensuado una respuesta incorrecta). Para comprender las diferencias entre ambos resultados, veamos las siguientes observaciones:

- La cuestión Q10 es interrogativa y la pregunta Q17 es una afirmación

El hecho de aparecer la conjunción en una oración interrogativa ha provocado una interpretación semántica de la expresión. El uso común que se hace de la disyunción para indicar una elección entre dos o más opciones, ha provocado comentarios como el siguiente:

«es como cuando te preguntan, ¿tú qué quieres, carne o pescado?»

- La pregunta Q10 tiene respuesta directa negativa (RDNEG), mientras que a Q17 hay que atribuirle un valor de verdad, concretamente el valor verdadero (AVERD). El modelo implícito de la disyunción exclusiva ha funcionado a nivel de acción, se ha hecho explícito en las situaciones de formulación y ha sido el modelo que ha funcionado también en la validación, manifestándose como un obstáculo epistemológico en la construcción del conocimiento lógico. Este obstáculo no se ha manifestado con Q10 porque, a pesar de haber funcionado como modelo implícito en la situación de acción, no ha interferido en la respuesta. La presencia de parejas de valores $(0,0)$ ha servido para responder correctamente, tanto con el modelo de conjunción inclusiva como exclusiva, que se diferencian únicamente en el par de valores $(1,1)$, es decir, cuando ambas proposiciones son verdaderas: 


\begin{tabular}{|l|l|l|l|l|l|l|l|l|l|l|l|l|l|l|l|l|l|l|l|l|}
\hline ¿Te gusta... & A & $\mathbf{B}$ & $\mathbf{C}$ & $\mathbf{D}$ & $\mathbf{E}$ & $\mathbf{F}$ & $\mathbf{G}$ & $\mathbf{H}$ & $\mathbf{I}$ & $\mathbf{J}$ & $\mathbf{K}$ & $\mathbf{L}$ & $\mathbf{M}$ & $\mathbf{N}$ & $\mathbf{O}$ & $\mathbf{P}$ & $\mathbf{Q}$ & $\mathbf{R}$ & $\mathbf{S}$ & $\mathbf{T}$ \\
\hline$\ldots$ & & & & & & & & & & & & & & & & & & & & \\
\hline $\begin{array}{l}\text { practicar de- } \\
\text { porte? (C2) }\end{array}$ & & 0 & 0 & & 0 & & & & & 0 & & 0 & 0 & & & 0 & & 0 & & 0 \\
\hline$\ldots$ & & & & & & & & & & & & & & & & & & & & \\
\hline $\begin{array}{l}\text { salir de } \\
\text { noche? (C5) }\end{array}$ & & 0 & 0 & & 0 & & & & & 0 & & 0 & 0 & & & 0 & & 0 & & 0 \\
\hline
\end{tabular}

Ejemplo:

$\checkmark$ «iA todos los estudiantes les gusta salir de noche o practicar deporte? No, porque hay un estudiante a quien no le gusta ni salir de noche ni practicar deporte »

Sin embargo, al responder a la pregunta Q17, ha sido posible comprobar la dificultad de los estudiantes para verificar el valor de verdad de una disyunción cuando son verdaderas ambas proposiciones, como ha sido el caso de responder si al estudiante E le gusta la playa o la montaña.

\begin{tabular}{|c|l|l|l|}
\hline ¿Te gusta... & & E & \\
\hline$\ldots$ & & & \\
\hline la playa? (C6) & & 1 & \\
\hline$\ldots$ & & & \\
\hline la montaña? (C9) & & 1 & \\
\hline
\end{tabular}

En la pregunta Q10 se había obtenido un $100 \%$ de respuestas correctas mientras que en la pregunta Q17 un 77,1\% en la sesión 1 y tan solo un 59,1\% en la sesión Los debates generados respecto a los gustos "playa o montaña" han puesto de manifiesto las dudas al respecto, siendo la identificación de la disyunción exclusiva el error más observado. Incluso se ha llegado a atribuir el error al propio formulario, alegando que si lo que se quería comprobar era el par de valores $(1,1)$ se tendría que 
haber dicho "y". En este sentido, se muestra cómo el lenguaje natural prevalece respecto a la interpretación de la conjunción y la disyunción.

La opinión de la mayoría ha sido, como en muchas otras ocasiones, determinante en la validación de la respuesta, siendo la disyunción exclusiva el modelo utilizado a nivel de formulación y validación.

Ejemplo:

$\checkmark \quad$ «Q17: Al estudiante E le gusta la playa o la montaña. Falso, porque le gustan las dos cosas. [...] Si no, diría 'y' »

\section{RAZONAMIENTO LÓGICO}

Bajo este epígrafe se han considerado el grupo de preguntas que deben ser verificadas a partir de la información aportada por la premisa dada, y razonar la respuesta sin búsqueda sobre la tabla (NTABL). El razonamiento lógico se considera una de las características de las siguientes cuestiones:

Pregunta Q19: A todos los del grupo les gusta nadar. R: No sé

Pregunta Q21: A los estudiantes no les gusta nadar.R: Falso

Pregunta Q22: Al estudiante H no le gusta nadar. R: Falso

Pregunta QN23: Al estudiante F le gusta nadar. R: No sé

Las preguntas Q20 y Q23 también se incluirían en este grupo de preguntas, aunque se han incluido anteriormente en el grupo correspondiente a la implicación lógica, al que también pertenecen.

La lógica de predicados y el uso de cuantificadores, combinados con la negación, se hacen necesarios en la producción de estas respuestas. Por ejemplo para responder que la proposición Q21 es falsa, hay que negar un cuantificador universal, lo que supone la existencia de algún estudiante que le guste nadar. Sin embargo, se han encontrado casos 
que han afirmado que la proposición Q22 es falsa porque a $\mathrm{H}$ le gusta nadar y no han sido capaces de responder correctamente en el caso de la proposición Q21.

También se han dado casos que afirman que la proposición Q21 es falsa. Esto debería suponer la existencia de algún estudiante al que le gustara nadar, hecho que es verificable con el estudiante de la tabla $\mathrm{H}$. En cambio, no han sido capaces de comprobar si a $\mathrm{H}$ le gusta nadar o no, para responder a proposición Q22, lo que da muestras de una respuesta no razonada.

Además, ha ocurrido de nuevo el mismo fenómeno que se había destacado en el análisis de las respuestas a la proposición Q20: la ausencia de valores en la tabla ha impedido encontrar las respuestas en situación de acción afirmando que falta información. Los estudiantes han tenido dificultad para llevar a cabo razonamientos a partir de las premisas. Las respuestas, en muchas ocasiones, han respondido a interpretaciones personales y añaden información a los enunciados, para poder derivar alguna conclusión.

Por ejemplo, en la proposición QN23 se han encontrado dos tipos de procesos en la obtención de una misma respuesta. En unos casos, se defiende la equivalencia entre la condicional y su inversa, que sería en este caso 'a los estudiantes que no les gusta practicar deporte, no les gusta nadar'. Sin embargo, la observación de la situación ha puesto en evidencia los procesos naturales del pensamiento, afirmando que 'nadar es un deporte', por lo tanto 'si no le gustan los deportes, no les gusta nadar'.

Además de las observaciones relacionadas con los conocimientos lógicos de los estudiantes, también se han observado las siguientes características del pensamiento natural:

\section{RESPUESTA SUBJETIVA DE INTERPRETACIÓN DE LA INFORMACIÓN}

En el estudio a priori del cuestionario, el grupo formado por las preguntas Q11, Q12 y Q13 se identificó como el grupo de preguntas del cuestionario para observar el subjetivismo en el tratamiento de la información, a pesar de la objetividad de los datos. 
Pregunta Q11: Los estudiantes $N$ y $R$, ¿tienen el mismo gusto para viajar? R: No ¿Por qué? ...

Pregunta Q12: ¿A qué pareja crees que es más probable encontrar en un mismo viaje, a J y $R, o$ o y $T$ ? R: J y $R$ ¿Por qué? ...

Pregunta Q13: Si fueras el agente de viajes, ¿qué tres criterios de los que aparecen en la tabla elegirías para proponer un viaje a estos estudiantes? R: C6, C10 y C12 ¿Por qué? ...

Este grupo de preguntas ha inducido a los estudiantes a pensar subjetivamente, tal y como se había previsto, debido principalmente al significado de las palabras utilizadas en su redacción:

- La expresión 'tener el mismo gusto', es utilizada en la pregunta Q11.

Los estudiantes han considerado como gusto el conjunto de gustos diferentes o preferencias que apuntan a un mismo estilo. Esto ha derivado en una interpretación personal.

- El verbo 'creer', es utilizado en la pregunta Q12.

El significado del verbo creer así como la pregunta en segunda persona del singular ha favorecido la aparición de las opiniones personales de los estudiantes.

- El planteamiento hipotético 'si fueras...' y el tiempo verbal utilizado, pretérito imperfecto del modo subjuntivo, han situado al estudiante en una situación no real, ficticia. Esto ha desencadenado una serie de opiniones no ajustadas a los datos de la tabla. 


\section{B. OBSERVACIONES RELACIONADAS CON LAS CARACTERÍSTICAS DEL PENSAMIENTO NATURAL}

\section{LA ANALOGÍA}

Para solucionar las discrepancias entre las interpretaciones de la disyunción, los estudiantes han tratado de buscar situaciones y contextos familiares donde utilizar expresiones similares.

Ejemplo 1:

$\checkmark \quad$ ¿Qué quieres, carne o pescado? (conjunción exclusiva)

$\checkmark$ Pero, si te gustan las dos cosas y te preguntan si te gusta la carne o el pescado, entonces, ¿ tú qué contestas? (conjunción inclusiva)

$\checkmark$ Tienes una casa en la playa y otra en la montaña entonces, ¿tienes una casa en la playa o en la montaña? Puedes tenerla en los dos sitios (conjunción inclusiva)

Ejemplo 2:

A mí me dicen que si te gusta la paella o el arroz al horno, voy a decir que sí

A mí si me preguntan si me gusta el blanco o el azul, ...Y yo digo que sí

Yo para mí poner que no es mentir

$\checkmark$ Escúchame que son preguntas trampa, mira como en la siguiente pregunta sí ponen que sí. Lo ponen para pillarnos

\section{LA TABLA Y EL CUESTIONARIO Q COMO MEDIO DE GESTIÓN DE LA CORRECCIÓN}

La responsabilidad por parte de los estudiantes para llevar a cabo la corrección del cuestionario pasa a ser responsabilidad del profesor en la quinta fase de la corrección, 
cuando las respuestas obtenidas no han sido todas consensuadas. Hay que destacar algunos de los momentos de la situación donde la propia tabla de datos ha servido como medio de información, si no para validar definitivamente, sí para invalidar algunos de los razonamientos de los estudiantes.

Ejemplo: (Grupo B1)

Pregunta Q14: Al estudiante que le gusta el frío, le gusta esquiar. Verdadero

- ¿Le gusta el frio? Sí, entonces ¿le gusta esquiar? Sí

¿Le gusta el frio? Sí, entonces ¿le gusta esquiar? Sí

¿Le gusta el frio? Sí, entonces ¿le gusta esquiar? Sí

(Un estudiante explica a otro estudiante de su grupo por qué la respuesta es afirmativa.

Para ello utiliza la tabla de datos. Al mismo tiempo que habla va señalando los valores de la tabla, recorriendo en primer lugar la fila correspondiente al criterio 'frío' y, solo en caso de haber un valor unitario, descendiendo por la columna hasta la fila del criterio "esquiar", comprobando que hay también un valor igual a uno).

- Vale, vale, está claro (El estudiante que recibe las explicaciones de su compañero, asiente enseguida, con el uso de la tabla de datos).

Pregunta Q16: Si a un estudiante no le gusta el deporte, entonces no le gustan los deportes acuáticos. Falso

- Yo he puesto verdadero, porque es de lógica: si no le gustan los deportes no le van a gustar los deportes acuáticos.

- Pero eso no es la lógica. Está puesto aquí: si no le gustan los deportes no le gustan los deportes acuáticos. Si miras aquí, ;mira el B! al B no le gustan los deportes y sí le gustan los deportes acuáticos. 
(Lo que dice el compañero sobre la tabla sirve para cambiar la respuesta y consecuentemente para validarla)

- Vale, vale, ...

- Entonces ponemos falso

Pregunta QN23: Al estudiante F le gusta nadar

En este caso, la tabla de datos y el cuestionario han servido para invalidar este tipo de razonamiento basado en el significado de las palabras con la cuestión Q16: 'Si a un estudiante no le gusta el deporte, entonces no le gustan los deportes acuáticos'

Esta cuestión, al ser respondida a partir de los datos de la tabla, ha servido para facilitar la observación siguiente:

- Al estudiante B no le gusta practicar deporte ipero sí le gustan los deportes acuáticos!

\subsection{Conclusiones}

El cuestionario $\mathrm{Q}$ sobre la tabla de datos $\mathrm{T}$ ha funcionado como instrumento fenomenotécnico con nuestros estudiantes universitarios, en situación adidáctica. Ha permitido observar diversos aspectos del pensamiento natural y cómo estos aspectos son un obstáculo en el desarrollo del razonamiento lógico. Lo que se había constatado ya en niveles educativos anteriores: educación primaria (Orús, 1992), educación secundaria (Pitarch, 2002, 2015) y niveles preuniversitarios (Zamora y otros, 2009), ahora podemos decir que persiste también a nivel universitario.

La confrontación entre las diferentes respuestas a una misma pregunta ha conducido al uso de la tabla binaria como medio material donde poder representar las diferentes formas de conocimiento, tanto de la lógica formal como del pensamiento natural. Es decir, hemos 
podido observar el funcionamiento de los diversos ostensivos que la tabla permite materializar, en relación con las operaciones lógicas y diversos tipos de razonamiento. También se ha podido observar las dificultades del profesor para gestionar la validez de los razonamientos de los alumnos cuando no ha utilizado la tabla como ostensivo del razonamiento.

Ha sido posible reconocer los errores o dificultades de los estudiantes respecto al razonamiento lógico así como los conocimientos que han funcionado en la corrección, así como las dificultades del profesor en la gestión de dichos errores.

La funcionalidad de los razonamientos lógicos en la validación de las respuestas, ha sido sustituida en ocasiones por la aceptación de respuestas elegidas por la mayoría. También en este sentido se ha observado el efecto causado por la intervención de ciertos miembros de los grupos que tienen el rol de líder, y cuya opinión ha influido más que las demás.

Los conocimientos lógicos de los estudiantes que han funcionado a nivel de acción y de validación han sido los siguientes:

- La negación de una proposición simple.

- La conjunción lógica

- La regla de inferencia conocida como Modus Ponendo Ponens

Las dificultades lógicas encontradas por los estudiantes en situaciones de formulación y validación:

- Ausencia de conocimiento respecto a la equivalencia lógica entre la condicional y su contrarrecíproca.

- La atribución del valor de verdad cuando intervienen los cuantificadores universales.

- La atribución del valor de verdad cuando interviene la negación sobre un cuantificador universal.

Errores de naturaleza lógica cometidos por los estudiantes en situaciones de validación: 
- Identificación de la disyunción como disyunción exclusiva.

- La aplicación de una falsa propiedad distributiva de la negación respecto a la conjunción, convirtiendo la negación de una conjunción en la conjunción de negaciones.

- Considerar la equivalencia falsa entre la condicional y su inversa, afirmando que si el antecedente implica el consecuente, entonces también la negación del antecedente implicará la negación del consecuente. Esto da lugar a un razonamiento incorrecto o falacia argumentativa conocida en lógica informal como «negación del antecedente»

- Considerar la equivalencia entre la condicional y su recíproca, es decir, afirmando que si se verifica que el antecedente implica el consecuente entonces también el consecuente implicará el antecedente. Esto da lugar a un razonamiento incorrecto o falacia argumentativa conocida en lógica informal como «afirmación del consecuente»

Nuestros estudiantes no todos han finalizado con éxito la corrección del cuestionario, después de una sesión de dos horas, sobre unas preguntas que no eran nuevas para ellos y con toda la información que se les ha ido dando al respecto: las respuestas de sus compañeros, la propia tabla, etc. Los resultados de la corrección han puesto de manifiesto la necesidad de realizar, a partir de la situación implementada, una secuencia de situaciones para la enseñanza de la lógica, de manera que permitan no solo hacer funcionar determinados modelos implícitos a nivel de acción, sino reconocerlos, utilizarlos de forma consciente en más situaciones y por supuesto reconstruir aquellos modelos que, tal y como se ha mostrado, permanecen como obstáculos a nivel de validación.

La ausencia de conocimiento lógico, hecho que ya se esperaba, así como la no utilización de la tabla como instrumento de validación ha impedido, a alumnos y profesor, hablar de 
lógica y utilizarla como una herramienta útil y necesaria en los debates de clase sobre la validez de los razonamientos.

Por falta de tiempo no se ha podido observar la fase de institucionalización.

A partir de nuestra experimentación, se podría proseguir el trabajo con el cuestionario Q, teniendo en cuenta las siguientes consideraciones:

1. La situación, como situación de aprendizaje de los conocimientos lógicos, no podemos decir que haya funcionado de forma generalizada, pero sí a nivel individual o grupal, como ha mostrado la observación. Fundamentalmente ha faltado la fase de institucionalización y por lo tanto no se puede afirmar que los conocimientos lógicos puestos en juego hayan sido enseñados, aunque quizás sí, algunos de ellos, hayan podido ser aprendidos. A partir de la observación podríamos proponer una secuencia con más tiempo (dos sesiones de dos horas cada una) que permitiera la institucionalización planteada.

2. Nuestra propuesta es que los conocimientos lógicos, dado el nivel de dificultad y la necesidad puesta de manifiesto, deberían ser incluidos en el currículo de los estudiantes del Grado de Maestro de Educación Primaria como un conocimiento a enseñar y a aprender.

3. La utilización del cuestionario Q como instrumento fenomenotécnico creemos que ya se ha comprobado, teniendo en cuenta los resultados obtenidos en los diferentes niveles formativos. Si se considera la Lógica como saber a enseñar en la Formación de Maestros, se podría utilizar el cuestionario Q sobre la tabla $\mathrm{T}$ para dar sentido a determinados aspectos del conocimiento lógico (proposición lógica, predicado, conjunción, implicación, ...). Para ello sería necesaria una adaptación de la situación, seleccionando las preguntas del cuestionario (las variables didácticas) que permitieran hacer funcionar los conocimientos lógicos seleccionados como objetos a enseñar. Se podrían eliminar 
aquellas cuestiones que, como ya se ha comprobado, no han supuesto ninguna dificultad para los estudiantes, ni se han manifestado necesarias para el correcto funcionamiento de la situación, como por ejemplo las preguntas que se habían incluido en el cuestionario para comprobar el uso correcto de la tabla. Además, se debería incluir la fase de institucionalización sobre los conocimientos lógicos que permite la tabla. De esta manera, la propia situación didáctica formaría parte de las praxeologías matemáticas a enseñar de los futuros maestros, no sólo para el aprendizaje de conocimientos básicos de lógica sino también mostrando su utilidad didáctica para la gestión del razonamiento natural y del razonamiento lógico en la escuela primaria. 
CONCLUSIONES

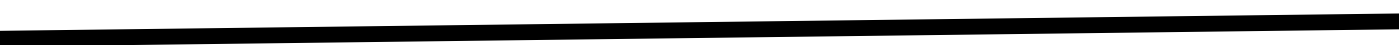


Esta tesis partía de unas preguntas iniciales, para indagar sobre la necesidad y la suficiencia de los conocimientos lógicos en los futuros maestros. Vamos pues a utilizar estas dos preguntas, para articular las respuestas y las conclusiones que hemos ido encontrando, a lo largo de este trabajo.

La codificación utilizada en la enumeración de las conclusiones irá indicando a qué hace referencia cada apartado, utilizando las iniciales N, S, M y R.

- N (N.C1, N.C2,...): conclusiones relacionadas con la necesidad de la lógica en la Formación de Maestros,

- S (S.C1, S.C2,...): conclusiones sobre los saberes o conocimientos disponibles de los futuros maestros y la suficiencia de dichos contenidos.

- M (M.C1, M.C2,...): conclusiones relacionadas con la metodología utilizada (la ingeniería didáctica como metodología de investigación en didáctica de las matemáticas)

- R (R.C1, R.C2,...): reflexiones sobre el trabajo llevado a cabo y propuestas de nuevas líneas de investigación.

\section{La lógica en la formación de maestros ¿necesaria?}

En el capítulo 1, hemos abordado la complejidad que tiene la palabra "razonamiento", al ser considerado como un objeto en diferentes instituciones de referencia. Desde la definición polisémica de la Real Academia de la Lengua, que muestra una doble interpretación -según se considere la acción de razonar o el resultado de dicha acción-, a la complejidad que ofrece el objeto razonamiento en la relación didáctica.

En la relación didáctica, los razonamientos lógicos se consideran una herramienta para la adquisición del conocimiento matemático y los procesos de razonamiento están relacionados con la adquisición de conocimiento. Razonar correctamente es sinónimo de aprendizaje ya que conduce a la producción, comunicación y validación de los 
conocimientos. En matemáticas, razonar correctamente significa llevar a cabo razonamientos lógicos para la comunicación y validación de los conocimiento matemáticos.

N.C1. La modelización del sistema de enseñanza, en el enfoque epistemológico de la Didáctica de las Matemáticas, ha permitido identificar las instituciones de referencia de los diversos objetos razonamiento que aparecen en la enseñanza de las matemáticas: la Lógica que estudia los razonamientos lógicos, las Matemáticas que produce y estudia los razonamientos matemáticos y utiliza los razonamientos lógicos y el Sistema de enseñanza, que necesita el razonamiento como producción de nuevos conocimientos, además de los razonamientos lógicos y de los matemáticos.

N.C2. Así mismo, dicha modelización nos ha permitido mostrar que las prácticas sociales de dichos objetos razonamiento, que son estudiados por diversas instituciones de referencia, según las distintas prácticas. La acción de producir razonamientos, es estudiada y analizada principalmente por las diversas ramas de la Psicología (genética, evolutiva, educativa, etc.); aunque también puede ser abordado este proceso, desde otras perspectivas, (la Antropología, la Sociología, la Neuropsicología, etc.), no las tendremos en cuenta, al considerar que exceden el marco de nuestro trabajo. La Lingüística, será el dominio de referencia si se analizan los resultados de la acción de razonar, es decir la formulación del razonamiento, que también lo conoce la Real Academia, como razonamiento y la Argumentación (también llamada Lógica Informal por algunos autores) si se analiza la validez social que se le concede a dichos razonamientos.

N.C3. El sistema de enseñanza se concibe en dicha modelización, como la institución cuya función es la difusión de los saberes culturales, con el objetivo de lograr una práctica social correcta y útil de dichos saberes. La Lógica es el saber de referencia para los razonamientos lógicos, pero no forma parte de los saberes a enseñar, tal como viene reflejado en los curricula oficiales; no aparece como contenido curricular; sólo existen los 
razonamientos matemáticos asociados a los distintos contenidos matemáticos. En el apartado 1.4. del capítulo 1 de la tesis, se analiza la presencia del razonamiento, en el currículum del Grado de Formación de Maestros, constatando la ausencia del razonamiento lógico como contenido, es decir, como saber cultural a enseñar.

N.C4. El análisis de los programas oficiales de formación de los futuros maestros, muestra que el razonamiento es considerado una "competencia", entendiendo por competencia la capacidad de un individuo para realizar todo tipo de actividades matemáticas, entre ellas, el razonamiento matemático.

N.C5. La modelización de la relación didáctica ha permitido continuar la identificación de los diferentes tipos de razonamiento que aparecen en ella, según la función que desempeñan: tanto en situación adidáctica como didáctica (producir, comunicar, explicar o probar). Los razonamientos lógicos en la relación didáctica aparecen (se hacen visibles), en las explicaciones y justificaciones que llevan a cabo los estudiantes cuando se dirigen al profesor o a sus compañeros en situación didáctica, en los momentos de su validación o institucionalización. Los niveles de estructuración del medio, que Brousseau propone en su modelización (Brousseau, 1990), nos ha permitido profundizar este análisis del objeto razonamiento en la relación didáctica, identificando distintos tipos de razonamiento, según el nivel del medio que se considere, coexistiendo todos ellos simultáneamente en la relación didáctica.

N.C6. La gestión de estos razonamientos lógicos en la enseñanza de las matemáticas, es identificado en el marco de la TSD, como un problema de contrato didáctico, ya que no es posible hablar de lógica, porque no ha sido tratada como un saber institucionalizado o en vías de institucionalización, porque no existe en el currículo de dicha materia. Se trata de un saber transparente no reconocido ni por los estudiantes ni por los profesores. De esta manera el pensamiento natural y el lenguaje natural, se manifiestan como obstáculos epistemológicos que impiden el correcto funcionamiento de los razonamientos 
lógicos. A su vez, dichos conocimientos lógicos no pueden ser enseñados, dando lugar a diferentes paradojas de contrato didáctico (Orús 1992).

N.C7. El razonamiento aparece como, una noción protomatemática, que el profesor sólo tiene en cuenta en caso de ocasionar errores (dificultad protomatemática). La única forma permitida de hacerse cargo de su enseñanza, es a través de la enseñanza de las matemáticas, y de sus razonamientos matemáticos; o a través de propuestas innovadoras que muestran cómo hacer un hueco en el currículo de la enseñanza obligatoria, para que el razonamiento pueda "aparecer" en la relación didáctica y que pueda ser objeto de aprendizaje: Orús, en enseñanza primaria (Orús, 1986, 1992); Pitarch en enseñanza secundaria (Pitarch, 2003, 2015).

N.C8. La necesidad del conocimiento lógico, según lo expuesto, se extiende a todos los niveles educativos, ya que los razonamientos lógicos son necesarios en su formación integral, tanto para la adquisición de conocimientos en general, como para la adquisición de los conocimientos matemáticos en particular. También el futuro maestro, necesita en su formación integral como estudiante, los conocimientos lógicos que subyacen en los razonamientos lógicos y en los razonamientos matemáticos.

N.C9. En las conclusiones anteriores hemos analizado cómo la modelización de la TSD, nos ha permitido mostrar la gran diversidad de objetos razonamiento que aparecen en la relación didáctica y la complejidad que exige su gestión. La Lógica aparece como el dominio cultural que aporta los conocimientos lógicos de referencia, necesarios para poder gestionar las diferentes prácticas sociales del razonamiento que aparecen en la relación didáctica. Es decir, la Lógica se muestra necesaria en la formación profesional de los futuros maestros.

N.C10. La modelización de la TAD, nos ha permitido complementar el estudio teórico de la necesidad de la lógica en la formación de maestros. A partir de la noción de "rapport aux savoirs" (relaciones institucionales con los objetos), nos ha permitido mostrar los 
diferentes razonamientos que aparecen según las diversas instituciones en que dicho objeto razonamiento puede existir según las diferentes prácticas culturales o sociales; lo que hemos llamado los dominios de referencia del razonamiento.

N.C11. La noción de transposición didáctica, fundamental en la TAD, nos ha permitido mostrar de nuevo el carácter paradójico de la gestión del razonamiento en la relación didáctica. Los saberes matemáticos aprendidos, necesitan de diversos tipos de razonamientos para producir nuevos conocimientos; es decir necesitan de diversos tipos de razonamientos (no sólo los matemáticos), para identificar, seleccionar, aplicar, etc., y convertir los conocimientos aprendidos, en conocimientos matemáticos disponibles. En la realización de cualquier activida matemática (tarea), se necesitan para identificar las técnicas a utilizar, para valorar la pertirnencia de dichas técnicas o para validarlas.

\section{¿Cuáles son los conocimientos lógicos disponibles de los futuros maestros?}

\section{El cuestionario $Q$}

La respuesta a esta pregunta la hemos obtenido a través del cuestionario Q y de la corrección colectiva de dicho cuestionario. El diagnóstico llevado a cabo con 501 estudiantes universitarios, futuros maestros, pertenecientes a las universidades Jaume I de Castellón y Universidad de Jaén, ha permitido identificar los conocimientos lógicos disponibles de dichos estudiantes. Para llevar a cabo el diagnóstico se ha utilizado un cuestionario Q, diseñado como una situación fundamental para la enseñanza de la lógica (Orús, 1992).

S.C1. El análisis a priori del cuestionario Q ha mostrado que las variables didácticas elegidas para dicho cuestionario modelizan, en la mayoría de las preguntas, operaciones lógicas con predicados, lo que aumenta la complejidad respecto a la lógica proposicional. Los conocimientos lógicos planteados han sido los siguientes: conjunción, disyunción, implicación, operaciones lógicas combinadas (negación de la conjunción, implicación 
con conjunción e implicación con negación), transformación de fórmulas (equivalencia entre implicación lógica y su contrarrecíproca y leyes de De Morgan), reglas de inferencia (Modus Ponendo Ponens) y atribución del valor de verdad de proposiciones y de predicados.

S.C2. El análisis de los resultados obtenidos tras la ejecución del cuestionario Q, ha servido en esta primera fase de la experimentación para diagnosticar algunos de los conocimientos lógicos de nuestros estudiantes universitarios.

Se ha comprobado, con las tres primeras preguntas del cuestionario, que la lectura de la tabla se ha realizado correctamente y no ha supuesto un obstáculo para el desarrollo de la experimentación. Estas preguntas han sido respondidas correctamente por un 99\% de los estudiantes, a excepción de una de ellas, cuyo porcentaje ha disminuido hasta un $80 \%$ debido a la confusión provocada por las palabras utilizadas en la redacción del enunciado, dando lugar a diferentes interpretaciones. La expresión "cosas para viajar" incluida en la pregunta ha provocado la confusión.

Las preguntas del cuestionario con operaciones lógicas combinadas se encuentran entre las preguntas que han obtenido mayor número de errores, de manera alarmante en el caso de la negación de la conjunción, con tan solo un 2,5\% de respuestas correctas. También el bloque de preguntas correspondiente a la atribución del valor de verdad y de razonamiento lógico ha conducido a error en las respuestas de los estudiantes, principalmente aquellas preguntas cuyas respuestas no se resuelven mediante una búsqueda directa sobre la tabla, entre ellas, las preguntas de respuesta desconocida, con niveles de éxito no superiores al $10 \%$.

Los conocimientos lógicos disponibles de los estudiantes, que han funcionado a nivel de acción, han sido la negación de una proposición, la conjunción y la regla de inferencia Modus Ponendo Ponens. 
S.C3. Los obstáculos de naturaleza lógica que han funcionado a nivel de acción y de validación (de la acción), observados en la clase, han sido la disyunción exclusiva, la propiedad distributiva de la negación respecto a la conjunción, la equivalencia lógica entre la condicional y su inversa (falacia argumentativa) y la equivalencia lógica entre la condicional y su recíproca. Se trata de los modelos implícitos de los estudiantes, que sin ser conocimientos lógicos, han funcionado como "conocimientos personales" y son dichos conocimientos los que han sido utilizados en la resolución del cuestionario.

S.C4. Las principales dificultades lógicas encontradas por los estudiantes en situaciones de formulación y validación han sido la ausencia de conocimiento respecto a la equivalencia lógica entre la proposición condicional y la proposición contrarrecíproca, la atribución del valor de verdad cuando intervienen los cuantificadores universales (valor de verdad de un predicado) y la atribución del valor de verdad cuando interviene la negación sobre un cuantificador universal (negación de un predicado). En estos casos se ha puesto de manifiesto la dificultad de los estudiantes debida a la ausencia del conocimiento lógico de referencia, lo que ha impedido el control de las respuestas. La relación personal de los estudiantes con el objeto razonamiento no utiliza los razonamientos lógicos, necesarios en las prácticas de la institución escolar.

S.C5. La atribución subjetiva de significados diferentes a una misma palabra, las interpretaciones personales de los enunciados, las analogías o la doble interpretación de la disyunción según funcione en oraciones interrogativas o afirmativas, son algunos aspectos que hemos podido observar de este fenómeno. En este sentido también han sido observados otros rasgos del pensamiento natural en la argumentación, siendo relevantes (incluso determinante) a la hora de tomar decisiones, aspectos que no tienen nada que ver con la validez de los argumentos: la influencia ejercida por los demás compañeros, dejarse convencer por la opinión de un "líder" cuya decisión se impone ante las demás o las decisiones tomadas por mayoría de votos. Incluso, los razonamientos lógicos utilizados de manera adecuada por algunos estudiantes no han sido aceptados como válidos, 
otorgando a la argumentación la forma de validación que prevalece en la relación entre iguales y no al razonamiento lógico.

\section{La ingeniería didáctica}

La ingeniería didáctica, como metodología de investigación en didáctica de las matemáticas, ha sido calificada de "metodología espiral" (Brousseau, 1986). Con esta expresión Brousseau se refiere a la oportunidad que brindan cada una de las realizaciones y observaciones de la ingeniería para poner a prueba los diferentes elementos que intervienen en su elaboración: las concepciones teóricas (variables didácticas, devolución, institucionalización,...), la tecnología didáctica (diseño de la ingeniería, prácticas docentes, experimentación,...) o los instrumentos de análisis de los resultados (análisis estadístico y análisis estadístico implicativo implementado con el programa CHIC).

La ingeniería diseñada e implementada, se ha llevado a cabo con un total de 77 estudiantes de la Titulación de Maestro de Educación Primaria de la Universitat Jaume I, que incluye de nuevo el uso de la tabla $\mathrm{T}$ y el cuestionario Q, con el objetivo de comprobar los conocimientos lógicos de los estudiantes así como identificar los conocimientos necesarios para la gestión de la propia situación.

M.C1. La tabla y el cuestionario han funcionado satisfactoriamente como instrumento fenomenotécnico con nuestros estudiantes universitarios, para poder identificar diferentes fenómenos didácticos relacionados con el conocimiento lógico, como se ha mostrado en las conclusiones anteriores.

M.C2. La primera fase de la experimentación ha permitido introducir una nueva variable didáctica en la ingeniería. Esta nueva variable (una nueva pregunta del cuestionario) ha sido introducida para clarificar en el estudio a priori, el motivo por el que 
se respondía de manera incorrecta a una cuestión determinada. Además, una vez incorporada en el instrumento de diagnóstico, el análisis de los resultados ha conducido a considerar pertinente la inclusión de dicha variable también en la ingeniería. Esta modificación es un efecto de la ingeniería como "método espiral".

M.C3. La observación de la ingeniería ha permitido el reconocimiento, a nivel de formulación y validación, de los razonamientos lógicos que el cuestionario había movilizado a nivel de acción.

M.C4. Nuestros estudiantes, a pesar de haber sido capaces de responder al cuestionario, no han finalizado con éxito la corrección y validación que preveía la ingeniería. La situación adidáctica ha permitido identificar a qué nivel han funcionado los razonamientos, que no han pasado de ser razonamientos-acción y razonamientosformulación (de la acción), muy ligados a la descripción y una validación también muy dependiente de la acción. Consecuentemente, nos permite confirmar que los conocimientos movilizados tanto en las respuestas del cuestionario Q como en la situación observada, han sido los conocimientos personales de los estudiantes y sus diferencias con los conocimientos lógicos en juego. El modelo de representación del pensamiento natural, de Wermus, nos ha facilitado la interpretación de los resultados observados: p. e. los conflictos ocasionados entre los predicados referidos a 'nadar' o 'deportes' en tanto que predicados amalgamados, los diferentes rasgos de la argumentación, el funcionamiento parcial de los conectores lógicos, etc.

M.C5. La restricción del tiempo de la experimentación ha jugado un papel muy importante en el desarrollo de la situación, limitando las posibilidades de la ingeniería y de su observación. Las restricciones del sistema educativo, que establece el desarrollo del currículum en función de las horas de clase, no ha permitido observar el funcionamiento de la fase de institucionalización tal y como estaba prevista en la ingeniería. 
M.C6. La ingeniería que implementaba la corrección del cuestionario, ha permitido observar la gestión de los razonamientos, tanto de los estudiantes como del profesor. Los estudiantes, ante conflictos de razonamiento entre compañeros, han dado explicaciones y argumentos propios del pensamiento natural. Se ha observado la dificultad por parte de los estudiantes para justificar sus razones sin disponer de un saber lógico de referencia.

Esta misma dificultad en la gestión de los razonamientos de los estudiantes, también ha sido observada en el profesor. En este caso, se ha evitado por parte del profesor hablar de lógica en la situación, ya que estaba previsto en la ingeniería un medio adidáctico para la lógica y esto ha sido un problema para el profesor en determinados momentos; ya que el uso explícito de nociones de lógica, le hubieran permitido eliminar del debate argumentos no pertinentes. Sin embargo, la tabla se ha mostrado en todo momento, como el instrumento que permite la gestión y validación (lógica) de los razonamientos de los estudiantes, sin necesidad de explicitar los conocimientos lógicos en juego. Esto se ha podido apreciar, de manera muy evidente, en las preguntas cuya respuesta no era resultado de una búsqueda directa sobre la tabla, las cuales requerían de una actividad de razonamiento para alcanzar la respuesta: en la clase que el profesor utilizó la tabla pudo materializar el razonamiento lógico correcto y zanjar las dudas del debate argumentativo de los alumnos. Mientras que en la primera sesión de observación, no utilizó la tabla y no pudo llegar a "corregir"/validar correctamente las respuestas, a esa misma pregunta.

M.C7. Los resultados de la observación de la ingeniería, nos han servido para poner de manifiesto la necesidad de los conocimientos lógicos para la gestión de los razonamientos, tanto como estudiantes de matemáticas, para gestionar los razonamientos y su validación, como para la gestión de los razonamientos de sus propios alumnos. También permite la observación mostrar y matizar el carácter insuficiente de los conocimientos lógicos de los alumnos de la experimentación, futuros maestros. 


\section{Reflexiones personales y futuras líneas de investigación:}

R.C1. Las situaciones didácticas para la enseñanza deben ser objeto de investigación antes que de enseñanza. En este sentido no consideramos que la ingeniería utilizada pueda considerarse una situación de enseñanza de la lógica.

R.C2. A partir de la situación implementada, se podría diseñar una secuencia de situaciones para la enseñanza de la lógica, de manera que permitieran no sólo hacer funcionar determinados modelos implícitos a nivel de acción, sino reconocerlos, utilizarlos de forma consciente en más situaciones y por supuesto reconstruir o eliminar aquellos modelos que han funcionado como obstáculos epistemológicos para el aprendizaje de la lógica.

R.C3. Las situaciones didácticas implementadas en clase con futuros maestros pueden funcionar como herramientas para la formación del profesorado, tanto para la formación matemática como didáctica, formando parte del equipamiento praxeológico del profesor.

R.C4. Los dispositivos necesarios para implementar nuevas situaciones son complejos y presentan restricciones institucionales difíciles de evitar. La tarea de observación es muy difícil tal y como hemos podido comprobar. En este sentido, los recursos del CRDM, fuente de numerosas situaciones didácticas para la educación primaria, procedentes de las investigaciones llevadas a cabo en Burdeos por Guy Brousseau, pueden agilizar el proceso y ser aprovechados en este sentido. Existen ya investigaciones que muestran, cómo es posible realizar este trabajo de utilización de los recursos del CRDM-Guy Brousseau, para la formación permanente del profesorado. 
- Aarnio, A. (1990). La tesis de la única respuesta correcta y el principio regulativo del razonamiento jurídico.

- Aciego, M. O. (2005). Lógica, matemática, deducción automática. La Gaceta de la RSME, 8, 93-119.Arsac, G. (1996). Un cadre d'étude du raisonnement mathématique. Séminaire didactique et technologies cognitives en mathématiques. Grenoble: IMAG.

- $\quad$ Agencia nacional de evaluación de la calidad y acreditación (2004). Libro blanco. Título del Grado en Magisterio. Vol. 1. Madrid. ANECA.

- Álvarez, L. (1994) Fundamentos de inteligencia artificial, Universidad de Murcia.

- $\quad$ Alfonso, C.; Camacho, M. y Socas, M. (1999). Teacher profile in the geometry curriculum based on the van Hiele Theory. En O. ZASLAVSKY (ed.). Proceedings of the XXIII Conference ofthe PME. Haifa, Israel: Israel Institute of Technology, Haifa, Israel: 2.1-2.8.

- Andrews, P. B. (2002). An introduction to mathematical logic and type theory: to truth through proof (Vol. 27). Springer.

- $\quad$ Andrich Miato, Silvia y Miato, Lidio (2013). Producir, una competencia cognitiva y social. (Col. Didáctica de las Operaciones Mentales, vol. 7). Madrid: Narcea Ediciones y Ministerio de Educación, Cultura y Deporte.

- $\quad$ Arsac, G., y Mante, M. (1997). Situations d'initiation au raisonnement déductif. Educational Studies in Mathematics, 33(1), 21-43.

- $\quad$ Artaud, M. (2007). La TAD comme théorie pour la formation des professeurs. Structures et fonctions. En L. Ruiz-Higueras, A. Estepa y F. J. García (Eds.), Sociedad, escuela y matemáticas. Aportaciones de la Teoría Antropológica de lo Didáctico (pp. 241-259). Jaén, España: Universidad de Jaén.

- $\quad$ Artigue, M., Douady, R., Moreno, L., y Gómez, P. (1995). Ingeniería didáctica en educación matemática. Un esquema para la investigación y la innovación en la enseñanza y el aprendizaje de las matemáticas. México: una empresa docente y Grupo Editorial Iberoamérica. 
- Artigue, M. (2011, May). La educación matemática como un campo de investigación y como un campo de práctica: Resultados, Desafíos. In XIII Conferência interamericana de educação matemática.

- $\quad$ Artigue, M. (2014). La educación matemática como un campo de investigación y como un campo de práctica: Resultados, Desafíos. Cuadernos de Investigación y Formación en Educación Matemática, (11), 43-59. Atienza, M. (1999). El Derecho como argumentación. Isegoría, (21), 37-47.

- $\quad$ Ayala, E. S. (1996). Enseñar a pensar al alumno del primer ciclo de primaria a través de la matemática. Suma: Revista sobre Enseñanza y Aprendizaje de las Matemáticas, (23), 7-20.

- Azcárate, P. (1996). Estudio de las concepciones disciplinares de futuros profesores de primaria en torno a las nociones de la aleatoriedad y probabilidad. Tesis doctoral. 1996. Granada: Comares.

- $\quad$ Azcárate, P., Cardeñoso, J. M. y Porlan, R. (1998). Concepciones de futuros profesores de primaria sobre la noción de aleatoriedad. Enseñanza de las Ciencias, 16 (1), 85-98.

- $\quad$ Bachelard, G. (1978). La filosofia del no. Buenos Aires: Amorrortu.

- $\quad$ Bachelard, G. (1990). La formación del espíritu científico. Contribución a un psicoanálisis del conocimiento objetivo. (16 $6^{\mathrm{a}} \mathrm{ed}$.). Buenos Aires: Argos

- $\quad$ Balacheff N. (1988) Etude des processus de preuve chez des élèves de Collège. Thèse de Doctorat d'état ès-sciences. Grenoble : Université Joseph Fourier.

- Balacheff, N. (1994). Didactique et intelligence artificielle. Recherches en didactique des mathématiques, 14.

- $\quad$ Berté, M. (2014). Reflexionar: Un modo mejor de pensar. . (Col. Didáctica de las Operaciones Mentales, vol. 11). Madrid: Narcea Ediciones y Ministerio de Educación, Cultura y Deporte.

- $\quad$ Berthelot, R. y Salin, M. H. (1992) Représentation de l'espace chez l'enfant et enseignement de la géométrie dans la scolarité obligatoire. Thèse, Université Bordeaux I. 
- Blanco, L. (1991). Conocimiento y acción en la enseñanza de las matemáticas de profesores de EGB y estudiantes para profesor. Tesis doctoral. Badajoz: Servicio de publicaciones de la UNEX.

- Blanco, L. (1992). Aproximación al conocimiento práctico personal de los profesores de matemáticas de EGB. Enseñanza de las Ciencias, 10 (2), 195-200.

- Bochenski I. M. Los Métodos actuales del pensamiento. Biblioteca del Pensamiento Actual, Ed. Rialp, Madrid, 1971.

- Borel, E. (1962). La definición en matemáticas. En F. Le Lionnais (Ed.), Las grandes corrientes del pensamiento matemático (pp. 25-35). Buenos Aires: Eudeba.

- $\quad$ Bosch, M. (2003). Un punto de vista antropológico: la evolución de los "elementos de representación" en la actividad matemática. In Cuarto simposio de la sociedad española de investigación en educación matemática (pp. 15-28). Sociedad Española de Investigación en Educación Matemática, SEIEM.

- $\quad$ Bosch, M. y Chevallard, Y. (1999). La sensibilité de l'activité mathématique aux ostensifs: objet d'étude et problématique. Recherches en didactique des mathématiques, 19(1), 77-123.

- Bosch, M., García, F., Gascón, J., y Ruiz Higueras, L. (2007). La modelización matemática y el problema de la articulación de la matemática escolar. Una propuesta desde la teoría antropológica de lo didáctico. Educación Matemática, 18(2), 37-74.

- $\quad$ Bosch, M., García, F., Gascón, J., y Ruiz Higueras, L. (2006). La modelización matemática y el problema de la articulación de la matemática escolar. Una propuesta desde la teoría antropológica de lo didáctico. Educación Matemática, 18(2), 37-74.

- Bosch, M. y Gascón, J. (2005). La praxeología local como unidad de análisis de los procesos didácticos. Análisis del currículo actual de matemáticas y posibles alternativas, 135-160.

- Bosch, M. y Gascón, J. (2006). Twenty-five years of the didactic transposition. ICMI Bulletin, 58, 51-63.

- Bosch, M. y Gascón, J. (2009). Aportaciones de la Teoría Antropológica de lo Didáctico a la Formación del Profesorado de Secundaria. En M. L. González, M. T. 
González y J. Murillo (Eds.) Investigación en Educación Matemática XIII, 89-113. Santander: SEIEM.

- Briand, J. (1993). L'énumération dans le mesurage des collections, un dysfonctionnement de la transposition didactique. Thèse de 3ème cycle, Université Bordeaux I

- Brodie, K. (2009). Teaching mathematical reasoning in secondary school classrooms. Springer.

- $\quad$ Brousseau, G. (1972). Processus de mathématisation. La mathématique à l'Ecole Elémentaire, 428-442.

- Brousseau, G. (1976). Les obstacles épistémologiques et les problèmes en mathématiques.

- $\quad$ Brousseau, G. (1978). Etude locale des processus d'acquisition en situations scolaires. Enseignement élémentaire des mathématiques, 18, 7-21.

- Brousseau, G. (1979). Etude dês situations: théorie des situations didactiques. Bordeaux: IREM de Bordeaux.

- $\quad$ Brousseau, G. (1984). Le rôle central du contrat didactique dans l'analyse et la construction des situations d'enseignement et d'apprentissage des mathématiques. Actes de la 3e école d'été de didactique des mathématiques.

- Brousseau G. (1986). Fondaments et méthodes de la didactique des mathématiques. Thèse d'Etat, Université de Bordeaux-I. Ed: LADIST-Université de Bordeaux II, Bordeaux.

- Brousseau, G. (1988). Les différents rôles du maître. Bulletin de l'AMQ. Montréal, (23), 14-24.

- Brousseau, G. (1989). Les obstacles épistémologiques et la didactique des mathématiques. Construction des savoirs. Obstacles et conflits, 41-64.

- Brousseau, G. (1989a). Utilidad e interés de la didáctica para un profesor. Suma, $4,5-12$. 
- $\quad$ Brousseau, G. (1990). Le contrat didactique: le milieu. Recherches en didactique des mathématiques, 9(9.3), 309-336.

- Brousseau, G. (1991). ¿Qué pueden aportar a los enseñantes los diferentes enfoques de la didáctica de las matemáticas? (Segunda parte). In Enseñanza de las Ciencias (Vol. 9, pp. 010-21).

- $\quad$ Brousseau, G. (1993). Analyse de données en didactique; I.F.E. Université Bordeaux 1.

- Brousseau, G. (1997). Theory of Didactical situations in mathematics 1970-1990, [Edited and translated M. Cooper, N. Balacheff, R. Sutherland and V. Warfield.].

- $\quad$ Brousseau, G. (2002). Les doubles jeux de l'enseignement des mathématiques. Revue du Centre de Recherches en Education, Université de Saint Etienne, (22-23), 83155.

- Brousseau, G. (2015). Commentaires 2015 de Guy Brousseau sur son petit livret de 1964 G. Brousseau, Les Mathématiques du cours préparatoire, premier fascicule, Dunod, 1965. Traducido por Mabel Aguilar y Dilma Fregona. Para los participantes del "Congreso Internacional de Didáctica de la Matemática. Una mirada epistemológica y empírica (Santa Marta, Colombia 2015)"

- $\quad$ Brousseau, G. y Centeno, J. (1991). Rôle de la mémoire didactique de l'enseignant. Recherches en didactique des mathématiques, 11(2.3), 167-210.

- $\quad$ Brousseau, G. y Gibel, P. (2005). Didactical handling of students' reasoning processes in problem solving situations. In Beyond the Apparent Banality of the Mathematics Classroom (pp. 13-58). Springer US.

- Buforn, Á. y Fernández, C. (2014). Conocimiento de Matemáticas Especializado de los Estudiantes para Maestro de Primaria en Relación al Razonamiento Proporcional. Boletim de Educação Matemática, 28(48), 21-41.

- $\quad$ Bunge M. (1963). La ciencia, su método y su filosofía. Buenos Aires: Siglo XX. 
- Cacciamani, S. (2014). Formular hipótesis. Para construir el conocimiento. (Col. Didáctica de las Operaciones Mentales, vol. 10). Madrid: Narcea Ediciones y Ministerio de Educación, Cultura y Deporte.

- Cardeñoso Domingo, J. M. (1998). Las creencias y el conocimiento de los profesores de Primaria andaluces sobre la matemática escolar. Modelización de concepciones sobre la aleatoriedad y la probabilidad. Tesis doctoral. Universidad de Cádiz.

- Carrillo, J. (1997). Modos de resolver problemas y concepciones sobre la matemática y su enseñanza de profesores de alumnos de más de 14 años. Aportaciones a la metodología de la investigación y estudio de posibles relaciones. Tesis doctoral. Huelva: Servicio de publicaciones de la Universidad de Huelva, 1996.

- Castañeda, A.; Rosas, A. y Molina, J. G. (2012). La institucionalización del conocimiento en la clase de matemáticas: Un estudio sobre el discurso del aula. Perfiles educativos, 34(135), 26-40.

- Castro, E. y Castro, E. (1996). Conocimiento de contenido pedagógico de los estudiantes de magisterio sobre estructura multiplicativa. En J. Giménez, S. Lunares y V. Sánchez (eds.). El proceso de llegar a ser un profesor de Primaria. Cuestiones desde la Educación Matemática. Granada, España: Comares, 119-141.

- Chevallard Y. (1989). Le concept de rapport au savoir. Rapport personnel, rapport institutionel, rapport officiel. Séminaire de Didactique des Mathématiques et de l'Informatique de Grenoble. LSD2-IMAG, Université Joseph-Fourier, Grenoble.

- Chevallard Y. (1991). Dimension instrumentale, dimension sémiotique de l'activité mathématique. Séminaire de Didactique des Mathématiques et de l'Informatique de Grenoble. LSD2-IMAG, Université Joseph-Fourier, Grenoble.

- Chevallard Y. (1992). Concepts fondamentaux de la didactique: perspectives apportées par une approche anthropologique. Recherches en Didactique des Mathématiques, Vol. 12, n.1 pp. 73-112.

- Chevallard, Y. (1998). La transposición didáctica. Del saber sabio al saber enseñado. $3^{\text {a }}$. Edición. Edit. Aique, Buenos Aires. 
- $\quad$ Chevallard, Y.; Bosch, M. y Gascón, J. (1997). Estudiar matemáticas. El eslabón perdido entre la enseñanza y el aprendizaje. Barcelona, España: ICE-Horsori.

- Chevallard, Y. (1999). El análisis de las prácticas docentes en la teoría antropológica de lo didáctico. Recherches en Didactique des Mathématiques, 19(2), 221266.

- Chevallard, Y. (2001). Aspectos problemáticos de la formación docente. Boletín del Seminario Interuniversitario de Investigación en Didáctica de las Matemáticas, 12.

- Chopin, M. P. (2007). Le temps didactique en Théorie Anthropologique du Didactique. Quelques remarques methodologiques á propos des moments d'étude. En L. Ruiz-Higueras, A. Estepa y F. J. García (Eds.), Sociedad, escuela y matemáticas. Aportaciones de la Teoría Antropológica de lo Didáctico (pp. 301-318). Jaén, España: Universidad de Jaén.

- $\quad$ Cirade, G. (2006). Devenir professeur de mathématiques: entre problèmes de la profession et formation en IUFM. Les mathématiques comme problème professionnel (Doctoral dissertation, Université de Provence-Aix-Marseille I).

- Colom R. y Juan-Espinosa M. Estudios sobre los fundamentos de la cognición. Ed. Promolibro, Valencia, 1990.

- Corradini, M. (2012). Crear. Cómo se desarrolla una mente creativa (Col. Didáctica de las Operaciones Mentales, vol. 2). Madrid: Narcea Ediciones y Ministerio de Educación, Cultura y Deporte.

- Cuadras, C. M. (1991). Métodos de análisis multivariante. Barcelona: PPU

- Czerwinsky Domenis, Loredana (2013). Observar. Los sentidos en la construcción del conocimiento (Col. Didáctica de las Operaciones Mentales, vol. 8). Madrid: Narcea Ediciones y Ministerio de Educación, Cultura y Deporte.

- Dasí C., y Algarabel S. (2003). Influencia del entrenamiento sobre el razonamiento deductivo: importancia del contenido y transferencia entre dominios. Psicothema, 15(3), 440-445. 
- Deaño A., Delval J. (1982). Jean Piaget. Estudios sobre lógica y psicología. Madrid: Alianza Editorial

- Deaño A. (1996) Introducción a la lógica formal. Madrid: Alianza Editorial.

- Deaño, A. (1980) Las concepciones de la Lógica. Madrid: Taurus Ediciones.

- De Guzmán, M. (2007). Enseñanza de las ciencias y la matemática. Revista Iberoamericana de educación, (43), 19-58.

- De Villiers, M. (1993). El papel y la función de la demostración en matemáticas. Epsilon, 26, 15-30.

- Digneau, J. M. (1980). Création d'un code à l'école maternelle: Etude d'un saut informationnel. Thèse de 3ème cycle, Université Bordeaux 1.

- Douady, R. (1995). La ingeniería didáctica y la evolución de su relación con el conocimiento. Ingeniería didáctica en educación matemática, 61-97.

- Durand-Guerrier, V (1996a). Conditionals, necessity, and contingence in mathematics class Teaching logic and reasoning in an illogical world, Rutgers University, Juillet.

- Durand-Guerrier V. (1996b). Logique et raisonnement mathématique. Défense et illustration de la pertinence du calcul des prédicats pour une approche didactique des difficultés liées à l'implication. Thèse. Université Claude Bernard Lyon 1.

- Durand-Guerrier, V. (2003a) Logic and mathematical reasoning from a didactical point of view. A model-theoretic approach. in Actes électroniques du Colloque CERME 3 (Conference on European Research in Mathematic Education, Bellaria, Italy, February 2003.

- Durand-Guerrier, V. (2003b) Which notion of implication is the right one? From logical considerations to a didactic perspective, Educational Studies in Mathematics 53, $5-34$. 
- Durand-Guerrier, V. (2005) Diplôme d'habilitation a diriger des recherches en Didactique des Mathématiques, obtenu à l'Université Lyon 1 en Juin 2005. Titre de la note de synthèse: Recherches sur l'articulation entre la logique et le raisonnement mathématique dans une perspective didactique. Un cas exemplaire de l'interaction entre analyses épistémologique et didactique. Apports de la théorie élémentaire des modèles pour une analyse didactique du raisonnement mathématique.Durand-Guerrier, V. (2008). Truth versus validity in mathematical proof. ZDM, 40(3), 373-384.

- Durand-Guerrier, V. y Arsac, G. (2003) Méthodes de raisonnement et leurs modélisations logiques. Le cas de l'analyse. Quelles implications didactiques? Recherches en Didactique des Mathématiques, 23/3, 295-342.

- Durand-Guerrier, V. y Arsac, G. (2009). Analyze of mathematical proofs. Some questions and first answers. In Proceedings of the ICMI Study 19 conference: Proof and Proving in Mathematics Education. (Vol. 1, pp. 148-153).

- Duval, R. (1992). Argumenter, démontrer, expliquer: continuité ou rupture cognitive. Petit x, 31, 37-61.

- Duval R. (2000) Ecriture, raisonnement et découverte de la démonstration en mathématiques. Recherches en didactique des mathématiques 20 (2) 135-170

- Farello, P. y Bianchi, F. (2012). Describir: implicaciones psicológicas, pedagógicas y sociales (Col. Didáctica de las Operaciones Mentales, vol. 4). Madrid: Narcea Ediciones y Ministerio de Educación, Cultura y Deporte.

- Ferrater Mora, J. y Leblanc, H. (1962). Lógica matemática. México, Fondo de Cultura Económica, 1, 210.

- Fregona, D. (1995). Las figuras planas como milieu en la enseñanza de la geometría; interacciones, contratos y transposiciones didácticas, tesis de doctorado, Universidad Bordeaux I, Francia.

- $\quad$ Fregona, D. y Orús, P. (2011). La noción de medio en la teoría de las situaciones didácticas. Una herramienta para analizar decisiones en las clases de matemática. Libros del Zorzal: Buenos Aires. 
- Fregona, D. (2013). Una propuesta de análisis para la preparación y gestión de clases de matemática. Cuadernos de Educación, 11(11).

- Galetto, M. y Romano, A. (2012). Experimentar: aplicación del método científico a la construcción del conocimiento (Col. Didáctica de las Operaciones Mentales, vol. 5). Madrid: Narcea Ediciones y Ministerio de Educación, Cultura y Deporte.

- Galipienso, M. I., Quevedo, M. A., Pardo, O., Ruiz, F., y Ortega, M. A. (2003). Inteligencia artificial: modelos, técnicas y áreas de aplicación. Editorial Paraninfo.

- $\quad$ Garcia, F. J., Pérez, J. G., Higueras, L. R., y Casabó, M. B. (2006). Mathematical modelling as a tool for the connection of school mathematics. ZDM, 38(3), 226-246, ZDM 38 (3), 226-246

- García Honrado, I. (2011). Contribución al estudio del razonamiento ordinario y la computación con palabras. Tesis. Universidad de León.

- Gascón, J. (1998). Evolución de la didáctica de las matemáticas como disciplina científica. Recherches en didactique des mathématiques, 18, 7-34.

- Gascón, J. (2001). Incidencia del modelo epistemológico de las matemáticas sobre las prácticas docentes. Relime, 4 (2) 129-159.

- Gascón, J. y Sierra, T. A. (2002). Reconstrucción escolar de la numeración para la formación de maestros. En M. Peñalva, G. Torregrosa y J. Valls (Eds.) Aportaciones de la Didáctica de las Matemáticas a Diferentes Perfiles Profesionales (pp. 213-227). Alicante: Universidad de Alicante.

- Gibel, P. (2007). Analysis of the teacher's arguments used in the didactical management of a problem solving situation.working group 4. Argumentation and proof 536, 633.

- Gibel, P. (2008). Analyse en théorie des situations d'une séquence destinée à développer les pratiques du raisonnement en classe de mathématiques à l'école primaire. In Annales de didactique et de sciences cognitives (Vol. 13, pp. 5-39). 
- Gibel, P. (2009). Analyse des connaissances et des savoirs utilisés par les élèves lors de l'élaboration de raisonnements en situation a didactique à l'école primaire. In Enseignement des mathématiques et développement: enjeux de société et de formation-Actes du colloque EMF2009 (pp. 286-292).

- Gil, F. (2000). Marco conceptual y creencias de los profesores sobre evaluación en matemáticas. Servicio de publicaciones, Universidad de Almería. Tesis doctoral. Universidad de Granada, 1999.

- Goñi, J. M. (1999). La evaluación en matemáticas dentro de una visión constructivista del curriculum: una experiencia. Tesis doctoral. Universidad del País Vasco.

- Godino, J. D., y Recio, Á. M. (2001). Significados Institucionales de la Demostración: Implicaciones para la educación matemática. Enseñanza de las ciencias: revista de investigación y experiencias didácticas, 19(3), 405-414.

- Godino, J. (2002). La formación matemática y didáctica de maestros como campo de acción e investigación para la didáctica de las matemáticas: el proyecto edumatmaestros. In $V$ Simposio sobre Aportaciones del área Didáctica de la Matemáticas a diferentes Perfiles Profesionales. Universidad de Alicante.

- Godino, J. D. (2009). Categorías de análisis de los conocimientos del profesor de matemáticas. Unión, Revista Iberoamericana de Educación Matemática, v. 20, pp. 13-31.

- $\quad$ Godino, J. D., Castro, W., Aké, L., y Wilhelmi, M. D. (2012). Naturaleza del razonamiento algebraico elemental. Boletim de Educação Matemática-BOLEMA, 26, 483-511.

- Gómez, L. S., y Havidich, M. C. (2004). Lógica y ciencia. In Summa logicae en el siglo XXI [Archivo de ordenador] (p. 18). (Corresponde a un artículo dentro de Summa logicae)

- Gras, R., Couturier, R., Bodin, A. (2007). Classification Hiérarchique Implicative et Cohésitive, CHIC. Software, versión 4.1. 
- $\quad$ Gras, R. y Kuntz, P. (2009). El Analisis Estadistico Implicativo (ASI) en respuesta a problemas que le dieron origen. En Orus P., Zemora L. y Gregori P. (Eds.). Teoria y aplicaciones del analisis estadistico implicativo: primera aproximación en lengua hispana (pp. 3-50). Castellón: Departamento de Matemáticas, Universitat Jaume I.

- Graterol, J. S. (2012). Hablando sobre Enseñanza de la Matemática con estudiantes futuros profesores de matemática. Números, (80), 119-134.

- Gromi, A. (2013) Juzgar. De la opinión no fundamentada al juicio elaborado. (Col. Didáctica de las Operaciones Mentales, vol. 6). Madrid: Narcea Ediciones y Ministerio de Educación, Cultura y Deporte.

- Gutiérrez, A., Jaime, A. y Fortuny, J. M. (1991). An alternative paradigm to evaluate the acquisition of the van Hiele levels. Journal for Research in Mathematics Education, 237-251.

- Gutiérrez, A. y Jaime, A. (1996). Uso de definiciones e imágenes de conceptos geométricos por estudiantes de Magisterio. En J. Giménez, S. Llinares y V. Sánchez (eds.). El proceso de llegar a ser un profesor de Primaria. Cuestiones desde la Educación Matemática. Granada-España: Comares, 143-170.

- Gutiérrez, A. y Jaime, A. (1999). Preservice primary teachers' understanding of the concept of altitude of a triangle. Journal of Mathematics Teacher Education, 2, 253275.

- Hanna, G., y De Villiers, M. (2008). ICMI study 19: Proof and proving in mathematics education. ZDM, 40(2), 329-336.

- Hache, C. y Mesnil, Z. (2012). Élaboration d'une formation à la logique pour les professeurs de mathématiques. In Élaboration d'une formation à la logique pour les professeurs de mathématiques (pp. 201-223).

- $\quad$ Inhelder, B. y Piaget, J. (1985) De la lógica del niño a la lógica del adolescente. Buenos Aires: Ed. Paidós

- $\quad$ Kilpatrick, J., Gómez, P., y Rico, L. (1998). Educación matemática. Errores y dificultades de los estudiantes. Resolución de problemas. Evaluación. Historia. una empresa docente. 
- Kneller, G. (1969) La lógica y el lenguaje en la Educación. Buenos Aires: El Ateneo.

- Kuhn, D. (1979). L'Etude des changements spontanés dans le raisonnement de l'adolescent par une méthode d'observation. Bulletin de Psychologie, XXXIII, 345, 649658.

- Lacasta, E. (1997). Estrategias del análisis estadístico para el tratamiento de las cuestiones didácticas.

- Lakatos, I. (1978). Pruebas y refutaciones. La lógica del descubrimiento matemático. Madrid: Alianza Universidad.

- León Corredor, O. L. / Calderón, D. I. "Validación y argumentación de lo matemático en el aula". Revista Latinoamericana de Investigación en Matemática Educativa, Marzo 2001, Vol. 4, no 001, 5-21.

- Llinares, S. (1998). La investigación sobre el profesor de matemáticas: aprendizaje del profesor y práctica profesional. Aula. Revista de Enseñanza e Investigación Educativa, 10, 153-179.

- Llinares, S. (1999). Conocimiento y práctica profesional del profesor de matemáticas. Características de una agenda de investigación». Zetetike, 17, n. ${ }^{\circ}$ 12, 9-36.

- Llinares, S. (2000). Intentando comprender la práctica del profesor de matemáticas. En J.Ponte y otros (eds.) Educagáo matemática em Portugal, Espanha e Italia. Lisboa, Portugal: SPCE-SEM, 109-132.

- Llinares, S. y García, M. (1994). Conocimiento de contenido pedagógico del profesor. Tareas y modos de representación para las fracciones. Revista de Educación, 304,199-225.

- Lloret, À. B., y Verdú, C. F. (2015). Cómo reconocen los estudiantes para maestro evidencias del razonamiento up and down en los estudiantes [How prospective teachers recognize evidence about students' reasoning up and down]. ENSAYOS. Revista de la Facultad de Educación de Albacete, 30(1), 9-21.

- $\quad$ Manzano, M. (2004). Summa logicae en el siglo XXI [Archivo de ordenador]. 
- Marcelo, C. (1994). Formación del profesorado para el cambio educativo. Barcelona: PPU.

- Margolinas, C.; Coulange, L. y Bessot, A. (2005). What can teacher learn in the classroom? Educational Studies in Mathematics 59 (1-3), 205-234.

- Maudet, C. (1982). Les Situations et les processus de l'apprentissage d'une fonction logique Thèse de l'université de Bordeaux 1.

- Maza, C. (2000). Análisis de la formulación y resolución de problemas porcentuales de cambio en estudiantes para maestro. Tesis doctoral. Universidad de Sevilla.

- Mesnil, Z. (2014). La logique: d'un outil pour le langage et le raisonnement mathématique vers un objet d'enseignement (Doctoral dissertation, Université Paris Diderot).

- $\quad$ Miranda, T. (2000) El juego de la argumentación. Proyecto Didáctico Quirón No 63. Madrid: Ed. De la Torre

- $\quad$ Miranda, T. (2202). Argumentos. Universidad de Valencia

- Morales, G. (2014). L'enseignement et l'apprentissage de la représentation Une étude de cas en maternelle: le «jeu des trésors » Thèse de Doctorat, Université Bretagne Occidentale

- Moreira, M. (1993). Le traitement de la vérité mathématique à l'école. Thèse de 3ème cycle, Université Bordeaux 1.

- $\quad$ Mullis, I. V., y Martin, M. O. (2014). TIMMS Advanced 2015 Assessment Frameworks. International Association for the Evaluation of Educational Achievement.

- $\quad$ Murcio Maghei, A. (2013) Interpretar. De la comprensión previa a la explicación de los acontecimientos. (Col. Didáctica de las Operaciones Mentales, vol. 9). Madrid: Narcea Ediciones y Ministerio de Educación, Cultura y Deporte.

- $\quad$ Nidditch, P. H. (1978). El desarrollo de la lógica matemática. Madrid: Cátedra. 
- $\quad$ Oliveras, M. L. (1996). Etnomatemáticas. Formación de profesores e innovación curricular. Granada: Comares: Tesis doctoral. Universidad de Granada, 1995.

- $\quad$ ORDEN ECI/3854/2007, de 27 de diciembre, (BOE de 29/12/2007), por la que se establecen los requisitos para la verificación de los títulos universitarios oficiales que habiliten para el ejercicio de la profesión de Maestro en Educación Infantil.

- ORDEN ECI/3857/2007, de 27 de diciembre, (BOE de 29/12/2007) por la que se establecen los requisitos para la verificación de los títulos universitarios oficiales que habiliten para el ejercicio de la profesión de Maestro en Educación Primaria.

- Orús, P. (1986). L'enseignement des méthodes de classification. Proposition d'une ingénierie pour le cours moyen. Memorie de D.E.A. Université de Bordeaux-I (Etudes de didactique des mathématiques. IREM, Bordeaux)

- $\quad$ Orús, P. (1992). Le raisonnement des élèves dans la relation didactique; effets d'une initiation à l'analyse classificatoire dans la scolarité obligatoire. Thèse, U.E.R. Scièntifique. Université de Bordeaux I, Ed. IREM de Bordeaux.

- $\quad$ Orús, P. (1993). La utilización de un concepto matemático-el análisis tipológicocomo útil didáctico en la escolaridad obligatoria. Enseñanza de las ciencias: revista de investigación y experiencias didácticas, 343-344.

- $\quad$ Orús, P., Zamora, L. y Gregori P. (Eds.) (2009). Teoría y aplicaciones del análisis estadístico implicativo: primera aproximación en lengua hispana. Castellón: Departamento de Matemáticas, Universitat Jaume I

- Panizza, M. (2005). Razonar y Conocer: Aportes a la comprensión de la racionalidad matemática de los alumnos (Vol. 4). Libros del Zorzal.

- Perelman, Chaïm. (2007). Lógica formal y lógica informal. Praxis Filosófica, Julio-Diciembre, 139-144.

- $\quad$ Peres, J. (1984). Utilisation d'une théorie des situations en vue de l'identification des phénomènes didactiques au cours d'une activité d'apprentissage scolaire: Construction d'un code de désignation d'objets à l'école maternelle. Thèse de $3^{\text {ième }}$ cycle Université Bordeaux II, publié par IREM de Bordeaux. 
- $\quad$ Pitarch, I. (2002). Estudio sobre la viabilidad y el interés didáctico del tratamiento de la información en la ESO. Trabajo de investigación del tercer ciclo presentado en la Universitat Jaume I y dirigido por Pilar Orús Báguena. (Ed: UJI, Castellón), 2002.

- Pitarch I. (2015). Desarrollar la competencia tratamiento de la información en la ESO, a través del trabajo conjunto de la lógica y los datos. Tesis. Universitat Jaume I, Castellón.

- $\quad$ Plessi, P. y otros (2012). Evaluar. Cómo aprenden los estudiantes el proceso de valoración. (Col. Didáctica de las Operaciones Mentales, vol. 3). Madrid: Narcea Ediciones y Ministerio de Educación, Cultura y Deporte.

- $\quad$ Pochulu, M. (2009). Análisis y categorización de errores en el aprendizaje de la matemática en alumnos que ingresan a la universidad. Colección Digital Eudoxus, (8).

- $\quad$ Popper K. (1979). El desarrollo del conocimiento científico. México: Siglo XXI

- $\quad$ Popper K. R. (1988) Conocimiento objetivo: un enfoque evolucionista. Madrid: Tecnos.

- $\quad$ Popper K. R. (1994) La lógica de la investigación científica. Madrid: Tecnos.

- $\quad$ Porter, A., McMaken, J., Hwang, J., y Yang, R. (2011). Common core standards the new US intended curriculum. Educational Researcher, 40(3), 103-116.

- $\quad$ Portugais, J., (1995) Didactique des mathematiques et formation des enseignants

- $\quad$ REAL DECRETO 1613/06 de 7 de diciembre, (BOE de 08/12/06), por el que se establecen las enseñanzas mínimas de la Educación Primaria.

- REAL DECRETO 1630/06 de 29 de diciembre, (BOE de 04/01/07), por el que se establecen las enseñanzas mínimas del segundo ciclo de Educación Infantil.

- $\quad$ REAL DECRETO 1631/06 de 29 de diciembre, (BOE de 05/01/07), por el que se establecen las enseñanzas mínimas correspondientes a la Educación Secundaria Obligatoria.

- REAL DECRETO 126/2014, de 28 de febrero, (BOE de 01/03/07), por el que se establece el currículo básico de la Educación Primaria. 
- $\quad$ REAL DECRETO 1467/2007, de 2 de noviembre, (BOE de 06/11/07), por el que se establece la estructura del bachillerato y se fijan sus enseñanzas mínimas.

- Recio A. M., Godino J. D. (2001) Institutional and personal meanings of mathematical proof, Educational Studies in Mathematics 48 (1), pp. 83-99

- $\quad$ Rico, Luis (1995). Errores y dificultades en el aprendizaje de las matemáticas. En Kilpatrick, J.; Rico, L.; Gómez, P. (Eds.), Educación Matemática. Errores y dificultades de los estudiantes. Resolución de problemas. Evaluación. Historia (pp. 69108). Bogotá: una empresa docente.

- $\quad$ Rico, L; Segovia, I. y González-López, M. J. (2000). Representación y resolución de problemas geométricos por profesores de matemáticas en formación. Educación Matemática, 12 (2), 5-26.

- Ruiz-Olarría, A. y Sierra, T.A. (2011). La formación matemático-didáctica del profesorado de secundaria. En M. Bosch, J. Gascón, A. Ruiz Olarría, M. Artaud, A. Bronner, Y. Chevallard, G. Cirade, C. Ladage y M. Larguier (Eds.), Un panorama de la TAD (pp. 465-483). CRM Documents, vol. 10. Bellaterra (Barcelona). Centre de Recerca Matemàtica.

- Ruiz, A. (2015). La formación matemático-didáctica del profesorado de secundaria. De las matemáticas por enseñar a las matemáticas para la enseñanza. Tesis. Universidad Autónoma de Madrid.

- Ruiz-Higueras, L. (2005). La construcción de los primeros conocimientos numéricos. En Chamorro, M.C. (Ed.).Didáctica de las matemáticas para Educación Infantil. (pp. 181, 219). Madrid: Pearson Educación.

- Ruiz-Higueras, L. y García, F. J. (2011). Análisis de las praxeologías didácticas: implicaciones en la formación de maestros. En M. Bosch, J. Gascón, A. Ruiz Olarría, M. Artaud, A. Bronner, Y. Chevallard, G. Cirade, C. Ladage y M. Larguier (Eds.), Un panorama de la TAD (pp. 431-464). CRM Documents, vol. 10. Bellaterra (Barcelona). Centre de Recerca Matemàtica.

- Sánchez, C. S. (2002). Enseñar o aprender a pensar. Escritos de psicología, (6), 53-71. 
- Salin M. H. (1976) Le rôle de l'erreur dans l'apprentissage des mathématiques de l'école primaire. Mémoire de DEA de Didactique des Mathématiques, IREM de Bordeaux.

- Salin, M. H. (2004). La enseñanza del espacio y la geometría en la escuela elemental. Números, formas y volúmenes en el entorno del niño. Madrid: Instituto Superior de Formación del Profesorado, Ministerio de Educación y Ciencia.

- Sánchez, M. (2002). La investigación sobre el desarrollo y la enseñanza de las habilidades de pensamiento. Revista Electrónica de Investigación Educativa 4, (1).

- Santamaría, C. (1995) Introducción al razonamiento humano. Madrid: Alianza. Psicología minor.

- Santaló, L. (2009, September). Matemática para no matemáticos. In Memórias del congreso iberoamericano: UNESCO, 1990, p. 1-12. UNESCO.

- $\quad$ Schoenfeld, A. H. (1992: "Learning to think mathematically: Problem Solving, Metacognition and Sense-making in Mathematics", en GROUWS, D. A. (ed). Handbook of Research in Mathematics Teaching and Learning, New York, MacMillan, pp.334-389.

- $\quad$ Sensevy, G.; Mercier, A. y Schubauer-Leoni, M. L. (2000). Vers un modèle de l'action didactique du professeur. A propos de la Course à 20. Recherches en Didactique des Mathématiques 20, 263-304.

- $\quad$ Sensevy, G.; Schubauer-Leoni, M. L.; Mercier, A.; Ligozat, F. y Perrot, G. (2005). An attempt to model the teacher's action in the mathematics class. Educational Studies in Mathematics 59 (1-3), 153-181.

- Shulman, L. S. (2005). Conocimiento y enseñanza: fundamentos de la nueva reforma. Profesorado: Revista de curriculum y formación del profesorado, 9(2), 1.

- $\quad$ Sierra, T.A. (2006). Lo matemático en el diseño y análisis de organizaciones didácticas. Los sistemas de numeración y la medida de magnitudes. Tesis doctoral, Universidad Complutense de Madrid. 
- $\quad$ Sierra Delgado, T. Á., Bosch Casabó, M., y Gascón Pérez, J. (2012). La formación matemático-didáctica del maestro de Educación Infantil: el caso de «cómo enseñar a contar». Revista de Educación, 357, 231-256.

- $\quad$ Sternberg, R.J. (1999). Enseñar a pensar. Madrid: Santillana.

- $\quad$ Suppes, P. y S. Hill. (1986) Introducción a la Lógica Matemática. Barcelona. Ed. Reverté.

- Tall, D. (1991). Advanced Mathematical Thinking. Dordrecht: Kluwer Academic Publishers.

- Tinland, F. (1991). Systèmes naturels, systèmes artificiels. Editions Champs Vallon, Seyssel.

- Tosolini, A. (2014). Comparar: una nueva lectura de la realidad plural (Col. Didáctica de las Operaciones Mentales, vol. 12). Narcea Ediciones y Ministerio de Educación, Cultura y Deporte.

- Trigueros, M. (2005). La noción de esquema en la investigación en matemática educativa a nivel superior. Educación Matemática, 17(1), 5-31.

- Tuffanelli, L. (2010). Comprender: ¿Qué es? ¿ Cómo funciona? (Col. Didáctica de las Operaciones Mentales, vol. 1). Madrid: Narcea Ediciones y Ministerio de Educación, Cultura y Deporte.

- $\quad$ Vázquez. M. J. (2000) Immanuel Kant, Madrid: Ediciones Akal

- Vergnaud, G. (1990). La teoría de los campos conceptuales. Recherches en didactique des mathématiques, 10(2), 3.

- Walton, D. N. (1990). What is reasoning? What is an argument? The Journal of Philosophy, 399-419.

- Wermus, H. (1976): Essai de représentation de certaines activités cognitives à l'aide des prédicats avec composantes contextuelles. Archives de Psychologie, Genève, 44, nº171, pp. 205-221. 
- $\quad$ Zamora, L., Alonso, I., Gorina, A., Álvarez, M. y Orús, P. (2009) "Tratamiento de datos, lógica y estadística elemental en la enseñanza preuniversitaria. Un estudio mediante la aplicación del chic". Departamento de Matemática. Facultad de Matemática y Computación. Universidad de Oriente. Cuba. Departamento de Matemáticas. Escuela de Tecnología y Ciencias Experimentales. Universidad Jaume I. España. 
ANEXO I

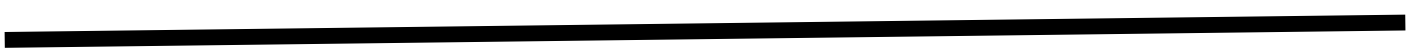




\section{EL PENSAMIENTO NATURAL (Wermus, 1976)}

«Las leyes de la Lógica Formal no son, en general, las leyes del pensamiento» (Wermus, 1978, parafraseando a Boole)

El pensamiento formal (PF) tan solo es la expresión de un tipo particular de pensamiento natural (PN). Los procesos del PN son mucho más complejos, así como la comprensión del paso de los hechos a la norma.

Wermus utiliza el concepto de predicado amalgamado (PA) para abordar esta problemática. Según Wermus, es posible tener en cuenta la influencia de los predicados con componentes contextuales, llamados predicados amalgamados, sobre la actividad inferencial del pensamiento natural (PN).

"Un predicado $\hat{P}$ es una representación semiótica ${ }^{20}$ de un cierto significado â (de un objeto o de un hecho) externo a la cognición del sujeto” (Wermus, 1983, p. 17).

Todo sujeto tiene una función semiótica que le permite reconocer propiedades de los objetos o sus relaciones, al mismo tiempo que esta función está condicionada por muchas limitaciones.

Descripción del concepto de PA: Un predicado $P_{1}$ de un objeto $a$, no es atribuido o identificado por un sujeto más que en contextos que presentan ciertas características, y que actúan conjuntamente, tratándose de una agrupación de predicados $P_{2}, P_{3}, P_{4}, \ldots, P_{n}$ (lugar, materia, relaciones con el entorno, efectos de una acción,...)

(1) $\quad P_{n} \ldots P_{2} P_{1} a$ abreviado $\dot{P} a$

\footnotetext{
${ }^{20}$ Semiótica: disciplina que aborda la interpretación y producción del sentido en base a la comunicación.
} 
$P_{l}$ es la componente dominante y $P_{k}$ las componentes contextuales $(c c)$.

$$
P_{n} \ldots P_{2} P_{1} a
$$

La expresión anterior se puede considerar lógicamente equivalente $(\leftrightarrow)$ a la expresión.

$$
\text { (2) } \quad P_{n} a \wedge \ldots \wedge P_{2} a \wedge P_{1} a
$$

En el plano cognitivo las componentes contextuales forman un todo y no se pueden separar, deben considerarse conjuntamente. Esto marca la diferencia entre (1) y (2).

En lógica formal (LF) se verifica el siguiente teorema:

$$
A \wedge B \Rightarrow A \quad \text { respectivamente } \quad A \wedge B \Rightarrow B
$$

Este teorema, en lógica formal permite separar las componentes:

$$
\text { (3) } \quad P_{n} a \wedge \ldots \wedge P_{2} a \wedge P_{1} a \Rightarrow P_{k} a \quad \forall k=1, \ldots, n
$$

En el pensamiento natural, los predicados amalgamados funcionan mediante distintas reglas. Veamos algunas reglas del tratamiento de los PA y sus interpretaciones:

- $\quad$ Regla $\boldsymbol{C}_{\boldsymbol{k}}$ : centración sobre la k-ésima $c c$ del PA

$$
P_{n} \ldots P_{k} \ldots P_{1} a \stackrel{c_{k}}{\longrightarrow} \dot{P}_{k} a
$$

Ejemplo: son unas chanclas de goma, entonces son unas chanclas.

Regla actv: activación de otras $c c$ por el $\dot{P} a$

$$
\dot{P} a \stackrel{a c t v}{\longrightarrow} \dot{S} \dot{P} a
$$

Ejemplo: Es un triángulo, entonces es un triángulo isósceles. 
- $\quad$ Regla d: la decantación, que realiza una parte de la equivalencia (2), es decir, la decantación parcial

$$
\dot{S} \dot{P} a \stackrel{d p}{\longrightarrow} \dot{S} a \wedge \dot{P} a
$$

Ejemplo: Son zuecos de madera, entonces son zuecos y son de madera.

Efectos de los PA sobre la relación entre las extensiones y las compresiones

Regla g: deslizamiento cognitivo, que sucede cuando la propiedad de un predicado $^{21}$ se le atribuye a un sujeto.

$$
\mu(P) \wedge P(x) \stackrel{g}{\longrightarrow} \mu(x) \wedge P(x)
$$

Ejemplo: Juan es buen cocinero. Juan es cocinero. Entonces Juan es bueno.

Regla t: transducción, cuando se atribuye a un objeto una propiedad a partir de una relación de 'semejanza' existente entre ambos objetos.

$$
\dot{P} a \wedge \dot{T} a b \stackrel{t}{\longrightarrow} \dot{P}(b)
$$

Ejemplo: Juan es rubio. Juan se parece a Ana. Entonces, Ana es rubia. (También pueden atribuirse relaciones: Juan es más alto que Ana. Ana se parece a María. Juan es más alto que María)

Regla T: transposición; un objeto con dos propiedades, tiene una tercera propiedad en común con otro objeto. El hecho de que éste tuviera una de las dos primeras propiedades, hace que se le asigne también la otra:

$$
\dot{P} a \wedge \dot{R} a, \quad \dot{T} a b, \quad \dot{P} b \stackrel{T}{\longrightarrow} \dot{R} b
$$

${ }^{21} \mu(P)$, siguiendo la nomenclatura utilizada por Wermus, es una modulación de P. 
Ejemplo: El bolso es de piel y rojo. La cartera y el bolso son caros. Entonces si la cartera es de piel entonces la cartera es roja.

Las operaciones aquí definidas no se corresponden con operaciones lógicas. El funcionamiento del pensamiento puede ser representado con mayor precisión a través de la modelización que nos ofrece Wermus y se aproxima más al funcionamiento real de los procesos del pensamiento natural que la lógica formal. Al mismo tiempo, las combinaciones de las diferentes reglas suponen demasiada complejidad, aunque sirve para mostrar la diferencia existente al considerar el pensamiento desde una perspectiva normativa de la LF y el pensamiento desde una perspectiva cognitiva del PN.

Con todo lo anterior, Wermus reconoce el funcionamiento de ciertos operadores "protológicos" también llamados operadores "reflexivos". Las valoraciones de los sujetos ante las diferentes representaciones pueden ser de aceptación, de rechazo o de indeterminación (en LF sólo existe $\mathrm{P}$ o $\neg \mathrm{P}$ ). Esta variedad de valores permite explicar formalmente diferentes formas del pensamiento, muy lejos de hacerlo realizable con la lógica formal.

\begin{tabular}{|c|c|c|c|}
\hline $\mathrm{P}$ & $\mathrm{u}_{0} \mathrm{P}$ & $\mathrm{n}_{0} \mathrm{P}$ & $\mathrm{C}_{0} \mathrm{P}$ \\
\hline+ & + & - & $*$ \\
\hline- & $*$ & $*$ & $*$ \\
\hline$*$ & $*$ & $*$ & + \\
\hline
\end{tabular}

Tabla 1: Tabla de definición de $u_{0} P, n_{0} P$ y $C_{0} P$ 
ANEXO II

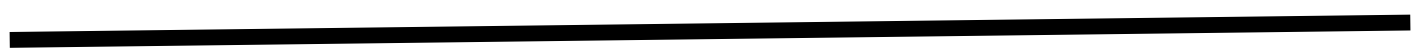




\begin{tabular}{|c|c|c|c|c|c|c|c|c|c|c|c|c|c|c|c|c|c|c|c|c|c|c|c|}
\hline & $\begin{array}{l}\mathrm{Q} \\
1\end{array}$ & $\frac{Q}{2}$ & $\begin{array}{l}\mathrm{Q} \\
3\end{array}$ & $\begin{array}{l}\mathrm{Q} \\
4\end{array}$ & $\begin{array}{l}Q \\
5\end{array}$ & $\begin{array}{l}Q \\
6\end{array}$ & $\begin{array}{l}\mathrm{Q} \\
7\end{array}$ & $\begin{array}{l}Q \\
8\end{array}$ & $\begin{array}{l}\mathrm{Q} \\
9\end{array}$ & $\begin{array}{l}\mathrm{Q} \\
1 \\
0\end{array}$ & $\begin{array}{l}\mathrm{Q} \\
1 \\
1\end{array}$ & $\begin{array}{l}\mathrm{Q} \\
1 \\
2\end{array}$ & $\begin{array}{l}\mathrm{Q} \\
1 \\
3\end{array}$ & $\begin{array}{l}Q \\
1 \\
4\end{array}$ & $\begin{array}{l}Q \\
1 \\
5\end{array}$ & $\begin{array}{l}\mathrm{Q} \\
1 \\
6\end{array}$ & $\begin{array}{l}Q \\
1 \\
7\end{array}$ & $\begin{array}{l}Q \\
1 \\
8\end{array}$ & $\begin{array}{l}Q \\
1 \\
9\end{array}$ & $\begin{array}{l}\mathrm{Q} \\
2 \\
0\end{array}$ & $\begin{array}{l}\mathrm{Q} \\
2 \\
1\end{array}$ & $\begin{array}{l}\mathrm{Q} \\
2 \\
2\end{array}$ & $\begin{array}{l}Q \\
2 \\
3\end{array}$ \\
\hline TABL & 1 & 1 & 1 & 0 & 0 & 0 & 1 & 1 & 1 & 1 & 1 & 1 & 0 & 1 & 1 & 1 & 1 & 1 & 0 & 0 & 0 & 0 & 0 \\
\hline ROBL & 0 & 1 & 1 & 0 & 0 & 0 & 1 & 0 & 0 & 0 & 0 & 0 & 1 & 0 & 0 & 0 & 0 & 0 & 0 & 0 & 0 & 0 & 0 \\
\hline RALT & 0 & 0 & 0 & 1 & 1 & 1 & 0 & 0 & 0 & 1 & 1 & 1 & 0 & 0 & 0 & 0 & 0 & 0 & 0 & 0 & 0 & 0 & 0 \\
\hline FDIF & 0 & 0 & 0 & 0 & 0 & 0 & 0 & 0 & 0 & 0 & 1 & 0 & 0 & 0 & 0 & 0 & 0 & 0 & 0 & 0 & 0 & 0 & 0 \\
\hline FCOI & 0 & 0 & 0 & 0 & 0 & 0 & 0 & 0 & 0 & 0 & 0 & 1 & 0 & 0 & 0 & 0 & 0 & 0 & 0 & 0 & 0 & 0 & 0 \\
\hline FPRE & 0 & 0 & 0 & 0 & 0 & 0 & 0 & 1 & 1 & 0 & 0 & 0 & 0 & 1 & 1 & 0 & 0 & 1 & 0 & 0 & 0 & 0 & 0 \\
\hline FAUS & 0 & 0 & 0 & 0 & 0 & 0 & 0 & 0 & 0 & 0 & 0 & 0 & 0 & 0 & 0 & 1 & 0 & 0 & 0 & 0 & 0 & 0 & 0 \\
\hline CSEM & 0 & 0 & 0 & 0 & 0 & 0 & 0 & 0 & 0 & 0 & 1 & 1 & 1 & 1 & 1 & 1 & 1 & 0 & 0 & 1 & 0 & 0 & 1 \\
\hline LIMP & 0 & 0 & 0 & 0 & 0 & 0 & 0 & 1 & 1 & 0 & 0 & 0 & 0 & 1 & 1 & 1 & 0 & 1 & 0 & 1 & 0 & 0 & 1 \\
\hline LIMPR & 0 & 0 & 0 & 0 & 0 & 0 & 0 & 0 & 1 & 0 & 0 & 0 & 0 & 0 & 1 & 0 & 0 & 0 & 0 & 0 & 0 & 0 & 1 \\
\hline LOPC & 0 & 0 & 0 & 0 & 0 & 0 & 1 & 0 & 0 & 0 & 0 & 0 & 0 & 0 & 0 & 1 & 0 & 1 & 0 & 1 & 0 & 0 & 1 \\
\hline LUNIUP & 0 & 0 & 0 & 1 & 1 & 1 & 0 & 0 & 0 & 0 & 0 & 0 & 0 & 0 & 0 & 0 & 0 & 0 & 1 & 0 & 1 & 0 & 0 \\
\hline LUNIVP & 0 & 0 & 0 & 0 & 0 & 0 & 0 & 1 & 1 & 1 & 0 & 0 & 0 & 1 & 1 & 1 & 0 & 1 & 0 & 1 & 0 & 0 & 1 \\
\hline $\mathrm{LCON}$ & 0 & 0 & 0 & 0 & 0 & 0 & 1 & 0 & 0 & 0 & 0 & 0 & 0 & 0 & 0 & 0 & 0 & 1 & 0 & 0 & 0 & 0 & 0 \\
\hline LDIS & 0 & 0 & 0 & 0 & 0 & 0 & 0 & 0 & 0 & 1 & 0 & 0 & 0 & 0 & 0 & 0 & 1 & 0 & 0 & 0 & 0 & 0 & 0 \\
\hline LNEG & 0 & 0 & 0 & 0 & 0 & 0 & 1 & 0 & 0 & 0 & 0 & 0 & 0 & 0 & 0 & 1 & 0 & 0 & 0 & 1 & 1 & 1 & 1 \\
\hline LMPON & 0 & 0 & 0 & 0 & 0 & 0 & 0 & 0 & 0 & 0 & 0 & 0 & 0 & 0 & 0 & 0 & 0 & 0 & 0 & 0 & 1 & 1 & 0 \\
\hline LFAL & 0 & 0 & 0 & 0 & 0 & 0 & 0 & 0 & 0 & 0 & 0 & 0 & 0 & 0 & 1 & 0 & 0 & 0 & 0 & 1 & 0 & 0 & 0 \\
\hline ARGU & 0 & 0 & 0 & 0 & 0 & 0 & 0 & 0 & 0 & 0 & 1 & 1 & 1 & 0 & 0 & 0 & 0 & 0 & 0 & 0 & 0 & 0 & 0 \\
\hline NTABL & 0 & 0 & 0 & 0 & 0 & 0 & 0 & 0 & 0 & 0 & 0 & 0 & 0 & 0 & 0 & 0 & 0 & 0 & 1 & 1 & 1 & 1 & 1 \\
\hline GEN & 0 & 0 & 0 & 0 & 0 & 0 & 0 & 0 & 0 & 0 & 0 & 0 & 0 & 0 & 0 & 0 & 0 & 0 & 1 & 0 & 1 & 0 & 0 \\
\hline CONTR & 0 & 0 & 0 & 0 & 0 & 0 & 0 & 0 & 0 & 0 & 0 & 0 & 0 & 0 & 0 & 0 & 0 & 0 & 0 & 0 & 0 & 0 & 1 \\
\hline RDAF & 0 & 0 & 0 & 1 & 1 & 0 & 0 & 0 & 1 & 0 & 0 & 0 & 0 & 0 & 0 & 0 & 0 & 0 & 0 & 0 & 0 & 0 & 0 \\
\hline RDNEG & 1 & 0 & 0 & 0 & 0 & 1 & 0 & 1 & 0 & 1 & 1 & 0 & 0 & 0 & 0 & 0 & 0 & 0 & 0 & 0 & 0 & 0 & 0 \\
\hline AV & 0 & 0 & 0 & 0 & 0 & 0 & 0 & 0 & 0 & 0 & 0 & 0 & 0 & 1 & 1 & 1 & 1 & 1 & 1 & 1 & 1 & 1 & 1 \\
\hline AVERD & 0 & 0 & 0 & 0 & 0 & 0 & 0 & 0 & 0 & 0 & 0 & 0 & 0 & 1 & 0 & 0 & 1 & 0 & 0 & 0 & 0 & 0 & 1 \\
\hline AFALS & 0 & 0 & 0 & 0 & 0 & 0 & 0 & 0 & 0 & 0 & 0 & 0 & 0 & 0 & 1 & 1 & 0 & 1 & 0 & 0 & 1 & 1 & 0 \\
\hline ANS & 0 & 0 & 0 & 0 & 0 & 0 & 0 & 0 & 0 & 0 & 0 & 0 & 0 & 0 & 0 & 0 & 0 & 0 & 1 & 1 & 0 & 0 & 0 \\
\hline
\end{tabular}

Tabla 1: MAP: matriz a priori del cuestionario $Q$ 
ANEXO III

1 
Indica la dificultad que podrían tener, según tu criterio, las preguntas del siguiente cuestionario. Para ello se considerará una pregunta fácil aquella que supere un porcentaje de respuestas correctas del 95\%; se considerará de dificultad media entre un $75 \%$ y un $95 \%$; y se considerará difícil si hay un porcentaje de respuestas correctas menor al $75 \%$. Señala, por favor, el porcentaje de éxito que crees que cabe esperar entre los estudiantes, para cada una de ellas.

Q1. ¿Al estudiante $\mathrm{C}$ le gusta salir de noche?

Hasta un $75 \% \quad$ Entre $75 \%$ y $95 \%$ Más del $95 \%$

Q2. ¿A cuántos estudiantes les gusta vivir aventuras?

Hasta un $75 \% \quad$ Entre $75 \%$ y $95 \%$ Más del $95 \%$

Q3. ¿Cuántas cosas le gustan al estudiante Q para viajar?
Hasta un $75 \%$
Entre $75 \%$ y $95 \%$
Más del 95\%

Q4. ¿Hay algo que les guste a todos los estudiantes? En caso afirmativo, indica lo que es.
Hasta un $75 \%$
Entre $75 \%$ y $95 \%$
Más del 95\%

Q5. ¿Hay algún estudiante a quien le guste todo? En caso afirmativo, indica su nombre.
Hasta un $75 \%$
Entre $75 \%$ y $95 \%$
Más del 95\%

Q6. ¿Hay más estudiantes a quienes les guste todo? En caso afirmativo, indica cuáles
Hasta un $75 \%$
Entre $75 \%$ y $95 \%$
Más del 95\%

Q7. ¿A cuántos estudiantes no les gustan las grandes ciudades y salir de noche?
Hasta un $75 \%$
Entre $75 \%$ y $95 \%$
Más del 95\%

Q8. ¿Todo lo que le gusta al estudiante R le gusta al estudiante J?
Hasta un $75 \%$
Entre $75 \%$ y $95 \%$
Más del 95\%

Q9. ¿Todo lo que le gusta al estudiante J le gusta al estudiante R?
Hasta un $75 \%$
Entre $75 \%$ y $95 \%$
Más del 95\%

Q10. ¿A todos los estudiantes les gusta salir de noche o practicar deporte?
Hasta un $75 \%$
Entre $75 \%$ y $95 \%$
Más del 95\%

Q11. Los estudiantes $\mathrm{N}$ y $\mathrm{R}$ ¿tienen el mismo gusto para viajar? ¿Por qué? 
Hasta un $75 \% \quad$ Entre $75 \%$ y $95 \%$ Más del $95 \%$

Q12. ¿A qué pareja crees que es más probable encontrar en un mismo viaje, a $\mathrm{J}$ y $\mathrm{R}$ o G y T? ¿Por qué? ...

Hasta un $75 \%$ Entre $75 \%$ y $95 \%$ Más del $95 \%$

Q13. Si fueras el agente de viajes, ¿qué tres criterios de los que aparecen en la tabla elegirías para proponer un viaje a estos estudiantes? ¿Por qué?

Hasta un $75 \%$ Entre $75 \%$ y $95 \%$ Más del $95 \%$

- Di si las siguientes afirmaciones son verdaderas o falsas

\begin{tabular}{|c|c|c|c|c|c|}
\hline & & & VERDADERO & FALSO & NO SÉ \\
\hline \multicolumn{3}{|c|}{ Q14. Al estudiante que le gusta el frío, le gusta esquiar. } & & & \\
\hline \multicolumn{3}{|c|}{$\begin{array}{l}\text { Q15. A todos los estudiantes que les gusta esquiar les } \\
\text { gusta el frío. }\end{array}$} & & & \\
\hline \multicolumn{3}{|c|}{$\begin{array}{l}\text { Q16. Si a un estudiante no le gusta el deporte, entonces no } \\
\text { le gustan los deportes acuáticos. }\end{array}$} & & & \\
\hline \multicolumn{3}{|c|}{ Q17. Al estudiante E le gusta la playa o la montaña. } & & & \\
\hline \multicolumn{3}{|c|}{$\begin{array}{l}\text { Q18. Lo que les gusta a los estudiantes } \mathrm{C} \text { y } \mathrm{F} \text { le gusta al } \\
\text { estudiante L. }\end{array}$} & & & \\
\hline
\end{tabular}


- Si fuera cierta la información sobre el grupo de que "a todos los estudiantes que les gusta practicar deporte les gusta nadar", indica si son verdaderas o falsas las siguientes afirmaciones:

\begin{tabular}{|c|c|c|c|c|c|}
\hline & & & VERDADERO & FALSO & NO SÉ \\
\hline \multicolumn{3}{|c|}{ Q19. A todos los del grupo les gusta nadar. } & & & \\
\hline $\begin{array}{l}\text { Q20. Si no le } \\
\text { Hasta un } 75 \%\end{array}$ & $\begin{array}{l}\text { usta practicar deport } \\
\text { Entre } 75 \% \text { y } 95 \%\end{array}$ & $\begin{array}{l}\text { no les gusta nad } \\
\text { Más del } 95 \%\end{array}$ & & & \\
\hline $\begin{array}{l}\text { Q21. A los es } \\
\text { Hasta un } 75 \%\end{array}$ & $\begin{array}{l}\text { liantes no les gusta } 1 \\
\text { Entre } 75 \% \text { y } 95 \%\end{array}$ & $\begin{array}{l}\text { ar. } \\
\text { Más del 95\% }\end{array}$ & & & \\
\hline \multicolumn{6}{|c|}{ Q22. Al estudiante $\mathrm{H}$ no le gusta nadar. } \\
\hline \multicolumn{6}{|c|}{ Q23. Si no les gusta nadar, no les gusta practicar deporte. } \\
\hline
\end{tabular}


ANEXO IV 
REFLEXIONES SOBRE LA DIDÁCTICA DE LAS MATEMÁTICAS (A partir de la corrección del cuestionario)

I. Conocimientos lógico-matemáticos en juego

II. Conocimientos didáctico-matemáticos experimentados

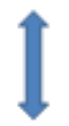

INSTITUCIONALIZACIÓN

I. Conocimientos lógico-matemáticos en juego

1. Lógica: ciencia que estudia los razonamientos válidos (lógica aristotélica)

2. Lógica: lenguaje formal (lógica simbólica)

2.1 Elementos del lenguaje (formación de fórmulas)

- Lógica proposicional: p, P(a), conectores lógicos

- Lógica de predicados: $\mathrm{P}(\mathrm{x}), \mathrm{x} \in \mathrm{X}$

2.2 Transformación de fórmulas:

- Reglas de inferencia

- Teoremas y demostraciones.

3. Conjuntos: conjunto complementario $(\bar{X})$, intersección $(\cap)$, unión $(\cup)$, cardinal de un conjunto $(|X|)$ 
$\mathrm{P}_{6}\left(\mathrm{x}_{3}\right)=\mathrm{Al}$ estudiante $\mathrm{C}$ le gusta la playa (VERDADERO)

\begin{tabular}{|l|l|l|l|l|l|l|l|l|}
\hline iTe gusa... & A & B & C & D & E & F & G & H \\
\hline & & & & & & & & \\
\hline & & & & & & & & \\
\hline & & & & & & & & \\
\hline & & & & & & & & \\
\hline & & & & & & & & \\
\hline la playa? (C6) & & & 1 & & & & & \\
\hline & & & & & & & & \\
\hline
\end{tabular}

"Al estudiante $\mathrm{C}$ le gustan la playa y la montanta"

"Al estudiante $\mathrm{C}$ le gusta la playa y al estudiante $\mathrm{C}$ le gusta la montania" $\mathrm{P}_{6}(\mathrm{xu}) \wedge \mathrm{P}_{9}(\mathrm{x} u)$ FALSO

\begin{tabular}{|l|l|l|l|l|l|l|}
\hline ¿Te gusta... & A & B & C & D & E & F \\
\hline & & & & & & \\
\hline & & & & & & \\
\hline & & & & & & \\
\hline & & & & & & \\
\hline la plyya? (C6) & & & & & & \\
\hline & & & 1 & & & \\
\hline & & & & & \\
\hline L moutaáa? (C9) & & & 0 & & & \\
\hline
\end{tabular}



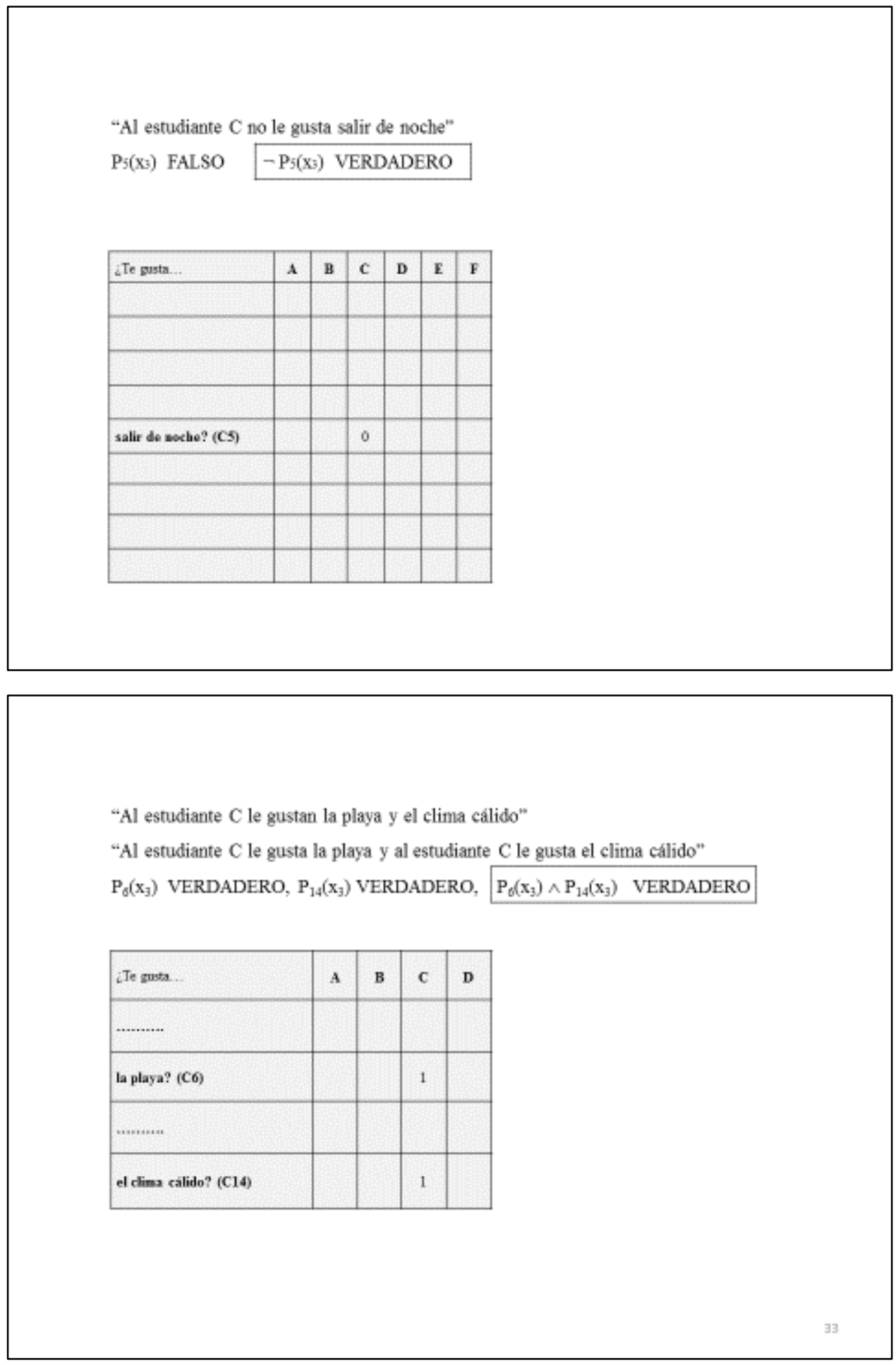
"Al estudiante C le gustan la playa o el clima cálido"

"Al estudiante C le gusta la playa o al estudiante C le gusta el clima cálido"

$\mathrm{P}_{6}\left(\mathrm{x}_{3}\right)$ VERDADERO, $\mathrm{P}_{44}\left(\mathrm{x}_{3}\right)$ VERDADERO, $\mathrm{P}_{6}\left(\mathrm{x}_{3}\right) \vee \mathrm{P}_{14}\left(\mathrm{x}_{3}\right)$ VERDADERO

\begin{tabular}{|l|l|l|l|l|}
\hline iTe gusta... & A & B & C & D \\
\hline$\ldots \ldots . .$. & & & & \\
\hline La playa? (C6) & & & 1 & \\
\hline$\ldots \ldots . .$. & & & & \\
\hline el clims calido? (C14) & & & 1 & \\
\hline
\end{tabular}

\section{TABLA DE VERDAD}

\begin{tabular}{|c|c|c|c|c|c|c|}
\hline $\mathrm{p}$ & $\mathrm{q}$ & $\begin{array}{c}\mathrm{p} \\
\text { Degación }\end{array}$ & $\begin{array}{c}\mathrm{p} \sim \mathrm{q} \\
\text { conjunción }\end{array}$ & $\begin{array}{c}\mathrm{p} \vee \mathrm{q} \\
\text { disyumción }\end{array}$ & $\begin{array}{c}\mathrm{p} \rightarrow \mathrm{q} \\
\text { condicional }\end{array}$ & $\begin{array}{c}\mathrm{p} \leftrightarrow \mathrm{q} \\
\text { doble condicional }\end{array}$ \\
\hline V & V & F & V & V & V & V \\
\hline V & F & F & F & V & F & F \\
\hline F & V & V & F & V & V & F \\
\hline F & F & V & F & F & V & V \\
\hline
\end{tabular}



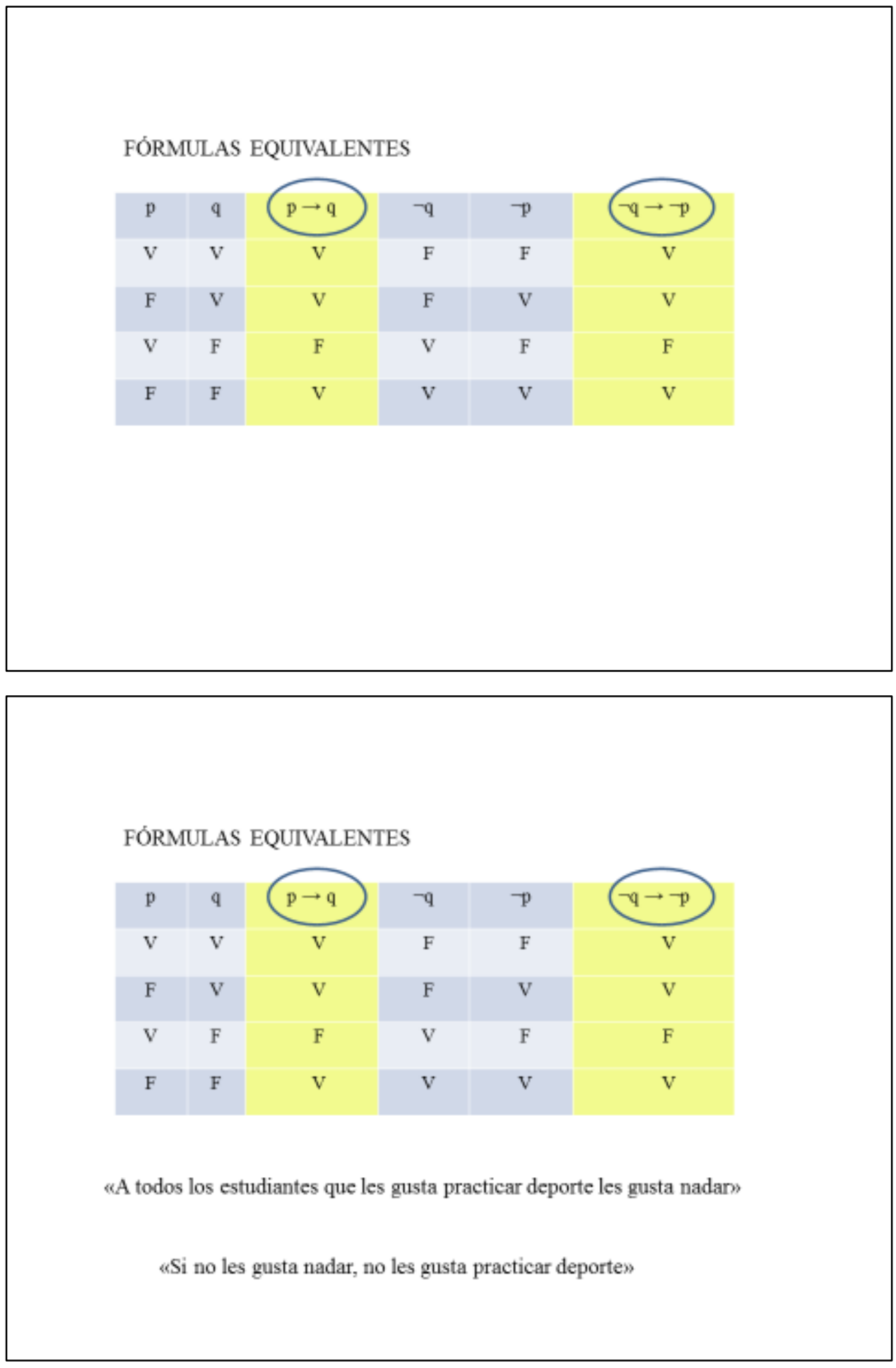


\section{A todos los estudiantes les gusta la playa} ( $\forall \mathrm{xi} \mathrm{P}_{6}(\mathrm{xi})$ VERDADERO)

A todos los estudiantes les gusta visitar museos $\left(\forall \mathrm{xi} \mathrm{P}_{6}(\mathrm{Xi}) \quad\right.$ FALSO porque $\exists \mathrm{xi}$ P(xi) FALSO)

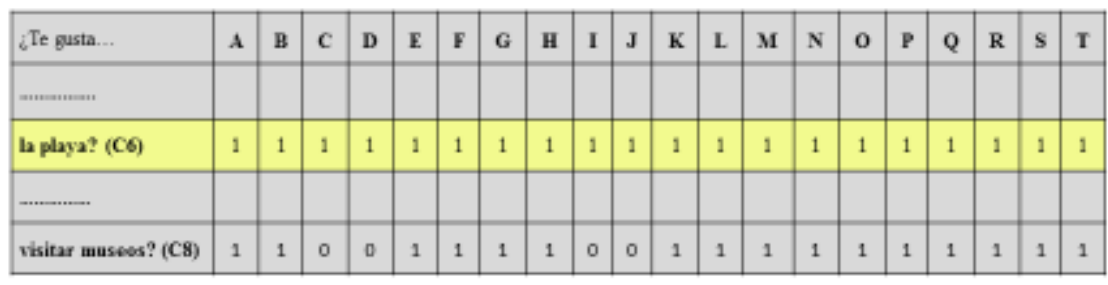

Conjunto de estudiantes que les gusta visitar museos $\mathrm{X}=\{\mathrm{A}, \mathrm{B}, \mathrm{E}, \mathrm{F}, \mathrm{G}, \mathrm{H}, \mathrm{K}, \mathrm{L}, \mathrm{M}, \mathrm{N}, \mathrm{O}, \mathrm{P}, \mathrm{Q}, \mathrm{R}, \mathrm{S}, \mathrm{T}\}$

Conjunto de estudiantes que les gusta conocer otras culturas $\mathrm{Y}=\{\mathrm{A}, \mathrm{B}, \mathrm{C}, \mathrm{E}, \mathrm{F}, \mathrm{G}, \mathrm{H}, \mathrm{I}, \mathrm{J}, \mathrm{K}, \mathrm{L}, \mathrm{M}, \mathrm{N}, \mathrm{O}, \mathrm{P}, \mathrm{Q}, \mathrm{R}, \mathrm{S}, \mathrm{T}\}$

Conjunto de estudiantes que les gusta visitar museos y conocer otras culturas $\mathrm{X} \cap \mathrm{Y}=\{\mathrm{A}, \mathrm{B}, \mathrm{E}, \mathrm{F}, \mathrm{G}, \mathrm{H}, \mathrm{K}, \mathrm{L}, \mathrm{M}, \mathrm{N}, \mathrm{O}, \mathrm{P}, \mathrm{Q}, \mathrm{R}, \mathrm{S}, \mathrm{T}\}$

Conjunto de estudiantes que les gusta visitar museos o conocer otras culturas $\mathrm{X} \cup \mathrm{Y}=\{=\{\mathrm{A}, \mathrm{B}, \mathrm{C}, \mathrm{E}, \mathrm{F}, \mathrm{G}, \mathrm{H}, \mathrm{I}, \mathrm{J}, \mathrm{K}, \mathrm{L}, \mathrm{M}, \mathrm{N}, \mathrm{O}, \mathrm{P}, \mathrm{Q}, \mathrm{R}, \mathrm{S}, \mathrm{T}\}$

Conjunto de los gustos del estudiante $\mathrm{F}$ $\mathrm{A}=\{\mathrm{C} 3, \mathrm{C} 5, \mathrm{C} 6, \mathrm{C} 8, \mathrm{C} 10, \mathrm{C} 12, \mathrm{C} 13\}$

Conjunto de los gustos del estudiante $\mathrm{J}$ $\mathrm{B}=\{\mathrm{C} 6, \mathrm{C} 10\}$

Conjunto de los gustos que no tiene el estudiante $\mathrm{F}$ $\mathrm{A}^{\mathrm{C}}=\{\mathrm{C} 1, \mathrm{C} 2, \mathrm{C} 4, \mathrm{C} 7, \mathrm{C} 9, \mathrm{C} 11, \mathrm{C} 14, \mathrm{C} 15\}$ 
II. Conocimientos didáctico-matemáticos experimentados

- Tipo de aprendizaje: activo, constructivista, ...

- Metodología docente: aprendizaje cooperativo

- Didáctica de las matemáticas: Teoría de Situaciones (Brousseau y col.)

- Situación didáctica: sujeto (alumno o profesor), interactuando con un medio.

- Situación adidáctica: alumno/s interactuando con el medio (aunque sea en presencia del profesor)

- Devolución: transmisión de la responsabilidad de la construcción del conocimiento (aprendizaje) a los alumnos a través de la situación

- Del trabajo lógico.

- De la validación del conocimiento construido. 